
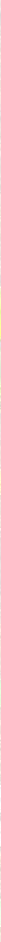



\section{Propositions}

I. Even with improved nitrogen management, current agricultural production levels in many world regions cannot be reconciled with air and water quality targets.

(this thesis)

2. A planetary boundary for human nitrogen use should be derived by aggregating regional boundaries that leave room to maximize food production within environmental limits.

(this thesis)

3. Predatory publishers are a symptom of the obsession with quantity over quality in academic evaluations.

4. For PhD students, programming is both a useful research tool as well as a welcome excuse to procrastinate real academic work.

5. To understand the complexity of farmer decision making, gardening beats modelling.

6. A mandatory paternity leave would benefit mothers' careers as well as both parents' happiness.

7. Debunking fake news is a democratic duty.

8. Whereas nitrogen emissions are caused by cows and cars, the Dutch 'nitrogen crisis' is caused by indecisive policy-makers.

Propositions belonging to thesis, entitled:

"Managing nitrogen to keep food production within environmental limits"

Lena F. Schulte-Uebbing

Wageningen, I I June 202 I 

Managing nitrogen to keep food production within environmental limits

Lena F. Schulte-Uebbing 


\section{Thesis committee}

\section{Promotors}

Prof. DrW. de Vries

Personal chair at the Environmental Systems Analysis Group

Wageningen University \& Research

Prof. Dr A.F. Bouwman

Professor of Geochemistry

Utrecht University

\section{Other members}

Dr B.L. Bodirsky, Potsdam Institute for Climate Impact Research (PIK), Potsdam, Germany Prof. Dr J.W. Erisman, Leiden University

Dr K. Fleischer, Max Planck Institute for Biogeochemistry, Jena, Germany Prof. Dr M.K. van Ittersum, Wageningen University \& Research

This research was conducted under the auspices of the Graduate School for SocioEconomic and Natural Sciences of the Environment (SENSE). 


\title{
Managing nitrogen to keep food production within environmental limits
}

\author{
Lena F. Schulte-Uebbing
}

Thesis

submitted in fulfilment of the requirements for the degree of doctor at Wageningen University

by the authority of Rector Magnificus,

Prof. Dr A.P.J. Mol,

in the presence of the

Thesis Committee appointed by the Academic Board

to be defended in public

on Friday II June 202I

at 4 p.m. in the Aula. 
Lena F. Schulte-Uebbing

Managing nitrogen to keep food production within environmental limits

312 pages

PhD thesis, Wageningen University, Wageningen, the Netherlands (202I)

With references, with summary in English

ISBN: 978-94-6395-758-8

DOI: https://doi.org/10.18174/544138 


\section{Table of Contents}

Chapter I General introduction

Chapter 2 Spatially explicit boundaries for agricultural nitrogen inputs in the

European Union to meet air and water quality targets

Chapter 3 Reconciling food production and environmental boundaries for nitrogen in the European Union

Chapter 4 From planetary to regional nitrogen boundaries for targeted policy support

Chapter 5 Global-scale impacts of nitrogen deposition on tree carbon sequestration in tropical, temperate and boreal forests: a meta-analysis

Chapter 6 Experimental evidence shows minor contribution of nitrogen deposition to global forest carbon sequestration

Chapter 7 Synthesis

References

Supp. Mat Supplementary Material for Chapters 2-7

Acknowledgements

About the author

Publication list

SENSE diploma 


\section{5.r. \\ (1)}

in

and 2004

20

ive

C.

- int 10

5) $/ \mathrm{s}$

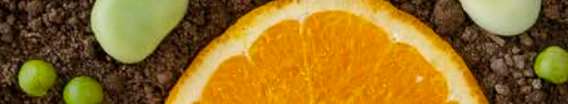

t) 2

(.) 8 )

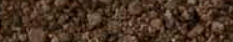

(4)

(3) 


\section{General introduction}

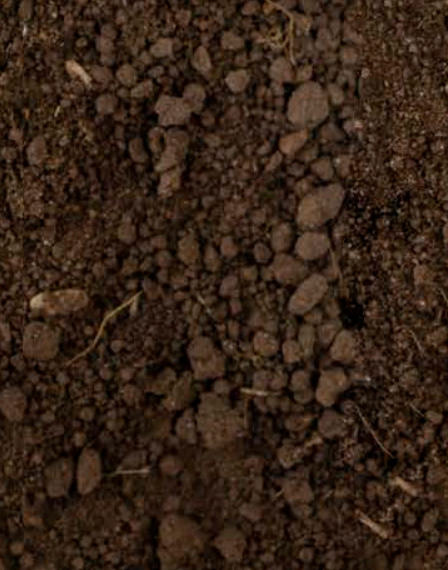




\section{I.I. Agriculture and human alteration of the global nitrogen cycle}

We currently live in the Anthropocene, the most recent period in Earth's history when human activity started to have a significant impact on the planet's climate, ecosystems and biogeochemical cycles (Steffen et al., 2007; Waters et al., 2016). Few elemental cycles have been altered more drastically by human activities than the nitrogen $(\mathrm{N}$ ) cycle (Canfield et al., 2010). Nitrogen hardly occurs in soil minerals, whereas it is the most abundant element in the Earth's atmosphere. However, before it is accessible to living organisms, atmospheric di-nitrogen gas $\left(\mathrm{N}_{2}\right)$ must be converted ('fixed') to reactive forms of nitrogen, specifically ammonium $\left(\mathrm{NH}_{4}^{+}\right)$and nitrate $\left(\mathrm{NO}_{3}{ }^{-}\right)$. In the absence of human interference, atmospheric $\mathrm{N}_{2}$ is fixed in natural terrestrial ecosystems $\left(58 \mathrm{Tg} \mathrm{N} \mathrm{yr}^{-1}\right)$ and oceans $\left(140 \mathrm{Tg} \mathrm{N} \mathrm{yr}^{-1}\right)$ through biological $\mathrm{N}_{2}$ fixation, as well as by lightning (5 $\mathrm{Tg} \mathrm{N} \mathrm{yr}^{-1}$ ) (Fowler et al., 2013). Currently, however, human activities fix more atmospheric $\mathrm{N}_{2}$ than all natural processes combined, mainly through synthetic fertilizer production $\left(120 \mathrm{Tg} \mathrm{N} \mathrm{yr}^{-1}\right)$, legume cultivation (60 Tg N $\mathrm{yr}^{-1}$ ) and fossil fuel combustion (30 $\mathrm{Tg} \mathrm{N} \mathrm{yr}^{-1}$ ) (Fowler et al., 2013). Agriculture is thus the dominant driver of human nitrogen fixation.

The global agricultural system crucially depends on the availability of reactive nitrogen. While several elements are essential for crop growth (including phosphorus, potassium, and several micronutrients), nitrogen is generally the most limiting one. For $98 \%$ of the period since humans started farming around 12,000 years ago, crop yields were limited by nitrogen availability. To increase crop yields, farmers mainly relied on organic nitrogen sources such as manure from rangeland animals, crop residues, human excrements, plant ashes, and guano (fertilizer from sea bird excrement), or they planted legumes, which fix nitrogen through symbiosis with bacteria. In the second half of the $19^{\text {th }}$ century, mineral fertilizers became increasingly available, for example in the form of sodium nitrate mined from natural deposits in Chile ('Chile saltpetre'). However, the nitrogen economy only changed drastically after the invention of the Haber-Bosch process in the mid- $20^{\text {th }}$ century, allowing humans to fix $\mathrm{N}_{2}$ directly from the atmosphere and convert it to ammonia $\left(\mathrm{NH}_{3}\right)$ (Erisman et al., 2008; Galloway et al., 2013). Since then, global nitrogen inputs to agricultural soils have tripled (Bouwman et al., 2013), strongly contributing to more than a doubling in average crop yields in the second half of the $20^{\text {th }}$ century (see Figure 1.1, $\mathrm{x}$-axis). This allowed the global population to increase from 1.7 billion in 1908 (the year Fritz Haber filed his patent) to 7.8 billion in 2021. 


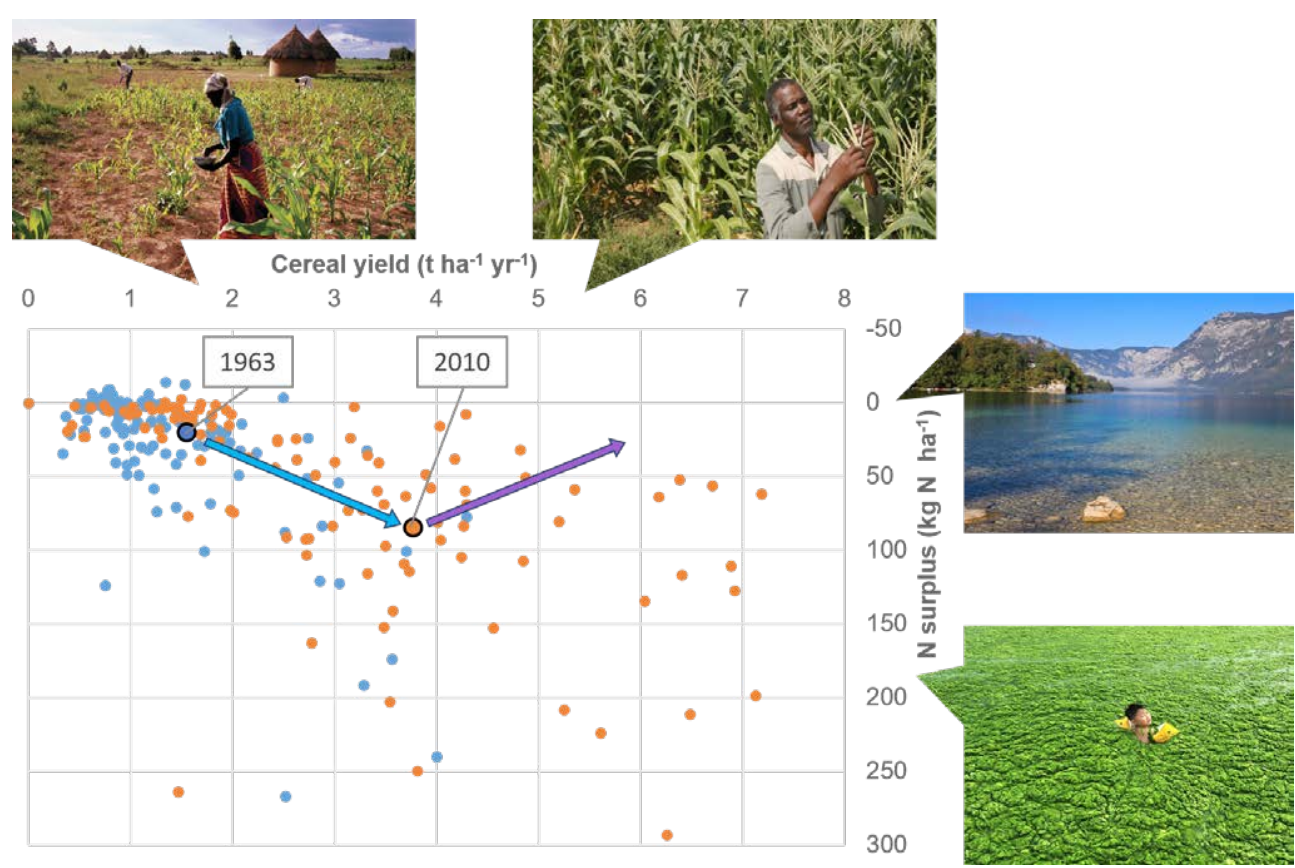

Figure I.I | Cereal yield and nitrogen surplus for II2 countries (each represented by a dot); average for the period 196I-1965 (blue dots) and 2008-2012 (orange dots). The two large dots represent the global average (weighted by cropland area). Data on cereal yield and harvested area from FAOSTAT (2018), data on nitrogen surplus from Zhang et al. (2015).

\section{I.2. Environmental impacts of reactive nitrogen}

With increasing agricultural nitrogen inputs, nitrogen surpluses (nitrogen input minus nitrogen uptake), and thereby nitrogen losses to the environment, also rose (see Figure 1.1, $\mathrm{y}$-axis). Nitrogen that is not taken up by crops or accumulated in the soil is lost from fields either in the form of gaseous emissions $\left(\mathrm{NH}_{3}, \mathrm{NO}_{\mathrm{x}}, \mathrm{N}_{2}, \mathrm{~N}_{2} \mathrm{O}\right)$ or leaching $\left(\mathrm{NO}_{3}^{-}, \mathrm{NH}_{4}^{+}\right)$. Nitrogen loading in the environment has several negative impacts, including eutrophication of aquatic ecosystems, acidification and eutrophication of terrestrial ecosystems, adverse effects on human health, and climate change (see Box 1.1). Next to agricultural nitrogen losses, other anthropogenic nitrogen sources from e.g. wastewater, combustion processes, and biomass burning also contribute to these impacts; the relative contribution of agriculture varies per impact, per region, and through time.

Once $\mathrm{N}_{2}$ has been converted to reactive nitrogen, it cascades through the environment and is subsequently converted into several reactive nitrogen forms (Galloway et al., 2003). One atom of nitrogen can thus contribute to several or even all of the environmental impacts 
Box I.I | Environmental impacts of reactive nitrogen

Eutrophication of aquatic ecosystems: Nitrogen inputs to freshwater ecosystems lead to eutrophication, changes in community structure (e.g. from macrophytes to fastN growing algae, from diatoms to flagellates), reduced water clarity, the proliferation of harmful or toxic algal blooms, benthic habitat loss, and the formation of hypoxia; i.e. conditions of low dissolved oxygen (Brooks et al., 2016; Conley et al., 2009; Duarte, 1995; Selman et al., 2008). Increased nutrient export by rivers has led to a large increase in the number of coastal 'dead zones' over the last decades (Diaz and Rosenberg, 2008).

Q206 Acidification and eutrophication of terrestrial ecosystems: At high concentrations, ?! ammonia $\left(\mathrm{NH}_{3}\right)$ and nitrogen oxide $\left(\mathrm{NO}_{\mathrm{x}}\right)$ are harmful to plants, causing foliar $\mathrm{NH}_{3}$ damage, soil acidification and increased susceptibility to pathogens (Cape et al., 2009; Krupa, 2003). High nitrogen deposition in terrestrial ecosystems leads to acidification and shifts in plant species composition (Aber et al., 1998; Hettelingh et al., 2015b; Midolo et al., 2019; Roth et al., 2013; Stevens et al., 2010). Increased nitrogen availability encourages plants favouring high nitrogen supply or more acidic conditions to out-compete a larger number of sensitive species, driving terrestrial biodiversity loss (Bobbink et al., 2010; Hettelingh et al., 2015b; Payne et al., 2017).

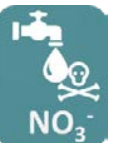

Adverse effects on human health: In intensive agricultural areas, nitrate $\left(\mathrm{NO}_{3}{ }^{-}\right)$ leaching can lead to $\mathrm{NO}_{3}{ }^{-}$concentrations in groundwater that exceed safe limits, to the formation of secondary air pollutants, mainly particulate matter, $\mathrm{NO}_{2}$, and ground-level ozone $\left(\mathrm{O}_{3}\right.$, formed by $\mathrm{NO}_{\mathrm{x}}$ in reaction with Volatile Organic Compounds) (Peel et al., 2013). Air pollution is mainly caused by nitrogen emissions from traffic and industry, but regionally agricultural emissions can contribute up to $30 \%$ of nitrogen-related air pollutants (Pozzer et al., 2017).

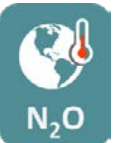

Climate change: Human nitrogen use causes emissions of nitrous oxide $\left(\mathrm{N}_{2} \mathrm{O}\right)$, a powerful greenhouse gas (Reay et al., 2012; UNEP, 2013). At the same time, nitrogen deposition may enhance growth and thus carbon sequestration in nitrogenlimited terrestrial ecosystems. This can be considered an unintended positive environmental consequence as it slows the growth of atmospheric carbon dioxide $\left(\mathrm{CO}_{2}\right)$ concentrations (Janssens and Luyssaert, 2009). Nitrogen further affects radiative forcing by contributing to formation of aerosols, which reflect sunlight and lead to cooling, as well as ground-level $\mathrm{O}_{3}$, which is a greenhouse gas and also negatively affects plant growth, possibly reducing the strength of the terrestrial carbon sink (De Vries et al., 2011a, 2017; Erisman et al., 2011). 
described in Box 1.1. This means that there is a risk of pollution swapping (Stevens and Quinton, 2009), as illustrated by the 'leaking pipe', symbolizing the agricultural system (Figure 1.2). Nitrogen enters the pipe in the form of fertilizer, manure, biological fixation or deposition, and leaves the pipe as nitrogen incorporated by crops. Various transformation processes within the pipe cause losses ('leaking') of different reactive nitrogen forms through holes in the pipe. A mitigation strategy that reduces a particular form of nitrogen loss by (partially) 'blocking' one of the holes may increase losses through one of the other outlets. These complexities need to be taken into account when developing policies for sustainable nitrogen management.

\section{I.3. Towards sustainable nitrogen management}

Several policies have been put in place to reduce nitrogen's negative externalities. At the global level, the UN Environmental Assembly recently adopted a resolution on sustainable nitrogen management (UNEP/EA.4/Res.14), calling for exploration of better management of the global nitrogen cycle, particularly in relation to the Sustainable Development Goals. At the regional level, the European Union (EU) has adopted several policies to address nitrogen pollution since the 1990s (Oenema et al., 2011), including the Ambient Air Quality Directive (EC, 2008), Nitrates Directive (EC, 1991a), Urban Wastewater Treatment Directive (EC, 1991b), Water Framework Directive (EC, 2000) and the National Emission Ceilings (EC, 2001). More recently, the 'Farm to Fork' strategy of the European Green Deal introduced the goal of reducing nutrient inputs by $20 \%$ and nutrient losses by $50 \%$ by 2030 (European Commission, 2020). At the national level, at least 145 countries have introduced some form of regulatory laws to limit the use of nitrogen fertilizers or to reduce the consequences of nitrogen pollution (Kanter et al., 2020).

However, most policies to date have focused on one specific sink or sector, with integration often lacking (Kanter et al., 2020), leading to the risk of pollution swapping (Figure 1.2). In addition, current policies tend to focus either on the beneficial effects of nitrogen (e.g., stimulating nitrogen fertilizer use by farmers through subsidies to boost yields) or regulating detrimental effects (e.g., restricting application of fertilizers during certain parts of the year to reduce environmental impacts) (Kanter et al., 2020). Global nitrogen solutions, however, require finding the right balance between nitrogen's benefits for crop yields and its negative environmental externalities (Houlton et al., 2019). This includes reversing the current global trend of increasing yields at the expense of increased nitrogen losses (blue arrow in Figure 1.1) towards simultaneously achieving high yields and low nitrogen losses (purple arrow 
in Figure 1.1). Some countries are already following trajectory of decoupling yields from nitrogen losses (Zhang et al., 2015), however, significant challenges remain.

The need to reconcile threats and benefits of nitrogen is also highlighted by exploring linkages between nitrogen and the Sustainable Development Goals (SDGs), a collection of 17 interlinked global goals adopted by the UNs' General Assembly (Sachs et al., 2019). Nitrogen is at the core of several SDGs. Some SDGs rely on realizing the full benefits of nitrogen, for example, increased access to nitrogen fertilizer is critical to achieve SDGs 1 and 2 (ending poverty and hunger). Others require reducing nitrogen losses to mitigate environmental impacts, such as SDGs 14 and 15 (conserving life below water and life on land). Finally, human disturbance of the nitrogen cycle also affects atmospheric composition and thereby climate change, with different nitrogen compounds leading to warming and cooling effects (Box 1.1), thus linking nitrogen to the SDG on climate action (SDG 13). Both scientists and policy makers frequently emphasize that achieving SDGs requires exploring potential interactions, co-benefits and trade-offs between goals (e.g., Nilsson et al., 2018), and consequently, this equally applies to the nitrogen challenge.

In the light of these complex challenges, relevant indicators for sustainable nitrogen management are needed to support policy making, monitoring and evaluation. Indicators condense information on complex systems into meaningful information to inform decisions and actions (Bossel, 1999; Spangenberg, 2019). Several studies have proposed and quantified

Table I.I | Examples of global indicators for sustainable nitrogen management related to either nitrogen's benefits for crop production or nitrogen's environmental impacts, including examples of studies presenting data on these indicators.

\begin{tabular}{ll}
\hline $\begin{array}{l}\text { Indicators related to } \mathbf{N} \text { benefits for crop } \\
\text { production }\end{array}$ & Indicators related to adverse impacts of $\mathbf{N}$ \\
\hline $\begin{array}{l}\text { Contribution of N to yield gap (e.g., Mueller et al., } \\
\text { 20I2) }\end{array}$ & N surplus (e.g., EEA, 20I9); see also Figure I.I \\
Access to N fertilizer (e.g., Sánchez, 20I0) & $\begin{array}{l}\text { N water footprint (e.g., Mekonnen and Hoekstra, } \\
2015)\end{array}$ \\
N fertilizer recovery (e.g., Cassman et al., 2002) & $\begin{array}{l}\text { Exceedance of N thresholds in surface water (e.g., } \\
\text { Gerten et al., 2020) }\end{array}$ \\
$\begin{array}{l}\text { Crop system N use efficiency (e.g., EU Nitrogen } \\
\text { Expert Panel, 20I5)' }\end{array}$ & $\begin{array}{l}\text { Food chain N use efficiency (e.g., Billen et al., 20I4) } \\
\text { Critical N loads for natural ecosystems (e.g., Bobbink } \\
\text { et al., 2003) } \\
\text { Crop system N use efficiency (e.g., EU Nitrogen } \\
\text { Expert Panel, 20I5)' }\end{array}$ \\
\hline
\end{tabular}

\footnotetext{
' Crop system nitrogen use efficiency may both reflect benefits of nitrogen for crop production and risk for adverse nitrogen impacts.
} 
indicators for nitrogen management, again usually either focusing on either benefits and threats of nitrogen (Table 1.1).

\section{I.4. Knowledge gaps and existing approaches}

It is clear that nitrogen in the environment has many different forms, sources, pathways, and multiple impacts, and environmental managers often face the problem of pollution swapping discussed above. Achieving environmental and Sustainable Development Goals related to nitrogen therefore requires a systems approach. In order to move towards global solutions, it is crucial to develop tools that can quantitatively assess the trade-offs associated with human nitrogen use, particularly for maximizing crop production while minimizing detrimental environmental impacts. More specifically, three questions are relevant for supporting nitrogen policy in bringing us closer to achieving SDGs:

1. How much nitrogen can we safely apply in agriculture before crossing thresholds for air and water quality?

2. How can we manage nitrogen to both achieve environmental targets and meet current and future feed and food demand?

3. What is the climatic impact of anthropogenic nitrogen inputs, i.e., how much additional carbon is stored in terrestrial systems due to anthropogenic nitrogen deposition, and to what extent does this 'carbon bonus' offset the climate impact of $\mathrm{N}_{2} \mathrm{O}$ emissions?

Given the large geographic variation in both nitrogen impacts and agricultural nitrogen inputs, spatially explicit models that illustrate issues at different scales and resolutions are highly relevant tools for analysing these questions. Information produced by these models, for example in the form of maps, can be helpful for decision makers by providing an overview on the magnitude of the problem, highlighting interactions and spatial variability, and identifying hot-spot regions. Current approaches to address questions 1-3 are discussed below, highlighting important knowledge gaps that are addressed in this thesis.

\section{I.4.I. Safe limits or 'boundaries' for agricultural nitrogen inputs}

Due to the manifold negative environmental consequences of nitrogen (see Section 1.2 and Box 1.1), environmental scientists have warned that humanity has transgressed the planetary boundary for disturbance of the nitrogen cycle. This suggests that human nitrogen 
fixation has pushed the Earth System beyond a critical threshold with possibly catastrophic and irreversible consequences (Rockström et al., 2009a, 2009b). The 'planetary boundary'concept has attracted considerable attention by scientists and policy makers since it was first introduced by Rockström et al. (2009b). In their seminal paper, they proposed a 'safe limit' for intentional nitrogen fixation of $30 \mathrm{Tg} \mathrm{N} \mathrm{yr}^{-1}$ (about one third of the current rate), which was later revised upwards to 62-82 $\mathrm{Tg} \mathrm{N} \mathrm{yr}^{-1}$ (De Vries et al., 2013; Steffen et al., 2015). Several studies have used this value as a benchmark to assess sustainability of food production systems under current conditions and future scenarios (e.g., Bodirsky et al., 2014; Conijn et al., 2018), but surprisingly few studies have challenged the boundary itself, despite several shortcomings of the approach.

The desire to further 'operationalize' the planetary nitrogen boundary has led to efforts to downscale the planetary boundary to countries (e.g., Switzerland, Dao et al., 2018) or regions (e.g., Europe, EEA and FOEN, 2020) based on economic or demographic allocation principles, such as allocating boundaries based on a country's share in the global population or its economic capability to contribute to mitigation efforts. However, unlike greenhouse gas emissions where emission reductions contribute to climate mitigation irrespective of where emissions are reduced, nitrogen-related problems are generally directly linked to local or regional losses. As the magnitude and type of problems vary strongly across regions, allocating a global nitrogen boundary to regions based on socio-economic criteria is of limited value. Furthermore, the current planetary boundary concept ignores the importance of increasing nitrogen inputs in many regions to boost food production.

Rather than deriving nitrogen boundaries using a top-down approach, thresholds should be derived locally while accounting for spatial variation in the vulnerability of local ecosystems. If such thresholds are derived within a consistent framework, they can then be aggregated towards regional or planetary nitrogen thresholds or boundaries. Such an approach has been taken under the Convention on Long-Range Transboundary Air Pollution (CLRTAP), where spatially explicit critical nitrogen loads on ecosystems were translated into policy targets for nitrogen emissions at the European and national level. Deriving boundaries for agricultural nitrogen inputs should follow a similar approach and start from critical thresholds for local ecosystems to derive needed reductions in nitrogen losses to respect these thresholds, as well as corresponding needed reductions in agricultural nitrogen inputs.

Knowledge gap: We thus lack a bottom-up approach to estimate spatially explicit critical nitrogen losses and related critical agricultural nitrogen surpluses and inputs, based on spatial variation in agricultural systems and environmental vulnerabilities, that can be aggregated to derive regional and planetary boundaries for nitrogen. 


\subsubsection{Meeting food demand while remaining within safe boundaries for nitrogen}

Global agricultural nitrogen inputs are very unevenly distributed, varying from excessive surpluses in many developed and rapidly growing economies (Vitousek et al., 2009) to no surplus and even nitrogen mining in many developing regions (see Figure 1.1). This includes much of Africa, where $80 \%$ of countries experience nitrogen scarcity (Liu et al., 2010b) as well as parts of Latin America and South East Asia (MacDonald et al., 2011). Low nitrogen input in these regions often limits yields and thus threatens food security (Mueller et al., 2012; Pradhan et al., 2015). Even though fertility rates have dropped sharply from about 5 children per woman in 1964 to about 2.5 in 2014 (The World Bank, 2018), human population will continue to grow during the next decades, along with food demand (Tilman et al., 2011).

The dual role of nitrogen as an essential agricultural nutrient as well as a major environmental pollutant raises the question which strategies are needed to reconcile environmental targets with agricultural systems that allow meeting current and future food demand. Previous studies addressing this issue broadly fall into two categories. The first category uses integrated assessment models to estimate to what extent different mitigation strategies can reduce nitrogen losses and nitrogen inputs (e.g., Bodirsky et al., 2014; Conijn et al., 2018; Zhang et al., 2015), and often use the planetary nitrogen boundary by Steffen et al. (2015) as a benchmark to determine whether realized reductions in nitrogen surplus are sufficient to protect the environment. The second category assesses whether nitrogen inputs can be 'optimized' by re-distributing nitrogen inputs from excess areas to deficit areas (e.g., Liu et al., 2016; Mueller et al., 2017, 2014, 2012). These studies assume that nitrogen use efficiency decreases with inputs, and thus lowering nitrogen inputs in excess regions hardly affects yields, whereas increasing nitrogen inputs in deficit regions increases yields without substantially increasing nitrogen losses. However, both approaches focus on reducing total nitrogen losses or inputs, while not accounting for variability in ecosystems' vulnerability to nitrogen losses.

Knowledge gap: We lack spatially explicit information to what extent redistributing nitrogen inputs is possible within safe limits for nitrogen losses, and what improvements in agricultural management are needed to reconcile agricultural production with targets for reducing nitrogen pollution.

\subsubsection{Nitrogen-induced carbon sequestration in forests and net greenhouse gas footprint of human nitrogen use}

The main reason that humans fix nitrogen is the desire to enhance the growth of agricultural crops. It is thus not surprising that when part of this nitrogen volatilizes and is deposited 
on natural ecosystems, plant growth in these ecosystems is also enhanced. This nitrogeninduced growth enhancement drives biodiversity loss (Hettelingh et al., 2015b; see Box 1.1), but may also contribute to climate change mitigation by enhancing carbon sequestration in plant biomass and soils, especially in forests. Forests occupy only one fifth of the Earths' land surface, but account for $90 \%$ of the terrestrial carbon sink (Harris et al., 2021; Pan et al., 2011a). Many forests in Western Europe and Southeast Asia currently receive more nitrogen via atmospheric deposition (Wang et al., 2017) than the average arable field in Sub-Saharan Africa receives via fertilizer, manure and biological nitrogen fixation combined (Liu et al., 2010b). Globally, about 20-30 Tg N emitted by human activities end up in forests after atmospheric transport and re-deposition each year (Lamarque et al., 2013; Schwede et al., 2018).

Quantifying the size of the nitrogen-induced carbon sink is relevant to estimate the current and future strength of the global terrestrial carbon sink in order to predict growth in atmospheric $\mathrm{CO}_{2}$ concentrations. It also allows to quantify the net climate impact of anthropogenic nitrogen use by comparing nitrogen-induced carbon sequestration to anthropogenic $\mathrm{N}_{2} \mathrm{O}$ emissions, which are relatively well constrained (also from atmospheric measurements; e.g. Tian et al., 2020). The size of the nitrogen-induced global carbon sink has been estimated by stoichiometric scaling (De Vries et al., 2014; Field et al., 1992; Peterson and Melillo, 1985; Schindler and Bayley, 1993), dynamic global vegetation models (DGVMs, e.g. Fleischer et al., 2015; Thornton et al., 2007; Zaehle et al., 2011) or observations of forest growth along nitrogen deposition gradients (Magnani et al., 2007; Thomas et al., 2010).

The amount of carbon stored in forests per unit of nitrogen deposition ('C-N response' from hereon) can also be estimated from forest fertilization experiments (e.g., Gundale et al., 2014; Högberg et al., 2006). C-N responses observed in fertilization experiments implicitly account for site factors such as soil and climate conditions and nitrogen and phosphorus availability, whereas models may not capture all relevant processes (Thomas et al., 2013; Wang et al., 2010). While observational studies face the challenge of isolating the effect of nitrogen deposition from other drivers of forest growth (Sutton et al., 2008), fertilization experiments can do this by comparing carbon sequestration in fertilized plots and to non-fertilized control plots. Meta-analyses quantitatively synthesize results from many fertilization experiments in different regions to estimate average $\mathrm{C}-\mathrm{N}$ responses, as well as site factors driving variability in $\mathrm{C}-\mathrm{N}$ response. Despite these advantages, results from forest fertilization experiments have hardly been used to estimate global nitrogen-induced carbon storage.

Knowledge gap: For estimating the overall greenhouse gas impact of nitrogen, we lack an extrapolation of the forest $\mathrm{C}-\mathrm{N}$ response based on forest fertilization experiments. Also, the 
net greenhouse gas impact of nitrogen has been quantified globally (Butterbach-Bahl et al., 2011; De Vries et al., 2017; Erisman et al., 2011), but information on its spatial variation is lacking.

\section{I.5. Objectives and outline of this thesis}

This thesis aims to provide information on policy-relevant nitrogen indicators that capture trade-offs between nitrogen's adverse impacts and benefits, to support policies on sustainable nitrogen management in Europe and globally. This objective is divided into three subobjectives:

Objective 1: To estimate spatially explicit critical agricultural nitrogen losses, surpluses and inputs related to targets for air and water quality, and aggregate spatially explicit thresholds to derive safe nitrogen boundaries at the regional, continental, and global level. (Chapters 2 and 4)

Objective 2: To assess to what degree redistributing nitrogen inputs and increasing nitrogen use efficiency can contribute to meeting food demand while remaining within safe boundaries for nitrogen losses to air and water. (Chapters 3 and 4 )

Objective 3: To quantify global variation in the net climate impact of human nitrogen use by empirically modelling the effect of nitrogen deposition on forest carbon sequestration based on meta-analysis of forest fertilization experiments, and by comparing nitrogeninduced carbon sequestration to human $\mathrm{N}_{2} \mathrm{O}$ emissions (Chapters 5 and 6).

The focus of the three research objectives addressed in Chapters 2-6 in relation to the conceptual framework of the 'leaky pipe' (see Section 1.2) is shown in Figure 1.2.

To address the first objective, this thesis presents an approach to derive critical agricultural nitrogen inputs from thresholds in relation to air and water quality targets. Calculations are carried out using process-based, empirical models of agricultural nitrogen flows in the EU (INTEGRATOR, Chapter 2) and the world (IMAGE-GNM, Chapter 4). Starting from thresholds related to eutrophication of terrestrial and aquatic ecosystems and health effect of nitrate in groundwater, critical agricultural nitrogen inputs are calculated from nitrogen losses at which thresholds are reached. Spatially explicit critical nitrogen inputs are then aggregated to estimate bottom-up nitrogen boundaries for countries, regions, and the world.

To address the second objective, Chapters 3 and 4 move on from critical nitrogen losses and 


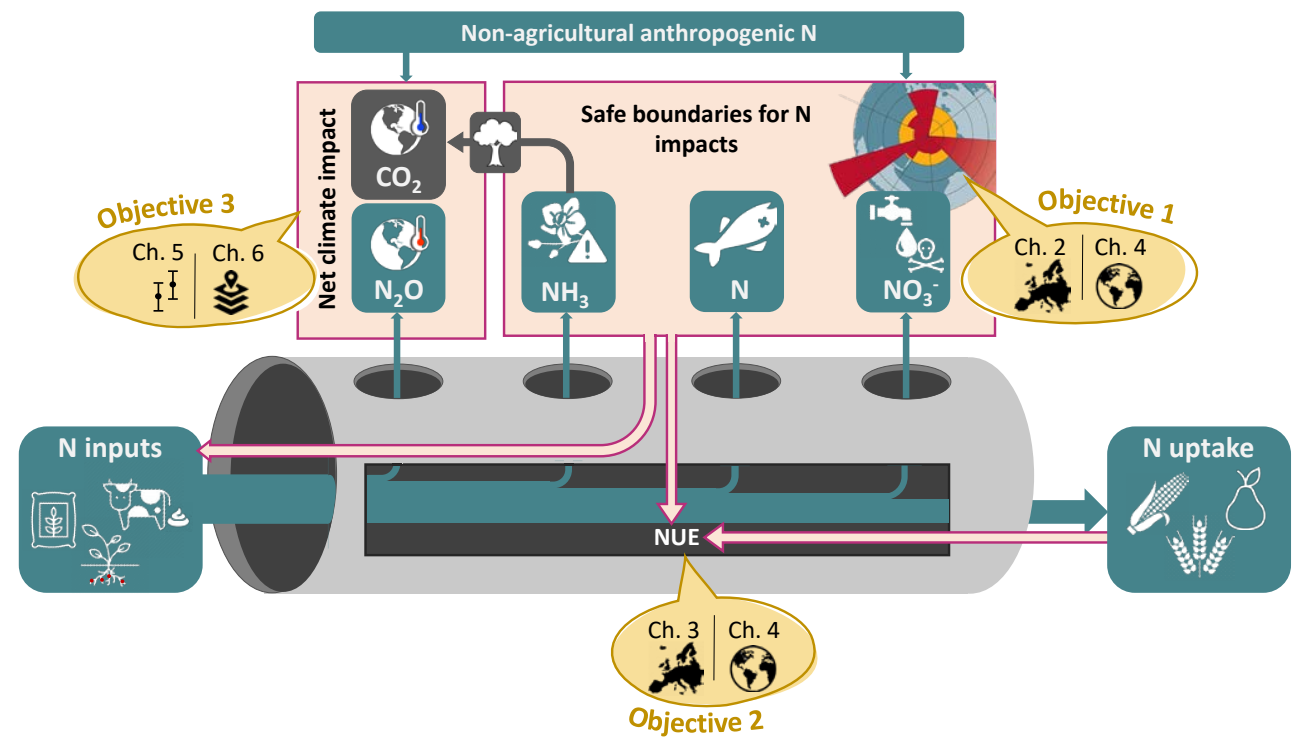

Figure I.2 | Schematic overview of the focus of the three research objectives addressed in this thesis and the corresponding chapters within the conceptual framework of the 'leaky pipe' as first proposed by Firestone and Davidson (1989) and further adapted by Oenema et al. (2009). Nitrogen inputs from fertilizer, biological nitrogen fixation, manure or deposition enter the pipe. Within the pipe, transformation processes lead to the escape of different forms of nitrogen through various 'holes', causing environmental impacts, while the remainder is taken up by crops. 'Blocking' one of the holes may increase leakages from other holes, unless inputs are decreased or nitrogen uptake is increased. For more information on the nitrogen impacts, see Box I.I.

nitrogen inputs (derived in Chapters 2 and 4) to assess possibilities for increasing nitrogen inputs to close yield gaps in regions where environmental thresholds have not been exceeded. To highlight the potential of improved nitrogen management to reconcile environmental and crop production targets, this thesis presents an approach to calculate spatially explicit targets for nitrogen use efficiency based on (i) safe limits for nitrogen losses and (ii) desired levels of crop production.

To meet the third objective, this thesis uses meta-analysis of forest fertilization experiments to quantify the nitrogen-induced carbon sink in aboveground tree woody biomass, a stable carbon pool with long turnover times. Average $\mathrm{C}-\mathrm{N}$ responses per forest biome derived from the meta-analysis are combined with nitrogen deposition estimates to derive global nitrogeninduced carbon storage (Chapter 5). Subsequently, meta-regression is used to disentangle environmental drivers of forest $\mathrm{C}-\mathrm{N}$ response (Chapter 6). Spatial variation in forest biomass $\mathrm{C}-\mathrm{N}$ response and nitrogen-induced forest carbon sink are estimated as a function 
of climate, soil fertility and tree characteristics. Results are compared to spatial variability in anthropogenic $\mathrm{N}_{2} \mathrm{O}$ emissions to assess how the net greenhouse gas impact of human nitrogen use varies globally.

The Synthesis (Chapter 7) summarizes the main findings, reflects on the methodology used to address the research questions and demonstrates two additional applications of the results presented in this thesis. First, the relationship between calculated nitrogen boundaries (Chapter 4) and the climatic impact of human nitrogen use (Chapter 6) is explored. Second, to demonstrate a possible policy application, results from Chapters 2, 3 and 4 are used to derive an indicator that can be used to measure countries' progress towards meeting nitrogen-related Sustainable Development Goals. 


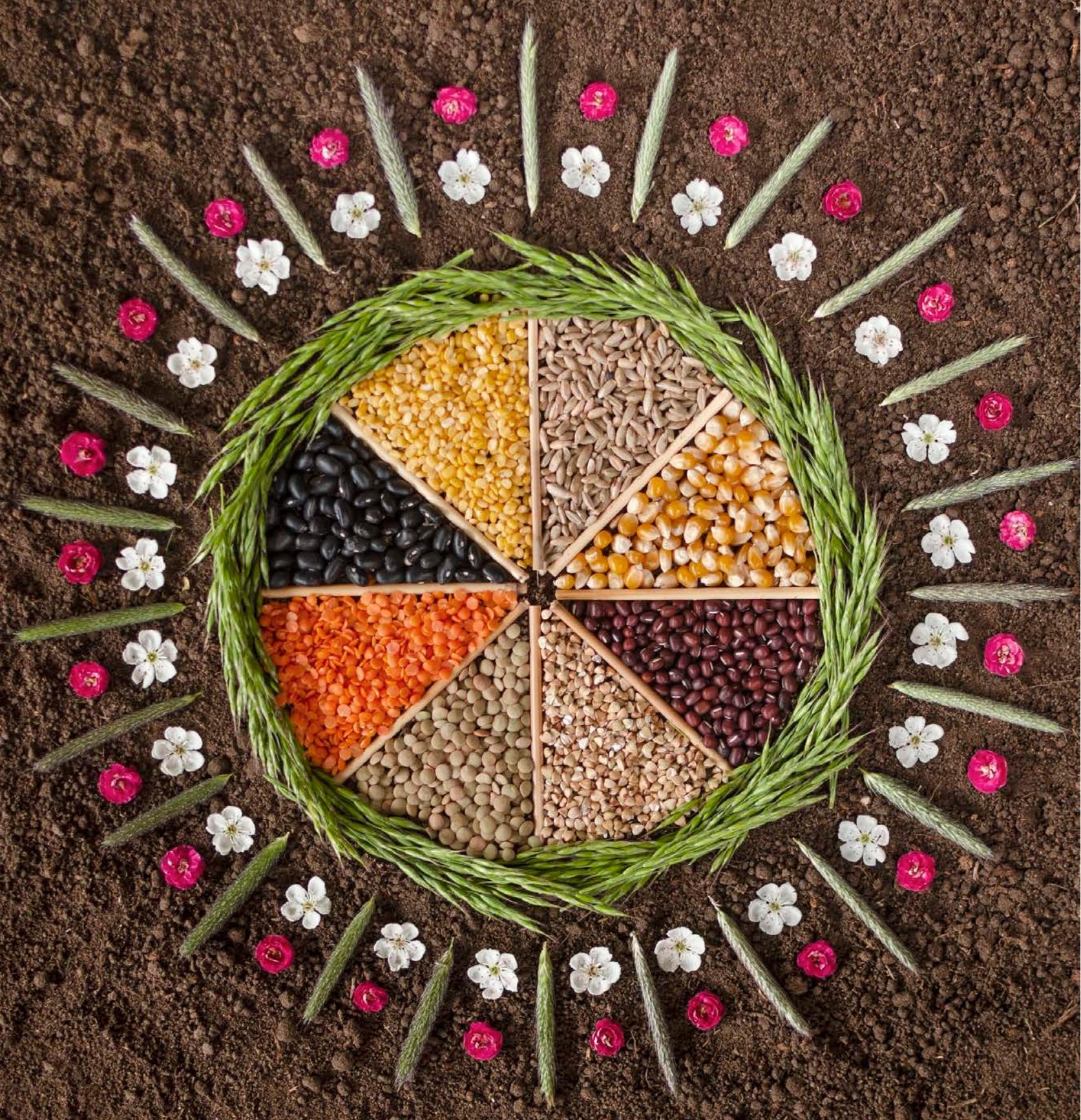




\section{Chapter 2}

Spatially explicit boundaries for agricultural nitrogen inpuits in the European Union to meet air and water quality targets

Pubjished as: Wim De Vries, Lena Schulte-Uebbing, Hans Kros, Jan Cees Voogd \& Geertrui loumagie (2021).

Science of the Jotal Environment, 147283. 


\section{Abstract}

Agricultural production in the EU has increased strongly since the 1940s, partly driven by increased nitrogen $(\mathrm{N})$ fertilizer and manure inputs. Increased $\mathrm{N}$ inputs and associated losses, however, adversely affect air and water quality, with widespread impacts on terrestrial and aquatic ecosystems and human health. Managing these impacts requires knowledge on 'safe boundaries' for $\mathrm{N}$ inputs, i.e., $\mathrm{N}$ flows that do not exceed environmental thresholds. We used a spatially explicit $\mathrm{N}$ balance model for the $\mathrm{EU}$ to derive boundaries for $\mathrm{N}$ losses and associated $\mathrm{N}$ inputs for three environmental thresholds: (i) $\mathrm{N}$ deposition onto natural areas to protect terrestrial biodiversity (critical $\mathrm{N}$ loads), (ii) $\mathrm{N}$ concentration in runoff to surface water $\left(2.5 \mathrm{mg} \mathrm{N}^{-1}\right)$ to protect aquatic ecosystems and (iii) nitrate $\left(\mathrm{NO}_{3}^{-}\right)$concentration in leachate to groundwater $\left(50 \mathrm{mg} \mathrm{NO}_{3}^{-1} \mathrm{1}^{-1}\right)$ to meet the EU drinking water standard. Critical $\mathrm{N}$ losses and inputs were calculated for $\sim 40,000$ unique soil-slope-climate combinations and then aggregated at country- and EU-level. To respect thresholds for $\mathrm{N}$ deposition, $\mathrm{N}$ inputs in the $\mathrm{EU}$ need to be reduced by $31 \%$ on average, ranging from $0 \%$ in several countries to $59 \%$ in Ireland and Denmark. The strongest reductions are required in intensive livestock regions, such as Benelux, Brittany and the Po valley. To respect thresholds for $\mathrm{N}$ concentration in runoff to surface water, $\mathrm{N}$ inputs need to be reduced by $43 \%$ on average, ranging from $2 \%$ in Estonia to $74 \%$ in the Netherlands. Average critical N inputs in view of the threshold for $\mathrm{NO}_{3}-$ concentration in leachate to groundwater are close to actual (year 2010) inputs, even though leaching thresholds are exceeded in $18 \%$ of agricultural land. Critical $\mathrm{N}$ inputs and their exceedances presented in this paper can inform more targeted mitigation policies than flat-rate targets for $\mathrm{N}$ loss reductions currently mentioned in $\mathrm{EU}$ policies.

\section{I. Introduction}

Nitrogen $(\mathrm{N})$ is an essential nutrient for plant growth. Since the late nineteenth century, human activities have approximately doubled reactive $\mathrm{N}$ inputs to the environment (Galloway et al., 2004). This increase has been driven by growing production of mineral $\mathrm{N}$ fertilizer (called 'fertilizer' hereafter), the cultivation of $\mathrm{N}$-fixing crops and the use of fossil fuels (Erisman et al., 2008; Fowler et al., 2013; Galloway et al., 2008; Smil, 2001). In Europe, crop production and livestock farming have increased rapidly since the early 1940s, associated with an increase in $\mathrm{N}$ fertilizer and manure inputs. Nitrogen inputs to EU agriculture reached a maximum around 1988 and decreased by 28\% between 1988 and 2010 while yields continued to increase (FAOSTAT, 2021). This decoupling of N inputs and yields was achieved through adoption of better farming practices stimulated by national implementation and 
enforcement of European legislation (e.g., Sutton et al., 2011). The number of dairy cattle in the EU, for example, decreased by about $1 \%$ per year since the implementation of the EU milk quota in 1984 until 2010, while milk production increased by $1 \%$ per year over the same period (FAOSTAT, 2021).

Only $60 \%$ of the $\mathrm{N}$ applied to agricultural land in Europe is taken up by crops, while much of the remainder is lost to the environment (Leip et al., 2011). Since the 1990s, the N use efficiency (NUE) of European agriculture has increased (van Grinsven et al., 2014) but by far not enough to reduce $\mathrm{N}$ losses sufficiently to meet environmental targets. Nitrogen that is lost to the environment leads to unwanted side-effects including: (i) ammonia $\left(\mathrm{NH}_{3}\right)$ emission, causing nutrient enrichment and decreases in plant species diversity through re-deposition onto terrestrial ecosystems (e.g., Spranger et al., 2008; De Vries et al., 2010) and affecting air quality by contributing to particulate matter (e.g., Pozzer et al., 2017); (ii) N runoff, causing eutrophication of surface waters (e.g., Camargo and Alonso, 2006); (iii) nitrate $\left(\mathrm{NO}_{3}^{-}\right)$ leaching to groundwater, affecting drinking water quality (e.g., Powlson et al., 2008; van Grinsven et al., 2006) and (iv) nitrous oxide $\left(\mathrm{N}_{2} \mathrm{O}\right)$ emissions, contributing to climate change (e.g., Freibauer, 2003). Nitrogen losses to air and water increased in Europe up to the late 1980s and decreased thereafter, due to overall reductions in $\mathrm{N}$ inputs as well as improved farming practices, such as better manure management in grasslands (Sutton et al., 2011).

Several policies at the international, European and national level have been implemented to reduce negative side-effects of excess $\mathrm{N}$ since 1990, including (i) the National Emission Ceilings Directive (EC, 2001) with emission targets for $\mathrm{NH}_{3}$ and nitrogen oxide $\left(\mathrm{NO}_{\mathrm{x}}\right)$, (ii) the Habitats Directive (EC, 1992), which indirectly regulates N emissions, (iii) the Nitrates Directive (EC, 1991) and Water Framework Directive (EC, 2000) with limits for N and phosphorus (P) concentrations in waterbodies and (iv) the Paris Agreement (UN, 2015) with targets for reducing emissions of greenhouse gases, such as $\mathrm{N}_{2} \mathrm{O}$ (Figure 2.1). However, integrated information on required reductions in agricultural $\mathrm{N}$ losses and related $\mathrm{N}$ inputs to meet policy targets is currently lacking. Such information is needed, for example, for evidence-based evaluation of targets stated in the recently released 'Farm to Fork' strategy (FFS) of the European Green Deal. The FFS aims for a sustainable food production system by reducing food waste, enhancing circularity (recycling of plant, animal and human waste) and improving nutrient use efficiency to 'protect the environment, preserve biodiversity and tackle climate change' (European Commission, 2020). One of targets of the FFS, linked to integrated nutrient management actions plans, is to reduce nutrient losses by at least $50 \%$ and fertilizer use by at least $20 \%$ in 2030 . Such generic targets for overall reductions in $\mathrm{N}$ inputs and losses link to the concept of a (planetary) boundary that defines a 'safe operating space' for human disturbance of the $\mathrm{N}$ cycle. 
Rockström et al. (2009a, 2009b) first proposed a planetary boundary for human $\mathrm{N}$ fixation (next to eight other Earth System processes), and claimed that avoiding the risk of transgressing tipping points requires drastic reductions in anthropogenic $\mathrm{N}$ inputs. A later assessment by De Vries et al. (2013), further elaborated by Steffen et al. (2015), improved the quantification of the planetary $\mathrm{N}$ boundary by accounting for several impacts on terrestrial and aquatic ecosystems (biodiversity loss and eutrophication) and for spatial variation in $\mathrm{N}$ inputs and related impacts, although only in a very approximate way. Various studies have downscaled the published planetary $\mathrm{N}$ boundary to estimate boundaries for countries or continents (e.g., Cole et al., 2014; Dao et al., 2018; EEA and FOEN, 2020; Nykvist et al., 2013), despite clear methodological drawbacks. Most importantly, regional boundaries derived in these studies do not reflect regional variation in agricultural $\mathrm{N}$ inputs and losses or the sensitivity of receiving ecosystems. Moreover, the current $\mathrm{N}$ boundary only considers required $\mathrm{N}$ input reductions to respect environmental thresholds, while strategies to balance benefits and threats of $\mathrm{N}$ should also consider possibilities to increase $\mathrm{N}$ inputs in areas where crop production is $\mathrm{N}$-limited and where $\mathrm{N}$ thresholds have not been exceeded (De Vries et al., 2013).

Moving from generic targets for reductions in total $\mathrm{N}$ inputs and $\mathrm{N}$ losses towards targeted mitigation actions in European policy requires identifying regional hotspots for $\mathrm{N}$-related impacts, i.e., areas where current $\mathrm{N}$ inputs and related $\mathrm{N}$ losses (strongly) exceed environmental thresholds. This requires a spatially explicit assessment of (i) $\mathrm{N}$ concentrations in environmental compartments that should not be exceeded to achieve environmental targets (called 'critical limits' hereafter), (ii) $\mathrm{N}$ losses at which critical limits are reached but not exceeded (called 'critical $\mathrm{N}$ losses' hereafter) and (iii) agricultural $\mathrm{N}$ inputs that correspond to these critical $\mathrm{N}$ losses (called 'critical $\mathrm{N}$ inputs' hereafter). Such an approach allows to derive $\mathrm{N}$ boundaries at EU- or country-level by aggregating local critical $\mathrm{N}$ inputs, rather than by downscaling a planetary $\mathrm{N}$ boundary based on per-capita shares (e.g., EEA and FOEN, 2020; Lucas et al., 2020) or other approaches.

This chapter presents spatially explicit critical $\mathrm{N}$ losses to air and water and related critical agricultural $\mathrm{N}$ inputs for the EU. Critical losses and inputs were calculated from thresholds to avoid (i) biodiversity loss due to $\mathrm{NH}_{3}$ emissions and re-deposition onto terrestrial ecosystems, (ii) eutrophication of surface water due to $\mathrm{N}$ runoff and (iii) $\mathrm{NO}_{3}{ }^{-}$pollution of drinking water due to leaching. Regional risks for $\mathrm{N}$ impacts were identified by assessing where $\mathrm{N}$ inputs and losses in the reference year (2010) exceed critical levels. All calculations were performed for the year 2010, but as $\mathrm{N}$ inputs in the EU have remained relatively constant since then, results still apply to the current situation. Critical $\mathrm{N}$ inputs were derived while assuming that the relations between inputs, losses and uptake remain unchanged. For example, NUE (defined 


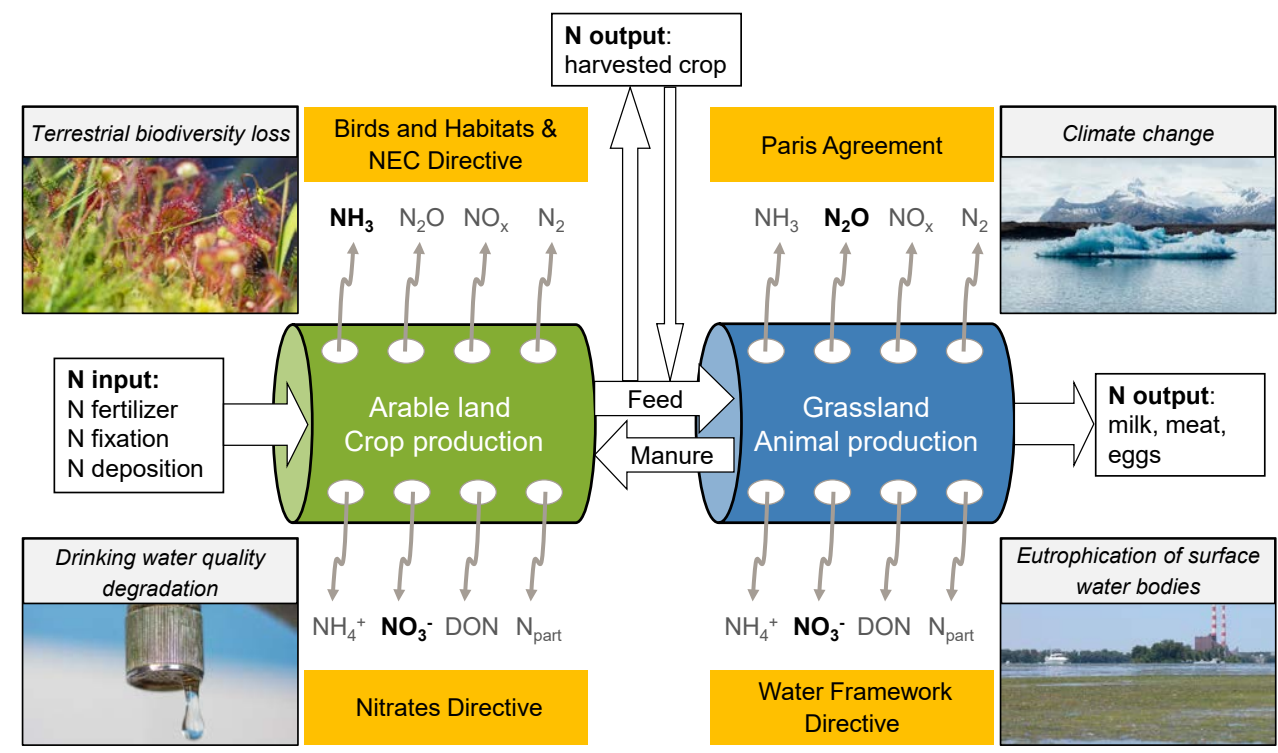

Figure 2.I | Illustration of agricultural $\mathrm{N}$ losses (arrows) and related impacts (illustrated by photographs), and European directives and agreements aiming to reduce these impacts (yellow boxes) (modified after Oenema et al., 2009).

as crop $\mathrm{N}$ removal divided by total $\mathrm{N}$ input) was assumed constant, thus implying that reducing $\mathrm{N}$ inputs to respect thresholds leads to reduced crop production. Opportunities to respect thresholds without crop production losses (or even while increasing yields) through improved agricultural management are explored Chapter 3.

\subsection{Methods and data}

Actual (year 2010) and critical $\mathrm{N}$ inputs and losses were calculated with the model INTEGRATOR (De Vries et al., 2011b), which is based on the MITERRA-Europe approach (Velthof et al., 2009). INTEGRATOR calculates $\mathrm{N}$ excretion in housing systems and $\mathrm{N}$ inputs to agricultural soils and uses empirical linear models to predict resulting $\mathrm{N}\left(\mathrm{NH}_{3}, \mathrm{~N}_{2} \mathrm{O}, \mathrm{NO}_{\mathrm{x}}\right.$, and $\mathrm{N}_{2}$ ) emissions, runoff and leaching (see Figure 2.2). INTEGRATOR calculates $\mathrm{N}$ balances for ca. 40,000 Nitrogen Calculation Units (NCUs), which are clusters of $1 \mathrm{~km} \times 1 \mathrm{~km}$ pixels with identical soil type, slope class and altitude class within a NUTS 3 region (De Vries et al., 2011b, 2011c; EC, 2017). Results thus obtained were aggregated at the level of member states (called 'countries' hereafter) and the EU. The following sections present an overview of the calculations and input data; details are provided in the Supplementary Material. 


\subsection{Assessment of actual nitrogen inputs, offtake and losses}

Data and approaches used to calculate $\mathrm{N}$ inputs, $\mathrm{N}$ offtake and $\mathrm{N}$ losses in INTEGRATOR are summarized below (see also Table 2.1), while details are provided in Suppl. Text S2.1-S2.2.

\section{Nitrogen inputs to agricultural soils}

Total $\mathrm{N}$ inputs to agricultural soils are calculated as the sum of $\mathrm{N}$ inputs from fertilizer, manure (either excreted by grazing animals or excreted in housing systems and applied to soils), biosolids, atmospheric deposition, biological fixation and net mineralisation (Figure 2.2).

Crop-specific fertilizer N inputs at NCU level were calculated using a 'balanced N fertilization approach. Fertilizer input was estimated as the difference between crop N demand and nonfertilizer $\mathrm{N}$ inputs, i.e., manure, biosolids, biological fixation and atmospheric deposition (see Table 2.1). Fertilizer inputs thus derived were scaled to ensure that aggregated country-level fertilizer inputs matched FAO data on total $\mathrm{N}$ fertilizer consumption for 2010. Further details are provided in Supplementary Text S2.1.1.

Manure $\mathrm{N}$ inputs were calculated by multiplying livestock numbers with country-specific $\mathrm{N}$ excretion rates for eight animal categories (Tables $2.1 \&$ S2.1). Total N excreted was divided over animals in housing systems and by grazing animals in pastures, based on country-level data on the number of grazing days (Klimont and Brink, 2004; Table S2.2). Manure excreted in housing systems was allocated to either arable land or grassland/fodder crops, based on country-specific fractions that also vary by manure type (Table S2.2). Further details are provided in Supplementary Text S2.1.2.

Biosolids $\mathrm{N}$ inputs, consisting of both sludge and compost, were calculated by multiplying national biosolids application rates with estimated $\mathrm{N}$ contents (dry matter basis), using national data for sludge and generic data (median values at EU level) for three compost types, as described in Supplementary Text S2.1.3. National biosolids N inputs were downscaled to NCUs based on the distribution of manure inputs.

Biological $\mathrm{N}$ fixation (BNF) by pulses and soybeans was calculated as 1.3 times the amount of $\mathrm{N}$ in harvested products. For other arable crops, BNF by free-living soil bacteria was set to $2 \mathrm{~kg} \mathrm{~N} \mathrm{ha}^{-1} \mathrm{yr}^{-1}$ (Paul and Clark, 1996). In grassland, BNF is determined by the clover fraction, which in turn is influenced by $\mathrm{N}$ inputs. At annual $\mathrm{N}$ input rates near $250 \mathrm{~kg} \mathrm{~N}$ $\mathrm{ha}^{-1}$, the contribution of BNF by clover is negligible and $\mathrm{N}$ is only fixed by free-living soil bacteria (van der Meer, 2002; van der Meer and Baan Hofman, 1989). As no information on grassland clover fraction was available, we assumed an average BNF rate of $5 \mathrm{~kg} \mathrm{~N} \mathrm{ha}^{-1} \mathrm{yr}^{-1}$ for grasslands, similar to Velthof et al. (2009). 


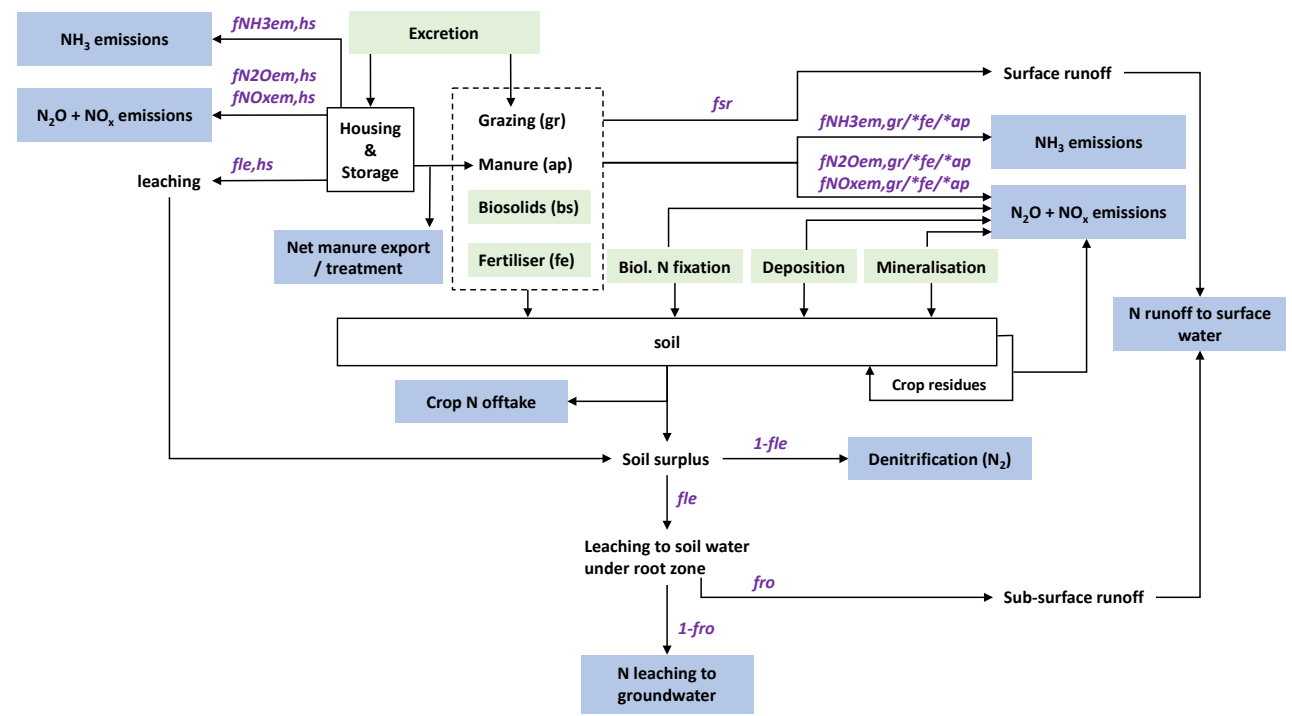

Figure 2.2 Schematic presentation of the calculated $\mathrm{N}$ flows in INTEGRATOR, adapted after the MITERRA-EUROPE model (Velthof et al., 2009); see main text for explanation of abbreviations and Supplementary Text S2.2 for description of calculation methods). At NCU level, the sum of total gross N inputs (green boxes) equals the sum of all $\mathrm{N}$ outputs (blue boxes).

Atmospheric $\mathrm{N}$ deposition at $50 \mathrm{~km} \times 50 \mathrm{~km}$ was derived from the EMEP model (Simpson et al., 2012) for the year 2010 (Fagerli et al., 2012) and downscaled to NCUs.

Net $\mathrm{N}$ mineralization (loss of soil $\mathrm{N}$ pool) was only assumed to occur in peat soils (accounting for $\sim 2 \%$ of EU agricultural area). Nitrogen supply via mineralization was calculated by dividing net $\mathrm{C}$ mineralization (derived as a function of groundwater level) by the soil C-N ratio. Information on water table depths was related to land use. Soil C-N ratios were set to 30 for oligotrophic peat soils and to 15 for eutrophic peat soils, based on mean C-N ratios for European peat soils from the WISE3 database (Batjes, 2009); see De Vries et al. (2021a) for details.

\section{Nitrogen offtake by crops}

Cropland: Crop $\mathrm{N}$ removal by harvest (here denoted as $\mathrm{N}$ offtake, but often referred to as $\mathrm{N}$ uptake or removal) was calculated by multiplying crop yields for approximately 30 major crops with crop-specific $\mathrm{N}$ contents in harvested products. Crop $\mathrm{N}$ contents were allowed to vary up to a maximum value (Table S2.3) depending on the availability of $\mathrm{N}$ input (see Supplementary Text S2.1.1). Country-level average yields for arable crops (in $\mathrm{kg}$ fresh weight) were derived from FAO statistics (FAOSTAT, 2018), and were downscaled to reflect 
Table 2.I | Data and approaches used to assess $\mathrm{N}$ inputs, $\mathrm{N}$ offtake and $\mathrm{N}$ losses in INTEGRATOR.

\begin{tabular}{|c|c|}
\hline Model input data & Assessment \& data sources \\
\hline$N$ excretion & $\begin{array}{l}\text { Livestock numbers multiplied with country-specific } \mathrm{N} \text { excretion rates for } 8 \text { animal } \\
\text { categories from Asman et al. (20II) as used in GAINS model (Amann et al., 20II). }\end{array}$ \\
\hline Livestock numbers & $\begin{array}{l}\text { Livestock numbers at NUTS } 3 \text { level from the EUROSTAT/EUROFARM database; } \\
\text { downscaled to } 1 \mathrm{~km} \times 1 \mathrm{~km} \text { and aggregated to NCU level }\end{array}$ \\
\hline $\mathrm{N}$ fertilizer application & $\begin{array}{l}\text { Country data from FAOSTAT (20I8), downscaled to NCUs based on crop N demand } \\
\text { accounting for non-fertilizer N inputs and using a balanced } \mathrm{N} \text { fertilization approach }\end{array}$ \\
\hline N grazing & $\mathrm{N}$ excreted by grazing animals multiplied by no. of grazing days (Klimont and Brink, 2004) \\
\hline $\mathrm{N}$ manure application & Total $\mathrm{N}$ excretion minus $\mathrm{N}$ grazing \& $\mathrm{N}$ losses from housing and manure storage systems \\
\hline $\mathrm{N}$ biosolids application & Country-level data downscaled to NCU level based on distribution of manure inputs \\
\hline Biological $\mathrm{N}$ fixation & $\begin{array}{l}\text { I. } 3 \text { times harvested } \mathrm{N} \text { for pulses and legumes }, 25 \mathrm{~kg} \mathrm{~N} \mathrm{ha}^{-1} \mathrm{yr}^{-1} \text { for rice, } 2 \mathrm{~kg} \mathrm{~N} \mathrm{ha-1}^{-1} \mathrm{yr}^{-1} \text { for } \\
\text { all other arable crops and } 5 \mathrm{~kg} \mathrm{~N} \mathrm{ha-1} \mathrm{yr}^{-1} \text { for grassland }\end{array}$ \\
\hline $\mathrm{N}$ deposition & Data from EMEP model for 2010 (Fagerli et al., 20I2), downscaled to NCU level \\
\hline $\mathrm{N}$ mineralisation & $\begin{array}{l}\text { Calculated for peat soil only by dividing } \mathrm{C} \text { mineralisation (estimated based on a } \\
\text { relationship with groundwater level) by soil C-N ratio }\end{array}$ \\
\hline Crop $\mathrm{N}$ offtake & Crop (or grassland) yields multiplied with crop $\mathrm{N}$ content \\
\hline Crop yield & $\begin{array}{l}\text { Country-level data from FAOSTAT; downscaled to NCU level based on spatial variation in } \\
\text { actual wheat yield from the GlobalYield Gap Atlas }\end{array}$ \\
\hline Grassland yield & $\begin{array}{l}\text { Publication by Smit et al. (2008) on production at field level. Removal by grazing or mowing } \\
\text { for consumption of grass is calculated by multiplying the grassland production with a } \\
\text { consumption ratio of } 0.8 \text { for intensively managed grasslands and of } 0.4 \text { for extensively } \\
\text { managed grasslands. Grassland with yields lower than } 4.5 \mathrm{t} \text { dry matter ha- } \mathrm{yr}^{-1} \text { are } \\
\text { considered extensive grasslands, above } 4.5 \mathrm{tdry} \text { matter ha-1 } \mathrm{yr}^{-1} \text { intensive grasslands. }\end{array}$ \\
\hline
\end{tabular}

\section{Crop $\mathrm{N}$ content}

$\mathrm{N}$ emission fractions \& $\mathrm{N}$ leaching fraction housing and manure storage (fNH $\mathrm{fN}_{3} \mathrm{em}$,hs; $\mathrm{fN}_{2} \mathrm{Oem}$,hs; $\mathrm{fNO}_{x} \mathrm{em}$,hs; fle,hs)

$\mathrm{N}$ emission fractions soil ( $\mathrm{fNH}_{3} \mathrm{em}$ (gr,fe,ap); $\mathrm{fN}_{2} \mathrm{Oem}$ (gr,fe,ap); fNOxem(gr,fe,ap))

\section{$\mathrm{N}$ surface runoff} fraction (fsr) $\mathrm{N}$ leaching fraction (fle)

$N$ sub-surface runoff fractions (fro)
Crop-specific $\mathrm{N}$ contents varying with $\mathrm{N}$ input up to a maximum value (see Table S2.3)

$\mathrm{NH}_{3}, \mathrm{~N}_{2} \mathrm{O}$ : Country-specific emission fractions for different housing systems based on GAINS model (Amann et al., 20II)

$\mathrm{NO}_{\mathrm{x}}: 0.3 \%$ of $\mathrm{N}$ excretion

Leaching: Function of manure type, housing system and floor type (Velthof et al., 2009)

$\mathrm{NH}_{3}$ : Country-specific data from GAINS model (Amann et al., 20I I). Grazing: countryspecific average emission fractions; Manure application: emission fractions for 8 animal categories and 2 manure types (solid/liquid), further adjusted based on assumed implementation of low-emission application techniques; Fertilizer application: countryspecific emission fractions for urea-based fertilizers and other fertilizers

$\mathrm{N}_{2} \mathrm{O}$ : Function of $\mathrm{N}$ source, application technique, soil type, land use and precipitation, based on Lesschen et al. (201 I)

$\mathrm{NO}_{\times}: 0.6 \times \mathrm{N}_{2} \mathrm{O}$ emission, based on a review paper of Skiba et al. (1997)

Fraction of $\mathrm{N}$ input to soil by inorganic and organic fertilizers, calculated as a function of slope class, land use, precipitation surplus, soil type and depth to rock (Velthof et al., 2009)

Fraction of soil $\mathrm{N}$ surplus, calculated as a function of soil type, land use, soil organic content, precipitation surplus, temperature and rooting depth (Velthof et al., 2009)

Fraction of $\mathrm{N}$ leaching below root zone, calculated as a function of soil type, moisture class and slope, derived from the IMAGE groundwater model (Keuskamp et al., 20I2)

\footnotetext{
' The value of I.3 for dry pulses and soy bean was calculated based on Herridge et al. (2008) as $N_{\text {shoots }} / N_{\text {grain }} \times I / H I \times S R_{\text {ratio }} \times$ frNfix; where $\mathrm{N}_{\text {shoots }}$ and $\mathrm{N}_{\text {grain }}$ is the $\mathrm{N}$ content in shoots and grain (\%), $\mathrm{HI}$ is harvest index, $\mathrm{SR}_{\text {ratio }}$ is the (shoot + root) / shoot ratio to account for $\mathrm{N}$ fixation in roots and frNfix is a crop-specific fraction of $\mathrm{N}$ in the crop that is derived from $\mathrm{N}$ fixation.
} 
sub-national variation in crop yields using data from the Global Yield Gap Atlas (GYGA, www.yieldgap.org). We used data on sub-national wheat yields from GYGA to introduce sub-national variation in yields of all INTEGRATOR crops; see Supplementary Text S2.1.4 for details.

Grassland: Spatially explicit grassland yields were derived from European grassland productivity estimates based on regional, national and international census statistics (Smit et al., 2008). Three grassland types were distinguished: intensively managed grasslands, extensively managed grasslands and rough grazing areas (the latter was not included in the assessments of critical $\mathrm{N}$ inputs). This distinction is used for the allocation of manure to these land use classes (see Supplementary Text S2.1.2). The total area of managed grassland in INTEGRATOR was obtained from the CLUE model and includes the CLUE category 'pasture'. Managed grasslands were classified as intensive (dry matter yield $>4.5 \mathrm{t} \mathrm{ha}^{-1} \mathrm{yr}^{-1}$ ) or extensive (dry matter yield $<4.5 \mathrm{t} \mathrm{ha}^{-1} \mathrm{yr}^{-1}$ ). $\mathrm{N}$ removal by grass intake (grazing) or harvest (mowing) was calculated by multiplying grassland production from Smit et al. (2008) with a grass removal ratio of 0.8 for intensive and 0.4 for extensive grasslands. The resulting EU average grass intake ratio $(0.63)$ is comparable to the ratio of total EU grass $\mathrm{N}$ intake by beef and dairy cattle and total grassland $\mathrm{N}$ production as derived with the GLEAM model for the year 2010 (Gerber et al., 2013).

\section{Nitrogen losses to air and water}

The fate of $\mathrm{N}$ in the agricultural system was calculated as a sequence of occurrences, adapted after the MITERRA-EUROPE model (Velthof et al., 2009; see Figure 2.2 for an overview and Supplementary Text S2.2 for details). Nitrogen emissions and surface runoff were calculated by multiplying $\mathrm{N}$ inputs with emission fractions (fem) and surface runoff fractions (fsr). Country- and input-specific emissions fractions were used to calculate $\mathrm{NH}_{3}, \mathrm{~N}_{2} \mathrm{O}, \mathrm{NO}_{\mathrm{x}}$ and $\mathrm{N}_{2}$ emissions from animal housing and manure storage system, from manure excreted by grazing animals and from manure and fertilizer application to soils (see Figure S2.1). The soil $\mathrm{N}$ surplus ( $\mathrm{N}$ inputs minus the sum of $\mathrm{N}$ offtake, $\mathrm{N}$ emission and $\mathrm{N}$ surface runoff) is either leached under the root zone (fle) or denitrified (1-fle). Leached $\mathrm{N}$ is divided over sub-surface runoff (fro) and leaching to (deep) groundwater (1-fro). All $\mathrm{N}$ transformation processes (emissions, offtake, leaching and runoff) are linear functions of $\mathrm{N}$ input.

$\mathrm{N}$ loss fractions are generally a function of the type of $\mathrm{N}$ management, climate, land use, soil and/or slope (Table 2.1). More specifically, $\mathrm{NH}_{3}$ emission fractions vary per fertilizer type, animal category (mainly cattle, pig and poultry) and manure type (solid or liquid); see Supplementary Text S2.2.1 for details. Emission fractions for $\mathrm{N}_{2} \mathrm{O}$ and runoff and leaching fractions are a function of land use (grassland, arable land), climate (precipitation, 
temperature), slope and soil texture and/or soil organic carbon (SOC); see Supplementary Text S2.2.2 for details. Soil properties were derived from the joint WISE, SPADE 1 and EFSDB databases, which contain data from approximately 3,600 soil profiles. Soil properties at NCU level were derived with a multivariate regression kriging model accounting for the spatial structure of the soil properties and their dependency on explanatory variables such as soil type and land cover (Heuvelink et al., 2016).

\subsubsection{Calculation of critical nitrogen losses and inputs}

Critical $\mathrm{N}$ inputs and $\mathrm{N}$ losses in view of thresholds for environmental impacts were derived in three steps (Figure 2.3):

1. Identification of critical limits for indicators related to environmental impacts of $\mathrm{N}$,

2. Calculation of critical $\mathrm{N}$ losses to air and water from critical limits,

3. Calculation of critical $\mathrm{N}$ inputs to agriculture from critical $\mathrm{N}$ losses.

Critical $\mathrm{N}$ inputs and losses were calculated for three critical limits: (i) atmospheric $\mathrm{N}$ deposition levels onto terrestrial ecosystems (critical loads) to limit biodiversity loss; (ii) $\mathrm{N}$ concentrations in runoff to surface water to limit eutrophication and (iii) $\mathrm{NO}_{3}{ }^{-}$concentration in leachate to groundwater to meet drinking water standards related to human health impacts (Figure 2.3). The assessment of critical $\mathrm{N}$ inputs did not include (i) impacts of $\mathrm{N}_{2} \mathrm{O}$ emissions on climate change and (ii) air quality impacts from particulate matter (PM) formation caused by $\mathrm{NH}_{3}$ emissions. For both impacts, deriving limits for agricultural emissions is somewhat arbitrary as other pollutants are the main contributors, and 'critical' levels for $\mathrm{N}_{2} \mathrm{O}$ in view of climate change or $\mathrm{NH}_{3}$ in view of $\mathrm{PM}$ formation are thus not given in legislation or literature. The contribution of $\mathrm{NH}_{3}$ to $\mathrm{PM}$ formation also varies in time and space and depends on local meteorological conditions, and an assessment would thus require detailed air quality models that capture these processes. Regarding nitrogen's impact on climate change, at the European level the cooling effect due to additional $\mathrm{CO}_{2}$ sequestration resulting from deposition of agricultural $\mathrm{NH}_{3}$ emissions onto forests largely offsets the warming effect of $\mathrm{N}_{2} \mathrm{O}$ (De Vries et al., 2011a), though the magnitude of $\mathrm{N}$-induced $\mathrm{CO}_{2}$ sequestration is much more uncertain than the magnitude $\mathrm{N}_{2} \mathrm{O}$ emissions.

Details on the approach to derive critical limits for $\mathrm{N}$ indicators and to calculate critical losses and inputs from these limits are presented in the following sections; an overview of central data and assumptions is shown in Table 2.2. 


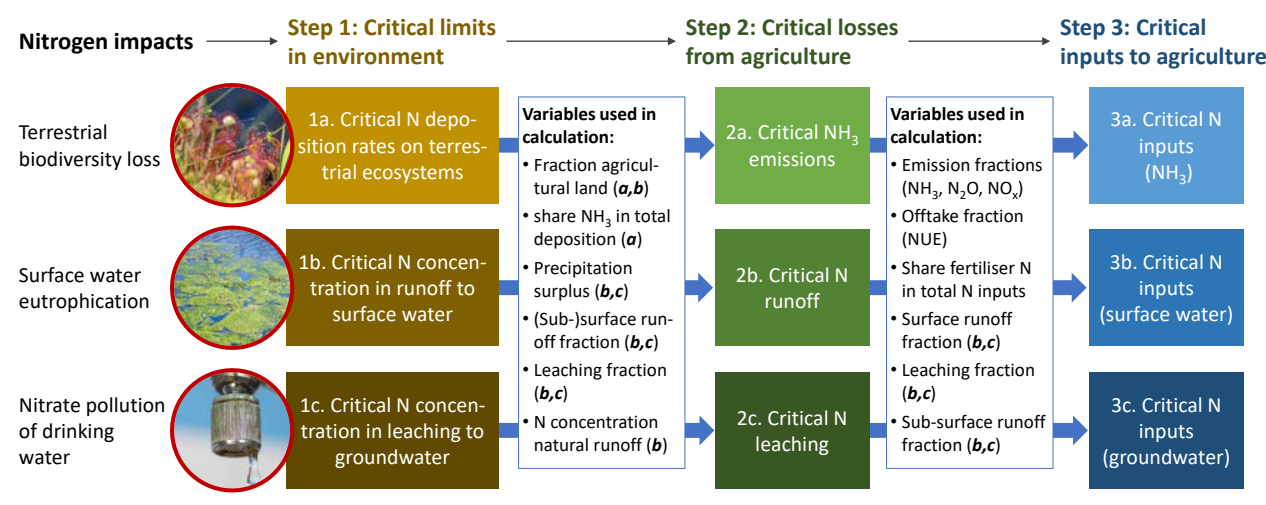

Figure 2.3 | Schematic overview of steps for calculation of critical $N$ inputs to respect thresholds for three nitrogen impacts (a, terrestrial biodiversity loss, b, surface water eutrophication and $\mathbf{c}$, nitrate pollution of drinking water). Steps are (I) derive indicators for critical limits in the environment to avoid impacts, (2) derive related critical $\mathrm{N}$ losses from agriculture and (3) derive associated critical $\mathrm{N}$ inputs to agriculture. White boxes show variables used in each step of the calculations.

\section{Critical limits for nitrogen indicators and related critical nitrogen losses}

Critical ammonia emissions in view of nutrient enrichment of terrestrial ecosystems (biodiversity effects)

Nitrogen deposition onto terrestrial ecosystems causes nutrient enrichment and shifts in plant species composition, resulting in biodiversity decline. Ecosystems differ strongly in their sensitivity to $\mathrm{N}$ deposition. To account for these differences, critical loads are derived for different ecosystem types. Critical loads are defined as $\mathrm{N}$ deposition rates below which risks for adverse effects on biodiversity are low.

Countries in Europe use different approaches to derive critical $\mathrm{N}$ loads, such as empirical values (e.g., Bobbink et al., 2003) or model calculations (e.g., De Vries et al., 2007), each with its own advantages and drawbacks (see De Vries et al., 2010). Spatially explicit critical N loads for Europe reported by countries have been presented in various papers (e.g., Hettelingh et al., 2014, 2015a), but as approaches vary between countries, differences in critical loads do not only reflect variation in ecosystems' sensitivity to $\mathrm{N}$ but also differences in methodology (as demonstrated by abrupt changes in critical loads at country borders).

Rather than using the country estimates, we derived critical $\mathrm{N}$ loads for Europe with a consistent model-based approach, based on a critical $\mathrm{N}$ concentration in soil solution. A critical concentration of $3 \mathrm{mg} \mathrm{N}^{-1}$ was used for forests and $3.5 \mathrm{mg} \mathrm{N}^{-1}$ for semi-natural vegetation, which are values that indicate risks for vegetation shifts (De Vries et al., 2007). Input data included data on land cover (Slootweg et al., 2005), soil type (from the European 
Table 2.2 | Overview of data and assumptions that were used to calculate critical nitrogen losses and related critical nitrogen inputs from defined critical limits for nitrogen indicators for impacts on terrestrial biodiversity, surface water eutrophication and drinking water quality.

\begin{tabular}{|c|c|c|c|}
\hline $\begin{array}{l}\mathbf{N} \text { indicators } \\
\& \text { used critical } \\
\text { limits }\end{array}$ & $\begin{array}{l}\text { Data affecting critical } \mathbf{N} \text { loss } \\
\text { calculations }\end{array}$ & Important assumptions & $\begin{array}{l}\text { Remarks on } \\
\text { relation between } \\
\text { indicator and risk }\end{array}$ \\
\hline $\begin{array}{l}\text { Critical } \mathrm{N} \\
\text { deposition rates } \\
\text { onto terrestrial } \\
\text { ecosystems to } \\
\text { avoid biodiversity } \\
\text { loss }\end{array}$ & $\begin{array}{l}\text { Critical } \mathrm{NH}_{3} \text { emissions from agri- } \\
\text { culture, based on (see Eq. } 2 . \mathrm{I} \text { ): } \\
\text { - Critical deposition threshold } \\
\text { (ecosystem-dependent critical } \\
\text { loads, from De Vries et al. } 2007 \\
\text { and Hettelingh et al. 20I4) } \\
\text { - Contribution of } \mathrm{NH}_{3} \text { to total } \\
\left(\mathrm{NH}_{3}+\mathrm{NO}_{x} \text { ) deposition }\right. \\
\text { - Share of agricultural land } \\
\text { within a region }\end{array}$ & $\begin{array}{l}\text { - Risk is related to the average critical } \\
\mathrm{N} \text { deposition level in a NUTS region } \\
\text { - For each } \mathrm{NCU} \text { within a NUTS } \\
\text { region, the } \mathrm{NH}_{3} \text { emission, should } \\
\text { not cause exceedance of the NUTS } \\
\text { average critical } \mathrm{N} \text { deposition level. } \\
\text { - } \mathrm{NO}_{x} \text { emissions reduced proportion- } \\
\text { ally with agricultural } \mathrm{NH}_{3} \text { emissions } \\
\text { - } \mathrm{N} \text { emission equals } \mathrm{N} \text { deposition } \\
\text { within a NUTS region i.e. no trans- } \\
\text { port of emitted } \mathrm{N} \text { across NUTS (see } \\
\text { Eq. } \mathrm{S} 2.3 .19 \text { ) } \\
\text { - Homogenous deposition rates } \\
\text { within a region (see Eq. S2.3.I8) }\end{array}$ & $\begin{array}{l}\text { - Risk also depend } \\
\text { on the presence } \\
\text { of vulnerable } \\
\text { / protected } \\
\text { ecosystems within } \\
\text { a NUTS region }\end{array}$ \\
\hline $\begin{array}{l}\text { Critical } \mathrm{N} \\
\text { concentration in } \\
\text { surface waters to } \\
\text { avoid eutrophi- } \\
\text { cation }\end{array}$ & $\begin{array}{l}\text { Critical } \mathrm{N} \text { runoff from agricul- } \\
\text { ture, based on (see Eq. } 2 \text { ): } \\
\text { - Critical } \mathrm{N} \text { concentration in } \\
\text { runoff }=2.5 \mathrm{mg} \mathrm{N}^{-1} \\
\text { - Water volume of runoff } \\
\text { - } \mathrm{N} \text { concentration in runoff from } \\
\text { natural land = } 0.5 \mathrm{mg} \mathrm{N}^{-1} \\
\text { - Share of agricultural runoff in } \\
\text { total runoff within a region }\end{array}$ & $\begin{array}{l}\mathrm{N} \text { concentration in runoff as a proxy } \\
\text { for } \mathrm{N} \text { concentration in surface water: } \\
\text { - } \mathrm{N} \text { load from non-agricultural sources } \\
\text { not considered } \\
\text { - } \mathrm{N} \text { removal / retention within surface } \\
\text { water not considered }\end{array}$ & $\begin{array}{l}\text { - Eutrophication } \\
\text { risk also depends } \\
\text { on phosphorus } \\
\text { load } \\
\text { - Critical } \\
\text { concentrations } \\
\text { vary depending on } \\
\text { the type of water } \\
\text { body (e.g., Poikane } \\
\text { et al., 2019) }\end{array}$ \\
\hline $\begin{array}{l}\text { Critical nitrate } \\
\text { concentration in } \\
\text { groundwater to } \\
\text { avoid exceeding } \\
\text { EU drinking } \\
\text { water norm }\end{array}$ & $\begin{array}{l}\text { Critical } \mathrm{N} \text { leaching from agricul- } \\
\text { ture, based on (see Eq. } 3 \text { ): } \\
\text { - Critical } \mathrm{N} \text { concentration in } \\
\text { leachate = } 11.3 \mathrm{mg} \mathrm{NO}_{3}-\mathrm{N}^{-1} \\
\text { - Water volume of leaching }\end{array}$ & $\begin{array}{l}\mathrm{N} \text { concentration in leachate as a proxy } \\
\text { for } \mathrm{N} \text { concentration in groundwater: } \\
\text { - Effects of } \mathrm{N} \text { accumulation and/ } \\
\text { or } \mathrm{N} \text { removal in groundwater not } \\
\text { considered } \\
\text { - Effects of lateral flow from neigh- } \\
\text { bouring regions not considered }\end{array}$ & $\begin{array}{l}\text { Not all ground- } \\
\text { water is used for } \\
\text { drinking water }\end{array}$ \\
\hline
\end{tabular}

Soil Database v2; JRC, 2006) and climate (Mitchell et al., 2004). Only in high-rainfall areas where our model-based approach lead to implausibly high critical $\mathrm{N}$ loads, we used critical N loads from Hettelingh et al. (2014). Derived critical N loads follow a similar pattern as those published in Hettelingh et al. (2014) but do not show abrupt changes at country borders. Critical $\mathrm{N}$ loads were calculated for more than 500,000 polygons and then aggregated by calculating area-weighted mean critical $\mathrm{N}$ loads at NUTS 3 resolution.

Critical levels of agricultural $\mathrm{NH}_{3}$ emission for each NCU were derived from average critical 
$\mathrm{N}$ deposition rates (i.e., critical loads) in the NUTS 3 region in which the NCU is located, accounting for dilution of agricultural $\mathrm{NH}_{3}$ emissions and the contribution of $\mathrm{NH}_{3}$ to total $\mathrm{N}\left(\mathrm{NH}_{3}+\mathrm{NO}_{\mathrm{x}}\right)$ deposition. We assumed that (i) all $\mathrm{NH}_{3}$ emitted in a NUTS 3 region is also deposited in the same NUTS region, (ii) $\mathrm{N}$ deposition rates on agricultural land and natural land are similar (see Figure S2.3) and (iii) the contribution of $\mathrm{NH}_{3}$ to total $\mathrm{N}\left(\mathrm{NH}_{3}\right.$ plus $\mathrm{NO}_{\mathrm{x}}$ ) deposition remains constant (see also Table 2.2). Critical agricultural $\mathrm{NH}_{3}$ emissions are thus calculated as (see Supplementary Text S2.3.1 for details):

$$
N H 3 e m_{(\text {crit })}=N d e p_{t o t(c r i t)} * \frac{f_{N H 3}}{f_{a g}}
$$

Where:

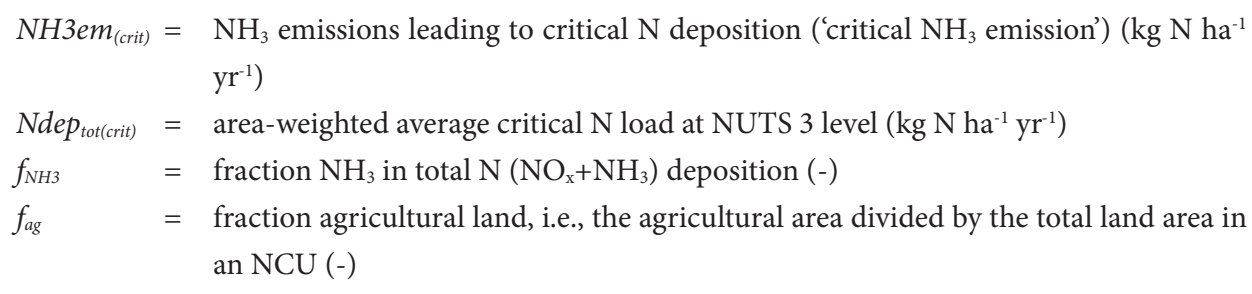

Critical nitrogen runoff in view of eutrophication of surface water (biodiversity and food chain effects) Increased $\mathrm{N}$ concentrations in surface water lead to eutrophication, characterized by excessive plant and algal growth and oxygen depletion, which negatively affects surface water quality and aquatic biodiversity. Critical concentrations for dissolved total $\mathrm{N}$ in surface water indicating eutrophication risk range between 1.0 and $2.5 \mathrm{mg} \mathrm{N}^{-1}$. This range is based on (i) an extensive study on the ecological and toxicological effects of inorganic $\mathrm{N}$ pollution (Camargo and Alonso, 2006), (ii) an overview of maximum allowable $\mathrm{N}$ concentrations in surface waters in national surface water quality standards (Liu et al., 2012), (iii) different European objectives for $\mathrm{N}$ loads (Laane, 2005), and (iv) critical limits for total dissolved N concentration in surface waters discharging into the North Sea and the Baltic Sea (Kunkel et al., 2017). For this study, we used the less restrictive limit of $2.5 \mathrm{mg} \mathrm{N} \mathrm{l}^{-1}$ in line with Mekonnen and Hoekstra (2015), who used a similar acceptable concentration in their assessment of $\mathrm{N}$ water footprints.

As a proxy for $\mathrm{N}$ concentration in surface water, we used $\mathrm{N}$ concentration in runoff to surface water (see also Table 2.2). Critical $\mathrm{N}$ concentration in agricultural runoff was derived from the critical $\mathrm{N}$ concentration of $2.5 \mathrm{mg} \mathrm{N}^{-1}$ for total runoff, accounting for dilution with runoff from non-agricultural land (Eq. 2.2a, see Supplementary Text S2.3.2 for the derivation). We

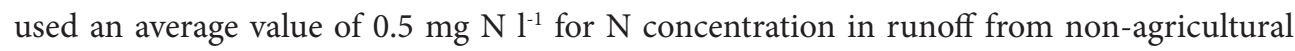


land, based on measurements of nitrate concentration in seepage water from $>500$ temperate forest sites in Europe from the 1990s (Gundersen et al., 2006). On the basis of data from 128 forested plots, De Vries et al. (2007) calculated a median N output near $1 \mathrm{~kg} \mathrm{~N} \mathrm{ha}^{-1} \mathrm{yr}^{-1}$, which equals an $\mathrm{N}$ concentration of $0.5 \mathrm{mg} \mathrm{N} \mathrm{l}^{-1}$, assuming a median precipitation surplus of 200 $\mathrm{mm} \mathrm{yr}^{-1}$.

Critical $\mathrm{N}$ runoff rates from agriculture were calculated by multiplying the critical $\mathrm{N}$ concentration in agricultural runoff with the precipitation surplus, multiplied with runoff fractions:

$$
\begin{aligned}
& {[N]_{\text {ag }(\text { crit })}=\frac{[N]_{\text {water }(\text { crit })}-\left(1-f_{\text {ag }}\right) *[N]_{\text {nag }}}{f_{a g}}} \\
& N_{S w(\text { crit })}=[N]_{\text {ag(crit })} * P S *\left(f_{\text {Sr }}+\left(1-f_{\text {sr }}\right) * f_{\text {ro }}\right) * c F_{C N}
\end{aligned}
$$

Where:

$$
\begin{array}{ll}
{[N]_{\text {ag(crit) }}} & =\text { Critical } \mathrm{N} \text { concentration in agricultural runoff }\left(\mathrm{mg} \mathrm{N} \mathrm{l}^{-1}\right) \\
{[N]_{\text {water(crit })}} & =\text { Critical } \mathrm{N} \text { concentration in surface water }\left(\mathrm{mg} \mathrm{N} \mathrm{l}^{-1}\right) \\
{[\mathrm{N}]_{\text {nag }}} & =\mathrm{N} \text { concentration in runoff from non-agricultural land }\left(\mathrm{mg} \mathrm{N}^{-1}\right) \\
N_{s w(c r i t)} & =\text { Critical N runoff to surface water }\left(\mathrm{kg} \mathrm{N} \mathrm{ha}^{-1} \mathrm{yr}^{-1}\right) \\
P S & =\text { Precipitation surplus }\left(\mathrm{m}^{3} \mathrm{~m}^{-2} \mathrm{yr}^{-1}\right) \\
f_{s r} & =\text { Surface runoff fraction, see Table } 2.1(-) \\
f_{r o} & =\text { Sub-surface runoff fraction, see Table } 2.1(-) \\
c F_{c N} & =\text { Conversion factor from } \mathrm{mg} \mathrm{N} \mathrm{l}^{-1} \text { to } \mathrm{kg} \mathrm{N} \mathrm{ha}^{-1} /\left(\mathrm{m}^{3} \mathrm{~m}^{-2}\right) \text {, i.e. } 10
\end{array}
$$

Precipitation surplus was estimated as the difference between long-term (1960-1990) average annual precipitation and evapotranspiration, also accounting for irrigation water supply and requirement, based on Keuskamp et al. (2012). Total precipitation surplus was divided over surface runoff, subsurface runoff (interflow through the shallow system) and leaching (base flow through the deep system; Keuskamp et al., 2012). As with N runoff (see Table 2.1), surface runoff fractions were derived as a function of slope, land use and soil type (see further Keuskamp et al., 2012; Velthof et al., 2009). Subsurface runoff (interflow) was assumed to occur in areas $<5 \mathrm{~m}$ above sea level and in grid cells containing natural surface waters (Keuskamp et al., 2012), using data from the CCM2 River and Catchment database (De Jager and Vogt, 2007). In other areas, precipitation surplus minus surface runoff was assumed be leaching to groundwater. To avoid extremely low critical $\mathrm{N}$ inputs, we set the minimum runoff to $10 \%$ of the rainfall (lowest value near $50 \mathrm{~mm} \mathrm{yr}^{-1}$ occurring in the semiarid regions in the Southern and Eastern part of the EU) based on Haddeland et al. (2006). 
Critical nitrate/nitrogen leaching to groundwater in view of health effects

High $\mathrm{NO}_{3}{ }^{-}$concentrations in drinking water are harmful to human health (Ward et al., 2018). The critical $\mathrm{NO}_{3}{ }^{-}$concentration in groundwater was set to the WHO drinking water limit of $50 \mathrm{mg} \mathrm{NO}_{3} \mathrm{l}^{-1}$ or $11.3 \mathrm{mg} \mathrm{NO}_{3}-\mathrm{N} \mathrm{l}^{-1}$, which is also the threshold stated in the EU Nitrates Directive (EC, 1991). This limit is based on epidemiological evidence for methemoglobinemia in infants (WHO, 2011). As a proxy for $\mathrm{NO}_{3}{ }^{-}$concentration in groundwater itself, we used the concentration in water leached to groundwater as the critical limit. As with runoff, critical N leaching rates from agriculture were calculated by multiplying the critical $\mathrm{N}$ concentration in leachate to groundwater with the share of precipitation surplus leached to groundwater as (see Table 2.2 for assumptions made and Supplementary Text S2.3.3 for details):

$$
N_{g w(c r i t)}=[N O 3]_{g w(c r i t)} * P S *\left(1-f_{s r}\right) *\left(1-f_{r o}\right) * c F_{c N O 3}
$$

Where:

$$
\begin{aligned}
& N_{g w(c r i t)}=\text { Critical } \mathrm{N} \text { leaching flux towards groundwater }\left(\mathrm{kg} \mathrm{N} \mathrm{ha}^{-1} \mathrm{yr}^{-1}\right) \\
& {[\mathrm{NO}]_{g w(c r i t)}=\text { Critical nitrate concentration in leaching flux towards groundwater }\left(\mathrm{mg} \mathrm{NO}_{3} \mathrm{l}^{-1}\right)} \\
& c F_{c \mathrm{NO} 3}=\text { Conversion factor from } \mathrm{mg} \mathrm{NO}_{3} \mathrm{l}^{-1} \text { to } \mathrm{kg} \mathrm{N} \mathrm{ha}^{-1} /\left(\mathrm{m}^{3} \mathrm{~m}^{-2}\right), \text { i.e. }(14 / 62)^{*} 10
\end{aligned}
$$

\section{Calculation of critical nitrogen inputs}

Total critical $\mathrm{N}$ inputs were calculated from either critical $\mathrm{NH}_{3}$ emissions, critical $\mathrm{N}$ runoff to surface water or critical $\mathrm{N}$ leaching to groundwater (see Figure 2.3). A full mathematical description of all steps to calculate critical N inputs is provided in Supplementary Text S2.3. For the calculation of critical inputs, we lumped BNF and $\mathrm{N}$ fertilizer as well as $\mathrm{N}$ biosolids and $\mathrm{N}$ excretion, assuming that the NUE of BNF is equal to $\mathrm{N}$ fertilizer and the NUE of $\mathrm{N}$ biosolids is equal to $\mathrm{N}$ manure (Figure S2.2). Inputs from $\mathrm{N}$ deposition were assumed to be a function of $\mathrm{NH}_{3}$ emissions, and inputs from $\mathrm{N}$ mineralisation (only on peat soils) were assumed constant (unaffected by changing $\mathrm{N}$ inputs). We further assumed that the relative contribution of fertilizer plus BNF to total farmer-managed inputs (i.e., the sum of fertilizer, BNF, manure and biosolids) remains constant (at its 2010 value; see Eq. S2.3.2).

All fractions (uptake, emission, runoff and leaching) were assumed to remain constant (2010 values). We assumed that there is no accumulation of $\mathrm{N}$ in the soil, and that thus the sum of critical $\mathrm{N}$ inputs (Eq. 2.4) equals the sum of $\mathrm{N}$ offtake and $\mathrm{N}$ losses (Eq. 2.5).

$$
\begin{aligned}
& N_{i n(c r i t)}=N_{f e+f i x(c r i t)}+N_{e x+b s(c r i t)}+N_{d e p(c r i t)}+N_{\min } \\
& N_{i n(c r i t)}=N_{o f f(c r i t)}+N_{d e(c r i t)}+N_{e m(c r i t)}+N_{s w(c r i t)}+N_{g w(c r i t)}
\end{aligned}
$$


Where:

$$
\begin{aligned}
& \mathrm{N}_{\text {in(crit) }} \quad=\text { Critical } \mathrm{N} \text { inputs }\left(\mathrm{kg} \mathrm{N} \mathrm{ha}^{-1} \mathrm{yr}^{-1}\right) \\
& \mathrm{N}_{\mathrm{fe}+\mathrm{fix}(\mathrm{crit})}=\text { Critical } \mathrm{N} \text { inputs from fertilizers and biological } \mathrm{N} \text { fixation }\left(\mathrm{kg} \mathrm{N} \mathrm{ha}^{-1} \mathrm{yr}^{-1}\right) \\
& \mathrm{N}_{\text {extbs(crit) }}=\text { Critical } \mathrm{N} \text { inputs from manure and biosolids }\left(\mathrm{kg} \mathrm{N} \mathrm{ha}^{-1} \mathrm{yr}^{-1}\right) \\
& \mathrm{N}_{\text {dep(crit) }} \quad=\mathrm{N} \text { deposition at critical inputs }\left(\mathrm{kg} \mathrm{N} \mathrm{ha}^{-1} \mathrm{yr}^{-1}\right) \\
& \mathrm{N}_{\min } \quad=\mathrm{N} \text { inputs from mineralisation (only on peat soils) }\left(\mathrm{kg} \mathrm{N} \mathrm{ha}^{-1} \mathrm{yr}^{-1}\right) \\
& \mathrm{N}_{\text {off(crit) }}=\mathrm{N} \text { crop offtake (removal by harvest) at critical } \mathrm{N} \text { input }\left(\mathrm{kg} \mathrm{N} \mathrm{ha}^{-1} \mathrm{yr}^{-1}\right) \\
& \mathrm{N}_{\text {de(crit) }}=\mathrm{N} \text { denitrification at critical } \mathrm{N} \text { input }\left(\mathrm{kg} \mathrm{N} \mathrm{ha}^{-1} \mathrm{yr}^{-1}\right) \\
& \mathrm{N}_{\text {em(crit) }} \quad=\text { Critical } \mathrm{N}\left(\mathrm{NH}_{3}, \mathrm{~N}_{2} \mathrm{O} \text { and } \mathrm{NO}_{\mathrm{x}}\right) \text { emissions }\left(\mathrm{kg} \mathrm{N} \mathrm{ha}^{-1} \mathrm{yr}^{-1}\right) \\
& \mathrm{N}_{\mathrm{sw}(\text { crit })}=\text { Critical } \mathrm{N} \text { runoff (surface }+ \text { sub-surface) to surface water }\left(\mathrm{kg} \mathrm{N} \mathrm{ha}^{-1} \mathrm{yr}^{-1}\right) \\
& \mathrm{N}_{\mathrm{gw}(\text { crit) }}=\text { Critical } \mathrm{N} \text { leaching to groundwater }\left(\mathrm{kg} \mathrm{N} \mathrm{ha}^{-1} \mathrm{yr}^{-1}\right)
\end{aligned}
$$

Peatlands where calculated critical inputs were negative because net $\mathrm{N}$ mineralisation alone led to runoff that exceeded critical limits (accounting for ca. 1\% of the total agricultural area) were excluded from the results. In areas where thresholds for $\mathrm{NH}_{3}$ emissions, $\mathrm{N}$ runoff or $\mathrm{N}$ leaching are not exceeded, critical $\mathrm{N}$ inputs can be higher than actual $\mathrm{N}$ inputs but were constrained by a maximum value, defined as the $\mathrm{N}$ input at which the maximum crop $\mathrm{N}$ content (Table S2.3) is reached.

\subsection{Results}

\subsection{Actual nitrogen inputs, offtake and losses}

Nitrogen inputs, offtake and losses vary strongly across Europe (Figure 2.4). On average, 145 $\mathrm{kg} \mathrm{N} \mathrm{ha-1}$ is added to European soils each year (Table 2.3). Most $\mathrm{N}$ comes from fertilizer, followed by manure deposition and BNF, and minor contributions from mineralization and biosolids (Table 2.3). In high-input regions, such as the Netherlands and Belgium, total $\mathrm{N}$ input rates exceed $300 \mathrm{~kg} \mathrm{~N} \mathrm{ha}^{-1} \mathrm{yr}^{-1}$ (Figure 2.4a). High input rates (between 200 and $300 \mathrm{~kg} \mathrm{~N} \mathrm{ha}^{-1} \mathrm{yr}^{-1}$ ) also occur in Ireland, Brittany in France, Northern Italy, Western UK, parts of Denmark and most of Germany. These areas are generally characterized by high livestock densities and thus high manure input (data not shown), which also leads to high $\mathrm{NH}_{3}$ emissions (Figure 2.4d). In contrast, $\mathrm{N}$ input rates in Spain, Romania, Baltic countries, southern Italy and Greece are often below 100 or even below $50 \mathrm{~kg} \mathrm{~N} \mathrm{ha}^{-1} \mathrm{yr}^{-1}$.

The average crop $\mathrm{N}$ offtake in the EU for the year 2010 is $92 \mathrm{~kg} \mathrm{~N} \mathrm{ha}^{-1} \mathrm{yr}^{-1}$, which implies an average NUE (defined as the ratio between crop offtake and total $\mathrm{N}$ input) of 0.63 and an $\mathrm{N}$ surplus (defined as input minus offtake) of $53 \mathrm{~kg} \mathrm{~N} \mathrm{ha}^{-1} \mathrm{y}^{-1}$ (Table 2.3). Overall, spatial variations in $\mathrm{N}$ offtake (Figure 2.4b), surplus (Figure 2.4c) and losses (Figures 2.4d-f) follow 

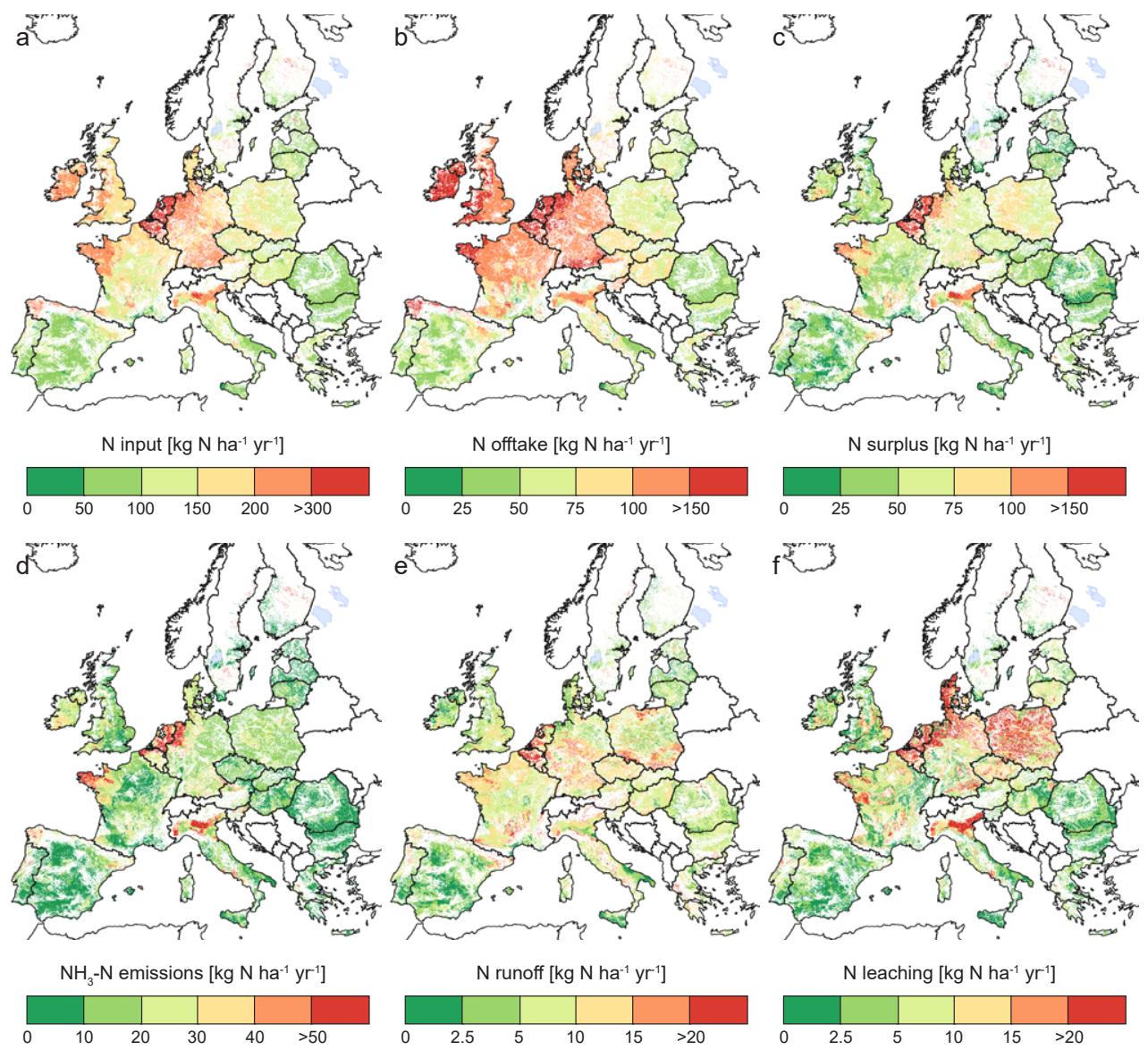

Figure 2.4 Spatial variation in different terms of the actual (year 2010) $\mathrm{N}$ balance for all agricultural land in the EU at NCU level. a, Actual total $\mathrm{N}$ input (external $\mathrm{N}$ input plus net $\mathrm{N}$ mineralisation), b, $\mathrm{N}$ offtake, c, $\mathrm{N}$ surplus (total $\mathrm{N}$ input minus $\mathrm{N}$ offtake), $\mathbf{d}, \mathrm{NH}_{3}-\mathrm{N}$ emissions, $\mathrm{e}, \mathrm{N}$ runoff to surface water and $\mathbf{f}, \mathrm{N}$ leaching to groundwater.

similar patterns as $\mathrm{N}$ inputs, with some notable differences. Across most of Poland, for example, $\mathrm{N}$ input rates $\left(100-200 \mathrm{~kg} \mathrm{~N} \mathrm{ha}^{-1} \mathrm{yr}^{-1}\right.$ ) are close to the European average (145 kg N $\left.\mathrm{ha}^{-1} \mathrm{yr}^{-1}\right)$ but $\mathrm{N}$ offtake rates are low (50-75 $\mathrm{kg} \mathrm{N} \mathrm{ha}^{-1} \mathrm{yr}^{-1}$, compared to EU average of $92 \mathrm{~kg}$ $\mathrm{N} \mathrm{ha}^{-1} \mathrm{yr}^{-1}$ ). The low NUE (country average $<0.5$ ) in Poland thus leads to an above-average $\mathrm{N}$ surplus (75-120 kg N ha-1 $\left.\mathrm{yr}^{-1}\right)$. Central France, on the other hand, is characterized by average $\mathrm{N}$ input rates but above-average $\mathrm{N}$ offtake and thus a relatively low surplus (Figure 2.4). Ireland and the UK are regions with high inputs, but comparatively low surpluses, due to high NUEs. Despite moderate N inputs, leaching is high in most of Poland (Figure 2.4f), due to a combination of high $\mathrm{N}$ surplus (Figure 2.4c) and high leaching fractions (data not 
shown). For Germany and Italy, $\mathrm{NH}_{3}$ emissions are concentrated in specific regions (Lower Saxony for Germany and the Po Valley for Italy, both regions with very high livestock densities; Figure 2.4d), while N runoff rates in these countries show much less spatial variation (Figure $2.4 \mathrm{e}$ ).

Average $\mathrm{N}$ budgets for different soil types (Table 2.3) illustrate differences in $\mathrm{N}$ loss processes reflected in INTEGRATOR. Average NUE decreases from clay soils (0.64) to sandy soils (0.61) to peat soils (0.55). The denitrification rate (fraction of $\mathrm{N}$ surplus transformed to N2) is highest for wet soils, and thus despite having the lowest NUE, peat soils also have the lowest share of $\mathrm{N}$ inputs lost to water (0.03), followed by clay soils (0.10) and sandy soils (0.16).

Table 2.3 | Average actual (year 2010) $\mathrm{N}$ budgets per soil type, and derived average $\mathrm{N}$ surplus, $\mathrm{N}$ use efficiency and $\mathrm{N}$ loss fraction to water for sandy soils, clay soils, peat soils. Results shown are for all agricultural land (cropland and grassland) in the EU for the year 2010.

\begin{tabular}{|c|c|c|c|c|}
\hline \multirow[b]{3}{*}{ Share of agricultural area } & \multicolumn{4}{|c|}{ N budget EU (kg N ha-1 yr') } \\
\hline & All soils & Clay soils & Sandy soils & Peat soils \\
\hline & $100 \%$ & $82 \%$ & $17 \%$ & $1 \%$ \\
\hline \multicolumn{5}{|l|}{$\mathbf{N}$ inputs } \\
\hline Fertilizer & 72 & 72 & 73 & 48 \\
\hline Biological $\mathrm{N}$ fixation & 7 & 7 & 7 & 6 \\
\hline Excretion & 54 & 51 & 67 & 98 \\
\hline Biosolids & I & I & 1 & 1 \\
\hline Deposition & 10 & 10 & 12 & 13 \\
\hline Mineralisation' & 1 & 0 & 0 & 92 \\
\hline Total $\mathrm{N}$ input & 145 & $|4|$ & 160 & 256 \\
\hline \multicolumn{5}{|l|}{$\mathbf{N}$ output from land } \\
\hline Crop offtake ${ }^{2}$ & 92 & 91 & 97 & 140 \\
\hline Air emission $\left(\mathrm{NH}_{3}, \mathrm{~N}_{2} \mathrm{O}, \mathrm{NO}_{\times}\right)$ & 19 & 18 & 23 & 29 \\
\hline Denitrification & 17 & 17 & 14 & 78 \\
\hline Runoff to surface water & 8 & 8 & 5 & 6 \\
\hline Leaching to groundwater & 9 & 6 & 21 & 3 \\
\hline Total N output & 145 & $|4|$ & 160 & 256 \\
\hline $\mathrm{N}$ surplus ${ }^{3}$ & 53 & 50 & 63 & 116 \\
\hline $\mathrm{N}$ use efficiency ${ }^{4}$ & 0.63 & 0.64 & 0.61 & 0.55 \\
\hline $\mathrm{N}$ loss fraction to water $^{5}$ & 0.11 & 0.10 & 0.16 & 0.03 \\
\hline \multicolumn{5}{|c|}{$\begin{array}{l}\text { ' Organic } \mathrm{N} \text { pool changes are only included for drained peat soils, where mineralisation rates are high. Because peat soils } \\
\text { account for only } 1 \% \text { of the agricultural area, the average } \mathrm{N} \text { mineralisation rate across all soil types is low. }\end{array}$} \\
\hline \multicolumn{5}{|c|}{${ }^{2}$ Crop offtake refers to the net removal (crop or grass) from agricultural land. } \\
\hline \multicolumn{5}{|c|}{${ }^{3}$ Calculated as total $\mathrm{N}$ input minus crop offtake. } \\
\hline \multicolumn{5}{|c|}{${ }^{4}$ Calculated as the $\mathrm{N}$ offtake (crop $\mathrm{N}$ removal) divided by the total $\mathrm{N}$ input. } \\
\hline${ }^{5}$ Calculated as the $\mathrm{N}$ runoff plus & ided & & & \\
\hline
\end{tabular}




\subsubsection{Critical nitrogen inputs and losses and their exceedances}

\section{Spatial variation in critical nitrogen losses and nitrogen inputs}

Critical $\mathrm{N}$ losses and associated critical $\mathrm{N}$ inputs and exceedances by current losses and inputs vary strongly across the EU, and between different impacts (Figure 2.5). Variation in critical $\mathrm{NH}_{3}$ emissions in view of biodiversity impacts are mainly driven by variation in critical loads (i.e., ecosystems' sensitivity to $\mathrm{N}$ deposition), and to a smaller extent by variation in the share of agricultural area and the contribution of $\mathrm{NO}_{\mathrm{x}}$ to $\mathrm{N}$ deposition. Critical $\mathrm{NH}_{3}$ emissions are lowest in Spain, Italy, Romania, Bulgaria and Greece $\left(0-5 \mathrm{~kg} \mathrm{~N} \mathrm{ha}^{-1} \mathrm{yr}^{-1}\right.$, Figure 2.5a). In Spain and Greece, this is mainly due to low $\mathrm{N}$ deposition thresholds $\left(<7 \mathrm{~kg} \mathrm{~N} \mathrm{ha}^{-1} \mathrm{yr}^{-1}\right.$, data not shown), while a high contribution of $\mathrm{NO}_{\mathrm{x}}$ to $\mathrm{N}$ emissions (especially in Italy where $\mathrm{NO}_{\mathrm{x}}$ contributes $>50 \%$, data not shown) and a high share of agricultural land (especially Romania) further reduce critical $\mathrm{NH}_{3}$ emissions (cf. Eq. 2.1). Some regions, such as the UK and Central/ Northern France, display relatively high critical N inputs (Figure 2.5b) despite relatively low critical $\mathrm{NH}_{3}$ emissions (Figure 2.5a), indicating low average $\mathrm{NH}_{3}$ emission fractions in these regions. The largest exceedances of critical $\mathrm{N}$ inputs by actual inputs occur in regions with high $\mathrm{N}$ manure inputs and/or low critical $\mathrm{NH}_{3}$ emissions (Figure 2.5c). Despite relatively high critical N inputs in the Netherlands, Belgium and Eastern Germany (150-200 kg N $\mathrm{ha}^{-1} \mathrm{yr}^{-1}$ ), owing to higher critical loads, high actual inputs in these regions (Figure 2.4a) still exceed critical inputs by $>100 \mathrm{~kg} \mathrm{~N} \mathrm{ha}^{-1} \mathrm{yr}^{-1}$ (Figure 2.5c).

Variation in critical $\mathrm{N}$ runoff and leaching are mainly driven by variation in precipitation surplus, land use, soil type and slope. Critical N runoff and leaching rates are low $(<2.5 \mathrm{~kg}$ $\mathrm{N} \mathrm{ha}^{-1} \mathrm{yr}^{-1}$ ) in Spain, Portugal, Italy and Greece (Figure 2.5d, g), because low runoff in these areas leads to limited dilution of agricultural $\mathrm{N}$ losses. Critical $\mathrm{N}$ runoff rates are usually lower than critical N leaching rates (Figure $2.5 \mathrm{~d}, \mathrm{~g}$ ), especially in Denmark, the Netherlands and North-West Germany, where critical leaching rates often exceed critical runoff rates by a factor 10. This is due to two reasons: first, shares of agricultural land in these regions are high, leading to limited dilution of agricultural with non-agricultural runoff and thus a lower critical $\mathrm{N}$ runoff (cf. Eq. 2.2a). Second, in these flat and low-lying areas a larger share of precipitation surplus is allocated to base flow to groundwater rather than interflow to surface water (i.e., surface and sub-surface runoff fractions are low, cf. Eq. 2.2a), leading to more dilution of $\mathrm{N}$ leaching below the rooting zone and thus higher critical $\mathrm{N}$ leaching.

Low critical $\mathrm{N}$ runoff and $\mathrm{N}$ leaching generally also imply low critical $\mathrm{N}$ inputs for the surface water and groundwater criteria (Figure 2.5e, h), but not always. For example, across large areas of Ireland, critical $\mathrm{N}$ input rates exceed $200 \mathrm{~kg} \mathrm{~N} \mathrm{ha}^{-1} \mathrm{yr}^{-1}$ despite low critical runoff and leaching rates of $0-10 \mathrm{~kg} \mathrm{~N} \mathrm{ha}^{-1} \mathrm{yr}^{-1}$. This can be explained by a high share of grasslands 
in Ireland, with higher denitrification and lower $\mathrm{N}$ losses to water compared to arable land. While critical $\mathrm{N}$ inputs for the surface water criterion are lowest in South-Eastern Europe (Figure 2.5e), the highest exceedances occur in North-Western Europe (Figure 2.5f), because actual inputs in these regions are much higher (Figure 2.4a). Critical N inputs for both the groundwater criterion (Figure 2.5h) and the surface water criterion (Figure 2.5e) show a decreasing trend from Northern to Southern Europe, mainly driven by a decrease in precipitation surplus. Due to the more stringent critical $\mathrm{N}$ concentration for runoff to surface water $\left(2.5 \mathrm{mg} \mathrm{N}^{-1}\right)$ compared to leachate to groundwater $\left(11.6 \mathrm{mg} \mathrm{N} \mathrm{l}^{-1}\right)$, the surface water criterion is almost always more stringent, i.e., critical $\mathrm{N}$ inputs are lower for the surface water threshold than for the groundwater threshold on $\sim 95 \%$ of the agricultural area (Figure 2.5e, h).

\section{Aggregated critical $\mathbf{N}$ losses and inputs at EU- and country-level}

Actual $\mathrm{N}$ inputs and losses exceed critical $\mathrm{N}$ inputs and losses for at least one of the three impacts on most of the agricultural area in the EU. The share of agricultural area where critical $\mathrm{N}$ losses are exceeded is highest for $\mathrm{N}$ runoff to surface water (74\%), followed by $\mathrm{NH}_{3}$ emissions (66\%) and lowest for $\mathrm{N}$ leaching to groundwater (18\%) (Table 2.4). For grassland and fodder crops, the highest exceedances occur for $\mathrm{NH}_{3}$ emissions (Table 2.4), due to both higher average manure inputs (with high $\mathrm{NH}_{3}$ emission fractions) to grassland and fodder crops, as well as lower runoff and leaching fractions (higher denitrification) in grassland.

Based on the derived spatially explicit critical $\mathrm{N}$ inputs, boundaries for $\mathrm{N}$ inputs and losses were derived at country- and EU-level. Figure 2.6 shows mean actual and critical $\mathrm{N}$ inputs to agriculture as well as mean actual and critical crop $\mathrm{N}$ offtake and $\mathrm{N}$ losses from agriculture for the EU (detailed N budgets are given in Table S2.4, whereas critical inputs differentiated by land use type are shown in Figure S2.4). Complying with thresholds for $\mathrm{N}$ runoff to surface water requires the highest reductions in $\mathrm{N}$ inputs (43\%), followed by thresholds for $\mathrm{NH}_{3}$ emissions (31\%, Figure 2.6a). Average critical $\mathrm{N}$ inputs related to thresholds for $\mathrm{N}$ leaching to groundwater (147 $\mathrm{kg} \mathrm{N} \mathrm{ha}^{-1} \mathrm{yr}^{-1}$ ) are $1 \%$ higher than actual $\mathrm{N}$ inputs, which means that on average, increases in $\mathrm{N}$ inputs in areas where thresholds are not exceeded are higher than needed reductions in areas where thresholds are exceeded.

Comparing actual $\mathrm{N}$ budgets to critical $\mathrm{N}$ budgets reveals a few interesting things. For all impacts, relative reductions needed to respect thresholds are higher for $\mathrm{N}$ losses than for $\mathrm{N}$ inputs (Figure 2.6 \& Figure S2.5). In order to respect thresholds for $\mathrm{N}$ runoff to surface water, for example, $\mathrm{N}$ runoff needs to decrease by $50 \%$ (from 8 to $4 \mathrm{~kg} \mathrm{~N} \mathrm{ha}^{-1} \mathrm{yr}^{-1}$, Table S2.4) while $\mathrm{N}$ inputs need to decrease by $43 \%$ (from 145 to $83 \mathrm{~kg} \mathrm{~N} \mathrm{ha}^{-1} \mathrm{yr}^{-1}$, Table S2.4 \& Figure 2.6). This implies that on average, higher reductions in $\mathrm{N}$ losses are required in areas with 

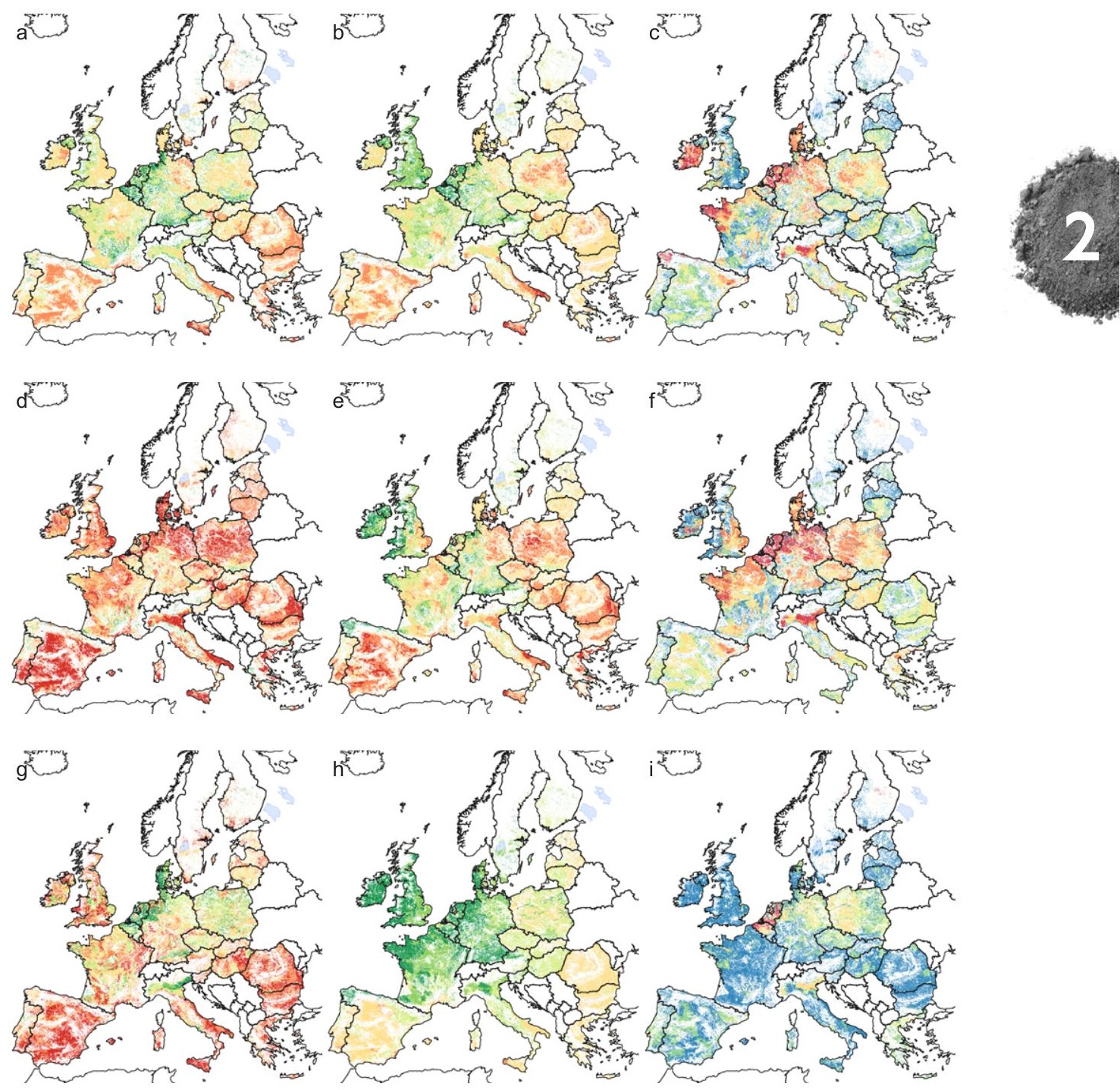

Critical N loss [kg N ha-1 $\left.\mathrm{yr}^{-1}\right]$

Critical $\mathrm{N}$ input [kg N ha-1 $\left.\mathrm{yr}^{-1}\right]$

Exceedance of critical $\mathrm{N}$ input [ $\left.\mathrm{kg} \mathrm{N} \mathrm{ha-1} \mathrm{yr}^{-1}\right]$
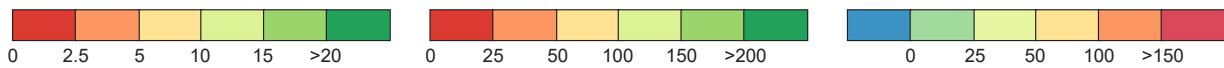

Figure 2.5 | Spatial variation in critical $\mathrm{N}$ losses (left), critical $\mathrm{N}$ inputs (middle) and exceedance of critical by actual (year 2010) $\mathrm{N}$ inputs (right) in view of a-c, critical $\mathrm{N}$ deposition rates to avoid terrestrial biodiversity loss, $\mathbf{d}-\mathbf{f}$, critical $\mathrm{N}$ runoff to surface water to avoid eutrophication and $\mathbf{g}-\mathbf{i}$, critical $\mathrm{N}$ leaching to groundwater to avoid exceedance of nitrate thresholds in drinking water. 
lower NUEs. While required reductions in $\mathrm{N}$ inputs are larger for the surface water threshold than for the $\mathrm{NH}_{3}$ emission / deposition threshold, associated reductions in $\mathrm{N}$ emissions are similar in both cases (36 vs. $38 \%$, Figure S2.5). This shows that needed N input reductions to respect deposition thresholds are especially high in areas with disproportionately high air emission fractions. For all thresholds, required reductions in manure inputs are higher than required reductions in fertilizer inputs, with the difference being especially pronounced for the deposition threshold (requiring a $48 \%$ reduction in manure inputs compared to a $20 \%$ reduction in fertilizer inputs, see Figures $2.6 \&$ S2.5), due to the higher $\mathrm{NH}_{3}$ emission fraction of manure compared to fertilizer.

Figure 2.7 and Tables S2.5 and S2.6 show derived boundaries for $\mathrm{N}$ inputs and their exceedances at the country level. On average, actual $\mathrm{N}$ inputs exceed critical $\mathrm{N}$ inputs for the surface water and the $\mathrm{N}$ deposition criteria in almost all countries (Figure 2.7a,b). The lowest critical $\mathrm{N}$ inputs in view of biodiversity impacts of $\mathrm{N}$ deposition $\left(<70 \mathrm{~kg} \mathrm{~N} \mathrm{ha}^{-1} \mathrm{yr}^{-1}\right)$ are found in Italy, Portugal, Romania and Slovakia (Figure 2.7 and Table S2.6). In these countries, low critical loads are combined with high $\mathrm{NH}_{3}$ emission fractions. The lowest critical $\mathrm{N}$ inputs in view of surface water quality $\left(<50 \mathrm{~kg} \mathrm{~N} \mathrm{ha}^{-1} \mathrm{yr}^{-1}\right)$ are found in Southern European countries with low precipitation surplus (Spain, Greece, Bulgaria) as well as countries with a low NUE (Poland). In order to respect thresholds for $\mathrm{N}$ runoff to surface water, country-level N inputs need to be reduced between 2\% (Estonia) and 74\% (the Netherlands, Table S2.6). For the groundwater criterion, actual $\mathrm{N}$ inputs exceed critical $\mathrm{N}$ inputs in only 9 countries, and exceedances are usually low $(<20 \%)$ except in Belgium, the Netherlands and Poland (Table S2.6).

\subsection{Discussion}

\subsection{Uncertainty in spatial variation of nitrogen inputs and losses}

Uncertainty in the calculated spatial variation in actual $\mathrm{N}$ inputs and $\mathrm{N}$ losses is determined by the uncertainty in input data and model assumptions, as discussed below. Uncertainty can be assessed by comparing model outputs with independent estimates or measurements, as done below for $\mathrm{N}$ fertilizer inputs and $\mathrm{N}$ losses $\left(\mathrm{NH}_{3}\right.$ emissions, $\mathrm{N}$ runoff and $\mathrm{N}$ leaching). Uncertainty in spatial variation of $\mathrm{N}$ offtake and NUE is discussed in Chapter 3.

\section{Crop-specific nitrogen fertilizer inputs}

Average country-level $\mathrm{N}$ fertilizer input rates for major crops as derived with INTEGRATOR 
Table 2.4 | Percentage of area where actual (year 2010) $\mathrm{N}$ inputs exceed critical $\mathrm{N}$ inputs in view of critical $\mathrm{NH}_{3}$ emissions to air, critical $\mathrm{N}$ runoff to surface water and critical $\mathrm{N}$ leaching to groundwater, separated by land use type.

\begin{tabular}{lcccc}
\hline Critical N loss & All agriculture & Arable & Fodder & Grassland \\
\hline $\mathrm{NH}_{3}$ emissions to air & $66 \%$ & $62 \%$ & $71 \%$ & $72 \%$ \\
Runoff to surface water & $74 \%$ & $88 \%$ & $64 \%$ & $45 \%$ \\
Leaching to groundwater & $18 \%$ & $22 \%$ & $6 \%$ & $14 \%$ \\
\hline
\end{tabular}
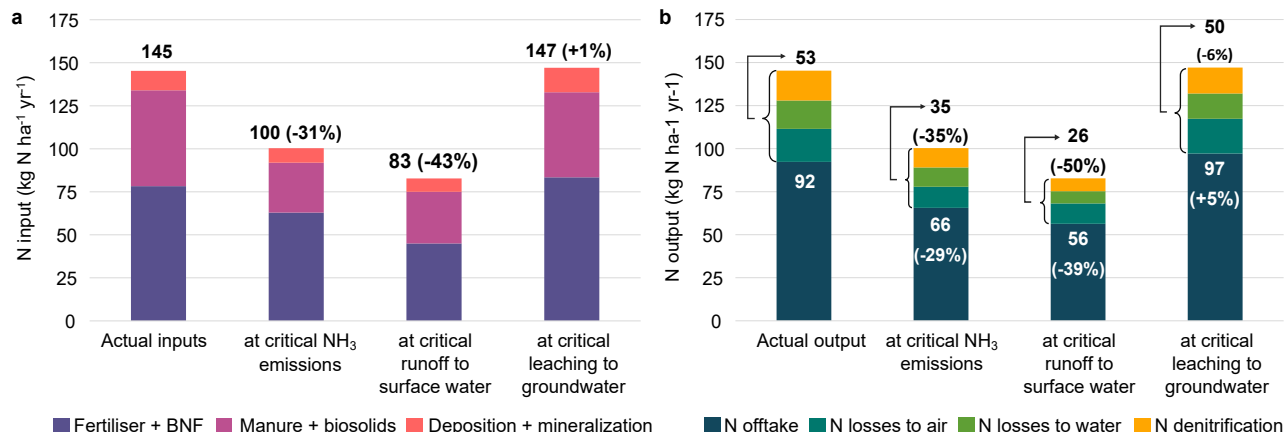

Figure 2.6 | Average actual (year 2010) and critical a, N inputs and b, $\mathrm{N}$ output for all agricultural land in the EU. In a, numbers above bars show total $\mathrm{N}$ inputs in $\mathrm{kg} \mathrm{N} \mathrm{ha}^{-1} \mathrm{yr}^{-1}$, in b, numbers above bars show total $\mathrm{N}$ losses, while numbers for $\mathrm{N}$ offtake are shown within bars (both in $\mathrm{kg} \mathrm{N} \mathrm{ha-1}^{-1} \mathrm{yr}^{-1}$ ). Percentages show difference between actual and critical $\mathrm{N}$ inputs, losses or offtake.
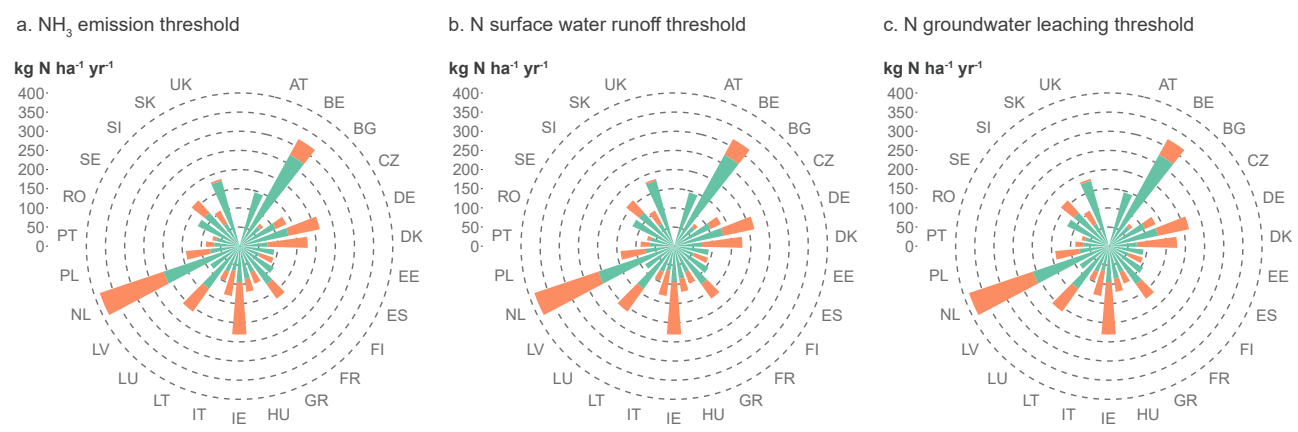

Figure 2.7 | Exceedance of critical $N$ inputs in view of three impacts by actual (year 2010) $N$ inputs, aggregated at country level. Wedges show total actual $\mathrm{N}$ inputs (in $\mathrm{kg} \mathrm{N} \mathrm{ha}^{-1} \mathrm{yr}^{-1}$ ) per country, green indicates the critical $\mathrm{N}$ input and red the exceedance of actual $\mathrm{N}$ inputs by critical $\mathrm{N}$ inputs. 
were compared to data from Fertilizers Europe, which are mainly based on expert judgment (Figure S2.6). On average, estimates compare reasonably well for grain crops (despite large variation for individual countries), while INTEGRATOR estimates structurally higher inputs for sugar beet and sunflower/soy/linseed, and lower inputs for oilseed rape. Results for potato, sugar beet and grain maize show large scatter. These crops receive relatively high amounts of manure, of which the amount and availability is relatively uncertain. However, the relative importance of these crops (in terms of area) is also much lower than for grain crops. Crop areas used by INTEGRATOR and Fertilizers Europe for the various crops are quite comparable and thus do not explain differences in $\mathrm{N}$ input rates (data not shown). However, expert estimates for crop-specific fertilizer inputs by Fertilizers Europe are also associated with considerable uncertainties.

\section{Nitrogen losses (ammonia emissions and nitrogen runoff and leaching)}

\section{Uncertainties related to empirical approaches}

Nitrogen losses in INTEGRATOR (e.g., $\mathrm{NH}_{3}$ emissions, $\mathrm{N}$ runoff and $\mathrm{N}$ leaching) are estimated using empirical fractions (export coefficients), which are functions of agricultural practices and site factors. Such empirical approaches have been widely used to model $\mathrm{N}$ emissions (e.g., Amann et al., 2011; van Grinsven et al., 2015a) and cropland N runoff and leaching (e.g., Liu et al., 2010b; Wang et al., 2014). Ammonia emissions are affected by housing and manure storage types, manure properties such as slurry dry matter content and $\mathrm{pH}$, manure application technique, meteorological conditions such as air temperature and precipitation, and soil properties such as texture (e.g., Ge et al., 2020; Hafner et al., 2019). Nitrogen runoff and leaching are affected by topography, land cover, climate, soil properties and agricultural management (e.g., Zhang et al., 2016). Several of these site factors are considered in deriving emission, runoff and leaching fractions in INTEGRATOR (see Section 2.2.1 and Supplementary Text S2.2.1 \& S2.2.2 for details). With respect to $\mathrm{NH}_{3}$ emission, regional information on housing and manure storage types, manure properties and manure application techniques is unfortunately missing and annual emission fractions are thus averaged based on national data on housing types and application techniques. Regarding $\mathrm{N}$ runoff and leaching, however, INTEGRATOR accounts for variation in e.g. slope class, land use, precipitation surplus, soil type or soil organic carbon content, precipitation surplus and temperature, based on Velthof et al. (2009).

An assessment of uncertainty propagation in INTEGRATOR using Monte Carlo analysis (Kros et al., 2012) showed that uncertainties related to estimates of $\mathrm{N}$ leaching and runoff (relative errors of $\sim 19 \%$ at EU level) were larger than for emissions of $\mathrm{NH}_{3}, \mathrm{~N}_{2} \mathrm{O}$ and $\mathrm{NO}_{\mathrm{x}}$ (relative errors of $\sim 12 \%$ at EU level). Uncertainties at EU level were much smaller than at the 
country-level, as errors canceled out due to spatial aggregation. At the country level, relative errors ranged from 13 to $34 \%$ for $\mathrm{NH}_{3}$ emissions, from 17 to $68 \%$ for $\mathrm{N}$ runoff and from 17 to $74 \%$ for N leaching, while relative errors at NCU level showed even wider ranges (see Tables 6 \& 7 in Kros et al., 2012).

Modelling approaches based on linear functions, such as INTEGRATOR, have been criticized as field observations regularly find non-linear responses of $\mathrm{N}$ losses to changing $\mathrm{N}$ inputs or environmental parameters (e.g., Hou et al., 2016; Kim et al., 2013; Schaefer and Alber, 2007; Sobota et al., 2009). For example, an empirical model for $\mathrm{N}$ leaching based on $\mathrm{NO}_{3}{ }^{-}$ concentration measurements at 51 sites across China showed a convex relationship between leaching rate and $\mathrm{N}$ input for most crop types, with variation in air temperature and soil organic carbon explaining most of the spatial variation (Gao et al., 2016). In INTEGRATOR, $\mathrm{N}$ leaching is calculated as a linear function of $\mathrm{N}$ surplus (rather than of $\mathrm{N}$ inputs), thus accounting for a convex relationship between $\mathrm{N}$ input and $\mathrm{N}$ leaching.

\section{Comparison with other models and national statistics}

A detailed comparison of INTEGRATOR results with other models of land $\mathrm{N}$ budgets in European agriculture shows that $\mathrm{NH}_{3}$ emissions estimates are quite comparable across models, while estimates for $\mathrm{N}$ runoff and leaching can vary by a factor two at EU level (De Vries et al., 2011b). The study also showed that these differences are mainly affected by differences in estimated manure inputs.

Country-level $\mathrm{NH}_{3}$ emissions from housing and from fertilizer and manure application estimated by INTEGRATOR compare well with emission data submitted by the Parties to the LRTAP Convention to the EMEP programme (Figure S2.7). Total agricultural $\mathrm{NH}_{3}$ emission from INTEGRATOR (2.5 $\mathrm{Tg} \mathrm{N} \mathrm{yr}^{-1}$ ) are 11\% lower than those reported to EMEP $(2.9 \mathrm{Tg} \mathrm{N}$ $\mathrm{yr}^{-1}$ ) for the year 2010. This difference is mainly caused by systematically lower $\mathrm{NH}_{3}$ emissions from manure storage and housing systems in INTEGRATOR compared to EMEP (1.1 vs. 1.5 $\mathrm{Tg} \mathrm{N} \mathrm{yr}{ }^{-1}$ ). Lower total $\mathrm{NH}_{3}$ emissions in INTEGRATOR may lead to an underestimation of the exceedance of critical $\mathrm{NH}_{3}$ emissions, but the EMEP emission estimates are uncertain as well.

\section{Comparison with measurements}

Most insight in model uncertainty is derived from comparing model results to measured spatial data, based on, e.g., detailed national field surveys. Such studies have been performed with INTEGRATOR by using more detailed national information on $\mathrm{N}$ inputs and comparing model outputs with observations for $\mathrm{NH}_{3}$ in air (Ge et al., 2020) and for $\mathrm{NO}_{3}{ }^{-}$concentrations 
in groundwater and $\mathrm{N}$ concentrations in surface water (Kros et al., 2018). For example, INTEGRATOR has been used to model $\mathrm{NH}_{3}$ emissions for Germany and Benelux at hourly time-scales, accounting for timing of manure application and sub-annual variation in rainfall and temperature (Ge et al., 2020). Results were combined with an atmospheric transport model to derive $\mathrm{NH}_{3}$ concentrations, which were compared with observations from ground measurements and satellite data. Results showed a reasonable correlation between modelled and observed concentrations, although comparison with satellite measurements showed that the model overestimated $\mathrm{NH}_{3}$ total columns in southern Germany and underestimated total columns in northern Germany (Ge et al., 2020). Kros et al. (2018) showed that spatial distribution of manure distribution and $\mathrm{N}$ losses (e.g., $\mathrm{NO}_{3}^{-}$leaching) for Denmark were closer to observed distributions when using detailed national statistics rather than Eurostat data. For effective support of environmental policymaking, it would thus be of great help when Member States both collect and submit high spatial resolution agricultural data to Eurostat (Kros et al., 2018).

Comparing modelled $\mathrm{NO}_{3}^{-}$concentrations in leachate to groundwater to measured groundwater $\mathrm{NO}_{3}{ }^{-}$concentrations reported under the Nitrates Directive for the years 20082011 (EC, 2013) shows that overall, values compare quite well (Figure S2.8). For individual countries, however, differences are large: in the Netherlands, Belgium, Denmark and Poland, predicted groundwater $\mathrm{N}$ concentrations are much higher than observed, while the reverse is true for Germany. For $\mathrm{N}$ concentrations in runoff to surface water, values predicted by INTEGRATOR tend to be higher than measured $\mathrm{N}$ concentrations in surface water (EC, 2013; data not shown). This implies that we may have overestimated the necessary reductions in $\mathrm{N}$ inputs to protect surface water quality.

Differences in measured and modelled concentrations can occur due to several reasons. First, measured concentrations are reported as 'share of sampling points' falling into different concentration classes (see Figure S2.8). Comparing these values to the share of total area where different concentrations are predicted by INTEGRATOR is only valid if sampling points are distributed homogeneously, which is not the case, as sampling sites are often concentrated in Nitrate Vulnerable Zones. Ideally, N concentrations at sampling locations should be compared to N concentrations modelled by INTEGRATOR for the same locations, however, data for individual sampling sites is not publicly available. Second, we used N concentrations in water fluxes (runoff to surface water and water leaching from the root zone to groundwater) as surrogates for $\mathrm{N}$ concentrations in water reservoirs (surface water and groundwater), thus neglecting the role of $\mathrm{N}$ accumulation over time, $\mathrm{N}$ delivery from upstream or via lateral transport, and $\mathrm{N}$ removal by denitrification and sedimentation. For surface water, we also did not consider additional $\mathrm{N}$ load from point sources, such as wastewater. 
On average, neglecting $\mathrm{N}$ load from point sources (leading to higher concentrations) and $\mathrm{N}$ removal processes (leading to lower concentrations) was assumed to cancel out, however, this assumption leads to large uncertainty in calculated $\mathrm{N}$ concentrations and associated critical $\mathrm{N}$ inputs at regional scales. An improvement of the approach may be expected if sitespecific data on measured $\mathrm{N}$ concentrations in ground- and surface water at EU level could be used to develop a data-driven upscaling model (see e.g., Gao et al., 2016; Hou et al., 2018; who developed such approaches for China), but the necessary data are currently not available (see above).

\subsubsection{Uncertainty in spatial variation of critical nitrogen inputs and losses}

The reliability of critical $\mathrm{N}$ inputs and critical $\mathrm{N}$ losses is especially affected by the critical limits used and the assumptions made in the various calculations.

\section{Critical ammonia emissions}

Critical $\mathrm{N}$ loads for terrestrial ecosystems used in this study are derived from critical $\mathrm{N}$ concentrations in soil solution related to risks for plant species diversity decline in forests and semi-natural vegetation (see Section 2.2.2). Resulting critical loads are comparable to empirical critical loads based on observed plant species diversity shifts in response to experimental $\mathrm{N}$ addition (Hettelingh et al., 2014).

Calculations of critical $\mathrm{NH}_{3}$ emissions from critical $\mathrm{N}$ loads further assume that $\mathrm{N}$ deposition rates on agricultural land and natural land are similar, which is substantiated by data (see Figure S2.3), and that the contribution of $\mathrm{NH}_{3}$ to total $\mathrm{N}$ deposition stays constant, implying that $\mathrm{NO}_{\mathrm{x}}$ emissions are reduced in the same proportion as $\mathrm{NH}_{3}$. Achieving targets for $\mathrm{NH}_{3}$ and $\mathrm{NO}_{\mathrm{x}}$ in the National Emission Ceilings (NEC) Directive on average requires larger reductions for $\mathrm{NO}_{\mathrm{x}}$ than for $\mathrm{NH}_{3}$. However, in regions with high $\mathrm{NH}_{3}$ emissions it is likely that NECs for $\mathrm{NH}_{3}$ will be lowered in the future. For example, the Netherlands aims to reduce both $\mathrm{NH}_{3}$ and $\mathrm{NO}_{\mathrm{x}}$ emissions by $50 \%$ in 2035 as compared to 2019, which would reduce $\mathrm{N}$ deposition to below critical loads on $75 \%$ of the area with $\mathrm{N}$-sensitive habitats (Adviescollege Stikstofproblematiek, 2020).

Another assumption is that $\mathrm{NH}_{3}$ emitted in a NUTS 3 region is deposited in the same region, while in fact only $50 \%$ of $\mathrm{NH}_{3}$ emissions are deposited within a radius of ca. $75 \mathrm{~km}$ and the remainder is transported over several hundreds of kilometers (Ferm, 1998). The size of NUTS 3 regions varies substantially $\left(20-100,000 \mathrm{~km}^{2}\right.$, with a median of $1,850 \mathrm{~km}^{2}$ and an average of $3,800 \mathrm{~km}^{2}$ ). In smaller NUTS 3 regions with high $\mathrm{NH}_{3}$ emissions relative to surrounding regions (i.e., regions where the amount of $\mathrm{NH}_{3}$ emissions exported to other regions exceeds 
the amount of $\mathrm{NH}_{3}$ emissions received from other regions), needed reductions to respect $\mathrm{N}$ deposition thresholds may have been over-estimated, while the reverse is true for regions with low $\mathrm{NH}_{3}$ emissions.

\section{Critical nitrogen runoff to surface water}

Critical $\mathrm{N}$ inputs to agriculture to avoid adverse impacts on surface water quality were based on a uniform critical $\mathrm{N}$ concentration in runoff of $2.5 \mathrm{mg} \mathrm{N}^{-1}$. The approach accounts for the dilution of agricultural with non-agricultural runoff, but neglects $\mathrm{N}$ load from point sources and $\mathrm{N}$ removal from surface water that also determine surface water $\mathrm{N}$ concentration (see Section 2.4.1). Several regional studies have used more detailed approaches to assess critical $\mathrm{N}$ inputs in view of surface water quality. Groenendijk et al. (2016) calculated required reductions in agricultural $\mathrm{N}$ load to comply with targets for the Water Framework Directive in the Netherlands. The study explicitly accounted for non-agricultural sources, which accounted for almost half of the total $\mathrm{N}$ load in the Netherlands. Kunkel et al. (2017) calculated required reductions in agricultural $\mathrm{N}$ surplus to comply with critical concentrations in surface water discharging into the North Sea $\left(2.8 \mathrm{mg} \mathrm{N}^{-1}\right)$ and the Baltic Sea (2.6 $\mathrm{mg} \mathrm{N}^{-1}$ ) for the German federal state Mecklenburg-Vorpommern, while accounting for both agricultural and non-agricultural sources and river/lake $\mathrm{N}$ retention. However, the data required for these more sophisticated approaches is not available at the European scale, justifying the use of a more simplified approach. Such an approach has also been used in a global study of safe $\mathrm{N}$ losses in relation to water quality (Gerten et al., 2020), which assumed that $71 \%$ of the $\mathrm{N}$ in leaching and runoff reaches surface waters and also neglected $\mathrm{N}$ load from point sources.

The uniform threshold value of $2.5 \mathrm{mg} \mathrm{N}^{-1}$ used in this study does not reflect variation in ecological criteria for different surface water types (e.g., rivers, lakes, coastal waters). The Water Framework Directive (WFD) does not provide targets for surface water N concentrations itself, but requires countries to determine criteria for 'good ecological status'. A recent review of nutrient criteria used by EU Member States to support good ecological status under the WFD shows that used thresholds vary widely, even within shared water body types (Poikane et al., 2019). partly due to different approaches used to determine critical concentrations. Overall, median values for critical $\mathrm{N}$ concentrations in lakes and rivers based on expert judgments or percentile distributions of $\mathrm{N}$ concentrations in water bodies (2.5-4.0 $\mathrm{mg} \mathrm{N}^{-1}$ ) are higher than median thresholds based on data-driven methods related to biological criteria $\left(0.68-1.5 \mathrm{mg} \mathrm{N} \mathrm{l}^{-1}\right)$ (Poikane et al., 2019). This indicates that the used threshold of $2.5 \mathrm{mg} \mathrm{N}^{-1}$ might be too lenient and that an ecologically relevant criterion may be closer to $1.0 \mathrm{mg} \mathrm{N} \mathrm{I}^{-1}$. However, as shown in Section 2.4.1, our model currently seems 
to overestimate actual $\mathrm{N}$ concentrations in surface water, and using a more lenient threshold for the critical concentration may compensate for this.

Some countries do not set targets at all for $\mathrm{N}$ concentrations for certain water body types, but focus only on $\mathrm{P}$. Despite the widely held belief that $\mathrm{P}$ limits primary production in freshwaters and $\mathrm{N}$ in coastal waters, ample evidence shows that $\mathrm{N}$ can equally limit primary production in lakes and rivers (Conley et al., 2009; Poikane et al., 2019). Both critical N and P load thus need to be considered when assessing surface water eutrophication risk.

\section{Critical nitrate leaching to groundwater}

Critical $\mathrm{N}$ inputs to agriculture to avoid adverse impacts on groundwater quality were based on a critical $\mathrm{NO}_{3}{ }^{-}$concentration in leachate to groundwater equal to the drinking water limit of the WHO, which is also a formal target under the EU Nitrates Directive. We used this critical concentration on all agricultural land, while many countries only apply it to Nitrate Vulnerable Zones where drinking water needs to be protected. Furthermore, the $\mathrm{NO}_{3}{ }^{-}$concentration in leachate to groundwater differs from the concentration in upper groundwater. Kunkel et al. (2017) thus calculated required reductions in agricultural $\mathrm{N}$ surplus to comply with the EU target value of $50 \mathrm{mg} \mathrm{NO}_{3}^{-} \mathrm{l}^{-1}$ while also accounting for denitrification in upper groundwater.

\section{Critical nitrogen inputs}

Critical $\mathrm{N}$ inputs to agriculture to avoid adverse impacts on terrestrial ecosystems, surface water or groundwater quality were derived assuming the current NUE and the current $\mathrm{NH}_{3}$ emission fractions for manure and fertilizer. Reaching such critical $\mathrm{N}$ inputs implies a decline in crop production when they are below current $\mathrm{N}$ inputs. In a Chapter 3, we assess possibilities to respect thresholds without yield reductions (or even while closing yield gaps) by increasing NUE and reducing $\mathrm{NH}_{3}$ emission fractions through improved agricultural management. Results show that technological improvements alone are not always sufficient to respect thresholds and maintain current production levels in intensive crop or livestock production areas (see Chapter 3). The political discussion in the Dutch Nitrogen crisis (see for example Stokstad, 2019) thus focuses on the best combination of technology and a decrease in livestock production to reduce $\mathrm{NH}_{3}$ emissions by $50-70 \%$. The European Green Deal aims to reduce nutrient losses by $50 \%$ in 2030, and economic implications of possible reductions in agricultural production that may be needed to achieve this goal are discussed in several papers (Beckman et al., 2020; Fuchs et al., 2020). Critical N inputs based on current $\mathrm{N}$ efficiency indicators (NUEs, $\mathrm{NH}_{3}$ emission fractions) indicate the challenge to solve $\mathrm{N}$-related environmental problems and, ceteris paribus, the implications for agricultural production. 


\subsubsection{A new European $\mathbf{N}$ boundary}

Until now, regional (continental or national) $\mathrm{N}$ boundaries have been derived by allocating a share of the planetary $\mathrm{N}$ boundary to the region, based on different allocation principles. For example, Lucas et al. (2020) allocated shares of the planetary boundary for intentional $\mathrm{N}$ fixation to the EU, US, China and India, using both production- and consumption-based approaches. A recent EEA study used various allocation principles, including equality, needs, and the right for economic development, to allocate shares of the planetary $\mathrm{N}$ boundary to the EU (EEA and FOEN, 2020). The study concluded that $\mathrm{N}$ losses caused by European consumption exceed the European boundary by a factor 3.3, which means that $\mathrm{N}$ losses need to be reduced by ca. $71 \%$. This is substantially higher than the needed reductions to respect thresholds derived by our study (which focuses on $\mathrm{N}$ losses in the EU, regardless of where produced goods are consumed).

In the studies described above, allocation principles are based on the experience from climate change negotiations, implementing notions of equity and fairness, such as current share in contributing to global environmental pressure and 'ability to pay' to reduce environmental pressure. However, these approaches all assume that the planetary $\mathrm{N}$ boundary by Steffen et al. (2015) is an adequate approximation of the planetary risk, whereas this boundary is highly uncertain, mainly because spatial variation is not well included. In addition, the planetary boundary neglects possible reallocation of $\mathrm{N}$ from regions where critical limits are exceeded to regions where losses can still increase without exceeding thresholds, as further explained in De Vries et al. (2013) and Steffen et al. (2015).

The EEA study concludes by noting that regional boundaries should "be made spatially explicit to account for local contexts and effects" (EEA and FOEN, 2020). In this study, we responded to this call and derived a new European $\mathrm{N}$ boundary by upscaling local critical $\mathrm{N}$ inputs. We thus acknowledge the large spatial variation in both agricultural systems affecting the relationship between $\mathrm{N}$ inputs and $\mathrm{N}$ losses and in the sensitivity of the receiving terrestrial ecosystems.

\subsection{Conclusions}

Protecting terrestrial and aquatic ecosystems requires reducing $\mathrm{EU} \mathrm{NH}_{3}$ emissions and $\mathrm{N}$ runoff to surface water by $38 \%$ and $50 \%$, respectively. These values are similar to the goal to reduce nutrient losses by 50\% stated in the 'Farm to Fork' strategy (FFS) of the European Green Deal. Required reductions in $\mathrm{N}$ inputs to protect terrestrial and aquatic ecosystems ( $31 \%$ and $43 \%$, respectively) are higher than the $20 \%$ reduction goal for fertilizer use in the 
FFS. In addition, respecting thresholds for $\mathrm{NH}_{3}$ emissions specifically requires reductions of manure $\mathrm{N}$ inputs. However, our results reflect required reductions at current $\mathrm{NUE}$ and $\mathrm{NH}_{3}$ emission fractions. Increasing NUE and/or reducing $\mathrm{NH}_{3}$ emission fractions is necessary to respect environmental thresholds without large reductions in crop and livestock production (see Chapter 3).

Critical $\mathrm{N}$ inputs and their exceedances vary strongly across the EU. Highest exceedances are found in regions with high total $\mathrm{N}$ inputs, such as Ireland, Benelux, Brittany in France and the Po valley in Italy, while in other regions, thresholds for one or several impacts are not exceeded. This highlights the need for region-specific mitigation policies based on regional information on critical $\mathrm{N}$ inputs and their exceedances with related environmental and health impacts. Results of this study could be used to develop such policies, while spatially explicit calculations of differences in actual and critical $\mathrm{N}$ inputs and $\mathrm{N}$ losses would then be relevant to evaluate the mitigation measures proposed. In addition, this study provides an elaborate documentation of the methodology and calculation steps, thus allowing the approach to calculate critical inputs to be applied in national or regional assessments based on more detailed models and input data. 
\%

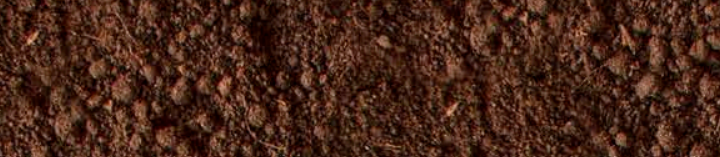

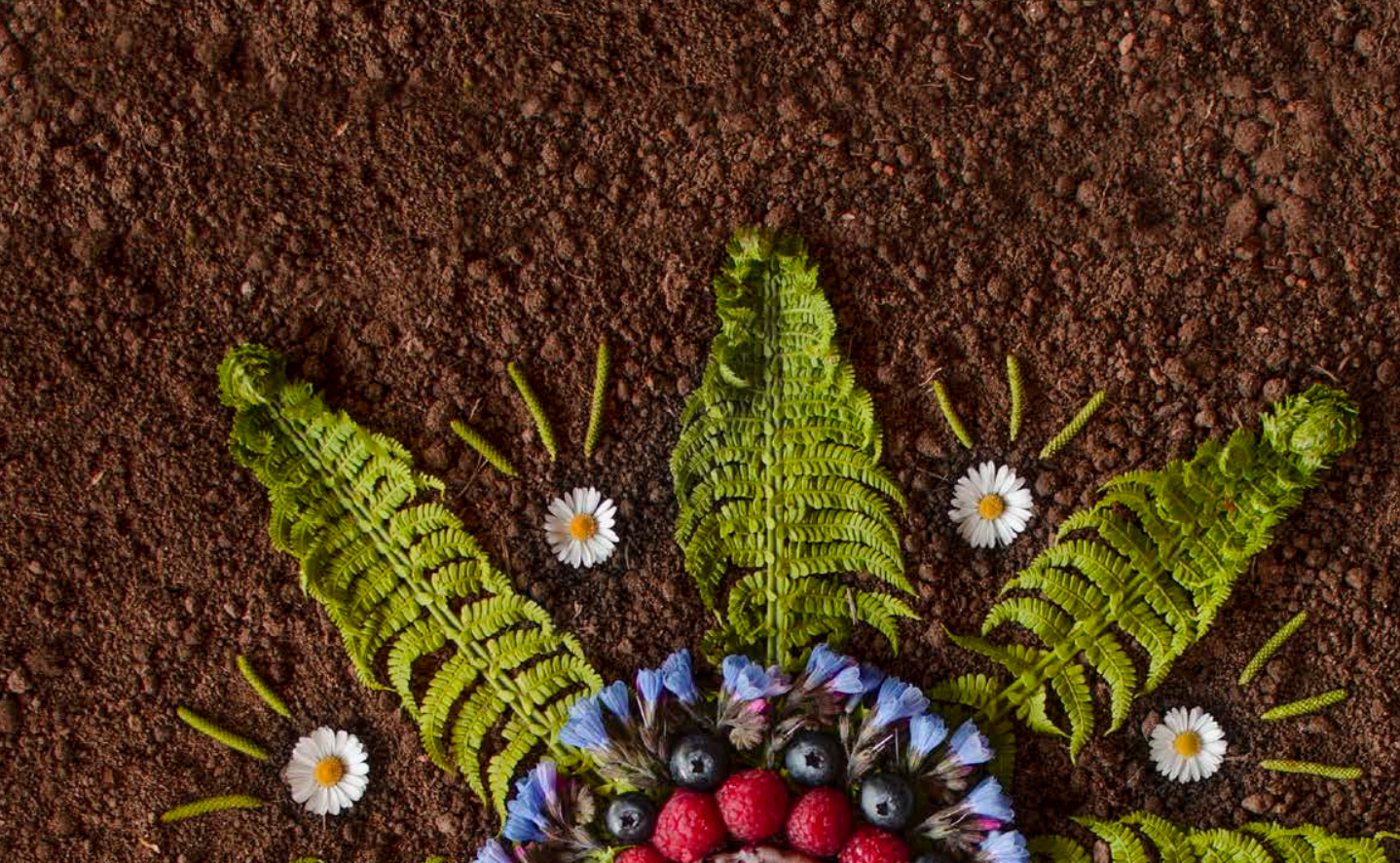

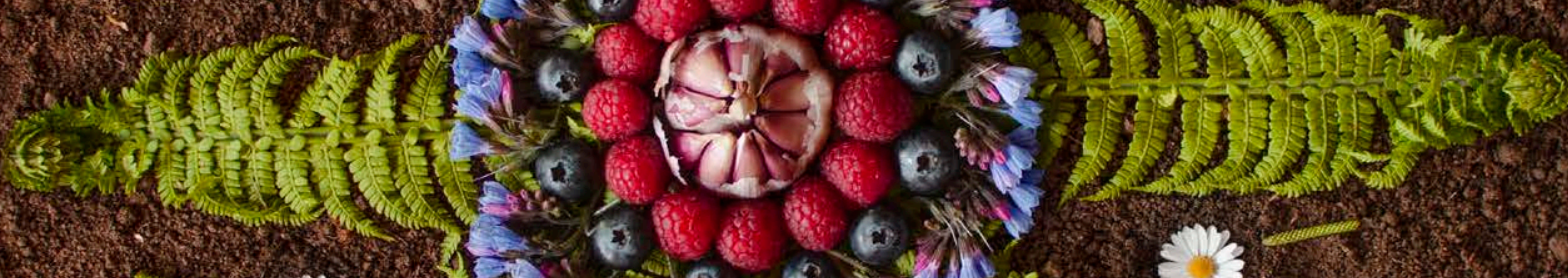
$16 e^{2}+2$

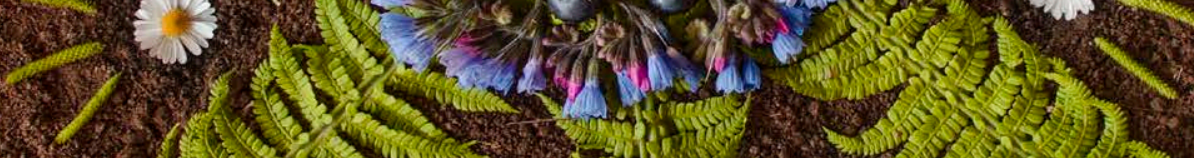
( $1 \times-2$

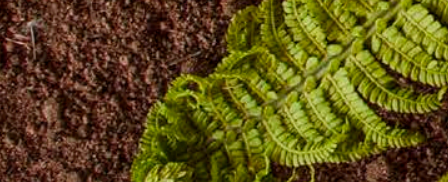

$2 x+5$

5 . 33

1.

(x) 10

$$
\text { (1) }
$$

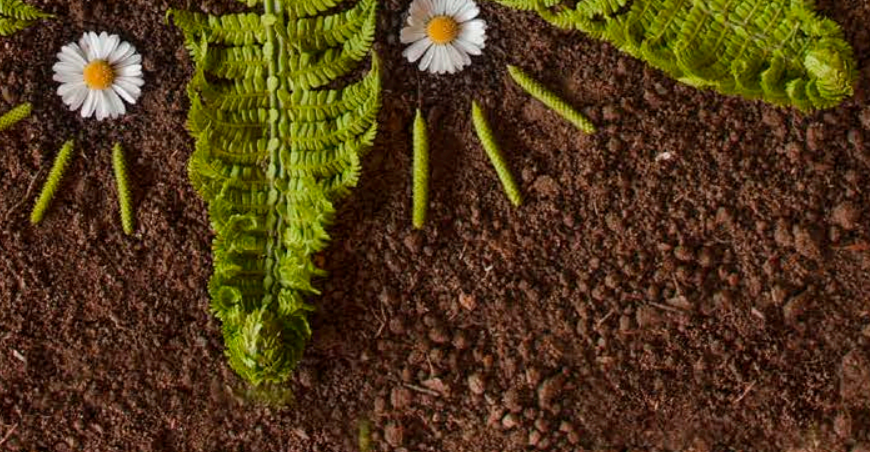

$\left.\sigma_{2}\right)$

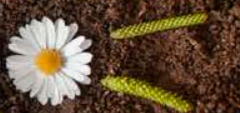




\section{Chapter 3}

Reconciling food production and environmental boundaries for nitrogen in the European Union

Published as: Lena Schulte-Uebbing \& Win de Vries (2021). Science of the Total Environment, 786:147427. 


\section{Abstract}

Meeting European policy targets for reducing nitrogen $(\mathrm{N})$ pollution while maintaining crop production is a large challenge. Strategies to tackle this dual challenge should assess where reducing $\mathrm{N}$ losses is most needed while accounting for variation in agricultural systems and ecosystems' vulnerability to $\mathrm{N}$ loading. We used a spatially explicit $\mathrm{N}$ balance model (INTEGRATOR) to assess whether crop production targets and thresholds for $\mathrm{N}$ impacts on biodiversity and water quality in the EU can be reconciled by (i) redistributing $\mathrm{N}$ inputs from excess regions to regions where environmental thresholds are not exceeded and (ii) improving $\mathrm{N}$ management to reduce ammonia $\left(\mathrm{NH}_{3}\right)$ emissions from manure and enhance field-level $\mathrm{N}$ use efficiency (NUE). At current NUE, reducing $\mathrm{N}$ inputs to comply with three environmental thresholds (critical $\mathrm{N}$ deposition on terrestrial ecosystems and critical $\mathrm{N}$ concentrations in surface water and groundwater) would reduce European crop production by $50 \%$. The widespread exceedance of thresholds does not provide much room for redistribution: increasing inputs to close yield gaps on land where $\mathrm{N}$ thresholds are not exceeded can only increase crop production by $3 \%$. To achieve surface water quality targets without crop production losses, average NUE needs to increase from 0.64 to 0.78 , whereas achieving groundwater targets requires a modest increase from 0.64 to 0.67 . In hotspot areas, however, crop production and $\mathrm{N}$ thresholds can only be reconciled at NUEs of $>0.90$, which is not feasible. Reducing manure $\mathrm{NH}_{3}$ emission fractions to 0.10 by adopting bestmanagement practices reconciles current crop production and thresholds for agricultural $\mathrm{NH}_{3}$ emission (in view of critical deposition) on only half of the agricultural area. In some regions, technologically feasible improvements in $\mathrm{N}$ management are thus insufficient to both maintain crop production and respect environmental boundaries. Overall, the evaluated measures could reconcile $\sim 80 \%$ of current EU crop production with $\mathrm{N}$ thresholds.

\section{I. Introduction}

Europe is one of the most food secure regions worldwide (FAOSTAT), yet the intensive agricultural systems that support European food production also harm ecosystems and biodiversity (EEA, 2020). A quarter of Europe's land area is dedicated to arable crops (compared to a global average of 11\%, FAOSTAT), and livestock densities are among the highest in the world (Gilbert et al., 2018). Both crop and grassland production are supported by high inputs of nitrogen $(\mathrm{N})$, an essential nutrient for plant production. Only about $60-65 \%$ of $\mathrm{N}$ applied to Europe's soils, however, is taken up by crops (De Vries et al., 2011; EUROSTAT, 2020; Leip et al., 2011a, 2011b). Much of the excess N is lost to the environment, 
which adversely affects soil, air and water quality. This has resulted in widespread impacts on ecosystems (Dise et al., 2011; Stevens et al., 2020) and human health (Pozzer et al., 2017), causing substantial societal costs (van Grinsven et al., 2013). Reducing N losses is pivotal for meeting several European targets related to water quality and biodiversity (EEA, 2019).

While reducing $\mathrm{N}$ losses is urgently needed to protect ecosystems, such reductions should not lead to large reductions in crop and livestock production. Despite already ranking among the world's highest-producing regions, Europe's agricultural production will probably need to increase in the future for several reasons. The first reason is geopolitical: Since 1990, Europe has shifted from food self-sufficiency to import dependency (Sadowski and Baer-Nawrocka, 2016). Many European countries currently produce less than $70 \%$ of their domestic demand (FAO, 2012; Puma et al., 2015; Sadowski and Baer-Nawrocka, 2016). Europe is also a net importer of plant proteins, mainly for animal feed (Lassaletta et al., 2014b). This import dependency makes Europe vulnerable in case of scarcity on global crop markets (Puma et al., 2015). The second reason is global food security: while Europe's food demand is only projected to increase by a few percent until 2050 (Bruinsma, 2012), a rapidly increasing global population and shifts towards higher animal protein shares in diets as well as rising demands for bioenergy feedstock (de Wit et al., 2011) are expected to increase global crop demand by $60 \%$ (FAO, 2017) to 100\% (Tilman et al., 2011) between 2010 and 2050. Current crop yield growth rates are likely insufficient to meet this demand (Ray et al., 2013, 2012), especially in Sub-Saharan Africa (van Ittersum et al., 2016) and some regions in Asia and South America (Fader et al., 2013). If growing demands cannot be met by domestic production and pressures on global food markets increase, it is likely that trade with Europe will play a role in meeting demands (Pradhan et al., 2014). The third reason is to avoid spill-over effects: at constant global demand, a reduction in European food production would shift production to other regions with potentially less strict environmental regulations, thus effectively relocating environmental damage (Fuchs et al., 2020).

Increasing agricultural output can be achieved in two ways: by increasing agricultural area (land expansion), or by enhancing productivity to close yield gaps on existing agricultural land (land intensification) (Tilman et al., 2011). Land expansion often increases greenhouse gas emissions and negatively affects biodiversity and ecosystem services (Foley et al., 2011; Lambin et al., 2013), and suitable land for agricultural expansion is increasingly scarce (Lambin and Meyfroidt, 2011). Closing yield gaps, on the other hand, usually requires increasing inputs, such as water, $\mathrm{N}$ and other nutrients. Increasing $\mathrm{N}$ inputs, however, may counteract efforts to reduce $\mathrm{N}$ pollution as mandated by several European Directives, such as the Water Framework Directive (EC, 2000) or the Nitrates Directive (EC, 1991). It is also in contradiction with the ambition of the European Green Deal to reduce agricultural nutrient 
losses by $50 \%$ in 2030 (European Commission, 2020). The challenge is therefore to maintain or even increase European agricultural production while remaining within safe thresholds for $\mathrm{N}$ pollution.

Two major options exist to remain within 'safe boundaries' for $\mathrm{N}$ losses without reducing (or even while increasing) crop yields. First, by spatially redistributing crop and animal production and associated $\mathrm{N}$ inputs and losses. This entails intensifying production (i.e., increasing $\mathrm{N}$ inputs) in regions where thresholds for $\mathrm{N}$ pollution are not yet exceeded, thus compensating for yield losses in areas where $\mathrm{N}$ inputs need to be reduced to respect those thresholds (Gerten et al., 2020; Mueller et al., 2012). Second, by improving N use efficiency (NUE) in both crop and animal production systems to reduce $\mathrm{N}$ losses and thus environmental impact while maintaining productivity levels. Crop production NUE can be increased by better matching $\mathrm{N}$ inputs with crop demand through improved fertilizer technologies and practices (Chen et al., 2014; Ju et al., 2009; Zhang et al., 2015), or by using improved crop varieties or crop rotations (Cormier et al., 2016; Davidson et al., 2015; Hirel et al., 2011). Nitrogen use efficiency in livestock production systems can be increased through improved manure management and recycling, herd management, nutrition, or technological adaptations to housing systems (Oenema et al., 2007; Uwizeye et al., 2020). From a biophysical perspective, each strategy's potential depends on the local characteristics of both agricultural systems (determining the relationship between $\mathrm{N}$ inputs and $\mathrm{N}$ losses) and the ecosystems receiving $\mathrm{N}$ losses (determining how much $\mathrm{N}$ inputs an ecosystem can tolerate). Socio-economic factors that determine whether and at what costs these strategies can be implemented are not considered here.

Given the large heterogeneity in agricultural production systems across Europe, developing strategies to balance environmental and production targets requires spatially explicit information on (i) 'safe' $\mathrm{N}$ losses to minimize environmental risks of $\mathrm{N}$, (ii) the potential to enhance crop production by increasing $\mathrm{N}$ inputs on existing agricultural land and (iii) the NUE at which both environmental and crop production objectives can be met. Chapter 2 presents a first spatially explicit assessment of 'safe' $\mathrm{N}$ input levels (called 'critical' $\mathrm{N}$ inputs hereafter) in the EU in view of thresholds for: (i) atmospheric $\mathrm{N}$ deposition onto terrestrial ecosystems to limit biodiversity loss; (ii) $\mathrm{N}$ concentration in surface water to limit eutrophication and (iii) nitrate $\left(\mathrm{NO}_{3}{ }^{-}\right)$concentration in groundwater to meet drinking water standards in view of human health impacts. Results showed that on $85 \%$ of EU agricultural area, current $\mathrm{N}$ losses exceed at least one of the three thresholds (Table 3.1). More importantly, results from Chapter 2 showed substantial spatial variation in the exceedance of $\mathrm{N}$ pollution thresholds, due to large variations in agricultural $\mathrm{N}$ inputs, in the biogeochemical and hydrological processes that determine $\mathrm{N}$ losses, as well as ecosystems' vulnerability to these 
Table 3.I| Thresholds for environmental impacts of nitrogen $(N)$ and associated agricultural $N$ losses, and share of agricultural area where thresholds are exceeded in the current (2010) situation (see Chapter 2).

\begin{tabular}{|c|c|c|}
\hline Thresholds for environmental impacts & $\begin{array}{l}\text { Thresholds for } \\
\mathrm{N} \text { losses from } \\
\text { agriculture }\end{array}$ & $\begin{array}{l}\text { Share of area } \\
\text { where threshold } \\
\text { is exceeded }\end{array}$ \\
\hline $\begin{array}{l}\text { Deposition: thresholds for } \mathrm{N} \text { deposition onto terrestrial } \\
\text { ecosystems in view of biodiversity impacts (ecosystem- } \\
\text { dependent critical loads) }\end{array}$ & Critical $\mathrm{NH}_{3}$ emissions & $66 \%$ \\
\hline $\begin{array}{l}\text { Surface water: threshold for } \mathrm{N} \text { concentration in runoff to } \\
\text { surface water in view of eutrophication impacts }\left(2.5 \mathrm{mg} \mathrm{N}^{-1}\right)\end{array}$ & $\begin{array}{l}\text { Critical } \mathrm{N} \text { runoff to } \\
\text { surface water }\end{array}$ & $74 \%$ \\
\hline $\begin{array}{l}\text { Groundwater: threshold for nitrate concentration in } \\
\text { groundwater in view of health effects }\left(50 \mathrm{mg} \mathrm{NO}_{3}^{-} \mathrm{I}^{-1}\right)\end{array}$ & $\begin{array}{l}\text { Critical } \mathrm{N} \text { leaching to } \\
\text { groundwater }\end{array}$ & $18 \%$ \\
\hline All thresholds respected simultaneously & Minimum of above losses & $85 \%$ \\
\hline
\end{tabular}

losses. To maximise nitrogen's benefits for EU food production while limiting its adverse impacts, this variation needs to be considered when developing $\mathrm{N}$ management strategies.

The aim of this chapter is to explore to what extent thresholds for $\mathrm{N}$ losses to air and water can be respected while maintaining (or even increasing) crop and grassland production in the EU. The chapter builds on the approach developed in Chapter 2 and presents shares of crop and grassland production that can be obtained within safe boundaries for $\mathrm{N}$ losses (i) under 'baseline' conditions, (ii) by increasing $\mathrm{N}$ inputs to close yield gaps in regions where thresholds allow, and (iii) by improving $\mathrm{N}$ management (increase NUE and/or reduce $\mathrm{NH}_{3}$ emission fractions). In regions where improving $\mathrm{N}$ management is insufficient to fully reconcile current crop production and $\mathrm{N}$ loss thresholds, environmental targets can only be met at lower yields. The approach assumes that current properties of the agricultural system are maintained, such as the agricultural area (no land expansion) and the mix of crop and livestock production, while not considering possibilities to reduce demand for agricultural produce through, e.g., avoiding food waste and reducing consumption of livestock products (Grizzetti et al., 2013; Westhoek et al., 2014). Results indicate the technical potential of various strategies to reconcile crop production with $\mathrm{N}$ thresholds, while not accounting for existing socio-economic, cultural or institutional barriers that may impede their implementation.

\subsection{Methods}

\subsection{Thresholds for nitrogen losses and inputs and their exceedances}

Thresholds for $\mathrm{N}$ losses and $\mathrm{N}$ inputs were derived with INTEGRATOR, a spatially 
explicit, process-based model that calculates $\mathrm{N}$ balances for agricultural land in the EU at a high spatial resolution for the year 2010. INTEGRATOR calculates manure excretion in housing systems and pastures, and $\mathrm{N}$ inputs to agricultural soils from different sources, i.e. manure, synthetic fertilizer, biosolids, biological fixation, atmospheric deposition, and net mineralization (only on peat soils). Resulting emissions of ammonia $\left(\mathrm{NH}_{3}\right)$, nitrous oxide $\left(\mathrm{N}_{2} \mathrm{O}\right)$ and nitrogen oxide $\left(\mathrm{NO}_{\mathrm{x}}\right)$ to the atmosphere, as well as $\mathrm{N}$ leaching and $\mathrm{N}$ runoff to groundwater and surface water are calculated empirically as a function of $\mathrm{N}$ input quantity and source, $\mathrm{N}$ management, land use, climate, soil type and slope. Crop $\mathrm{N}$ uptake is estimated based on national yield statistics for $\sim 35$ crops represented in INTEGRATOR from FAOSTAT (downscaled to zones of similar climate), and $\mathrm{N}$ contents and harvest indices from the literature. Grassland yields are estimated based on Smit et al. (2008). Calculations are performed for approximately 40,000 Nitrogen Calculation Units (NCUs), which in turn are sub-divisions of 1,244 NUTS 3 regions (administrative areas in the EU of $160-440 \mathrm{~km}^{2}$ ). For a detailed description of the INTEGRATOR model, see Chaper 2.

'Critical $\mathrm{N}$ inputs', defined as $\mathrm{N}$ inputs that cause $\mathrm{N}$ losses at exactly the environmental threshold, were derived in three steps (Figure 3.1a). First, environmental thresholds to avoid $\mathrm{N}$ impacts were defined for (i) $\mathrm{N}$ deposition to terrestrial ecosystems to avoid terrestrial biodiversity loss (based on critical loads for nature areas), (ii) $\mathrm{N}$ concentration in runoff to surface water to avoid eutrophication, and (iii) $\mathrm{NO}_{3}{ }^{-}$concentration in leachate to groundwater to avoid health risks (based on the EU drinking water norm) (step 1 in Figure 3.1a; see also Figure 3.1b \& Table 3.1). Second, critical $\mathrm{N}$ losses $\left(\mathrm{NH}_{3}\right.$ emissions, $\mathrm{N}$ runoff and $\mathrm{N}$ leaching) were back-calculated from environmental thresholds (step 2 in Figure 3.1a) while also accounting for $\mathrm{N}$ losses from other sectors (e.g., $\mathrm{NO}_{\mathrm{x}}$ emissions from traffic and industry) and for dilution of agricultural $\mathrm{N}$ losses (e.g., dilution of agricultural runoff by runoff from natural areas). Third, critical $\mathrm{N}$ inputs were back-calculated from critical $\mathrm{N}$ losses, based on current $\mathrm{N}$ loss fractions and $\mathrm{N}$ uptake fractions (step 3 in Figure 3.1a). A full description of the approach and used thresholds is given in Chapter 2.

Critical N inputs were compared with current (2010) N inputs to determine reductions needed to respect environmental thresholds. Where thresholds are exceeded, reducing $\mathrm{N}$ inputs to critical levels leads to lower crop production (step 4 in Figure 3.1a), unless $\mathrm{N}$ management factors are improved (Figure 3.1b). A higher NUE leads to a lower soil surplus and thus $\mathrm{N}$ runoff and/or leaching per unit of $\mathrm{N}$ input, while a lower $\mathrm{NH}_{3}$ emission fraction (EF) leads to lower $\mathrm{NH}_{3}$ emissions per unit of $\mathrm{N}$ input (and thus indirectly also to a higher NUE; Figure 3.1b). Consequently, it is possible to derive changes in management factors needed to meet crop production targets while simultaneously respecting thresholds for $\mathrm{N}$ losses (step 5 in see Figure 3.1a, see also Section 3.2.3). 


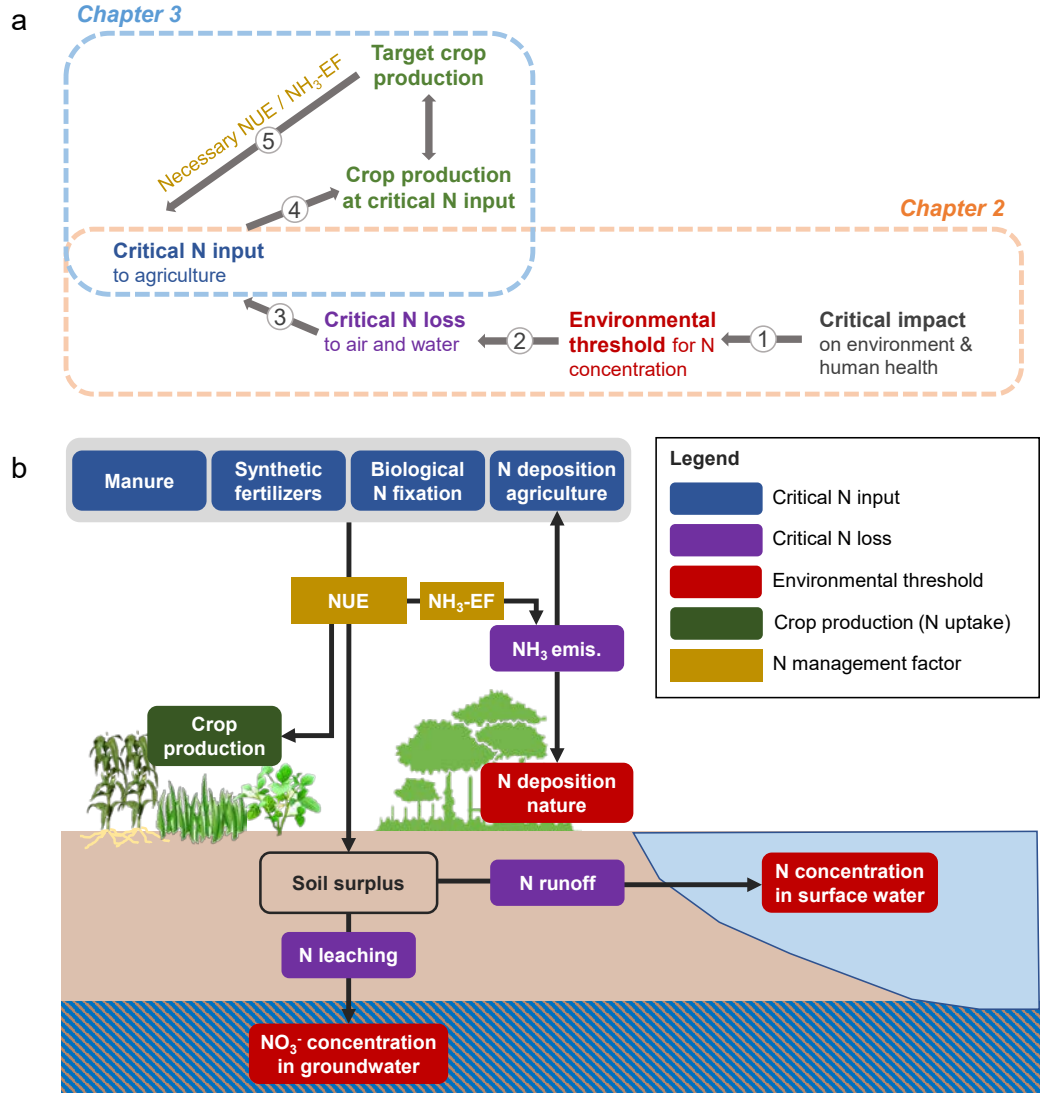

Figure 3.I | a, Steps for back-calculating critical nitrogen $(N)$ inputs from environmental thresholds for $\mathrm{N}$ and related critical $\mathrm{N}$ losses, as well as the necessary nitrogen use efficiency (NUE) or $\mathrm{NH}_{3}$ emission fraction (EF) to reconcile environmental thresholds with crop production targets. Dashed boxes indicate which steps are described in this chapter (blue) and in Chapter 2 (orange). b. Simplified representation of relationships between critical $\mathrm{N}$ inputs, critical $\mathrm{N}$ losses, environmental thresholds (see also Table 3.I), crop production (crop $\mathrm{N}$ uptake) and $\mathrm{N}$ management factors.

\subsubsection{Required nitrogen inputs to obtain target yields}

\section{Yield potentials and target yields}

To determine target yields in regions where $\mathrm{N}$ inputs can safely increase without exceeding environmental thresholds, we estimated spatially explicit, crop-specific yield potentials for all crops included in INTEGRATOR. A crop's 'yield potential' is defined as the maximum possible yield for a given climate and soil under optimal management, and the 'yield gap' as the difference between yield potential and actual yield (van Ittersum et al., 2013). The Global Yield Gap Atlas (GYGA, www.yieldgap.org) provides data on actual yields and yield potentials (both under water-limited and irrigated conditions) for a variety of staple crops 
and countries. GYGA yield potentials are estimated by a bottom-up approach using crop growth models calibrated for specific weather stations, and upscaled to the country-level using zones of similar climate (Grassini et al., 2015; van Bussel et al., 2015). This approach produces more accurate estimates than top-down approaches that rely on global datasets of weather, soil and crop management (van Ittersum et al., 2013).

For the EU, GYGA currently reports actual yields (Ya), water-limited yield potentials (Yw) and yield gaps only for wheat, barley and maize in most countries (Schils et al., 2018b; Table S3.1). Data for other crops are not available (neither from GYGA nor from other sources) and yield potentials for these crops were thus estimated by assuming that relative yield gaps follow the same pattern as yield gaps for rainfed wheat (see Supplementary Text S3.1). Rainfed wheat was used in the scaling approach as it is the most important arable crop in Europe; accounting for about a quarter of the total cropland area. Yield potentials for all crops were estimated by multiplying actual yields from INTEGRATOR by the ratio Yw/Ya for rainfed wheat from GYGA. Resulting yield potentials were then corrected to account for the fact that yield gaps for other crops may differ from yield gaps for wheat by multiplying with the ratio of the 'maximum yield ratios' for the respective crop and wheat (see Eq. S3.1). The 'maximum yield ratio' expresses the relation between the average crop yield in a given country and the highest country-level crop yield in the EU. Country-level yield potentials for barley and maize estimated with this procedure were compared to GYGA data, which generally gave good results (Figure S3.1c,d). Scaling with the maximum yield ratio improved the fit compared to scaling with Yw/Ya for rainfed wheat only (Figure S3.1a,b). As data on yield potentials for other crops in Europe are not available, we could not validate estimated yield potentials for these crops.

The 'target yield' was set to $80 \%$ of the estimated water-limited yield potential. Eighty percent of the biophysical potential is generally considered the economic optimum for farmers under most conditions (Lobell et al., 2009; van Ittersum et al., 2013). For grassland, target yields were only estimated for intensively managed grassland (defined as grasslands with dry matter production $>4,500 \mathrm{~kg} \mathrm{ha}^{-1} \mathrm{yr}^{-1}$ ), as we assumed that extensive grasslands are not managed by farmers to maximise yields.

\section{Required nitrogen inputs to obtain target yields}

Nitrogen inputs required to obtain target yields were calculated by multiplying actual (year 2010) $\mathrm{N}$ inputs by the ratio of target yield and actual yield (i.e., assuming that NUE is constant). On the one hand, the assumption of constant NUE may lead to an overestimation of required $\mathrm{N}$ inputs, as additional input in the form of synthetic fertilizer generally has a higher NUE than the current mix of $\mathrm{N}$ sources (which includes less-available $\mathrm{N}$ from 
manure). On the other hand, according to the law of diminishing returns, the yield response to N inputs (and thus NUE) declines with increasing N input (Bodirsky and Müller, 2014; de Wit, 1992). The net effect of both mechanisms depends on local circumstances, such as the presence of other yield-limiting factors; for this study we assumed that on average both effects compensate each other. This approach is supported by studies showing that diminishing yield responses to inputs mainly occur when yields approach $80 \%$ of their biophysical potential (van Ittersum et al., 2013; Van Ittersum and Rabbinge, 1997).

\subsubsection{Opportunities to achieve crop production goals while respecting environmental thresholds for nitrogen}

We explored possibilities for reconciling crop production goals with environmental thresholds for $\mathrm{N}$ by redistributing $\mathrm{N}$ inputs from areas with excess $\mathrm{N}$ to areas where thresholds are not exceeded, by improving $\mathrm{N}$ management, and by combining redistribution and $\mathrm{N}$ management improvements.

\section{Opportunities for redistributing nitrogen inputs}

Possibilities for maximising crop production while respecting environmental thresholds for $\mathrm{N}$ by redistributing $\mathrm{N}$ inputs were assessed as follows: First, in areas where environmental thresholds are exceeded $\left(\mathrm{Nin}_{\text {crit }} \leq \mathrm{Nin}_{\text {act }}\right), \mathrm{N}$ inputs were reduced to the critical input level (Eq. 3.1, first row). Second, in areas where thresholds are not exceeded $\left(\mathrm{Nin}_{\text {crit }}>\mathrm{Nin}_{\text {act }}\right), \mathrm{N}$ inputs were increased up to the critical input level (Eq. 3.1, second row), but no further than the level required to obtain target yield at current NUE (in order to avoid unrealistically high $\mathrm{N}$ inputs in areas where environmental constraints are not limiting, Eq. 3.1, third row).

$$
\text { Nin }_{\text {redist }}= \begin{cases}\text { Nin }_{\text {crit }} & \text { if } \mathrm{Nin}_{\text {crit }} \leq \mathrm{Nin}_{\text {act }} \\ \text { Nin }_{\text {crit }} & \text { if } \mathrm{Nin}_{\text {act }}<\mathrm{Nin}_{\text {crit }} \leq N_{\text {tar }} \\ \mathrm{Nin}_{\text {tar }} & \text { if } \mathrm{Nin}_{\text {act }}<N \mathrm{Ni}_{\text {tar }}<N_{\text {crit }}\end{cases}
$$

Where:

$$
\begin{aligned}
\text { Nin }_{\text {redist }}= & \mathrm{N} \text { input after redistribution to maximise crop production while respecting } \\
& \text { environmental thresholds }\left(\mathrm{kg} \mathrm{N} \mathrm{ha}^{-1} \mathrm{yr}^{-1}\right) \\
\text { Nin }_{\text {crit }}= & \text { Critical } \mathrm{N} \text { input, i.e. maximum allowable input while respecting environmental } \\
& \text { thresholds for deposition, surface water and groundwater - }\left(\mathrm{kg} \mathrm{N} \mathrm{ha}^{-1} \mathrm{yr}^{-1}\right) \\
\text { Nin }_{\text {act }}= & \text { Actual (year 2010) } \mathrm{N} \text { inputs }\left(\mathrm{kg} \mathrm{N} \mathrm{ha}^{-1} \mathrm{yr}^{-1}\right) \\
\text { Nin }_{\text {tar }}= & \mathrm{N} \text { input required to obtain target yield at current } \mathrm{NUE}\left(\mathrm{kg} \mathrm{N} \mathrm{ha}^{-1} \mathrm{yr}^{-1}\right)
\end{aligned}
$$

Possibilities for redistribution were assessed for each threshold individually, and for all thresholds combined. Crop yield losses or gains from redistributing $\mathrm{N}$ inputs were calculated assuming a constant NUE. 


\section{Opportunities for improved nitrogen management}

Opportunities to reconcile thresholds for $\mathrm{N}$ with crop production by improved $\mathrm{N}$ management were assessed by deriving $\mathrm{N}$ management factors at which current or target crop yields can be obtained without exceeding thresholds for $\mathrm{N}$ losses (Figure 3.1a, step 5). For the thresholds for surface water and groundwater, we focused on NUE, while for the deposition threshold we manipulated the $\mathrm{NH}_{3}$ emission fraction (EF). The $\mathrm{NH}_{3} \mathrm{EF}$ is in fact one of the factors determining overall NUE (a lower $\mathrm{NH}_{3}$ EF implies a higher NUE, see Figure 3.1b). However, as the overall NUE is also driven by other losses, the $\mathrm{NH}_{3} \mathrm{EF}$ is a more meaningful indicator in the context of reducing $\mathrm{NH}_{3}$ emissions to respect deposition thresholds.

Nitrogen use efficiency is defined here as the ratio of crop $\mathrm{N}$ removal (by harvest or grazing) to total $\mathrm{N}$ input (sum of inputs from synthetic fertilizer, gross manure excretion, biosolids, biological $\mathrm{N}$ fixation, deposition and mineralization). The $\mathrm{NH}_{3} \mathrm{EF}$ is defined as the ratio of total $\mathrm{NH}_{3}$ emissions to total $\mathrm{N}$ input for a defined $\mathrm{N}$ source. As $80 \%$ of European $\mathrm{NH}_{3}$ emissions stem from manure, we derived necessary reductions in manure $\mathrm{NH}_{3} \mathrm{EF}$ while assuming a constant fertilizer $\mathrm{NH}_{3}$ EF. The manure $\mathrm{NH}_{3} \mathrm{EF}$ was calculated by dividing total $\mathrm{NH}_{3}$ emissions from housing systems, manure deposited by grazing animals and manure application by total $\mathrm{N}$ manure inputs to soils. This approach implicitly assumes that excretion in housing systems occurs in the same region where the manure is applied. While INTEGRATOR does consider manure export if application of all manure excreted within a region exceeds maximum application rates $\left(250 \mathrm{~kg} \mathrm{~N} \mathrm{ha}^{-1} \mathrm{yr}^{-1}\right.$ for the Netherlands and Denmark and $170 \mathrm{~kg} \mathrm{~N} \mathrm{ha}^{-1} \mathrm{yr}^{-1}$ for all other countries), this only occurs in $5 \%$ of the agricultural area, and thus this simplification does not substantially affect results.

For areas where critical $\mathrm{NH}_{3}$ emissions are exceeded, we calculated the 'necessary' $\mathrm{NH}_{3} \mathrm{EF}$ for manure, i.e., the EF at which current or target yields can be obtained at critical $\mathrm{NH}_{3}$ emissions (see Supplementary Text S3.2 for details on calculations). Low-emission manure application and adaptations to manure storage and housing systems can reduce $\mathrm{NH}_{3}$ emissions by 20-80\% (Oenema et al., 2009; Velthof et al., 2009). We assumed a 'feasible' minimum $\mathrm{NH}_{3}$ EF of 0.15 , based on a $40 \%$ reduction from the current average value of $\sim 0.25$, and a 'possible' minimum $\mathrm{NH}_{3}$ EF of 0.10 , based on a $80 \%$ reduction in $\mathrm{NH}_{3}$ emissions from housing and manure application, and animal grazing during most of the year (grazing emissions vary mostly between 0.06 and 0.10 , see Chapter 2).

For areas where critical $\mathrm{N}$ runoff to surface water or critical $\mathrm{N}$ leaching to groundwater are exceeded, we calculated the 'necessary' NUE, i.e., the NUE at which current or target yields can be obtained at critical $\mathrm{N}$ runoff or $\mathrm{N}$ leaching rates (see Supplementary Text S3.3 for details on calculations). At increased NUE, a given yield can be obtained at a lower N input, 
while the critical $\mathrm{N}$ input increases because a smaller fraction of $\mathrm{N}$ is lost to the environment. We assumed a 'feasible' maximum NUE of 0.75 , which can be achieved by adopting wellproven mostly low-cost measures such as balanced $\mathrm{N}$ fertilization and precision farming, such as $\mathrm{N}$ application in the right amount, at the right time and right place (Bodirsky et al., 2014; Zhang et al., 2015). As some $\mathrm{N}$ losses to air and water are unavoidable, the 'possible' maximum NUE was set to 0.90 (EU Nitrogen Expert Panel, 2015).

\subsection{Results}

\subsection{Required nitrogen inputs to obtain target yields}

Averaged over all crops grown in the EU, derived target yields exceed actual (year 2010) yields by $26 \%$ (Table S3.2). The estimated gap between actual and target yield varies substantially between crop groups, with target yields exceeding actual yields by $16 \%$ for roots \& tubers and by $34 \%$ for cereals (Table S3.2). The largest gaps are found in Baltic countries, Romania, Bulgaria and Portugal (Figure 3.2b and Table S3.3).

a

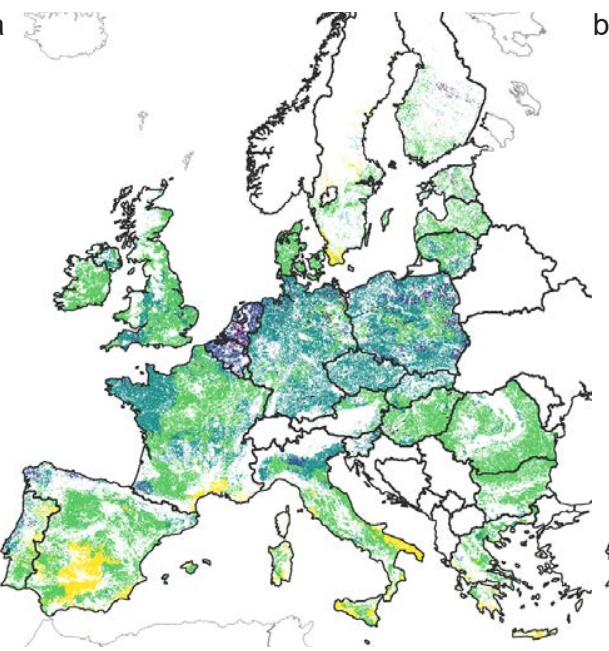

Required $\mathrm{N}$ input for target yield [kg N ha-1 $\left.\mathrm{yr}^{-1}\right]$

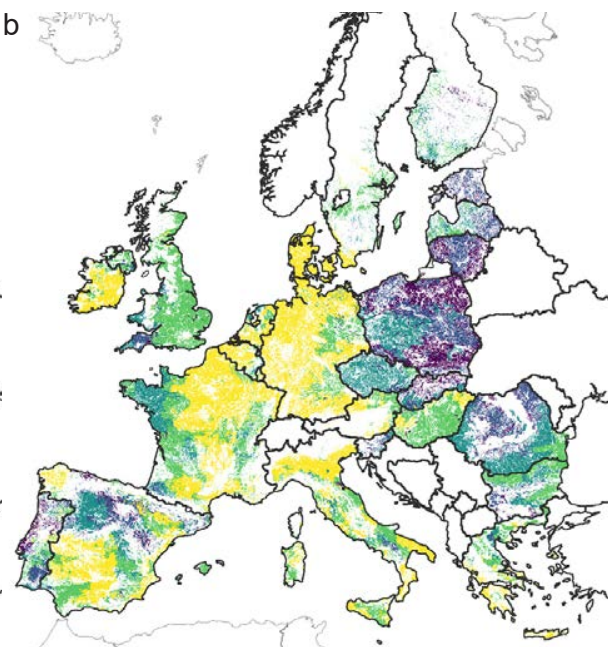

Gap between current \& required $\mathrm{N}$ input $\left[\mathrm{kg} \mathrm{N} \mathrm{ha}^{-1} \mathrm{yr}^{-1}\right]$

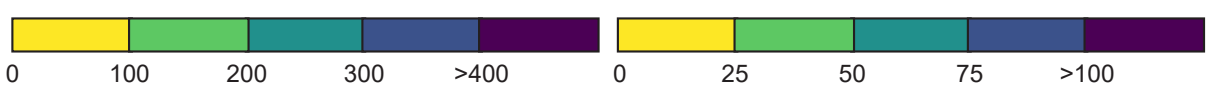

Figure 3.2 | a, Regional variation in required nitrogen $(N)$ input to obtain target yields (i.e., $80 \%$ of estimated water-limited crop yield potential, see Tables S3.2 \& S3.3) for arable crops (all agricultural crops excluding grassland and fodder crops); $\mathbf{b}$, regional variation in the gap between actual (year 2010) $\mathrm{N}$ inputs and required $\mathrm{N}$ inputs. White $=$ no arable crops. 
For cereal crops, closing the gap between actual and target yields everywhere in the EU at current NUE would require a 36\% increase in $\mathrm{N}$ inputs (from an average input rate of 131 to $179 \mathrm{~kg} \mathrm{~N} \mathrm{ha}^{-1} \mathrm{yr}^{-1}$; Table S3.3). Considering all crops, closing yield gaps requires a $27 \%$ increase in $\mathrm{N}$ inputs (from 145 to $185 \mathrm{~kg} \mathrm{~N} \mathrm{yr}^{-1}$, data not shown). Total required $\mathrm{N}$ input increases to achieve target yields for the three most important cereals (wheat, barley and rice) is 2.3 $\mathrm{Mt} \mathrm{N} \mathrm{yr}^{-1}$, which is close to the $\mathrm{N}$ uptake gap of 3.0 $\mathrm{Mt} \mathrm{N} \mathrm{yr}^{-1}$ for these crops estimated by Schils et al. (2018b). For most countries, $\mathrm{N}$ inputs need to increase by roughly the same ratio as the ratio of target yield to actual yield, though small differences occur due to regional variations in NUE (Table S3.3). For Portugal, for example, increasing cereal yields by $72 \%$ on average requires $\mathrm{N}$ inputs to increase by $89 \%$, showing that the largest yield increases are projected in areas with below-average NUE (Table S3.3). The largest N input gaps occur in Poland, Romania, Baltic states, Northern Spain and Portugal (Figure 3.2b and Table S3.3). Required $\mathrm{N}$ inputs to obtain target yields are highest in the Netherlands and Belgium (Figure 3.2a \& Table S3.3), but as input rates in these countries are already very high, the $\mathrm{N}$ input gap is small (Figure $3.2 \mathrm{~b}$ ).

\subsubsection{Reconciling environmental thresholds for nitrogen and crop production goals}

\section{Opportunities for spatially redistributing nitrogen inputs}

At 2010 inputs, one or more $\mathrm{N}$ loss thresholds are exceeded on 85\% of agricultural land, with stronger exceedances on arable land than on grassland (except for the $\mathrm{NH}_{3}$ emission threshold in view of critical $\mathrm{N}$ deposition on natural areas, see Table S3.4). Increasing $\mathrm{N}$ inputs to levels required to obtain target yields would increase the area with exceedances to $89 \%$ (Table S3.4). Respecting $\mathrm{N}$ thresholds under current management requires reducing annual $\mathrm{N}$ inputs by 7.6 Mt N (35\%) for the deposition threshold, $10.1 \mathrm{Mt} \mathrm{N}$ (46\%) for the surface water threshold, $2.1 \mathrm{Mt} \mathrm{N}$ (10\%) for the groundwater threshold, and 11.8 Mt N (54\%) to respect all thresholds simultaneously (Figure 3.3 \& Table S3.5). At constant NUE, these $\mathrm{N}$ inputs reductions would reduce annual crop production by $7-50 \%$, depending on the threshold considered (Table S3.6). Crop production losses vary between crop groups: reducing $\mathrm{N}$ inputs to respect thresholds for $\mathrm{N}$ runoff to surface water, for example, leads to production losses of $74 \%$ for roots and tubers and only $19 \%$ for grass and fodder (Table S3.6b). For all criteria, relative reductions in $\mathrm{N}$ inputs to respect thresholds (Table S3.5) are slightly higher than associated relative reductions in crop yields (Table S3.6), indicating that crops and regions where the strongest reductions are required have a below-average NUE.

For most thresholds, increasing $\mathrm{N}$ inputs in areas where thresholds allow can only compensate a small share of the required $\mathrm{N}$ input reductions in excess regions. Only for the groundwater 




Net impact of reductions and increases of $\mathrm{N}$ inputs within environmental thresholds [ $\left.\mathrm{kg} \mathrm{N} \mathrm{ha}^{-1} \mathrm{yr}^{-1}\right]$

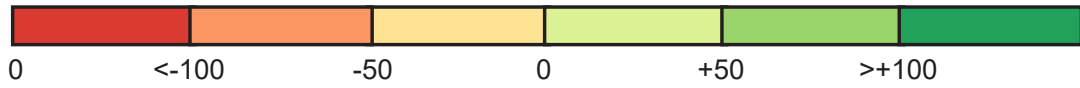

Figure 3.2 | Restrictions and opportunities for redistributing nitrogen $(N)$ inputs on current agricultural land while respecting thresholds for $\mathbf{a}, \mathrm{NH}_{3}$ emissions, $\mathbf{b}, \mathrm{N}$ runoff to surface water, $\mathbf{c}, \mathrm{N}$ leaching to groundwater and $\mathbf{d}$, all thresholds simultaneously. Red areas show required $\mathrm{N}$ input reductions to respect thresholds; green areas show allowable $\mathrm{N}$ input increases within thresholds. Numbers above maps show total required reductions (red) and allowable increases (green), percentages show change relative to current total $\mathrm{N}$ input (21.8 $\mathrm{Mt} \mathrm{N} \mathrm{yr}^{-1}$ in 2010). White $=$ no agricultural land. 


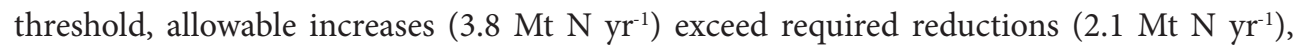
leading to a small net increase in $\mathrm{N}$ inputs of $8 \%$ (Figure 3.3c \& Table S3.5c). The net impact of redistributing $\mathrm{N}$ inputs also varies per crop group: while average $\mathrm{N}$ inputs increase for cereals and grass \& forage, they decrease for roots \& tubers, oil crops and other crops (Table S3.5c). For the deposition threshold the net impact of redistribution on $\mathrm{N}$ inputs is $-29 \%$, and for the surface water threshold $-42 \%$ (Figure 3.3a,b \& Table S5a,b). If all thresholds need to be respected, the options are even more limited: $\mathrm{N}$ inputs can safely increase by only $0.5 \mathrm{Mt}$ $\mathrm{N} \mathrm{yr}^{-1}(2 \%)$, hardly compensating for the needed reductions of $11.8 \mathrm{Mt} \mathrm{N} \mathrm{yr}^{-1}$ (54\%) (Figure 3.3d \& Table S3.5d). At current NUE, crop production that can be obtained while remaining within environmental thresholds is thus only $172 \mathrm{Mt} \mathrm{yr}^{-1}(-56 \%)$ for grains, $123 \mathrm{Mt} \mathrm{yr}^{-1}(-75 \%)$

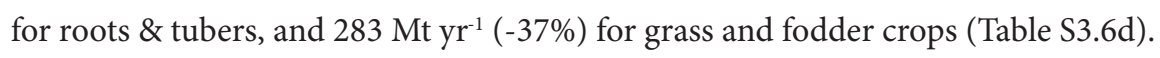

The spatial pattern in reductions needed to respect thresholds varies between the three thresholds (Figure 3.3), though all thresholds require strong reductions $\left(>100 \mathrm{~kg} \mathrm{~N} \mathrm{ha}^{-1}\right.$ $\mathrm{yr}^{-1}$ ) in hotspot regions with high inputs such as Germany, Benelux, the UK, Ireland, and Brittany in France. For Ireland, large reductions are required to respect critical $\mathrm{NH}_{3}$ emission thresholds (Figure 3.3a), but $\mathrm{N}$ inputs can increase while still respecting thresholds for $\mathrm{N}$ runoff and $\mathrm{N}$ leaching (Figure 3.3b,c), whereas the opposite is true for large parts of the UK. The highest potential for increasing $\mathrm{N}$ inputs within thresholds is found in Estonia, Latvia and Portugal (Figure 3.3d).

\section{Opportunities for improved nitrogen management}

On about a third of agricultural land, $\mathrm{NH}_{3}$ emission thresholds are respected at current $\mathrm{N}$ inputs (Table 3.2, a-i), while an additional 13\% of agricultural land can remain within thresholds without yield losses by reducing the $\mathrm{NH}_{3} \mathrm{EF}$ for manure, assuming a minimum of 0.15 ('beast feasible', Table 3.2, a-ii). Assuming a possible reduction of manure $\mathrm{NH}_{3} \mathrm{EF}$ to 0.10 ('best possible'), threshold exceedance can be reversed without yield losses on $26 \%$ of the agricultural area (Table 3.2, a-ii). To respect thresholds, the average $\mathrm{NH}_{3} \mathrm{EF}$ for manure needs to decrease from 0.27 to 0.20 (assuming a minimum EF of 0.15 ) or from 0.26 to 0.16 (assuming a minimum EF of 0.10; Table 3.2, a-ii). Conversely, this implies that in $41-54 \%$ of the agricultural area, reducing $\mathrm{NH}_{3} \mathrm{EF}$ is not sufficient to respect $\mathrm{NH}_{3}$ emission thresholds without yield losses (Table 3.2, a-iii \& Figure S3.2a). These areas are mainly situated in the Netherlands, Northern Germany, Poland, Italy, Ireland, Brittany in France, and Spain (Figure 3.4a). Low necessary $\mathrm{NH}_{3}$ EFs occur both in regions with vulnerable ecosystems (low critical $\mathrm{N}$ loads) and/or in regions with high current $\mathrm{N}$ inputs, yields and livestock numbers. The strongest absolute reductions in $\mathrm{NH}_{3} \mathrm{EF}$ (reductions by > 0.30) are needed in parts of Eastern Germany, Poland, Italy and Spain (Figure 3.4d). In Ireland, despite low absolute needed 

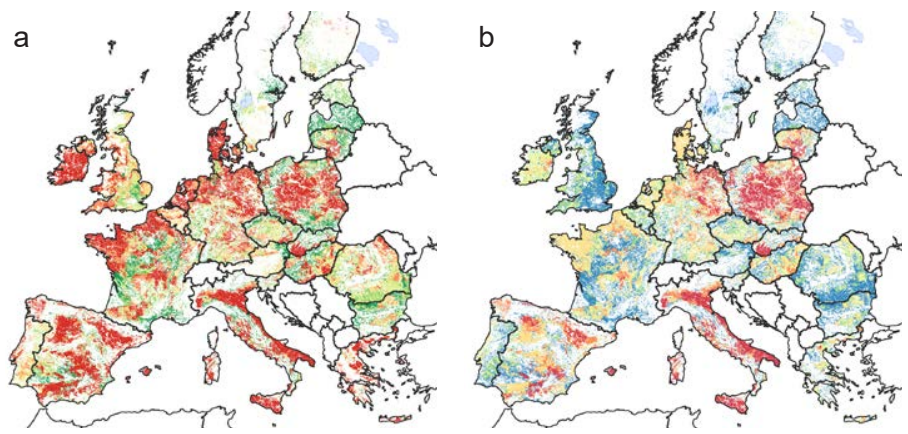

Necessary $\mathrm{NH}_{3}-\mathrm{EF}$ manure [-]

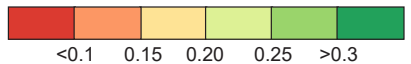

Necessary reduction $\mathrm{NH}_{3}-\mathrm{EF}$ manure [-]
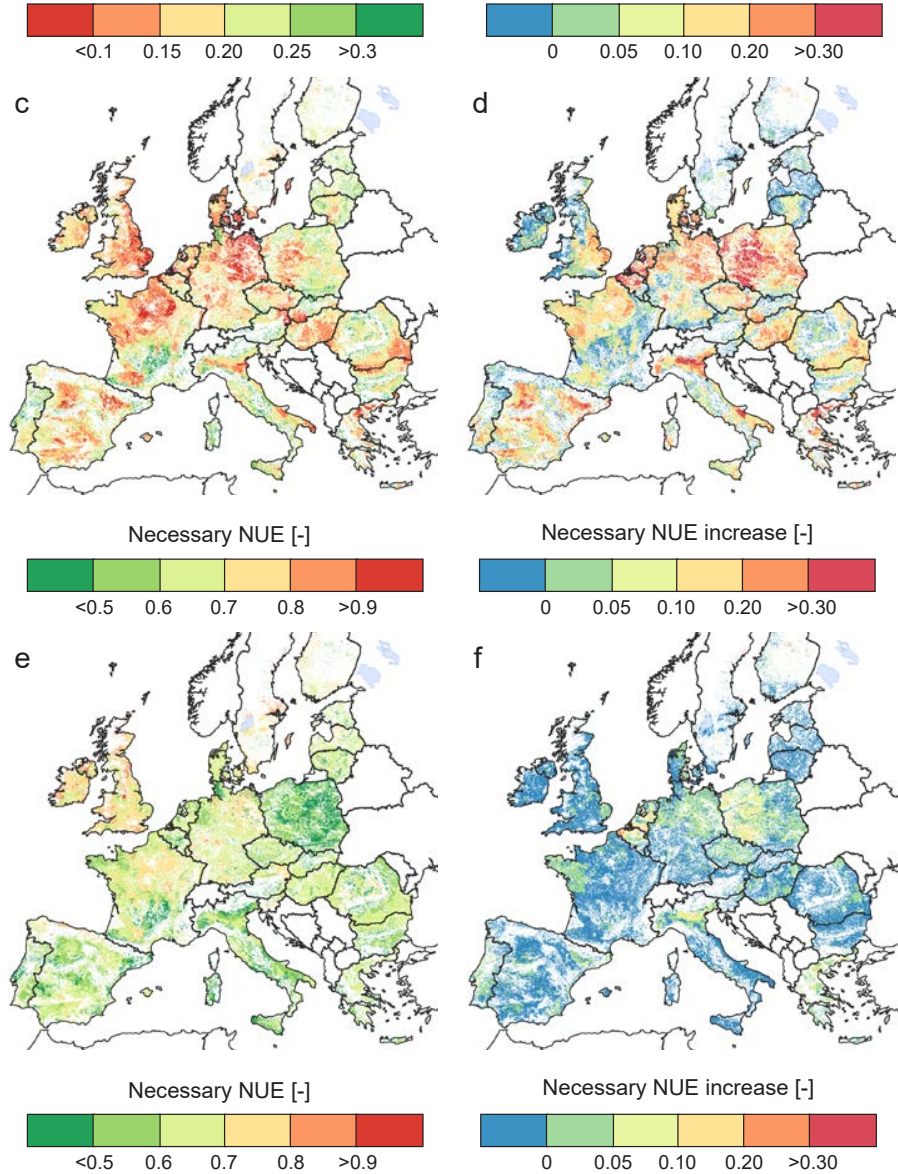

Figure 3.4 Regional variation in necessary improvements in $\mathrm{N}$ management factors to obtain current yields while respecting environmental thresholds. a, Necessary $\mathrm{NH}_{3} \mathrm{EF}$ for manure to obtain current yields while respecting thresholds for $\mathrm{NH}_{3}$ emissions, b, necessary NUE to obtain current yields while respecting thresholds for $\mathrm{N}$ runoff to surface water, $\mathbf{c}$, necessary NUE to obtain current yields while respecting thresholds for $\mathrm{N}$ leaching to groundwater, $\mathbf{d}-\mathbf{f}$, necessary changes in $\mathrm{NH}_{3} \mathrm{EF} / \mathrm{NUE}$ relative to current (year 2010) values. Corresponding results for target yields are shown in Figure S3.3. 
Table 3.2 | Share of agricultural area and current / necessary $N$ management factors for (i) land where environmental threshold is not exceeded, (ii) land where threshold is exceeded but current crop production can be obtained within thresholds by a, reducing $\mathrm{NH}_{3} \mathrm{EF}$ to minimum $=0.15$ (best feasible) or 0.1 (best possible) or by b,c, increasing NUE to a maximum of 0.75 (best feasible) or 0.90 (best possible); (iii) land where current crop production and thresholds cannot be reconciled. Current and necessary $\mathrm{NH}_{3} \mathrm{EF} / \mathrm{NUE}$ for each of the three categories, and (iv) the average across all land.

\begin{tabular}{|c|c|c|c|c|c|c|}
\hline \multirow[b]{2}{*}{ (a) Deposition } & \multirow[t]{2}{*}{$\begin{array}{l}\text { (i) Thres- } \\
\text { hold not } \\
\text { exceeded }\end{array}$} & \multicolumn{2}{|c|}{$\begin{array}{l}\text { (ii) Threshold exceeded, } \\
\text { reconciliation possible at } \\
\text { improved management }{ }^{(1)}\end{array}$} & \multicolumn{2}{|c|}{$\begin{array}{l}\text { (iii) Threshold exceeded, } \\
\text { reconciliation not possible } \\
\text { by improved management }\end{array}$} & \multirow[t]{2}{*}{$\begin{array}{l}\text { (iv) } \\
\text { Overall }\end{array}$} \\
\hline & & $E F_{\min }=0.15$ & $E F_{\min }=0.10$ & $E F \min =0.15$ & $E F_{\min }=0.10$ & \\
\hline Share of area & $33 \%$ & $13 \%$ & $26 \%$ & $54 \%$ & $41 \%$ & $100 \%$ \\
\hline Current $\mathrm{NH}_{3} \mathrm{EF}$ & 0.22 & 0.27 & 0.26 & 0.25 & 0.25 & 0.24 \\
\hline Necessary $\mathrm{NH}_{3} \mathrm{EF}$ & -- & 0.20 & 0.16 & 0.06 & 0.04 & 0.13 \\
\hline (b) Surface Water & & $N U E_{\max }=0.75$ & $N U E_{\max }=0.90$ & $N U E_{\max }=0.75$ & $N U E_{\max }=0.90$ & \\
\hline Share of area & $26 \%$ & $25 \%$ & $59 \%$ & $49 \%$ & $15 \%$ & $100 \%$ \\
\hline Current NUE & 0.74 & 0.50 & 0.58 & 0.65 & 0.68 & 0.64 \\
\hline Necessary NUE & -- & 0.64 & 0.75 & 0.87 & 0.95 & 0.78 \\
\hline (c) Groundwater & & $N U E_{\max }=0.75$ & $N U E_{\max }=0.90$ & $N U E_{\max }=0.75$ & $N U E_{\max }=0.90$ & \\
\hline Share of area & $82 \%$ & $18 \%$ & $18 \%$ & $1 \%$ & $0 \%$ & $100 \%$ \\
\hline Current NUE & 0.69 & 0.49 & 0.49 & 0.49 & n.a. & 0.65 \\
\hline Necessary NUE & -- & 0.57 & 0.58 & 0.78 & n.a. & 0.67 \\
\hline
\end{tabular}

(1) For the deposition threshold, reconciliation is possible if the manure $\mathrm{NH}_{3}$ emission fraction at which current crop production can be obtained without exceeding critical $\mathrm{NH}_{3}$ emissions is higher than 0.15 (for 'best feasible' $\mathrm{N}$ management) or 0.10 (for 'best possible' management). For the surface water and groundwater thresholds, reconciliation is possible if the NUE at which current crop production can be obtained without exceeding critical $\mathrm{N}$ runoff or leaching is lower than 0.75 (for 'best feasible' $\mathrm{N}$ management) or 0.90 (for 'best possible' management).

reductions $(\sim 0.05$, Figure $3.4 \mathrm{~d})$ the necessary $\mathrm{NH}_{3} \mathrm{EF}$ is mostly below the 'best possible' minimum of 0.10 (Figure 3.4a), as current $\mathrm{NH}_{3}$ EFs are only around 0.15 (due to high prevalence of grazing systems with relatively low $\mathrm{NH}_{3} \mathrm{EFs}$ ).

On a quarter of agricultural land, thresholds for $\mathrm{N}$ runoff to surface water are currently not exceeded (Table 3.2, b-i), while on an additional 25\% thresholds can be respected without yield losses if NUE is increased to the 'best feasible' maximum of 0.75 , and on an additional and $59 \%$ if NUE is increased to the 'best possible' maximum of 0.90 (Table 3.2, b-ii). On land where thresholds can be respected without yield losses by increasing NUE, average NUE needs to increase from 0.50 to 0.64 (for a maximum of 0.75 ) or from 0.58 to 0.75 (for a maximum of 0.90 ; Table 3.2, b-ii). On $49 \%$ of the agricultural area, increasing NUE to 0.75 is not sufficient to respect thresholds for $\mathrm{N}$ runoff while maintaining current crop production, while this is only $15 \%$ at a maximum NUE of 0.90 (Table 3.2, a-iii \& Figure S3.2b). Areas where increasing NUE to 0.90 is not sufficient to reconcile environmental goals and current production levels are mainly situated in Eastern Germany, Eastern UK and 

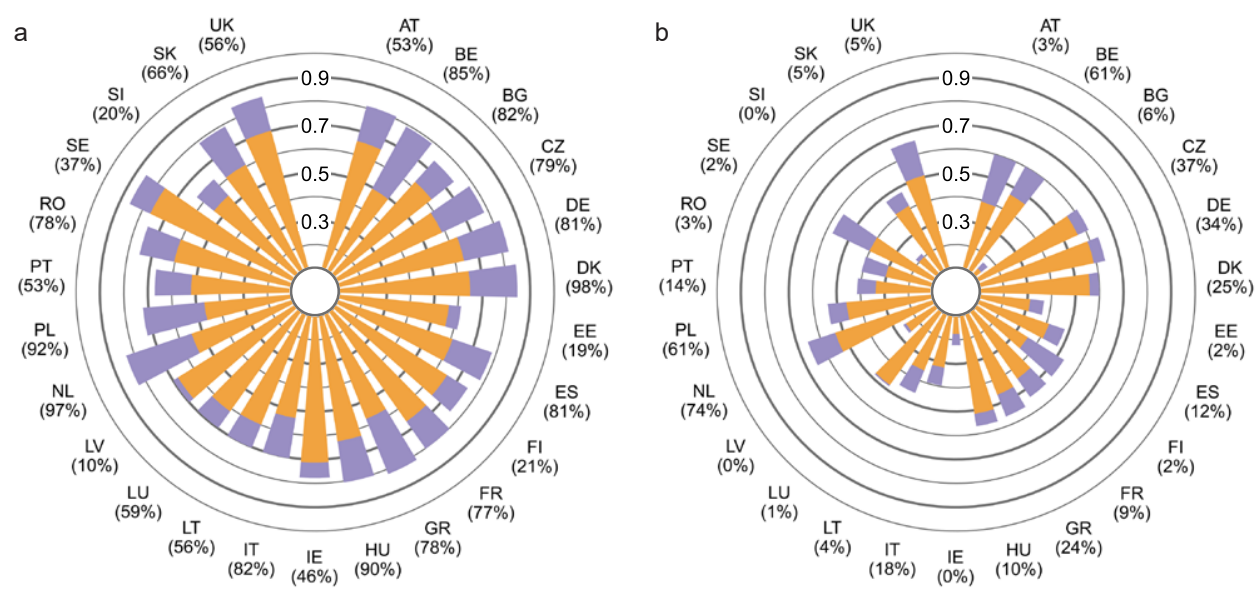

Figure 3.5 | Actual (year 2010) nitrogen use efficiency (NUE) of agricultural production in areas where thresholds are exceeded (orange), and necessary NUE to respect thresholds without yield losses (purple) for $25 \mathrm{EU}$ countries. a, N runoff to surface water and $\mathbf{b}, \mathrm{N}$ leaching to groundwater. Percentages in brackets show share of agricultural area where threshold is exceeded (and for which current and necessary NUEs are thus shown).

Northern France (Figure 3.4b). Those areas generally either have a low precipitation surplus (low runoff volume), a high share of land used for agriculture (leading to limited dilution of agricultural runoff by runoff from natural land) and/or high current $\mathrm{N}$ uptake (leading to high absolute losses even at a high NUE). The highest absolute NUE increases necessary to respect thresholds for $\mathrm{N}$ runoff without crop production losses occur in the Netherlands, Belgium, Greece, and Poland (Figure 3.4e and Figure 3.5a).

For groundwater, small increases in average NUE (from 0.65 to 0.67 ) are sufficient to respect thresholds for $\mathrm{N}$ leaching without yield losses on virtually all agricultural land (Table 3.2, c-ii, Figure 3.4c \& Figure S3.2c). Where increasing NUE is necessary to respect leaching thresholds, these necessary increases are mostly $<0.1$, except for small areas in the Netherlands, Belgium, South/Central France and Northern Italy (Figure 3.4f).

Average country-level NUEs necessary to reconcile current yields with $\mathrm{N}$ thresholds vary from 0.61 for Estonia to 0.86 for Sweden for the surface water threshold (Figure 3.5a), and from 0.17 for Bulgaria to 0.66 for the UK for the groundwater threshold (Figure 3.5b). For all countries, average NUEs necessary to comply with the surface water threshold are higher than for the groundwater threshold. Several countries where $\mathrm{N}$ leaching thresholds are exceeded on only a small fraction of agricultural area have very low current average NUEs in these areas $(<0.30$, Figure 3.5$)$. 


\section{Combining redistribution and improved nitrogen management}

Figure 3.6 shows to what extent improved $\mathrm{N}$ management, alone or in combination with spatially redistributing $\mathrm{N}$ inputs, can reconcile crop production with environmental thresholds. At current $\mathrm{NH}_{3}$ emission fractions, 68\% of current crop production can be obtained within safe limits for $\mathrm{NH}_{3}$ emissions (Figure 3.6b \& Table S3.6a). Gradually reducing the manure $\mathrm{NH}_{3}$ EF only slightly increases this share to $75 \%$ at the 'feasible' minimum of 0.15 and $80 \%$ at the 'possible' minimum of 0.10 (Figure 3.6b, solid line). If both $\mathrm{NH}_{3} \mathrm{EF}$ is reduced and $\mathrm{N}$ inputs are increased in regions where critical $\mathrm{NH}_{3}$ emission rates are not exceeded, this share increases to $\sim 95 \%$ (Figure 3.6b, dashed line).

At current NUE, only $58 \%$ of current crop production can be obtained within safe limits for $\mathrm{N}$ runoff to surface water, but almost $100 \%$ can be obtained if NUE is increased to 0.80 in combination with increasing $\mathrm{N}$ inputs and yields where this is possible within thresholds (Figure 3.6c). For groundwater, $\mathrm{N}$ inputs and crop production are not strongly constrained by complying with thresholds for $\mathrm{N}$ leaching, and thus NUE improvements have limited impact on the share of current crop yield that can safely be obtained (Figure 3.6d). At a NUE of $0.75, \mathrm{~N}$ inputs can even be increased to the level required to obtain target yields without exceeding $\mathrm{N}$ leaching thresholds almost everywhere in Europe (Figure 3.6d \& Figure S3.4d)

The potential of different strategies to reconcile $\mathrm{N}$ thresholds with crop production varies between countries (Figure S3.4). Most countries can obtain between 33 and 67\% of current crop production while respecting thresholds for $\mathrm{N}$ runoff to surface water at current NUE (Figure S3.4a-i), whereas this percentage is between 67 and $100 \%$ for most countries if NUE is increased to 0.75 (Figure $\mathrm{S} 3.4 \mathrm{~b}-\mathrm{i}$ ). All countries can obtain current yields while respecting thresholds for N leaching to groundwater at a NUE of 0.75 (see Figure S3.4b-ii).

\subsection{Discussion}

\subsection{Plausibility of the results}

In this section, we discuss the plausibility of several assumptions underlying the calculations. For an additional discussion of uncertainties related to $\mathrm{N}$ budgets in INTEGRATOR and the assumptions used in the calculation of critical $\mathrm{N}$ inputs, see Chapter 2.

\section{Plausibility of calculated nitrogen use efficiencies}

Country-level NUE estimates from INTEGRATOR were compared to estimates from Lassaletta et al. (2014a, for arable crops only) and EUROSTAT (2020) (Table S3.7). For most 
a. Explanation of figure

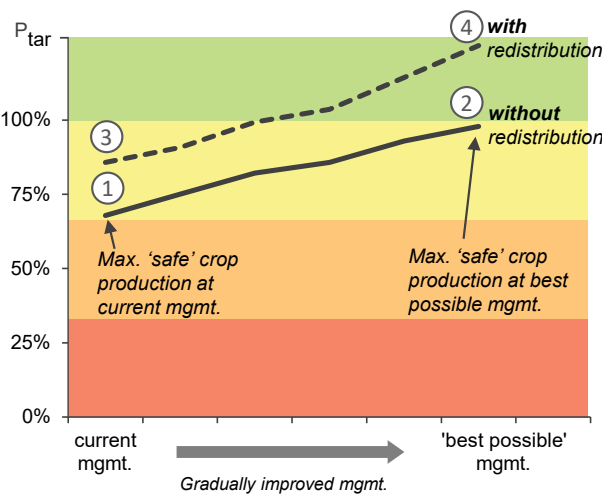

c. Threshold $=\mathbf{N}$ runoff to surface water

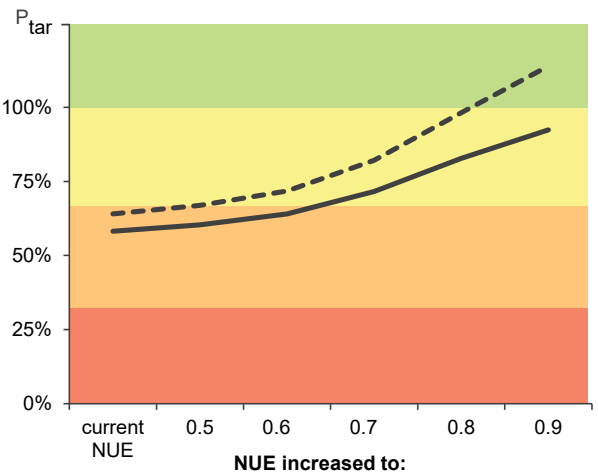

b. Threshold $=\mathrm{NH}_{3}$ emissions

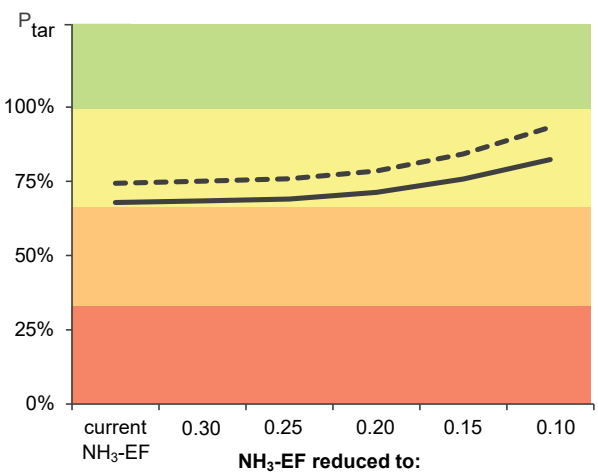

d. Threshold $=\mathbf{N}$ leaching to groundwater

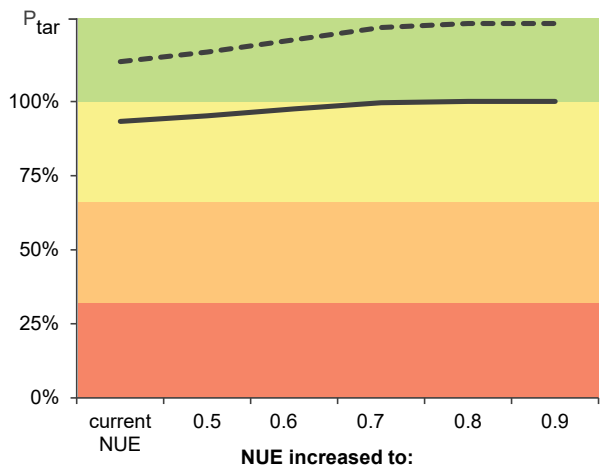

Share of current crop production $\left(\mathrm{P}_{\text {act }}\right)$ that can be obtained while respecting threshold at current/improved $\mathrm{NUE}_{\text {or }} \mathrm{NH}_{3}-\mathrm{EF}$

\begin{tabular}{|l|l|l|ll|}
\hline & & & & \\
\hline $0 \%$ & $33 \%$ & $67 \%$ & $100 \%$ & $P_{\text {tar }} / P_{\text {act }}$
\end{tabular}

Figure 3.6 | Maximum crop production that can be obtained while respecting environmental thresholds at current or gradually improved $\mathrm{N}$ management factors. Panel a illustrates the figure concept; panels $\mathbf{b}-\mathbf{d}$ show results for three thresholds. $\mathrm{P}_{\mathrm{act}}=$ current crop production, $\mathrm{P}_{\mathrm{tar}}=$ crop production at target yields. a, In this hypothetical example, only two thirds of $P_{\text {act }}$ can safely be obtained within threshold at current $\mathrm{N}$ management (point (1)), while this share increases to almost $100 \%$ at 'best possible management' (2). If $\mathrm{N}$ inputs are redistributed to regions where this is possible within thresholds (dashed line), $\sim 80 \%$ of $\mathrm{P}_{\text {act }}$ can be obtained within thresholds at current management (3)). If redistribution and improved management are combined, crop production can be increased to $P_{\text {tar }}$ without exceeding thresholds (4)). $b-d$, Maximum crop production (expressed as share of $\mathrm{P}_{\text {act }}$ ) that can be obtained while respecting thresholds at $\mathbf{b}$, current and gradually reduced manure $\mathrm{NH}_{3} \mathrm{EF}$ and at $\mathbf{c}, \mathbf{d}$, current and gradually increased NUE.

countries, values agree reasonably well (deviations between -8 to $+18 \%$ for Lassaletta et al. (2014a) and between -18 and $+25 \%$ for EUROSTAT). For Bulgaria, Spain, the Netherlands and Sweden, NUE estimates from Lassaletta are $32-47 \%$ lower than our estimates, mainly 
because Lassaletta uses higher $\mathrm{N}$ input rates for these countries. A possible explanation is that they over-estimate manure application to cropland, as they only use one value for the fraction of manure applied to croplands for the whole EU, while INTEGRATOR uses country-specific values varying from $5-100 \%$ (see Chapter 2). EUROSTAT NUE estimates are substantially (20-30\%) lower for Finland, Greece, Luxembourg and UK, mainly because estimated uptake is lower, and $48 \%$ higher for Romania due to both a lower estimated input and a higher estimated uptake (Table S3.7).

Nitrogen use efficiencies needed to respect environmental thresholds for runoff to surface water without yield losses are in good agreement with the 'desired range' for NUE defined by the EU Nitrogen Expert Panel (2015), while the derived N output at target yields provides support for the postulated minimum productivity target by the Expert Panel (Figure 3.7). For the current (year 2010) situation, four out of 25 countries had average NUEs below the minimum target of 0.50 , while $\mathrm{N}$ removal by cereals was below the suggested minimum productivity target of $80 \mathrm{~kg} \mathrm{~N} \mathrm{ha}^{-1} \mathrm{yr}^{-1}$ in more than half of all countries (Figure 3.7a). Estimated necessary NUEs to reconcile crop production with environmental thresholds are above the minimum NUE target of 0.50 for all countries (Figure 3.7b). Moreover, at our estimated target level for $\mathrm{N}$ input for closing yield gaps and related $\mathrm{N}$ output, all countries except one are above the minimum productivity target of $80 \mathrm{~kg} \mathrm{~N} \mathrm{ha}^{-1} \mathrm{yr}^{-1}$, while NUEs are between 0.66 and 0.90 (Figure 3.7c).

\section{Uncertainties and limitations in calculating critical $\mathbf{N}$ inputs and required nitrogen use efficiencies and ammonia emission fractions}

In this study, we used a uniform threshold for $\mathrm{N}$ concentration in runoff to surface water, similar to previous global studies that used critical $\mathrm{N}$ concentrations to assess $\mathrm{N}$ water footprints (Mekonnen and Hoekstra, 2015, who used a threshold of $2.9 \mathrm{mg} \mathrm{N}^{-1}$ ) or required reductions in agricultural $\mathrm{N}$ loads (e.g., Gerten et al., 2020 and Yu et al., 2019; who both used a threshold of $1 \mathrm{mg} \mathrm{N}^{-1}$ ). However, such a uniform threshold does not reflect variation in ecological criteria for different surface water types (e.g., highland or lowland lakes, calcareous or siliceous rivers). Nutrient criteria for surface water used to support 'good ecological status' under the Water Framework Directive vary widely across water body types and across Member States (Poikane et al., 2019). For example, median values for N concentration thresholds in lakes and rivers range between 0.7 to $4.0 \mathrm{mg} \mathrm{N} \mathrm{l}^{-1}$, and vary substantially within shared water body types due to different approaches used to set threshold $\mathrm{N}$ concentrations. Some Member States do not define criteria for $\mathrm{N}$ concentrations in rivers of lakes at all (Poikane et al., 2019), based on the widely held belief that phosphorus (P) is the primary limiting nutrient in freshwater whereas $\mathrm{N}$ is most limiting in coastal waters (Schindler et 

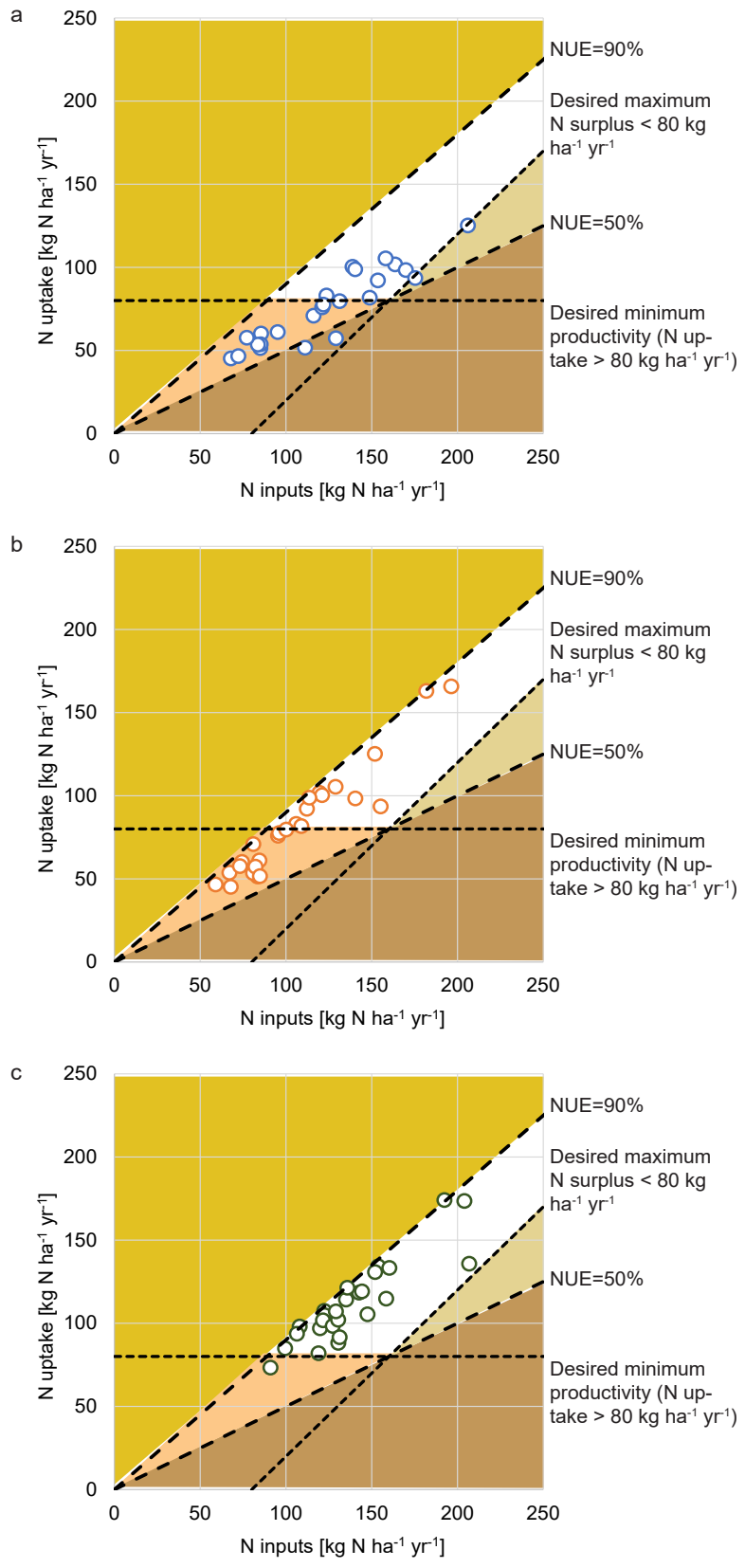

Figure 3.7 | Country-average $\mathrm{N}$ inputs and $\mathrm{N}$ uptake for cereal crops in the EU from INTEGRATOR, following the graphical representation proposed by the EU Nitrogen Expert Panel (2015), a, for the current situation, $\mathbf{b}$, at necessary NUE to remain within thresholds for $\mathrm{N}$ runoff to surface water and $\mathbf{c}$, at required $\mathrm{N}$ inputs to obtain target yields and necessary NUE to remain within thresholds for $\mathrm{N}$ runoff to surface water. The white area delineates the desired range for NUE, $\mathrm{N}$ surplus and productivity. In panel a, Belgium ( $\mathrm{N}$ input $=356 \mathrm{~kg} \mathrm{~N} \mathrm{ha}^{-1} \mathrm{yr}^{-1} ; \mathrm{N}$ uptake $\left.=166 \mathrm{~kg} \mathrm{~N} \mathrm{ha}^{-1} \mathrm{yr}^{-1} ; \mathrm{NUE}=0.46\right)$ and the Netherlands $\left(\mathrm{N}\right.$ input $=328 \mathrm{~kg} \mathrm{~N} \mathrm{ha}^{-1} \mathrm{yr}^{-1} ; \mathrm{N}$ uptake $\left.=163 \mathrm{~kg} \mathrm{~N} \mathrm{ha}^{-1} \mathrm{yr}^{-1} ; \mathrm{NUE}=0.50\right)$ fall off the scale. 
al., 2016). However, recent evidence shows that $\mathrm{N}$ often equally limits primary production in lakes and that reducing both $\mathrm{N}$ and $\mathrm{P}$ is required to achieve good ecological status (e.g., Dolman et al., 2016; Elser et al., 2007; Paerl et al., 2016).

The threshold for $\mathrm{N}$ concentration in runoff to surface water used in this study is only a proxy for $\mathrm{N}$ concentration in surface water itself, which is also affected by $\mathrm{N}$ inputs from other sources (e.g., sewage), legacy $\mathrm{N}$ related to fertilization in the past (Bouraoui and Grizzetti, 2014; Van Meter et al., 2016), and removal and retention processes in groundwater, riparian areas and surface waters. We assumed that the effect of ignoring $\mathrm{N}$ load from non-agricultural sources roughly compensates for neglecting $\mathrm{N}$ removal processes in water bodies (see also Chapter 2 for further discussion). Further improving the approach could entail using basinlevel targets for 'good ecological status' instead of one flat-rate target for all water bodies, as well as including a more detailed representation of other sources contributing to freshwater $\mathrm{N}$ pollution. Such detailed assessments have been performed for e.g., the Netherlands (Groenendijk et al., 2016) and the German region of Mecklenburg-Vorpommern (Kunkel et al., 2017). However, obtaining the required data at European level may prove challenging.

Similar to $\mathrm{N}$ concentrations in surface water, $\mathrm{N}$ deposition on terrestrial ecosystems is also affected by non-agricultural emissions, mainly $\mathrm{NO}_{\mathrm{x}}$ emissions from transport and industry. Our approach assumes that these emissions are reduced proportionally with agricultural $\mathrm{NH}_{3}$ emissions. In reality, mitigating $\mathrm{N}$ losses from other sources may in specific situations be easier to achieve, thus reducing the need for changing agricultural practices (see also Chapter 2 for further discussion).

Impacts of $\mathrm{N}$ input changes on yields in this study is assessed assuming a constant NUE, i.e. NUE changes linearly with $\mathrm{N}$ inputs. Other studies proposed an asymptotic function to describe the relationship between $\mathrm{N}$ inputs and yields ( $\mathrm{N}$ uptake) (Lassaletta et al., 2016, 2014a; Mueller et al., 2014), where yields show a decreasing response to $\mathrm{N}$ inputs at increasing fertilization rates. Compared to these studies, our study may underestimate marginal reductions in $\mathrm{N}$ losses from input reductions at high inputs as well as $\mathrm{N}$ losses caused by increasing current to target $\mathrm{N}$ inputs. NUE response to $\mathrm{N}$ inputs also strongly depends on other yield-limiting factors (de Wit, 1992), and alleviating these factors may increase NUE without affecting $\mathrm{N}$ inputs.

Finally, the assumed values for 'best feasible' and 'best possible' $\mathrm{NUE}$ and $\mathrm{NH}_{3} \mathrm{EF}$ used to estimate crop production shares that can be reconciled with $\mathrm{N}$ thresholds through improved management are rough estimates. Opportunities to increase NUE or reduce $\mathrm{NH}_{3}$ EF are affected strongly by local circumstances, such as climate, soil and crop type, manure management system and the availability of technologies such as manure processing. Where 
reducing the $\mathrm{NH}_{3} \mathrm{EF}$ of manure is not sufficient to comply with $\mathrm{NH}_{3}$ emission thresholds, farmers may also substitute manure by nitrate fertilizers, however, this implies that livestock numbers need to be reduced or excess manure needs to be disposed of.

\subsubsection{Redistributing nitrogen inputs}

Several studies showed that redistributing $\mathrm{N}$ inputs from excess areas to areas where thresholds are not exceeded can reduce $\mathrm{N}$ losses substantially while maintaining crop and livestock production. Liu et al. (2016) used a global crop growth model at high spatial and temporal resolution to assess $\mathrm{N}$ losses and yields for wheat, rice and maize under different fertilization schemes. They found that distributing global $\mathrm{N}$ inputs homogeneously over all cropland would decrease $\mathrm{N}$ losses by $11 \%$ and increase yields by $7 \%$. If, in addition to this redistribution, $\mathrm{N}$ was applied continuously throughout the growing season, global $\mathrm{N}$ losses decreased by $23 \%$ (21\% for Europe) and crop production increased by $10 \%$ (16\% for Europe). Mueller et al. (2012) used regression-based nutrient-yield response curves to assess the global potential for closing yield gaps while reducing nutrient overuse, and found that global $\mathrm{N}$ input could be reduced by $28 \%$ without yield losses for major cereals. In a follow-up study, Mueller et al. (2014) used a trade-off frontier to reallocate global N inputs to maximize crop production and minimize losses. They found that under optimal allocation, $50 \%$ less $\mathrm{N}$ fertilizer would be needed to achieve production levels for major cereal crops. For Europe, such an 'optimal' allocation implied redistributing $\mathrm{N}$ inputs from Western to Eastern Europe.

All previous studies, however, optimize for overall reductions in $\mathrm{N}$ losses without considering region-specific environmental vulnerabilities. While in line with previous studies (see also e.g. Pradhan et al., 2015) we found large potentials to close yield gaps by increasing $\mathrm{N}$ fertilization in Eastern Europe, respecting environmental boundaries does not allow for such increases at current NUE. In large regions of Poland, Czech Republic and Romania, for example, thresholds for $\mathrm{N}$ pollution are already exceeded and increasing $\mathrm{N}$ inputs to close yield gaps would further exacerbate N-related problems (e.g., Figure 3.3 \& Figure 3.4).

For the livestock sector, van Grinsven et al. (2018) showed that relocating pig production in the EU could reduce external costs of $\mathrm{N}$ pollution and the exceedance of critical $\mathrm{N}$ deposition, especially when combined with best-management practices. They also note that such relocations may meet socio-economic barriers, such as national economic interests, stakeholder objections or a lack of infrastructure (van Grinsven et al., 2018). While this equally applies to a redistribution of crop production and associated $\mathrm{N}$ inputs, the need to comply with targets set under the Green Deal and other EU directives will likely provide strong policy incentives to reduce $\mathrm{N}$ pollution and may stimulate investments that are necessary to overcome such barriers. 


\subsubsection{Nitrogen use efficiency targets in policies and scientific literature}

Partially as a result of European and national policies aimed at reducing N pollution, average farm-level NUE in European has increased since the 1990s (van Grinsven et al., 2014; Velthof et al., 2014), though not sufficiently to meet environmental targets (EEA, 2019). To date, however, most policies lacked integration and generally regulated only one type of $\mathrm{N}$ compound (Brink et al., 2011), for example nitrate in the Nitrates Directive (EC, 1991) or $\mathrm{NO}_{\mathrm{x}}$ and $\mathrm{NH}_{3}$ emissions in the National Emission Ceilings Directive (EC, 2001). The recently launched "Farm to Fork Strategy" (FFS) as part of the European Green Deal represents a shift away from single-issue policies towards a more holistic approach aimed at reducing all adverse $\mathrm{N}$ impacts simultaneously. The FFS has set the Europe-wide target to reduce nutrient losses by $50 \%$ and fertilizer use by $20 \%$ (European Commission, 2020). Achieving these targets while maintaining current crop production implies an increase in average NUE from currently 0.63 to 0.77 (own calculations). Zhang et al. (2015) estimated target NUEs per world region to meet 2050 food demand while remaining within safe planetary boundaries for $\mathrm{N}$ losses, and derived an NUE target of 0.75 for the EU, while Sutton et al. (2013) proposed 0.70 as a long-term target for crop-system NUE. These values agree well with our derived average 'necessary' NUEs to achieve water quality targets at current or target crop production of 0.67 (groundwater) or 0.78 (surface water), see Table 3.2.

However, no previous study has differentiated the goals by region by accounting for variation in current agricultural systems and in environmental vulnerabilities. By doing this, we show that necessary improvements in management vary greatly between regions, and that averaged targets have limited usefulness. Even if all regions achieve an average target NUE of 0.75 , thresholds for $\mathrm{N}$ runoff to surface water would still be exceeded on half of all agricultural land (Figure S3.2b). Average necessary NUEs vary between countries (Figure 3.5) as well as within countries (Figure 3.4). In some regions, necessary NUEs exceed 0.90, a level that is likely difficult to obtain (see also Section 3.4.4). Very high needed NUEs to avoid $\mathrm{N}$ impacts were also found for China, where respecting critical $\mathrm{N}$ loads to surface water while maintaining crop production required NUE to increase to $~ 87 \%$ (from currently $36 \%$ ) for the whole of China, and to $>95 \%$ for several provinces (Yu et al., 2019).

\subsubsection{Approaches to increase nitrogen use efficiency}

The most practical way to improve NUE is by tuning the rate, timing, method and type of $\mathrm{N}$ application (Snyder, 2017), with the goal to improve matching of $\mathrm{N}$ supply with crop demand. Measures to increase NUE can be taken by farmers voluntarily (e.g., to save costs on fertilizers, Houlton et al., 2019), but are often legally required through policies. Policy measures such as maximum $\mathrm{N}$ manure application rates (EC, 1991), mandatory incorporation of manure 
(e.g. in Denmark; Kronvang et al., 2008) or prohibiting manure application during the winter period (Liu et al., 2018) have greatly increased NUE in many European countries.

Several studies have assessed possibilities to increase cropping system NUEs. However, comparison of achievable NUEs with required NUEs reported in this study is complicated by different definitions of NUE in the literature. An assessment of options to increase NUE in European farming systems found that implementation of a multitude of technical options can increase NUE to max. 82\% (Northern Europe) and 92\% (Southern Europe), but the study only considered inputs of 'virgin' $\mathrm{N}$ from outside the agricultural system (Hutchings et al., 2020). Nitrogen use efficiencies reported in field trials are often expressed as partial factor productivity (PFPN), defined as crop uptake divided by fertilizer inputs, which means that for a given situation PFPN is lower than NUE that also consider non-fertilizer N sources (Balasubramanian et al., 2004). Extensive field trials in China have shown that integrated soil management strategies can increase PFPN of grain cropping systems by $30-45 \%$, to levels of $60 \%$ (rice), 78\% (wheat) and 67\% (maize) (Chen et al., 2014). The PFPN achieved by the bestperforming farmers in a certain region can also be seen as a target value for PFPN increases. Cui et al. (2014) for example found that grain farmers in China achieved PFPN of $~ 40 \%$ on average, while best-performing farmers achieved $68-80 \%$. Achievable NUEs also depend on the mix of input sources, e.g. for manure, only $50 \%$ of the $\mathrm{N}$ is immediately available for crop uptake on average (Webb et al., 2013), though manure use can also increase NUE by improving soil organic carbon content and structure and reducing soil acidification (Duan et al., 2011).

Approaches to increase NUE which are targeted on industry are potentially easier to implement as a smaller number of actors is involved (Kanter and Searchinger, 2018). Increasing sale shares of enhanced-efficiency fertilizers, such as fertilizers amended with $\mathrm{N}$ inhibitors or slow-release fertilizers could on average increase NUE while maintaining yields (Abalos et al., 2014; Chen et al., 2018; Krol et al., 2020). Mandatory targets for the fertilizer industry regarding the production, efficiency and sales of enhanced-efficiency fertilizers could thus increase NUE while avoiding high transaction costs associated with regulating millions of farmers (Kanter and Searchinger, 2018).

\subsubsection{Beyond farm-level nitrogen use efficiency}

In regions where best possible improvements in $\mathrm{N}$ management are insufficient to respect $\mathrm{N}$ pollution thresholds (red areas in Figure 3.4), environmental targets can only be achieved at reduced $\mathrm{N}$ inputs, even if this leads to lower agricultural output. For example, our results show that even with technological improvements, $\mathrm{N}$ deposition cannot be reduced to critical 
loads while maintaining current agricultural production levels everywhere, which implies that livestock numbers need to be reduced. This discussion is also at the core of the Dutch 'nitrogen crisis' (Stokstad, 2019), where a high court ruled that the Dutch government needs to take immediate action to reduce $\mathrm{NH}_{3}$ and $\mathrm{NO}_{\mathrm{x}}$ emissions to reverse widespread exceedance of critical loads on terrestrial ecosystems, and to comply with the requirements of the Birds and Habitat Directive. De Vries et al. (2020) estimated that $\mathrm{N}$ emissions have to be reduced by $25 \%, 50 \%$ and $80 \%$, respectively, to protect $50 \%, 75 \%$ and $95 \%$ of all Dutch Natura 2000 sites (i.e., reach critical $\mathrm{N}$ loads), although required emission reductions are slightly lower if reductions focus specifically on $\mathrm{NH}_{3}$ sources near sensitive terrestrial ecosystems. While reducing $\mathrm{NH}_{3}$ emission by $25 \%$ may be possible with technical measures, more ambitious targets can only be met by also reducing the numbers of cows, pigs and chicken (livestockrelated emissions alone account for $75 \%$ of Dutch $\mathrm{NH}_{3}$ emissions, Oenema, 2019).

The avoided costs to society by reducing $\mathrm{N}$ pollution by extensification could outweigh the lost income from reduced crop production (van Grinsven et al., 2015b). Farmers could be compensated for losses in crop production through price premiums or receive compensation for farm closure. Removing $\mathrm{N}$ from the environment in areas with excess $\mathrm{N}$ runoff where NUE increases cannot sufficiently mitigate agricultural losses is another way of reducing environmental pressure (Houlton et al., 2019). Examples are wetland and riparian restoration projects aimed at filtering $\mathrm{N}$ runoff and leaching flows in landscapes.

This study only analysed the potential to restore a safe operating space for $\mathrm{N}$ without losing crop production by increasing NUE and redistributing $\mathrm{N}$ inputs on existing agricultural land. However, further reductions in $\mathrm{N}$ losses without affecting agricultural output may be possible by also allowing for a redistribution of cropland within certain constraints, as shown by previous studies (e.g., Gerten et al., 2020; Heck et al., 2018b). Land conversion does not always have adverse effects, for example in the case of restoring abandoned croplands with a low value for biodiversity, which is widespread in Eastern Europe (Alcantara et al., 2013). In each case, negative impacts of land conversion in Europe always have to be weighed against potential impacts of land conversion in high-biodiversity areas in other world regions that might indirectly be triggered by sparing land in Europe as long as global demands remain unchanged (Fuchs et al., 2020). Concerns have been raised that reductions in the use of agricultural input and land proposed by the European Farm to Fork and Biodiversity Strategies may lead to reductions in crop production, possibly driving up global good prices (Beckman et al., 2020). This may in turn drive expansion of agricultural production in other regions, possibly resulting in impacts that outweigh the benefits of more sustainable production in Europe from a global conservation perspective (Fuchs et al., 2020). 
As measures taken at the farm level are not sufficient to respect $\mathrm{N}$ thresholds and maintain production everywhere, targeting other levels of the food chain to improve overall foodchain NUE is needed to reduce N losses, as has been pointed out by other studies (e.g., Bodirsky et al., 2014; Grizzetti et al., 2013; Springmann et al., 2018; Westhoek et al., 2014). Such strategies include reducing food waste and the share of animal protein in diets, and have in common that they reduce the need for crop production and thus associated $\mathrm{N}$ inputs and losses. This is also recognized in the FFS, which includes commitments to reduce food waste and inform consumers to support sustainable food choices (European Commission, 2020). The FFS, however, does not explicitly mention targets for reducing consumption of animal products, even though two thirds of EU cereal production (Kelly, 2019) and 80\% vegetal protein (Lassaletta et al., 2016) is used as feed for livestock. Reducing consumption of animal products in Europe has many co-benefits next to reducing $\mathrm{N}$ losses, such as reducing greenhouse gas emissions (Leip et al., 2015), reducing Europe's reliance on imported N in feedstuffs (Lassaletta et al., 2014b) and health benefits (Willett et al., 2019).

\subsection{Conclusions}

Maintaining or increasing Europe's crop producing while meeting targets to improve water quality and halt biodiversity loss requires a mix of strategies. We found that increasing $\mathrm{N}$ inputs to close yield gaps (ignoring environmental constraints) could increase European crop production by about $30 \%$. However, as critical $\mathrm{N}$ losses are already exceeded on most agricultural land, little of this additional crop production can be realized within safe environmental limits for $\mathrm{N}$ losses. Remaining within thresholds for $\mathrm{N}$ deposition on terrestrial (semi)natural ecosystems and $\mathrm{N}$ concentrations in surface water and groundwater at current NUE requires a reduction in $\mathrm{N}$ inputs of $\sim 50 \%$, with large regional differences. Reducing manure $\mathrm{NH}_{3}$ EFs or increasing NUE to best possible values $\left(0.10\right.$ for $\mathrm{NH}_{3} \mathrm{EF}$ for manure and 0.90 for NUE) can reduce $\mathrm{N}$ pollution below thresholds without yield losses in $44 \%$ of the area where one or more thresholds are exceeded, and can reconcile approximately $80 \%$ of current crop production with $\mathrm{N}$ thresholds. Increases in NUE and reductions in $\mathrm{NH}_{3} \mathrm{EF}$ can be achieved by improved agricultural management, such as applying $4 \mathrm{R}$ strategies for fertilizer and manure application, better manure management, or by crop and livestock breeding. In hotspot regions, however, required improvements in $\mathrm{N}$ management to avoid environmental impacts at current production levels are beyond what is considered technologically feasible. Therefore, to conserve our environment, redistribution of $\mathrm{N}$ inputs and improved $\mathrm{N}$ management need to be complemented by other strategies, such as reducing crop demand by cutting food waste and animal protein consumption. 


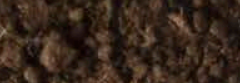

1628.
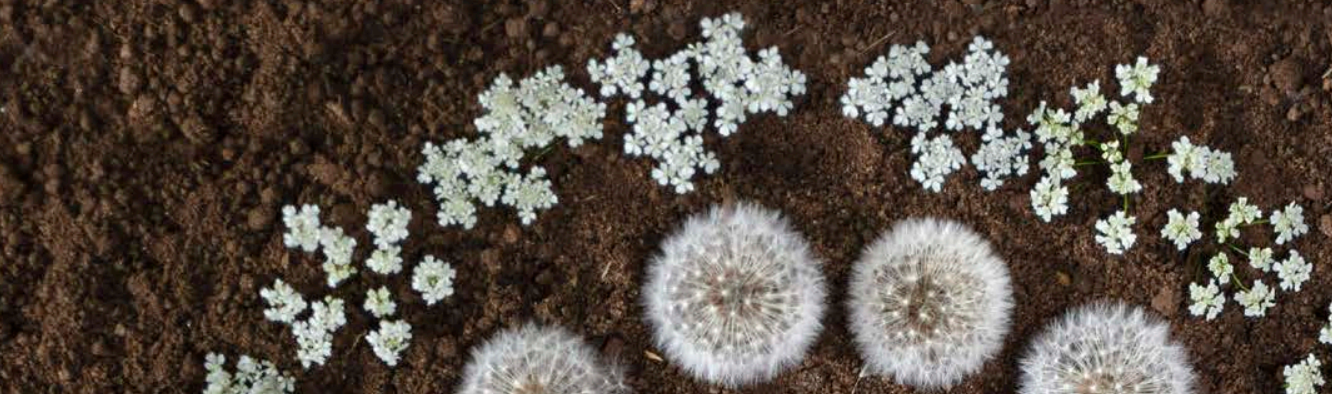

is

$y^{2}+2,15$

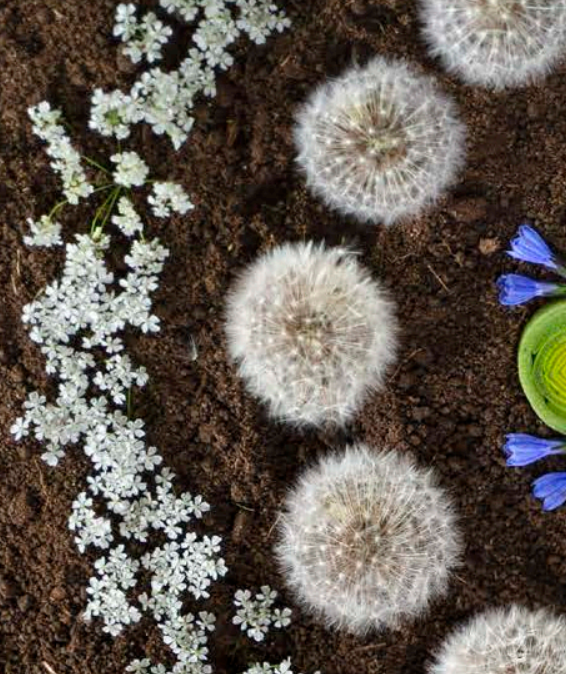

W.

If

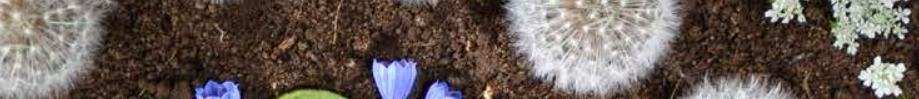
$4 x^{2}$
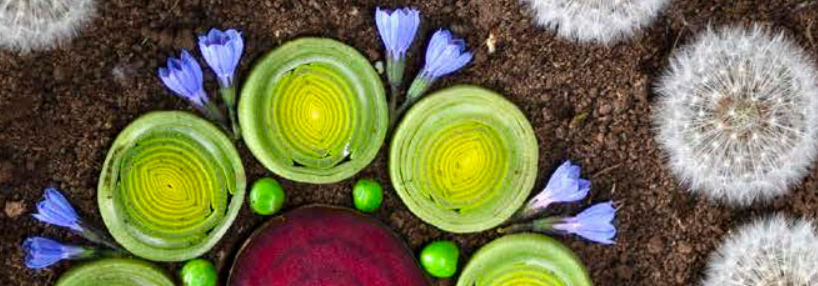

$\rightarrow+2 x^{2}$

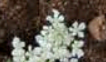

xon

8 


\section{Chapter 4}

From planetary to regional nitrogen boundaries for targeted policy

support

Based on: Lena Schulte-Uebbing, Arthur Beusen, Lex Bouwman \& Wim De Vries. (under review) 


\section{Abstract}

Excessive agricultural nitrogen $(\mathrm{N})$ use causes serious environmental problems globally, to an extent that scientists have claimed that the safe planetary boundary has been exceeded. Earlier estimates for the planetary $\mathrm{N}$ boundary, however, did not account for spatial variability in both ecosystem's sensitivity to nitrogen pollution and agricultural nitrogen losses. Here we used a spatially explicit model to establish regional boundaries for agricultural $\mathrm{N}$ inputs from thresholds for eutrophication of terrestrial and aquatic ecosystems and nitrate in groundwater. We show that regional boundaries for agricultural nitrogen pollution reveal both overuse and room for intensification. The aggregated global boundary to respect all thresholds is $110 \mathrm{Mt} \mathrm{N} \mathrm{yr}^{-1}$, 57\% lower than current (2010) $\mathrm{N}$ inputs (255 Mt N yr-1). Allowing $\mathrm{N}$ inputs to increase to close yield gaps in regions where environmental thresholds are not exceeded lifts the planetary $\mathrm{N}$ boundary to $145 \mathrm{Mt} \mathrm{N} \mathrm{yr}^{-1}$. Feeding the world without trespassing the planetary $\mathrm{N}$ boundary requires large increases in nitrogen use efficiencies accompanied by mitigation of non-agricultural $\mathrm{N}$ sources such as sewage water. This asks for coordinated action, recognizing the heterogeneity of agricultural systems, non-agricultural $\mathrm{N}$ losses, and environmental vulnerabilities.

\section{I. Introduction}

Nitrogen $(\mathrm{N})$ is at the core of several Sustainable Development Goals related to both food security and a clean environment (Dobermann, 2016; Kanter et al., 2016). Food production depends on inputs of reactive $\mathrm{N}$ (Erisman et al., 2008). In order make $\mathrm{N}$ available for crop growth, it is 'fixed' from the atmosphere during fertilizer production and through biological fixation by leguminous crops, such as soybean (Galloway et al., 2008). With inherent inefficiencies in crop and livestock production, however, much of the reactive $\mathrm{N}$ inputs to food production are lost to the environment, resulting in multiple pollution threats, such as dead zones in coastal oceans (Diaz and Rosenberg, 2008), harmful algal blooms (Glibert, 2017), terrestrial and aquatic biodiversity loss (Bleeker et al., 2011; Bobbink et al., 2010; Erisman et al., 2013), nitrate contamination of drinking water (Ward et al., 2018) and climate change (Davidson, 2012; Davidson and Kanter, 2014). Therefore, intentional N fixation has been proposed as one of the control variables to monitor whether humanity transgresses 'planetary boundaries' (Rockström et al., 2009b, 2009a; Steffen et al., 2015) for human disturbance of Earth System processes. 
A planetary boundary for intentional $\mathrm{N}$ fixation (i.e., $\mathrm{N}$ fixed during synthetic fertilizer production and by leguminous crops) has first been presented by Rockström et al. (2009b) and later revised to an upper limit of 62-82 Tg N per year (De Vries et al., 2013; Steffen et al., 2015), about half the current rate. Many studies assessed whether global food security can be achieved without transgressing this planetary boundary under both current conditions and future scenarios (Bodirsky et al., 2014; Conijn et al., 2018; Gerten et al., 2020; Heck et al., 2018a; Springmann et al., 2018; Uwizeye et al., 2020; Willett et al., 2019). The usefulness of a planetary $\mathrm{N}$ boundary for evaluating regional problems such as $\mathrm{N}$ pollution has, however, been questioned due to the large spatial variation in $\mathrm{N}$ losses and related impacts (Brook et al., 2013; Heistermann, 2017; Lewis, 2012). Several studies have inferred N boundaries for countries and regions (Cole et al., 2014; Dao et al., 2018; EEA and FOEN, 2020; Kahiluoto et al., 2015; Nykvist et al., 2013), generally by allocating an equal share of the planetary boundary to each global inhabitant. Planetary boundaries were, however, 'not designed to be downscaled or disaggregated' (Steffen et al., 2015) and such approaches ignore regional differences in agricultural systems, soils and ecosystems affecting both $\mathrm{N}$ losses and resulting impacts.

In addition, the current quantification approach for the planetary $\mathrm{N}$ boundary (De Vries et al., 2013; Steffen et al., 2015) has several limitations. First, it defines limits for 'intentional human $\mathrm{N}$ fixation', which does not account for regional impacts of $\mathrm{N}$ losses from recycled $\mathrm{N}$ sources, such as animal manure. Second, the planetary $\mathrm{N}$ boundary only considered reductions needed to respect environmental thresholds (De Vries et al., 2013), but should also allow for increases in $\mathrm{N}$ inputs where possible within thresholds, given that low $\mathrm{N}$ inputs constrain yields in large parts of the world (Mueller et al., 2012). Third, the boundary was derived for agricultural $\mathrm{N}$ inputs while not considering $\mathrm{N}$ pollution from other sources, such as $\mathrm{NO}_{\mathrm{x}}$ emissions from traffic and industry and $\mathrm{N}$ discharge in wastewater. Fourth, boundaries were derived for several N-related impacts individually (De Vries et al., 2013), while a safe limit should avoid all N-related problems simultaneously. Finally, the approach did not consider differences between crop and grazing systems, which require different approaches to relate $\mathrm{N}$ levels, pollution and productivity.

Here we present a new approach for estimating regional and planetary boundaries for agricultural $\mathrm{N}$ inputs, based on spatially explicit environmental thresholds. Thresholds were defined for (i) $\mathrm{N}$ deposition rates (to avoid or limit terrestrial biodiversity loss), (ii) $\mathrm{N}$ concentrations in surface water (to limit eutrophication) and (iii) $\mathrm{N}$ concentrations in groundwater (to meet drinking water standards). Nitrogen's contribution to climate change through $\mathrm{N}_{2} \mathrm{O}$ emissions as well as health impacts of air pollution from $\mathrm{NH}_{3}$ emissions were not considered (see Section 4.7). We mapped where one or several of these thresholds 
are transgressed, and where $\mathrm{N}$ inputs can safely increase to close yield gaps. To this end, we configured the Integrated Model to Assess the Global Environment (IMAGE) - Global Nutrient Model (GNM) (Beusen et al., 2015) to calculate 'critical' agricultural N inputs (input levels at which thresholds are reached) at a $0.5^{\circ} \times 0.5^{\circ}$ resolution for the year 2010 .

Our $\mathrm{N}$ boundary covers all agricultural $\mathrm{N}$ inputs (rather than 'intended human $\mathrm{N}$ fixation'), including 'new' inputs from fertilizer and biological fixation as well as 'recycled' inputs from manure and deposition. Non-agricultural $\mathrm{N}$ pollution (e.g. $\mathrm{NO}_{\mathrm{x}}$ emissions from transport and industry, $\mathrm{N}$ load to surface water from wastewater and erosion) was assumed constant. The critical $\mathrm{N}$ input limit in each grid cell thus depends on the sensitivity of the ecosystem (acceptable losses), the properties of the agricultural system (e.g. yields, N management and efficiency), and $\mathrm{N}$ loading caused by non-agricultural sources. Critical $\mathrm{N}$ inputs for each grid cell were aggregated to derive regional and planetary $\mathrm{N}$ boundaries. We also tested how varying assumptions regarding reductions of non-agricultural $\mathrm{N}$ losses affected our results.

\subsection{Planetary nitrogen boundary}

Reductions in agricultural $\mathrm{N}$ inputs required to respect thresholds for deposition levels, surface water quality and groundwater quality differ strongly. In line with Steffen et al. (2015), we find that surface water quality is the most stringent criterion and requires the highest reductions in global $\mathrm{N}$ inputs: from 255 to $138 \mathrm{Mt} \mathrm{N} \mathrm{yr}^{-1}$ (Figure 4.1c). In contrast, $\mathrm{N}$ input boundaries to avoid deposition rates that threaten terrestrial biodiversity (174 Mt $\mathrm{N} \mathrm{yr}^{-1}$, Figure 4.1b) and to avoid exceedance of health-impacting nitrate concentrations in groundwater (179 $\mathrm{Mt} \mathrm{N} \mathrm{yr}^{-1}$, Figure 4.1d) are about 30\% lower than current (2010) N inputs. The boundary for all impacts combined is even lower (110 Mt $\mathrm{N} \mathrm{yr}^{-1}$, Figure 4.1a), revealing that in many places of the world individual thresholds amplify each other.

Unlike the earlier planetary $\mathrm{N}$ boundary (Steffen et al., 2015), we not only considered required reductions in $\mathrm{N}$ inputs where thresholds are transgressed, but also production gains from potential increases in $\mathrm{N}$ inputs. In regions where thresholds are not transgressed, $\mathrm{N}$ inputs were increased up to the level needed to reach yield potentials at current $\mathrm{N}$ use efficiency (see Section 4.7). To respect all three N-related thresholds, $\mathrm{N}$ inputs would need to decrease by $74 \%$ (from 197 to $52 \mathrm{Mt} \mathrm{N} \mathrm{yr}^{-1}$ ) in land where thresholds are exceeded, but can increase by $59 \%$ (from 58 to $93 \mathrm{Mt} \mathrm{N} \mathrm{yr}^{-1}$ ) in land where thresholds are not exceeded (Figure 4.1a), lifting the global $\mathrm{N}$ boundary to $145 \mathrm{Mt} \mathrm{N} \mathrm{yr}^{-1}$. For individual thresholds, increasing $\mathrm{N}$ inputs to close yield gaps on land where thresholds have not been transgressed increases global boundaries to 214-266 $\mathrm{Mt} \mathrm{N} \mathrm{yr}^{-1}$ (Figure 4.1b-d). 


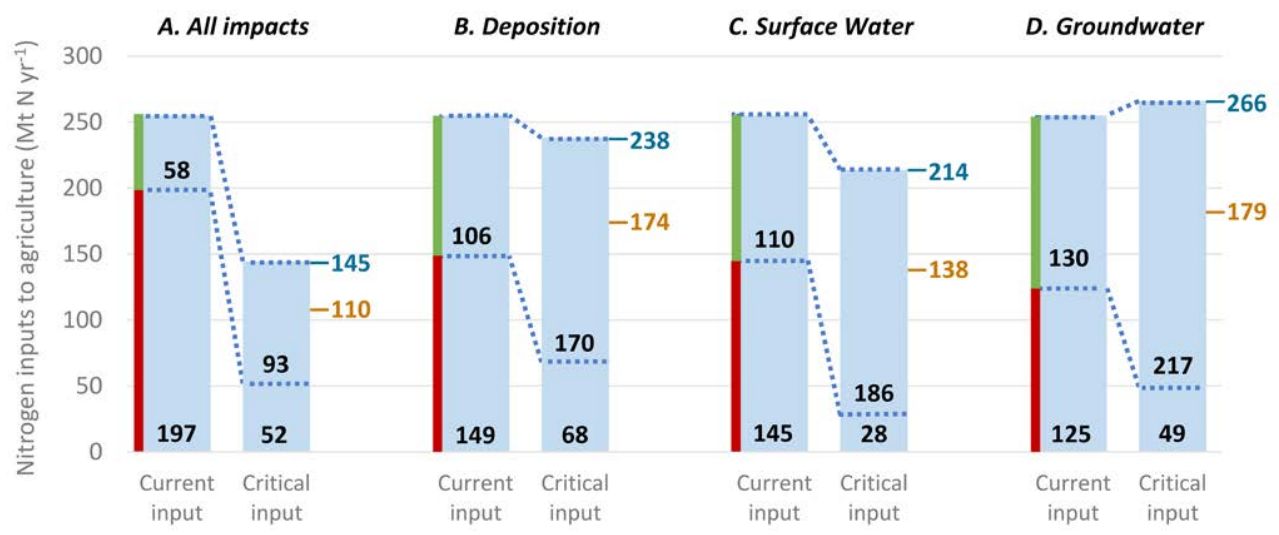

Figure 4.I | Current (2010) and critical nitrogen (N) inputs to agricultural land for a, all thresholds combined, $\mathbf{b}$, critical $\mathrm{N}$ deposition to limit terrestrial biodiversity loss, c, critical $\mathrm{N}$ load to surface water to limit eutrophication and d, critical $\mathrm{N}$ leaching to groundwater to meet drinking water standards. Red edges for current input bars indicate current inputs to land where thresholds are exceeded, green edges indicate current inputs to land where thresholds are not exceeded. Numbers right of critical input bars indicate global $\mathrm{N}$ boundaries when only reducing $\mathrm{N}$ inputs where thresholds are exceeded (orange) and when also allowing $\mathrm{N}$ inputs to increase where possible within thresholds (blue). Values are in $\mathrm{Mt} N \mathrm{yr}^{-1}$.

Even considering allowable increases in $\mathrm{N}$ inputs in regions where thresholds have not yet been transgressed, global critical inputs are still lower than actual (2010) N inputs, except for the groundwater criterion. For all criteria, $\mathrm{N}$ fertilizer inputs need to be reduced more strongly than $\mathrm{N}$ manure inputs (Figure E4.1). This is because areas with a high share of $\mathrm{N}$ fertilizer in general also show a large exceedance of the thresholds (Figure E4.2). As our approach reduces inputs from fertilizer and manure in the same proportion until thresholds are no longer exceeded, absolute reductions of fertilizer inputs are larger than those of manure.

\subsection{Spatial variation in risk areas}

Exceedances of critical inputs for all impacts show strong regional variation (Figure 4.2a and Figure E4.3) and are remarkably similar in croplands and grasslands (Figure E4.4). The spatial variation in exceedances results from heterogeneity in both current $\mathrm{N}$ losses and sensitivity of ecosystems to $\mathrm{N}$ losses (Figure E4.5). Exceedances are most severe in North-Western Europe (especially Germany + BENELUX), India/Pakistan and Eastern China. Smaller regions with high exceedances include the Nile Basin, areas in Saudi-Arabia and along the Peruvian Coast. In these regions often reductions of $>100 \mathrm{~kg} \mathrm{~N} \mathrm{ha}^{-1} \mathrm{yr}^{-1}$ would be needed in order to comply 
with all three thresholds. In 66\% of the global agricultural land area (accounting for as much as $77 \%$ of global $\mathrm{N}$ inputs), at least one of the thresholds has been exceeded (i.e., critical inputs are lower than current inputs). These widespread required reductions result from combining the spatially distinct transgression patterns for the individual thresholds (Figure E4.6). China, Western Europe and the Eastern US are primarily affected by transgressions of surface water limits and/or deposition limits, while the US Midwest and Central Europe are dominated by transgression of surface- and / or groundwater limits (Figure 4.2b). Parts of the eastern United States, Northern India, northeast China and eastern Europe face transgression of the three critical limits simultaneously (Figure 4.2b). In many regions where thresholds for $\mathrm{N}$ load to surface water are exceeded, thresholds for $\mathrm{N}$ leaching to groundwater are also exceeded, and vice versa (Figure 4.2b), while the threshold for $\mathrm{N}$ deposition is often transgressed in areas where water-related thresholds are not. Groundwater thresholds are exceeded more frequently on arable land than on grassland (Figure E4.6).

In contrast to the surplus regions, thresholds have not yet been exceeded for any of the three criteria in 34\% of all agricultural land, situated mostly in Sub-Saharan Africa, Central and South America and South-East Asia (Figure 4.2b). N inputs in these regions could safely increase without exceeding environmental limits, potentially allowing for increases in food production.

\subsection{Option space for agriculture}

Reducing agricultural inputs alone not always suffices to avoid N-related impacts. Previous assessments of planetary $\mathrm{N}$ boundaries focused exclusively on the agricultural sector (Conijn et al., 2018; De Vries et al., 2013; Gerten et al., 2020; Steffen et al., 2015), while our new approach explicitly accounts for $\mathrm{N}$ loss contributions from non-agricultural sources. Half of all agricultural land is located in areas where at least one of the three thresholds is exceeded even without any losses from agriculture (Figure 4.3a), with similar patterns in croplands and intensively managed grasslands (Figure E4.7). This phenomenon is especially widespread for the surface water criterion, where thresholds are exceeded even assuming zero agricultural $\mathrm{N}$ inputs in $44 \%$ of all agricultural land (Figure 4.3c). In these areas, $\mathrm{N}$ discharge from sewage or runoff from natural land alone leads to exceedance of critical $\mathrm{N}$ concentrations (Figure E4.6a,b). For deposition onto terrestrial systems, $\mathrm{NO}_{\mathrm{x}}$ emissions from industry and traffic alone exceed thresholds in areas containing 9\% of all agricultural land, mainly situated in China, Eastern US and Western Europe (Figure 4.3b and Figure E4.6d). Total N deposition in these areas is almost three times the average deposition rate $\left(25 \mathrm{~kg} \mathrm{~N} \mathrm{ha}^{-1}\right.$, compared to 9 



Exceedance of critical nitrogen $(\mathrm{N})$ inputs by current inputs [ $\left.\mathrm{kg} \mathrm{N} \mathrm{ha}^{-1} \mathrm{yr}^{-1}\right]$

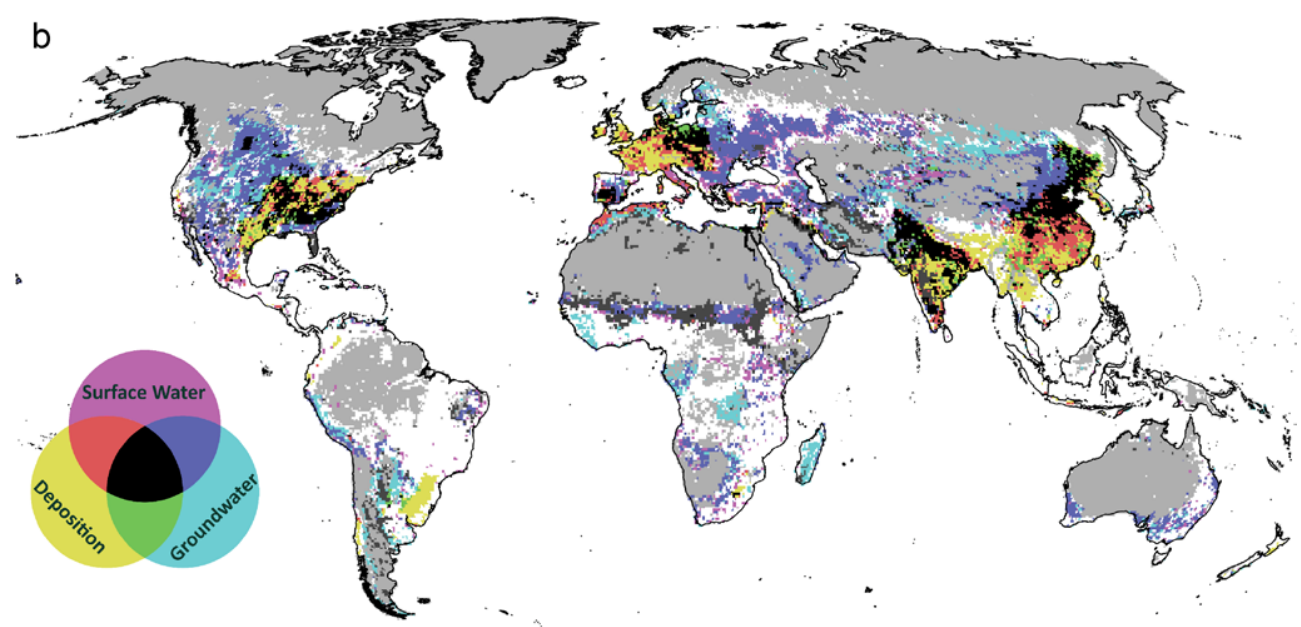

Figure 4.2 | a, Spatial variation in reductions of agricultural $\mathrm{N}$ inputs that are required to respect all three environmental thresholds. Positive values (red) indicate needed reductions, negative values (green) indicate possible increases within thresholds. Needed reductions to respect individual thresholds are shown in Figure E4.2. b. Spatial variation in the type of $\mathrm{N}$-related impact (critical $\mathrm{N}$ deposition, critical $\mathrm{N}$ load to surface water and critical $\mathrm{N}$ leaching to groundwater) for which thresholds are exceeded. Exceedance of thresholds for none (white), one, two or all three impacts (see legend). Areas with no agricultural land are light grey, areas where critical inputs could not be calculated are dark grey. 
a

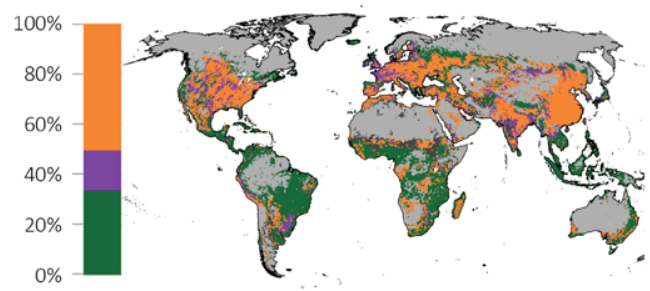

C

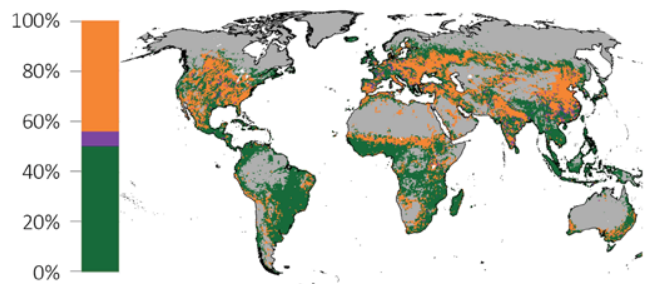

b

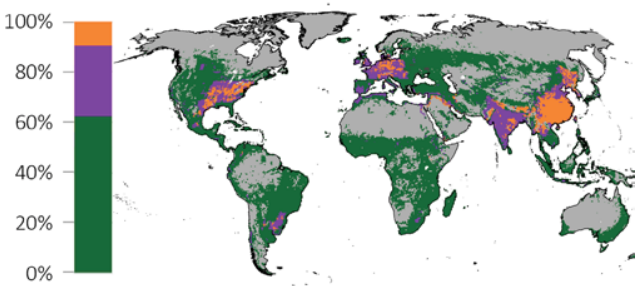

d

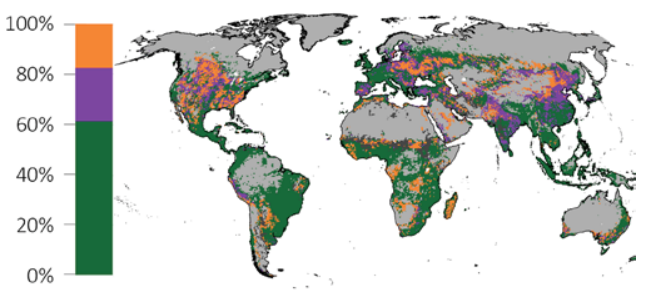

Threshold not exceeded (reducing $\mathrm{N}$ losses not necessary)
Threshold exceeded; reducing agricultural inputs sufficient to respect threshold
Threshold exceeded; reducing agricultural inputs alone not sufficient to respect threshold (non-agricultural $\mathrm{N}$ losses alone exceed threshold)

Figure 4.3 | Possibilities for respecting environmental thresholds by reducing agricultural $\mathrm{N}$ inputs alone for a, all thresholds combined, $\mathbf{b}$, critical $\mathrm{N}$ deposition to limit terrestrial biodiversity loss, $\mathbf{c}$, critical $\mathrm{N}$ load to surface water to limit eutrophication and $\mathbf{d}$, critical $\mathrm{N}$ leaching to groundwater to meet drinking water standards. Bars show the share of global agricultural land within each category. Areas with no agricultural land are shown in grey.

$\mathrm{kg} \mathrm{N} \mathrm{ha}{ }^{-1}$ for all grid cells with agricultural land) and $\mathrm{NO}_{\mathrm{x}}$ on average accounts for $78 \%$ of the deposition. The critical $\mathrm{N}$ load to groundwater is exceeded at zero inputs to agriculture in $17 \%$ of the total agricultural area (Figure $4.3 \mathrm{~d}$ ). We tested how varying assumptions regarding reductions of non-agricultural $\mathrm{N}$ losses affected our results and found a notable impact on global $\mathrm{N}$ boundaries. Fully reducing other $\mathrm{N}$ losses, for example, lifts the boundary for all impacts by ca. $42 \%$ (to $219 \mathrm{Mt} \mathrm{N} \mathrm{yr}^{-1}$ ) (Figure E4.9).

\subsection{Food Security Implications}

Feeding a future population of $\sim 10$ billion people while remaining within the safe operating space for $\mathrm{N}$ is only possible through drastic changes to both food production systems and consumption patterns. Assessments that have attempted to model a world where sufficient 

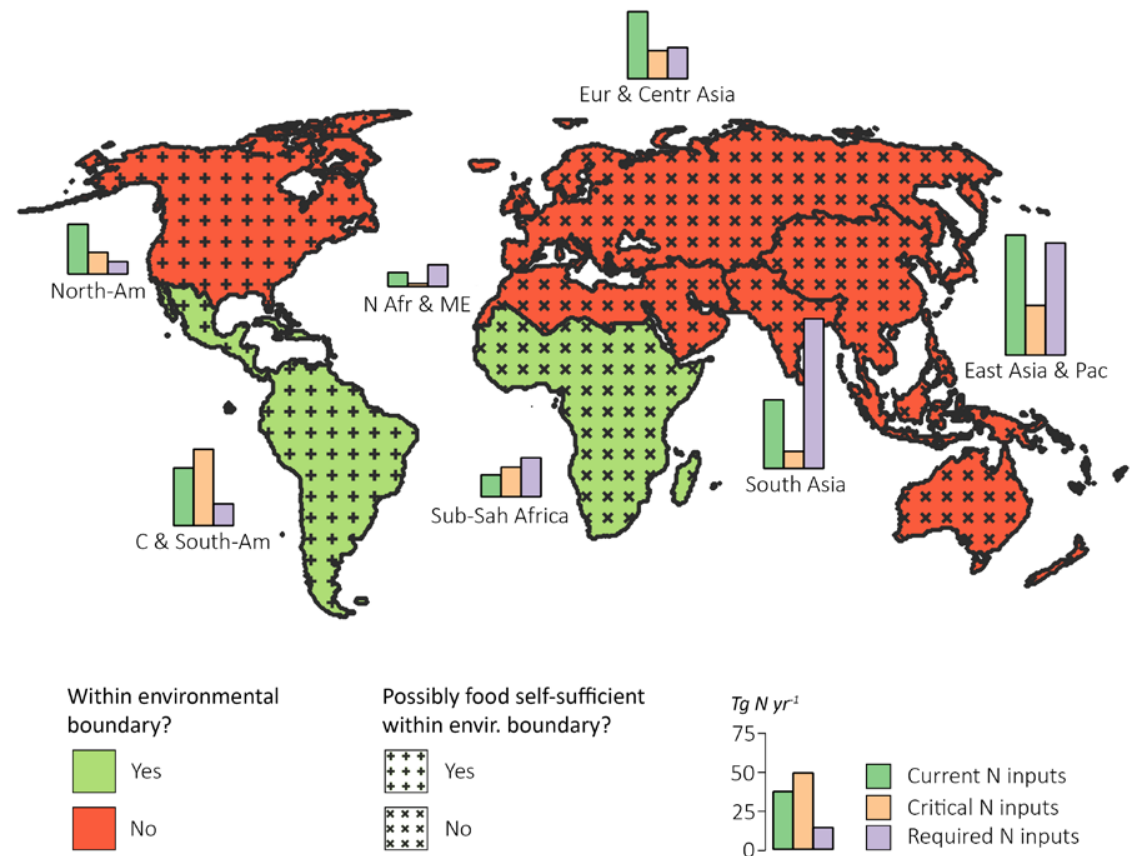

$$
\begin{aligned}
& \text { Possibly food self-sufficient }
\end{aligned}
$$

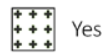

$$
\begin{aligned}
& \left.\begin{array}{lll}
x & x & x \\
x & x & x \\
x & x & x
\end{array}\right] \text { No }
\end{aligned}
$$$$
\text { within envir. boundary? }
$$

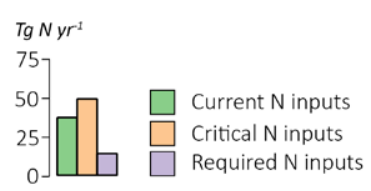

Figure 4.4 | Exceedance of environmental boundaries and possibility for food self-sufficiency within boundaries per world regions. Bar charts show current (2010) $\mathrm{N}$ input, critical $\mathrm{N}$ input (to avoid all impacts) and required $\mathrm{N}$ input to meet domestic protein demand (based on a protein intake of $3 \mathrm{~kg} \mathrm{~N}$ person $^{-1}$ year-1 $^{-1}$ and food chain $\mathrm{N}$ use efficiencies from the literature, see Section 4.7). Colours indicate whether a region is currently within environmental boundaries (current input < critical input), patterns indicate whether a region can be food self-sufficient while respecting boundaries at current efficiencies (required input $<$ critical input).

food can be supplied within environmental thresholds found that this can only be achieved by combining efficiency improvements, dietary changes, re-distributing $\mathrm{N}$ inputs and cropland, reducing food waste and recycling nutrients (Conijn et al., 2018; Springmann et al., 2018; Willett et al., 2019). Optimizing the distribution of cropland, production and N inputs could contribute substantially to producing more crops with less $\mathrm{N}$ pollution (Folberth et al., 2020; Gerten et al., 2020; Mueller et al., 2012), but may clash with goals of regional and national food self-sufficiency (Heck et al., 2018b). We find that under current production conditions, only two out of seven world regions (Latin America and Sub-Saharan Africa) can safely increase $\mathrm{N}$ inputs (critical inputs > current inputs, Figure 4.4). However, even if SubSaharan Africa were to increase $\mathrm{N}$ inputs up to the regional boundary, this level would not be enough to achieve food self-sufficiency (critical inputs < required inputs, Figure 4.4). For five out of seven regions, agricultural $\mathrm{N}$ inputs need to be reduced in order to stay within safe limits for $\mathrm{N}$ pollution (critical inputs $<$ current inputs). 
Reducing agricultural $\mathrm{N}$ implies loss of crop production, unless NUE (the share of $\mathrm{N}$ applied that is taken up by crops) is increased. Globally, maintaining current (year 2010) yields without exceeding thresholds for groundwater $\mathrm{N}$ leaching requires NUE to increase from currently $47 \%$ to $74 \%$ (Table E4.1). On ca. half of the agricultural land, the NUE at which losses are reduced to critical values without reductions in crop and grass production is higher than $80 \%$. For surface water $\mathrm{N}$ load (currently transgressed on $50 \%$ of the agricultural area), NUE has to increase on average from currently $48 \%$ to $95 \%$ (Table E4.1). Such high increases are beyond what is considered feasible (Zhang et al., 2015) and far from trajectories that countries are currently on (Lassaletta et al., 2014a).

\subsection{From planetary to regional boundaries}

Aggregating our spatially explicit $\mathrm{N}$ input thresholds for protecting air, surface water and groundwater quality results in a planetary boundary for $\mathrm{N}$ inputs in croplands and grasslands. The most important result, however, is the insight in the spatial distribution of acceptable environmental $\mathrm{N}$ losses for different $\mathrm{N}$ impacts as well as $\mathrm{N}$ pollution from non-agricultural sources. Results can be used to derive bottom-up national and regional boundaries (Figure E4.10 and Table E4.2) and can thus replace current top-down $\mathrm{N}$ boundaries based on equal per capita shares that ignore environmental heterogeneity (e.g., Cole et al., 2014).

The $\mathrm{N}$ boundaries presented in this paper represent thresholds for the current agricultural system, but the approach in theory allows for a dynamic assessment of $\mathrm{N}$ boundaries under changing conditions and practices, for example using scenarios such as the shared socioeconomic pathways (Riahi et al., 2017). If agricultural systems become more efficient in the future, the planetary boundary for $\mathrm{N}$ inputs increases, as a lower share of inputs is lost to the environment. Similarly, mitigation of N pollution from other sectors affects the boundary for agricultural $\mathrm{N}$ inputs as more 'space' becomes available for agricultural $\mathrm{N}$ losses.

The Sustainable Development Goals adopted by the UN aim to improve human well-being while protecting ecosystems. Our results highlight the magnitude of this challenge with regards to agricultural $\mathrm{N}$ use. Fixation of reactive $\mathrm{N}$ will remain vital for sustaining crop production, but the costs to the environment are high, with thresholds for several N-related problems already exceeded on most of the agricultural land. Producing more food with less pollution will require targeted strategies, with increases in efficiency and/or extensification in areas with vulnerable ecosystems, and increases in $\mathrm{N}$ inputs in areas where additional losses are acceptable from an environmental perspective. Feeding the world without trespassing a planetary $\mathrm{N}$ boundary thus requires a coordinated action that has to recognize the regional diversity of agricultural systems and multiple environmental impacts. 


\subsection{Methods}

Spatially explicit boundaries for agricultural nitrogen $(\mathrm{N})$ inputs were derived in three steps (see Figure 4.5a): Step 1; establish thresholds for $\mathrm{N}$ concentrations at which unacceptable impacts occur ('critical concentration'), Step 2; derive N losses at which critical concentrations are reached but not exceeded ('critical losses') and Step 3; calculate agricultural $\mathrm{N}$ inputs that correspond to critical losses ('critical inputs', step 3).

\section{Thresholds for nitrogen impacts}

Critical agricultural $\mathrm{N}$ inputs are for $\mathrm{N}$ impacts, using thresholds for: (i) $\mathrm{N}$ deposition in natural ecosystems (related to biodiversity and acidification in terrestrial systems), (ii) $\mathrm{N}$ concentrations in surface water (related to eutrophication impacts on aquatic biodiversity) and (iii) $\mathrm{N}$ concentrations in groundwater (related to drinking water norms).

Critical $\mathrm{N}$ deposition rates to limit terrestrial biodiversity loss were derived for each of the 14 biomes represented in the IMAGE model (Stehfest et al., 2014), mainly based on Bobbink et al. (2010). Critical deposition rates vary from 5 to $20 \mathrm{~kg} \mathrm{~N} \mathrm{ha}^{-1} \mathrm{yr}^{-1}$ for the most and least sensitive biomes, respectively (see Supplementary Text S4.1.1).

Critical N concentration in surface water to limit eutrophication impacts was set to $2.5 \mathrm{mg} \mathrm{N}$ (total dissolved N) per litre, based on (i) an extensive study on the ecological and toxicological effects of inorganic N pollution (Camargo and Alonso, 2006), (ii) an overview of maximum allowable surface water $\mathrm{N}$ concentrations in national surface water quality standards (Laane, 2005) and (iii) different European objectives for N compounds. Rather than imposing limits for $\mathrm{N}$ concentrations in surface water itself, we used a threshold for $\mathrm{N}$ concentration in runoff to surface water. This threshold was set to $5.0 \mathrm{mg} \mathrm{N} \mathrm{l}^{-1}$, based on the assumption that on average $50 \%$ of $\mathrm{N}$ entering surface water is removed through retention and sedimentation (see Supplementary Text S4.1.2).

Critical $\mathrm{N}$ concentration in groundwater to limit health effects was set to $50 \mathrm{mg} \mathrm{NO}_{3} \mathrm{l}^{-1}(11.3$ mg $\mathrm{NO}_{3}-\mathrm{N}^{-1}$ ), based on WHO guidelines for drinking water (WHO, 2011). We imposed this threshold concentration for excess water leached from agricultural land.

Two other impacts of $\mathrm{N}$ were not considered: the climate impact of $\mathrm{N}_{2} \mathrm{O}$ emissions and health effects of air pollution by $\mathrm{NH}_{3}$, either directly or by contributing to particulate matter (PM) formation. These impacts were not considered for several reasons: First, $\mathrm{N}_{2} \mathrm{O}$ is not the major contributor to climate warming, and deriving a critical limit for $\mathrm{N}_{2}$ emissions thus requires making assumptions on reductions in other greenhouse gases. Second, $\mathrm{N}_{2} \mathrm{O}$ concentrations only show slight interhemispheric and seasonal variations, making a spatially 
explicit calculation of critical inputs irrelevant. Third, at the global scale, part of the warming effect from $\mathrm{N}_{2} \mathrm{O}$ emissions may be compensated by additional carbon sequestration induced by enhanced $\mathrm{N}$ deposition, mainly in forests (De Vries et al., 2017; Schulte-Uebbing and De Vries, 2018). For air pollution impacts of $\mathrm{NH}_{3}$, critical limits could be derived based on thresholds for PM10 and PM2.5 and the relative contribution of $\mathrm{NH}_{3}$ to $\mathrm{PM}$ formation. The contribution of $\mathrm{NH}_{3}$ and $\mathrm{NO}_{\mathrm{x}}$ to overall $\mathrm{PM}$ concentrations varies considerably between population centres and is estimated to be on average 30\% in urban areas and $15 \%$ in rural areas for PM2.5 (Putaud et al., 2004). However, the effects of $\mathrm{NH}_{3}$ on PM formation strongly depend on meteorological conditions that vary in time in space, and such an assessment would thus require detailed air quality models that capture these processes.

\section{IMAGE-GNM model}

All calculations are performed for the year 2010 at a spatial resolution of $0.5 \times 0.5$ degrees, based on output files from the Global Nutrient Model (GNM), a sub-model of the Integrated Model to Assess the Global Environment (IMAGE). IMAGE is a comprehensive integrated modelling framework that allows to analyse interactions between human development and global change (Stehfest et al., 2014). IMAGE-GNM simulates the fate of $\mathrm{N}$ and phosphorus (P) in the soil-hydrological system (for a comprehensive description of IMAGE-GNM, see Beusen et al., 2015). Total $\mathrm{N}$ load to surface water in IMAGE-GNM consists of (also see Figure 4.5b):

i. N load from point sources that enter surface water directly, including wastewater, aquaculture, allochthonous organic matter and direct deposition to surface water,

ii. N load from soil erosion (both from agricultural and natural land) and

iii. $\mathrm{N}$ load from soil $\mathrm{N}$ budgets that are susceptible to surface runoff and leaching. Nitrogen leached from the root zone travels through the soil profile and is eventually delivered to surface water via sub-surface runoff. Sub-surface delivery of $\mathrm{N}$ to surface water is calculated while accounting for travel times, historical $\mathrm{N}$ inflows and $\mathrm{N}$ removal through denitrification in soils and riparian zones.

Surface water $\mathrm{N}$ concentration is derived from total $\mathrm{N}$ load, transport of $\mathrm{N}$ from upstream grid cells and in-stream nutrient retention (Beusen et al., 2015).

\section{Major assumptions in calculating critical nitrogen losses and inputs}

Spatially explicit boundaries were derived for total $\mathrm{N}$ inputs from fertilizer, manure, biological $\mathrm{N}$ fixation and deposition, rather than for 'intentional $\mathrm{N}$ fixation', used as an indicator 
a

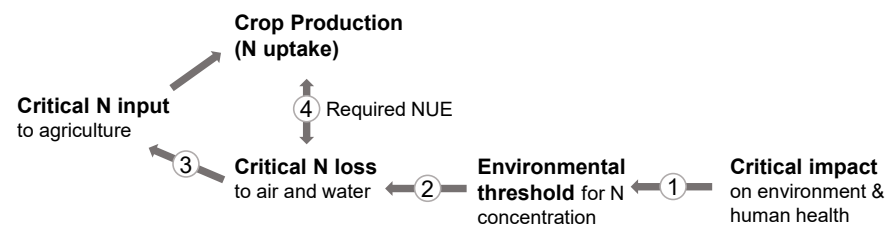

b

$N$ inputs:

- $\mathrm{N}$ fertilizer $(1,2)$

- $\mathrm{N}$ manure $(1,2,3)$

- $\mathrm{N}$ fixation

- $\mathrm{N}$ deposition

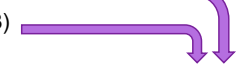

N point sources:

- N allochthonous organic matter

- $\mathrm{N}$ direct deposition

- $\mathrm{N}$ wastewater

- N aquaculture

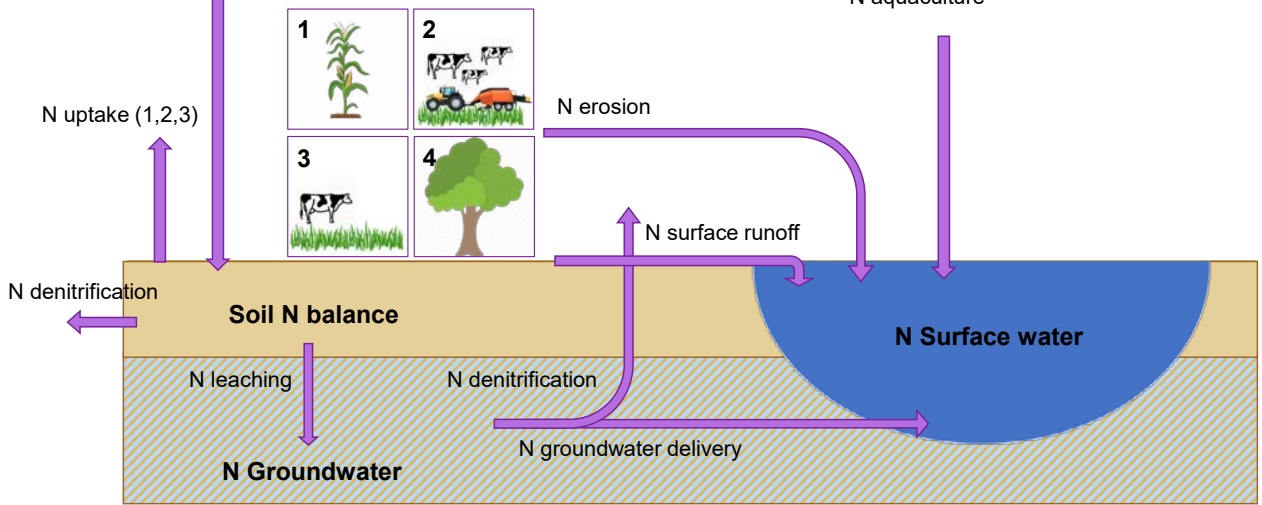

Figure 4.5 | Schematic illustrations of the modelling approach. a, Schematic representation of the steps for back-calculating critical $\mathrm{N}$ inputs from critical impacts as well as required NUEs to reconcile environmental and crop production targets. $\mathbf{b}$, Simplified schematic representation of the calculations of $\mathrm{N}$ losses in the IMAGE-GNM model used in the back-calculation of critical agricultural $\mathrm{N}$ inputs. Boxes represent different land use types $(I=$ arable land, $=$ intensively managed grassland, $3=$ extensively managed grassland, 4 = natural land).

previous assessments of planetary $\mathrm{N}$ boundaries (Steffen et al., 2015). While intentionally fixed $\mathrm{N}$ is a good indicator for the degree of human appropriation of the global $\mathrm{N}$ cycle, the sum of both new and recycled $\mathrm{N}$ inputs to agricultural systems is a more relevant indicator for assessing spatial patterns in the transgression of environmental limits. For example, $\mathrm{N}$ fixation is high in South American soy production, whereas the adverse impacts of this newly fixed $\mathrm{N}$ largely occur in other parts of the world where the $\mathrm{N}$ incorporated in soy is imported as feed for intensive animal husbandry systems (Lassaletta et al., 2014b).

Critical $\mathrm{N}$ inputs were calculated using IMAGE-GNM (see Figure 4.5b) with several assumptions (see below). All equations used for calculating critical $\mathrm{N}$ inputs, as well as an overview of all gridded IMAGE data-files used as input in the calculations, can be found in the Supplementary Text S4.1, Table S4.2 \& Table S4.3. 
Assumption 1: Changes in agricultural $\mathrm{N}$ inputs. Total $\mathrm{N}$ inputs to agriculture consist of $\mathrm{N}$ inputs from mineral fertilizer, manure, biological $\mathrm{N}$ fixation and deposition (see Figure 4.5b). Critical inputs are calculated by varying only those inputs directly managed by farmers, i.e. mineral fertilizer and manure. Inputs from biological $\mathrm{N}$ fixation were assumed to be constant, and inputs from deposition were calculated as a linear function of $\mathrm{NH}_{3}$ and $\mathrm{NO}_{\mathbf{x}}$ emissions at critical $\mathrm{N}$ inputs. Nitrogen inputs from fertilizer and manure were reduced (or increased) in equal proportions until thresholds are no longer exceeded.

Assumption 2: Constant $\mathrm{N}$ losses from other sources. All $\mathrm{N}$ losses from non-agricultural sources were assumed constant. This includes $\mathrm{NO}_{\mathrm{x}}$ emissions from stationary and mobile combustion, as well as $\mathrm{N}$ load to surface water from point sources and erosion (see Figure 4.5b). Where $\mathrm{N}$ loss thresholds are exceeded, agriculture thus has to carry the full burden of reductions. We also tested the impact of alternative assumptions regarding non-agricultural loses on the results (see Section on 'Scenarios' under 4.7 and Figure E4.9).

Assumption 3: Constant properties of the agricultural system. $\mathrm{N}$ losses and uptake were assumed to change linearly with $\mathrm{N}$ inputs. We assumed no changes in extent and distribution of agricultural land. Land use classes in IMAGE were aggregated to four land-use types: 1 . arable land, 2. intensively managed grassland, 3. extensively managed grassland (pastoral land) and 4. natural land (see Figure 4.5b). Critical $\mathrm{N}$ inputs were calculated only for landuse types 1 and 2, while $\mathrm{N}$ inputs to (and $\mathrm{N}$ losses from) 3 and 4 were assumed constant (except for inputs from deposition related to $\mathrm{NH} 3$ emissions from manure and fertilizer inputs to 1 and 2).

Assumption 4: $\mathrm{N}$ emissions and $\mathrm{N}$ deposition. Nitrogen deposition within a grid cell was assumed to be homogeneously distributed (i.e., same deposition rates for all land use types within a grid cell). Total $\mathrm{N}\left(\mathrm{NH}_{3}+\mathrm{NO}_{\mathrm{x}}\right)$ emissions were assumed equal to total $\mathrm{N}$ deposition within a grid cell, i.e., we assumed no inter-grid transport of $\mathrm{N}$ emissions. $\mathrm{NO}_{\mathrm{x}}$ emissions were calculated as the difference between $\mathrm{N}$ deposition and $\mathrm{NH}_{3}$ emissions. Spatial distribution of $\mathrm{N}$ deposition in IMAGE is derived from the TM5 model (Dentener et al., 2006), corrected for the difference in emission estimate between TM5 and IMAGE at the level of world regions. If $\mathrm{NH}_{3}$ emissions exceeded $\mathrm{N}$ deposition in a grid cell, $\mathrm{N}$ deposition was set equal to $\mathrm{NH}_{3}$ emissions. This increased total global $\mathrm{N}$ deposition by $\sim 10 \%$ (from 82 to $90 \mathrm{Mt} \mathrm{N} \mathrm{yr} \mathrm{r}^{-1}$ ), a figure that is well within the uncertainty range for global $\mathrm{N}$ deposition estimates (Dentener et al., 2014).

Assumption 5: Legacy $\mathrm{N}$ delivery. Depending on the travel time distribution for the lateral flow, a part of $\mathrm{N}$ delivered to surface water via groundwater ("N groundwater delivery" in Figure $4.5 \mathrm{~b}$ ) is caused by $\mathrm{N}$ inputs in the past. To reflect this time-lag in our calculations, 
$\mathrm{N}$ groundwater delivery was split into a variable component (assumed to change linearly with $\mathrm{N}$ inputs) and a fixed component (assumed constant). The fraction of the variable component was derived as a function of precipitation surplus, and increases linearly from 0 at no precipitation surplus to 0.95 at a precipitation surplus of $2000 \mathrm{~mm} \mathrm{yr}^{-1}$ and higher.

\section{Cut-off value for critical inputs}

In areas where $\mathrm{N}$ losses are (far) below environmental thresholds, critical $\mathrm{N}$ inputs need to be constrained by a maximum value in order to avoid unrealistically high $\mathrm{N}$ inputs. Such a maximum value should reflect that farmers will not apply more $\mathrm{N}$ than required for crop production, but also that current $\mathrm{N}$ inputs constrain yields in many regions (Mueller et al., 2014). We thus set the maximum level for critical $\mathrm{N}$ inputs, $\mathrm{Nin}_{(\mathrm{crit}, \max )}$, to the input required to obtain crop yield potentials at current nitrogen use efficiency (NUE):

$$
\begin{aligned}
& \operatorname{Nin}_{(\operatorname{crit}, \max )}=N u p_{(Y p)} / N U E \\
& \operatorname{Nup}_{(Y p)}=N u p * Y p / Y a
\end{aligned}
$$

Where Yp is the yield potential (either for arable land or intensively managed grassland), Ya is the current yield, $\operatorname{Nup}_{(\mathrm{Yp})}$ is the $\mathrm{N}$ uptake at crop yield potential, and NUE is calculated as $\mathrm{N}$ uptake divided by total $\mathrm{N}$ inputs. As high NUEs occur in regions where $\mathrm{N}$ is mined from the soil, we capped the NUE for the calculation of maximum $\mathrm{N}$ input at 0.8 .

Yield potentials for arable land were derived based on attainable yields for 17 crops and 155 countries presented in Mueller et al. (2012), and yield potentials for intensively managed grassland were derived based on maximum livestock densities and feed requirements from Rolinski et al. (2018), see Supplementary Text S4.1 for details.

\section{Aggregation to regional and planetary boundaries}

Regional and planetary boundaries for agricultural $\mathrm{N}$ inputs were calculated as the sum of critical $\mathrm{N}$ inputs for all grid cells within a region. Boundaries were calculated for each of the three thresholds individually, and for all thresholds simultaneously (based on the minimum of the individual boundaries in each grid cell). Where $\mathrm{N}$ losses from non-agricultural sources alone exceeded thresholds, critical $\mathrm{N}$ inputs from fertilizer and manure were set to zero. 


\section{Scenarios for non-agricultural nitrogen losses}

Non-agricultural $\mathrm{N}$ losses contribute substantially to the exceedance of critical thresholds (see Figure E4.8). In the standard calculation of critical N inputs, these losses were assumed constant (year 2010 values). To test the impact of alternative assumptions regarding nonagricultural $\mathrm{N}$ losses on agricultural $\mathrm{N}$ input boundaries, critical $\mathrm{N}$ inputs were calculated for two scenarios. In the Scenario "Mitigation", $\mathrm{NO}_{\mathrm{x}}$ emissions and $\mathrm{N}$ load to surface water from wastewater were reduced by $50 \%$ in each grid cell. In the Scenario "Agriculture First", all non-agricultural $\mathrm{N}$ losses were set to zero, and all $\mathrm{N}$ delivery to groundwater was assumed to occur due to recent inputs (i.e., the scenario does not account for 'legacy $\mathrm{N}$ load').

\section{Required nitrogen input for food self-sufficiency}

The required agricultural $\mathrm{N}$ input for food self-sufficiency in each IMAGE region was calculated as:

$$
N i n, r e q_{(i)}=\frac{\operatorname{pop}_{(i)} * N_{\text {demand }} *\left(\frac{f N_{\text {veg }}}{\text { NUE, }_{\text {chain }} \text { veg }}+\frac{f N_{\text {ani }}}{\text { NUE,chain }_{\text {ani }}}\right)}{N U E, \text { field }_{(i)}}
$$

Where:

$$
\begin{aligned}
& \text { Nin, req }_{(i)}=\mathrm{N} \text { input required to produce enough protein to be food self-sufficient for region } \\
& \text { i [ } \mathrm{kg} \mathrm{N} \mathrm{yr}^{-1} \text { ] } \\
& \operatorname{pop}_{(i)} \quad=\text { population for region i for the year } 2019 \text { [\# persons] (obtained from World } \\
& \text { Bank, 2020) } \\
& N_{\text {demand }}=\text { per capita } \mathrm{N} \text { intake requirement }\left[\mathrm{kg} \mathrm{N}_{\text {person }}{ }^{-1} \text { year }^{-1}\right] \text {; set to } 3 \mathrm{~kg} \mathrm{~N} \text { person }{ }^{-1} \\
& \mathrm{yr}^{-1} \text { (based on Westhoek et al., 2011) } \\
& f N_{\text {veg }} \quad=\text { average share of vegetal protein in total protein intake [-], set to } 2 / 3 \text { (based on } \\
& \text { Westhoek et al., 2011) } \\
& f \mathrm{~N}_{\text {ani }}=\text { average share of animal protein in total protein intake [-], set to } 1 / 3 \text { (based on } \\
& \text { Westhoek et al., 2011) } \\
& \text { NUE, } \text { chain }_{\text {veg }}=\text { average food chain NUE for vegetal protein, i.e., the share of } \mathrm{N} \text { in harvested } \\
& \text { crops that is ingested by humans [-]; estimated at } 45 \% \text { (based on Galloway and } \\
& \text { Cowling, 2002) }
\end{aligned}
$$

Results at the level of 26 IMAGE regions were then aggregated to seven World Bank regions. 


\section{Required nutrient use efficiency to reconcile nitrogen thresholds and food production}

In areas where $\mathrm{N}$ loss thresholds are exceeded, respecting thresholds without crop yield losses is only possible at a higher nitrogen use efficiency (NUE). The required NUE to respect thresholds for $\mathrm{N}$ load to surface water or $\mathrm{N}$ leaching to groundwater without yield reductions was estimated for each grid cell by dividing current (year 2010) N uptake by the sum of current $\mathrm{N}$ uptake and critical $\mathrm{N}$ losses, as:

$$
N U E_{(r e q)}=\frac{N u p_{(2010)}}{\operatorname{Nup}_{(2010)}+\operatorname{Nloss}_{(2010)}}
$$

This based on the assumption that in each grid cell critical $\mathrm{N}$ input equals the sum

of current uptake and critical losses ( $\mathrm{N}$ input $=\mathrm{N}$ output). Critical $\mathrm{N}$ losses are the sum of $\mathrm{NH} 3$ emissions, $\mathrm{N}$ runoff, $\mathrm{N}$ leaching and $\mathrm{N}$ denitrification at critical $\mathrm{N}$ inputs. Results thus derived represent an approximation of actual required NUEs, as calculations do not account for the fact that at higher NUE less inputs are required for obtaining the same uptake.

Required NUEs were calculated for (i) all agricultural land where $\mathrm{N}$ loss thresholds are exceeded and (ii) only for regions where both thresholds are exceeded and thresholds are not exceeded by non-agricultural losses alone (where this is the case, critical $\mathrm{N}$ losses are zero and the required NUE is thus 1 ). 


\section{Extended Data}
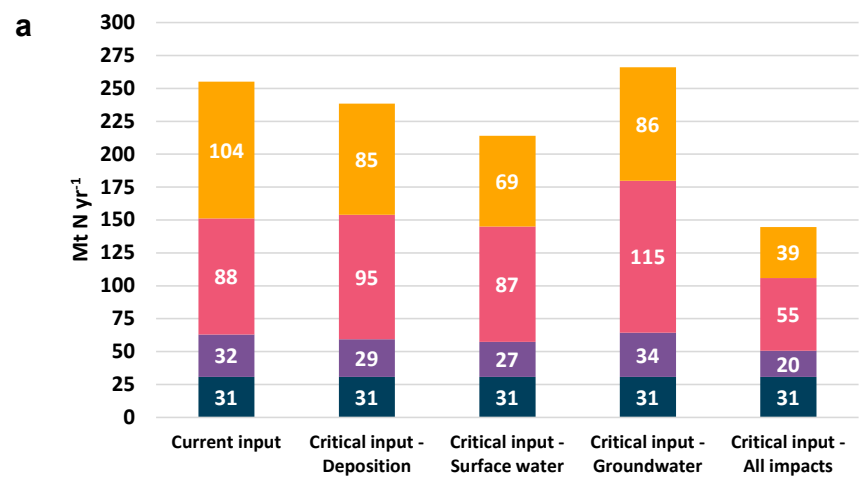

b

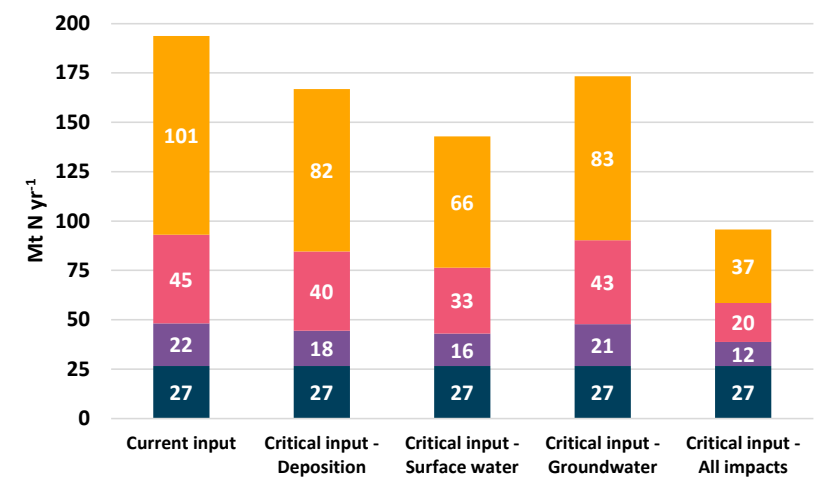

C

100

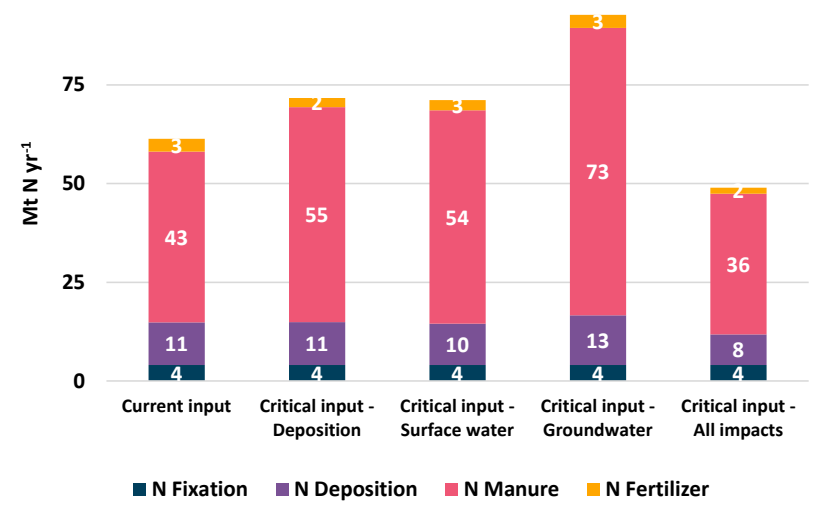

Figure E4.I | Current \& critical inputs by source and land use type. Global current (year 2010) N inputs and critical $\mathrm{N}$ inputs related to three thresholds ( $\mathrm{N}$ deposition to limit terrestrial biodiversity loss, $\mathrm{N}$ load to surface water to limit eutrophication, and $\mathrm{N}$ leaching to groundwater to meet drinking water standards), and for all thresholds combined. Inputs are disaggregated by source and shown for $\mathbf{a}$, all agricultural land, $\mathbf{b}$, arable land and $\mathbf{c}$, intensively managed grassland. To convert inputs in $\mathrm{Mt} \mathrm{N}_{\mathbf{y r}} \mathrm{r}^{-1}$ to input rates in $\mathrm{kg} \mathrm{N} \mathrm{ha}^{-1} \mathrm{yr}^{-1}$, divide by 2.3 for all agricultural land, by 1.5 for arable land and by 0.8 for intensively managed grassland. 


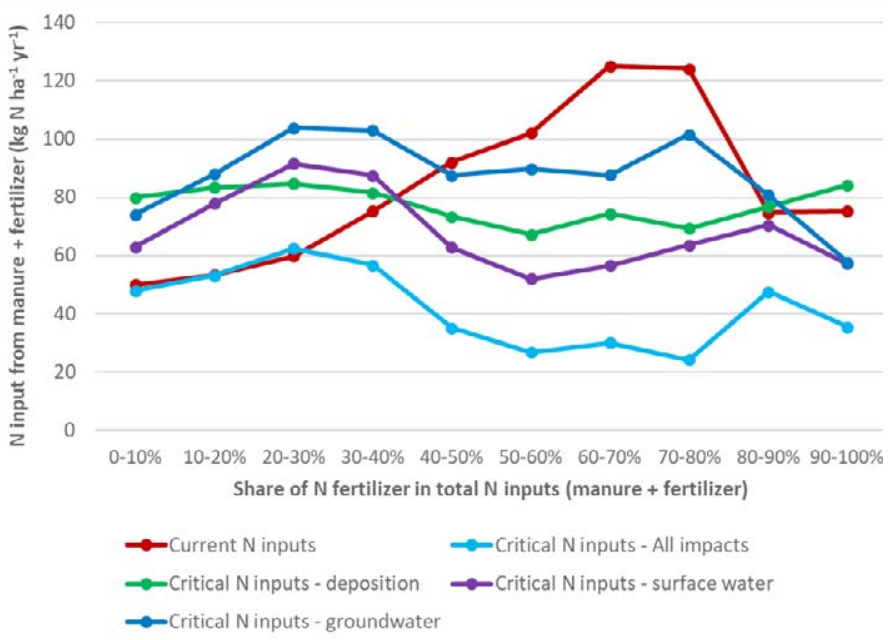

Figure E4.2 | Average $\mathrm{N}$ input rate $\left(\mathrm{kg} \mathrm{N} \mathrm{ha}^{-1} \mathrm{yr}^{-1}\right)$ for different classes of $\mathrm{N}$ fertilizer share in total $\mathrm{N}$ inputs (fertilizer and manure). Global average current (year 2010) $\mathrm{N}$ input rates from manure and fertilizer for and critical $\mathrm{N}$ input rates from manure and fertilizer related to different impacts.

a
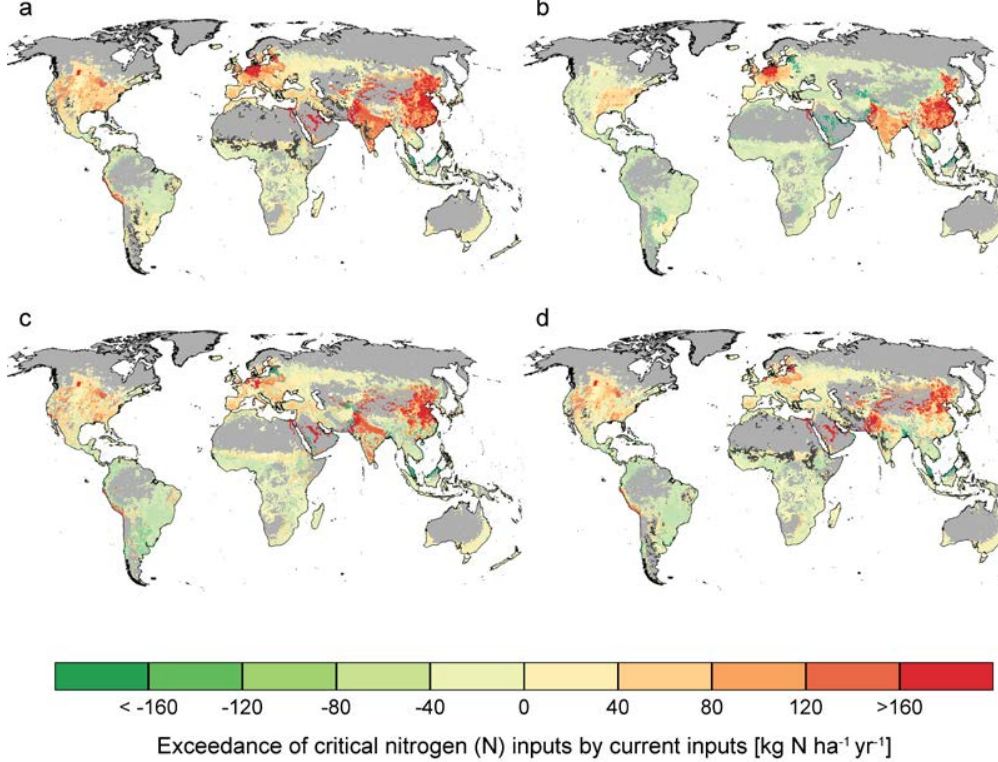

b

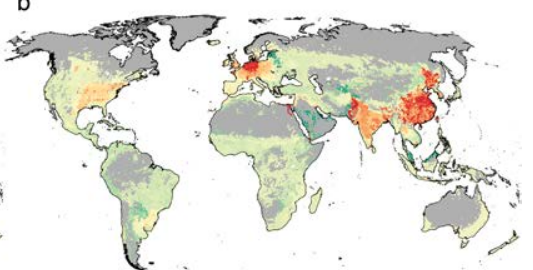

d

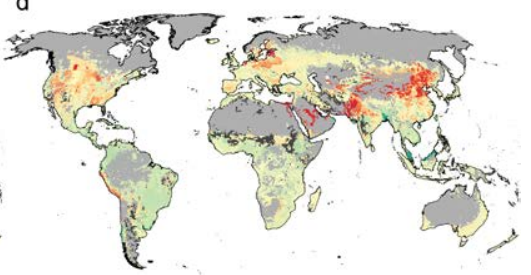

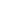



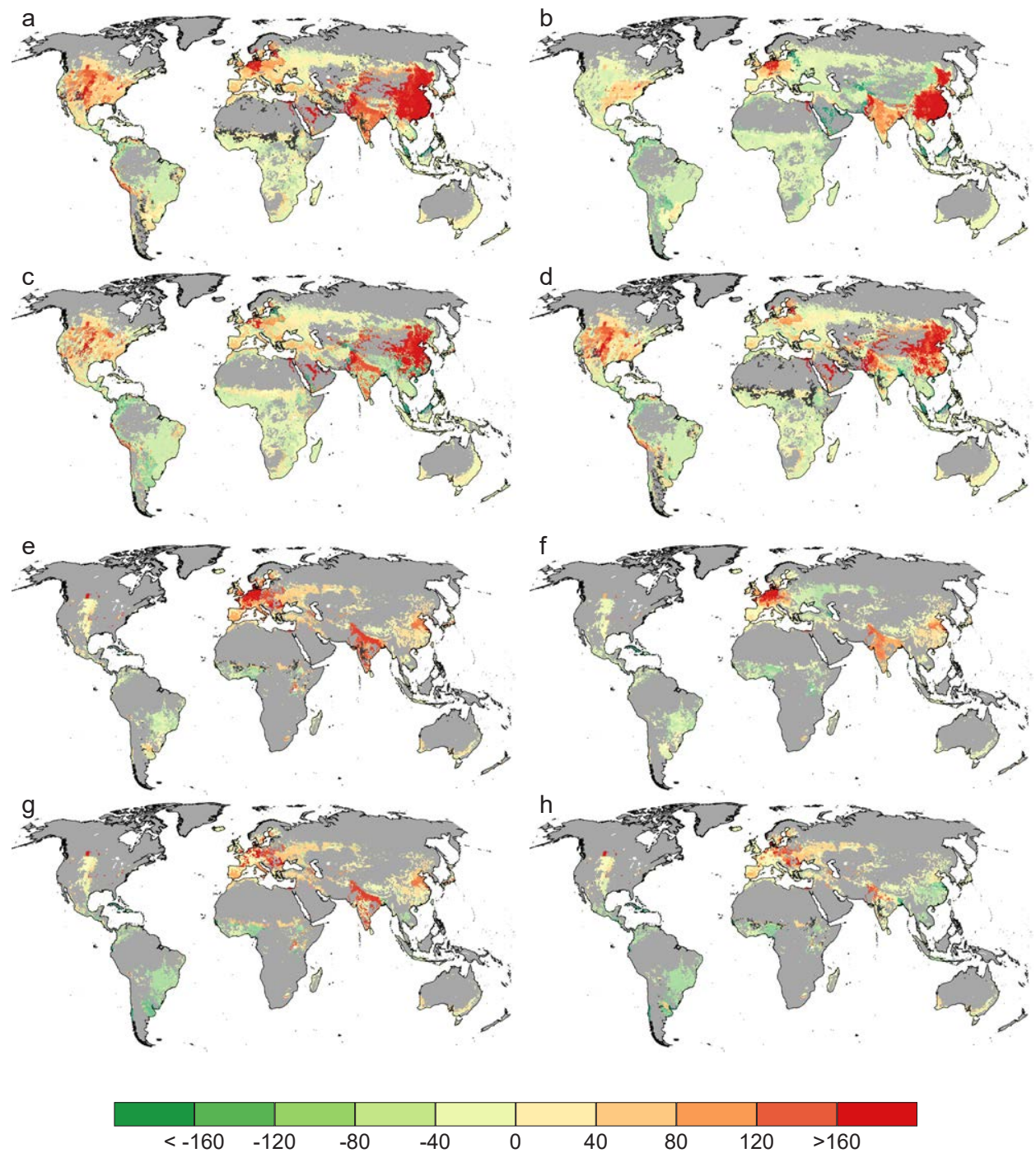

Exceedance of critical nitrogen $(\mathrm{N})$ inputs by current inputs $\left[\mathrm{kg} \mathrm{N} \mathrm{ha}^{-1} \mathrm{yr}^{-1}\right]$

Figure E4.4 | Spatial variation of the exceedance of critical $\mathrm{N}$ inputs in agricultural production by current inputs on $\mathbf{a}-\mathbf{d}$, arable land and $\mathbf{e}-\mathbf{h}$, intensively managed grassland; related to $\mathbf{a}+\mathbf{e}$, all impacts combined, $\mathbf{b}+\mathbf{f}$, critical deposition to limit terrestrial biodiversity loss, $\mathbf{c}+\mathbf{g}$, critical $\mathrm{N}$ load to surface water to limit eutrophication, and $\mathbf{d}+\mathbf{h}$, critical $\mathrm{N}$ leaching to groundwater to meet drinking water standards. Positive values indicate that $\mathrm{N}$ inputs to agriculture need to decrease in order to avoid exceeding the environmental thresholds. Negative values indicate that $\mathrm{N}$ inputs to agriculture can increase without exceeding thresholds. 


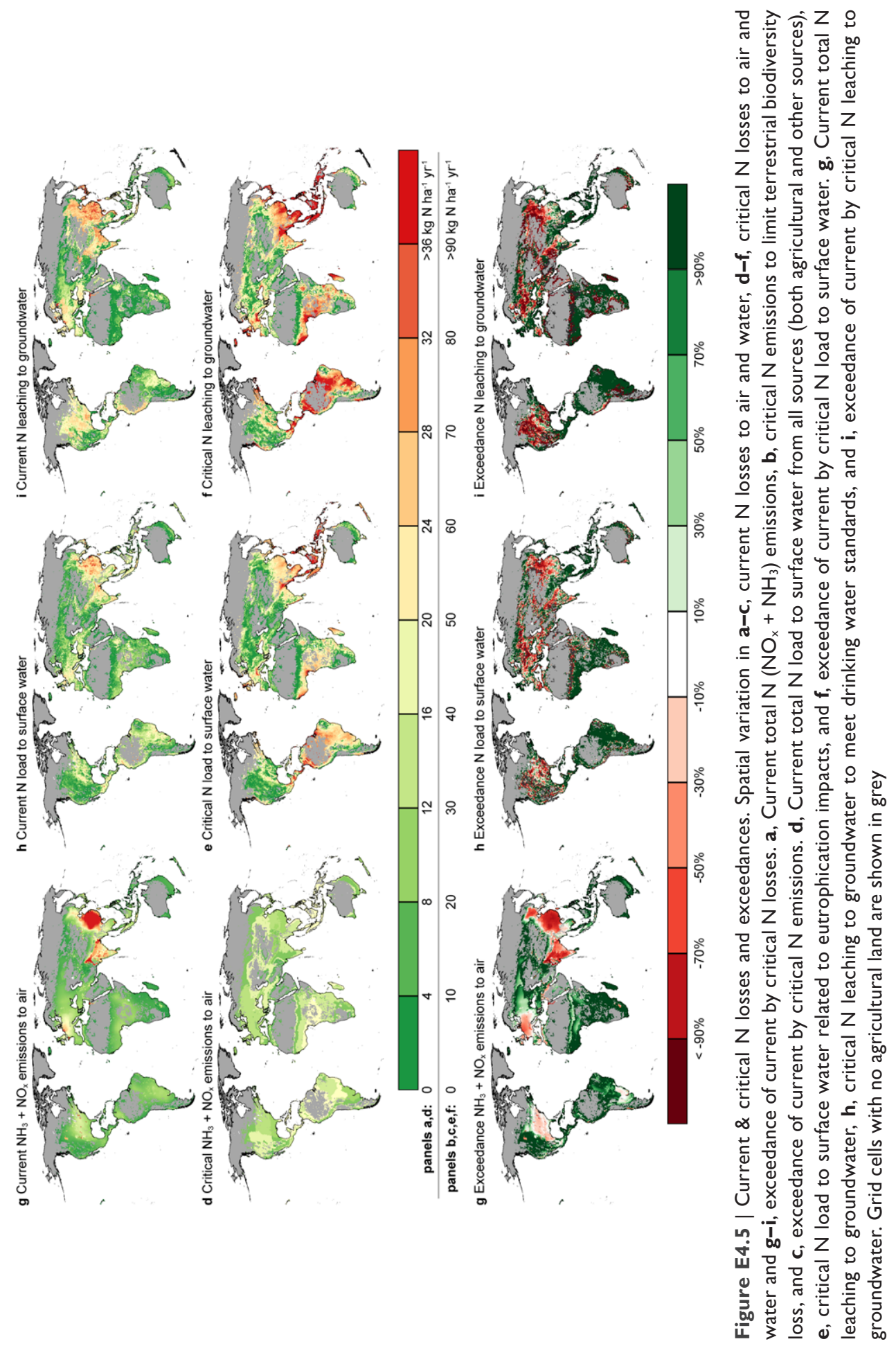



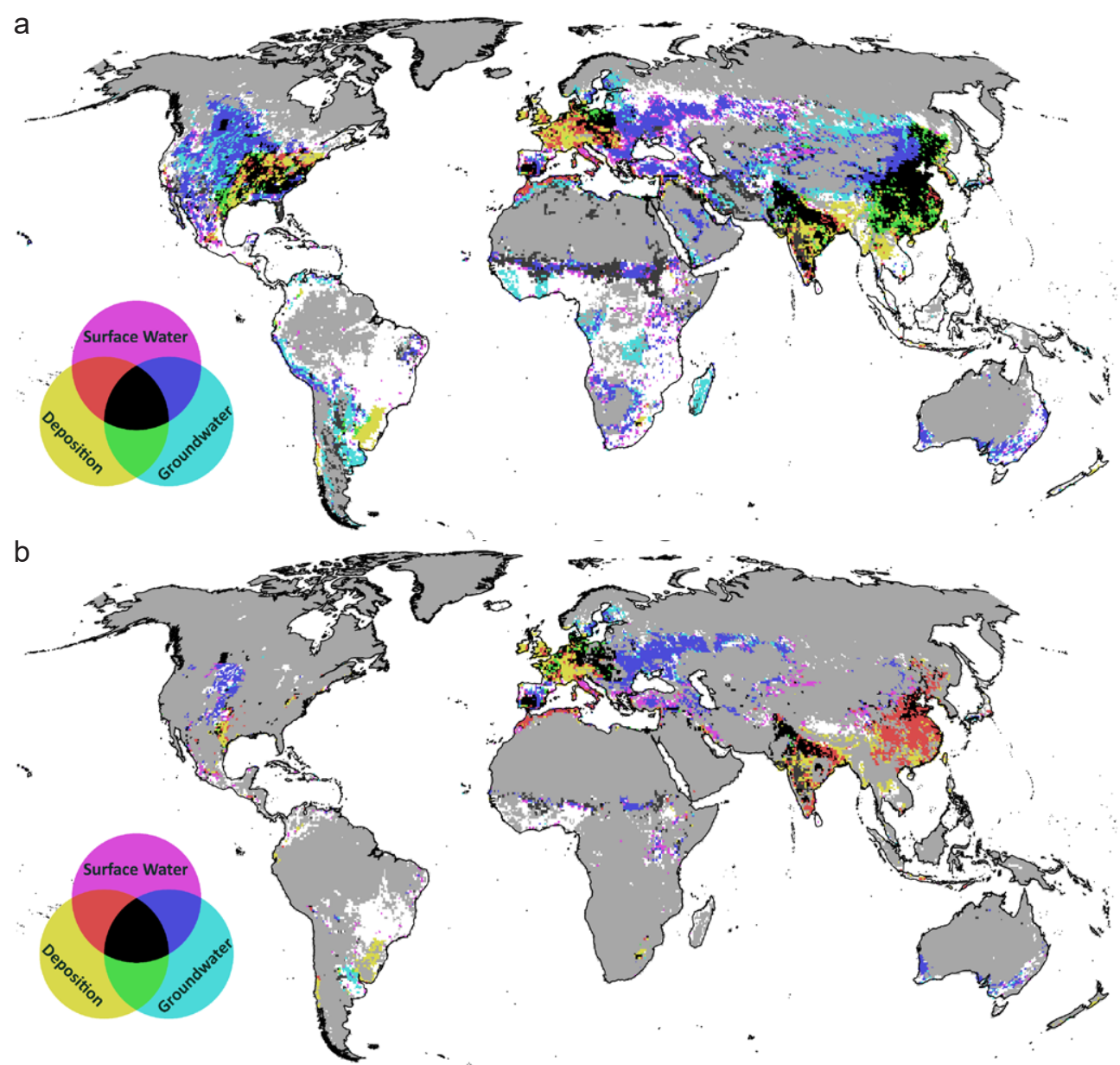

Figure E4.6 | Threshold exceedance per impact type. Exceedance of thresholds for three N-related environmental impacts (critical deposition to limit terrestrial biodiversity loss, critical $\mathrm{N}$ load to surface water to limit eutrophication, and critical $\mathrm{N}$ leaching to groundwater to meet drinking water standards) for $\mathbf{a}$, arable land and $\mathbf{b}$, intensively managed grassland. Colours indicate how many and which of the thresholds is exceeded: none (white), one threshold (magenta, cyan, yellow), two thresholds (red, blue, green) or all thresholds (black); see legend for impact type per colour. Grey = areas with no arable land / intensively managed grassland. 
a

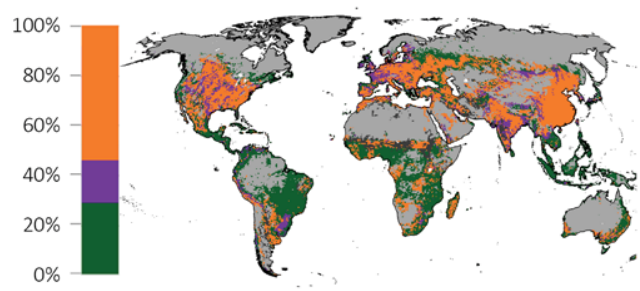

C

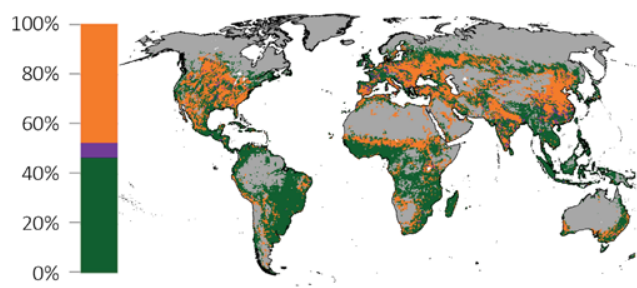

$0 \%$ b

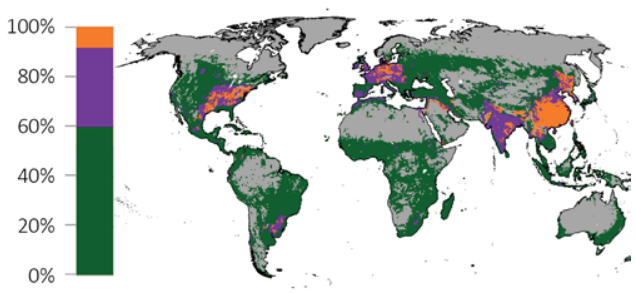

d

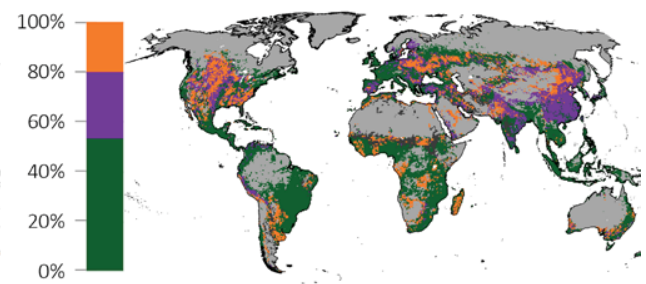

\section{f}

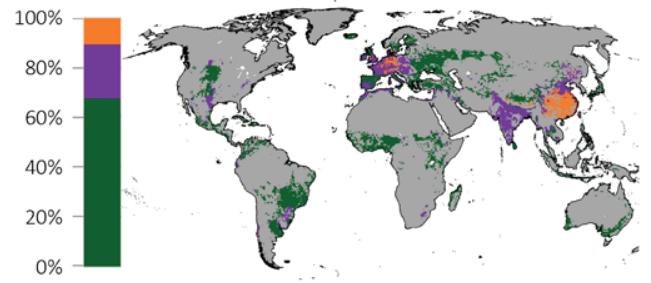

h

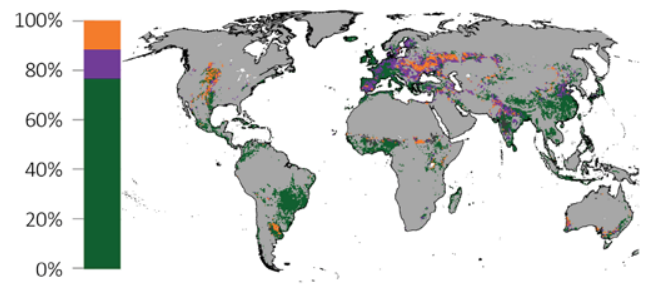

列
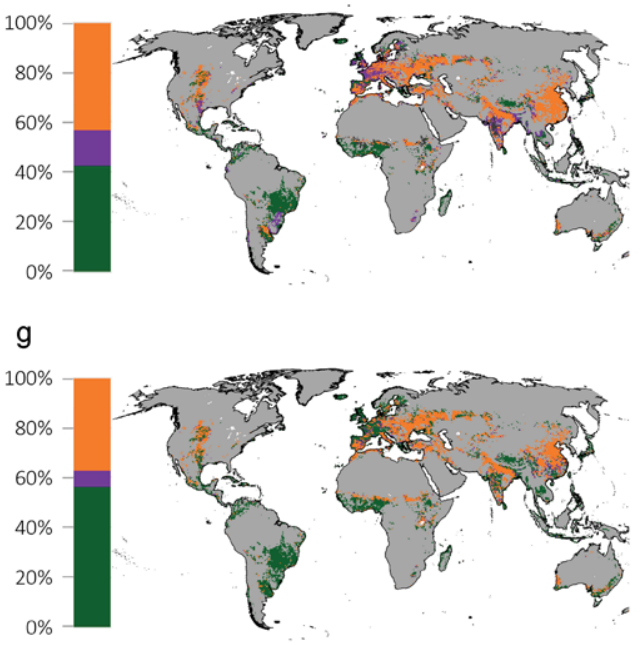

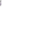

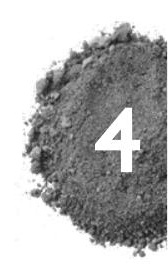

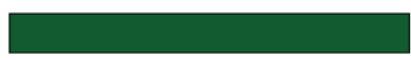

Threshold not exceeded (reducing $\mathrm{N}$ losses not necessary)

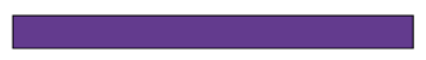

Threshold exceeded; reducing agricultural inputs sufficient to respect threshold
Threshold exceeded; reducing agricultural inputs alone not sufficient to respect threshold (non-agricultural $\mathrm{N}$ losses alone exceed threshold)

Figure E4.7 | Option space for agricultural $\mathrm{N}$ loss reductions. Possibilities for respecting environmental thresholds by reducing agricultural $\mathbf{N}$ inputs alone on $\mathbf{a}-\mathbf{d}$, arable land and $\mathbf{e}-\mathbf{h}$, intensively managed grassland. a,e, all thresholds combined, b,f, critical deposition to limit terrestrial biodiversity loss, $\mathbf{c , g}$, critical $\mathrm{N}$ load to surface water to limit eutrophication and $\mathbf{d , h}$, critical $\mathrm{N}$ leaching to groundwater to meet drinking water standards. Bars show the share of land within each category. Grey = no arable land / intensively managed grassland. 

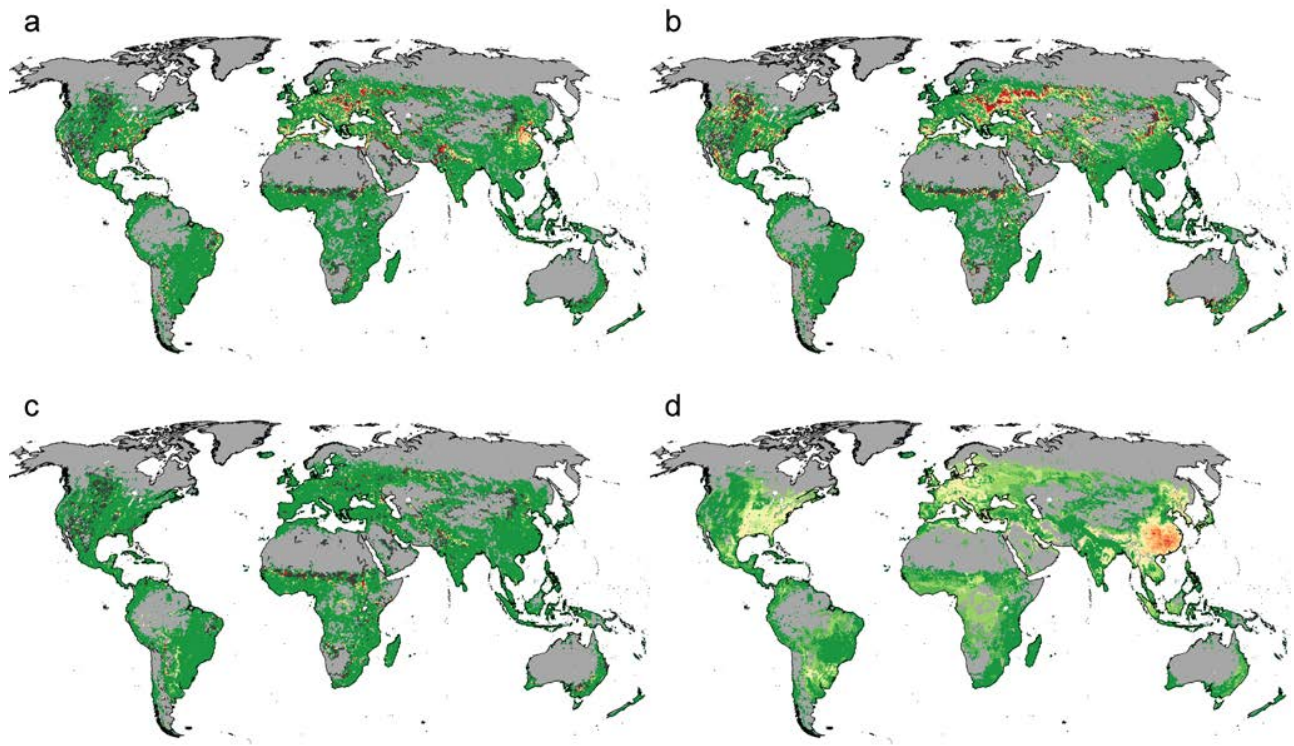

d
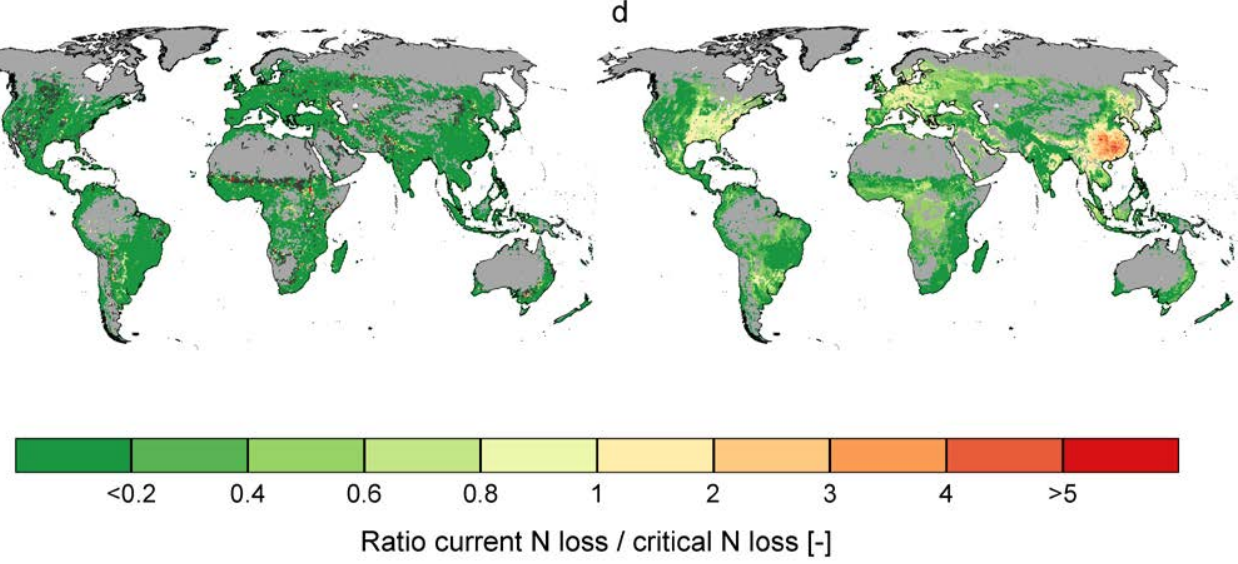

Figure E4.8 | Critical vs. current $\mathrm{N}$ losses from different sources. Ratio between current (year 2010) $\mathrm{N}$ losses from non-agricultural sources and total critical $\mathrm{N}$ losses. a, Ratio between current $\mathrm{N}$ load from wastewater and critical $\mathrm{N}$ load to surface water (to avoid eutrophication impacts). b, Ratio between current $\mathrm{N}$ load from erosion (both from agricultural land and natural land) and critical $\mathrm{N}$ load to surface water. c, Ratio between current $\mathrm{N}$ load from allochthonous organic matter and total critical $\mathrm{N}$ load to surface water. d, Ratio between current $\mathrm{NO}_{x}$ emissions and total critical $\mathrm{N}$ emissions to limit deposition on terrestrial ecosystems and resulting biodiversity loss. A ratio $>\mathrm{I}$ indicates that $\mathrm{N}$ losses from an individual source alone exceeds thresholds, and thus that thresholds for surface water $\mathrm{N}$ concentrations or $\mathrm{N}$ deposition are exceeded even at zero inputs to agriculture. Grey $=$ no agricultural land. 


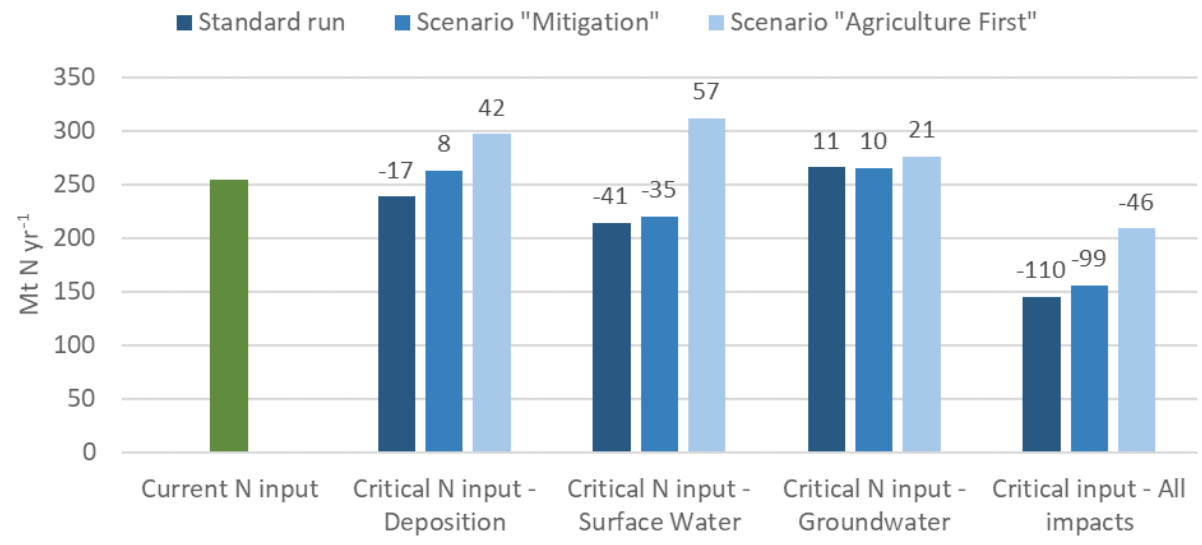

Figure E4.9 | Scenarios for non-agricultural nitrogen losses. Current (year 2010) N inputs and critical $\mathrm{N}$ inputs for three thresholds under different assumptions regarding non-agricultural $\mathrm{N}$ losses. In the scenario "Mitigation", $\mathrm{NO}_{x}$ emissions and wastewater $\mathrm{N}$ load to surface water are reduced by $50 \%$. In the Scenario "Agriculture First", all sources contributing to $\mathrm{N}$ losses (i.e., $\mathrm{NO}_{x}$ emissions as well as $\mathrm{N}$ load from natural areas, point sources and erosion) are reduced to zero, meaning that agriculture can 'claim' the full environmental space. Numbers above bars show the absolute difference between critical

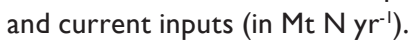



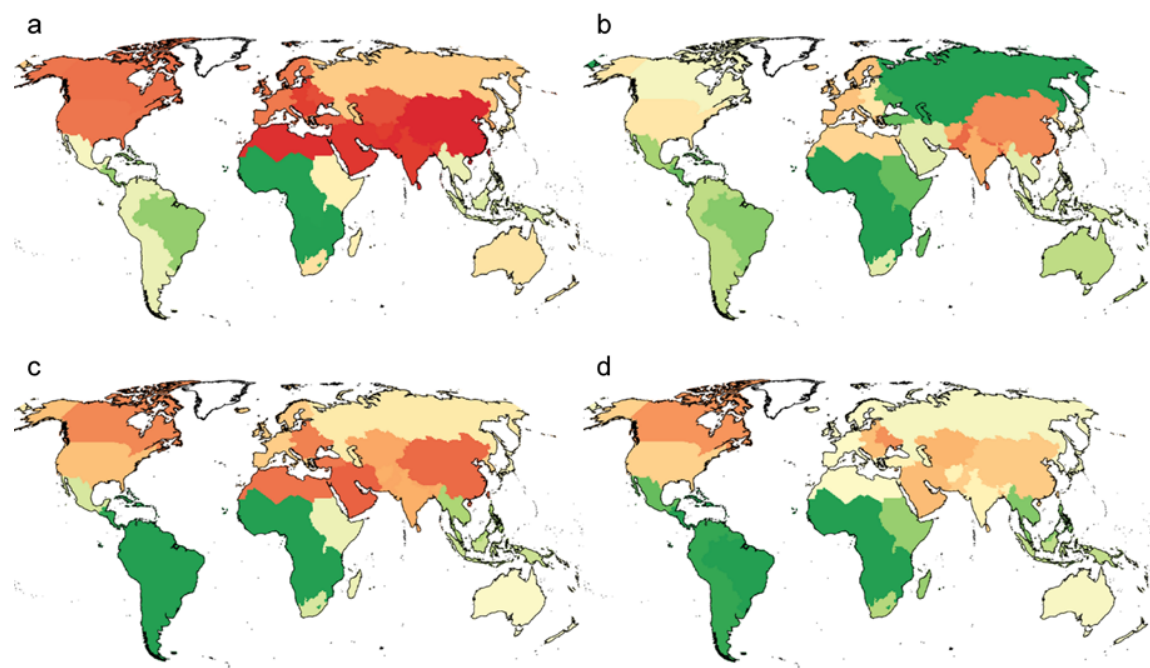

d
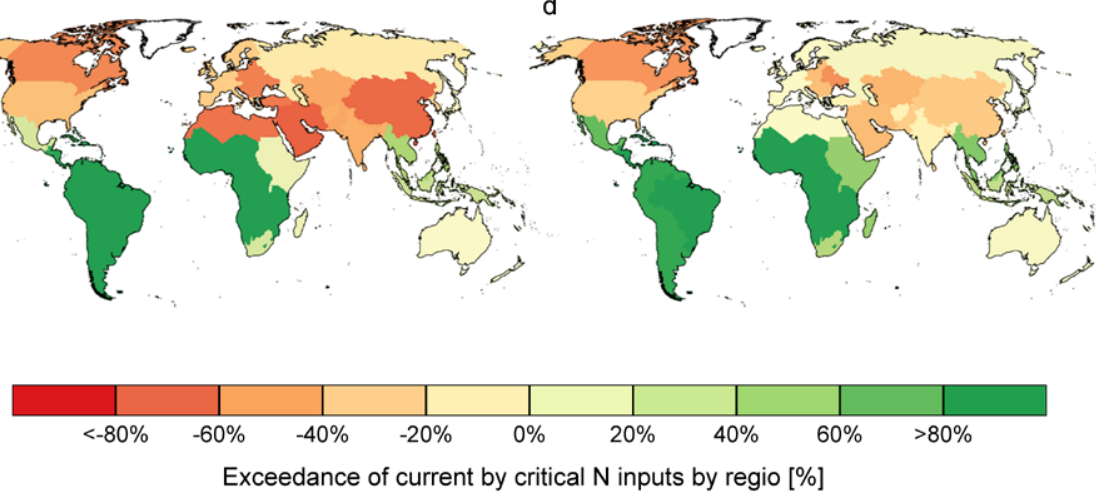

Figure E4.10 | Exceedance of current by critical $\mathrm{N}$ inputs by region. Exceedance of current (year 2010) $N$ inputs by critical $N$ inputs, for all agricultural land, aggregated to the level of 26 world regions represented in the IMAGE model. Percentages indicate by how much current inputs need to decrease (red) in order to respect environmental thresholds or may increase (green) to close yield gaps while still respecting thresholds for $\mathbf{a}$, all impacts combined, $\mathbf{b}$, critical deposition to limit terrestrial biodiversity loss, c, critical $\mathrm{N}$ load to surface water to limit eutrophication and $\mathbf{d}$, critical $\mathrm{N}$ leaching to groundwater to meet drinking water standards. Current and critical $\mathrm{N}$ inputs for each world region are shown in Table E4.2.

Table E4.I | Required nitrogen use efficiencies to reconcile environmental and crop production targets. Current nitrogen use efficiency (NUE) and required NUE to respect environmental thresholds while maintaining crop yields for $\mathbf{a}, \mathrm{N}$ concentration in runoff to surface water and $\mathbf{b}, \mathrm{N}$ concentration in leaching to groundwater. Current and required NUEs are shown for $\mathbf{i}$, all agricultural land where thresholds for either surface water or groundwater are exceeded and ii, only agricultural land where thresholds are exceeded and reducing agricultural inputs is sufficient to reduce $\mathrm{N}$ losses to the threshold value (i.e., thresholds are not exceeded by $\mathrm{N}$ losses from non-agricultural sources alone).

\begin{tabular}{llllllll}
\hline & \multicolumn{3}{c}{ a. Surface Water } & \multicolumn{3}{c}{ b. Groundwater } \\
\cline { 2 - 7 } & $\begin{array}{l}\text { Share of } \\
\text { ag. land }\end{array}$ & $\begin{array}{l}\text { Current } \\
\text { NUE }\end{array}$ & $\begin{array}{l}\text { Required } \\
\text { NUE }\end{array}$ & $\begin{array}{l}\text { Share of } \\
\text { ag. land }\end{array}$ & $\begin{array}{l}\text { Current } \\
\text { NUE }\end{array}$ & $\begin{array}{l}\text { Required } \\
\text { NUE }\end{array}$ \\
\hline $\begin{array}{l}\text { i. All land where thresholds are } \\
\text { exceeded }\end{array}$ & $50 \%$ & 0.48 & 0.95 & $38 \%$ & 0.47 & 0.74 \\
$\begin{array}{l}\text { ii. Only land where thresholds are } \\
\text { exceeded but reducing agricultural } \\
\text { inputs is sufficient to reduce N losses } \\
\text { to the threshold value }\end{array}$ & $6 \%$ & 0.49 & 0.59 & $22 \%$ & 0.43 & 0.56 \\
\hline
\end{tabular}


Table E4.2 | Current (year 2010) and critical $\mathrm{N}$ input rates to all agricultural land in view of thresholds related to three environmental impacts, and for all impacts combined. Both current and critical $\mathrm{N}$ inputs are given as rates $\left(\mathrm{kg} \mathrm{N} \mathrm{ha}^{-1} \mathrm{yr}^{-1}\right)$ rather than totals, for easier comparison between regions with different agricultural areas. Percentages in brackets show relative difference between critical and current $\mathrm{N}$ input.

\begin{tabular}{|c|c|c|c|c|c|c|c|c|c|}
\hline \multirow{3}{*}{$\begin{array}{l}\text { IMAGE region } \\
\text { Canada }\end{array}$} & \multicolumn{9}{|c|}{$\mathbf{N}$ input to all agricultural land (kg N ha- $\left.\mathbf{y r}^{\prime}\right)$} \\
\hline & \multirow{2}{*}{$\begin{array}{c}\text { Current } \\
\mathrm{N} \text { input }\end{array}$} & \multicolumn{2}{|c|}{$\begin{array}{l}\text { Critical } N \text { input: } \\
\text { Deposition }\end{array}$} & \multicolumn{2}{|c|}{$\begin{array}{l}\text { Critical } N \text { input: } \\
\text { Surface Water }\end{array}$} & \multicolumn{2}{|c|}{$\begin{array}{l}\text { Critical } N \text { input: } \\
\text { Groundwater }\end{array}$} & \multicolumn{2}{|c|}{$\begin{array}{l}\text { Critical } N \text { input: } \\
\text { All impacts }\end{array}$} \\
\hline & & 83 & $(+4 \%)$ & 38 & $(-53 \%)$ & 40 & $(-49 \%)$ & 32 & $(-59 \%)$ \\
\hline USA & 101 & 89 & $(-12 \%)$ & 66 & $(-34 \%)$ & 74 & $(-26 \%)$ & 42 & $(-58 \%)$ \\
\hline Mexico & 77 & 116 & $(+49 \%)$ & 93 & $(+20 \%)$ & 125 & $(+62 \%)$ & 81 & $(+4 \%)$ \\
\hline Central America & 95 & 160 & $(+69 \%)$ & 168 & $(+77 \%)$ & 189 & $(+99 \%)$ & 140 & $(+47 \%)$ \\
\hline Brazil & 98 & 151 & $(+54 \%)$ & 179 & $(+83 \%)$ & 185 & $(+89 \%)$ & 145 & $(+48 \%)$ \\
\hline Rest of South Am. & 101 & $|4|$ & $(+40 \%)$ & 195 & $(+94 \%)$ & 177 & $(+75 \%)$ & 111 & $(+10 \%)$ \\
\hline Northern Africa & 100 & 73 & $(-28 \%)$ & 42 & $(-58 \%)$ & 100 & $(-1 \%)$ & 24 & $(-76 \%)$ \\
\hline Western Africa & 42 & 93 & $(+124 \%)$ & 90 & $(+116 \%)$ & 93 & $(+123 \%)$ & 75 & $(+79 \%)$ \\
\hline Eastern Africa & 65 & 108 & $(+66 \%)$ & 71 & $(+9 \%)$ & 96 & $(+47 \%)$ & 60 & $(-8 \%)$ \\
\hline South Africa & 73 & 83 & $(+13 \%)$ & 88 & $(+20 \%)$ & 100 & $(+37 \%)$ & 61 & $(-16 \%)$ \\
\hline Western Europe & $|5|$ & 98 & $(-36 \%)$ & 108 & $(-28 \%)$ & 150 & $(-1 \%)$ & 65 & $(-57 \%)$ \\
\hline Central Europe & 116 & 98 & $(-15 \%)$ & 53 & $(-55 \%)$ & 75 & $(-35 \%)$ & 31 & $(-73 \%)$ \\
\hline Turkey & 87 & 142 & $(+63 \%)$ & 38 & $(-57 \%)$ & 81 & $(-7 \%)$ & 32 & $(-63 \%)$ \\
\hline Ukraine region & 66 & 117 & $(+76 \%)$ & 30 & $(-55 \%)$ & 33 & $(-50 \%)$ & 21 & $(-68 \%)$ \\
\hline Central Asia & 58 & 106 & $(+81 \%)$ & 33 & $(-44 \%)$ & 36 & $(-39 \%)$ & 19 & $(-68 \%)$ \\
\hline Russia region & 37 & 79 & $(+116 \%)$ & 32 & $(-12 \%)$ & 38 & $(+4 \%)$ & 26 & $(-29 \%)$ \\
\hline Middle East & 94 & 106 & $(+13 \%)$ & 35 & $(-63 \%)$ & 60 & $(-36 \%)$ & 23 & $(-75 \%)$ \\
\hline India & 184 & 95 & $(-48 \%)$ & 108 & $(-4 \mid \%)$ & $17 \mid$ & $(-7 \%)$ & 49 & $(-73 \%)$ \\
\hline Korea region & 148 & 112 & $(-24 \%)$ & 110 & $(-26 \%)$ & 149 & $(+\mid \%)$ & 82 & $(-45 \%)$ \\
\hline China region & 167 & 79 & $(-52 \%)$ & 65 & $(-61 \%)$ & 118 & $(-29 \%)$ & 31 & $(-81 \%)$ \\
\hline South-eastern Asia & 144 & 168 & $(+16 \%)$ & 202 & $(+40 \%)$ & 221 & $(+53 \%)$ & 158 & $(+10 \%)$ \\
\hline Indonesia region & $|3|$ & 159 & $(+22 \%)$ & 165 & $(+26 \%)$ & 170 & $(+30 \%)$ & 156 & $(+19 \%)$ \\
\hline Japan & 254 & 266 & $(+4 \%)$ & 244 & $(-4 \%)$ & 271 & $(+7 \%)$ & 220 & $(-13 \%)$ \\
\hline Oceania & 48 & 63 & $(+33 \%)$ & 48 & $(+0 \%)$ & 49 & $(+2 \%)$ & 40 & $(-15 \%)$ \\
\hline Rest of South Asia & 274 & 97 & $(-65 \%)$ & 154 & $(-44 \%)$ & 201 & $(-27 \%)$ & 61 & $(-78 \%)$ \\
\hline Rest of Southern Afr. & 29 & 77 & $(+|6| \%)$ & 67 & $(+\mid 28 \%)$ & 65 & $(+\mid 22 \%)$ & 60 & $(+105 \%)$ \\
\hline World & 110 & 103 & $(-7 \%)$ & 93 & $(-16 \%)$ & 115 & $(+4 \%)$ & 63 & $(-43 \%)$ \\
\hline
\end{tabular}





\section{Chapter 5}

Global-scale impacts of nitrogen deposition on tree carbon sequestration in tropical, temperate and boreal forests: a meta-analysis

Published as: Lena schulte Uebbing \& Wim de Vies (2018). Global Change Biology, $123(4): 142-156$. 


\section{Abstract}

Elevated nitrogen $(\mathrm{N})$ deposition may increase net primary productivity in $\mathrm{N}$-limited terrestrial ecosystems and thus enhance the terrestrial carbon (C) sink. To assess the magnitude of this $\mathrm{N}$-induced $\mathrm{C}$ sink, we performed a meta-analysis on data from forest fertilization experiments to estimate $\mathrm{N}$-induced $\mathrm{C}$ sequestration in aboveground tree woody biomass, a stable $\mathrm{C}$ pool with long turnover times. Our results show that boreal and temperate forests responded strongly to $\mathrm{N}$ addition and sequestered on average an additional 14 and $13 \mathrm{~kg} \mathrm{C}$ per $\mathrm{kg} \mathrm{N}$ in aboveground woody biomass, respectively. Tropical forests, however, did not respond significantly to $\mathrm{N}$ addition. The common hypothesis that tropical forests do not respond to $\mathrm{N}$ because they are phosphorus-limited could not be confirmed, as we found no significant response to phosphorus addition in tropical forests. Across climate zones, we found that young forests responded more strongly to $\mathrm{N}$ addition, which is important as many previous meta-analyses of $\mathrm{N}$ addition experiments rely heavily on data from experiments on seedlings and young trees. Furthermore, the $\mathrm{C}-\mathrm{N}$ response (defined as additional mass unit of $\mathrm{C}$ sequestered per additional mass unit of $\mathrm{N}$ addition) was affected by forest productivity, experimental $\mathrm{N}$ addition rate, and rate of ambient $\mathrm{N}$ deposition. The estimated $\mathrm{C}-\mathrm{N}$ responses from our meta-analysis were generally lower that those derived with stoichiometric scaling, dynamic global vegetation models, and forest growth inventories along $\mathrm{N}$ deposition gradients. We estimated $\mathrm{N}$-induced global $\mathrm{C}$ sequestration in tree aboveground woody biomass by multiplying the $\mathrm{C}-\mathrm{N}$ responses obtained from the metaanalysis with $\mathrm{N}$ deposition estimates per biome. We thus derived an $\mathrm{N}$-induced global $\mathrm{C}$ sink of about 177 (112-243) $\mathrm{Tg} \mathrm{C} \mathrm{yr}^{-1}$ in above- and below-ground woody biomass, which would

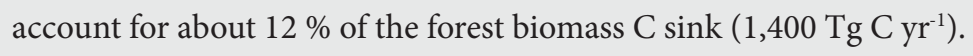

\section{I. Introduction}

The terrestrial biosphere takes up a substantial share of the carbon dioxide $\left(\mathrm{CO}_{2}\right)$ emitted by human activities, thereby mitigating climate change (Le Quéré et al., 2015; Myneni et al., 2001; Pan et al., 2011a). The amount of $\mathrm{CO}_{2}$ absorbed by the terrestrial biosphere is driven by, amongst others, changes in climate, land use, $\mathrm{CO}_{2}$ concentrations and nitrogen $(\mathrm{N})$ deposition (Sitch et al., 2015). Atmospheric $\mathrm{N}$ deposition on forests has increased strongly over the last decades as a result of $\mathrm{N}$ use in agriculture and the emission of $\mathrm{N}$ compounds from combustion processes (Fowler et al., 2013; Galloway et al., 2008). The terrestrial carbon (C) and $\mathrm{N}$ cycles are closely linked: most terrestrial ecosystems are $\mathrm{N}$ limited, and increased $\mathrm{N}$ deposition thus stimulates biomass production and potentially terrestrial $\mathrm{C}$ sequestration 
(Bala et al., 2013; LeBauer and Treseder, 2008; Thomas et al., 2010; Zaehle, 2013). Only few global earth system models, however, include a representation of the $\mathrm{N}$ cycle and can assess impacts of $\mathrm{N}$ limitation and $\mathrm{N}$ deposition on the global $\mathrm{C}$ sink. The size of nitrogen's contribution to the global terrestrial $\mathrm{C}$ sink is still debated, and estimates ranging from as low

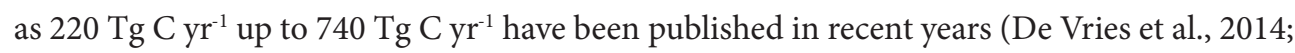
Fleischer et al., 2015; Jain et al., 2009; Zaehle et al., 2011).

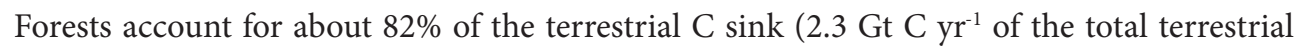
sink of 2.8 Gt C $\mathrm{yr}^{-1}$ for the period 2000-2009; Pan et al., 2011a; Le Quéré et al., 2015). At the global scale, forest soils and forest biomass both contain roughly equal amounts of $\mathrm{C}$, but living biomass and dead wood accounts for about $75 \%$ of the $\mathrm{C}$ sequestered in forests (Ciais et al., 2008; Pan et al., 2011a). Even in regions where most $\mathrm{C}$ is contained in soils (i.e. where the soils is the largest $\mathrm{C}$ pool), biomass often still accounts for most of the additional sequestered C (i.e., biomass is the largest $\mathrm{C}$ sink). For example, for Europe it is estimated that while tree biomass accounts for only $35 \%$ of the forest $\mathrm{C}$ pool, $70 \%$ of the forest $\mathrm{C}$ sink can be ascribed to $\mathrm{C}$ sequestered in tree biomass and $30 \%$ to $\mathrm{C}$ sequestered in the soil (Janssens et al., 2003; Nabuurs et al., 2003). Naturally, this distribution varies between biomes (Luyssaert et al., 2007) and over time (Nabuurs et al., 2013).

The stimulating effect of $\mathrm{N}$ deposition on forest $\mathrm{C}$ sequestration can be estimated by multiplying total $\mathrm{N}$ deposition on forests with the $\mathrm{C}-\mathrm{N}$ response ratio of each forest ecosystem compartment. The $\mathrm{C}-\mathrm{N}$ response ratio (hereafter referred to as $\mathrm{C}-\mathrm{N}$ response) is defined as the additional mass unit of $\mathrm{C}$ sequestered per additional mass unit of $\mathrm{N}$ deposition. It is thus a measure of the efficiency with which forests use the additional $\mathrm{N}$. The size of the $\mathrm{N}$-induced $\mathrm{C}$ sink is mainly determined by $\mathrm{N}$-induced changes in $\mathrm{C}$ sequestration in pools with long turnover times: the tree C pool (wood) and the soil C pool (soil organic matter) (De Vries et al., 2014; Luyssaert et al., 2007; Nabuurs et al., 2003) (Figure 5.1). At decadal time scales (not accounting for large disturbances such as forest fires or harvest), $\mathrm{N}$-induced $\mathrm{C}$ sequestration in the tree $\mathrm{C}$ pool is determined by additional above- and below-ground woody biomass production (stem, branches and coarse roots). Nitrogen-induced $\mathrm{C}$ sequestration in the soil $\mathrm{C}$ pool is determined by inputs from additional above- and below-ground litter production (leaves and fine roots), and losses from soil respiration (Figure 5.1). The Net Ecosystem Production (NEP) is defined as the sum of the tree C pool and the soil C pool and thus reflects the total amount of $\mathrm{C}$ sequestered in an undisturbed forest ecosystem. The Net Biome Production (NBP) is defined as NEP minus C losses through disturbances such as harvest and fires and thus reflects long-term net $\mathrm{C}$ sequestration in the tree and soil pools. In this study, we focus on the tree $\mathrm{C}$ pool and how it responds to $\mathrm{N}$ addition. 
The forest $\mathrm{C}-\mathrm{N}$ response, sometimes also referred to as $\mathrm{N}$ use efficiency, has been estimated by several approaches, each with its own strength and weaknesses. A relatively simple approach to estimating the $\mathrm{C}-\mathrm{N}$ response is stoichiometric scaling. In this approach, an estimate of the fraction of deposited $\mathrm{N}$ retained in the forest ecosystem (retention fraction) is multiplied with $\mathrm{N}$ allocation fractions and C:N ratios of each ecosystem compartment (e.g., de Vries et al., 2014; Nadelhoffer et al., 1999). The approach thus can account for variations in $\mathrm{N}$ retention, $\mathrm{N}$ allocation, and $\mathrm{C}: \mathrm{N}$ ratios between ecosystems, but relies on accurate estimates of these parameters, which are not always available at the global scale. Also, the stoichiometric scaling approach assumes that $\mathrm{N}$ retention and allocation fractions and C:N ratios remain constant while these parameters might change over time under increasing levels of $\mathrm{N}$ deposition. Dynamic global vegetation models (DGVMs) have also been used to estimate C-N responses (e.g., Jain et al., 2009; Zaehle et al., 2011; Fleischer et al., 2015). The advantage of these models is that they can account for spatial and temporal variation in factors driving forest productivity (such as tree species, climate, $\mathrm{CO}_{2}$ concentration or soil texture). However, models do not capture all relevant processes, such as soil biological processes (Wieder et al., 2015) or limitations by other nutrients affecting $\mathrm{C}-\mathrm{N}$ responses. For example, hardly any of the current DGVMs include phosphorus (P) cycle dynamics, while $\mathrm{P}$ limitation of the terrestrial $\mathrm{C}$ sink can be important in the tropics and becomes increasingly important in regions with high $\mathrm{N}$ deposition rates (Braun et al., 2010; Peñuelas et al., 2013; Sitch et al., 2015). Finally, gradient studies assess C-N responses using large datasets, for example from growth observations at forest monitoring plots or eddy correlation measurements, to correlate forest productivity changes to environmental variables, including N deposition (e.g., de Vries et al., 2008; Fleischer et al., 2013; Laubhann et al., 2009; Magnani et al., 2007; Solberg et al., 2009; Thomas et al., 2010). The advantage of these studies is that they rely on actually observed changes and thus include all other factors affecting forest productivity. However, isolating the effect of $\mathrm{N}$ deposition is tricky as $\mathrm{N}$ deposition may covary with other environmental drivers such as climate and ozone exposure (Fleischer et al., 2013; Sutton et al., 2008).

Fertilization experiments are the most direct way to assess forest $\mathrm{C}-\mathrm{N}$ responses. In those experiments, $\mathrm{N}$ is added to an experimental forest plot and changes in ecosystem response parameters are measured over a period of time. Forest fertilization experiments have been conducted in many parts of the world and can provide powerful insights in the isolated effects of $\mathrm{N}$ deposition on forest $\mathrm{C}$ sequestration, and potential co-limitation by other nutrients, such as P (Vadeboncoeur, 2010). However, their results are only valid for the conditions at the specific location where the experiment has been performed. While some experiments show a strong stimulation of tree $\mathrm{C}$ sequestration resulting from $\mathrm{N}$ addition (e.g., Liu et al., 


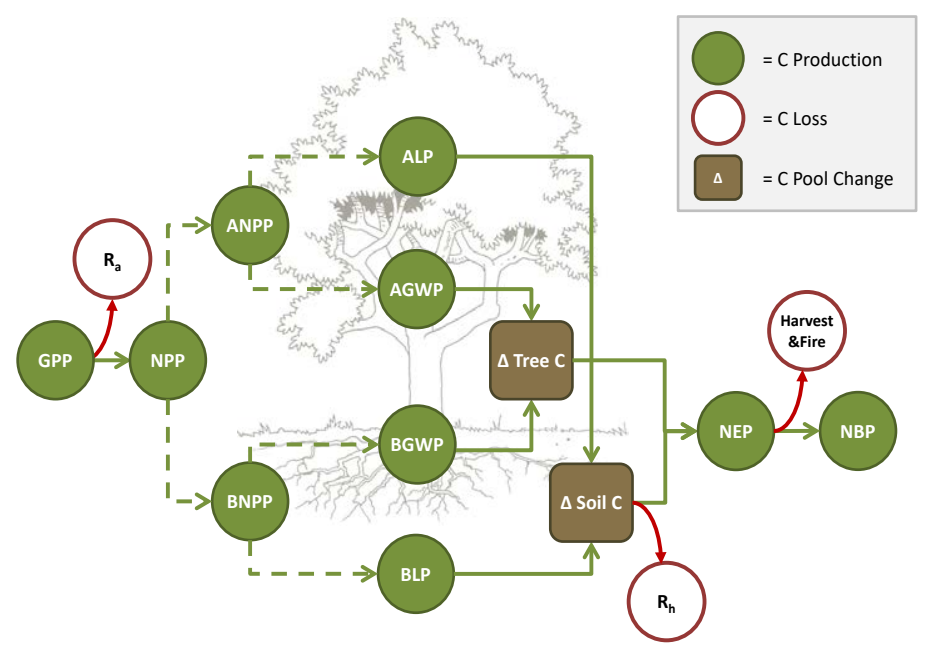

Figure 5.I | Conceptualization of the allocation of carbon assimilated through gross primary production (GPP) to the tree and the soil forest carbon pools. All circles and squares represent carbon fluxes (e.g.,

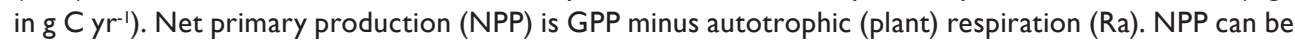
split up in aboveground NPP (ANPP) and belowground NPP (BNPP). Both ANPP and BNPP can be split up in a litter component (aboveground litter production $(A L P)=$ leaves, belowground litter production $(B L P)=$ fine roots) and a woody component (aboveground woody biomass production (AGWP) = stem and branches; belowground woody biomass production (BGWP) = coarse roots). Together, AGWP and BGWP form the inputs to the tree carbon pool (Tree C). ALP and BLP form inputs to the soil carbon pool (Soil C), from which carbon is lost through heterotrophic respiration (Rh). Based on De Vries et al., 2014.

2010a; Tanner et al., 1990), others find that $\mathrm{N}$ addition does not significantly affect tree C sequestration (e.g., Lovett et al., 2013).

Meta-analysis is a powerful tool to synthesize quantitative information from a large number of $\mathrm{N}$ addition experiments performed under different environmental and experimental conditions (Knorr et al., 2005) and thus allows to derive more general statements on the forest $\mathrm{C}$ sink response to $\mathrm{N}$ deposition from fertilization experiments. Several meta-analyses have assessed $\mathrm{N}$ addition effects on forest $\mathrm{C}$ fluxes and pools (see Table S5.1 for an overview). However, several limitations impede using results of these meta-analyses for estimating forest $\mathrm{C}-\mathrm{N}$ responses and thus the global $\mathrm{N}$-induced forest $\mathrm{C}$ sink. A first limitation is that many meta-analyses assess the effect of $\mathrm{N}$ addition on $\mathrm{C}$ fluxes, and thus results from these studies cannot be used to assess effect of $\mathrm{N}$ addition on the forest $\mathrm{C}$ pool, that is, the tree $\mathrm{C}$ pool and soil C pool. For example, many meta-analyses focus on $\mathrm{N}$ effects on aboveground or total net primary production (ANPP or NPP), and include observations of $\mathrm{N}$ addition effects on litter production, fine root production and woody biomass production (LeBauer and Treseder, 2008; Maynard et al., 2014; Tian et al., 2016; Vadeboncoeur, 2010; Xia and Wan, 2008). 
Furthermore, several meta-analyses have focused on $\mathrm{N}$ addition effects on (components of) soil respiration (Janssens et al., 2010; Knorr et al., 2005; Liu and Greaver, 2010; Lu et al., 2011; Zhou et al., 2014), but it is not possible to directly infer $\mathrm{N}$ addition effects on forest soil $\mathrm{C}$ sequestration from these studies as these studies generally do not look at the net effect of $\mathrm{N}$ on $\mathrm{C}$ inputs (above- and below-ground litter production) and losses.

A second limitation of previous meta-analyses is that nearly all of them report response ratios (for example, a $30 \%$ productivity increase after $\mathrm{N}$ addition) instead of absolute responses (e.g., $\mathrm{kg} \mathrm{C} \mathrm{ha}^{-1} \mathrm{yr}^{-1}$ ). This is true for several studies that focused on impacts of $\mathrm{N}$ addition on aboveground woody biomass production (AGWP) (Newton and Amponsah, 2006), tree C pool changes (Janssens et al., 2010) and soil C pool changes (Janssens et al., 2010; Lu et al., 2011; Nave et al., 2009). Using relative responses (ratios) as effect size in meta-analyses has the advantage that observations of fluxes of different magnitudes (for example, changes in litter production of tree seedlings in the order of tens of $\mathrm{kg} \mathrm{C} \mathrm{ha}^{-1} \mathrm{yr}^{-1}$ and changes in total biomass production in a mature tropical humid forest in the order of thousands of $\mathrm{kg} \mathrm{C}$ $\mathrm{ha}^{-1} \mathrm{yr}^{-1}$ ), as well as observations of responses measured in different units (for example, stem diameter increment in $\mathrm{cm} \mathrm{yr}^{-1}$ and fine root production in $\mathrm{g} \mathrm{C} \mathrm{m}^{-2} \mathrm{yr}^{-1}$ ) can be grouped, as all responses are normalized to \% increase. However, as those meta-analyses neither report absolute responses nor give information on sensitivity of the response parameters to the amount of $\mathrm{N}$ added (i.e., \% NPP increase or $\mathrm{kg} \mathrm{C}$ sequestered per $\mathrm{kg} \mathrm{N}$ added), their results cannot be used to estimate $\mathrm{C}-\mathrm{N}$ responses and thus the global $\mathrm{N}$-induced forest $\mathrm{C}$ sink. The few meta-analyses that report absolute $\mathrm{C}$ pool changes per $\mathrm{kg} \mathrm{N}$ addition are limited to certain regions or based on a limited amount of studies. For example, Liu and Greaver (2009) estimated that forests sequester $24.5 \pm 8.7 \mathrm{~kg}$ C per $\mathrm{kg} \mathrm{N}$ in tree biomass and soils, but their meta-analysis is based on only 9 experimental studies in the US and does not distinguish $\mathrm{N}$-induced $\mathrm{C}$ fluxes changes in forest compartments with short and long turnover times.

Another limitation of previous meta-analyses is that they hardly ever consider the effect of stand age on $\mathrm{N}$-induced changes in $\mathrm{C}$ fluxes. This is especially important as most published $\mathrm{N}$ fertilization experiments are performed on seedlings or very young trees, which can be assumed to respond more strongly to $\mathrm{N}$ due to lower $\mathrm{N}$ recycling rates and high $\mathrm{N}$ requirements per unit of biomass production (Sun et al., 2016). The only meta-analysis on $\mathrm{N}$ addition effects on forests that assessed the influence of stand age did indeed find a decrease in $\mathrm{N}$ response with increasing stand age (Vadeboncoeur, 2010), though the effect was not significant when including other factors in a multiple regression. A global-scale meta-analysis of the effect of $\mathrm{N}$ addition on $\mathrm{C}$ sequestration in woody biomass and the factors affecting this response, which is crucial for predicting the long-term response of the terrestrial $\mathrm{C}$ sink based on results from forest fertilization experiments, is currently lacking. 
While $\mathrm{N}$ is generally assumed to be the most limiting nutrient in most forest ecosystems (LeBauer and Treseder, 2008; Vitousek et al., 1997), forests also require other elements for growth, such as $\mathrm{P}$. High levels of $\mathrm{N}$ deposition over the last decades have not been matched by equal increases in $\mathrm{P}$ inputs, and resulting nutritional imbalances may ultimately limit forest growth (Braun et al., 2010; Jonard et al., 2015; Peñuelas et al., 2013). Growth enhancement following $\mathrm{N}$ additions has been shown to increase $\mathrm{P}$ demand and decrease plant $\mathrm{P}$ concentrations and N:P ratios ( $\mathrm{Li}$ et al., 2016). A global meta-analysis of nutrient limitations in terrestrial, freshwater and marine systems found strong evidence for co-limitation by $\mathrm{N}$ and $\mathrm{P}$ in all ecosystems (stronger response to $\mathrm{N}$ and $\mathrm{P}$ addition than to either one of these nutrients applied in isolation) (Elser et al., 2007), while a meta-analysis in northern hardwood forests found some evidence for co-limitation by $\mathrm{P}$ and calcium (Vadeboncoeur, 2010). In general, tropical forests are considered to be less responsive to $\mathrm{N}$ addition, as their old and weathered soils are thought to cause P limitation (Vitousek et al., 1993).

In this paper, we present for the first time a meta-analysis of the effects of $\mathrm{N}$ and $\mathrm{P}$ addition on $\mathrm{C}$ sequestration in tree woody biomass in boreal, temperate and tropical forests and assess factors affecting the variation in this effect. In order to test whether P limitation can explain a lack of response to $\mathrm{N}$ addition in tropical forests (due to inherent $\mathrm{P}$ limitation) and in temperate and boreal forests (due to high $\mathrm{N}$ inputs), we also included experiments that assess $\mathrm{P}$ addition effects on tree woody biomass. Our major aim is to answer the following questions: (1) How does woody biomass production respond to $\mathrm{N}$ and $\mathrm{P}$ addition (both absolute response per unit of $\mathrm{N}$ or $\mathrm{P}$ addition and relative response)? (2) How is the $\mathrm{C}-\mathrm{N}$ (or C-P) affected by stand characteristics (biome, forest net primary production (NPP), stand age, ambient $\mathrm{N}$ deposition) and experimental factors ( $\mathrm{N}$ or $\mathrm{P}$ addition level, form of $\mathrm{N}$ fertilizer)? and (3) What is the contribution of $\mathrm{N}$ deposition to the global forest $\mathrm{C}$ sink?

\subsection{Materials and methods}

Meta-analysis is a method that quantitatively synthesizes results from many studies (Hedges et al., 1999). We followed the steps for meta-analysis described in Borenstein et al. (2009).

\subsection{Identification of literature, data selection and data extraction}

An initial search in Scopus using a specific search string (see Table S5.2) led to 2,115 results. From these initial search results, we selected publications that met the following criteria: (i) the experiment was performed on natural forests or forest plantations older than 10 years at the start of the experiment (ii) the experiment included a control treatment, (iii) the 
publication reported above- or below-ground woody biomass production (AGWP or BGWP) in $\mathrm{kg} \mathrm{C} \mathrm{ha}^{-1} \mathrm{yr}^{-1}$, or a response that could be used to estimate AGWP or BGWP in $\mathrm{kg} \mathrm{C} \mathrm{ha-1}$ $\mathrm{yr}^{-1}$, (iv) the publication reported a measure of variance of the response, (v) the response variables were measured for at least one year after the first fertilization, (vi) response variables were measured on plants that represent $90 \%$ or more of ecosystem biomass. We identified 25 publications containing 70 observations for $\mathrm{N}$ addition experiments and 9 publications containing 28 observations for $\mathrm{P}$ addition experiments for use in our meta-analysis. As hardly any of the studies reported BGWP, we restricted our analysis to AGWP.

Data on woody biomass increment in the fertilized and control plots were extracted from the selected publications, either directly from tables and/or text or from figures using Plot Digitizer 2.6.6 (http://plotdigitizer.sourceforge.net). If required data were not reported in the publication, we e-mailed authors and asked them to provide us with additional data.

Several publications did not provide data on woody biomass production directly, but reported data that could be used to estimate it. If publications provided data on volumetric increments (e.g., $\mathrm{m}^{3} \mathrm{ha}^{-1} \mathrm{yr}^{-1}$ ), we multiplied those values with species-specific wood densities obtained from a global wood density database (http://db.worldagroforestry.org//wd) and a C content of $50 \%$ to calculate AGWP in $\mathrm{kg} \mathrm{C} \mathrm{ha}^{-1}$. If publications provided data on AGWP at tree level, we multiplied those values with plot-specific tree densities to obtain a per-area estimate.

If a publication reported data for several treatments (e.g., several levels of $\mathrm{N}$ addition) or for several study sites (e.g., several sites along an elevation gradient), those treatments were included as independent observations (in accordance with other meta-analyses, see e.g. Zhou et al., 2014). If data on woody biomass increment from several years were reported, we calculated the average annual response over the longest period for which data were available.

For each observation, we included additional information on characteristics of the experimental plot (latitude and longitude, tree species, age) and the experiment ( $\mathrm{N}$ addition level, experimental duration, form of $\mathrm{N}$ fertilizer, etc.). Table S5.3 provides additional information on the experimental sites (including country, location, forest type, etc.) while Tables S5.4 and S5.5 provide additional information on the experimental treatments for the $70 \mathrm{~N}$ addition experiments and $28 \mathrm{P}$ addition experiments, respectively. We classified each forest as either "young" (10-20 years), "intermediate" (20-50 years) or "old" (> 50 years), based on information on stand age provided in the publication. If stand age was not given, we classified a forest as belonging to one of the three age classes based on the available information (e.g., a 'mature' forest was considered old). Information on background $\mathrm{N}$ deposition was assessed at each plot by an overlay with $\mathrm{NH}_{\mathrm{x}}$ and $\mathrm{NO}_{\mathrm{x}}$ deposition simulated with the TM5 atmospheric model on a $1^{\circ} \mathrm{x} 1^{\circ}$ grid for the year 2000 (Dentener et al., 2006). 
Each experimental location was categorized as either "tropical and subtropical forest", "temperate forest" or "boreal forest" by overlaying coordinates of experimental plots with a map of terrestrial ecoregions (Olson et al., 2001; see Figure S5.1). For more information on classification of ecoregions, see Supplementary Text.

\subsubsection{Meta-analysis}

For each individual observation, we calculated three different effect sizes and their variances (see (Borenstein et al., 2009; Hedges et al., 1999). For simplicity we refer to the effects of $\mathrm{N}$ addition in the following only; $\mathrm{P}$ addition effects were calculated in exactly the same way.

(1) The absolute effect of $\mathrm{N}$ addition (AE) as:

$$
A E=\bar{X}_{N}-\bar{X}_{C}
$$

where $\mathrm{X}_{\mathrm{N}}$ and $\mathrm{X}_{\mathrm{C}}$ are the mean aboveground woody biomass $\mathrm{C}$ increments for the $\mathrm{N}$ addition and control plot, respectively (in $\mathrm{g} \mathrm{C} \mathrm{m}^{-2} \mathrm{yr}^{-1}$ ), and its variance as:

$$
\begin{aligned}
& v=\frac{n_{N}+n_{C}}{n_{N} * n_{C}} * S_{\text {pooled }} \\
& S_{\text {pooled }}=\sqrt{\frac{\left(n_{N}-1\right) s_{N}^{2}+\left(n_{C}-1\right) s_{C}^{2}}{n_{N}+n_{C}-2}}
\end{aligned}
$$

where $n_{N}$ and $n_{C}$ are the number of replicates for the $\mathrm{N}$ addition and the control treatment, respectively and $\mathrm{s}_{\mathrm{N}}$ and $\mathrm{s}_{\mathrm{C}}$ are the sample standard deviations for the $\mathrm{N}$ addition and the control treatment, respectively.

(2) The absolute sensitivity to $\mathrm{N}$ addition (AS) as:

$$
A S=\frac{\left(\bar{X}_{N}-\bar{X}_{C}\right)}{N_{\text {add }}}
$$

where $\mathrm{N}_{\text {add }}$ is the average amount of $\mathrm{N}$ fertilizer addition over the experimental period in $\mathrm{kg}$ $\mathrm{N} \mathrm{ha}^{-1} \mathrm{yr}^{-1}$, calculated as the total amount of $\mathrm{N}$ added to the treated plots divided by the duration of the observation period.

(3) The relative response to $\mathrm{N}$ addition, calculated as the log response ratio:

$$
\ln \_R=\ln \left(\frac{\bar{X}_{N}}{\bar{X}_{C}}\right)
$$

and its variance as:

$$
V_{\text {lnRR }}=S_{\text {pooled }}^{2}\left(\frac{1}{n_{N}\left(X_{N}\right)^{2}}\right)+\left(\frac{1}{n_{C}\left(X_{C}\right)^{2}}\right)
$$


Meta-analysis was performed in R 3.1.3 (R Core Team, 2019) with the metafor package (Viechtbauer, 2010). We fitted both random- and mixed-effects models using climate zone, productivity (NPP), stand age, $\mathrm{N}$ addition rate, source of $\mathrm{N}$ fertilizer and ambient $\mathrm{N}$ deposition as moderators. As we did not have data on NPP for most plots, we used aboveground woody biomass production (AGWP) in the control plot as a proxy for NPP. The random effects model calculates the mean effect size as the weighted mean of individual effect sizes, using the inverse of the sum of the within-study variance (due to sampling error) and between-study variance (due to variation in experimental conditions) as weights (Borenstein et al., 2009). The Der Simonian and Laird method was used to calculate betweenstudy variances. The $95 \%$ confidence interval for each mean effect size was calculated as the effect size \pm 1.96 times the standard error. The effect of $\mathrm{N}$ on woody biomass increment was considered significant if the $95 \%$ confidence interval did not overlap with 1 (for the absolute effect and absolute sensitivity) or with 0 (for the response ratio).

\subsubsection{Estimation of the global nitrogen-induced carbon sink}

To calculate global $\mathrm{C}$ sequestration in forests' woody biomass resulting from $\mathrm{N}$ deposition, we multiplied average $\mathrm{C}-\mathrm{N}$ responses of (sub-)tropical, temperate and boreal forests with the amount of total ambient $\mathrm{N}\left(\mathrm{NH}_{\mathrm{x}}+\mathrm{NO}_{\mathrm{y}}\right)$ deposition on these forest types. Total $\mathrm{N}$ deposition per forest biome was estimated by first overlaying a land cover map (GLC, 2003) with a map of terrestrial ecoregions (Olson et al., 2001) to obtain a global map of forest classified into (sub-) tropical, temperate and boreal forests. We then made an overlay with gridded TM5 model estimates of total $\mathrm{NH}_{\mathrm{x}}+\mathrm{NO}_{\mathrm{y}}$ deposition for the year 2000 (Dentener et al., 2006) to estimate average $\mathrm{N}$ deposition rates per forest biome. For more information, see Supplementary Text.

\subsection{Results}

\subsection{Effects of nitrogen addition on aboveground woody biomass production} Across all studies, $\mathrm{N}$ addition significantly increased AGWP by about $11 \mathrm{~kg} C$ per $\mathrm{kg} \mathrm{N}$ ( $\mathrm{p}$ $<0.0001$, see Figure 5.2a). The effect of $\mathrm{N}$ addition on AGWP differed per climate zone. In boreal and temperature forests, average AGWP increased significantly by about 14 and 12 $\mathrm{kg}$ C per kg N, respectively. Contrarily, AGWP in tropical forests did not show a significant response to $\mathrm{N}$ addition ( $\mathrm{p}=0.6$ ). The relative increase in AGWP in response to $\mathrm{N}$ addition showed a similar pattern, with $\mathrm{N}$ addition increasing AGWP in boreal and temperate forests by 20 and $17 \%$ respectively, while tropical forests showed a non-significant increase of $5 \%$ (Figure 5.2b). 
(a)

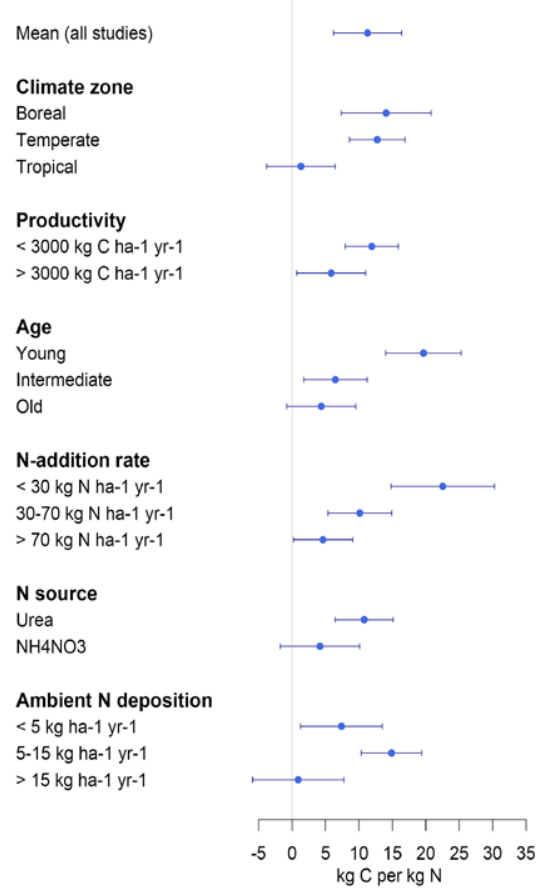

$E$ (n) (b)

$\begin{array}{ll}11.3(70) & \text { Mean (all studies) } \\ & \text { Climate zone } \\ 14.1(12) & \text { Boreal } \\ 12.7(41) & \text { Temperate } \\ 1.3(17) & \text { Tropical } \\ & \\ & \text { Productivity } \\ 11.9(40) & <3000 \mathrm{~kg} \mathrm{C} \text { ha-1 } \mathrm{yr}-1 \\ 5.8(30) & >3000 \mathrm{~kg} \mathrm{C} \text { ha-1 } \mathrm{yr}-1 \\ & \\ & \text { Age } \\ 19.7(22) & \begin{array}{l}\text { Young } \\ 6.5(28)\end{array} \\ 4.4(20) & \text { Intermediate }\end{array}$

$\mathrm{N}$-addition rate

$22.5(13)<30 \mathrm{~kg} \mathrm{~N}$ ha-1 $\mathrm{yr}-1$

10.1 (26) $30-70 \mathrm{~kg} \mathrm{~N}$ ha-1 yr-1

4.6 (31) $>70 \mathrm{~kg} \mathrm{~N}$ ha-1 yr-1

\section{N source}

10.8 (41) Urea

4.2 (18) $\quad \mathrm{NH} 4 \mathrm{NO} 3$

Ambient $\mathbf{N}$ deposition

$7.4(23) \quad<5 \mathrm{~kg} \mathrm{ha}-1 \mathrm{yr}-1$

$7.4(23)$
$14.9(36) \quad 5-15 \mathrm{~kg} \mathrm{ha}-1 \mathrm{yr}-1$

$0.9(11) \quad>15 \mathrm{~kg} \mathrm{ha}-1 \mathrm{yr}-1$
$E$ (n)

$1.16(70)$

$1.20(12)$

$1.17(41)$

$1.05(17)$

$1.24(40)$

$1.07(30)$

$1.27(22)$

$1.08(28)$

$1.12(20)$

$1.20(13)$

$1.20(26)$

$1.10(31)$

$1.16(41)$

$1.12(18)$

$1.11(23)$

$1.20(36)$

$1.04(11)$

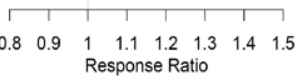

Figure 5.2 Nitrogen addition effects on forest aboveground woody biomass increment, expressed as $\mathbf{a}$, the absolute sensitivity to nitrogen $(\mathrm{N})$ addition in $\mathrm{kg}$ carbon $(\mathrm{C})$ per $\mathrm{kg} \mathrm{N}$ and, $\mathbf{b}$, the response ratio. Dots show mean effect sizes, bars are $95 \%$ confidence intervals. The last column shows mean effect sizes and the number of observations in parentheses.
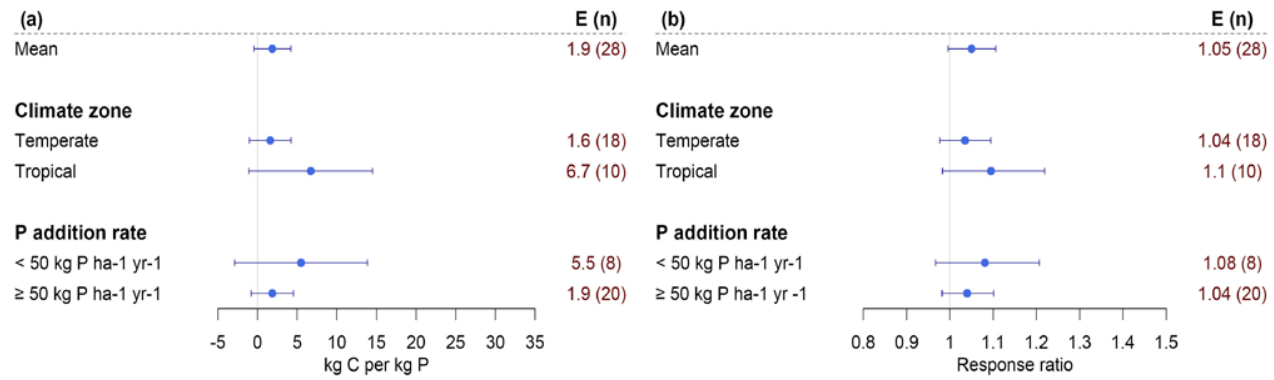

Figure 5.3 | Phosphorus addition effects on forest aboveground woody biomass increment, expressed as $\mathbf{a}$, the absolute sensitivity to phosphorus $(\mathrm{P})$ addition in $\mathrm{kg}$ carbon $(\mathrm{C})$ per $\mathrm{kg} \mathbf{P}$ and $\mathbf{b}$, the response ratio. Dots show mean effect sizes, bars are $95 \%$ confidence intervals. The last column shows mean effect sizes and the number of observations in parentheses. 
$\mathrm{N}$ addition led to a significantly stronger relative increase in AGWP in forests with a lower productivity (24\%) than in forests with a higher productivity (7\%). The absolute sensitivity to $\mathrm{N}$ addition was also higher in low-productivity forests $(11.9 \mathrm{~kg} \mathrm{C}$ per $\mathrm{kg} \mathrm{N})$ than in highproductivity forests $(5.8 \mathrm{~kg} \mathrm{C}$ per $\mathrm{kg} \mathrm{N})$, but here the difference was not significant $(\mathrm{p}=0.07)$.

Forest age had a strong effect on forests' absolute sensitivity to N addition, with AGWP in young forests (stand age $<20$ years) responding significantly stronger to $\mathrm{N}$ addition (19.7 $\mathrm{kg} \mathrm{C}$ per $\mathrm{kg} \mathrm{N}$ ) than AGWP in intermediate and old forests (6.5 and $4.4 \mathrm{~kg} \mathrm{C}$ per $\mathrm{kg} \mathrm{N}$, respectively). This difference is also apparent in the relative sensitivity: $\mathrm{N}$ addition increased AGWP in young forest stands by $27 \%$ versus 8 and $12 \%$ in intermediate and old forest stands, respectively (Figure 5.2b).

Nitrogen addition increased AGWP at all rates of $\mathrm{N}$ addition, but the efficiency with which additional $\mathrm{N}$ was converted to woody biomass decreased with increasing rates of $\mathrm{N}$ addition. While $\mathrm{N}$ addition rates below $30 \mathrm{~kg} \mathrm{ha}^{-1}$ increased AGWP by about $23 \mathrm{~kg} \mathrm{C}$ per $\mathrm{kg} \mathrm{N}, \mathrm{N}$ addition rates between 30 and $70 \mathrm{~kg} \mathrm{~N} \mathrm{ha}^{-1} \mathrm{yr}^{-1}$ only increased AGWP by $10 \mathrm{~kg} C$ per $\mathrm{kg} \mathrm{N}$, and $\mathrm{N}$ addition rates above $70 \mathrm{~kg} \mathrm{~N} \mathrm{ha}^{-1} \mathrm{yr}^{-1}$ increased AGWP by $5 \mathrm{~kg} \mathrm{C}$ per $\mathrm{kg} \mathrm{N}$ on average (Figure 5.2a). The relative increase in AGWP in response to $\mathrm{N}$ addition, however, was equal for $\mathrm{N}$ addition rates below $30 \mathrm{~kg} \mathrm{~N} \mathrm{ha}^{-1} \mathrm{yr}^{-1}$ and between 30 and $70 \mathrm{~kg} \mathrm{~N} \mathrm{ha}^{-1} \mathrm{yr}^{-1}$ (an increase of 20\%), while higher levels of $\mathrm{N}$ addition only led to a $10 \%$ increase in AGWP on average (Figure 5.2b).

Most of the experiments in the database used either ammonium nitrate $\left(\mathrm{NH}_{4} \mathrm{NO}_{3}\right)$ or urea as a source of N. Fertilization with urea increased AGWP by about $11 \mathrm{~kg}$ C per $\mathrm{kg} \mathrm{N}$ while fertilization with $\mathrm{NH}_{4} \mathrm{NO}_{3}$ increased $\mathrm{AGWP}$ by about $4 \mathrm{~kg} \mathrm{C}$ per $\mathrm{kg} \mathrm{N}$, but this difference was not significant $(\mathrm{p}=0.08$ ) (Figure 5.2). In terms of response ratios, there was hardly a difference.

Forest AGWP response to $\mathrm{N}$ addition was significantly lower at high rates of ambient $\mathrm{N}$ deposition (> $15 \mathrm{~kg} \mathrm{ha}^{-1} \mathrm{yr}^{-1}$ ) than at ambient $\mathrm{N}$ deposition levels between 5 and $15 \mathrm{~kg} \mathrm{~N}$ $\mathrm{ha}^{-1} \mathrm{yr}^{-1}$ (Figure 5.2). At even lower rates of ambient $\mathrm{N}$ deposition $\left(<5 \mathrm{~kg} \mathrm{~N} \mathrm{ha}^{-1} \mathrm{yr}^{-1}\right)$ forest AGWP response seemed to decline again, however, the difference with AGWP response at intermediate levels of $\mathrm{N}$ deposition was not significant. The response ratio follows a pattern similar to that of the absolute sensitivity; however, differences between groups are not significant here. 


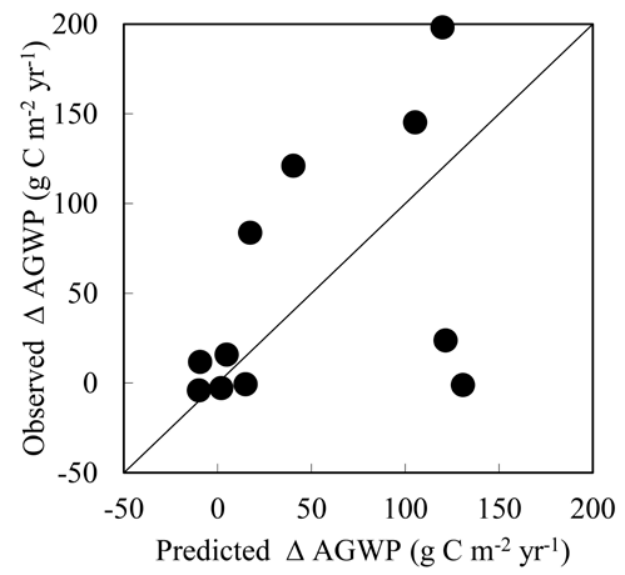

Figure 5.4 | Observed absolute changes in aboveground woody biomass production (AGWP) in response to nitrogen $(N)+$ phosphorus $(P)$ addition, and predicted AGWP response to NP addition, calculated as the sum of the individual response of $A G W P$ to $N$ and $P$ addition. Dots below the I:I line indicate an antagonistic effect (the effect of NP addition is smaller than the sum of the individual effects of $\mathrm{N}$ and $\mathrm{P}$ addition), while dots on or close to the line indicate an additive effect (the effect of NP addition is equal to the sum of the individual effects of $\mathrm{N}$ and $\mathrm{P}$ addition) and dots above the line indicate synergistic effects (the effect of NP addition is larger than the sum of the individual effects of $N$ and $P$ addition)

\subsubsection{Effects of phosphorus addition on aboveground woody biomass production}

Across all studies, $P$ addition did not significantly increase AGWP production $(p=0.1$, see Figure 5.3a). The mean response for tropical forests was higher ( $6.7 \mathrm{~kg} \mathrm{C}$ per $\mathrm{kg} \mathrm{P}$ ) than for temperate forests $(1.6 \mathrm{~kg} \mathrm{C}$ per $\mathrm{kg} \mathrm{P})$, but both responses were not significant. Similar to N, the $\mathrm{C}-\mathrm{P}$ response, also denoted as $\mathrm{P}$ use efficiency, seems to decrease with increasing rates of $\mathrm{P}$ addition (from $5.5 \mathrm{~kg} \mathrm{C}$ per $\mathrm{kg} \mathrm{P}$ at $\mathrm{P}$ addition levels below $50 \mathrm{~kg} \mathrm{P}^{-1} \mathrm{yr}^{-1}$ to $1.9 \mathrm{~kg} \mathrm{C}$ per $\mathrm{kg} \mathrm{P}$ at $\mathrm{P}$ addition levels above $\left.50 \mathrm{~kg} \mathrm{P} \mathrm{ha}^{-1} \mathrm{yr}^{-1}\right)$. However, again this difference was not significant.

The fact that tropical forests show no significant response to either $\mathrm{N}$ addition or $\mathrm{P}$ addition led to the question whether co-limitation by both nutrients could explain this lack of a response. We selected experiments from the database that included N, P and N+P (NP) treatments to test whether the effects of $\mathrm{N}$ and $\mathrm{P}$ are synergistic. In case of a synergistic effect, the effect of NP addition would be larger than the sum of the individual effects of $\mathrm{N}$ and $\mathrm{P}$ addition. Results are shown in Figure 5.4. Indeed, most sites seemed to be co-limited by $\mathrm{N}$ and $\mathrm{P}$ as the response to NP addition was higher than the combined responses to $\mathrm{N}$ and $\mathrm{P}$ addition. However, three plots also showed antagonistic effects. 


\subsubsection{Global nitrogen-induced forest carbon sink}

Based on an overlay with a global land cover map and spatially explicit estimates of $\mathrm{N}$ deposition for the year 2000, we estimated a global N-induced C sequestration in AGWP

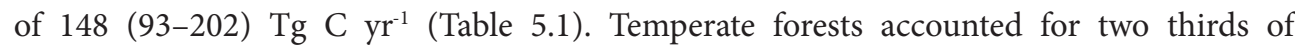

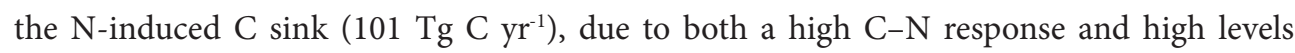
of atmospheric $\mathrm{N}$ deposition (ca. $7.8 \mathrm{~kg} \mathrm{~N} \mathrm{ha}^{-1} \mathrm{yr}^{-1}$ ). Boreal and tropical forests together accounted for one third of global $\mathrm{N}$-induced $\mathrm{C}$ sequestration (Table 5.1). Global C sequestration in tropical forests was limited by a very low (non-significant) $\mathrm{C}-\mathrm{N}$ response in aboveground woody biomass. $\mathrm{N}$-induced $\mathrm{C}$ sequestration in boreal forests was limited as $\mathrm{N}$ deposition levels in this region are relatively low (ca. $1.8 \mathrm{~kg} \mathrm{~N} \mathrm{ha}^{-1} \mathrm{yr}^{-1}$ ).

Our estimate of $\mathrm{N}$-induced $\mathrm{C}$ sequestration in woody biomass only includes aboveground woody biomass, as hardly any of the studies in our meta-analysis reported BGWP. The amount of C allocated to coarse roots is typically $20 \%$ of the C allocation to aboveground woody biomass, with little variation between biomes (Cleveland et al., 2013). If we assume that fertilization does not change biomass allocation fractions to tree compartments and thus the belowground woody biomass pool responds to $\mathrm{N}$ deposition in a similar manner (which is supported by several fertilization experiments, see for example Iivonen et al., 2006), we can calculate total woody biomass $\mathrm{C}$ increment due to $\mathrm{N}$ deposition by multiplying the AGWP estimate by 1.2. Our estimate of the total global $\mathrm{N}$-induced $\mathrm{C}$ sink in woody biomass thus obtained is 177 (112-243) Tg C $\mathrm{yr}^{-1}$ (see Table S5.6). This would account for about $12 \%$ of the forest biomass $\mathrm{C} \operatorname{sink}\left(1,400 \mathrm{Tg} \mathrm{C}^{-1} \mathrm{yc}^{-1}\right.$ according to Pan et al., 2011a).

\subsection{Discussion}

\subsection{Limitations of the research}

While meta-analysis attempts to infer conclusions from individual experimental results to a larger population, there are several limitations in doing this. First of all our database lacks geographical balance: while most forests are situated in boreal and tropical regions (FAO, 2016; see Table 5.1), by far the most observations in our database (41 out of 70) are from temperate forests (see Figure S5.1). Another limitation in extrapolating results from our meta-analysis to global forests is that the $\mathrm{N}$ addition rates used in the experiments in our database are generally much higher (between 30 and $300 \mathrm{~kg} \mathrm{~N} \mathrm{ha}^{-1} \mathrm{yr}^{-1}$ ) than atmospheric $\mathrm{N}$ addition rates that forests currently experience (between 2 and $35 \mathrm{~kg} \mathrm{~N} \mathrm{ha}^{-1} \mathrm{yr}^{-1}$ ). In addition, atmospheric $\mathrm{N}$ deposition occurs continuously throughout the year, while in the experiments 
Table 5. I | Summary effect sizes for $\mathrm{C}-\mathrm{N}$ responses per forest biome obtained from the meta-analysis (I), estimates of total $\mathrm{N}\left(\mathrm{NH}_{x}+\mathrm{NO}_{y}\right)$ deposition per forest biome (2), total forest area per forest biome (3) and the calculated nitrogen-induced carbon sink (4).Values shown are means; values in brackets are confidence intervals ( \pm I standard error).

\begin{tabular}{|c|c|c|c|c|}
\hline & $\begin{array}{l}\text { (I) C-N response } \\
\text { AGWP }\end{array}$ & $\begin{array}{l}\text { (2) Average } \\
\mathrm{NH}_{\mathrm{x}}+\mathrm{NO}_{\mathrm{y}} \\
\text { deposition }^{(1)}\end{array}$ & $\begin{array}{l}\text { (3) Forest } \\
\text { area }\end{array}$ & $\begin{array}{l}\text { (4) N-induced C sink } \\
\text { AGWP }=(1) *(2) \\
*(3)\end{array}$ \\
\hline & {$\left[\mathrm{kg} \mathrm{C} \mathrm{kg} \mathrm{N}^{-1}\right]$} & {$\left[\mathrm{kg} \mathrm{N} \mathrm{ha-1} \mathrm{yr}^{-1}\right]$} & {$\left[\mathrm{ha} * 10^{\circ}\right]$} & {$\left[\mathrm{Tg} C \mathrm{yr}^{\prime}\right]$} \\
\hline Tropical forests $(n=17)$ & $1.3\left({ }^{-1} .3-3.9\right)$ & 6.4 & 1.79 & $15\left({ }^{-1} 5-44\right)$ \\
\hline Temperate forests $(n=4 I)$ & $12.7(|0.6-| 4.9)$ & 7.8 & 1.02 & $101(84-119)$ \\
\hline Boreal forests $(n=12)$ & $14.1(10.6-17.5)$ & 1.8 & 1.21 & $32(24-39)$ \\
\hline All $(n=70)$ & $11.3(8.7-13.9)$ & 5.4 & 4.02 & I48 (93-202) \\
\hline
\end{tabular}

(1) $\mathrm{N}$ deposition estimates are based on an overlay of the GLC 2000 and the total deposition of $\mathrm{NH}_{x}$ and $\mathrm{NO}_{x}$ at I $x$ I degree calculated with the TM5 model for the year 2000 (Dentener et al., 2006). Note that the C-N response for "All" is the weighted mean response across all experiments, not an area-weighted mean of the C-N responses per biome.

fertilizers are applied every few months to years. It is likely to assume that experiments with high $\mathrm{N}$ addition rates and large time intervals (several years or more) between $\mathrm{N}$ applications underestimate the response to $\mathrm{N}$ addition, as with continuous low $\mathrm{N}$ addition plant $\mathrm{N}$ demand and supply are better matched. However, only very few studies were designed to mimic atmospheric $\mathrm{N}$ deposition by adding $\mathrm{N}$ at low rates during a long time period. Those studies, which have mostly been conducted in boreal forests, find $\mathrm{C}-\mathrm{N}$ responses between 16 and $25 \mathrm{~kg} \mathrm{C} \mathrm{kg}$ per N, slightly higher than our estimate for boreal forests of $10.6-17.5 \mathrm{~kg}$ C per kg N (see Table 5.1) (Gundale et al., 2014; Högberg et al., 2006; Hyvönen et al., 2008; Magill et al., 2004; Pregitzer et al., 2008). Similarly, another meta-analysis found no significant effect of $\mathrm{N}$ addition frequency on ANPP response to $\mathrm{N}$ addition (Tian et al., 2016). Finally, about half of the forest plots in our database were planted forests, while globally, planted forests only account for $7 \%$ of the forest area (FAO, 2016).

In our analysis of the experimental data we implicitly assume that everything in the experimental plots is equal, except for the added fertilizer. However, in some cases the pretreatment growth rate might have been different in fertilized and control plots. In these cases, the difference in woody biomass accumulation between the fertilized and control plots does not give an accurate indication of the effect of fertilizer addition. A comparison of the growth rate in fertilized plots after fertilization compared to before fertilization might be a better indicator, but these data were usually not available.

When determining the impact of nutrient additions on $\mathrm{C}$ sequestration in tree biomass, we are interested in the $\mathrm{C}$ contained in the whole stand, rather than $\mathrm{C}$ contained in individual 
trees. However, many studies are based on measurements of a number of sample trees. If tree mortality is not included, this can distort results. For example, Shryock et al. (2014) found that while $\mathrm{N}$ fertilization led to a significant increase in the tree $\mathrm{C}$ pool ( $10 \%$ increase on average), it did not lead to a significant increase in tree $\mathrm{C}$ sequestration at stand level, because mortality was higher in fertilized trees. Shen et al. (2001) also found that mortality in Douglas fir was about 1.4 and 2.1 times higher in stands fertilized with 224 and $448 \mathrm{~kg} \mathrm{~N}$ $\mathrm{ha}^{-1} \mathrm{yr}^{-1}$, respectively, than in unfertilized plots. On the other hand, such $\mathrm{N}$ inputs are much higher than atmospheric $\mathrm{N}$ addition rates to forests, as mentioned above, and may thus have less relevance for the field situation.

\subsubsection{Factors affecting forest carbon response to nitrogen addition}

\section{Biome}

The decrease in forest $\mathrm{C}$ sequestration in response to $\mathrm{N}$ addition with latitude that we observe in our data is in line with the common hypothesis that boreal forest respond most strongly to $\mathrm{N}$ addition because $\mathrm{N}$ mineralization is limited at low temperatures. Forests on tropical soils are generally assumed to be less responsive to $\mathrm{N}$ addition because they are mainly $\mathrm{P}$ limited. N-rich tropical forests are often characterized by high rates of $\mathrm{N}$ cycling, a high soil $\mathrm{N}$ availability and high rates of $\mathrm{N}$ losses, both by air emissions and leaching. Nitrate leaching is associated with leaching of aluminium and base cations and soil acidification (Fang et al., 2009; Lu et al., 2014). Nitrogen deposition can thus contribute to soil acidification in tropical ecosystems and thereby reduce rather than stimulate growth and $\mathrm{C}$ sequestration. Indeed, we did not find a significant response of woody biomass increment to $\mathrm{N}$ addition in tropical forests (neither for the response ratio nor for the $\mathrm{C}-\mathrm{N}$ response). This contradicts the results of LeBauer and Treseder (2008) who found a significant increase in NPP in response to N addition in tropical forests of $20 \%$, similar to the response that they found for temperate and boreal forests.

Comparing our estimates for $\mathrm{C}-\mathrm{N}$ responses for AGWP in different biomes to estimates obtained by stoichiometric scaling (De Vries et al., 2014) and the global dynamic vegetation model LPJ-GUESS (Fleischer et al., 2015), we find that estimates from our meta-analysis are generally lower (see Table 5.2). For tropical forests, our results for AGWP response are lower than the estimate from stoichiometric scaling $(5.0 \mathrm{~kg} \mathrm{C}$ per $\mathrm{kg} \mathrm{N})$, and much lower than the estimate for AGWP+BGWP from the DGVM (25.9 $\mathrm{kg} \mathrm{C} \mathrm{per} \mathrm{kg} \mathrm{N})$. One reason for the much higher response found by the DGVM might be that the model lacks a representation of the $\mathrm{P}$ cycle, and also for tropical forests there are much fewer observations that can constrain the model (Fleischer et al., 2015). 
Table 5.2 | Comparison of $\mathrm{C}-\mathrm{N}$ responses for tree woody biomass obtained by our meta-analysis and other approaches. Values shown are means \pm I standard error. AGWP $=$ aboveground woody biomass production, $\mathrm{BGWP}=$ belowground woody biomass production, $\mathrm{DGVM}=$ dynamic global vegetation model

\begin{tabular}{lccccc}
\hline & $\begin{array}{c}\text { Meta-analysis } \\
\text { (this study) }\end{array}$ & Stoichiometric scaling (De Vries et al., 20 I4) & $\begin{array}{c}\text { DGVM' (Fleischer } \\
\text { et al., 20I5) }\end{array}$ \\
\cline { 2 - 6 } Compartment & AGWP & AGWP & BGWP & AGWP+BGWP & AGWP+ BGWP \\
\hline Tropical forests & $1.3 \pm 2.6$ & $5.0 \pm 1.7$ & $1.1 \pm 0.3$ & $6.1 \pm 2.0$ & $25.9 \pm 10.8$ \\
Temperate forests & $12.7 \pm 2.2$ & $14.4 \pm 2.8$ & $3.1 \pm 0.6$ & $17.5 \pm 3.5$ & $24.0 \pm 2.4$ \\
Boreal forests & $14.1 \pm 3.5$ & $21.3 \pm 4.3$ & $5.0 \pm 1.0$ & $26.3 \pm 5.3$ & $17.5 \pm 5.2$ \\
All & $11.3 \pm 2.6$ & & & & $23.0 \pm 7.5$ \\
\hline
\end{tabular}

' Site-scale simulations calibrated with data from 68 forest FLUXNET sites

Table 5.3 | Response ratios for tree biomass response to nitrogen addition found in other meta-analyses. $A G B P=$ aboveground biomass production, $A G W P=$ aboveground woody biomass production .

\begin{tabular}{|c|c|c|c|c|c|c|}
\hline & $\begin{array}{c}\text { Xia \& Wan } \\
(2008)\end{array}$ & $\begin{array}{c}\text { Newton \& } \\
\text { Amposah }\end{array}$ & $\begin{array}{c}\text { Janssen et al. } \\
\qquad(2010)\end{array}$ & $\begin{array}{l}\text { Vadeboncoeur } \\
(2010)\end{array}$ & $\begin{array}{c}\text { LeBauer \& } \\
\text { Treseder (2008) }\end{array}$ & This study \\
\hline Response parameter & AGBP & AGWP & AGBP & AGWP & AGBP & AGWP \\
\hline All forest & 1.61 & & & & & $\begin{array}{l}1.16 \\
(1.09-1.23)\end{array}$ \\
\hline Tropical forests & & & & & $\begin{array}{l}1.20 \\
(1.04-1.40)\end{array}$ & $\begin{array}{l}1.05 \\
(0.94-1.18)\end{array}$ \\
\hline Temperate forests & & & $\begin{array}{l}1.36 \\
(1.17-1.56)\end{array}$ & $\begin{array}{l}1.51 \\
(1.16-1.97)\end{array}$ & $\begin{array}{l}1.19 \\
(1.11-1.28)\end{array}$ & $\begin{array}{l}1.17 \\
(1.10-1.25)\end{array}$ \\
\hline Boreal forests & & $1.06-1.23^{\prime}$ & & & & $\begin{array}{l}1.20 \\
(1.08-1.33)\end{array}$ \\
\hline
\end{tabular}

' Represents range of means across investigated species and site qualities

For temperate forests, the $\mathrm{C}-\mathrm{N}$ response for AGWP estimated by the meta-analysis (12.7 $\mathrm{kg} \mathrm{C}$ per $\mathrm{kg} \mathrm{N}$ ) is very similar to the estimate for AGWP from stoichiometric scaling (14.4 $\mathrm{kg} \mathrm{C}$ per $\mathrm{kg} \mathrm{N}$ ) and lower than the estimate for AGWP+BGWP from the DGVM (24.0 $\mathrm{kg} \mathrm{C}$ per $\mathrm{kg} \mathrm{N}$ ). Our estimate is lower than that from a meta-analysis by Liu and Greaver (2009) that estimated a C-N response in of $24.5 \pm 8.7 \mathrm{~kg}$ C per $\mathrm{kg} \mathrm{N}$ based on fertilization experiments in the US (mainly temperate forests). However, this analysis included $\mathrm{N}$-induced $\mathrm{C}$ sequestration in both the tree and the soil $\mathrm{C}$ pools. Assuming that the tree biomass pool accounts for about half of total $\mathrm{N}$-induced $\mathrm{C}$ sequestration (as supported by e.g. Janssens et al., 2010), their estimate can be considered similar to our results. A study using data from forest inventories in the northeastern and north-central United States found that tree C sequestration increased linearly over the observed range of $\mathrm{N}$ deposition and deduced an 
effect of 61 (51-82) kg C per kg N (Thomas et al., 2010). Two studies in Europe, using similar methods, also found C-N responses between 19 and $26 \mathrm{~kg} \mathrm{C}$ per $\mathrm{kg} \mathrm{N}$ (Laubhann et al., 2009; Solberg et al., 2009). However, isolating the effect of $\mathrm{N}$ deposition in these empirical studies is tricky as it might co-vary with other environmental drivers such as climate and ozone exposure (De Vries et al., 2008; Sutton et al., 2008).

For boreal forests, the C-N response for AGWP estimated by the meta-analysis $(14.1 \mathrm{~kg} \mathrm{C}$ per $\mathrm{kg} \mathrm{N})$ is slightly lower than the estimate for AGWP+BGWP from the DGVM $(17.5 \mathrm{~kg}$ C per $\mathrm{kg} \mathrm{N}$ ), while the estimate from stoichiometric scaling for AGWP is about $50 \%$ higher (21.3 kg C per $\mathrm{kg} \mathrm{N}$ ). Our estimate is similar to a recent long-term fertilization experiment in a boreal forest by Gundale et al. (2014) who estimate the $\mathrm{C}-\mathrm{N}$ response of boreal forests (AGWP+BGWP) at $16 \mathrm{~kg} \mathrm{C}$ per $\mathrm{kg} \mathrm{N}$.

\section{Productivity}

None of the previous meta-analysis that assessed $\mathrm{N}$ fertilization effects on forest growth response has assessed how the response to $\mathrm{N}$ addition is affected by the productivity of the forest site. This is an important omission as most previous meta-analyses have reported tree biomass response to $\mathrm{N}$ addition as relative responses (response ratios, see Table S5.1). However, a certain relative response to $\mathrm{N}$ addition in a highly productive forest means a much stronger stimulation of the forest $\mathrm{C}$ sink in absolute terms than the same response in a low-productivity forest. Our results showed that $\mathrm{N}$-induced relative AGWP increase was about three times higher in forests with a low productivity than in forests with a higher productivity ( $24 \%$ vs $7 \%$ ). The absolute response to $\mathrm{N}$ addition ( $\mathrm{C}-\mathrm{N}$ response) was also higher in low-productivity forests, although the difference was not significant. One possible explanation is that highly productive forests are less likely to be limited by N. For the response of soil respiration to $\mathrm{N}$ addition, a meta-analysis by Janssens et al. (2010) showed that the reduction of soil respiration is stronger at sites with a higher productivity (meaning that $\mathrm{N}$ has a stronger effect on soil $\mathrm{C}$ sequestration at sites with a higher productivity), probably because at less productive, $\mathrm{N}$-limited sites $\mathrm{N}$ immobilization is stronger and thus the effect of $\mathrm{N}$ on respiration is less pronounced.

\section{Age}

The relevance of stand age for forest $\mathrm{C}$ flows has long been recognized (Pregitzer and Euskirchen, 2004) and was confirmed by our results, as we found that AGWP in young forests responded more strongly to $\mathrm{N}$ addition than in older forests. The absolute sensitivity of AGWP to $\mathrm{N}$ addition was more than twice as high in young forests (stand age 10-20 years) than in forests 20 years or older. In young forest stands, high nutrient requirements for growth and higher dependence on external $\mathrm{N}$ inputs might exacerbate nutrient limitation 
(Sun et al., 2016), explaining the stronger response to $\mathrm{N}$ addition in these stands. The only other meta-analysis on $\mathrm{N}$ addition effects on forests that assessed the influence of stand age also found a decrease in $\mathrm{N}$ response with increasing stand age (Vadeboncoeur, 2010). Most previous meta-analysis rely heavily on data from very young forest stands and/or seedlings. In our analysis we attempted to reduce the bias by excluding experiments performed on forest stands younger than 10 years. This might explain why our biome-level responses are lower than those found in previous meta-analyses (see Table 5.3).

\section{Nitrogen addition rate}

We found a strong decrease in $\mathrm{C}-\mathrm{N}$ response with increasing $\mathrm{N}$ inputs. These results confirm results from a recent meta-analysis by Tian et al. (2016) that investigated $\mathrm{N}$ fertilization experiments with multiple levels of $\mathrm{N}$ addition and also found a sharp decrease in ANPP response to $\mathrm{N}$ addition at $\mathrm{N}$ addition levels above $40 \mathrm{~kg} \mathrm{~N} \mathrm{ha}^{-1} \mathrm{yr}^{-1}$. At high levels of $\mathrm{N}$ addition, $\mathrm{N}$ leaching starts to increase and $\mathrm{N}$ retention starts to decrease (Templer et al., 2012). For example, an $\mathrm{N}$ fertilization experiment in Sweden showed that long-term addition of $34 \mathrm{~kg} \mathrm{~N} \mathrm{ha}^{-1} \mathrm{yr}^{-1}$ increased woody biomass increment in Norway spruce by $25 \mathrm{~kg} \mathrm{C}$ per $\mathrm{kg} \mathrm{N}$, while addition of $68 \mathrm{~kg} \mathrm{~N} \mathrm{ha}^{-1} \mathrm{yr}^{-1}$ only led to an increase of $6 \mathrm{~kg} \mathrm{C}$ per $\mathrm{kg} \mathrm{N}$ and addition of $108 \mathrm{~kg} \mathrm{~N} \mathrm{ha}^{-1} \mathrm{yr}^{-1}$ led to no increase in woody biomass altogether (Högberg et al., 2006). Data from eddy flux measurements at 68 sites across the globe found that the increase in photosynthetic capacity with increasing levels of $\mathrm{N}$ deposition levels off at an ambient $\mathrm{N}$ deposition of $8 \mathrm{~kg} \mathrm{~N} \mathrm{ha}^{-1} \mathrm{yr}^{-1}$ in evergreen needleleaf forests (Fleischer et al., 2013).

For the relative AGWP response to $\mathrm{N}$ addition (response ratio), we also found a decrease with increasing level of $\mathrm{N}$ deposition. However, this decrease was not as clear as the decrease in the absolute sensitivity to $\mathrm{N}$ addition. Similarly, other meta-analyses that used the response ratio as effect size did not find a significant effect of $\mathrm{N}$ addition level on forest ecosystem $\mathrm{C}$ content (Liu and Greaver, 2009) or on NPP (Xia and Wan, 2008).

\section{Nitrogen source}

AGWP response to $\mathrm{N}$ addition might vary between different $\mathrm{N}$ fertilizer types due to differences in $\mathrm{N}$ losses and related $\mathrm{N}$ availability in time and space to the plants. In line with previous meta-analyses (e.g., LeBauer and Treseder, 2008; Liu and Greaver, 2009; Vadeboncoeur, 2010), we did not find $\mathrm{N}$ source to have a significant effect on biomass response (in our case the absolute sensitivity or relative response of AGWP to N addition). The absolute sensitivity was slightly higher in experiments that used urea, but this effect was not significant. In a long-term fertilization experiment in a Swedish pine forests where forest plots were fertilized with either $\mathrm{NH}_{4} \mathrm{NO}_{3}$ or urea, no difference in needle $\mathrm{N}$ content, $\mathrm{N}$ accumulation in the organic layer and extractable $\mathrm{NO}_{3}{ }^{-}$in the soil solution were found 
(Högberg et al., 2014). However, urea-fertilized plots showed a larger fractionation of ${ }^{15} \mathrm{~N}$ in needle biomass, which shows that the pathways through which $\mathrm{N}$ becomes available are different between these two $\mathrm{N}$ sources. Du et al. (2014) performed an experiment in which $\mathrm{NH}_{4} \mathrm{NO}_{3}$ and urea were used to fertilize temperate forest soils for two years, showing that $\mathrm{NH}_{4} \mathrm{NO}_{3}$ inhibited soil $\mathrm{C}$ cycle processes, such as soil respiration and enzymatic activities, while urea promoted these processes. Similarly, Liu and Greaver (2010) found that fertilizer type significantly influenced several below-ground responses to $\mathrm{N}$ addition, such as dissolved organic $\mathrm{C}$, microbial biomass $\mathrm{C}$ and soil respiration. Overall, $\mathrm{N}$ form seems to be an important factor for $\mathrm{N}$-induced changes in belowground $\mathrm{C}$, but less so for biomass response.

\section{Ambient nitrogen deposition}

Forest stands that receive high rates of ambient $\mathrm{N}$ deposition are expected to slowly become $\mathrm{N}$ saturated and thus show a lower response to $\mathrm{N}$ addition. We did indeed find that the AGWP response to $\mathrm{N}$ addition was significantly lower at ambient $\mathrm{N}$ deposition rates above $15 \mathrm{~kg} \mathrm{~N} \mathrm{ha}^{-1} \mathrm{yr}^{-1}$ (though it should be noted here that we used model estimates of ambient $\mathrm{N}$ deposition that might not always accurately reflect actual ambient $\mathrm{N}$ deposition rates). Several previous meta-analyses confirm the importance of ambient $\mathrm{N}$ deposition when interpreting results from forest fertilization experiments. For example Knorr et al. (2005) found that $\mathrm{N}$ addition only stimulated litter decay at plots with low levels of ambient $\mathrm{N}$ deposition, and Vadeboncoeur (2010) found some indication that NPP response to N addition in northeastern deciduous forests was lower at high $\mathrm{N}$ addition rates. Tian et al. (2016) did not find a significant effect of ambient $\mathrm{N}$ deposition level on $\mathrm{N}$ response efficiency, but their database might include too few observations from plots with ambient $\mathrm{N}$ deposition exceeding $15 \mathrm{~kg} \mathrm{~N}$ $\mathrm{ha}^{-1} \mathrm{yr}^{-1}$ to detect an effect.

\subsubsection{Comparison of response ratios with other meta-analyses of forest nitrogen fertilization experiments}

This study is the first to perform a meta-analysis on $\mathrm{N}$ fertilization experiments that uses the absolute sensitivity of woody biomass to $\mathrm{N}$ addition $(\mathrm{kg} \mathrm{C}$ per $\mathrm{kg} \mathrm{N}$ ) as response variable. As mentioned in the introduction, several other meta-analyses have previously investigated the impact of $\mathrm{N}$ addition on forest productivity (see Table S5.1 for an overview). However, those meta-analyses have either not focused on the AGWP response or report only relative AGWP responses rather than absolute $\mathrm{C}-\mathrm{N}$ responses.

Comparing the response ratios from our meta-analysis with results from other studies shows that our results are comparable, though they are at the low end of previous estimates (Table 5.3). A possible explanation is that we applied more stringent criteria when selecting 
experiments to include in the analysis. For example, we only included observations from forest plots that were at least ten years old, while other studies also include observations on seedlings and young trees. In general, most published studies on fertilization experiments are performed on seedlings, which means that if age is not a criterion in the selection of studies, most observations on which a meta-analysis is based will come from studies on seedlings. For example, the study by Xia and Wan (2008) contains 501 observations for $\mathrm{N}$ addition effects on tree biomass of which more than $80 \%$ comes from experiments performed on seedlings or juvenile trees. The meta-analysis by Janssens et al. (2010) contains 24 observations of $\mathrm{N}$ addition effects on tree biomass, of which half are from experiments performed on seedlings or trees younger than three years old. As our results show, young trees respond more strongly to $\mathrm{N}$ addition than older trees, and thus the high prevalence of experiments on seedlings in previous meta-analyses might explain the higher response found in these studies. In addition, some of the other studies include observations on forest plots that received additional treatments next to $\mathrm{N}$ addition. For example the study by Janssens et al. (2010) includes several observations from plots that received warming and $\mathrm{CO}_{2}$ fertilization treatments along with $\mathrm{N}$ addition, and the study by Newton and Amposah (2006) includes observations from plots that received additional micro-nutrients. This might also explain the higher responses found in these studies as compared to our study.

\subsubsection{Role of phosphorus}

While $\mathrm{N}$ is generally assumed to be the primary limiting nutrient in forests, enhanced $\mathrm{N}$ inputs over time may induce limitations of other nutrients, most importantly P. Observations in forests plots across Europe show that foliar P concentrations are decreasing, while N:P ratios are increasing (Braun et al., 2010; Jonard et al., 2015). Increasing N:P ratios under N addition were also found in a meta-analysis of fertilization experiments by Yuan and Chen (2015). This study also found that next to anthropogenic N deposition, other global changes such as warming and drought also increase N:P ratios, which might lead to an additional increase in $\mathrm{P}$ demand relative to $\mathrm{N}$ in the future. This deterioration in the $\mathrm{P}$ nutritional status is expected to limit tree response to $\mathrm{N}$ deposition and thus the capacity of forests to act as $\mathrm{C}$ sinks. $\mathrm{N}$ deposition can induce $\mathrm{P}$ limitation through two mechanisms: a) enhanced nutrient requirements to maintain growth under $\mathrm{N}$ fertilization and $\mathrm{b}$ ) reduced investment in fine roots and mycorrhizal interactions (Jonard et al., 2015). In contrast to the increasing availabilities of $\mathrm{N}$ to ecosystems in large parts of the world through deposition, $\mathrm{P}$ is an earthbound element. Limited $\mathrm{P}$ availability will likely reduce the future forest $\mathrm{C}$ sink, as increasing $\mathrm{N}$ inputs are not matched by increasing P inputs (Peñuelas et al., 2013).

Despite evidence for increasing P limitation in terrestrial systems that are subjected to long- 
term $\mathrm{N}$ inputs, we did not find a significant response to $\mathrm{P}$ addition in our meta-analysis. Specifically for tropical forests, this result was unexpected. We found some evidence for colimitation of $\mathrm{N}$ and $\mathrm{P}$ as in several plots AGWP responded more strongly to combined $\mathrm{N}$ and $\mathrm{P}$ addition than the sum of the individual responses (Figure 5.4), but we have too little data to be confident about this. Another recent meta-analysis of $\mathrm{P}$ addition effects, however, found that P addition under ambient N significantly increased ANPP in tropical forests by $92 \%$ on average (Li et al., 2016). One possible explanation for this much higher response is that the study by Li et al. is based on many observations on seedlings and very young trees, which are expected to show a much stronger relative response to nutrient addition than mature trees.

One possible explanation for the low response to $\mathrm{P}$ addition is that the added $\mathrm{P}$ is not immediately available for plant uptake. Unlike N, P is adsorbed to soil particles and thus added $\mathrm{P}$ replenishes the soil $\mathrm{P}$ pool, but only slowly becomes available to plants over time (Shen et al., 2011). This is also shown in agricultural soils, where even in instances where $\mathrm{P}$ application rates have declined, uptake and yields continued to increase due to the continued supply of plant-available P from the residual soil P pool (Jungk et al., 1993; Sattari et al., 2012). This means that while often no growth response to $P$ addition is observed on the short term, P could significantly enhance growth over the lifespan of a forest as the added P slowly becomes available through adsorption/desorption. On the other hand, Markewitz et al. (2012) found that fertilization of a secondary tropical forest with $100 \mathrm{~kg} \mathrm{P} \mathrm{ha}^{-1}$ doubled plant available $\mathrm{P}$ in the soil solution, indicating that at least a part of the added phosphorus is immediately available to plants.

\subsubsection{Global nitrogen-induced forest carbon sequestration}

The contribution of $\mathrm{N}$ to global terrestrial $\mathrm{C}$ sequestration has been debated for decades, with early estimates in the 1980s and 1990s ranging from less than $100 \mathrm{Tg} \mathrm{C} \mathrm{yr}^{-1}$ up to more than 2,000 Tg C yr$^{-1}$ (Field et al., 1992; Hudson et al., 1994; Nadelhoffer et al., 1999; Peterson and Melillo, 1985; Schindler and Bayley, 1993; Townsend et al., 1996). Estimates published in the last decade show less variation and vary mostly between 220 and $720 \mathrm{Tg} \mathrm{C} \mathrm{yr}^{-1}$ sequestered in terrestrial ecosystems due to $\mathrm{N}$ deposition (De Vries et al., 2014; Fleischer et al., 2015; Jain et al., 2009; Liu and Greaver, 2009; Thomas et al., 2010; Thornton et al., 2007; Zaehle et al., 2011). Our estimate cannot be compared to these estimates directly as we only assessed $\mathrm{N}$-induced $\mathrm{C}$ sequestration in the tree $\mathrm{C}$ pool through increased woody biomass accumulation, while other estimates also include $\mathrm{N}$-induced $\mathrm{C}$ sequestration in the soil $\mathrm{C}$ pool through increased litter inputs and/or reduced soil organic matter decomposition. The soil $\mathrm{C}-\mathrm{N}$ response is determined by $\mathrm{N}$-induced changes in $\mathrm{C}$ input by litterfall and the $\mathrm{N}$-induced changes in $\mathrm{C}$ losses from respiration (see Figure 5.1). Several meta-analyses have found that $\mathrm{N}$ addition 
Table 5.4 | Overview of published estimates of nitrogen-induced forest carbon sequestration $\left(\mathrm{Tg} C \mathrm{yr}^{1}\right)$. Only estimates that specify the individual contributions of vegetation and soil to total nitrogen-induced carbon sequestration are listed. The last row shows the relative contribution of the soil to total $\mathrm{N}$-induced C sequestration. DGVM = Dynamic global vegetation model.

\begin{tabular}{|c|c|c|c|c|c|c|c|}
\hline Reference & $\begin{array}{l}\text { Peterson } \\
\text { \& Melillo } \\
\text { 1985 }\end{array}$ & $\begin{array}{l}\text { Townsend } \\
\text { et al. } 1996\end{array}$ & $\begin{array}{l}\text { Nadelhoffer } \\
\text { et al. } 1999\end{array}$ & $\begin{array}{l}\text { Jain et al. } \\
2009\end{array}$ & $\begin{array}{l}\text { De Vries et } \\
\text { al. } 2014\end{array}$ & $\begin{array}{l}\text { Fleischer } \\
\text { et al. } \\
2015^{(1)}\end{array}$ & This study $y^{(2)}$ \\
\hline Method ${ }^{(3)}$ & $\begin{array}{l}\text { Stoichiom. } \\
\text { scaling }\end{array}$ & DGVM & $\begin{array}{l}\text { Stoichiom. } \\
\text { scaling }\end{array}$ & DGVM & $\begin{array}{l}\text { Stoichiom. } \\
\text { scaling }\end{array}$ & DGVM & Meta-analysis \\
\hline Vegetation & 52 & 607 & 144 & 130 & $200(155-246)$ & 345 & $177($ (I | 2-243) \\
\hline Tropical & & & & & $42(28-56)$ & 155 & $18\left(-{ }^{-1} 8-53\right)$ \\
\hline Temperate & & & & & |24 (99-|48) & 136 & $|2|(|0|-\mid 42)$ \\
\hline Boreal & & & & & $35(28-42)$ & 49 & $38(28-47)$ \\
\hline Soil & 45 & 133 & 107 & 130 & $152(|2|-202)$ & 214 & - \\
\hline Total & 97 & 740 & 251 & 260 & $352(276-448)$ & 560 & - \\
\hline \% Soil & $47 \%$ & $18 \%$ & $43 \%$ & $50 \%$ & $43 \%$ & $38 \%$ & - \\
\hline
\end{tabular}

\footnotetext{
' Estimates from the global-scale simulations.

${ }^{2}$ Estimate includes aboveground woody biomass presented in Table 5.1 multiplied by a factor 1.2 to account for additional $\mathrm{N}$-induced carbon sequestration in belowground woody biomass, see Table S5.3.

${ }^{3}$ Estimates presented in this table do not only vary due to differences in methodologies and $\mathrm{C}-\mathrm{N}$ response ratios, but also due to differences in the underlying $\mathrm{N}$ deposition estimates. For all estimates, $\mathrm{N}$ deposition refers to total (natural + anthropogenic) $\mathrm{N}$ deposition. Duce et al. (2008) estimated that $77 \%$ of the $\mathrm{N}$ deposited on land comes from anthropogenic sources. Multiplying our estimate with this fraction, we estimated that carbon sequestration in woody biomass induced by anthropogenic $\mathrm{N}$ deposition is about $136 \mathrm{Tg} \mathrm{C} \mathrm{yr}^{-1}$ (114 Tg C yr $\mathrm{T}^{-1}$ in aboveground woody biomass).
}

reduces forest soil respiration and increases soil C sequestration (Janssens et al., 2010; Nave et al., 2009; Zhou et al., 2014), others found no effect of $\mathrm{N}$ on soil respiration but an increase in aboveground litter inputs (Liu and Greaver, 2010). Several mechanisms through which $\mathrm{N}$ affects soil respiration have been proposed, such as an increase in litter quality, decrease in belowground $\mathrm{C}$ allocation, shifts in microbial community composition, alterations in mycorrhizal interactions and SOM stabilization following $\mathrm{N}$ addition (see for example Janssens et al. 2010 for an overview).

Table 5.4 presents published estimates of the global $\mathrm{N}$-induced forest $\mathrm{C}$ sink split up into the contributions of the tree (vegetation) and soil $\mathrm{C}$ sinks. While estimates of the magnitude of the total $\mathrm{N}$-induced forest $\mathrm{C}$ sink vary between 97 and $740 \mathrm{Tg} \mathrm{C} \mathrm{yr}^{-1}$, the relative contribution of soil $\mathrm{C}$ sequestration to total $\mathrm{N}$-induced $\mathrm{C}$ sequestration is rather constant between 38 and $50 \%$. Stoichiometric scaling studies have estimated that the soil accounts for $43-47 \%$ of the additional N-induced C sequestration (Peterson \& Melillo, 1985; Nadelhoffer et al., 1999; de Vries et al., 2014; see Table 5.4). These studies generally assume that $50-70 \%$ of the deposited $\mathrm{N}$ is allocated to the soil (vs. only $5-8 \%$ to woody biomass), however, the soil C:N ratio (ca. 20:1-30:1) is much lower than the woody biomass C:N ratio (ca. 150:1-500:1). 
Estimates of global N-induced C sequestration derived by DGVMs vary between 260 and 740 Tg C per year (Townsend et al., 1996; Jain et al., 2009; Fleischer et al., 2015; see Table 5.4). Also here, the soil accounts for about $38-50 \%$ of the total $\mathrm{N}$-induced $\mathrm{C}$ sequestration, with the exception of Townsend et al. (1996), where the soil only contributes $18 \%$. A longterm fertilization experiment in a boreal forest found that about $38 \%$ of the $\mathrm{N}$-induced $\mathrm{C}$ sequestration effect is due to enhanced C soil organic horizon (Gundale et al., 2014; Maaroufi et al., 2015). A similar experiment at four temperate forest sites found that the soil accounted for $58 \%$ of $\mathrm{N}$-induced $\mathrm{C}$ sequestration on average, with large variations between the four sites in the study (14-77\%) (Pregitzer et al., 2008). A recent meta-analysis also concluded that the size of the $\mathrm{N}$-induced $\mathrm{C}$ sequestration effect in the soil is equivalent in magnitude to the effect of $\mathrm{N}$ deposition on tree $\mathrm{C}$ sequestration (Janssens et al., 2010).

Our estimate for total $\mathrm{N}$-induced C sequestration in trees' woody biomass of 177 (112-243) Tg C yr ${ }^{-1}$ is slightly higher than estimates by Nadelhoffer et al. (1999) and Jain et al. (2009), slightly lower than recent estimates by de Vries et al. (2014), and about half of the estimate by the DGVM of Fleischer et al. (2015). Notably, the difference with the estimate from Fleischer et al. is mainly because their model predicted that $\mathrm{N}$ deposition greatly enhances $\mathrm{C}$ sequestration in tropical forests, while we found no evidence for a response of the tree $\mathrm{C}$ pool to $\mathrm{N}$ addition in tropical forests. Based on our results we conclude that DGVMs likely overestimate $\mathrm{N}$-induced $\mathrm{C}$ sequestration in the tropics.

\subsubsection{Considerations for up-scaling $\mathbf{C}-\mathbf{N}$ responses to estimate global nitrogen-induced forest carbon sequestration}

We used average $\mathrm{C}-\mathrm{N}$ responses per biome to scale-up our estimates of $\mathrm{N}$-induced $\mathrm{C}$ sequestration based on plot-level observations to the global scale, in line with previous studies (De Vries et al., 2014; Nadelhoffer et al., 1999; Thomas et al., 2010). However, our meta-analysis revealed that factors other than biome, such as forest productivity, stand age, and $\mathrm{N}$ addition rate, also affect the $\mathrm{C}-\mathrm{N}$ response. For some of these variables it is not possible to use them in upscaling. The decline in forest $\mathrm{C}-\mathrm{N}$ response with increasing rates of $\mathrm{N}$ addition, for example, cannot be reflected in an upscaling approach, as $\mathrm{N}$ deposition rates that forests currently experience almost all fall into the lowest rate used in $\mathrm{N}$ addition experiments - most forest plots in our database receive somewhere between 2 and $35 \mathrm{~kg}$ $\mathrm{N} \mathrm{ha}^{-1} \mathrm{yr}^{-1}$ (mean: $5.4 \mathrm{~kg} \mathrm{~N} \mathrm{ha}^{-1} \mathrm{yr}^{-1}$ ) while experimental $\mathrm{N}$ additions rates in our database varied between 30 and $300 \mathrm{~kg} \mathrm{~N} \mathrm{ha}^{-1} \mathrm{yr}^{-1}$ (mean: $71 \mathrm{~kg} \mathrm{~N} \mathrm{ha}^{-1} \mathrm{yr}^{-1}$ ). The difference in response to $\mathrm{N}$ addition between young and old forest stands can also not be used for upscaling $\mathrm{C}-\mathrm{N}$ responses, as there are currently no global maps of forest stand age (though there is data available at the continental scale, for example for North American forests; Pan et al., 2011b). 
If there had been clear correlations between the climate zone (biome) and other determinants of forests' response to $\mathrm{N}$ addition, this might have affected the upscaling procedures as it would have influenced the observed differences in AGWP response between the climate zones. For example, climate zone might be correlated with stand age (tropical and boreal forests might be older than temperate forests) and ambient $\mathrm{N}$ deposition rate (temperate forests might receive higher rates of ambient $\mathrm{N}$ deposition than boreal and tropical forests). It was not the aim of this paper to disentangle all possible interactions between variables, but we did check for correlations (see Table S5.7). Results showed that boreal forest plots in our database on average had a lower productivity and received lower experimental $\mathrm{N}$ addition rates than temperate and tropical forest plots. This will have affected the higher $\mathrm{C}-\mathrm{N}$ response of boreal forests. For productivity, it is plausible to assume that the differences between experimental plots reflect actual differences in the field, which makes upscaling based on climate zones an adequate first rough approach. However, for experimental $\mathrm{N}$ addition rate, differences between climate zones do not reflect real-life variation and thus this effect of cannot be adequately reflected in an upscaling approach. The decrease in $\mathrm{C}-\mathrm{N}$ response with increasing $\mathrm{N}$ inputs that we found also implies that $\mathrm{C}-\mathrm{N}$ responses in temperate and tropical forests might have been underestimated, as experimental $\mathrm{N}$ addition rates for these biomes received vastly exceeded typical ambient $\mathrm{N}$ deposition rates. In addition, we found that average $\mathrm{N}$ deposition in boreal forest plots in our database $\left(7.8 \mathrm{~kg} \mathrm{~N} \mathrm{ha}^{-1} \mathrm{yr}^{-1}\right.$, see Table S5.7) was much higher than the model-derived average for all boreal forests $\left(1.8 \mathrm{~kg} \mathrm{~N} \mathrm{ha}^{-1}\right.$ $\mathrm{yr}^{-1}$, see Table 5.1). Given the decline in $\mathrm{C}-\mathrm{N}$ response with increasing levels of ambient $\mathrm{N}$ deposition, this might mean that the $\mathrm{C}-\mathrm{N}$ response for boreal forests that we derived is an underestimation.

Another caveat when upscaling results from fertilization experiments is that responses at very low rates of $\mathrm{N}$ addition might be lower than mean response rates from experiments suggest. Previous studies show that forests hardly respond to $\mathrm{N}$ deposition at levels below approximately 3-5 $\mathrm{kg} \mathrm{N} \mathrm{ha}^{-1} \mathrm{yr}^{-1}$ because of microbial competition with plant (tree) uptake (Kaye and Hart, 1997) and reduced biological $\mathrm{N}$ fixation due to enhanced $\mathrm{N}$ deposition (Gundale et al., 2011). This might have led to an overestimation of the global N-induced C sink in boreal forests, where ambient $\mathrm{N}$ deposition rates are low. On the other hand, response rates may be underestimated in the range from 3-5 up to $10-15 \mathrm{~kg} \mathrm{~N} \mathrm{ha}^{-1} \mathrm{yr}^{-1}$ where $\mathrm{N}$ deposition may stimulate growth quite strongly (e.g., Thomas et al., 2010). Overall, it is not clear whether use of a mean $\mathrm{C}-\mathrm{N}$ response over the whole $\mathrm{N}$ deposition range leads to an over- or underestimation of the $\mathrm{N}$ deposition impact on global forest $\mathrm{C}$ sequestration.

While this study has focused on $\mathrm{C}-\mathrm{N}$ responses in (aboveground) biomass, soils also account for a substantial share of the $\mathrm{N}$-induced $\mathrm{C}$ sequestration response. While several studies 
have estimated $\mathrm{N}$-induced soil C sequestration (see for example Table S5.1 and Table 5.4), disentangling the various mechanisms through which $\mathrm{N}$ affects soil biological processes is still a puzzle that needs to be solved in order to improve predictions of future $\mathrm{N}$-induced soil C sequestration. Improving estimates of global $\mathrm{N}$-induced forest $\mathrm{C}$ sequestration from empirical data furthermore requires more quantitative insight in the factors affecting forests' response to $\mathrm{N}$ addition at different $\mathrm{N}$ input levels. This includes factors related to site fertility, such as nutrient concentrations and/or ratios in foliage and soil (e.g., Fernández-Martínez et al., 2014), climatic factors, such as temperature (e.g., Sigurdsson et al., 2013) and precipitation (e.g., Lim et al., 2015), as well as variations in $\mathrm{C}-\mathrm{N}$ responses between tree species in view of different symbiotic relations with mycorrhizal fungi (e.g., Chalot \& Brun, 1998; Thomas et al., 2010; Averill et al., 2014). Scaling up plot-level results to the global scale also depends on the availability of global datasets with information on factors governing $\mathrm{C}-\mathrm{N}$ responses. 
NITROGEN IMPACTS ON TREE CARBON SEQUESTRATION IN GLOBAL FORESTS:A META-ANALYSIS 


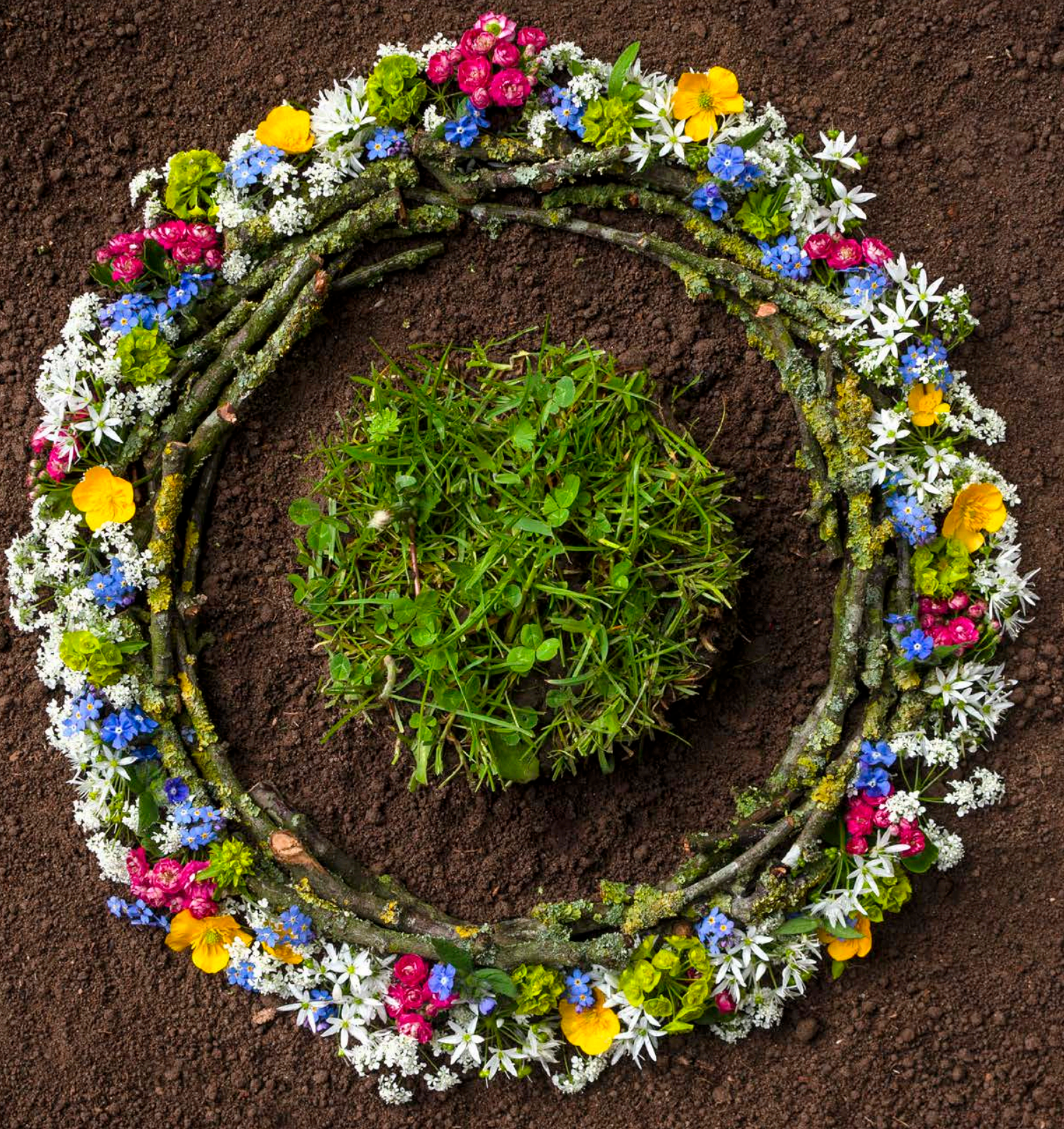

(a)

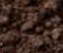

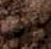




\section{Chapter 6}

\section{Experimental evidence shows minor contribution of nitrogen deposition to global forest carbon sequestration}

Based on: Lena Schulte-Uebbing, Gerard Ros \& Wim de Vries. 


\section{Abstract}

Human activities have drastically increased nitrogen $(\mathrm{N})$ deposition onto forests. This may have alleviated $\mathrm{N}$ limitation and stimulated carbon (C) sequestration in aboveground woody biomass (AGWB), a stable $\mathrm{C}$ pool with long turn-over times. Nitrogen deposition-induced forest $\mathrm{C}$ sequestration partly offsets the climate impact of $\mathrm{N}_{2} \mathrm{O}$ emissions caused by human $\mathrm{N}$ use, but its magnitude and spatial variation are uncertain. Here we use a meta-regression approach to identify sources of heterogeneity in tree biomass $\mathrm{C}-\mathrm{N}$ responses (additional C stored per unit of $\mathrm{N}$ ) based on data from forest fertilization experiments across the globe. We estimate forest biomass $\mathrm{C}-\mathrm{N}$ response as a function of climate (potential evapotranspiration), soil fertility ( $\mathrm{N}$ content) and tree characteristics (stand age). Based on this relation, we quantify global spatial variation in $\mathrm{N}$-induced forest biomass $\mathrm{C}$ sequestration. Results show that $\mathrm{N}$ increases forest biomass $\mathrm{C}$ sequestration in only one third of global forests, mainly in boreal regions, while $\mathrm{N}$ reduces $\mathrm{C}$ sequestration in $5 \%$ of forests, mainly in tropical regions. In the remaining $59 \%$ of global forests, $\mathrm{N}$ addition had no impact on biomass $\mathrm{C}$ sequestration. Average C-N responses were 11 (4 to 21) $\mathrm{kg} \mathrm{C}$ per kg N for boreal, 4 (0 to 8$) \mathrm{kg} \mathrm{C}$ per $\mathrm{kg} \mathrm{N}$ for temperate and 0 ( -4 to 5$) \mathrm{kg} \mathrm{C}$ per $\mathrm{kg} \mathrm{N}$ for tropical forests. Our global estimate of the

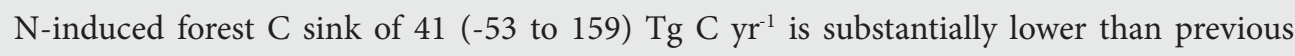
estimates, mainly due to the absence of any response in tropical forest (accounting for $58 \%$ of the global forest area). Overall, the $\mathrm{N}$-induced $\mathrm{C}$ sink in AGWB is negligible when compared to either the climate impact of $\mathrm{N}_{2} \mathrm{O}$ emissions or the overall size of the forest $\mathrm{C}$ sink.

\section{I. Introduction}

Human acceleration and disturbance of the nitrogen $(\mathrm{N})$ cycle have drastically increased emissions of reactive $\mathrm{N}$ to the environment, resulting in adverse impacts on water, air and soil quality, ecosystems and biodiversity (Fowler et al., 2013; Galloway et al., 2008; Sutton et al., 2011a; Vitousek et al., 1997). Reactive $\mathrm{N}$ emissions also alter radiative forcing by directly or indirectly affecting emissions of several greenhouse gases $\left(\mathrm{N}_{2} \mathrm{O}, \mathrm{CH}_{4}, \mathrm{CO}_{2}\right.$ and $\left.\mathrm{O}_{3}\right)$ as well as aerosol formation (Butterbach-Bahl et al., 2011; de Vries et al., 2017, 2011; Erisman et al., 2011). The two strongest influences of reactive $\mathrm{N}$ on radiative forcing are the warming impact of increased $\mathrm{N}_{2} \mathrm{O}$ emissions (Reay et al., 2012; Tian et al., 2020; UNEP, 2013) and the cooling impact of increased carbon (C) sequestration in terrestrial and marine ecosystems that occurs when $\mathrm{N}$ deposition stimulates productivity in N-limited systems (De Vries et al., 2017, 2011a; LeBauer and Treseder, 2008; Vitousek and Howarth, 1991; Xia and Wan, 2008). This 'carbon bonus' is considered an unintended benefit of human disturbance of the 
N cycle (Janssens and Luyssaert, 2009) and should be accounted for when balancing threats and benefits of $\mathrm{N}$ for sustainable development (Zhang et al., 2015).

The largest N-induced C sink likely occurs in forests (De Vries et al., 2017; Liu and Greaver, 2009). Despite rapid deforestation and adverse effects of multiple global change drivers on forest growth, forests represented a net $\mathrm{C}$ sink of 2,100 Tg C per year over the period 2001-2019 (Harris et al., 2021), absorbing about 18\% of global fossil fuel emissions (Friedlingstein et al., 2020). Regional N deposition has increased by a factor 1.5-7 since pre-industrial times, particularly in Europe and Asia (Wang et al., 2017). In 2010, forests received $23 \mathrm{Tg} \mathrm{N} \mathrm{yr}^{-1}$ via atmospheric deposition or $6 \mathrm{~kg} \mathrm{~N} \mathrm{ha}^{-1} \mathrm{yr}^{-1}$ on average (Schwede et al., 2018). Although the amount of $\mathrm{N}$ supplied by deposition is small compared to the rate of internal N cycling (Cleveland et al., 2013; Du and De Vries, 2018; Högberg, 2012), it might substantially increase forest $\mathrm{C}$ sequestration if this $\mathrm{N}$ is retained in stable $\mathrm{C}$ pools with long turnover times. Nitrogen deposition can increase forest $\mathrm{C}$ sequestration by increasing net primary productivity ( $\mathrm{C}$ assimilation through photosynthesis, NPP), by increasing the share of $\mathrm{C}$ allocated to wood (with higher $\mathrm{C}: \mathrm{N}$ ratios than other tree compartments), or by increasing litter inputs and/or reducing soil respiration and thereby increasing $\mathrm{C}$ storage in soils (Janssens et al., 2010; Janssens and Luyssaert, 2009). The size of the global N-induced C sink is thus determined by total $\mathrm{N}$ deposition onto forests and the amount of $\mathrm{C}$ sequestered per unit of $\mathrm{N}$ deposition ('C-N response' from hereon).

The magnitude and spatial variation of the $\mathrm{N}$-induced forest $\mathrm{C}$ sink and its contribution to 'offsetting' global $\mathrm{N}$-induced $\mathrm{N}_{2} \mathrm{O}$ emissions is highly uncertain. Nitrogen-induced $\mathrm{C}$ sequestration has been estimated with different approaches: (i) dynamic global vegetation models (DGVMs) (Fleischer et al., 2015, 2013; Jain et al., 2009; Lu and Tian, 2013; Zaehle et al., 2011), (ii) stoichiometric scaling (Du and De Vries, 2018; Nadelhoffer et al., 1999; Wang et al., 2017; Zhu et al., 2017), (iii) observational studies along deposition gradients (Flechard et al., 2020; Magnani et al., 2007; Solberg et al., 2009; Thomas et al., 2010) and (iv) meta-analyses of data from forest fertilization experiments (Liu and Greaver, 2010; SchulteUebbing and De Vries, 2018; Vadeboncoeur, 2010). While early studies put the upper limit

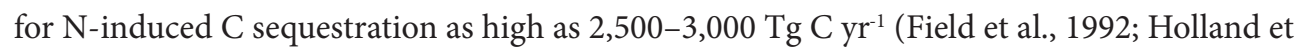
al., 1997; Hudson et al., 1994; Schindler and Bayley, 1993), more recent estimates have been constrained to a relatively narrow range from 250 to $560 \mathrm{Tg} \mathrm{C} \mathrm{yr}^{-1}$ for both forest biomass and soils and from 130 to $345 \mathrm{Tg} \mathrm{C} \mathrm{yr}^{-1}$ for forest biomass only (based on estimates published by de Vries et al., 2014; Du and de Vries, 2018; Fleischer et al., 2015; Jain et al., 2009; Liu and Greaver, 2009; Nadelhoffer et al., 1999; Schulte-Uebbing and de Vries, 2018; Thomas et al., 2010; Thornton et al., 2007; Wang et al., 2017; Zaehle et al., 2011). 
Current approaches to estimating the global $\mathrm{N}$-induced $\mathrm{C}$ sink hardly consider site factors affecting variation in $\mathrm{C}-\mathrm{N}$ response. Most empirical studies simply multiply a global average C-N response with global $\mathrm{N}$ deposition (e.g., Nadelhoffer et al., 1999b; Thomas et al., 2010) or at most distinguish average C-N responses for major biomes (e.g., Du and de Vries, 2018; Schulte-Uebbing and de Vries, 2018). However, forest fertilization experiments show that the $\mathrm{C}-\mathrm{N}$ response varies strongly even within biomes. For example, the reported response to $\mathrm{N}$ addition in temperate forest sites ranges from a strong stimulation (e.g., Gentilesca et al., 2013) to no response (e.g., Finzi, 2009) or even a reduction (e.g., Lovett et al., 2013) of the forest biomass $\mathrm{C}$ sink. Site factors potentially affecting variation in C-N response include biome, tree and stand characteristics, nutrient and water availability, and $\mathrm{N}$ saturation.

First, the forest $\mathrm{C}$ sink response to $\mathrm{N}$ addition decreases from boreal to tropical regions. In boreal regions, low temperatures constrain $\mathrm{N}$ mineralization, whereas tropical forests are characterized by high $\mathrm{N}$ inputs from both mineralization and biological $\mathrm{N}_{2}$ fixation (BNF) as well as high $\mathrm{N}$ losses through leaching and denitrification (Bai et al., 2012; Brookshire et al., 2012; Cleveland et al., 1999; Vitousek et al., 2013). Both symbiotic and asymbiotic BNF strongly decline with latitude (Menge et al., 2014; Wang and Houlton, 2009), and average rates of BNF across tropical forests are a factor 2-20 higher than in temperate and boreal forests (Cleveland et al., 1999; Du and De Vries, 2018; Vitousek et al., 2013).

Second, findings from fertilization experiments and forest growth inventories reveal that C-N response is affected by stand characteristics and tree species (Allen et al., 2010; Lovett et al., 2013; Solberg et al., 2009), potentially moderated by preferential associations with either arbuscular (AM) or ectomycorrhizal (EM) fungi (Thomas et al., 2010). While both fungi provide trees with $\mathrm{N}$ in exchange for $\mathrm{C}$ from root exudates, $\mathrm{AM}$ fungi obtain this $\mathrm{N}$ mainly from inorganic $\mathrm{N}$, while EM fungi can access $\mathrm{N}$ from soil organic matter (Bradford, 2014). Hence, trees associated with AM fungi may benefit more from $\mathrm{N}$ addition (Thomas et al., 2010). Association with EM fungi might also increase soil C storage by limiting available $\mathrm{N}$ to free-living composers (Averill et al., 2014). Young stands have been found to respond more strongly to $\mathrm{N}$ addition than old stands (Schulte-Uebbing and De Vries, 2018; Vadeboncoeur, 2010), possibly because N increases NPP through an increase in canopy leaf area index, which has less benefits in older forests where the canopy is already closed (De Vries and Posch, 2011; McCarthy et al., 2006). In addition, younger forests have a higher nutrient demand and their growth is less limited by light availability (Sun et al., 2016), and soil pH declines as forest stands mature even under natural conditions (Binkley and Högberg, 2016), which reduces availability of micro-nutrients.

Third, according to the Liebig's law of the minimum (Liebig, 1840), N only stimulates forest 
growth if growth is not limited by the availability of other nutrients or water. Phosphorus (P) limitation in tropical forests might constrain the $\mathrm{C}$ sink response to $\mathrm{N}$ addition (Cusack et al., 2011; Tanner et al., 1998), a hypothesis supported by observed increases in forest biomass production after P addition (Jiang et al., 2020; Li et al., 2016). The absence of a growth response to $\mathrm{N}$ in forest fertilization experiments has often been explained by (micro)nutrient deficiency such as calcium $(\mathrm{Ca})$, as evidenced by low foliar Ca:N ratios (Baribault et al., 2010; Lovett et al., 2013; Mainwaring et al., 2014). Forests on fertile soils also display a higher ratio of net ecosystem productivity (NEP) to gross primary productivity (GPP) (Fernández-Martínez et al., 2014) and allocate more $C$ to wood production (Vicca et al., 2012). This suggests that these forests are more efficient in sequestering $C$ assimilated through photosynthesis compared to forests on less fertile soils, ultimately resulting in larger $\mathrm{C}-\mathrm{N}$ responses (Janssens and Luyssaert, 2009). Finally, NPP response to $\mathrm{N}$ has been shown to increase with precipitation rates in arid and semi-arid regions (Yahdjian et al., 2011), showing the relevance of water availability.

Lastly, at high levels of $\mathrm{N}$ addition, $\mathrm{N}$ leaching increases and $\mathrm{N}$ retention decreases (Aber et al., 1989; Templer et al., 2012), evidenced by a decreasing response to $\mathrm{N}$ with increasing levels of $\mathrm{N}$ application in fertilization experiments (Högberg et al., 2006; Schulte-Uebbing and De Vries, 2018; Tian et al., 2016). Forest C-N response may thus be smaller in sites with high current or historical (cumulative) rates of $\mathrm{N}$ deposition.

A better understanding of site factors determining variation in $\mathrm{C}-\mathrm{N}$ response is key to improving estimates of the global $\mathrm{N}$-induced forest $\mathrm{C}$ sink and its spatial variation under current and future reactive $\mathrm{N}$ deposition. The main aim of this study is to derive spatially explicit estimates of $\mathrm{C}-\mathrm{N}$ responses and total $\mathrm{N}$-induced $\mathrm{C}$ sequestration in forest aboveground woody biomass (AGWB). This study focused on $\mathrm{N}$-induced $\mathrm{C}$ sequestration in AGWB only, neglecting $\mathrm{N}$-induced $\mathrm{C}$ sequestration in belowground biomass and soil. Belowground woody biomass production is typically around 20\% of AGWB (Cleveland et al., 2013), and thus assuming a similar response to $\mathrm{N}$ addition as for AGWB, the effect of neglecting this sink is likely small. Nitrogen addition can also increase soil $\mathrm{C}$ sequestration either by increasing litter inputs and/or by reducing soil respiration (Janssens et al., 2010). Soil C sequestration was not included in our meta-analysis because very few long-term fertilization experiments have measured changes in soil C. We used multiple regression to disentangle the drivers of variation in $\mathrm{C}-\mathrm{N}$ response and to quantify spatial variation in $\mathrm{C}-\mathrm{N}$ response and $\mathrm{N}$-induced forest $\mathrm{C}$ sequestration, based on data from forest fertilization experiments as presented in Chapter 5 . We also quantify the net contribution of human $\mathrm{N}$ use on greenhouse gas (GHG) emissions by comparing $\mathrm{N}$-induced $\mathrm{C}$ sequestration in $\mathrm{AGWB}$ to anthropogenic $\mathrm{N}_{2} \mathrm{O}$ emissions. 


\subsection{Methods}

\subsubsection{Meta-regression}

\section{Estimation of effect sizes and variances}

We used meta-regression based on data from forest $\mathrm{N}$ fertilization experiments to test hypotheses on drivers affecting $\mathrm{C}-\mathrm{N}$ response and to predict global variation in $\mathrm{C}-\mathrm{N}$ response. Data on forest $\mathrm{AGWB}$ production in response to $\mathrm{N}$ fertilization were collected from original studies. The steps for the literature search, criteria for the inclusion of experiments, data extraction, calculation of effect sizes and their variances and characteristics of the study plots have been described in detail in Chapter 5. In summary, the effect size (C-N response) for each experiment was calculated by subtracting total AGWB increment (expressed in $\mathrm{kg}$ C) in unfertilized plots from total AGWB increment in fertilized plots, and dividing this by the total amount of $\mathrm{N}$ added over the course of the experiment. Both mean responses of fertilized and unfertilized plots and their variances were extracted, and the variance of the effect size was calculated as the sum of the squared standard errors of the mean response in the fertilized and unfertilized plot (Borenstein et al., 2009; Hedges et al., 1999).

For the analysis, we slightly modified the original dataset described in Chapter 5. C-N responses were log-transformed to better fit a normal distribution. In addition, five observations with unusually high C-N responses (between 60 and $160 \mathrm{~kg} \mathrm{C}$ per $\mathrm{kg} \mathrm{N}$ ) from a single study in Scotland (Gentilesca et al., 2013) were adapted. Due to high leverage of these observations, we constrained these to a maximum of $60 \mathrm{~kg} \mathrm{C}$ per $\mathrm{kg} \mathrm{N}$, in line with previous studies that indicate that $\mathrm{C}-\mathrm{N}$ responses mostly range between $5-35 \mathrm{~kg} \mathrm{C}$ per $\mathrm{kg} \mathrm{N}$ with a maximum near 50 (30-70) kg C per kg N (De Vries et al., 2014, 2009; Sutton et al., 2008).

\section{Deriving data on site factors}

We hypothesized that $\mathrm{C}-\mathrm{N}$ response increases with water availability (precipitation and precipitation excess) and with soil fertility (cation exchange capacity, clay content, organic $\mathrm{C}, \mathrm{N}$ content, $\mathrm{pH}$ ), and decreases with tree age, $\mathrm{N}$ saturation (cumulative $\mathrm{N}$ deposition or $\mathrm{N}$ addition rate, $\mathrm{N}$ addition rate, soil $\mathrm{C}: \mathrm{N}$ ratio), and from boreal to tropical regions (temperature, potential evapotranspiration, latitude). Data on site factors were obtained from the original publications for tree age, $\mathrm{N}$ addition rate and latitude or derived from global datasets (for climate, soil parameters and $\mathrm{N}$ deposition, see Table 6.1).

Climate data were obtained from WorldClim 2.1 (Fick and Hijmans, 2017) and CRU TS4.04 (Harris et al., 2020). As an indicator for water availability, precipitation excess was calculated as the difference between potential evapotranspiration (from CRU) and actual evapotranspiration derived from precipitation and potential evapotranspiration following 
Zhang et al. (2001). Soil properties (soil N content, organic C content, cation exchange capacity, clay content and soil $\mathrm{pH}$ ) were retrieved at depth intervals of $0-5 \mathrm{~cm}, 5-15 \mathrm{~cm}$ and $15-30 \mathrm{~cm}$ from ISRIC soil grids (Hengl et al., 2017). The weighted mean for the $0-30 \mathrm{~cm}$ soil layer was calculated given the relevance for trees' growing conditions. Soil C:N ratio was derived by dividing soil organic $\mathrm{C}$ by soil $\mathrm{N}$. Ambient $\mathrm{N}$ deposition rates to forests were obtained from Schwede et al. (2018) who estimate forest-specific N deposition rates for the year 2010 based on results from the EMEP model (Simpson et al., 2012). Cumulative $\mathrm{N}$ deposition was estimated for each experiment by summing annual deposition values for the 50 years prior to start of the fertilization experiment. Annual $\mathrm{N}$ deposition for the years 1950-2010 was estimated based on data for the years 1900-2050 from Rao et al. (2017). As the spatial resolution of this dataset is coarse, we interpolated between available years based on deposition trends from decadal data from Galloway et al. (2004), and finally derived annual values by linear interpolation. In addition, information on tree species was extracted from the original studies, and all species were classified according to preferential association with either AM or EM fungi (Brundrett, 2009). However, as many study plots contained both trees with AM and EM associations (or with unclear associations), plots could not be unambiguously classified as either 'AM' or 'EM', and therefore mycorrhizal interaction was not included in the analysis.

\section{Model development}

To explore the controls of forest $\mathrm{C}-\mathrm{N}$ response, we built linear mixed-effects regression models based on hypotheses regarding factors driving $\mathrm{C}-\mathrm{N}$ response (Viechtbauer et al., 2015) as follows:

$$
\mathrm{y}_{\mathrm{i}}=\beta_{0}+\beta_{1}{ }^{*} \mathrm{x}_{\mathrm{i} 1}+\beta_{2}{ }^{*} \mathrm{x}_{\mathrm{i} 2}+\ldots+\beta_{\mathrm{p}}{ }^{*} \mathrm{x}_{\mathrm{ip}}+\mathrm{u}_{\mathrm{i}}+\varepsilon_{\mathrm{i}}
$$

where $x_{i}$ denotes the value of the $j^{\text {th }}$ explanatory variable in the $i^{\text {th }}$ study, $\beta_{j}$ represents the corresponding model coefficient indicating how the size of the effect changes as $\mathrm{x}_{\mathrm{i}}$ increases by one unit, $\beta_{0}$ stands for the model intercept, $u_{i}$ denotes a random effect and $e_{i}$ the withinstudy error.

Meta-analytical regression models assume that observed effects among studies are independent. However, in practice dependencies exist, for example when a study reports results from multiple treatments (which are compared with the same control plot) or when a study reports observations from several locations (Gleser and Olkin, 2009). We accounted for this non-independence by using multivariate meta-modelling with restricted maximumlikelihood estimation, as implemented in metafor (Viechtbauer, 2017, 2010), and used "Paper ID" to specify the random-effects structure of the model. 
Table 6.I | Global datasets used to derive data on site factors for experimental plots used in the metaregression and for estimating global spatial variation in $\mathrm{C}-\mathrm{N}$ responses.

\begin{tabular}{|c|c|c|c|}
\hline Variable & Data source \& explanation & $\begin{array}{l}\text { Spatial } \\
\text { resolution }\end{array}$ & Reference \\
\hline $\begin{array}{l}\text { Mean annual temperature } \\
(M A T)\end{array}$ & WorldClim 2.1 (1970-2000) & $0.16^{\circ} \times 0.16^{\circ}$ & $\begin{array}{l}\text { (Fick and Hijmans, } \\
2017 \text { ) }\end{array}$ \\
\hline Precipitation (PREC) & idem & idem & idem \\
\hline $\begin{array}{l}\text { Potential } \\
\text { evapotranspiration (PET) }\end{array}$ & CRUTS 4.04 (2011-2019) & $0.5^{\circ} \times 0.5^{\circ}$ & (Harris et al., 2020) \\
\hline Precipitation excess (PE) & $\begin{array}{l}\text { Calculated as precipitation (PREC) minus actual } \\
\text { evapotranspiration (AET) }\end{array}$ & $0.5^{\circ} \times 0.5^{\circ}$ & Own calculations \\
\hline Soil N content (SoilN) & ISRIC soil grids (weighted average $0-30 \mathrm{~cm}$ ) & $250 \times m 250 \mathrm{~m}$ & (Hengl et al., 2017) \\
\hline Soil clay content (CLAY) & idem & idem & idem \\
\hline Soil organic $\mathrm{C}$ content $(O C)$ & idem & idem & idem \\
\hline Soil $p H(p H)$ & idem & idem & idem \\
\hline $\begin{array}{l}\text { Ambient } \mathrm{N} \text { deposition } \\
(D E P)\end{array}$ & $\begin{array}{l}\text { Forest-specific } \mathrm{N} \text { deposition rates based on the } \\
\text { EMEP model for the year } 2010\end{array}$ & $1^{\circ} \times 1^{\circ}$ & $\begin{array}{l}\text { (Schwede et al., } \\
2018)\end{array}$ \\
\hline $\begin{array}{l}\text { Cumulative } \mathrm{N} \text { deposition } \\
\text { (DEPcum) }\end{array}$ & $\begin{array}{l}\text { N deposition data for } 1900,1950 \text { \& } 2000 \text {, and } \\
\text { projections for } 2050 \text { based on SSP scenarios; } \\
\text { interpolation based on decadal emission estimates } \\
\text { from Galloway et al. (2004) }\end{array}$ & $1^{\circ} \times 1^{\circ}$ & $\begin{array}{l}\text { (Galloway et al., } \\
2004 \text {; Rao et al., } \\
2017 \text { ) }\end{array}$ \\
\hline Tree age $(A G E)$ & For regression: extracted from original studies & & \\
\hline Tree age & $\begin{array}{l}\text { For global upscaling: Global Tree age database } \\
\text { (GFADVI.I); tree age was calculated as weighted } \\
\text { mean based on forest cover fraction per plant } \\
\text { functional type and age class }\end{array}$ & $0.5^{\circ} \times 0.5^{\circ}$ & $\begin{array}{l}\text { (Poulter et al., } \\
2019 \text { ) }\end{array}$ \\
\hline
\end{tabular}

Table 6.2 | Global datasets used for estimating N-induced forest $\mathrm{C}$ sequestration and net GHG emissions from human $\mathrm{N}$ use.

\begin{tabular}{|c|c|c|c|}
\hline Variable & Data source \& explanation & $\begin{array}{l}\text { Spatial } \\
\text { resolution }\end{array}$ & Reference \\
\hline Fraction forest cover & Global Forest Monitoring Project & $20 \mathrm{~km} \times 20 \mathrm{~km}$ & $\begin{array}{l}\text { (Hansen et al., } \\
2013)\end{array}$ \\
\hline Forest biome & $\begin{array}{l}\text { WWF ecoregions aggregated to } 4 \text { classes (see } \\
\text { Table SI) combined with FAO Global Ecological } \\
\text { Zones (GEZ) (see Figure S6.Ib) where WWF } \\
\text { regions are classified as 'other' }\end{array}$ & -- (vector) & $\begin{array}{l}\text { (FAO/IIASA, 20I2; } \\
\text { Olson et al., 200I) }\end{array}$ \\
\hline $\mathrm{N}_{2} \mathrm{O}$ from cropland soils & $\begin{array}{l}\text { Multi-model mean from six dynamic global } \\
\text { vegetation models for the years } 2007-2016\end{array}$ & $0.5^{\circ} \times 0.5$ & $\begin{array}{l}\text { (Tian et al., 2020, } \\
2019)\end{array}$ \\
\hline $\begin{array}{l}\mathrm{N}_{2} \mathrm{O} \text { due to } \mathrm{N} \text { deposition } \\
\text { on land }\end{array}$ & idem & idem & idem \\
\hline Regional $\mathrm{N}_{2} \mathrm{O}$ emissions & $\begin{array}{l}\text { Average emission estimates from several models } \\
\text { and datasets for the years } 2007-2016\end{array}$ & $\begin{array}{l}10 \text { world } \\
\text { regions }\end{array}$ & (Tian et al., 2020) \\
\hline
\end{tabular}


We first tested our hypotheses by regressing individual predictors and combinations of

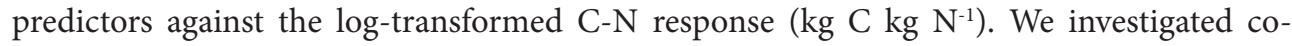
linearity among explanatory variables to ensure independence. Most explanatory variables followed a log-normal distribution and were thus log-transformed. McFadden's pseudo $\mathrm{R}^{2}$ values and Akaike's Information Criterion (AIC) were used to compare regression models, where the best model is characterised by high $\mathrm{R}^{2}$ and low AIC values.

\subsubsection{Spatial variation in nitrogen-induced forest carbon sink and climate footprint of human nitrogen use}

\section{Spatial variation in nitrogen-induced forest carbon sink}

To make spatial predictions for $\mathrm{C}-\mathrm{N}$ response, global datasets for site-factors best explaining variation in $\mathrm{C}-\mathrm{N}$ response (PET, soil $\mathrm{N}$ and tree age) were re-projected to a common resolution of $0.5^{\circ} \times 0.5^{\circ}$. Mean tree age class was obtained from the Global Forest Age Dataset (GFAD) V1.1 (Poulter et al., 2019), which provides fractions of tree cover for 15 age classes and four plant functional types (Table 6.2). Spatial variation in forest C-N response was predicted from variation in site factors based on the regression model (Section 6.2.1). Uncertainty in the predicted C-N responses assessed by calculating the $95 \%$ confidence interval.

Total N-induced $\mathrm{C}$ sequestration in forest AGWB was calculated by multiplying C-N responses with forest-specific $\mathrm{N}$ deposition rates from the EMEP model (Table 6.1). Total $\mathrm{N}$ deposition was calculated by multiplying forest-specific $\mathrm{N}$ deposition rates (in $\mathrm{mg} \mathrm{N}$ $\mathrm{m}-2$ ) with forest area, derived by multiplying the fraction forest cover from Hansen et al. (2013) with grid cell area (Table 6.2). To summarize the effect per biome we delineated global biomes based on a combination of WWF ecoregions and FAO Global ecological zones (Table 6.2 \& Table S6.1). Mean C-N responses were calculated as weighted means of predictions using grid cell forest area as weights.

\section{Climate footprint of human nitrogen use}

Both natural and anthropogenic sources contribute to $\mathrm{N}$ deposition. Anthropogenic emissions have been estimated to contribute $78 \%$ to total $\mathrm{N}$ deposition onto oceans (Duce et al., 2008) and $84 \%$ to terrestrial $\mathrm{N}$ deposition in the US (Zhang et al., 2012). The relative contribution of natural emission sources to total $\mathrm{N}$ deposition declines with the total $\mathrm{N}$ deposition rate and rarely exceeds $2 \mathrm{~kg} \mathrm{~N} \mathrm{ha}^{-1} \mathrm{yr}^{-1}$ (Zhang et al., 2012). We thus estimated the anthropogenic share in total $\mathrm{N}$ deposition onto forests (Ndep) as $\mathrm{Ndep} \times 0.8$ for regions where Ndep $<10 \mathrm{~kg} \mathrm{~N} \mathrm{ha}^{-1} \mathrm{yr}^{-1}$, and as Ndep - 2 for regions where Ndep $>10 \mathrm{~kg} \mathrm{~N} \mathrm{ha}^{-1} \mathrm{yr}^{-1}$. This resulted in a global average contribution of anthropogenic sources to total $\mathrm{N}$ deposition 
of $85 \%$. Nitrogen-induced C sequestration in forest AGWB attributable to human $\mathrm{N}$ use was calculated by multiplying anthropogenic deposition with mean $\mathrm{C}-\mathrm{N}$ responses.

Human $\mathrm{N}$ use leads to emissions of $\mathrm{N}_{2} \mathrm{O}$, which absorbs $\sim 300$ times as much energy as $\mathrm{CO}_{2}$ over a 100-year time span (Stocker et al., 2013). As greenhouse gasses are well-mixed in the atmosphere, their climate impact is global, independent on the location of the source. However, as $\mathrm{N}$-induced forest $\mathrm{C}$ sequestration varies in space, the net climate impact of $\mathrm{N}$ use (i.e., the net result of the warming effect of $\mathrm{N}_{2} \mathrm{O}$ emissions and the cooling effect of $\mathrm{N}$-induced forest $\mathrm{C}$ sequestration) does depend on its spatial pattern (assuming that the same activities cause both $\mathrm{N}_{2} \mathrm{O}$ emissions and $\mathrm{N}$ deposition). The spatial variation in the net $\mathrm{GHG}$ footprint of human $\mathrm{N}$ use was calculated by estimating the proportion of anthropogenic $\mathrm{N}_{2} \mathrm{O}$ emissions (converted to C-equivalents ) that is 'offset' by forest $\mathrm{C}$ sequestration induced by anthropogenic $\mathrm{N}$ deposition.

Spatially explicit direct and indirect anthropogenic $\mathrm{N}_{2} \mathrm{O}$ emissions were estimated based on data presented in Tian et al. (2020), who distinguish three sources of anthropogenic $\mathrm{N}_{2} \mathrm{O}$ : (i) agriculture (including the sub-categories cropland soils, pastures, manure management and aquaculture), (ii) other anthropogenic sources (fossil fuels, industry, wastewater and biomass burning), (iii) indirect emissions from anthropogenic $\mathrm{N}$ additions (emissions from inland waters and due to $\mathrm{N}$ deposition on land and oceans). Emissions of $\mathrm{N}_{2} \mathrm{O}$ from 'perturbed fluxes' (due to changes in climate, $\mathrm{CO}_{2}$ and land cover) were not included. Spatially explicit anthropogenic $\mathrm{N}_{2} \mathrm{O}$ emissions were estimated by combining estimates for $\mathrm{N}_{2} \mathrm{O}$ emissions from cropland soils and due to deposition on land from the multi-model mean of six terrestrial biosphere models (NMIP; Tian et al., 2019) with regional estimates for the other sub-categories (Table 6.2). Regional emission estimates were allocated to a grid assuming that emissions from pastures, manure management and aquaculture follow the same spatial pattern as cropland $\mathrm{N}_{2} \mathrm{O}$ emissions, while the remaining anthropogenic emissions were distributed homogeneously within a region.

\subsection{Results}

\subsection{Predictors of $\mathbf{C}-\mathbf{N}$ response and model selection}

Across all studies, $\mathrm{N}$ addition enhanced forest AGWB $\mathrm{C}$ sequestration $(\mathrm{p}<0.01)$, but the direction and strength of the response was affected by site factors (Figure S6.2 \& Table S6.2). Forest C-N response increased with decreasing absolute latitude (from tropical to boreal regions, $\mathrm{p}<0.01)$ and also with decreasing temperature $(\mathrm{p}=0.06)$ and PET $(\mathrm{p}<0.01)$. As 
expected, these variables showed a strong correlation (R2>0.7; Figure S6.3). Furthermore, $\mathrm{C}-\mathrm{N}$ response decreased with tree age $(\mathrm{p}<0.01$; Table $\mathrm{S} 6.2)$. Neither $\mathrm{N}$ deposition rate nor cumulative $\mathrm{N}$ deposition explained variation in $\mathrm{C}-\mathrm{N}$ response, but the response tends to decrease with $\mathrm{N}$ addition level ( $\mathrm{p}=0.06$; Table $\mathrm{S6.2}$ ). The $\mathrm{C}-\mathrm{N}$ response strongly increased with soil $\mathrm{N}$ content $(\mathrm{p}<0.01)$, tends to increase with soil organic $\mathrm{C}$ content $(\mathrm{p}=0.15)$ and tends to decline with soil $\mathrm{pH}(\mathrm{p}=0.16)$. The variability in $\mathrm{C}-\mathrm{N}$ response could be described by soil $\mathrm{N}$ content, PET and tree age (Table 6.3) where these site factors explained $68 \%$ of the observed variance in $\mathrm{C}-\mathrm{N}$ responses.

\subsubsection{Forest carbon-to-nitrogen response}

Spatial variation in mean C-N response for forest AGWB is shown in Figure 6.1. Overall, $\mathrm{C}-\mathrm{N}$ response decreases with latitude, from around $8-16 \mathrm{~kg} \mathrm{C}$ per $\mathrm{kg} \mathrm{N}$ in boreal regions to small negative responses from 0 to $-4 \mathrm{~kg} \mathrm{C}$ per $\mathrm{kg} \mathrm{N}$ in the tropics (Figure 6.1a and Figure S6.4). The global (forest-area weighted) average $\mathrm{C}-\mathrm{N}$ response was $2 \mathrm{~kg} \mathrm{C}$ per $\mathrm{kg} \mathrm{N}$ (Table ). This low average is largely driven by the negligible response of tropical forests of $0 \mathrm{~kg} \mathrm{C}$ per $\mathrm{kg} \mathrm{N}$ (ranging from -4 up to 5), which account for $58 \%$ of the global forest area. Average responses for temperate and boreal forests are 4 and $11 \mathrm{~kg} \mathrm{C}$ per $\mathrm{kg} \mathrm{N}$, respectively (Table $6.4)$.

For $59 \%$ of the global forest area we found no significant response of forest AGWB C sequestration to $\mathrm{N}$ addition (Figure 6.1, Table 6.5 \& Figure S6.5). This includes almost 90\% of tropical forests (Table S6.3), but also temperate regions in the US and Southern Europe (Figure 6.1). About one third of global forests responded to $\mathrm{N}$ addition by increasing AGWB $\mathrm{C}$ sequestration $(\mathrm{p}<0.05$; Table 6.5$)$, of which the majority is situated in the boreal region (Figure 6.1 and Table S6.3). Only 5\% of global forests responded to $\mathrm{N}$ addition by decreasing AGWB C sequestration ( $\mathrm{p}<0.05$ ), particularly in the tropics (Figure 6.1 and Table S6.3) and on average receive the lowest rates of $\mathrm{N}$ deposition (4.9 $\mathrm{kg} \mathrm{N} \mathrm{ha}^{-1} \mathrm{yr}^{-1}$, Table 6.5).

Table 6.3 | Summary of selected model for predicting (log-transformed) forest AGWB C-N response

\begin{tabular}{lcccc}
\hline & Coefficient & Lower bound $\mathbf{C l}_{95}$ & Upper bound $\mathbf{C l}_{95}$ & p-value \\
\hline Intercept & 6.10 & 3.25 & 8.95 & $<0.0001$ \\
$\log ($ SoilN $)$ & 0.20 & 0.03 & 0.37 & 0.0257 \\
$\log (\mathrm{PET})$ & -0.51 & -0.87 & -0.14 & 0.0063 \\
$\log ($ Age $)$ & -0.15 & -0.27 & -0.03 & 0.0139 \\
\hline
\end{tabular}




\subsubsection{Global nitrogen-induced forest carbon sink}

Globally, we estimate that $\mathrm{N}$ deposition on forest increases the forest AGWB C sink by 41 $\mathrm{Tg} \mathrm{C} \mathrm{yr}^{-1}$ (Table 6.4). This $\mathrm{C}$ sequestration is realized in only one third of the global forest area where $\mathrm{N}$ significantly increased $\mathrm{C}$ sequestration (Table 6.5). The largest $\mathrm{N}$-induced $\mathrm{C}$ sink occurs in temperate forests of Central Europe, Southern China, Southern Korea, Japan, New Zealand and the Northeast of North America (Figure 6.2a). While C-N response was largest in boreal forests, $\mathrm{N}$-induced stimulation of the forest $\mathrm{C}$ sink was about twice as large in temperate forests compared to boreal forests (Table 6.4 \& Figure 6.2b), due to higher levels of $\mathrm{N}$ deposition in temperate regions (Table $6.4 \&$ Figure S6.6).

The largest negative $\mathrm{N}$-induced $\mathrm{C}$ sink (i.e., $\mathrm{C}$ release) is found for tropical rain-forests (Amazon and the Congolian rainforest; Figure 6.2a). However, in 95\% of forests where mean $\mathrm{C}-\mathrm{N}$ response was negative, the direction of this response was uncertain $(\mathrm{p}>0.05$, Figure 6.1), leading to a mean $\mathrm{N}$-induced $\mathrm{C}$ release of $20 \mathrm{Tg} \mathrm{C} \mathrm{yr}^{-1}$ in tropical forests that might vary from


the uncertainty associated with the estimated $\mathrm{N}$-induced forest $\mathrm{C}$ sequestration increases from boreal to temperate to tropical areas, showing that forests can act as $\mathrm{C}$ sink as well as $\mathrm{C}$ source (Figure 6.2b).

\subsubsection{Climate footprint of human nitrogen use}

Comparing spatial variation in anthropogenic $\mathrm{N}_{2} \mathrm{O}$ emissions to forest $\mathrm{C}$ sequestration induced by anthropogenic $\mathrm{N}$ deposition shows that the warming effect of $\mathrm{N}_{2} \mathrm{O}$ outweighs the cooling effect of $\mathrm{C}$ sequestration almost everywhere (Figure 6.3). In most regions where $\mathrm{N}$ deposition increases forest AGWB C sequestration, this effect compensates less than $20 \%$ of the warming effect of $\mathrm{N}_{2} \mathrm{O}$. The only exception are regions in Russia, where the warming $\mathrm{N}_{2} \mathrm{O}$ effect is fully offset by $\mathrm{N}$-induced C sequestration, but this is mainly because $\mathrm{N}_{2} \mathrm{O}$ emissions in this region are low (Figure 6.3). For the whole boreal region, which has both the highest anthropogenic $\mathrm{N}$-induced $\mathrm{C}$ sequestration and the lowest $\mathrm{N}_{2} \mathrm{O}$ emissions, the share of $\mathrm{N}_{2} \mathrm{O}$ warming compensated is $23 \%$, while this is only $5 \%$ in the temperate region and $1 \%$ in the tropics (Table 6.6).

\subsection{Discussion \& Conclusion}

\subsection{Site factors explaining variation in $\mathrm{C}-\mathrm{N}$ response}

Biome: In line with previous studies, we found a decrease in $\mathrm{C}-\mathrm{N}$ response from boreal to 


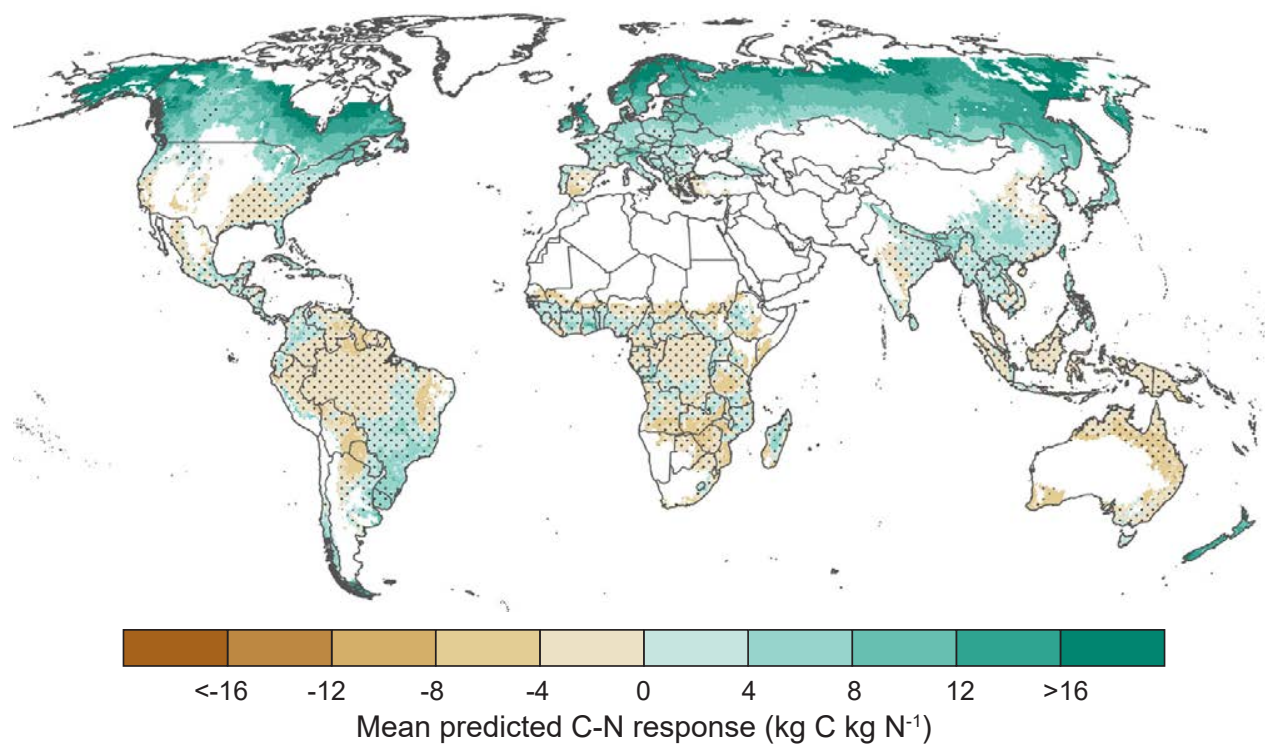

Figure 6.I | Spatial variation in mean C-N response in forest aboveground woody biomass predicted by the regression model based on spatial variation soil $\mathrm{N}$ content, mean tree age and potential evapotranspiration (PET). Maps showing spatial variation in the upper and lower confidence limits for the $\mathrm{C}-\mathrm{N}$ response are shown in Figure S6.5. Dots indicate regions where the predicted response was not significant $(p>0.05)$. Grid cells with forest cover $<5 \%$ are masked.

a

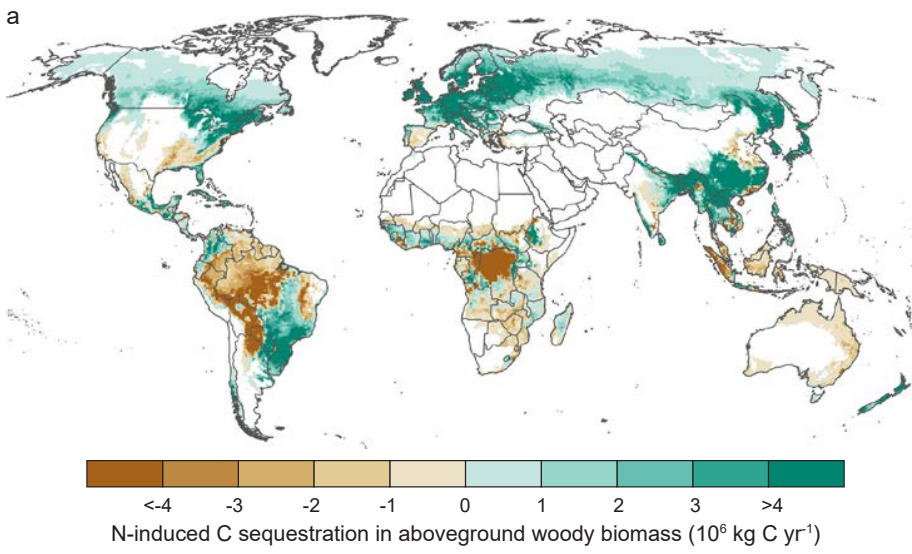

Boreal Temperate Tropical

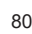

60

40

$\overbrace{0}^{2}$

0

$-20$

$-40$

$-60$

Figure 6.2 | a, Spatial variation in the $\mathrm{N}$-induced forest $\mathrm{C}$ sink in aboveground woody biomass estimated by multiplying mean $\mathrm{C}-\mathrm{N}$ responses (Figure 6.I) with $\mathrm{N}$ deposition to forests. Maps showing estimated $\mathrm{N}$-induced forest $\mathrm{C}$ sink using the upper and lower prediction limits for $\mathrm{C}-\mathrm{N}$ response are shown in Figure S6.7. b. Total $\mathrm{N}$-induced $\mathrm{C}$ sink on forest aboveground woody biomass in boreal, temperate and tropical forests, shown separately for grid cells where the mean predicted $\mathrm{C}-\mathrm{N}$ response was positive (green bars) or negative (brown bars). Error bars show $95 \% \mathrm{Cl}$. 
Table 6.4 | Total forest area, total and mean $\mathrm{N}$ deposition rates, mean $\mathrm{C}-\mathrm{N}$ response predicted by the model, and total and mean $\mathrm{N}$-induced $\mathrm{C}$ sequestration for each biome. For the last three columns, upper and lower $95 \%$ confidence limits shown in brackets.

\begin{tabular}{|c|c|c|c|c|c|c|}
\hline & $\begin{array}{l}\text { Forest area } \\
\left(10^{8} \mathrm{ha}\right)^{1}\end{array}$ & $\begin{array}{l}\text { N deposition } \\
\left(T g \mathrm{Nr}^{-}\right)^{2}\end{array}$ & 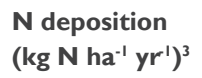 & $\begin{array}{l}\text { N-ind. C seq. } \\
\left(T g C_{y r^{1}}\right)^{4}\end{array}$ & 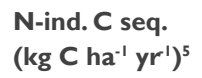 & 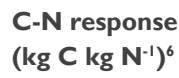 \\
\hline Boreal & 6.8 & 1.1 & 1.7 & $13(5-23)$ & $19(7-35)$ & II (4-2I) \\
\hline Temperate & 6.8 & 6.7 & 9.8 & $25(0-55)$ & $37(0-82)$ & $4(0-8)$ \\
\hline Tropical & 18.3 & 15.3 & 8.4 & $3(-58-81)$ & $2(-33-46)$ & $0(-4-5)$ \\
\hline World & 31.9 & 23.1 & 7.3 & $4 \mid(-53-159)$ & $13(-|7-5|)$ & $2(-2-7)$ \\
\hline
\end{tabular}

' Derived from an overlay of fraction forest cover at $20 \times 20 \mathrm{~km}^{2}$ from Hansen et al. (2013) with biome map (see Figure S6. Ia).

${ }^{2}$ Derived by multiplying forest-specific $\mathrm{N}$ deposition rates for 2010 from Schwede et al. (2018) with total forest area.

${ }^{3}$ Total $\mathrm{N}$ deposition divided by total forest area.

${ }^{4}$ Calculated by multiplying the mean predicted $\mathrm{C}-\mathrm{N}$ response in each grid cell with total $\mathrm{N}$ deposition to forests. Lower and upper limits of the range are derived by multiplying the lower and upper $95 \%$ confidence limits of predicted C-N responses with $\mathrm{N}$ deposition to forests.

${ }^{5}$ Total $\mathrm{C}$ sequestration divided by total forest area

${ }^{6}$ Forest-area-weighed $\mathrm{C}-\mathrm{N}$ responses, calculated by dividing mean total $\mathrm{C}$ sequestration by total $\mathrm{N}$ deposition. Lower and upper limits of the range are derived by dividing the lower/upper confidence limit for total $\mathrm{C}$ sequestration by total $\mathrm{N}$ deposition.

Table 6.5 | Share of global forests in regions where the regression model predicts a positive C-N response $(\mathrm{Cl} 95, \mathrm{lb}>0, \mathrm{p}<0.05)$, negative $\mathrm{C}-\mathrm{N}$ response $(\mathrm{Cl} 95, \mathrm{ub}<0, \mathrm{p}<0.05)$, or no significant $\mathrm{C}-\mathrm{N}$ response (dotted areas in Figure 6.I). For each region, the table presents mean $\mathrm{C}-\mathrm{N}$ response, mean $\mathrm{N}$ deposition rates and total $\mathrm{N}$-induced $\mathrm{C}$ sequestration.

\begin{tabular}{|c|c|c|c|c|}
\hline & $\begin{array}{l}\text { Share of global } \\
\text { forest area }\end{array}$ & $\begin{array}{l}\text { N deposition } \\
\left(\mathbf{k g ~ N ~ h a - 1 ~} \mathbf{y r}^{-1}\right)\end{array}$ & $\begin{array}{c}\text { N-induced } C \text { sequestr. } \\
\left(\operatorname{Tg} C \mathrm{yr}^{\prime}\right)\end{array}$ & $\begin{array}{l}\text { C-N response } \\
\left(\mathrm{kgC} \mathrm{kg} \mathrm{N}^{-1}\right)\end{array}$ \\
\hline Positive $C-N$ response $(p<0.05)$ & $36 \%$ & 5.4 & $45(16$ to 81$)$ & $7(3$ to 13$)$ \\
\hline Negative C-N response $(p<0.05)$ & $5 \%$ & 4.9 & $-4(-7$ to -1$)$ & $-5(-8$ to -1$)$ \\
\hline Insignificant $\mathrm{C}-\mathrm{N}$ response & $59 \%$ & 8.5 & $3(-65$ to 85$)$ & $0(-4$ to 5$)$ \\
\hline
\end{tabular}

tropical regions, represented by a negative correlation of $\mathrm{C}-\mathrm{N}$ response with $\mathrm{PET}$, temperature and latitude (Figure S6.2). PET, temperature and latitude were strongly correlated (Figure S6.3) whereas PET explained slightly more of the variation in $\mathrm{C}-\mathrm{N}$ response than temperature and latitude. This might be because PET (in contrast to latitude) captures differences between tropical lowland and highland forests, supporting the hypothesis that $\mathrm{N}$ limitation increases with elevation due to temperature and moisture effects on mineralization rates (Dalling et al., 2016) whereas P limitation decreases with elevation (Fisher et al., 2013) and thus highelevation sites (with lower PET) respond more strongly to $\mathrm{N}$ addition.

Tree and stand characteristics: As expected, young forests responded more strongly to $\mathrm{N}$ addition than old stands, with age alone explained 33\% of the variance in $\mathrm{C}-\mathrm{N}$ response. 


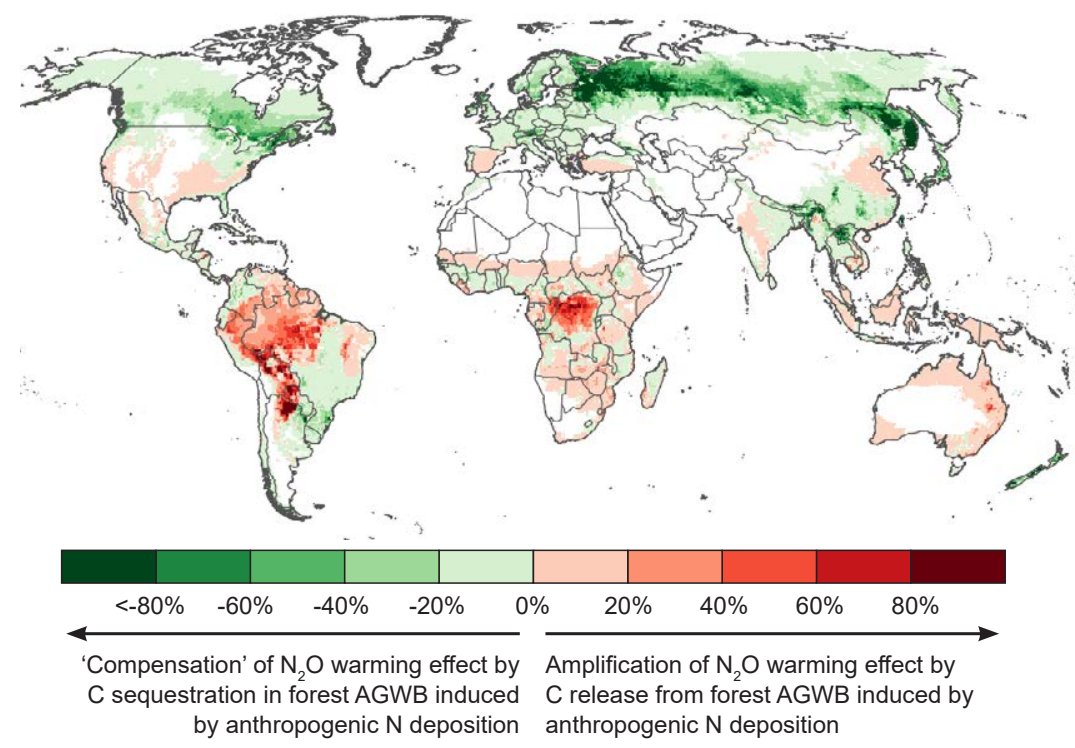

Figure 6.3 | Spatial variation in the ratio of $\mathrm{N}$-induced forest $\mathrm{C}$ sequestration in forest aboveground woody biomass (considering anthropogenic $\mathrm{N}$ deposition only) to anthropogenic $\mathrm{N}_{2} \mathrm{O}$ emissions (expressed in C-equivalents). Green areas indicate a reduction of $\mathrm{N}_{2} \mathrm{O}$ 's climate impact by $\mathrm{N}$-induced $\mathrm{C}$ sequestration, red areas an amplification the climate impact of $\mathrm{N}_{2} \mathrm{O}$ by $\mathrm{N}$-induced $\mathrm{C}$ release. Data on anthropogenic $\mathrm{N}_{2} \mathrm{O}$ emissions are derived from Tian et al. (2020); see Table 6.2. Grid cells with forest cover $<5 \%$ are masked; though note that $\mathrm{N}_{2} \mathrm{O}$ emissions also occur in grid cells without forest.

Table 6.6 | Anthropogenic $\mathrm{N}_{2} \mathrm{O}$ emissions, $\mathrm{N}$-induced forest $\mathrm{C}$ sequestration in forest aboveground woody biomass (considering anthropogenic $\mathrm{N}$ deposition only) and net climate impact of both fluxes (expressed in $\mathrm{Tg} \mathrm{C}$-equivalents per year). Positive fluxes represent a flux leading to an increase in atmospheric GHG concentrations, negative fluxes represent a removal from the atmosphere. Percentages in columns (B) and (C) show ratio between $C$ sequestration or release to anthropogenic $\mathrm{N}_{2} \mathrm{O}$ emissions in column (A) (analogue to percentages shown in Figure 6.3).

\begin{tabular}{|c|c|c|c|c|}
\hline & $\begin{array}{l}\text { Anthr. } \mathrm{N}_{2} \mathrm{O} \\
\text { emissions } \\
\left(\mathrm{Tg} \mathrm{C} \text {-e } \mathrm{yr}^{-1}\right)^{\prime}\end{array}$ & $\begin{array}{l}\text { C seq. in forest } \\
\text { AGWB due to anthr. } \\
\mathrm{N} \text { deposition ( } \mathrm{Tg} \mathrm{C} \\
\left.\mathrm{yr}^{-1}\right)^{2}\end{array}$ & $\begin{array}{l}\text { C release from forest } \\
\text { AGWB due to anthr. } N \\
\text { deposition }\left(\mathrm{Tg} C \mathrm{yr}^{\prime}\right)^{3}\end{array}$ & $\begin{array}{l}\text { Net climate impact } \\
\text { of anthr. } \mathrm{N}_{2} \mathrm{O} \& \text { net } \\
\mathrm{N} \text {-induced } \mathrm{C} \text { sink ( } \mathrm{Tg} \\
\mathrm{C} \text {-e } \mathrm{yr}^{\prime} \text { ) }\end{array}$ \\
\hline & $A$ & $B$ & $C$ & $A+B+C$ \\
\hline Boreal & 45 & $-10(-22 \%)$ & $0(+0 \%)$ & 35 \\
\hline Temperate & 404 & $-23(-6 \%)$ & $2(+0 \%)$ & 383 \\
\hline Tropical & 432 & $-20(-5 \%)$ & $16(+4 \%)$ & 427 \\
\hline World & 882 & $-53(-6 \%)$ & 17 (+2\%) & 846 \\
\hline
\end{tabular}

I Obtained from an overlay of biomes with spatially explicit anthropogenic $\mathrm{N}_{2} \mathrm{O}$ emissions for the years 2007-2016 estimated based on data presented in Tian et al. (2020), see "Climate footprint of human nitrogen use" in Section 6.2.2.

${ }^{2}$ Obtained by multiplying predicted $\mathrm{C}-\mathrm{N}$ responses with anthropogenic $\mathrm{N}$ deposition to forests only for grid cells where mean predicted $\mathrm{C}-\mathrm{N}$ response $>0$ (i.e., where $\mathrm{N}$ was estimated to increase $\mathrm{C}$ sequestration)

${ }^{3}$ Obtained by multiplying predicted $\mathrm{C}-\mathrm{N}$ responses with anthropogenic $\mathrm{N}$ deposition to forests only for grid cells where mean predicted $\mathrm{C}-\mathrm{N}$ response $<0$ (i.e., where $\mathrm{N}$ was estimated to reduce $\mathrm{C}$ sequestration) 
Nutrient and water availability: We hypothesized that forests on fertile soils respond more strongly to $\mathrm{N}$ addition because they convert more GPP to woody biomass (FernándezMartínez et al., 2014; Vicca et al., 2012) and response to $\mathrm{N}$ addition is not constrained by availability of other nutrients (such as $\mathrm{P}, \mathrm{Ca}$ and $\mathrm{Mg}$ ). From all soil fertility indicators (organic $\mathrm{C}$ content, soil $\mathrm{pH}, \mathrm{CEC}$, clay content and $\mathrm{N}$ content), only $\mathrm{N}$ content explained a substantial share of variation in $\mathrm{C}-\mathrm{N}$ response, which was somewhat unexpected as forests with high $\mathrm{N}$ availability would be expected less sensitive to $\mathrm{N}$ addition. On the other hand, $\mathrm{N}$ immobilization may occur in soils with low $\mathrm{N}$ contents, meaning that less of the added $\mathrm{N}$ is available for growth (Schimel and Weintraub, 2003). This possibility agrees with the finding that $\mathrm{C}-\mathrm{N}$ response tends to decrease with $\mathrm{C}: \mathrm{N}$ ratio (though the relation was not significant). Water availability (precipitation and precipitation excess) had no effect on C-N response, possibly because of the low number of experimental fields located in semi-arid regions where growth is water-limited, or because annual PET or PE are poor indicators for (seasonal) water stress on local sites. Using soil moisture in the rootzone as a proxy for water availability, Baribault et al. (2010) found that NPP in northern hardwood forests was equally limited by $\mathrm{N}$ and water availability. This suggests that more site specific indicators for water availability (possibly derived from remote sensing) might help to unravel its impact on global scale. Similarly, accurate information of soil properties across forests soils might lead to additional spatial variation in soil-induced variation in $\mathrm{C}-\mathrm{N}$ responses.

N saturation: Decreasing C-N responses at higher levels of $\mathrm{N}$ addition have been reported by both long-term fertilization experiments (Binkley and Högberg, 2016) and meta-analyses (Schulte-Uebbing and De Vries, 2018; Tian et al., 2016). At high levels of N addition, other nutrients ( $\mathrm{P}, \mathrm{Ca}, \mathrm{Mg}$ ) become increasingly limiting, and $\mathrm{N}$ saturation may leads to negative impacts on growth (Aber et al., 1989). However, we found no negative interaction between $\mathrm{C}-\mathrm{N}$ response and either ambient or cumulative $\mathrm{N}$ deposition, likely because $\mathrm{N}$ deposition rates are lower than $\mathrm{N}$ addition rates at which $\mathrm{C}-\mathrm{N}$ response decline $\left(>40 \mathrm{~kg} \mathrm{~N} \mathrm{ha}^{-1} \mathrm{yr}^{-1}\right)$ (Schulte-Uebbing and De Vries, 2018; Tian et al., 2016). The C-N response was indeed lower in experiments with high $\mathrm{N}$ addition rates, but spatial correlation between $\mathrm{N}$ addition and other site properties confound the impact of $\mathrm{N}$ addition on the variation in observed $\mathrm{C}-\mathrm{N}$ responses. For example, tropical forests received significantly higher $\mathrm{N}$ addition rates than boreal forests (see Table S5.1), showing that additional experimental data is needed to disentangle this effect.

\subsubsection{Comparison with previous studies}

\section{Strength and weaknesses of approaches to estimate forest $\mathbf{C}-\mathbf{N}$ response}

Each of the approaches to estimate $\mathrm{C}-\mathrm{N}$ responses and $\mathrm{N}$-induced $\mathrm{C}$ sequestration has its 
own strengths and limitations, generally balancing between two opposing goals: observing $\mathrm{N}$ effects on forest growth under realistic conditions, and isolating the effect of $\mathrm{N}$ from other drivers of forest growth. Process-based C-N cycle models and growth observations along deposition gradients are at two opposite ends of this spectrum: Models can clearly isolate the effect of $\mathrm{N}$ by simulating forest $\mathrm{C}$ sink changes with and without $\mathrm{N}$ deposition, while accounting for interactions with changing $\mathrm{CO}_{2}$, temperature or land use . However, current models might overlook the impact of site properties because they do not include all relevant biochemical processes related to $\mathrm{N}$ cycling (Thomas et al., 2015), for example, many coupled C-N models do not account for co-limitation by phosphorus (P) (Esser et al., 2011; Zaehle, 2013), important in tropical forests. In contrast, growth observation studies strongly rely on actual observations at sites with different $\mathrm{N}$ deposition rates but disentangling drivers of $\mathrm{N}$ induced forest growth is challenging due to its collinearity with undetermined site properties as well as climatic variables (De Vries et al., 2008; Magnani et al., 2007; Sutton et al., 2008).

Fertilization experiments fall between these two extremes: they observe responses based on measured observations and can isolate the effect of $\mathrm{N}$ addition by comparing growth responses in fertilized and unfertilized plots. However, both treated and control plots also receive ambient $\mathrm{N}$ deposition, and thus any fertilizer-induced response is additional to the forest's response to deposition. More importantly, experimental $\mathrm{N}$ rates are often a factor 5-10 higher than ambient levels of $\mathrm{N}$ deposition, which leads to an underestimation of $\mathrm{C}-\mathrm{N}$ response if $\mathrm{C}-\mathrm{N}$ response declines with $\mathrm{N}$ input rates (Binkley and Högberg, 2016). Also, representativeness is an issue as fertilization experiments are concentrated in a few regions only (see Section 6.4.2). Finally, fertilization experiments conducted for several years only cannot provide information in changes in $\mathrm{C}-\mathrm{N}$ response over a forests' lifetime. These limitations of fertilizer experiments are also applicable for stoichiometric scaling approaches, which rely on experimental-derived $\mathrm{N}$ retention and allocation fractions (Nadelhoffer et al., 1999). Stoichiometric scaling approaches also assume constant C:N rations even under elevated $\mathrm{N}$, while $\mathrm{N}$ concentrations in stem wood have been shown to increase substantially in stands exposed to elevated $\mathrm{N}$ deposition due to luxury consumption (De Vries et al., 2021c).

\section{C-N responses in temperate and boreal forests}

Our estimates for average $\mathrm{C}-\mathrm{N}$ responses for boreal and temperate are lower than results from forest growth inventories along deposition gradients which range from 20 to 30 (De Vries et al., 2008; Fleischer et al., 2013; Solberg et al., 2009) or even up to $50 \mathrm{~kg} \mathrm{C}$ per kg N (Flechard et al., 2020). They are, however, similar to results from stoichiometric scaling (Du and De Vries, 2018) for temperate forests ( 4 vs. $5 \mathrm{~kg} \mathrm{C}$ per $\mathrm{kg} \mathrm{N}$ ) and only slightly lower for boreal 
forests (11 vs. $14 \mathrm{~kg}$ C per kg N; Table S6.5). The estimated C-N response for temperate forests derived in Chapter 5 is substantially higher $(13 \mathrm{~kg} \mathrm{C}$ per $\mathrm{kg} \mathrm{N})$ due to differences in statistical approach (see Section 6.2.1) and site properties accounted for (Figure S6.8): while in Chapter $5, \mathrm{C}-\mathrm{N}$ responses were derived as weighted means from all observations, this study accounts for spatially explicit drivers controlling $\mathrm{C}-\mathrm{N}$ response. Temperate forests on average have a higher PET, lower soil $\mathrm{N}$ content and higher age than the forest plots where observations derived from fertilizer experiments (Figure 6.4), all leading to lower $\mathrm{C}-\mathrm{N}$ responses. This highlights the relevance of robust and sound upscaling procedures from experimental fields to global scale.

We found no significant $\mathrm{C}$ response to $\mathrm{N}$ addition in one third of temperate forests (Table S6.3), which is consistent with multiple forest fertilization experiments (e.g., Lovett and Goodale, 2011; McNulty et al., 2005). Possible causes of a lack of $\mathrm{N}$ induced C sequestration include (i) foliar nutrient imbalances following $\mathrm{N}$ addition leading to increased susceptibility to pests and pathogens; (ii) $\mathrm{N}$ induced soil $\mathrm{pH}$ changes lowering $\mathrm{P}$ availability due to enhanced sorption to iron oxides, (iii) increased soil acidity leading to a depletion of base cations, and (iv) increased solubility of potentially toxic elements. For example, Mainwaring et al. (2014) found that Douglas fir stands only responded to $\mathrm{N}$ fertilization at soil Ca: $\mathrm{N}$ ratios above 0.06 , indicating that Ca availability limits tree growth below this threshold. Lovett et al. (2013) also found no significant response to $\mathrm{N}$ addition for six tree species, possible caused by low cation availability (<2\%; Templer et al., 2005) and secondary effects of long-term excess inputs of $\mathrm{N}$ such as soil acidification and base cation leaching. Analyses of long-term trends in foliar nutrients in Europe (Jonard et al., 2015) also show that many trees are not $\mathrm{N}$ limited but increasingly P-limited.

\section{C-N responses in tropical forests}

Tropical forest account for almost two thirds of the global forest area, and $\mathrm{N}$ deposition levels are almost as high as for temperature forests ( $8.4 \mathrm{vs} 9.8 \mathrm{~kg} \mathrm{~N} \mathrm{ha}^{-1} \mathrm{yr}^{-1}$ ), and thus even a small difference in $\mathrm{C}-\mathrm{N}$ response substantially impacts the size of the estimated global $\mathrm{N}$-induced forest $\mathrm{C}$ sink. At least two recent estimates of the global $\mathrm{N}$-induced forest $\mathrm{C}$ sink predict an $\mathrm{N}$-induced $\mathrm{C}$ sink in the tropics of $260 \mathrm{Tg} \mathrm{C} \mathrm{yr}^{-1}$ (Fleischer et al., 2015, based on a DGVM) and $80 \mathrm{Tg} \mathrm{C} \mathrm{yr}^{-1}$ (Du and de Vries, 2018, based on stoichiometric scaling). In contrast, we found no substantial $\mathrm{N}$-induced $\mathrm{C}$ sequestration in the tropics. Nitrogen addition experiments generally found no effect of $\mathrm{N}$ addition on productivity (Cusack et al., 2011; Homeier et al., 2012), confirming the hypothesis that tree growth is mainly P-limited on $\mathrm{N}$-rich, highly weathered tropical soils with high levels of $\mathrm{N}$ availability. $\mathrm{N}$ addition has even been shown to reduce stimulating effect of $\mathrm{P}$ addition on biomass in tropical forests ( $\mathrm{Li}$ 

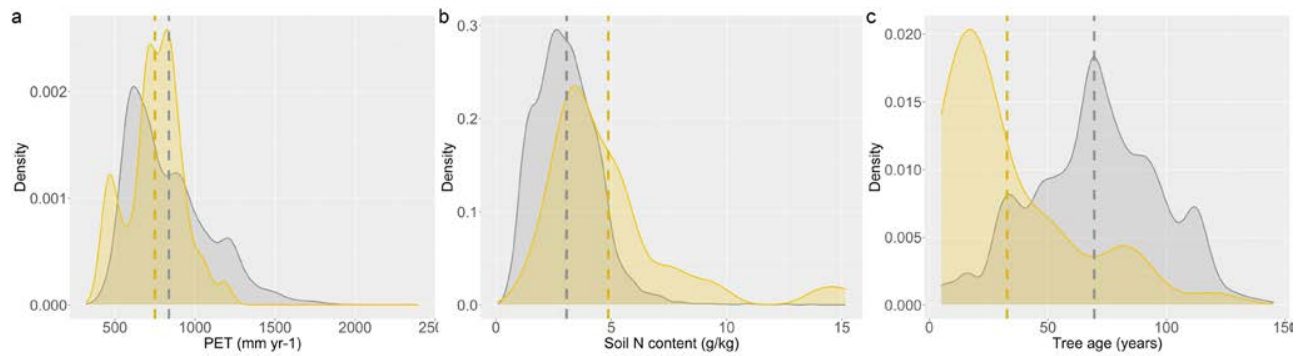

Figure 6.4 | Density plots showing the distribution of the three variables included in the model used to predict $\mathrm{C}-\mathrm{N}$ response in temperate forest locations in the database (yellow) and in global temperate forests (grey). For the density plots for global forests, frequency of each occurrence was weighted by forest area (i.e., can be read as "frequency for $\mathrm{km} 2$ forest"). Distributions for other forest biomes and for all forest biomes combined are shown in Figure S6.8.

et al., 2016), potentially due to detrimental effects on growth through soil acidification (Tian and Niu, 2015). $\mathrm{N}$ deposition also may reduce BNF and thus not lead to more $\mathrm{N}$ availability at the tree level (Esser et al., 2011). A negligible effect of $\mathrm{N}$ deposition on $\mathrm{C}$ sequestration in the tropical region has also been found by another DGVM (Zaehle et al., 2011).

\subsubsection{Uncertainties in data used in upscaling of $\mathbf{C}-\mathbf{N}$ responses to estimate nitrogen -induced forest carbon sink}

Upscaling C-N responses from experimental locations to the global scale might lead to substantial variation not only due to differences in $\mathrm{C}-\mathrm{N}$ responses, but also uncertainty in input data used for upscaling, including forest cover, biomes and $\mathrm{N}$ deposition. For example, differences in estimated forest area explain 34\% of the difference between our estimate for

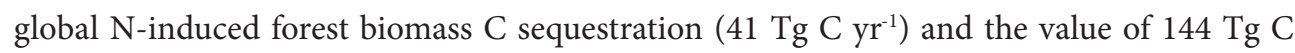
$\mathrm{yr}^{-1}$ by $\mathrm{Du}$ and de Vries (2018; see Table S6.5). Estimates for global forest area vary widely, due to differences in technologies, approaches and definition of what constitutes a 'forest'. Our estimate for global forest area is based on fraction forest cover data derived from highresolution Landsat imagery (Hansen et al., 2013) resulting in an area being 25\% lower than the value reported in the Global Forest Resources Assessment (FAO, 2020) as used by de Vries \& Du (2018). While the FAO estimate is based on self-reported values by participating countries and uses a definition based on land use (according to which a recently cut-down forest plantation is still considered a 'forest', while a tree patch on agricultural land is not), satellite images detect actual land cover and are therefore considered more relevant for studying forest C dynamics (Sexton et al., 2016). However, even satellite-based estimates of tree and forest cover show discrepancies, especially in regions with low tree density (Sexton et al., 2016, 2015). 
Delineation of biomes also varies between studies, with some studies including 'sub-tropical' as an additional category (De Vries et al., 2014; Du and De Vries, 2018; Esser et al., 2011; Fleischer et al., 2015; Schwede et al., 2018). Not all studies clearly report criteria used to delineate biomes, while this can seriously affect upscaling results. For our results, delineating biomes based on FAO Global Ecological Zones leads to substantially lower N deposition rates for temperate and tropical forests, while the additional category 'sub-tropical forests' receives by far the highest rates of $\mathrm{N}$ deposition (see Table S6.4).

Finally, estimates of $\mathrm{N}$ deposition vary substantially between studies estimating global $\mathrm{N}$-induced C sequestration. Our estimate is based on forest-specific deposition rates, which leads to higher deposition values than using grid-cell averages, as factors such as surface roughness and canopy height exert a great influence on $\mathrm{N}$ deposition rates (Schwede et al., 2018). The use of forest-specific deposition rates compared to grid average values increased the estimate for total $\mathrm{N}$ deposition to forest by $12 \%$ (from 20.6 to $23 \mathrm{Tg} \mathrm{N} \mathrm{yr}^{-1}$, with the largest relative increase in temperate forest), however, for certain regions the difference can be up to a factor two. As long as modelled $\mathrm{N}$ deposition rates strongly vary and often deviate from measurements (Tan et al., 2018), accurate $\mathrm{N}$ induced C sink in forests is still challenging.

\subsubsection{Nitrogen deposition as driver of the terrestrial carbon sink}

The terrestrial biosphere acts as a $\mathrm{C}$ sink absorbing between 18 and $25 \%$ of global $\mathrm{CO}_{2}$ emissions (Friedlingstein et al., 2020). Forests account for a substantial part of this $\mathrm{C}$ sink, and drivers that have been proposed to account for increased forest growth include $\mathrm{CO}_{2}$ fertilization, increasing temperatures (leading to longer growing seasons in high latitude forests), forest management and N deposition (De Vries and Posch, 2011; Hyvönen et al., 2007). The contribution of $\mathrm{N}$ to forest $\mathrm{C}$ sequestration has been disputed, with some studies claiming that $\mathrm{N}$ deposition controls a large part of the forest $\mathrm{C}$ sink (Magnani et al., 2007), while others find a minor role (Du and De Vries, 2018). Our results show that $\mathrm{N}$-induced $\mathrm{C}$ sequestration is negligible compared to either the gross or net forest $\mathrm{C}$ sink (Figure 6.5), especially in tropical forests.

In this study we focus on $\mathrm{AGWB}$ and ignore the impact of $\mathrm{N}$ on soil $\mathrm{C}$ sequestration. The impact of $\mathrm{N}$ addition on soil $\mathrm{C}$ is often estimated indirectly via respiration measurements or tracer experiments and stoichiometric scaling. Most studies find that $\mathrm{N}$ addition increases soil C sequestration (Janssens et al., 2010; Nave et al., 2009; Zhou et al., 2014), either by increasing litter inputs or by reducing respiration through interactions with SOM stabilisation and microbial community (see e.g., Janssens et al., 2010 for an overview). Overall, the magnitude of $\mathrm{N}$-induced soil $\mathrm{C}$ sequestration is likely in the same order of magnitude or smaller than the $\mathrm{C}$ sequestered in forest biomass (also see Table 5.4). 


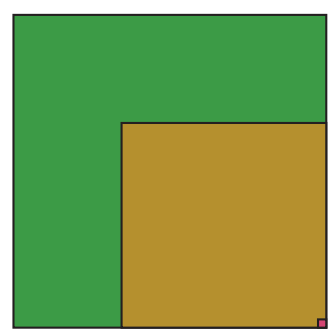

Tropical forest

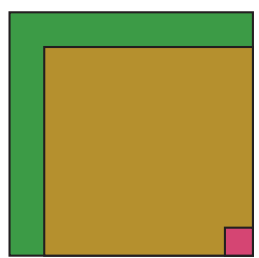

Temperate forest



Boreal forest

Figure 6.5 | Size of the gross forest $C$ sink (total $C$ removal in above- and belowground biomass), net forest $C$ sink (gross forest $C$ sink minus $C$ emissions due to deforestation, forestry, urbanization and wildfires), and $\mathrm{N}$-induced $\mathrm{C}$ sink estimated by this study per forest biome. Area of the squares is proportional to size of $C$ sink. Estimates for gross and net $C$ sink per biome were obtained from high-resolution maps of the global gross and net forest $C$ sink for the years 200I-2019 estimated by combining ground and earth observation data (Harris et al., 202I).

Results from studies assessing $\mathrm{N}$-induced $\mathrm{C}$ sequestration alone do not allow to draw conclusions on the long-term fate of $\mathrm{C}$ sequestered in forests, as they assess $\mathrm{N}$ impacts on $\mathrm{Net}$ Ecosystem Productivity ( $\mathrm{C}$ uptake by photosynthesis minus respiration losses) rather than Net Biome Productivity (accounting for $\mathrm{C}$ removal from disturbances and harvest). Whether the additional $\mathrm{C}$ sequestered in forests will be removed from the atmosphere over the course of decades or centuries (policy-relevant time-scales for climate change mitigation) depends on its persistence in biomass and soil. It has been proposed, for example, that trees that grow faster (due to $\mathrm{N}$ deposition, $\mathrm{CO}_{2}$ fertilization or warming) also die younger (Büntgen et al., 2019), which would reduce the residence time of carbon in wood (Körner, 2017). For managed forests, increased woody biomass growth may also lead to earlier harvesting and the fate of sequestered $\mathrm{C}$ depends on how the harvested wood is used (i.e., burned or used in products with a long life-span). For natural forests, faster growth may just imply that forests reach their steady-state $\mathrm{C}$ pool faster, thus not increasing net $\mathrm{C}$ sequestration over the forests' lifetime (Körner, 2017). On the other hand, even old-growth forests might continue to accumulate C (Luyssaert et al., 2008). Finally, actual C sequestration strongly depends on anthropogenic or natural disturbances that are not related to $\mathrm{N}$ deposition, such as forest fires, deforestation and forest degradation.

We conclude that the contribution of $\mathrm{N}$ deposition to forest biomass $\mathrm{C}$ sequestration likely is small, and negligible when compared to the overall size of the forest $\mathrm{C}$ sink. Nitrogeninduced $\mathrm{C}$ sequestration in forests is not sufficient to balance the warming impact of anthropogenic $\mathrm{N}_{2} \mathrm{O}$ emissions, even assuming $\mathrm{N}$-induced $\mathrm{C}$ sequestration in soils in the same order of magnitude as for biomass. While $\mathrm{N}$ may also lead to cooling by increasing $\mathrm{CH}_{4}$ 
consumption and by increasing formation of aerosols that reflect sunlight, available evidence shows that this effect is likely small compared to the warming effect of $\mathrm{N}_{2} \mathrm{O}$ (De Vries et al., 2017; Erisman et al., 2011). Therefore, reducing reactive N losses is likely to benefit climate mitigation. 
MINOR CONTRIBUTION OF NITROGEN DEPOSITION TO GLOBAL FOREST CARBON SEQUESTRATION 


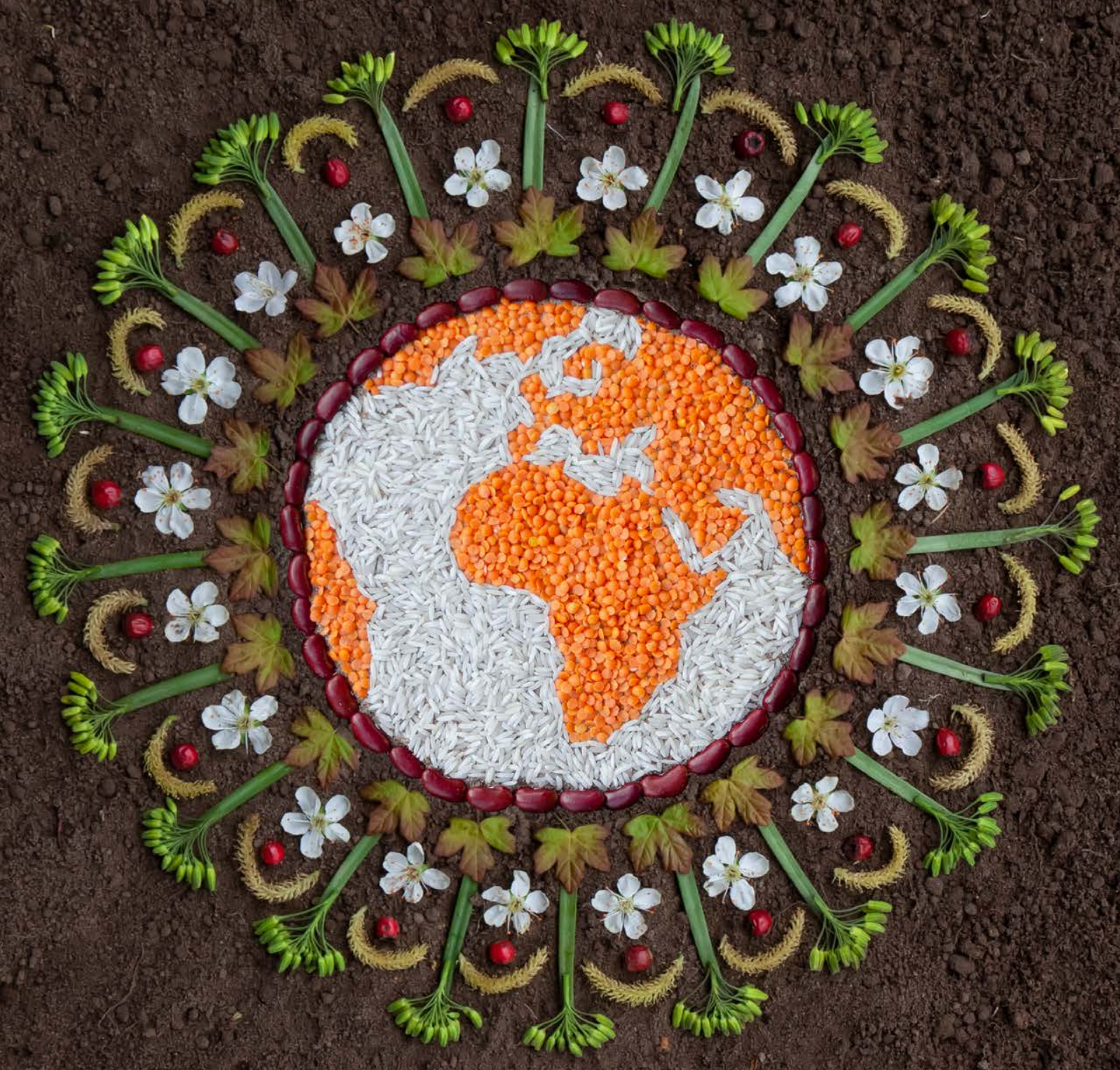




\section{Synthesis}


The aim of this thesis was to increase our knowledge on the spatial distribution of environmental impacts of agricultural nitrogen use, as well as trade-offs between these impacts and the benefits of nitrogen for crop production. I used spatially explicit modelling to derive indicators that can be used to support policy making for sustainable nitrogen management in Europe and globally. The following three objectives have been addressed in five scientific papers:

Objective 1: To estimate spatially explicit critical agricultural nitrogen losses, surpluses and inputs related to targets for air and water quality, and aggregate spatially explicit thresholds to derive nitrogen boundaries at the regional, continental, and global level. (Chapters 2 and 4)

Objective 2: To assess to what degree redistributing nitrogen inputs and increasing nitrogen use efficiency can contribute to meeting food demand while remaining within safe boundaries for nitrogen losses to air and water. (Chapters 3 and 4)

Objective 3: To quantify global variability in the net climate impact of human nitrogen use by empirically modelling the effect of nitrogen deposition on forest carbon sequestration based on meta-analysis of forest fertilization experiments, and by comparing nitrogen-induced carbon sequestration to human $\mathrm{N}_{2} \mathrm{O}$ emissions. (Chapters 5 and 6)

Figure 7.1 presents a summary of the main findings related to each objective. In this Synthesis chapter, I summarize the main findings in the context of the overall objective (providing information on policy-relevant nitrogen indicators to support policies on sustainable nitrogen management), and critically discuss the approaches chosen to answer the research questions (Sections 7.1-7.3). In addition, I address the relationship between nitrogen boundaries estimated in Chapter 4 and the climatic impact of human nitrogen use estimated in Chapter 6 (Section 7.4.1), and show how results from Chapters 2-4 can improve calculations of a key indicator used to track countries' progress towards sustainable nitrogen management (Section 7.4.2).

\section{I. Safe boundaries for agricultural nitrogen inputs}

The extensive threats of nitrogen to ecosystems and human health in the EU and worldwide have led scientists to conclude that human nitrogen use has exceeded its safe planetary boundary (Rockström et al., 2009b; Steffen et al., 2015). In this thesis, I presented a modelling framework to establish regional and global boundaries for agricultural nitrogen losses, surpluses and inputs from spatially explicit thresholds. The approach accounts for spatial variability in both ecosystem's sensitivity to nitrogen pollution and in features of agricultural 


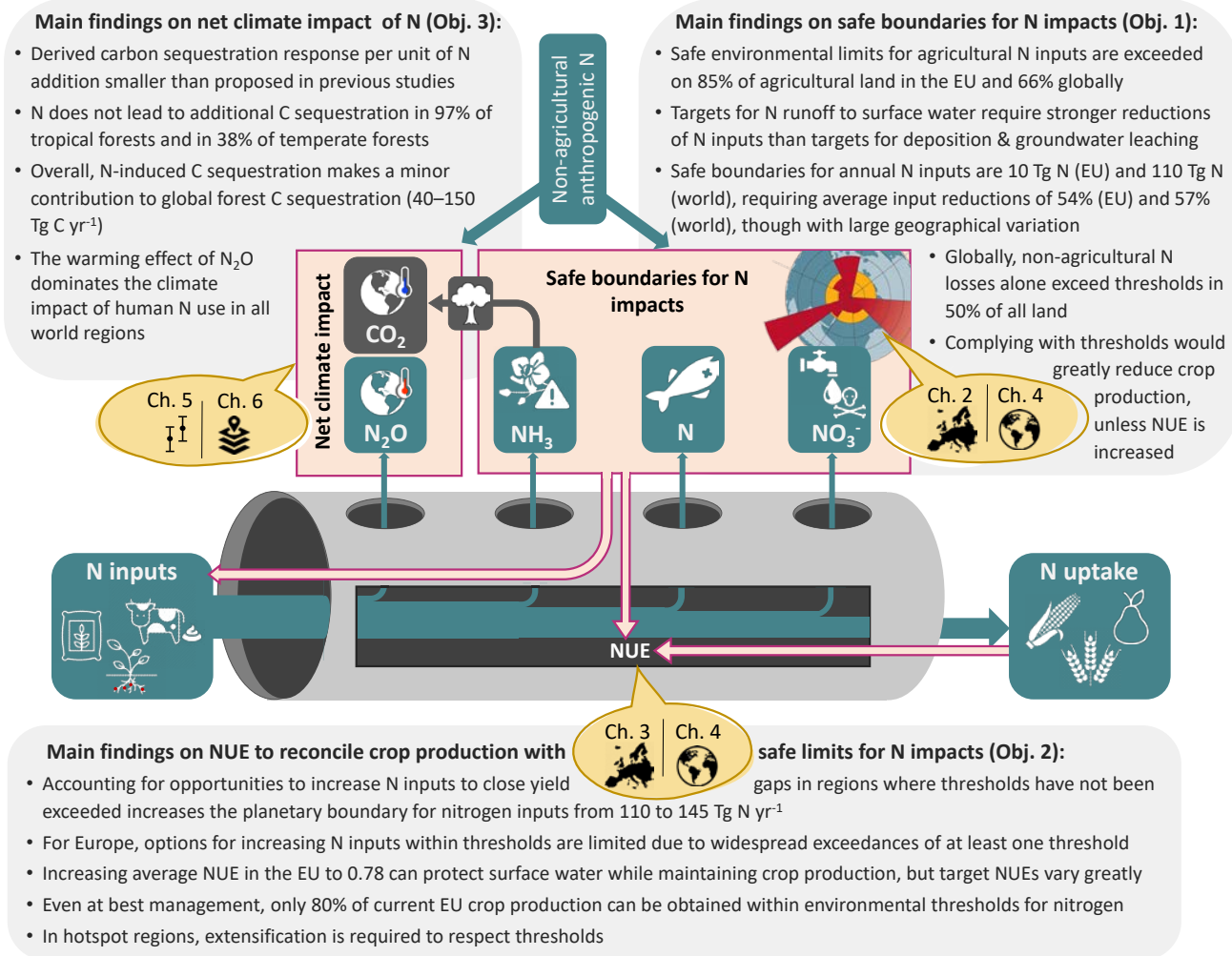

Figure 7.I | Summary of the main findings of this thesis related to the three research objectives addressed in Chapters 2-6 within the conceptual framework of the 'leaky pipe' (cf. Figure I.2).

systems (e.g., nitrogen use efficiency or contribution or mix of nitrogen sources). I used two nitrogen balance models (INTEGRATOR and IMAGE-GNM) to estimate spatially explicit critical nitrogen losses, surpluses and inputs from thresholds for eutrophication of terrestrial and aquatic ecosystems and nitrate in groundwater for the EU and the world. These spatially explicit critical inputs were aggregated to derive a first quantitative, bottom-up estimate of safe boundaries for agricultural nitrogen inputs at the country, regional and global level.

\section{I.3. Main findings}

Current agricultural nitrogen inputs exceed safe thresholds in most agricultural land: at least one of the three nitrogen thresholds is exceeded in $85 \%$ of all agricultural land in the EU, and $66 \%$ of all agricultural land globally. Avoiding risks of surface water eutrophication from nitrogen runoff generally requires the largest nitrogen input reductions both in the EU and globally, followed by thresholds for ammonia emissions to avoid risks of eutrophication from 
deposition and thresholds for nitrate leaching to avoid exceeding drinking water standards (Figures $2.6 \& 4.1$ ).

In Europe, regions with intensive livestock farming, such as the Netherlands, Brittany in France and the Po valley in Italy are hotspots for exceedance of critical inputs (Figure 2.5). Globally, hotspots include Western Europe, India, China, North America and the Middle East (Figure 4.2a). In these regions, thresholds for several nitrogen-related impacts are usually exceeded simultaneously (Figure 4.2b), highlighting the need for an integrated approach to avoid pollution swapping. Thresholds are often exceeded most in regions with large nitrogen surpluses, such as the Netherlands and South China. However, results also highlight regions with substantial nitrogen surplus but small threshold exceedances, and vice versa, reflecting heterogeneity in ecosystem risk. Consequently, I argue that the exceedance of critical nitrogen thresholds (where thresholds may refer to either inputs, losses or surpluses) presented in this thesis is a more relevant indicator for informing decision-making than absolute nitrogen surplus, which is currently used for reporting on nitrogen management by, for example, the EEA (EEA, 2019).

The aggregated boundary for agricultural nitrogen inputs to respect all thresholds for Europe (10 $\mathrm{Tg} \mathrm{N} \mathrm{yr}^{-1}$ ) is 54\% lower than current inputs (22 $\left.\mathrm{Tg} \mathrm{N} \mathrm{yr}^{-1}\right)$, while the aggregated boundary for nitrogen losses $\left(3.3 \mathrm{Tg} \mathrm{N} \mathrm{yr}^{-1}\right)$ is $59 \%$ lower than current losses $(7.9 \mathrm{Tg} \mathrm{N}$ $\left.\mathrm{yr}^{-1}\right)$. The boundary for nitrogen losses estimated in this thesis provides evidence-based support for the target set by the Farm to Fork-strategy of the European Green Deal to reduce nutrient losses by $50 \%$ by 2030 (European Commission, 2020). At the same time, results also highlight that needed reductions in some regions are substantially higher than in others. The boundary for nitrogen losses estimated in this thesis is $60 \%$ higher than the boundary of 2.1 $\mathrm{Tg} \mathrm{N} \mathrm{yr}^{-1}$ proposed in a recent EEA report (EEA and FOEN, 2020), which was derived by disaggregating the global planetary boundary by Steffen et al. (2015) based on different (mainly economic) allocation principles.

The planetary boundary for agricultural nitrogen inputs to respect all thresholds (110 ${\left.\mathrm{Mt} \mathrm{yr}^{-1}\right)}^{-1}$ is $57 \%$ lower than current inputs ( $255 \mathrm{Mt} \mathrm{yr}^{-1}$ ). The magnitude of needed reductions is thus in line with the goal stated in the UN Colombo Declaration to "halve nitrogen waste by 2030 ". Considering newly fixed nitrogen from synthetic fertilizer and biological nitrogen fixation only, the boundary ( $55 \mathrm{Tg} \mathrm{N} \mathrm{yr}^{-1}$ ) is at the low end of the range for a planetary boundary

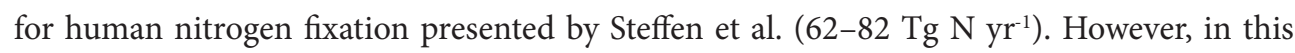
thesis I also derive a boundary that accounts for possibilities to increase nitrogen inputs to benefit crop production where thresholds are not exceeded, which leads to higher estimates (see Section 7.2.). 
Despite more widespread exceedances of thresholds in the EU than globally (exceedance in $85 \%$ vs. $66 \%$ of all land), required reductions in nitrogen inputs to respect thresholds are similar (54\% for EU and 57\% globally). This is mainly because the global nitrogen boundary was calculated while assuming constant nitrogen losses from other sources, which contribute considerably to the exceedance of nitrogen thresholds in air and water. Non-agricultural nitrogen losses include both nitrogen load to surface water from anthropogenic sources (e.g. wastewater and aquaculture) and from natural sources (e.g., allochthonous organic matter), as well as $\mathrm{NO}_{\mathrm{x}}$ emissions to air from traffic and industry (see Figure 4.5b). Globally, these losses alone exceed one or several thresholds in $>50 \%$ of all land (Figure 4.3 ). This emphasizes that a boundary for agricultural nitrogen use needs to account for (spatial variability in) contribution of other sectors to thresholds exceedance.

\section{I.2. Methodological reflections}

The strength of the approach presented in this thesis is its consideration of the spatial variability in both ecosystems' sensitivity to nitrogen pollution and agricultural nitrogen losses. Safe thresholds presented in this thesis combine several nitrogen-related problems, and can be derived for either nitrogen inputs, surpluses or losses (or even for specific nitrogen compounds, such as ammonia), and aggregated at the desired scale to derive national or global nitrogen boundaries.

Use of large scale nitrogen budget models in relation to thesis objective. Nitrogen balance models, similar to the models used in this thesis have been widely applied in regional and global nitrogen assessments (e.g., GLOBIOM; Mosnier et al., 2013 or MAgPIE; Popp et al., 2010). Estimates for nitrogen budget terms and their spatial variation differ considerably between models, reflecting global uncertainties in the quantification of activity data related to several nitrogen budget terms (Zhang et al., 2020). Both models used in this thesis (INTEGRATOR and IMAGE-GNM) have been validated by comparing nitrogen inputs and losses with available measurements and independent statistics (Beusen et al., 2015; Bouwman et al., 2017, 2009; Kros et al., 2012; van Grinsven et al., 2014). Results from Monte Carlo analyses showed that uncertainty associated with INTEGRATOR results decreased from smaller to larger spatial scales, because errors partly cancel out through spatial aggregation (Kros et al., 2012). Comparison of surface water N concentration in IMAGE GNM with observed concentrations for several river basins produced acceptable results (Beusen et al., 2015). This underpins that despite uncertainties, the models used in this thesis are suitable for presenting large scale variability in nitrogen budgets, thus allowing support of large-scale polices. 
Assumptions on non-agricultural nitrogen sources. While this thesis derived boundaries for agricultural nitrogen inputs and losses, non-agricultural sources contributes substantially to global nitrogen pollution. Estimating agricultural nitrogen boundaries thus requires making assumptions on these losses. For the European assessment (Chapter 2), I assumed that nonagricultural nitrogen emissions to air decrease proportionally with agricultural emissions, whereas I made no explicit assumptions regarding the contribution of other sectors to surface water nitrogen load. For the global assessment (Chapter 4), I explicitly accounted for non-agricultural nitrogen losses, and assumed that these remain constant (while also testing the impact of alternative assumptions on agricultural nitrogen boundaries, see Figure E4.9). Assuming constant non-agricultural nitrogen losses may place an unreasonable burden on the agricultural sector. An alternative would be to allocate reductions of different nitrogen sources based on cost-effectiveness, such as implemented for greenhouse gas mitigation in the GAINS model (Amann et al., 2011) or for abatement of agricultural nitrogen losses in Europe (Oenema et al., 2009). However, data on costs related to different nitrogen abatement options at the global scale are currently scarce.

Critical limits and considered pathways for surface water eutrophication. As nitrogen concentration in surface water emerged as the most stringent criterion (requiring the largest reductions in nitrogen inputs), further improvement of the methodology should focus on refining the assessment of nitrogen impacts on aquatic eutrophication. Current calculations use nitrogen concentration in runoff to surface water as a proxy for nitrogen concentration in surface water. This may be too stringent in regions where 'clean' water delivered from upstream grid cells dilutes nitrogen concentrations in runoff. In addition, I used a global average fraction to estimate nitrogen removal from surface water by retention, thus not accounting for variation in this fraction between and within river basins. Accounting for inter-grid transport, as well as nitrogen retention processes in surface water, is theoretically possible within the current approach, as these processes are captured by IMAGE-GNM. However, this introduces new challenges, such as the allocation of required reductions to different grid cells within a watershed. In addition, a substantial part of nitrogen load to surface water is from nitrogen 'legacies' due to slow transport through the vadose zone (Ascott et al., 2017; Bouraoui and Grizzetti, 2014; Van Meter et al., 2016). This is reflected in the global-scale approach by keeping a fraction of groundwater nitrogen delivery constant, which neglects that, on the long term, reductions in nitrogen inputs would eventually translate into reduced loads. Finally, assessing eutrophication risk should also account for phosphorus loads, as reductions in phosphorus are often equally important in improving water quality (Schindler et al., 2016). Eutrophication risk is related to nutrient imbalances (stoichiometry) rather than to enrichment per se (Conley et al., 2009), and to better reflect this, phosphorus (and possibly 
Si, such as in the ICEP ratio; Garnier et al., 2010) should be included in future versions.

Linear relationship between nitrogen inputs and losses. Nitrogen losses in INTEGRATOR and IMAGE-GNM are generally linearly related to nitrogen input or nitrogen surplus, with nitrogen loss fractions being a function of climate, soil type, nitrogen source, and other factors. In calculating critical nitrogen inputs I assumed that these loss fractions remain constant at changing inputs. Although linear relationships have been reported (e.g. for ammonia, Cui et al., 2014), many field studies provide evidence for non-linear relations between nitrogen inputs and losses, such as an exponential increase in $\mathrm{N} 2 \mathrm{O}$ emission rate with nitrogen addition (Bouwman et al., 2002; Hoben et al., 2011; Kim et al., 2013), or a decrease in nitrate removal rates by denitrification with increasing nitrogen concentrations (Alexander et al., 2009). Furthermore, climate change may affect loss fractions, such as ammonia emission fractions, in the future (e.g., Sutton et al., 2013b). Overall, the uncertainty introduced by assuming a linear relation between nitrogen inputs and losses and by neglecting impacts of climate change on loss fraction is likely small compared to the uncertainty related to nitrogen budgets and thresholds discussed above.

\section{I.3. Outlook}

The notion that the planetary nitrogen boundary has been exceeded has further helped to put nitrogen on the (international) policy agenda. Approaches to derive critical nitrogen inputs presented in this thesis further operationalize the concept of a 'nitrogen boundary', and improve its relevance for informing targeted mitigation policies based on regional information. To further increase its relevance, the approach should be adopted in the future to include region-specific environmental thresholds. For example in Europe, the generic target for surface water nitrogen concentration $\left(2.5 \mathrm{mg} \mathrm{N} \mathrm{l}^{-1}\right)$ could be replaced by basinspecific targets as specified under the Water Framework Directive (Poikane et al., 2019).

The approaches presented in this thesis allow for establishing 'bottom-up' regional and planetary nitrogen boundaries based on aggregated spatially explicit boundaries, reflecting variation ecosystems' vulnerability to environmental risk. Quantification of other planetary boundaries with a strong spatial component, such as the phosphorus boundary or the water boundary, could benefit from a similar approach. This is supported by the work of Gleeson et al. (2020), who present seven criteria for defining a useful water planetary boundary, most of which are fulfilled by the approach presented in this thesis. 


\subsection{Reconciling crop production with environmental thresholds}

The conclusion that safe thresholds for nitrogen inputs have already been exceeded in most agricultural land both in the EU and globally raises an important question: can food demands be met while returning to a 'safe operating space' for nitrogen pollution? To answer this question, I investigated the potential of two strategies to respect thresholds for nitrogen concentrations in air and water while maximizing crop production. First, I estimated the potential for realizing additional crop production in regions where thresholds are not exceeded by increasing nitrogen inputs to close yield gaps. Second, I quantified the nitrogen use efficiency (NUE) at which nitrogen losses comply with critical thresholds without affecting crop production. For the EU, I further distinguished required reductions in manure $\mathrm{NH}_{3}$ emission fractions to respect deposition thresholds without crop production losses, and required increases in NUE to respect thresholds for runoff and leaching. Given limits to what is technically feasible in terms of reducing $\mathrm{NH}_{3}$ emission fractions and increasing NUE, I estimated the crop production volume that can be obtained without exceeding thresholds under best management practices for the EU.

\subsection{Main findings}

Returning to a safe operating space for nitrogen pollution by reducing nitrogen inputs at current NUE would decrease EU crop production by $50 \%$. Due to the widespread transgression of thresholds, options for increasing nitrogen inputs to close yield gaps on land where thresholds are not transgressed are limited, only allowing for a small increase crop production of $4 \%$ (Figure 3.3d). Globally, reducing nitrogen inputs to respect thresholds leads to a similar loss in crop production volume (57\%). However, there is more room for intensification: increasing nitrogen inputs in regions where thresholds are not exceeded, mainly in Latin America and Sub-Saharan Africa, would increase global crop production by $14 \%$. Leaving room to maximize food production within environmental limits when calculating the planetary boundary leads to a substantially higher boundary for nitrogen inputs (145 $\mathrm{Mt} \mathrm{N} \mathrm{yr}^{-1}$ ) than when considering required reductions only (110 $\mathrm{Mt} \mathrm{N} \mathrm{yr}^{-1}$, Figure 4.1).

Achieving surface water targets in the EU without crop production losses requires substantial increases in cropping-system NUE, from currently 0.64 to 0.78 (Table 3.2). Achieving groundwater targets requires a modest increase in average NUE to 0.67 (Table 3.2). Most countries can achieve surface water targets at a NUE of 0.70-0.80, and groundwater targets at an average NUE of $0.50-0.60$ (Figure 2.5). Increasing NUE to 0.75-0.80, a target indicated in the Farm to Fork Strategy as part of the European Green Deal, is sufficient to reconcile 
environmental thresholds and current crop production on most, but not all agricultural land in the EU. In hotspot regions, crop production and nitrogen thresholds can only be reconciled at NUEs of $>0.90$ (Figure 3.4), which is not feasible. Even at best management, I estimate that only $80 \%$ of current crop production in Europe can be obtained without exceeding nitrogen thresholds.

Globally, nitrogen inputs can increase while respecting thresholds on one third of all agricultural land, potentially allowing to compensate part of the crop yield losses from reducing nitrogen inputs in regions where thresholds are exceeded. However, I estimated that out of seven world regions, only Latin America can achieve regional food self-sufficiency in terms of nitrogen without exceeding thresholds at current NUE (Figure 4.4). Required NUE increases to reconcile crop production and nitrogen thresholds are substantial and strongly depend on assumptions regarding mitigation of non-agricultural nitrogen losses (Table E4.1).

\subsubsection{Methodological reflections}

This thesis presents the first backward-calculation of needed changes in nitrogen management, starting from spatially explicit environmental and crop production targets and quantifying the management factor at which both can be achieved. Results can be used to establish performance targets for the agricultural sector, and are thus a valuable addition to 'forward-calculations' assessing the effect of mitigation measures on nitrogen losses (e.g., Bodirsky et al., 2014). In addition, I quantified the potential for realizing additional crop production by increasing nitrogen inputs while only allowing for increases in nitrogen inputs where environmental thresholds are not exceeded. This is an important complementary approach to earlier studies that assessed the potential of redistributing nitrogen inputs to minimize total nitrogen losses (Mueller et al., 2012) or to maximize NUE (Mueller et al., 2017) without considering geographical variation environmental vulnerabilities.

Uncertainties in crop yield gaps. Quantification of the potential to increase crop production in regions where thresholds are not exceeded would greatly benefit from better information on yield potentials, as well as factors constraining yields. For the European assessment, we used data on yield potentials for wheat from the Global Yield Gap Atlas, which are generally considered reliable (Grassini et al., 2015), but assessing yield potentials for other crops based on spatial variation in wheat yield potentials introduces high uncertainty (see e.g. Figure S3.1). However, due to widespread exceedances of thresholds in Europe, uncertainties in yield potentials have a small effect on uncertainty in the estimated nitrogen boundaries.

Estimates for crop yield potentials with a global coverage are very limited and highly 
uncertain (van Ittersum et al., 2013). For the global calculations in Chapter 4, I derived regional target yields based on highest-observed yields within zones of similar climate from Mueller et al. (2012). However, these yields likely underestimate biophysical yield potentials, especially as observed yields are for the year 2000. Finally, as we lacked information on factors constraining yields at the global scale, we assumed that target yields can be obtained by increasing nitrogen inputs, while in many regions crops are equally constrained by availability of phosphorus or water (Mueller et al., 2012).

Uncertainties in maximum achievable NUEs. Several recent studies have shown that NUE increases can contribute greatly to reducing $\mathrm{N}$ losses (Bodirsky et al., 2014; Zhang et al., 2015), and different targets for NUE have been proposed in the scientific literature (e.g., Sutton et al., 2013a; Zhang et al., 2015). However, improving targets for NUEs or quantifying levels of crop production that can be realized within environmental boundaries would benefit from information on limits to the maximum NUEs that can be achieved. Maximum NUEs have been reported to vary between cropping systems (Cui et al., 2014) and climatic regions (Hutchings et al., 2020). Future research should assess 'NUE potentials' (in analogy to the concept of yield potentials), for example by combining data on NUEs achieved in field trials for different crops and under different conditions and crop modelling.

Linear relation between nitrogen inputs and uptake. Estimation of critical nitrogen inputs as well as required nitrogen inputs to obtain target yields in this thesis assumes a linear relation between nitrogen input and crop uptake. Other global nitrogen assessments (e.g., Mueller et al., 2017) have assumed that yield response declines with increasing nitrogen input, according to the law of diminishing returns (Spillman, 1923). Historical relationships between yields and nitrogen fertilizer input at the country level indeed show a decline in NUE with increasing nitrogen inputs (Bodirsky and Müller, 2014; Lassaletta et al., 2014a), although a linear trend (de Wit, 1992) or even an reversal of the relationship due to improved technologies (Zhang et al., 2015) has also been reported. At the farm level, diminishing returns to inputs may only occur when yields approach $80 \%$ of their biophysical potential (van Ittersum et al., 2013), and thus assuming a linear response may be reasonable under a wide range of conditions.

\subsubsection{Outlook}

Improving nitrogen management, for example by better matching nitrogen inputs and crop demand, is indispensable for agricultural sustainability. However, improved crop management is not a panacea for solving the nitrogen challenge. As this thesis shows, increasing NUE alone is likely not sufficient to achieve environmental targets everywhere. 
This underpins that feeding a future population of $\sim 10$ billion people while remaining within the safe operating space for nitrogen is only possible through drastic changes to both food production systems and consumption patterns, as well as mitigation of non-agricultural nitrogen sources.

While numerous scientific studies have pointed out the potential of food-chain mitigation strategies, such as reducing consumption of animal protein and food waste (Bodirsky et al., 2014; Corrado et al., 2020; Grizzetti et al., 2013; Lassaletta et al., 2016; Springmann et al., 2018), there is a discrepancy with the apparent lack of attention to this issue in policy. The European Green Deal, for example mentions 'sustainable consumption' but does not explicitly mention livestock production (and thus meat and dairy consumption) as an important lever to reduce agricultural pollution. Aiming to substantially reduce nitrogen losses in Europe without also focusing on reducing consumption, however, might just increase Europe's reliance on other regions to fulfill nitrogen demands even further, effectively outsourcing environmental damage to these regions.

\subsection{Nitrogen-induced enhancement of forest carbon sink}

The climatic impact of human nitrogen use is mainly determined by the warming impact of nitrogen-induced $\mathrm{N}_{2} \mathrm{O}$ emissions on the one hand and the cooling impact of nitrogeninduced carbon sequestration in forests on the other. While estimates for $\mathrm{N}_{2} \mathrm{O}$ emissions are relatively well constrained, the contribution of nitrogen to carbon sequestration is more uncertain. The contribution of nitrogen to carbon sequestration in forest biomass has been estimated with several approaches (see Chapter 5 for a discussion), however, the use of data from forest fertilization has been under-explored. This thesis presents the first global estimate of spatial variation in nitrogen-induced forest carbon sequestration based on a meta-analysis of forest fertilization experiments.

\subsection{Main findings}

Nitrogen-induced carbon sequestration is quantified by estimating additional carbon sequestered in forest aboveground woody biomass per unit of nitrogen deposition ('C-N response'). Results presented in Chapters 5 and 6 confirm the general pattern of a decrease in C-N response from boreal forests (mean estimated C-N response between 11-14 kg C per $\mathrm{kg} \mathrm{N}$ ) to temperate forests (mean estimated C-N response between 4-13 $\mathrm{kg} \mathrm{C}$ per $\mathrm{kg} \mathrm{N}$ ) to tropical forests (no significant $\mathrm{C}-\mathrm{N}$ response) (Tables 5.1 \& 6.4). Across biomes, variability $\mathrm{C}-\mathrm{N}$ response was explained by factors related to stand characteristics (old forests responded 
less than young forests), climate (C-N response decreased with PET) and soil (C-N response increased with soil nitrogen content).

Results from upscaling C-N responses by combining meta-regression with global datasets for drivers of $\mathrm{C}-\mathrm{N}$ response showed no significant response to nitrogen addition for two thirds of the world's forest, mainly in the tropical region (Figure 6.1). Although tropical forests account for by far the largest area of forests, the estimated C-N response is based on only few experimental data. However, our results confirm the well-established hypothesis that tropical forests are not nitrogen limited due to high mineralization rates and high rates of biological nitrogen fixation.

Estimates for global nitrogen-induced carbon sequestration in tree aboveground woody

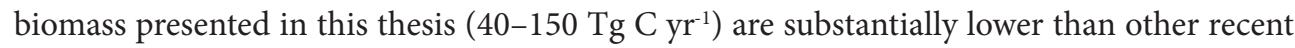
estimates based on various approaches (130-345 Tg C, see Section 6.1). However, they confirm the general picture that nitrogen-induced carbon sequestration makes a minor contribution to the global carbon sink, and hardly offsets the warming impact of offsets $\mathrm{N}_{2} \mathrm{O}$ emissions ( $\sim 880 \mathrm{Tg} \mathrm{C}$-eq $\mathrm{yr}^{-1}$, Table 6.6 ). A regional exception is northern Russia, where nitrogen-induced carbon sequestration fully offsets the climatic impact of $\mathrm{N}_{2} \mathrm{O}$ (Figure 6.3).

\subsubsection{Methodological reflections}

This thesis presents the first estimate of global forest biomass $\mathrm{C}-\mathrm{N}$ response and nitrogeninduced carbon sequestration based on a meta-analysis of data from forest fertilization experiments. While several meta-analyses have investigated ecosystem response to nitrogen addition from fertilization experiments (see Table S5.1), most of these studies focused on relative responses and no previous study has estimated the carbon to nitrogen response in woody biomass. Previous meta-analyses also commonly neglect important drivers of variation in $\mathrm{C}-\mathrm{N}$ response, such as tree age (see Section 5.4.2).

Saturation of $\mathrm{C}-\mathrm{N}$ response. Compared to other approaches used for estimating forest C-N response, fertilization experiments have several advantages (see Section 6.4.2), but also limitations. Experimental nitrogen addition rates are often a factor 5-10 higher than ambient nitrogen deposition rates. While high nitrogen addition rates may still increase biomass carbon sequestration, the $\mathrm{C}-\mathrm{N}$ response might saturate at high nitrogen input levels, as illustrated in Figure 7.2. The nitrogen-saturation-hypothesis is supported by evidence from long-term forest fertilization experiments (Binkley and Högberg, 2016), meta-analyses of NPP response in different ecosystems (Tian et al., 2016 and Figure 5.2 in this thesis) and long-term growth observation studies (Etzold et al., 2020). Forests' response to nitrogen inputs may decrease at high input levels because other nutrients become increasingly liming 


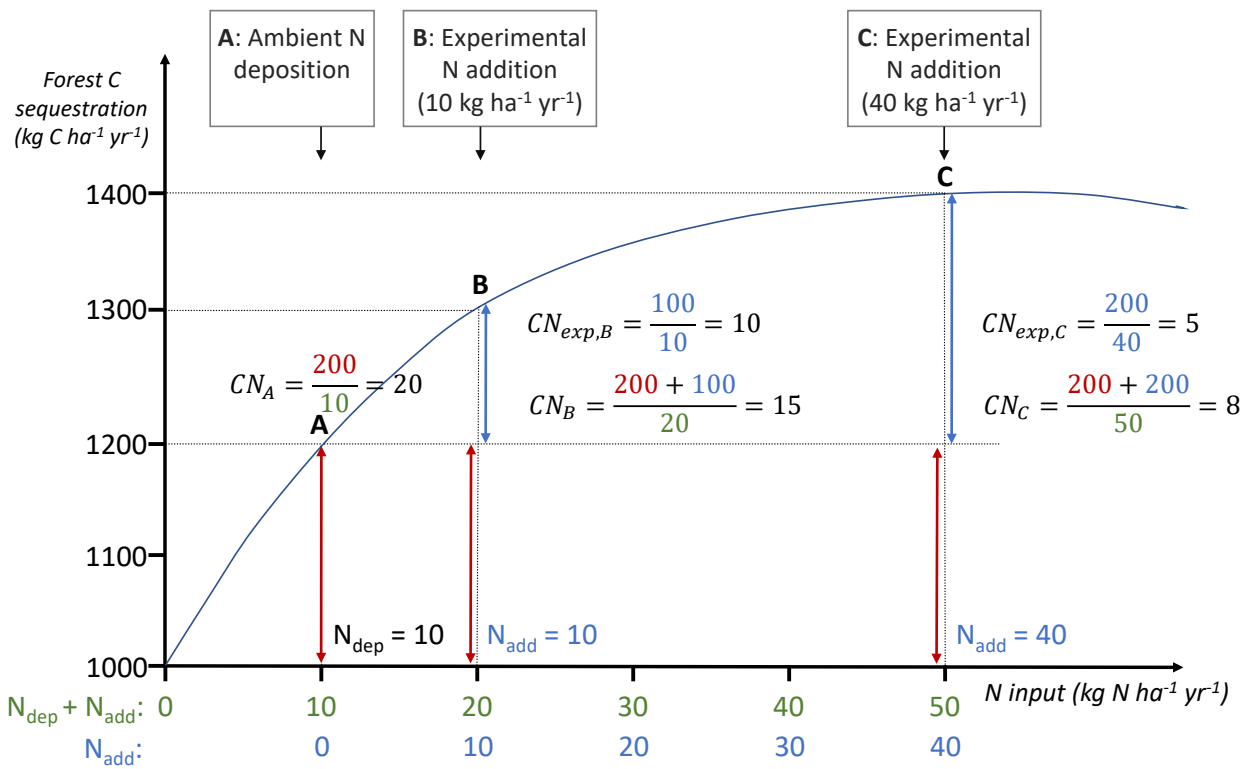

Figure 7.2 Schematic representation of C-N response following hypothesis of a saturating response of forest carbon sequestration ( $y$-axis) with increasing levels of nitrogen $(N)$ input ( $x$-axis). Nitrogen inputs are shown for total inputs from deposition and fertilizer (green) and for fertilizer only (blue). Calculations for $\mathrm{C}-\mathrm{N}$ response are shown for ambient level of nitrogen deposition $(\mathrm{A})$, and at experimental nitrogen

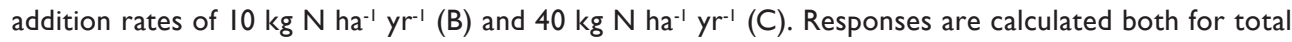
nitrogen inputs (' $\mathrm{CN}$ ', including ambient nitrogen deposition) and only fertilizer nitrogen inputs (' $\mathrm{CN}$ exp'), which is equivalent to $\mathrm{C}-\mathrm{N}$ response detected in fertilization experiments.

and/or excess nitrogen negatively affects growth, with the threshold generally believed to occur between 20 and $30 \mathrm{~kg} \mathrm{~N} \mathrm{ha}^{-1} \mathrm{yr}^{-1}$ (De Vries and Schulte-Uebbing, 2019). Following this hypothesis, fertilization experiments would underestimate forests' response to ambient nitrogen deposition levels (illustrated in Figure 7.2 by $\mathrm{CN}_{\mathrm{A}}>\mathrm{CN}_{\mathrm{B}}>\mathrm{CN}_{\mathrm{C}}$ ). In addition, as both fertilized plots and control plots receive nitrogen from ambient deposition, experiments can only detect the additional effect of nitrogen fertilizer, also leading to lower $\mathrm{C}-\mathrm{N}$ responses (illustrated in Figure 7.2 by $\mathrm{CN}_{\mathrm{B}}>\mathrm{CN}_{\text {exp,B }}$ and $\mathrm{CN}_{\mathrm{C}}>\mathrm{CN}_{\text {exp,C}}$ ).

Nitrogen-induced soil carbon sequestration. A complete picture of nitrogen-induced carbon sequestration would also include soils, where nitrogen might increase carbon storage through either increasing carbon inputs or reducing respiration losses through different mechanisms. Studies assessing the global nitrogen-induced carbon sink have attributed between 40 and $50 \%$ to soils (see Table 5.4), which are proportions also found in long-term nitrogen addition experiments (Hyvönen et al., 2008; Pregitzer et al., 2008). Overall, the nitrogen-induced carbon sink in soils is likely either similar or smaller than the nitrogen-induced biomass sink. 


\subsubsection{Outlook}

Evidence presented in this thesis shows that the contribution of anthropogenic nitrogen deposition to the forest biomass carbon sink is small and only offsets a small fraction of anthropogenic $\mathrm{N}_{2} \mathrm{O}$ emissions. For the future, the contribution of nitrogen deposition to forest carbon sequestration is likely to decline due to several reasons. First, evidence shows that forests increasingly shift towards phosphorus limitation in regions with high nitrogen deposition (Du et al., 2021; Jonard et al., 2015). Second, I showed that the largest nitrogeninduced forest carbon sink occurs in boreal forests, where future climate warming will likely increase nitrogen mineralization (Melillo et al., 2011), alleviating nitrogen limitation. Finally, increasing $\mathrm{CO}_{2}$ concentrations are expected to stimulate biological nitrogen fixation (Esser et al., 2011), thereby increasing nitrogen availability to forests and potentially reducing the role of deposition in nitrogen supply.

The lower or even insignificant $\mathrm{C}-\mathrm{N}$ responses reported in this thesis compared to earlier studies may in part be attributable to saturation of the forest C-N response at high experimental nitrogen addition rates. However, even considering the highest estimates for nitrogen-induced carbon sequestration in forest biomass from recent studies that also include carbon sequestration in soils (up to $560 \mathrm{Tg} \mathrm{C} \mathrm{yr}^{-1}$, Table 5.4), the share of global $\mathrm{N}_{2} \mathrm{O}$ emissions offset by nitrogen-induced carbon sequestration would at most be $\sim 60 \%$. Overall, this shows that the net climatic impact of reactive nitrogen is likely a warming effect, further stressing the need to mitigate nitrogen losses.

\subsection{Trade-offs in sustainable nitrogen management}

The approaches developed in this thesis contribute to informing decision making on nitrogen management by using spatially explicit modelling to provide quantitative insights on trade-offs between benefits of agricultural nitrogen use for crop production and threats to the environment, as well as the net climatic impact of nitrogen use. In this section, I combine results from Chapters 4 and 6 to assess links between critical nitrogen inputs and the climatic impact of nitrogen (Section 7.4.1). I also illustrate how the developed indicators could be used to improve the calculation of the Sustainable Nitrogen Management Index, one of the indicators currently used to measure countries' progress towards achieving SDG 2 (Section 7.4.2).

\subsection{Implications of nitrogen boundaries for nitrogen's climate footprint}

Spatially explicit thresholds for safe agricultural nitrogen inputs (critical nitrogen inputs) 
Table 7.I | Anthropogenic $\mathrm{N}_{2} \mathrm{O}$ emissions (including emissions from agriculture and other sectors, based on Tian et al., 2020) and nitrogen-induced carbon (C) sink in forest aboveground biomass (estimated based on the approach described in Chapter 6) for the baseline situation (year 2010), and after (i) reducing nitrogen (N) inputs to critical levels in areas where thresholds are currently exceeded, (ii) increasing nitrogen inputs where possible within thresholds and (iii) both reductions and increases. Percentages in brackets indicate relative change compared to emissions in the Baseline scenario.

\begin{tabular}{|c|c|c|c|c|}
\hline & $\begin{array}{l}\text { Baseline } \\
(2010)\end{array}$ & $\begin{array}{l}\text { After reducing } \\
\mathbf{N} \text { inputs } \\
\text { to respect } \\
\text { thresholds }\end{array}$ & $\begin{array}{l}\text { After } \\
\text { increasing N } \\
\text { inputs within } \\
\text { thresholds }\end{array}$ & $\begin{array}{l}\text { After both reducing } \\
\mathrm{N} \text { inputs to respect } \\
\text { thresholds and increasing } \\
\mathrm{N} \text { inputs within thresholds }\end{array}$ \\
\hline A. $\mathrm{N}_{2} \mathrm{O}$ emissions [ $\mathrm{Tg} \mathrm{C}$-eq $\left.\mathrm{yr}^{\prime}\right]$ & 869 & $55 I(-37 \%)$ & $973(+12 \%)$ & $654(-25 \%)$ \\
\hline B. N-induced $C$ sink $\left[\mathrm{Tg} C \mathrm{yr}^{\prime}\right]$ & 43 & $36(-16 \%)$ & $44(+4 \%)$ & $37(-12 \%)$ \\
\hline C. Net effect A-B [Tg C-eq yr'] & 827 & $515(-38 \%)$ & $929(+12 \%)$ & $617(-25 \%)$ \\
\hline
\end{tabular}

presented in Chapters 2 and 4 are based on thresholds to avoid three environmental impacts: terrestrial eutrophication due to nitrogen emissions and subsequent re-deposition, surface water eutrophication due to nitrogen runoff, and groundwater pollution due to nitrate leaching. A threshold for impacts of nitrogen use on climate change is not included, as emissions of long-lived, well-mixed greenhouse gasses (GHGs) affect the climate everywhere, and thus spatially explicit thresholds become irrelevant. While in theory, a global GHG emission threshold to limit temperature increase to below 1.5 or 2 degrees (e.g., Rogelj et al., 2011) could be distributed spatially based on various allocation principles, resulting emission thresholds would not reflect sensitivity of ecosystems in regions where emissions occur, and thus be fundamentally different from the approach presented in this thesis.

While nitrogen boundaries presented in this thesis do not include a threshold for climate change, the impact of reducing inputs to critical limits on nitrogen-related GHG emissions can be estimated. To this end, I combined results from Chapter 4 and 6 to assess how global anthropogenic $\mathrm{N}_{2} \mathrm{O}$ emissions and nitrogen-induced carbon sequestration in forest biomass change when agricultural nitrogen inputs are (i) reduced to respect thresholds in regions where thresholds are exceeded, (ii) increased to close yield gaps in regions where thresholds are not exceeded and (iii) a combination of (i) and (ii).

Reducing nitrogen inputs to respect thresholds leads to a 37\% reduction in anthropogenic $\mathrm{N}_{2} \mathrm{O}$ emissions and a $16 \%$ reduction in nitrogen-induced forest carbon sequestration (Table 7.1). Increasing nitrogen inputs to close yield gaps in regions where thresholds are not exceeded increases $\mathrm{N}_{2} \mathrm{O}$ emissions by $12 \%$ but hardly affects the nitrogen-induced carbon sink, as increases in nitrogen inputs mainly occur in tropical regions (see Figure 4.2a) where C-N responses are low (see Figure 6.1). As shown in Chapter 6, the net climate footprint of human nitrogen use is dominated by the warming impact of $\mathrm{N}_{2} \mathrm{O}$, which is about a factor 


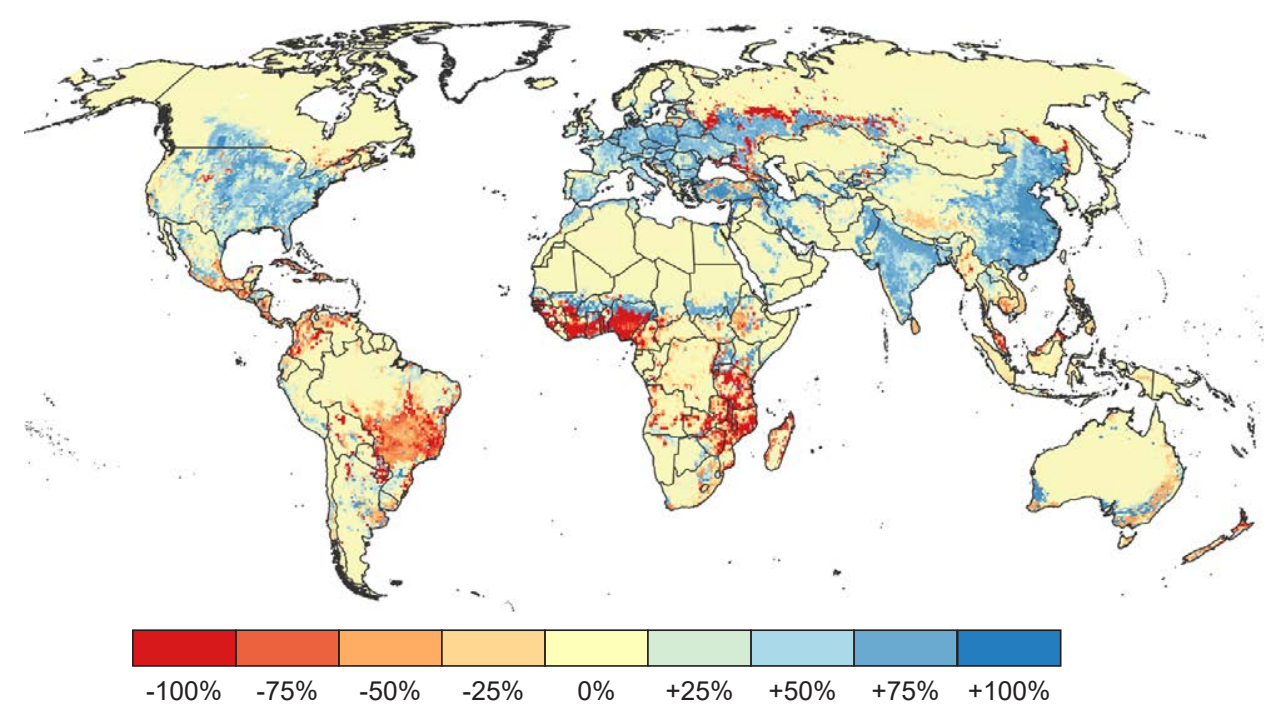

Change in GHG footprint of human N use at critical N inputs compared to baseline

Figure 7.3 Change in net GHG footprint of anthropogenic nitrogen when agricultural nitrogen inputs are changed from current inputs (year 2010) to critical nitrogen inputs as assessed in Chapter 4 (considering both reducing nitrogen inputs to respect thresholds and increasing nitrogen inputs within thresholds). Net GHG footprint includes the combined effect of $\mathrm{N}_{2} \mathrm{O}$ emissions and nitrogen-induced forest carbon sequestration (expressed in $\mathrm{Tg} \mathrm{C}$-eq $\mathrm{yr}^{-1}$ ).

35-50 higher than the estimated cooling impact of nitrogen-induced carbon sequestration in forest biomass under all scenarios (Table 7.1). Spatial patterns in the change in net GHG footprint from current to critical inputs depend on the conditions in regions where required reductions to respect thresholds lead to decreasing $\mathrm{N}_{2} \mathrm{O}$ emissions, and where increases in nitrogen inputs within thresholds lead to increasing $\mathrm{N}_{2} \mathrm{O}$ emissions (Figure 7.3).

\subsubsection{An indicator for sustainable nitrogen management}

Harnessing nitrogen's benefits for food production while reducing its negative externalities is a complex challenge and requires a spatially explicit approach, as demonstrated in this thesis. However, aggregate indicators are nevertheless useful to reduce complexity for the sake of benchmarking, a quick comparison of performance across countries and regions, and tracking progress in meeting targets over time. Two commonly used indicators to illustrate the two sides of the coin of the dual nitrogen management challenge are crop nitrogen yield (reflecting benefits of nitrogen) and NUE (reflecting pollution risk). Individually, however, both indicators do not provide a holistic picture of sustainable nitrogen management. High NUEs are often achieved in cropping systems with low yields and soil nitrogen mining (Figure 7.4a, red box), while high yields often come at the expense of severe nitrogen 
a

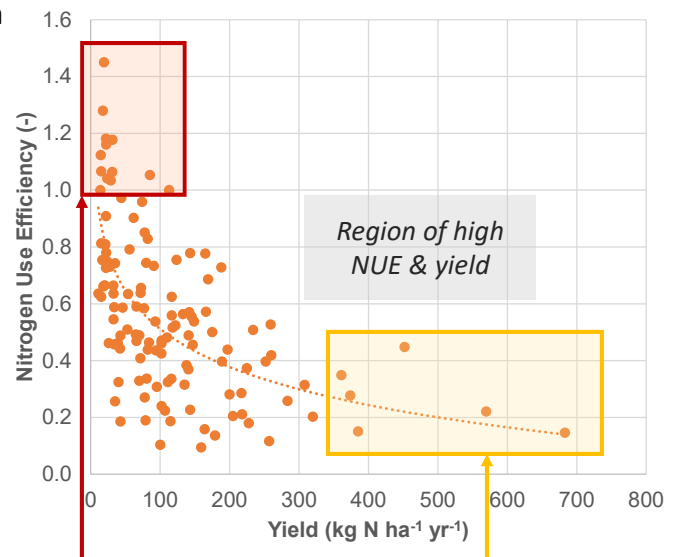

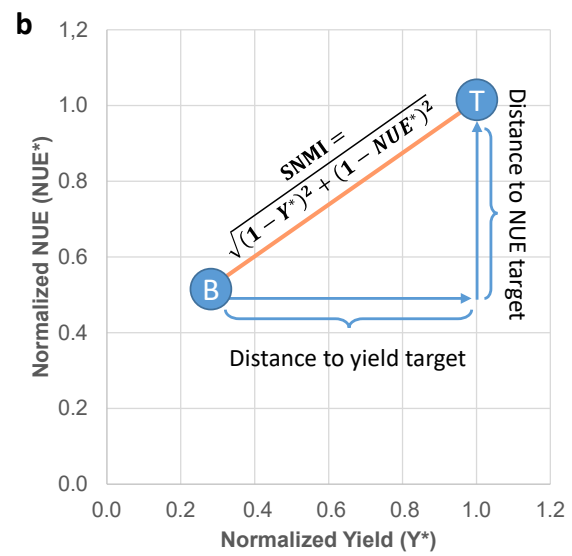
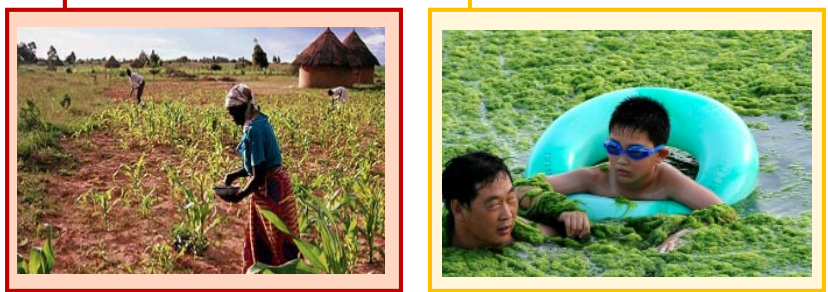

Figure 7.4 | a, Correlation between country-level cropland NUE and yield (expressed in harvested nitrogen) for the year 20II. Each dot represents a country, data are from Zhang et al. 20I5. b, Scheme demonstrating calculation of Sustainable Nitrogen Management Index (SNMI) based on the distance of normalized yield ( $\left.Y^{*}\right)$ and NUE (NUE*) to target values, as proposed by Zhang and Davidson (2019). "B", = baseline, "T" = target.

pollution (Figure 7.4a, yellow box). The "Sustainable Nitrogen Management Index" (SNMI) has been proposed as a new indicator to reflect performance on both aspects of the dual nitrogen management challenge.

The SNMI (Zhang and Davidson, 2019) is a one-dimensional ranking score calculated based on the combined distance-to-target for NUE and yield (see Figure 7.4b); a favourable SNMI rating thus requires good performance on both aspects. The SNMI is currently one of the indicators for monitoring progress towards meeting SDG 2 ("End Hunger, achieve food security and improved nutrition and promote sustainable agriculture“). However, an important issue that remains underexposed is which benchmarks (targets) for yields and NUEs should be used to calculate the SNMI. Country-scores for SNMI in the current SDG Index (Sachs et al., 2019, www.sdgindex.org) are based on a universal target yield of $90 \mathrm{~kg}$ $\mathrm{N} \mathrm{ha}^{-1} \mathrm{yr}^{-1}$ (equal to the average global required nitrogen yield to meet demands in 2050 without land expansion; Zhang et al., 2015), and a universal target NUE of 1, while regions with NUEs > 1 are 'penalized' for potential soil mining (Figure 7.5, left column). 
However, as I demonstrate in this thesis, large regional variation occurs in both achievable yields and in environmental sensitivities to nitrogen losses, which makes universal targets less suitable to rank country performance on nitrogen management. Based on the approaches developed in this thesis, I propose a revised method to calculate the SNMI using regional maximum attainable yields as a benchmark for yields, and 'necessary NUE' (NUE at which yields can be obtained without transgressing environmental thresholds) as a benchmark for NUE (Figure 7.5, right column). Using both approaches, I calculated normalized yield, normalized NUE and SNMI at a 0.5x0.5 degree resolution using data from IMAGE-GNM for the year 2010 (results shown in Figure 7.5). Average SNMI scores were calculated for 26 world regions.

Performance scores for SNMI calculated with approach B were structurally lower (= better) than scores calculated with approach A (cf. Figure 7.5a-iii \& 7.5b-iii), mostly because using 'required NUE' as a benchmark (being always $<1$ ) always leads to higher score than using 1 as a benchmark (cf. Figure 7.5a-ii \& 7.5b-ii). When comparing the two approaches, relative difference in countries' ranking are more interesting than absolute differences, and thus regional SNMI scores derived with approach B (as shown in Figure 7.6) were normalized based on the global average SNMI score from approach A.

The new approach yields lower (= better) SNMI scores for most regions, with differences being especially pronounced for Japan, Oceania, Canada, and Korea (Figure 7.6a). For Oceania, for example, using target yields rather than a universal benchmark of $90 \mathrm{~kg} \mathrm{~N} \mathrm{ha}^{-1}$ $\mathrm{yr}^{-1}$ leads to more favourable scores for normalized yield (cf. Figure 7.5a-i \& 7.5b-i), probably because attainable yields are limited by water availability. For Central Europe, on the other hand, the new approach yields a higher (= worse) SNMI score, because estimated target yields exceed $90 \mathrm{~kg} \mathrm{~N} \mathrm{ha}^{-1} \mathrm{yr}^{-1}$ in this region.

Regional SNMI scores derived with the new approach (Figure 7.6b) indicate that 'major challenges' remain for most of Africa, Central and Eastern Europe, Middle East and much of Asia, and that 'significant challenges' remain for South Africa, Oceania, Mexico and Central America. Only Western Europe and Indonesia obtain the designation 'SDG achieved'.

A high SNMI score for Western Europe seems to contradict results presented in Chapters 2 and 3, where I show that current nitrogen inputs exceed thresholds for nitrogen pollution across much of Europe (Figure 2.5), and that large NUE increases are required to reconcile crop production with thresholds (Figure 3.4). The high SNMI score for Western Europe is explained by two factors: First, across regions, yield performance has a larger impact on SNMI scores than NUE performance. Target yields can exceed actual yields by a factor 2-3 in some regions, while target NUEs only exceed actual NUEs by a factor 1-1.7, thus leading 


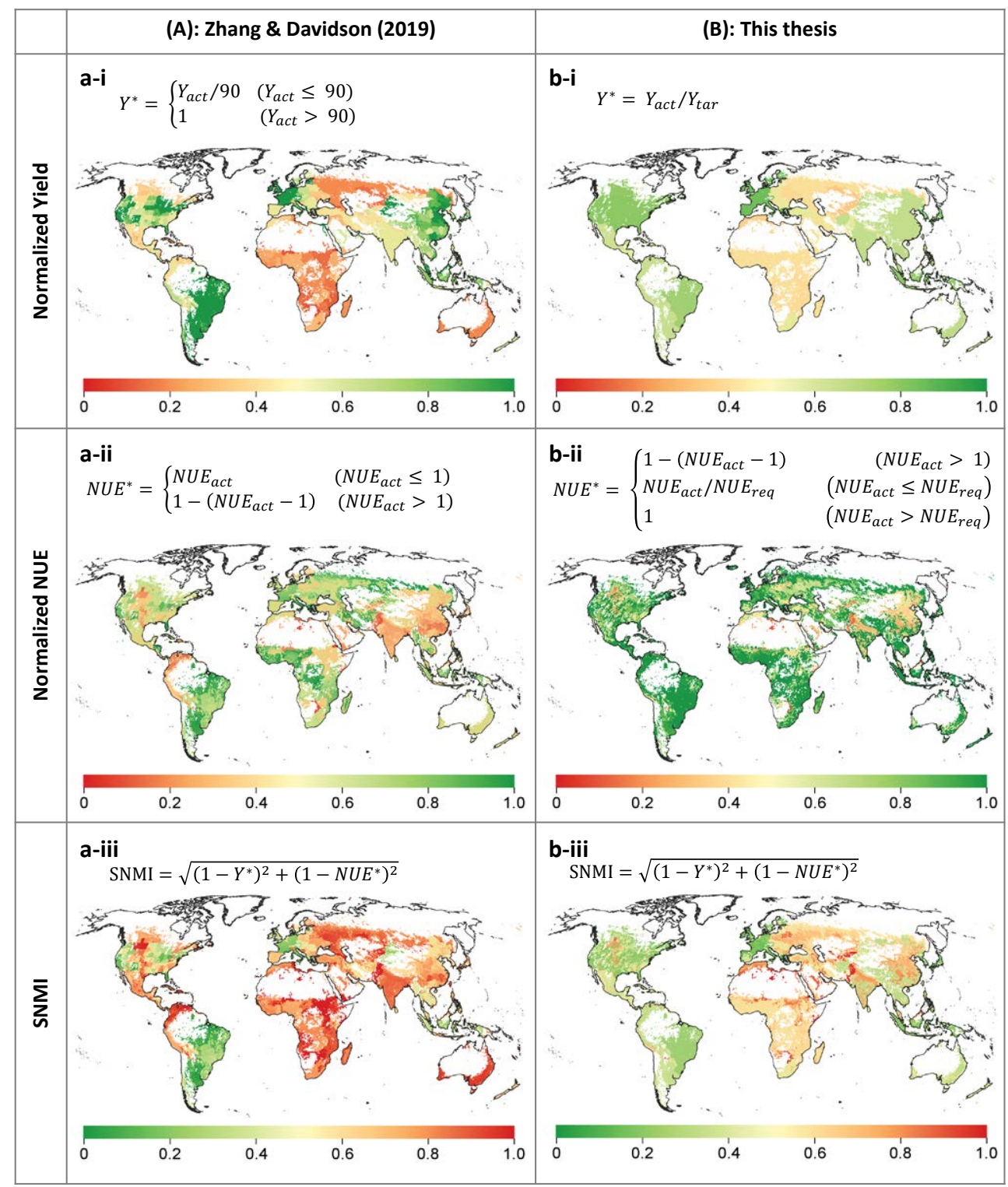

Figure 7.5 | Approaches to calculating normalized yield, normalized NUE and SNMI as proposed by A: Zhang and Davidson (2019, left) and B: this thesis (right). Yact $=$ actual yield, Ytar $=$ target yield (see Supplementary Text 4.I for how target yields were derived), NUEact $=$ actual NUE, NUEreq = required NUE to obtain target yield without exceeding threshold for nitrogen runoff to surface water (see Section 4.7. for description how required NUEs were derived). Maps show spatial variation in normalized yield, normalized NUE and SNMI at a resolution of $0.5 \times 0.5$ degrees calculated with IMAGE (data for 20I0). 
a

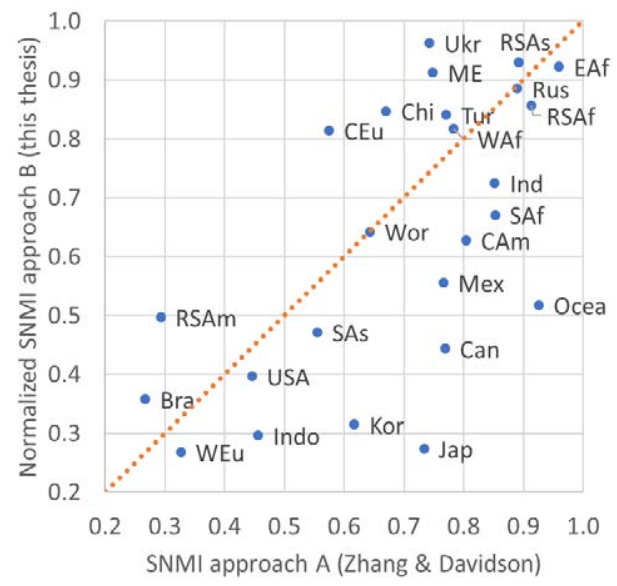

b

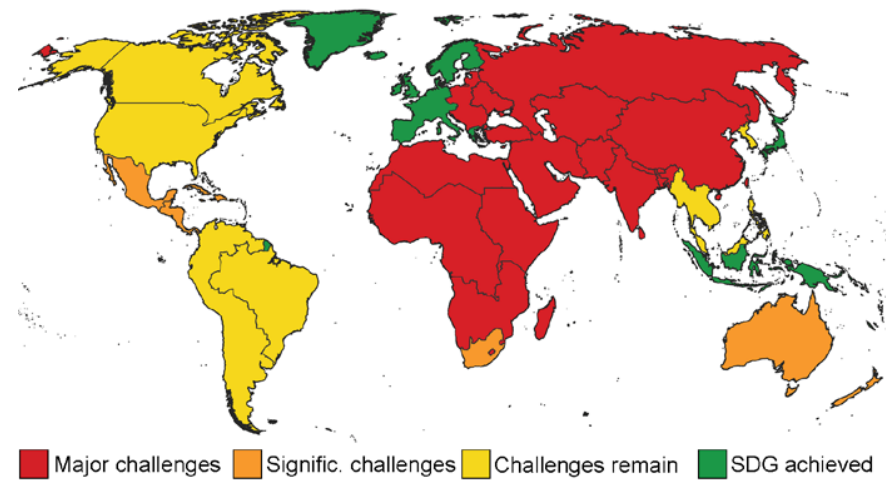

Figure 7.6 | a, SNMI score per IMAGE region calculated based on benchmarks for yield and NUE as currently used in SDG reporting ("approach A", Zhang \& Davidson) versus normalized SNMI score calculated based on new proposed benchmarks for yield and NUE ("approach B", this thesis). For explanation of region abbreviations, see Table S7.I. b, Normalized SNMI score as calculated with our approach per IMAGE region, colour classification follows SDG dashboard (www.sdgindex.org).

to wider ranges for normalized yield than for normalized NUE (cf. Figures 7.5b-i \& 7.5b-ii). Yield gaps in Western Europe are small compared to the global average (Table S4.4), which explains high performance on SNMI. Second, the average SNMI calculated for Western Europe as a whole obscures performance differences between countries. To show this, I used target yields and required NUEs for Europe derived with INTEGRATOR (Chapter 3) to calculate SNMI scores for European countries, using the approach described above. Results (Figure S7.1) show that while many Western European countries indeed receive the rating 'SDG achieved', challenges remain in the Netherlands, Belgium, Finland, Spain, Greece and Italy, and significant challenges remain in Portugal. Central European countries obtain lower scores than Western European countries (all countries receive yellow or orange rating); which is in line with the lower SNMI for Central Europe calculated with IMAGE (Figure 7.6b). 
Overall, the advantage of the SNMI is that it captures progress towards both harnessing the benefits of nitrogen and reducing environmental nitrogen losses. However, the downside is that resulting scores are difficult to interpret, and that the contribution of each component to the final score is not transparent. Nevertheless, using the SNMI to assess countries' progress towards sustainable nitrogen management as one indicator for progress towards the SDGs is useful, but benchmarks used in the calculations should better reflect regional differences in target yields and NUEs, as argued above.

\subsection{Integrated assessment modelling for sustainable nitrogen management}

Nitrogen management faces several complex challenges: nitrogen affects different environmental compartments, losses are caused by many different sectors, and we depend on its abundant availability for producing food while we must also limit its negative impacts to remain within a safe operating space. Despite - or perhaps, due to - these inherent complexities, nitrogen still receives far less attention than issues like climate change or biodiversity loss in national and international policy arenas. However, recently an increasing number of policies recognizes the need for an integrated approach to the nitrogen challenge and include goals for overall reductions in nitrogen losses (e.g. the Farm to Fork Strategy or the UN Colombo Declaration) rather than for a specific nitrogen compound only. Information presented in this thesis supports integrated policies on nitrogen by providing insights into the magnitude of the nitrogen problem and, importantly, its geographical variation. The quantitative assessment of trade-offs between nitrogen's adverse impacts and benefits presents in this thesis can help decision makers identify opportunities as well as threats, and highlight hot-spot regions for both.

Our scientific understanding of the nitrogen cycle is far from complete. Partially, understanding is still hampered by fragmentation of nitrogen research between different scientific disciplines, each focusing on their own piece of the nitrogen puzzle (e.g., agronomists focusing on modelling yield response and aquatic ecologists trying to understand lakes' response to nitrogen enrichment). Currently, UN-sponsored efforts towards an 'International Nitrogen Management System (INMS)' aim to bring stakeholders from both science and policy together to synthesize evidence in support of international policy development on nitrogen management. This and other initiatives will contribute towards increasing integration of scientific disciplines as well as information exchange between scientist and other stakeholders, thereby hopefully increasing visibility of the 
nitrogen problem and catalysing action.

During the final stages of working on this thesis, the Dutch nitrogen crisis unfolded - suddenly, nitrogen was national front page news for months in a row. However, more than a year after the Dutch State Council ruled that the policies in place did not sufficiently guarantee progress towards emission reductions and nature protection, the government has still taken little action, despite large economic damage caused by many projects that cannot be realized in lack of nitrogen permits. The Dutch situation highlights the large complexity of agricultural nitrogen emissions reductions: losses are diffuse and caused by many actors, and farming is much more than a business operation: it provides vital commodities, shapes landscapes, and is strongly connected with tradition and identity. Many of these complexities cannot be captured by models. In the coming years, societal dialogue will reveal which options for emission reductions, such as reducing livestock numbers, will receive support from different actors and the general public. While understanding differences in values and perceptions should be an integral part of such dialogues, so should an evidence-based understanding of the (biophysical) realities of the nitrogen cycle. Therefore, integrated nitrogen assessment models will continue to make valuable contributions to solving nitrogen problems in the Netherlands, Europe, and globally. 


\section{References}

Abalos, D., Jeffery, S., Sanz-Cobena, A., Guardia, G., \& Vallejo, A. (20l4). Meta-analysis of the effect of urease and nitrification inhibitors on crop productivity and nitrogen use efficiency. Agriculture, Ecosystems and Environment, I89, I36-144. https://doi.org/I0.1016/j.agee.2014.03.036

Aber, J. D., Nadelhoffer, K. J., Steudler, P., \& Melillo, J. M. ( 1989 ). Nitrogen Saturation in Northern Forest Ecosystems. BioScience, 39(6), 378-386. https://doi.org//0.2307//31/ 067

Aber, J. D., McDowell, W., Nadelhoffer, K., Magill, A., Berntson, G., Kamakea, M., ... Fernandez, I. (I998). Nitrogen Saturation in Temperate Forest Ecosystems. BioScience, 48(I I), 92 I-934. https://doi.org/ / 0.2307// 3 I 3296

Adamek, M., Corre, M. D., \& Hölscher, D. (2009). Early effect of elevated nitrogen input on above-ground net primary production of a lower montane rain forest, Panama. Journal of Tropical Ecology, 25(06), 637. https:// doi.org/10.1017/S0266467409990253

Adviescollege Stikstofproblematiek. (2020). Niet alles kan overal. Eindadvies over structurele aanpak op lange termijn. Den Haag: Ministerie van LNV. Retrieved from https:/www.rijksoverheid.nl/documenten/ rapporten/2020/06/08/niet-alles-kan-overal

Alcantara, C., Kuemmerle, T., Baumann, M., Bragina, E. V., Griffiths, P., Hostert, P., ... Radeloff, V. C. (20I3). Mapping the extent of abandoned farmland in Central and Eastern Europe using MODIS time series satellite data. Environmental Research Letters, 8(3), 035035. https://doi.org/I0.1088/I748-9326/8/3/035035

Alexander, R. B., Böhlke, J. K., Boyer, E. W., David, M. B., Harvey, J. W., Mulholland, P. J., ... Wollheim, W. M. (2009). Dynamic modeling of nitrogen losses in river networks unravels the coupled effects of hydrological and biogeochemical processes. Biogeochemistry, 93(I-2), 9I-I I6. https://doi.org/ I 0. I007/s I0533-008-9274-8

Allen, M. F., Allen, E. B., Lansing, J. L., Pregitzer, K. S., Hendrick, R. L., Ruess, R.W., \& Collins, S. L. (20I0). Responses to chronic $\mathrm{N}$ fertilization of ectomycorrhizal piñon but not arbuscular mycorrhizal juniper in a piñon-juniper woodland. Journal of Arid Environments, 74(I0), I I70-I I 76. https://doi.org/I0.1016/j.jaridenv.2010.05.00 I

Amann, M., Bertok, I., Borken-Kleefeld, J., Cofala, J., Heyes, C., Höglund-lsaksson, L., ... Winiwarter, W. (20II). Cost-effective control of air quality and greenhouse gases in Europe: Modeling and policy applications. Environmental Modelling and Software, 26(I2), I489-I50I. https://doi.org/10.1016/j.envsoft.201 I.07.012

Ares, A., \& Fownes, J. H. (200I). Productivity, resource use, and competitive interactions of Fraxinus uhdei in Hawaii uplands. Canadian Journal of Forest Research, (31), I32-I42.

Ascott, M. J., Gooddy, D. C., Wang, L., Stuart, M. E., Lewis, M.A., Ward, R. S., \& Binley, A. M. (20I7). Global patterns of nitrate storage in the vadose zone. Nature Communications, 8(I), I-6. https://doi.org/I0.1038/s4I467-0I7$0132 \mathrm{I}-\mathrm{W}$

Asman, W. A. H., Klimont, Z., \& Winiwarter, W. (20II). A simplified model of nitrogen flows from manure management. IIASA Interim Report IR-I I-030. Laxenburg, Austria: International Institute for Applied Systems Analysis (IIASA).

Averill, C., Turner, B. L., \& Finzi, A. C. (20I4). Mycorrhiza-mediated competition between plants and decomposers drives soil carbon storage. Nature, 505(7484), 543-545. https://doi.org/ I0.1038/nature I 290 I

Bai, E., Houlton, B. Z., \& Wang, Y. P. (20I2). Isotopic identification of nitrogen hotspots across natural terrestrial ecosystems. Biogeosciences, 9(8), 3287-3304. https://doi.org/ I0.5 I 94/bg-9-3287-20I2

Bala, G., Devaraju, N., Chaturvedi, R. K., Caldeira, K., \& Nemani, R. (20I3). Nitrogen deposition: How important is it for global terrestrial carbon uptake. Biogeosciences, I0, 7I47-7/60. https://doi.org/ I0.5 I94/bg-I0-7|47-20 I 3

Balasubramanian, V., Alves, B., Aulakh, M., Bekunda, Z., Cai, L., Drinkwater, D., ... Oenema, O. (2004). Crop, environmental, and management factors affecting nitrogen use efficiency. In A. R. Mosier, J. K. Syers, \& J. R. Freney (Eds.), Agriculture and the nitrogen cycle (pp. 19-33).Washington, D.C.: Island Press.

Baribault, T. W., Kobe, R. K., \& Rothstein, D. E. (2010). Soil calcium, nitrogen, and water are correlated with aboveground net primary production in northern hardwood forests. Forest Ecology and Management, 260(5), 723-733. https://doi.org/10.1016/j.foreco.2010.05.029

Batjes, N. H. (2009). Harmonized soil profile data for applications at global and continental scales: Updates to the 
WISE database. Soil Use and Management, 25(2), I24-127. https://doi.org/ I0. I I I I/j. I 475-2743.2009.00202.x

Beckman, J., Ivanic, M., Jelliffe, J. L., Baquedano, F. G., \& Scott, S. G. (2020). Economic and Food Security Impacts of Agricultural Input Reduction Under the European Union Green Deal's Farm to Fork and Biodiversity Strategies. U.S. Department of Agriculture, Economic Research Service. Retrieved from www.ers.usda.gov

Beusen, A. H. W., Van Beek, L. P. H., Bouwman, A. F., Mogollón, J. M., \& Middelburg, J. J. (20I5). Coupling global models for hydrology and nutrient loading to simulate nitrogen and phosphorus retention in surface water - Description of IMAGE-GNM and analysis of performance. Geoscientific Model Development, 8( I2), 40454067. https://doi.org/10.5I94/gmd-8-4045-20I5

Billen, G., Lassaletta, L., \& Garnier, J. (20I4). A biogeochemical view of the global agro-food system: Nitrogen flows associated with protein production, consumption and trade. Global Food Security, 3(3-4), 209-219. https:// doi.org/10.1016/j.gfs.2014.08.003

Binkley, D., \& Högberg, P. (2016). Tamm Review: Revisiting the influence of nitrogen deposition on Swedish forests. Forest Ecology and Management, 368, 222-239. https://doi.org/10.1016/j.foreco.2016.02.035

Bleeker, A., Hicks, W. K., Dentener, F., Galloway, J., \& Erisman, J.W. (20I I). N deposition as a threat to the World's protected areas under the Convention on Biological Diversity. Environmental Pollution, I59( I0), 2280-2288. https://doi.org/10.1016/j.envpol.2010.10.036

Bobbink, R., Ashmore, M., Braun, S., Flückiger,W., \& van den Wyngaert, I. (2003). Empirical nitrogen critical loads for natural and semi-natural ecosystems: 2002 update. In B. Achermann \& R. Bobbink (Eds.), Empirical Critical Loads for Nitrogen (pp. 43-I70). Bern, Switzerland: Swiss Agency for Environment, Forest and Landscape SAEFL.

Bobbink, R., Hicks, K., Galloway, J., Spranger,T.,Alkemade, R.,Ashmore, M., ... De Vries, W. (2010). Global assessment of nitrogen deposition effects on terrestrial plant diversity: A synthesis. Ecological Applications, 20(I), 30-59. https://doi.org/10.1890/08-I |40.I

Bodirsky, B. L., \& Müller, C. (20I4). Robust relationship between yields and nitrogen inputs indicates three ways to reduce nitrogen pollution. Environmental Research Letters, 9(II), I I I005. https://doi.org/I0.1088/I 7489326/9/1 I/IIII005

Bodirsky, B. L., Popp, A., Lotze-Campen, H., Dietrich, J. P., Rolinski, S., Weindl, I., ... Stevanovic, M. (20I4). Reactive nitrogen requirements to feed the world in 2050 and potential to mitigate nitrogen pollution. Nature Communications, 5, 3858. https://doi.org//0.1038/ncomms4858

Borenstein, M., Hedges, L.V., Higgins, J. P., \& Rothstein, H. R. (2009). Introduction to meta-analysis. John Wiley \& Sons.

Bossel, H. (1999). Indicators for Sustainable Development: Theory, Method, Applications. Winnipeg, Canada: International Institute for Sustainable Development (IISD). Retrieved from http://iisd.ca/about/prodcat/ ordering.htm

Bouraoui, F., \& Grizzetti, B. (2014, January I5). Modelling mitigation options to reduce diffuse nitrogen water pollution from agriculture. Science of the Total Environment. https://doi.org/10.1016/j.scitotenv.2013.07.066

Bouwman, A. F., Beusen, A. H. W., \& Billen, G. (2009). Human alteration of the global nitrogen and phosphorus soil balances for the period 1970-2050. Global Biogeochemical Cycles, 23(4), n/a-n/a. https://doi. org/I0.1029/2009GB003576

Bouwman, A. F., Beusen, A. H.W., Lassaletta, L., Van Apeldoorn, D. F., van Grinsven, H. J. M., Zhang, J., \& Ittersum Van, M. K. (2017). Lessons from temporal and spatial patterns in global use of $\mathrm{N}$ and $\mathrm{P}$ fertilizer on cropland. Scientific Reports, 7. https://doi.org/10.1038/srep40366

Bouwman, A. F., Boumans, L. J. M., \& Batjes, N. H. (2002). Modeling global annual N2O and NO emissions from fertilized fields. Global Biogeochemical Cycles, I6(4), 28-I-28-29. https://doi.org/I0. I029/200 Igb00I8I2

Bouwman, A. F., Goldewijk, K. K., Van Der Hoek, K. W., Beusen, A. H. W., Van Vuuren, D. P., Willems, J., ... Stehfest, E. (20I3). Exploring global changes in nitrogen and phosphorus cycles in agriculture induced by livestock production over the 1900-2050 period. Proceedings of the National Academy of Sciences of the United States of America, I I0(52), 20882-20887. https://doi.org/I 0. I073/pnas. 1012878108

Bradford, M.A. (20I4). Ecology: Good dirt with good friends. Nature, 505(7484), 486-487. https://doi.org/I0.I038/ nature 12849

Braun, S., Thomas, V. F. D., Quiring, R., \& Flückiger, W. (2010). Does nitrogen deposition increase forest 
production? The role of phosphorus. Environmental Pollution, 158(6), 2043-2052. https://doi.org//0.1016/j. envol.2009.1 I.030

Brink, C., van Grinsven, H., Jacobsen, B. H., Rabl,A., Gren, I.-M., Holland, M., ... Webb, J. (20I I). Costs and benefits of nitrogen in the environment. In The European Nitrogen Assessment (pp. 5/3-540). https://doi.org/ $0.1017 /$ cbo97805 II 976988.025

Brook, B. W., Ellis, E. C., Perring, M. P., Mackay, A. W., \& Blomqvist, L. (2013). Does the terrestrial biosphere have planetary tipping points? Trends in Ecology \& Evolution, 28(7), 396-40I. https://doi.org/10.1016/j. tree.2013.01.016

Brooks, B. W., Lazorchak, J. M., Howard, M. D. A., Johnson, M.-V.V., Morton, S. L., Perkins, D. A. K., .. Steevens, J. A. (2016). Are harmful algal blooms becoming the greatest inland water quality threat to public health and aquatic ecosystems? Environmental Toxicology and Chemistry, 35(I), 6-13. https://doi.org// 0.1002/etc.3220

Brookshire, E. N. J., Gerber, S., Menge, D. N. L., \& Hedin, L. O. (20I2). Large losses of inorganic nitrogen from tropical rainforests suggest a lack of nitrogen limitation. Ecology Letters, I5(I), 9-16. https://doi.org/I 0. I I I / j. I 46I$0248.2011 .01701 . x$

Bruinsma, J. (2012). European and Central Asian Agriculture Towards 2030 and 2050. Budapest, Hungary: FAO Regional Office for Europe and Central Asia. Retrieved from http://www.fao.org/3/a-aq34l e.pdf

Brundrett, M. C. (2009). Mycorrhizal associations and other means of nutrition of vascular plants: understanding the global diversity of host plants by resolving conflicting information and developing reliable means of diagnosis. Plant and Soil, 320(I-2), 37-77. https://doi.org//0.1007/s I I 04-008-9877-9

Büntgen, U., Krusic, P. J., Piermattei, A., Coomes, D. A., Esper, J., Myglan, V. S., ... Körner, C. (2019). Limited capacity of tree growth to mitigate the global greenhouse effect under predicted warming. Nature Communications, I0(I), I-6. https://doi.org/I0.1038/s4| 467-019-10174-4

Butterbach-Bahl, K., Nemitz, E., Zaehle, S., Billen, G., Boeckx, P., Erisman, J.W., .. Sutton, M. A. (20I I). Nitrogen as a threat to the European greenhouse balance. The European Nitrogen Assessment, 434-462. https://doi. org/I0.1017/cbo97805II 976988.022

Camargo, J. A., \& Alonso, Á. (2006). Ecological and toxicological effects of inorganic nitrogen pollution in aquatic ecosystems: A global assessment. Environment International, 32(6), 831-849. https://doi.org//0.1016/j. envint.2006.05.002

Canfield, D. E., Glazer, A. N., \& Falkowski, P. G. (2010). The evolution and future of earth's nitrogen cycle. Science, 330(600I), 192-196. https://doi.org/I0.1 I26/science. I I86/20

Cape, J. N., van der Eerden, L. J., Sheppard, L. J., Leith, I. D., \& Sutton, M. A. (2009). Evidence for changing the critical level for ammonia. Environmental Pollution, 157(3), I033-1037. https://doi.org/I 0. I016/j.envpol.2008.09.049

Cassman, K. G., Dobermann, A., \& Walters, D. T. (2002). Agroecosystems, nitrogen-use efficiency, and nitrogen management. In Ambio (Vol. 3I, pp. 132-140). Royal Swedish Academy of Sciences. https://doi. org/I0.1579/0044-7447-31.2.132

Chalot, M., \& Brun, A. (1998). Physiology of organic nitrogen acquisition by ectomycorrhizal fungi and ectomycorrhizas. FEMS Microbiology Reviews, 22(I), 2I-44. https://doi.org/I0.1016/S0I68-6445(98)00004-7

Chen, J., Lü, S., Zhang, Z., Zhao, X., Li, X., Ning, P., \& Liu, M. (2018). Environmentally friendly fertilizers: A review of materials used and their effects on the environment. Science of the Total Environment. Elsevier B.V. https:// doi.org/I0.1016/j.scitotenv.2017.09.186

Chen, X., Cui, Z., Fan, M., Vitousek, P., Zhao, M., Ma, W., ... Zhang, F. (2014). Producing more grain with lower environmental costs. Nature, 514(7253), 486-489. https://doi.org/I0.1038/nature 13609

Ciais, P., Schelhaas, M. J., Zaehle, S., Piao, S. L., Cescatti, A., Liski, J., ... Nabuurs, G. J. (2008). Carbon accumulation in European forests. Nature Geoscience, I (7), 425-429. https://doi.org/10.1038/ngeo233

Cleveland, C. C., Houlton, B. Z., Smith, W. K., Marklein, A. R., Reed, S. C., Parton, W., .. Running, S. W. (2013). Patterns of new versus recycled primary production in the terrestrial biosphere. Proceedings of the National Academy of Sciences of the United States of America, I10(3I), I2733-12737. https://doi.org//0.1073/ pnas. 1302768110

Cleveland, C. C., Townsend, A. R., Schimel, D. S., Fisher, H., Howarth, R. W., Hedin, L. O., ... Wasson, M. F. (1999). Global patterns of terrestrial biological nitrogen (N2) fixation in natural ecosystems. Global Biogeochemical 
Cycles, I3(2), 623-645. https://doi.org//0.1002/(ISSN) 1944-9224

Cole, M. J., Bailey, R. M., \& New, M. G. (2014). Tracking sustainable development with a national barometer for South Africa using a downscaled "safe and just space" framework. Proceedings of the National Academy of Sciences of the United States of America, I I I (42), E4399-E4408. https://doi.org/ I 0. 1073/pnas. I 400985 I I I

Conijn, J. G., Bindraban, P. S., Schröder, J. J., \& Jongschaap, R. E. E. (2018). Can our global food system meet food demand within planetary boundaries? Agriculture, Ecosystems and Environment, 25I, 244-256. https://doi. org/I0.1016/j.agee.2017.06.00I

Conley, D. J., Paerl, H.W., Howarth, R.W., Boesch, D. F., Seitzinger, S. P., Havens, K. E., ... Likens, G. E. (2009, February 20). Ecology - Controlling eutrophication: Nitrogen and phosphorus. Science. https://doi.org//0.1/26/ science. 1167755

Cormier, F., Foulkes, J., Hirel, B., Gouache, D., Moënne-Loccoz, Y., \& Le Gouis, J. (2016). Breeding for increased nitrogen-use efficiency: a review for wheat ( T. aestivum L.). Plant Breeding, 135(3), 255-278. https://doi. org/I0.1 III/pbr. I237I

Corrado, S., Caldeira, C., Carmona-Garcia, G., Körner, I., Leip, A., \& Sala, S. (2020). Unveiling the potential for an efficient use of nitrogen along the food supply and consumption chain. Global Food Security, 25, 100368. https://doi.org//0.1016/j.gfs.2020.100368

Cui, Z.,Wang, G.,Yue, S.,Wu, L., Zhang,W., Zhang, F., \& Chen, X. (2014). Closing the N-use efficiency gap to achieve food and environmental security. Environmental Science \& Technology, 48(10), 5780-5787. https://doi. org/ $10.1021 / \mathrm{es} 5007 / 27$

Cusack, D. F., Silver, W. L., Torn, M. S., \& McDowell, W. H. (20II). Effects of nitrogen additions on above- and belowground carbon dynamics in two tropical forests. Biogeochemistry, I04(I-3), 203-225. https://doi. org/10.1007/s 10533-010-9496-4

Dalling, J.W., Heineman, K., Lopez, O. R., Wright, S. J., \& Turner, B. L. (2016). Nutrient Availability in Tropical Rain Forests:The Paradigm of Phosphorus Limitation. In G. Goldstein \& L. Santiago (Eds.), Tropical Tree Physiology (pp. 26I-273). Springer. https://doi.org/I0.1007/978-3-319-27422-5_I2

Dao, H., Peduzzi, P., \& Friot, D. (2018). National environmental limits and footprints based on the Planetary Boundaries framework: The case of Switzerland. Global Environmental Change, 52(May), 49-57. https://doi. org/10.1016/j.gloenvcha.2018.06.005

Davidson, E. A. (2012). Representative concentration pathways and mitigation scenarios for nitrous oxide. Environmental Research Letters, 7(2), 024005. https://doi.org//0.1088/1748-9326/7/2/024005

Davidson, E. A., \& Kanter, D. (2014). Inventories and scenarios of nitrous oxide emissions. Environmental Research Letters, 9(I0), I050I2. https://doi.org/I0.1088//748-9326/9/I0/1050I2

Davidson, E.A., Suddick, E. C., Rice, C.W., \& Prokopy, L. S. (2015). More Food, Low Pollution (Mo Fo Lo Po):A Grand Challenge for the 2Ist Century. Journal of Environmental Quality, 44(2), 305-3II. https://doi.org/I0.2I34/ jeq2015.02.0078

De Jager, A., \& Vogt, J. (2007). Rivers and Catchments of Europe - Catchment Characterisation Model (CCM). Ispra, Italy: European Commission, Joint Research Centre (JRC). Retrieved from http://data.europa.eu/89h/ fel878e8-754I-4c66-8453-afdae746922।

De Vries, W., Du, E., \& Butterbach-Bahl, K. (2014). Short and long-term impacts of nitrogen deposition on carbon sequestration by forest ecosystems. Current Opinion in Environmental Sustainability, 9-10, 90-104. https:// doi.org//0.1016/j.cosust.2014.09.001

De Vries, W., Du, E., Butterbach-Bahl, K., Dentener, F., \& Schulte-Uebbing, L. (2017). Global-scale impact of human nitrogen fixation on greenhouse gas emissions. Oxford Research Encyclopedia of Environmental Science. https://doi.org/10.1093/acrefore/9780199389414.013.13

De Vries, W., Kros, H., Reinds, G. J., Wamelink, W., Mol, J.,Van Dobben, H., ... Hettelingh, J.-P. (2007). Developments in deriving critical limits and modelling critical loads of nitrogen for terrestrial ecosystems in Europe.Alterrarapport 1382. Alterra, Wageningen and CCE, Bilthoven.

De Vries, W., Kros, J., Kroeze, C., \& Seitzinger, S. P. (2013). Assessing planetary and regional nitrogen boundaries related to food security and adverse environmental impacts. Current Opinion in Environmental Sustainability, 5(3-4), 392-402. https://doi.org//0.1016/j.cosust.2013.07.004 
De Vries, W., Kros, J., Reinds, G. J., \& Butterbach-Bahl, K. (20I la). Quantifying impacts of nitrogen use in European agriculture on global warming potential. Current Opinion in Environmental Sustainability, 3(5), 29|-302. https://doi.org/10.1016/j.cosust.2011.08.009

De Vries, W., Leip, A., Reinds, G. J., Kros, J., Lesschen, J. P., \& Bouwman, A. F. (20I Ib). Comparison of land nitrogen budgets for European agriculture by various modeling approaches. Environmental Pollution, I59(II), 32543268. https://doi.org/I0.1016/j.envpol.20II.03.038

De Vries, W., Leip, A., Reinds, G. J., Kros, J., Lesschen, J. P., Bouwman, A. F., ... Winiwarter, W. (20I Ic). Geographical variation in terrestrial nitrogen budgets across Europe. In M. Sutton, C. Howard, J. Erisman, G. Billen, A. Bleeker, P. Grennfelt, ... B. Grizzetti (Eds.), The European Nitrogen Assessment (pp. 317-344). Cambridge, United Kingdom: Cambridge University Press. https://doi.org/I0.1017/cbo97805I I 976988.018

De Vries, W., \& Posch, M. (20II). Modelling the impact of nitrogen deposition, climate change and nutrient limitations on tree carbon sequestration in Europe for the period 1900-2050. Environmental Pollution, 159(10), 2289-2299. https://doi.org/10.1016/j.envpol.2010.11.023

DeVries,W., Ros, G., Kros, H., \& Jongeneel, R. (2020). Eindrapport Adviescollege Stikstofproblematiek: een evaluatie. Milieu, 4, 4I-47.

De Vries, W., \& Schulte-Uebbing, L. (2019). Impacts of nitrogen deposition on forest ecosystem services and biodiversity. In M. Schröte, A. Bonn, S. Klotz, R. Seppelt, \& C. Baessler (Eds.), Atlas of Ecosystem Services. Drivers, Risks, and Societal Responsess (pp. 183-189). Springer. https://doi.org//0.1007/978-3-3/9-96229-0

De Vries, W., Schulte-Uebbing, L., Kros, H., \& Voogd, J. C. (202 Ia). Assessment of spatially explicit actual, required and critical nitrogen inputs in EU-27 agriculture. Wageningen, the Netherlands: Wageningen Environmental Reserach (in press).

De Vries, W., Schulte-Uebbing, L., Kros, H., Voogd, J. C., \& Louwagie, G. (202 Ib). Spatially explicit boundaries for agricultural nitrogen inputs in the European Union to meet air and water quality targets. Science of The Total Environment, I47283. https://doi.org//0.1016/j.scitotenv.202I.147283

De Vries, W., de Jong, A., Kros, J., \& Spijker, J. (202/c). The use of soil nutrient balances in deriving forest biomass harvesting guidelines specific to region, tree species and soil type in the Netherlands. Forest Ecology and Management, 479, I I859I. https://doi.org/I0.1016/j.foreco.2020.1 I859 I

De Vries, W., Solberg, S., Dobbertin, M., Sterba, H., Laubhahn, D., Reinds, G. J., ... Sutton, M. A. (2008). Ecologically implausible carbon response? Nature, 45I (7I80), EI-E3. https://doi.org// 0.1038/nature06579

De Vries, W., Solberg, S., Dobbertin, M., Sterba, H., Laubhann, D., van Oijen, M., ... Sutton, M. A. (2009). The impact of nitrogen deposition on carbon sequestration by European forests and heathlands. Forest Ecology and Management, 258(8), 18|4-1823. https://doi.org//0.1016/j.foreco.2009.02.034

De Vries, W.,Wamelink, G.W.W., Dobben, H. van, Kros, J., Reinds, G. J., Mol-Dijkstra, J. P., ... Bobbink, R. (2010). Use of dynamic soil-vegetation models to assess impacts of nitrogen deposition on plant species composition: an overview. Ecological Applications, 20(I), 60-79. https://doi.org/ 10.1890/08-1019.1

de Wit, C. T. (1992). Resource use efficiency in agriculture. Agricultural Systems, 40(I-3), I25-15I. https://doi. org/10.1016/0308-52IX(92)90018-J

de Wit, M., Londo, M., \& Faaij, A. (20II). Productivity developments in European agriculture: Relations to and opportunities for biomass production. Renewable and Sustainable Energy Reviews, 15(5), 2397-24I2. https:// doi.org/I0.1016/J.RSER.20II.02.022

Dentener, F., Drevet, J., Lamarque, J. F., Bey, I., Eickhout, B., Fiore, A. M., ... Wild, O. (2006). Nitrogen and sulfur deposition on regional and global scales: A multimodel evaluation. Global Biogeochemical Cycles, 20(4), GB4003. https://doi.org// 0.1029/2005GB002672

Dentener, F., Vet, R., Dennis, R. L., Du, E., Kulshrestha, U. C., \& Galy-Lacaux, C. (2014). Progress in monitoring and modelling estimates of nitrogen deposition at local, regional and global scales. In Nitrogen Deposition, Critical Loads and Biodiversity: Proceedings of the International Nitrogen Initiative Workshop, Linking Experts of the Convention on Long-Range Transboundary Air Pollution and the Convention on Biological Diversity (pp. 7-22). https://doi.org/I0.1007/978-94-007-7939-6_2

Diaz, R. J., \& Rosenberg, R. (2008, August 15). Spreading dead zones and consequences for marine ecosystems. Science. American Association for the Advancement of Science. https://doi.org/ I 0.1 I 26/science. I I 5640 I 
Dise, N. B., Ashmore, M., Belyazid, S., Bleeker, A., Bobbink, R., Vries, W. De, ... Berg, L.Van Den. (20II). Chapter 20: Nitrogen as a threat to European biodiversity. The European Nitrogen Assessment. https://doi.org/ I0.1017/ CBO97805II976988.023

Dobermann,A. (2016). Looking forward to 2030: Nitrogen and the Sustainable Development Goals. Retrieved from www.ini2016.com

Dolman, A. M., Mischke, U., \& Wiedner, C. (2016). Lake-type-specific seasonal patterns of nutrient limitation in German lakes, with target nitrogen and phosphorus concentrations for good ecological status. Freshwater Biology, 6 I (4), 444-456. https://doi.org/I0.1 I I I/fwb. 12718

Du, E., \& De Vries, W. (20I8). Nitrogen-induced new net primary production and carbon sequestration in global forests. Environmental Pollution, 242, I476-1487. https://doi.org/10.1016/j.envpol.2018.08.04 I

Du, E., van Doorn, M., \& De Vries, W. (2021). Spatially divergent trends of nitrogen versus phosphorus limitation across European forests. Science of the Total Environment, 77I, 14539I. https://doi.org/10.1016/j. scitotenv.2021.145391

Du, Y., Guo, P., Liu, J.,Wang, C., Yang, N., \& Jiao, Z. (20I4). Different types of nitrogen deposition show variable effects on the soil carbon cycle process of temperate forests. Global Change Biology, 20(I0), 3222-3228. https://doi. org/I0.1 II I/gcb. 12555

Duan, Y., Xu, M.,Wang, B., Yang, X., Huang, S., \& Gao, S. (20I I). Long-Term Evaluation of Manure Application on Maize Yield and Nitrogen Use Efficiency in China. Soil Science Society of America Journal, 75(4), I 562-I573. https:// doi.org/I0.2136/sssaj2010.0315

Duarte, C. M. (I995). Submerged aquatic vegetation in relation to different nutrient regimes. Ophelia, 4I (I), 87-II 2. https://doi.org/10.1080/00785236.1995.10422039

Duce, R. A., LaRoche, J., Altieri, K., Arrigo, K. R., Baker, A. R., Capone, D. G., ... Zamora, L. (2008). Impacts of atmospheric anthropogenic nitrogen on the open ocean. Science, 320(5878), 893-897. https://doi. org/10.1126/science.1150369

EC. (199Ia). Council Directive of 12 December 199I concerning the protection of waters against pollution caused by nitrates from agricultural sources (9//676/EEC). Brussels: European Commission.

EC. (199/b). Council Directive of 2I May 199I concerning urban waste water treatment (9//27I/EEC). Brussels: European Commission.

EC. (1992). Council Directive of 21 May 1992 on the conservation of natural habitats and of wild fauna and flora (92/43/EEC). Brussels: European Commission.

EC. (2000). Directive 2000/60/EC of the European Parliament and of the Council of 23 October 2000 establishing a framework for Community action in the field of water policy. Brussels: European Commission.

EC. (200I). Directive 200I/8I/EC of the European Parliament and of the Council of 23 October 200I on national emission ceilings for certain atmospheric pollutants. Brussels: European Commission.

EC. (2008). Directive 2008/50/EC of the European Parliament and of the Council of 2I May 2008 on ambient air quality and cleaner air for Europe. Brussels: European Commission. Retrieved from http://data.europa.eu/eli/ $\operatorname{dir} / 2008 / 50 / 2015-09-18$

EC. (20I3). Report from the Commission to the Council and the European Parliament on the implementation of Council Directive $91 / 676 /$ EEC concerning the protection of waters against pollution caused by nitrates from agricultural sources based on Member State reports fo. Brussels: European Commission.

EC. (2017). Regulation (EC) No 1059/2003 of the European Parliament and of the Council of 26 May 2003 on the establishment of a common classification of territorial units for statistics (NUTS). Brussels: European Commission.

EEA. (2019). The European environment-state and outlook 2020. Knowledge for transition to a sustainable Europe. Copenhagen: European Environment Agency (EEA). https://doi.org/ 10.2800/96749

EEA. (2020). State of nature in the EU. Copenhagen. https://doi.org//0.2800/088I78

EEA, \& FOEN. (2020). Is Europe living within the limits of our planet? An assessment of Europe's environmental footprints in relation to planetary boundaries. EEA Report No 01/2020. Copenhagen / Bern: European Environmental Agency (EEA); Federal Office for the Environment (FOEN). https://doi.org/ 10.2800/89067

Elser, J. J., Bracken, M. E. S., Cleland, E. E., Gruner, D. S., Harpole, W. S., Hillebrand, H., ... Smith, J. E. (2007). Global 
analysis of nitrogen and phosphorus limitation of primary producers in freshwater, marine and terrestrial ecosystems. Ecology Letters, I0( I2), I I35-I I 42. https://doi.org/ I 0. I I I/j. I 46 I-0248.2007.0 I I I3.x

Erisman, J. W., Galloway, J. N., Seitzinger, S., Bleeker, A., Dise, N. B., Petrescu, A. M. R., ... de Vries, W. (2013). Consequences of human modification of the global nitrogen cycle. Philosophical Transactions of the Royal Society of London. Series B, Biological Sciences, 368(I62I), 20130I I6. https://doi.org/I0.1098/rstb.2013.0I I6

Erisman, J. W., Galloway, J., Seitzinger, S., Bleeker, A., \& Butterbach-Bahl, K. (20II). Reactive nitrogen in the environment and its effect on climate change. Current Opinion in Environmental Sustainability, 3(5), 28I-290. https://doi.org/10.1016/j.cosust.2011.08.012

Erisman, J.W.J., Sutton, M.A., Galloway, J., Klimont, Z., \& Winiwarter,W. (2008). How a century of ammonia synthesis changed the world. Nature Geoscience, I (I0), 636-639. https://doi.org/I0.1038/ngeo325

Esser, G., Kattge, J., \& Sakalli, A. (20II). Feedback of carbon and nitrogen cycles enhances carbon sequestration in the terrestrial biosphere. Global Change Biology, 17(2), 8/9-842. https://doi.org//0.1 III/j.13652486.2010.0226I.x

Etzold, S., Ferretti, M., Reinds, G. J., Solberg, S., Gessler, A., Waldner, P., ... De Vries, W. (2020). Nitrogen deposition is the most important environmental driver of growth of pure, even-aged and managed European forests. Forest Ecology and Management, 458. https://doi.org/10.1016/j.foreco.2019.1 17762

EU Nitrogen Expert Panel. (2015). Nitrogen Use Efficiency (NUE) - an indicator for the utilization of nitrogen in agriculture and food systems. Wageningen, Netherlands:Wageningen University,Alterra.

European Commission. (2020). Farm to Fork Strategy. European Commission. https://ec.europa.eu/food/sites/food/ files/safety/docs/f2f_action-plan_2020_strategy-info_en.pdf

EUROSTAT. (2020). Gross Nutrient Balance. Retrieved from https://appsso.eurostat.ec.europa.eu/nui/ setupDownloads.do

Fader, M., Gerten, D., Krause, M., Lucht, W., \& Cramer, W. (2013). Spatial decoupling of agricultural production and consumption: Quantifying dependences of countries on food imports due to domestic land and water constraints. Environmental Research Letters, 8(I). https://doi.org//0.1088//748-9326/8/I/0I4046

Fagerli, H., Gauss, M., Benedictow, A., Jonson, J. E., Nyıri, A., Schulz, M., ... Bergström, R. (2012). Transboundary Acidification, Eutrophication and Ground Level Ozone in Europe in 2010. EMEP Status Report 1/2012. Norwegian Meteorological Institute.

Fan, H., Wu, J., Liu, W., Yuan, Y., Huang, R., Liao, Y., \& Li, Y. (20I4). Nitrogen deposition promotes ecosystem carbon accumulation by reducing soil carbon emission in a subtropical forest. Plant and Soil, 379(I-2), 36I-37I. https://doi.org// 0.1007/s I I 104-014-2076-y

Fang, Y., Zhu, W., Gundersen, P., Mo, J., Zhou, G., \& Yoh, M. (2009). Large loss of dissolved organic nitrogen from nitrogen-saturated forests in subtropical China. Ecosystems, I2(I), 33-45. https://doi.org//0.1007/s I002I008-9203-7

FAO/IIASA. (20I2). Global Agro-ecological Zones (GAEZ): Model Documentation. Retrieved from http://www.fao. org/fileadmin/user_upload/gaez/docs/GAEZ_Model_Documentation.pdf

FAO. (20 I 2a). FAO Statistical Pocketbook 20 I2. Retrieved from http://www.fao.org/docrep/0 /6/i2493e/i2493e.pdf

FAO. (20I2b). Global ecological zones for FAO forest reporting: 2010 Update. Rome, Italy. Retrieved from http:// www.fao.org/3/a-ap86le.pdf

FAO. (2016). Global Forest Resources Assessment 20I5. Rome. Retrieved from http://www.fao.org/3/a-i4793e.pdf

FAO. (2017). The future of food and agriculture: Trends and challenges. Rome. Retrieved from http://www.fao. org/3/a-i6583e.pdf

FAO. (20I8). FAOSTAT Statistics Database. Rome, Italy: Food and Agriculture Organization of the United Nations (FAO). Retrieved from http://www.fao.org/faostat/en/\#data

FAO. (2020). Global Forest Resources Assessment 2020. Global Forest Resources Assessment 2020. https://doi. org/10.4060/ca9825en

Ferm, M. (1998). Atmospheric ammonia and ammonium transport in Europe and critical loads: A review. Nutrient Cycling in Agroecosystems, 5I(I), 5-17. https://doi.org/I0.1023/A: 1009780030477

Fernández-Martínez, M.,Vicca, S., Janssens, I.A., Sardans, J., Luyssaert, S., Campioli, M., ... Peñuelas, J. (2014). Nutrient 
availability as the key regulator of global forest carbon balance. Nature Climate Change, 4(6), 47I-476. https://doi.org/10.1038/nclimate2177

Fick, S. E., \& Hijmans, R. J. (20I7).Worldclim 2: New I-km spatial resolution climate surfaces for global land areas. International Journal of Climatology, 37(I2), 4302-43I5. https://doi.org/I0.1002/joc.5086

Field, C. B., Chapin III, F. S., Matson, P. A., \& Mooney, H. A. (1992). Responses of terrestrial ecosystems to the changing atmosphere: a resource-based approach. Annual Review of Ecology and Systematics, 23(I), 20 I-235. https://doi.org/10.1 146/annurev.es.23.110192.001221

Finzi, A. C. (2009). Decades of atmospheric deposition have not resulted in widespread phosphorus limitation or saturation of tree demand for nitrogen in southern New England. Biogeochemistry, 92(3), 217-229. https:// doi.org/I0.1007/s 10533-009-9286-z

Firestone, M. K., \& Davidson, E.A. ( 1989 ). Microbiologial Basis of NO and N20 production and consumption in soil. Exchange of Trace Gases between Terrestrial Ecosystems and the Atmosphere, (January 1989), 7-2I.

Fisher, J. B., Malhi,Y., Torres, I. C., Metcalfe, D. B., van de Weg, M. J., Meir, P., ... Huasco,W. H. (20I3). Nutrient limitation in rainforests and cloud forests along a 3,000-m elevation gradient in the Peruvian Andes. Oecologia, I72(3), 889-902. https://doi.org/I0.1007/s00442-012-2522-6

Flechard, C. R.,Van Oijen, M., Cameron, D. R., DeVries,W., Ibrom,A., Buchmann, N., .. Sutton, M.A. (2020). Carbonnitrogen interactions in European forests and semi-natural vegetation - Part 2: Untangling climatic, edaphic, management and nitrogen deposition effects on carbon sequestration potentials. Biogeosciences, 17(6), I62|-1654. https://doi.org/|0.5 I94/bg-17-1621-2020

Fleischer, K., Rebel, K. T., van der Molen, M. K., Erisman, J.W., Wassen, M. J., van Loon, E. E., ... Dolman, A. J. (20I3). The contribution of nitrogen deposition to the photosynthetic capacity of forests. Global Biogeochemical Cycles, 27(I), 187-199. https://doi.org/I0.1002/gbc.20026

Fleischer, K., Wårlind, D., van der Molen, M., Rebel, K., Arneth, A., Erisman, J. W., ... Dolman, A. J. (20I5). Low historical nitrogen deposition effect on carbon sequestration in the boreal zone. Journal of Geophysical Research: Biogeosciences, I20(I2), 2542-256I. https://doi.org/I0.1002/20I5JG002988

Folberth, C., Khabarov, N., Balkovič, J., Skalský, R., Visconti, P., Ciais, P., ... Obersteiner, M. (2020). The global cropland-sparing potential of high-yield farming. Nature Sustainability, 3(4), 28I-289. https://doi.org//0.1038/ s41893-020-0505-x

Foley, J.A., Ramankutty, N., Brauman, K.A., Cassidy, E. S., Gerber, J. S., Johnston, M., ... Zaks, D. P. M. (20I I). Solutions for a cultivated planet. Nature, 478(7369), 337-342. https://doi.org/ /0.1038/nature 10452

Fowler, D., Coyle, M., Skiba, U., Sutton, M.A., Cape, J. N., Reis, S., ... Voss, M. (20I3). The global nitrogen cycle in the twenty-first century. Philosophical Transactions of the Royal Society of London. Series B, Biological Sciences, 368(I62I), 20130164. https://doi.org/10.1098/rstb.2013.0164

Freibauer, A. (2003). Regionalised inventory of biogenic greenhouse gas emissions from European agriculture. European Journal of Agronomy, 19(2), I 35-160. https://doi.org/ I0.1016/SI I 6I-030 I(02)00020-5

Friedlingstein, P., O’Sullivan, M., Jones, M.W., Andrew, R. M., Hauck, J., Olsen, A., ... Zaehle, S. (2020). Global Carbon Budget 2020. Earth System Science Data, I2(4), 3269-3340. https://doi.org/ I0.5 I 94/essd-I 2-3269-2020

Fuchs, R., Brown, C., \& Rounsevell, M. (2020). Europe's Green Deal offshores environmental damage to other nations. Nature, 586(783 I), 67I-673. https://doi.org/I0.1038/d4I586-020-0299I-I

Galloway, J. N., Dentener, F. J., Capone, D. G., Boyer, E.W., Howarth, R.W., Seitzinger, S. P., ... Vörösmarty, C. J. (2004). Nitrogen cycles: Past, present, and future. Biogeochemistry, 70(2), I53-226. https://doi.org/I0.1007/s I0533004-0370-0

Galloway, J. N.,Aber,J.D., Erisman, J.W., Seitzinger, S.P., Howarth, R.W., Cowling, E. B., \& Cosby, B.J. (2003).The nitrogen cascade. BioScience, 53(4), 34I-356. https://doi.org/ I0.I64I/0006-3568(2003)053[034I:TNC]2.0.CO;2

Galloway, J. N., Townsend,A. R., Erisman, J.W., Bekunda, M., Cai, Z., Freney, J. R., .. Sutton, M.A. (2008). Transformation of the nitrogen cycle: Recent trends, questions, and potential solutions. Science, 320(5878), 889-892. https:// doi.org/I0.II26/science. II 36674

Galloway, J. N., \& Cowling, E. B. (2002). Reactive nitrogen and the world: 200 years of change. Ambio, 3 I (2), 64-7I https://doi.org//0.1579/0044-7447-31.2.64

Galloway, J. N., Leach, A. M., Bleeker, A., \& Erisman, J.W. (20I3). A chronology of human understanding of the 
nitrogen cycle. Philosophical Transactions of the Royal Society of London. Series B, Biological Sciences, 368(I62I), 20130120. https://doi.org//0.1098/rstb.2013.0120

Gao, S., Xu, P., Zhou, F., Yang, H., Zheng, C., Cao, W., ... Chen, M. (2016). Quantifying nitrogen leaching response to fertilizer additions in China's cropland. Environmental Pollution, 2II, 24I-25I. https://doi.org//0.1016/j. envpol.2016.01.010

Garnier, J., Beusen, A., Thieu, V., Billen, G., \& Bouwman, L. (2010). N:P:Si nutrient export ratios and ecological consequences in coastal seas evaluated by the ICEP approach. Global Biogeochemical Cycles, 24(2). https:// doi.org// 0.1029/2009GB003583

Ge, X., Schaap, M., Kranenburg, R., Segers, A., Jan Reinds, G., Kros, H., \& De Vries, W. (2020). Modeling atmospheric ammonia using agricultural emissions with improved spatial variability and temporal dynamics. Atmospheric Chemistry and Physics, 20(24), I6055-16087. https://doi.org//0.5194/acp-20-16055-2020

Gentilesca,T.,Vieno, M., Perks, M. P., Borghetti, M., \& Mencuccini, M. (2013). Effects of Long-Term Nitrogen Addition and Atmospheric Nitrogen Deposition on Carbon Accumulation in Picea sitchensis Plantations. Ecosystems, 16(7), I310-1324. https://doi.org//0.1007/s 1002I-013-9685-9

Gerber, P. J., Steinfeld, H., Henderson, B., Mottet, A., Opio, C., Dijkman, J., ... Tempio, G. (2013). Tackling climate change through livestock - A global assessment of emissions and mitigation opportunities. Rome: Food and Agriculture Organization of the United Nations (FAO).

Gerten, D., Heck,V., Jägermeyr, J., Bodirsky, B. L., Fetzer, I., Jalava, M., ... Schellnhuber, H. J. (2020). Feeding ten billion people is possible within four terrestrial planetary boundaries. Nature Sustainability, 3(3), 200-208. https:// doi.org//0.1038/s41893-019-0465-I

Gilbert, M., Nicolas, G., Cinardi, G., Van Boeckel, T. P., Vanwambeke, S. O., Wint, G. R. W., \& Robinson, T. P. (2018). Global distribution data for cattle, buffaloes, horses, sheep, goats, pigs, chickens and ducks in 20I0. Scientific Data, 5(I), I-I I. https://doi.org/I0.1038/sdata.2018.227

GLC. (2003). The Global Land Cover Map for the Year 2000. GLC2000 database, European Commision Joint Research Centre (JRC), obtained at: http://www-gem.jrc.it/glc2000. Retrieved from http://www-gem.jrc.it/ glc2000

Gleeson, T., Wang-Erlandsson, L., Zipper, S. C., Porkka, M., Jaramillo, F., Gerten, D., ... Famiglietti, J. S. (2020). The Water Planetary Boundary: Interrogation and Revision. One Earth, 2(3), 223-234. https://doi.org//0.1016/j. oneear.2020.02.009

Gleser, L. J., \& Olkin, I. (2009). Stochastically dependent effect sizes. In The Hand. of Res. Synthesis and MetaAnalysis, 2nd Ed. (pp. 357-376). New York, NY, US: Russell Sage Foundation.

Glibert, P. M. (2017). Eutrophication, harmful algae and biodiversity - Challenging paradigms in a world of complex nutrient changes. Marine Pollution Bulletin, I24(2), 59I-606. https://doi.org/I0. I016/j.marpolbul.2017.04.027

Grassini, P., van Bussel, L. G. J., Van Wart, J., Wolf, J., Claessens, L., Yang, H., ... Cassman, K. G. (2015). How good is good enough? Data requirements for reliable crop yield simulations and yield-gap analysis. Field Crops Research, 177, 49-63. https://doi.org//0.1016/j.fcr.2015.03.004

Grizzetti, B., Pretato, U., Lassaletta, L., Billen, G., \& Garnier, J. (2013). The contribution of food waste to global and European nitrogen pollution. Environmental Science and Policy, 33, 186-195. https://doi.org//0.1016/j. envsci.2013.05.013

Groenendijk, P., Boekel, E.Van, Renaud, L., Greijdanus,A., \& Koeijer,T. De. (2016). Landbouw en de KRW-opgave voor nutriënten in regionale wateren. Rapport 2749. Wageningen, the Netherlands: Wageningen Environmental Research.

Gundale, M. J., Deluca, T. H., \& Nordin, A. (20I I). Bryophytes attenuate anthropogenic nitrogen inputs in boreal forests. Global Change Biology, I 7(8), 2743-2753. https://doi.org/ I0. I I I/j. I 365-2486.20 I I.02407.x

Gundale, M. J., From, F., Bach, L. H., \& Nordin, A. (2014). Anthropogenic nitrogen deposition in boreal forests has a minor impact on the global carbon cycle. Global Change Biology, 20(I), 276-286. https://doi.org/ I0.1 II I/ gcb. 12422

Gundersen, P., Schmidt, I. K., \& Raulund-Rasmussen, K. (2006). Leaching of nitrate from temperate forests - Effects of air pollution and forest management. Environmental Reviews, I ( (I), I-57. https://doi.org/ I0.1 I39/a05-015

Haddeland, I., Lettenmaier, D. P., \& Skaugen, T. (2006). Effects of irrigation on the water and energy balances of 
the Colorado and Mekong river basins. Journal of Hydrology, 324(I-4), 210-223. https://doi.org//0.1016/j. jhydrol.2005.09.028

Hafner, S. D., Pacholski, A., Bittman, S., Carozzi, M., Chantigny, M., Génermont, S., ... Sommer, S. G. (2019). A flexible semi-empirical model for estimating ammonia volatilization from field-applied slurry. Atmospheric Environment, 199, 474-484. https://doi.org/I0.1016/j.atmosenv.2018.11.034

Hansen, M. C., Potapov, P.V., Moore, R., Hancher, M., Turubanova, S. A., Tyukavina, A., ... Townshend, J. R. G. (2013).


org// 0.11 26/science. 1244693

Harrington, C. A., \& Devine, W. D. (20II). Stand development following precommercial thinning and fertilization treatments in a western redcedar (Thuja plicata) dominated forest. Canadian Journal of Forest Research, 4I(I), I5I-164. https://doi.org/I0.1139/X10-193

Harris, I. C., Jones, P. D., \& Osborn, T. (2020). CRU TS4.04: Climatic Research Unit (CRU) Time-Series (TS) version 4.04 of high-resolution gridded data of month-by-month variation in climate (Jan. 190IDec. 2019). Centre for Environmental Data Analysis. Retrieved from https://catalogue.ceda.ac.uk/ uuid/89e le34ec3554dc98594a5732622bce9

Harris, N. L., Gibbs, D. A., Baccini, A., Birdsey, R. A., Bruin, S. de, Farina, M., ... Tyukavina, A. (202I). Global maps of twenty-first century forest carbon fluxes. Nature Climate Change, II, 234-240. https://doi.org/ I0.1038/ s41558-020-00976-6

Heck, V., Gerten, D., Lucht, W., \& Popp, A. (2018a). Biomass-based negative emissions difficult to reconcile with planetary boundaries. Nature Climate Change, 8(2), I5I-155. https://doi.org/ I0. 1038/s41558-0 17-0064-y

Heck, V., Hoff, H., Wirsenius, S., Meyer, C., \& Kreft, H. (2018b). Land use options for staying within the Planetary Boundaries - Synergies and trade-offs between global and local sustainability goals. Global Environmental Change, 49, 73-84. https://doi.org/10.1016/j.gloenvcha.2018.02.004

Hedges, L. V., Gurevitch, J., \& Curtis, P. S. (1999). The meta-analysis of response ratios in experimental ecology. Ecology, 80(4), II50-I I56. https://doi.org//0.2307//77062

Heistermann, M. (2017). HESS Opinions: A planetary boundary on freshwater use is misleading. Hydrology and Earth System Sciences, 2I (7), 3455-346I. https://doi.org/I0.5I94/hess-2I-3455-20I7

Helmisaari, H.-S., Hanssen, K. H., Jacobson, S., Kukkola, M., Luiro, J., Saarsalmi, A., ... Tveite, B. (20I I). Logging residue removal after thinning in Nordic boreal forests: Long-term impact on tree growth. Forest Ecology and Management, 26I(II), 1919-1927. https://doi.org/I0.1016/j.foreco.201 I.02.015

Hengl, T., De Jesus, J. M., Heuvelink, G. B. M., Gonzalez, M. R., Kilibarda, M., Blagotić, A., ... Kempen, B. (2017). SoilGrids250m: Global gridded soil information based on machine learning. PLoS ONE, I2(2), e0169748. https://doi.org//0.137|/journal.pone.0169748

Herbert, D. A., \& Fownes, J. H. (1995). Phosphorus limitation of forest leaf area and net primary production on a highly weathered soil, Biogeochemistry, 29(3), 223-235. https://doi.org//0.1007/BF02186049

Herbert, D. A., Fownes, J. H., \& Vitousek, P. M. (1999). Hurricane Damage to a Hawaiian Forest: Nutrient Supply Rate Affects Resistance and Resilience. Ecology, 80(3), 908-920. https://doi.org//0.1890/00I29658(1999)080[0908:HDTAHF]2.0.CO;2

Herridge, D. F., Peoples, M. B., \& Boddey, R. M. (2008). Global inputs of biological nitrogen fixation in agricultural systems. Plant and Soil, 3 I I(I-2), I-I8. https://doi.org/ I0. 1007/s I I I04-008-9668-3

Hettelingh, J.-P., Posch, M., Slootweg, J., \& Mathijssen, L. (2014). Exposure of ecosystems to acidification and eutrophication in Europe: an update of EEA-Core Set Indicator 005. In J. Slootweg, M. Posch, J.-P. Hettelingh, \& L. Mathijssen (Eds.), Modelling and Mapping the impacts species diversity deposition on plant of atmospheric in Europe, CCCE status report 2014 (Pp. 13-27). Coordination Centre for Effects (CCE).

Hettelingh, J.-P., Posch, M., Slootweg, J., Reinds, G. J., Vries, W. de, Le Gall, A.-C., \& Maas, R. (2015). Effects-Based Integrated Assessment Modelling for the Support of European Air Pollution Abatement Policies BT - Critical Loads and Dynamic Risk Assessments: Nitrogen, Acidity and Metals in Terrestrial and Aquatic Ecosystems. In W. de Vries, J.-P. Hettelingh, \& M. Posch (Eds.), Critical Loads and Dynamic Risk Assessments: Nitrogen, Acidity and Metals in Terrestrial and Aquatic Ecosystems (pp. 613-635). Dordrecht: Springer Netherlands.

Hettelingh, J.-P., Stevens, C. J., Posch, M., Bobbink, R., \& De Vries, W. (2015). Assessing the Impacts of Nitrogen 
Deposition on Plant Species Richness in Europe. In W. de Vries, J.-P. Hettelingh, \& M. Posch (Eds.), Critical Loads and Dynamic Risk Assessments: Nitrogen,Acidity and Metals in Terrestrial and Aquatic Ecosystems (pp. 573-586). Dordrecht: Springer Netherlands.

Heuvelink, G. B. M., Kros, J., Reinds, G. J., \& De Vries,W. (20I6). Geostatistical prediction and simulation of European soil property maps. Geoderma Regional, 7(2), 20I-2I5. https://doi.org/10.1016/j.geodrs.2016.04.002

Hirel, B., Tétu, T., Lea, P. J., \& Dubois, F. (20I I). Improving nitrogen use efficiency in crops for sustainable agriculture. Sustainability, 3(9), | 452-I485. https://doi.org/I0.3390/su309|452

Hoben, J. P., Gehl, R. J., Millar, N., Grace, P. R., \& Robertson, G. P. (20II). Nonlinear nitrous oxide $\left(\mathrm{N}_{2} \mathrm{O}\right)$ response to nitrogen fertilizer in on-farm corn crops of the US Midwest. Global Change Biology, I7(2), II40-II52. https://doi.org/10.1 I I I/j.1365-2486.2010.02349.x

Högberg, P., Johannisson, C., \& Högberg, M. N. (20I4). Is the high I5N natural abundance of trees in N-loaded forests caused by an internal ecosystem $\mathrm{N}$ isotope redistribution or a change in the ecosystem $\mathrm{N}$ isotope mass balance? Biogeochemistry, II7(2-3), 35I-358. https://doi.org/ I0.1007/s I0533-0I3-9873-x

Högberg, P. (20I2). What is the quantitative relation between nitrogen deposition and forest carbon sequestration? Global Change Biology, I8(I), I-2. https://doi.org/I0.I I I I/j.I365-2486.20 I I.02553.x

Högberg, P., Fan, H., Quist, M., Binkley, D., \& Tamm, C. O. (2006). Tree growth and soil acidification in response to 30 years of experimental nitrogen loading on boreal forest. Global Change Biology, I2(3), 489-499. https://doi. org/I0.1 I II/j.1365-2486.2006.0II02.x

Holland, E. A., Braswell, B. H., Lamarque, J. F., Townsend, A., Sulzman, J., Müller, J. F., ... Roelofs, G. J. ( I997). Variations in the predicted spatial distribution of atmospheric nitrogen deposition and their impact on carbon uptake by terrestrial ecosystems. Journal of Geophysical Research:Atmospheres, I02(I3), I 5849-I 5866. https://doi. org/10.1029/96JD03164

Homeier, J., Hertel, D., Camenzind,T., Cumbicus, N. L., Maraun, M., Martinson, G. O., ... Leuschner, C. (20I2). Tropical Andean forests are highly susceptible to nutrient inputs--rapid effects of experimental $\mathrm{N}$ and $\mathrm{P}$ addition to an Ecuadorian montane forest. PloS One, 7(I0), e47I 28. https://doi.org/I0.I37I/journal.pone.0047I 28

Hopmans, P., \& Elms, S. R. (20I3). Impact of defoliation by Essigella californica on the growth of mature Pinus radiata and response to N, P and S fertilizer. Forest Ecology and Management, 289, 190-200. https://doi. org/10.1016/j.foreco.2012.10.018

Hou, X., Zhan, X., Zhou, F.,Yan, X., Gu, B., Reis, S., ... Tang,Y.(2018). Detection and attribution of nitrogen runoff trend in China's croplands. Environmental Pollution, 234, 270-278. https://doi.org/I0.1016/j.envpol.2017.II.052

Hou, X., Zhou, F., Leip, A., Fu, B., Yang, H., Chen, Y., ... Ma, L. (20I6). Spatial patterns of nitrogen runoff from Chinese paddy fields. Agriculture, Ecosystems and Environment, 23I, 246-254. https://doi.org/I0.1016/j. agee.2016.07.00I

Houlton, B. Z.,Almaraz, M.,Aneja,V., Austin,A.T., Bai, E., Cassman, K. G., ... Zhang, X. (2019).A World of Cobenefits: Solving the Global Nitrogen Challenge. Earth's Future, 7(8), 865-872. https://doi.org/ I0.1029/20I9EF00I 222

Hudson, R. J. M., Gherini, S. A., \& Goldstein, R. A. (1994). Modeling the global carbon cycle: nitrogen fertilization of the terrestrial biosphere and the "missing" $\mathrm{CO}_{2}$ sink. Global Biogeochemical Cycles, 8(3), 307-333. https:// doi.org/I0.1029/94GB01044

Hutchings, N. J., Sørensen, P., Cordovil, C. M. d. S., Leip, A., \& Amon, B. (2020). Measures to increase the nitrogen use efficiency of European agricultural production. Global Food Security, 26, 10038I. https://doi.org/10.1016/j. gfs.2020.10038I

Hyvönen, R., Ågren, G. I., Linder, S., Persson, T., Cotrufo, M. F., Ekblad, A., ... Wallin, G. (2007). The likely impact of elevated $\mathrm{CO} 2$, nitrogen deposition, increased temperature and management on carbon sequestration in temperate and boreal forest ecosystems: A literature review. New Phytologist, 173(3), 463-480. https://doi. org/I0.1 III/j.1469-8137.2007.01967.x

Hyvönen, R., Persson, T., Andersson, S., Olsson, B., Ågren, G. I., \& Linder, S. (2008). Impact of long-term nitrogen addition on carbon stocks in trees and soils in northern Europe. Biogeochemistry, 89(I), I2I-I37. https:// doi.org/I0.1007/s 10533-007-9121-3

livonen, S., Kaakinen, S., Jolkkonen, A.,Vapaavuori, E., \& Linder, S. (2006). Influence of long-term nutrient optimization on biomass, carbon, and nitrogen acquisition and allocation in Norway spruce. Canadian Journal of Forest 
Research, 36(6), I563-1571. https://doi.org//0.1139/×06-035

Iversen, C. M., \& Norby, R. J. (2008). Nitrogen limitation in a sweetgum plantation: implications for carbon allocation and storage. Canadian Journal of Forest Research, 38(5), I02 I-1032. https://doi.org/ I0. I I39/X07-2 I3

Jain, A., Yang, X., Kheshgi, H., McGuire, A. D., Post, W., \& Kicklighter, D. (2009). Nitrogen attenuation of terrestrial carbon cycle response to global environmental factors. Global Biogeochemical Cycles, 23(4), GB4028. https:// doi.org/10.1029/2009GB003519

Janssens, I. A., Dieleman, W., Luyssaert, S., Subke, J.-A., Reichstein, M., Ceulemans, R., ... Law, B. E. (2010). Reduction of forest soil respiration in response to nitrogen deposition. Nature Geoscience, 3(5), 315-322. https://doi. org/10.1038/ngeo844

Janssens, I.A., Freibauer, A., Ciais, P., Smith, P., Nabuurs, G. J., Folberth, G., ... Dolman, A. J. (2003). Europe's terrestrial biosphere absorbs 7 to $12 \%$ of European anthropogenic CO2 emissions. Science, 300(5625), 1538-1542. https://doi.org//0.1 I26/science. 1083592

Janssens, I. A., \& Luyssaert, S. (2009). Nitrogen's carbon bonus. Nature Geoscience, 2, 318-319. https://doi. org// $0.1038 /$ ngeo505

Jassal, R.S., Black,T.A., Cai,T., Ethier, G., Pepin, S., Brümmer, C., ... Trofymow,J.A. (20 I0). Impact of nitrogen fertilization on carbon and water balances in a chronosequence of three Douglas-fir stands in the Pacific Northwest. Agricultural and Forest Meteorology, I50(2), 208-218. https://doi.org/I0.1016/j.agrformet.2009.10.005

Jiang, M., Caldararu, S., Zhang, H., Fleischer, K., Crous, K.Y., Yang, J., ... Medlyn, B. E. (2020). Low phosphorus supply constrains plant responses to elevated $\mathrm{CO}_{2}$ : A meta-analysis. Global Change Biology, 26(10), 5856-5873. https://doi.org/10.111 I/gcb.15277

Jonard, M., Fürst, A., Verstraeten, A., Thimonier, A., Timmermann, V., Potočić, N., .. Rautio, P. (2015). Tree mineral nutrition is deteriorating in Europe. Global Change Biology, 2I(I), 4/8-430. https://doi.org/I0.1III/ gcb. 12657

JRC. (2006). The European Soil Data Base, distribution version v2.0. Ispra, Italy: Joint Research Center (JRC).

Ju, X.-T., Xing, G.-X., Chen, X.-P., Zhang, S.-L., Zhang, L.-J., Liu, X.-J., ... Zhang, F.-S. (2009). Reducing environmental risk by improving $\mathrm{N}$ management in intensive Chinese agricultural systems. Proceedings of the National Academy of Sciences of the United States of America, 106(9), 304I-3046. https://doi.org//0.1073/pnas.08I34I7I 06

Jung, K., \& Chang, S. X. (2012). Four years of simulated $\mathrm{N}$ and $\mathrm{S}$ depositions did not cause $\mathrm{N}$ saturation in a mixedwood boreal forest ecosystem in the oil sands region in northern Alberta, Canada. Forest Ecology and Management, 280, 62-70. https://doi.org/I0.1016/j.foreco.20I2.06.002

Jungk,A., Claassen, N., Schulz,V., \& Wendt, J. (1993).Availability of Phosphate Reserves in Arable Soils. Zeitschrift Für Pflanzenernährung Und Bodenkunde, I56(5), 397-406.

Kahiluoto, H., Kuisma, M., Kuokkanen, A., Mikkilä, M., \& Linnanen, L. (2015). Local and social facets of planetary boundaries: Right to nutrients. Environmental Research Letters, I0(10), I04013. https://doi.org// 0. I088/I 7489326/10/10/1040/3

Kanter, D. R., Chodos, O., Nordland, O., Rutigliano, M., \& Winiwarter,W. (2020). Gaps and opportunities in nitrogen pollution policies around the world. Nature Sustainability 3, 956-963. https://doi.org//0.1038/s4/893-0200577-7

Kanter, D. R., \& Searchinger, T. D. (2018). A technology-forcing approach to reduce nitrogen pollution. Nature Sustainability, I(I0), 544-552. https://doi.org/I0.1038/s4I893-018-0I43-8

Kanter, D. R., Zhang, X., \& Howard, C. M. (2016). Nitrogen and the Sustainable Development Goals. In Proceedings of the 2016 International Nitrogen Initiative Conference, "Solutions to improve nitrogen use efficiency for the world", 4 - 8 December 2016. Melbourne,Australia. Retrieved from www.ini2016.com

Kaye, J. P., \& Hart, S. C. (1997). Competition for nitrogen between plants and soil microorganisms. Trends in Ecology and Evolution, I2(4), 139-143. https://doi.org/I0.1016/S0169-5347(97)0 I00I-X

Kelly, P. (2019). The EU cereals sector: Main features, challenges and prospects. European Parliamentary Research Service (EPRS). European Parliamentary Research Service (EPRS).

Keuskamp, J.A.,Van Drecht, G., \& Bouwman, A. F. (2012). European-scale modelling of groundwater denitrification and associated $\mathrm{N}_{2} \mathrm{O}$ production. Environmental Pollution, 165, 67-76. https://doi.org//0.1016/j. envpol.2012.02.008 
Kilpeläinen, J., Räisänen, M., Mehtätalo, L., Sutinen, S., Rummukainen, A., Repo, T., \& Lehto, T. (20I3). The longevity of Norway spruce responses to boron fertilization. Forest Ecology and Management, 307, 90-100. https://doi. org/10.1016/j.foreco.2013.06.054

Kim, D. G., Hernandez-Ramirez, G., \& Giltrap, D. (2013). Linear and nonlinear dependency of direct nitrous oxide emissions on fertilizer nitrogen input: A meta-analysis. Agriculture, Ecosystems and Environment, I68, 53-65. https://doi.org/10.1016/j.agee.2012.02.021

Klimont, Z., \& Brink, C. (2004). Modelling of emissions of air pollutants and greenhouse gases from agricultural sources in Europe. Interim Report IR-04-048. Laxenburg, Austria: International Institute for Applied Systems Analysis (IIASA). Retrieved from http://user.iiasa.ac.at/ schoepp/bologna/ir-04-048_final.pdf

Knorr, M., Frey, S. D., \& Curtis, P. S. (2005). Nitrogen additions and litter decomposition: A meta-analysis. Ecology, 86(I2), 3252-3257. https://doi.org/I0.1890/05-0I50

Körner, C. (20 I7). A matter of tree longevity. Science, 355(632 I), I 30-13 I. https://doi.org/I0. I I 26/science.aal2449

Krol, D. J., Forrestal, P. J., Wall, D., Lanigan, G. J., Sanz-Gomez, J., \& Richards, K. G. (2020). Nitrogen fertilizers with urease inhibitors reduce nitrous oxide and ammonia losses, while retaining yield in temperate grassland. Science of the Total Environment, 725, I 38329. https://doi.org/I0.1016/j.scitotenv.2020.138329

Kronvang, B., Andersen, H. E., Børgesen, C., Dalgaard, T., Larsen, S. E., Bøgestrand, J., \& Blicher-Mathiasen, G. (2008). Effects of policy measures implemented in Denmark on nitrogen pollution of the aquatic environment. Environmental Science and Policy, I I (2), I44-I52. https://doi.org/I0.10 I6/j.envsci.2007.I0.007

Kros, J., Heuvelink, G. B. M., Reinds, G. J., Lesschen, J. P., loannidi, V., \& De Vries, W. (20I2). Uncertainties in model predictions of nitrogen fluxes from agro-ecosystems in Europe. Biogeosciences, 9(I ), 4573-4588. https:// doi.org/10.5194/bg-9-4573-2012

Kros, J., Hutchings, N. J., Kristensen, I. T., Kristensen, I. S., Børgesen, C. D., Voogd, J. C., ... De Vries, W. (20I8). A comparison of disaggregated nitrogen budgets for Danish agriculture using Europe-wide and national approaches. Science of the Total Environment, 643, 890-90 I. https://doi.org/I0.10 I6/j.scitotenv.2018.06.267

Krupa, S. V. (2003). Effects of atmospheric ammonia $\left(\mathrm{NH}_{3}\right)$ on terrestrial vegetation: A review. Environmental Pollution, I24(2), I79-22I. https://doi.org/I0.1016/S0269-749I(02)00434-7

Kunkel, R., Herrmann, F., Kape, H. E., Keller, L., Koch, F., Tetzlaff, B., \& Wendland, F. (20I7). Simulation of terrestrial nitrogen fluxes in Mecklenburg-Vorpommern and scenario analyses how to reach $\mathrm{N}$-quality targets for groundwater and the coastal waters. Environmental Earth Sciences, 76(4), I-19. https://doi.org/I0.1007/ s|2665-0|7-6437-8

Laane, R.W. P. M. (2005). Applying the critical load concept to the nitrogen load of the river Rhine to the Dutch coastal zone. Estuarine, Coastal and Shelf Science, 62(3), 487-493. https://doi.org/I 0.10 I6/J.ECSS.2004.09.012

Lamarque, J. F., Dentener, F., McConnell, J., Ro, C. U., Shaw, M., Vet, R., ... Nolan, M. (20I3). Multi-model mean nitrogen and sulfur deposition from the atmospheric chemistry and climate model intercomparison project (ACCMIP): Evaluation of historical and projected future changes. Atmospheric Chemistry and Physics, I3(I6), 7997-80 18. https://doi.org/I0.5 I94/acp-13-7997-2013

Lambin, E. F., Gibbs, H. K., Ferreira, L., Grau, R., Mayaux, P., Meyfroidt, P., ... Munger, J. (20I3). Estimating the world's potentially available cropland using a bottom-up approach. Global Environmental Change, 23(5), 892-90I. https://doi.org/10.1016/j.gloenvcha.2013.05.005

Lambin, E. F., \& Meyfroidt, P. (20 I I). Global land use change, economic globalization, and the looming land scarcity. Proceedings of the National Academy of Sciences of the United States of America 108(9), 3454-3472. https:// doi.org/I0.1073/pnas. II 00480108

Lassaletta, L., Billen, G., Garnier, J., Bouwman, L., Velazquez, E., Mueller, N. D., \& Gerber, J. S. (20I6). Nitrogen use in the global food system: Past trends and future trajectories of agronomic performance, pollution, trade, and dietary demand. Environmental Research Letters, I I(9), 095007. https://doi.org/I0.I088/I7489326/II/9/095007

Lassaletta, L., Billen, G., Grizzetti, B., Anglade, J., \& Garnier, J. (20I4a). 50 year trends in nitrogen use efficiency of world cropping systems: The relationship between yield and nitrogen input to cropland. Environmental Research Letters, 9(10), I050I I. https://doi.org/I0.1088/1748-9326/9/10/1050I I

Lassaletta, L., Billen, G., Grizzetti, B., Garnier, J., Leach,A. M., \& Galloway, J. N. (20I4b). Food and feed trade as a driver 
in the global nitrogen cycle: 50-year trends. Biogeochemistry, II8(I-3), 225-24I. https://doi.org/I0.1007/ s10533-013-9923-4

Laubhann, D., Sterba, H., Reinds, G. J., \& De Vries, W. (2009). The impact of atmospheric deposition and climate on forest growth in European monitoring plots: An individual tree growth model. Forest Ecology and Management, 258(8), I75 I-I76I. https://doi.org/I0.1016/j.foreco.2008.09.050

Le Quéré, C., Moriarty, R., Andrew, R. M., Canadell, J. G., Sitch, S., Korsbakken, J. I., ... Zeng, N. (2015). Global Carbon Budget 2015. Earth System Science Data, 7(2), 349-396. https://doi.org/10.5I94/essd-7-349-20I5

LeBauer, D. S., \& Treseder, K. K. (2008). Nitrogen limitation of net primary productivity in terrestrial ecosystems is globally distributed. Ecology, 89(2), 37I-379. https://doi.org//0.1890/06-2057.I

Leip, A., Achermann, B., Billen, G., Bleeker, A., Bouwman, A., de Vries, W., ... Winiwarter, W. (20II). Integrating nitrogen fluxes at the European scale. In M. A. Sutton, C. M. Howard, J. W. Erisman, G. Billen, A. Bleeker, P. Grennfelt, ... B. Grizzetti (Eds.), The European Nitrogen Assessment (pp. 345-376). Cambridge University Press.

Leip,A., Billen, G., Garnier,J., Grizzetti, B., Lassaletta, L., Reis, S., ... Westhoek, H. (20I5). Impacts of European livestock production: nitrogen, sulphur, phosphorus and greenhouse gas emissions, land-use, water eutrophication and biodiversity. Environmental Research Letters, I0(II), II5004. https://doi.org//0.1088//7489326/10/II/II5004

Leip, A., Britz, W., Weiss, F., \& De Vries, W. (201I). Farm, land, and soil nitrogen budgets for agriculture in Europe calculated with CAPRI. Environmental Pollution, 159(II), 3243-3253. https://doi.org//0.1016/j. envpol.2011.01.040

Lesschen, J. P., Velthof, G. L., De Vries, W., \& Kros, J. (20II). Differentiation of nitrous oxide emission factors for agricultural soils. Environmental Pollution, 159(II), 3215-3222. https://doi.org/10.1016/j.envpol.201 I.04.00I

Lewis, S. L. (2012).We must set planetary boundaries wisely. Nature, 485(7399), 417. https://doi.org// 0. I038/485417a

Li, Y., Niu, S., \& Yu, G. (2016). Aggravated phosphorus limitation on biomass production under increasing nitrogen loading: a meta-analysis. Global Change Biology, 22(2), 934-943. https://doi.org//0.1 I I /gcb. I3 25

Liebig, J. (1840). Die organische Chemie in ihrer Anwendung auf Agricultur und Physiologie (Organic chemistry in its applications to agriculture and physiology). Braunschweig, Germany: Friedrich Vieweg und Sohn Publ. Co.

Lim, H., Oren, R., Palmroth, S., Tor-ngern, P., Mörling, T., Näsholm, T., ... Linder, S. (2015). Inter-annual variability of precipitation constrains the production response of boreal Pinus sylvestris to nitrogen fertilization. Forest Ecology and Management, 348, 31-45. https://doi.org/I0. I016/j.foreco.2015.03.029

Liu, C., Kroeze, C., Hoekstra, A.Y., \& Gerbens-Leenes, W. (20I2). Past and future trends in grey water footprints of anthropogenic nitrogen and phosphorus inputs to major world rivers. Ecological Indicators, 18, 42-49. https://doi.org/10.1016/J.ECOLIND.2011.10.005

Liu, J.X., Zhou, G.Y., Zhang, D. Q., Xu, Z. H., Duan, H. L., Deng, Q., \& Zhao, L. (20I0a). Carbon dynamics in subtropical forest soil: effects of atmospheric carbon dioxide enrichment and nitrogen addition. Journal of Soils and Sediments, 10(4), 730-738. https://doi.org/I0.1007/s I I368-009-0I78-6

Liu, J., Kleinman, P. J. A., Aronsson, H., Flaten, D., McDowell, R. W., Bechmann, M., ... Veith, T. L. (2018). A review of regulations and guidelines related to winter manure application. Ambio, 47(6), 657-670. https://doi. org/ $10.1007 / \mathrm{s} \mid 3280-018-1012-4$

Liu, J., You, L., Amini, M., Obersteiner, M., Herrero, M., Zehnder, A. J. B., \& Yang, H. (2010b). A high-resolution assessment on global nitrogen flows in cropland. Proceedings of the National Academy of Sciences, 107(17), 8035-8040. https://doi.org//0.1073/pnas.0913658107

Liu, L., \& Greaver, T. L. (2009). A review of nitrogen enrichment effects on three biogenic GHGs: the $\mathrm{CO}_{2}$ sink may be largely offset by stimulated $\mathrm{N}_{2} \mathrm{O}$ and $\mathrm{CH}_{4}$ emission. Ecology Letters, I2(10), I 103-1 I 17. https://doi. org/I0.1III/j. I 46I-0248.2009.0135I.x

Liu, L., \& Greaver, T. L. (2010). A global perspective on belowground carbon dynamics under nitrogen enrichment. Ecology Letters, I3(7), 819-828. https://doi.org/I0.1 I I I/j. I 46I-0248.2010.01482.x

Liu, W., Yang, H., Liu, J., Azevedo, L. B., Wang, X., Xu, Z., ... Schulin, R. (2016). Global assessment of nitrogen losses and trade-offs with yields from major crop cultivations. Science of the Total Environment, 572, 526-537. https://doi.org//0.1016/j.scitotenv.2016.08.093 
Lobell, D. B., Cassman, K. G., \& Field, C. B. (2009). Crop yield gaps: their importance, magnitudes, and causes. Annual Review of Environment and Resources, 34(I), 179-204. https://doi.org//0.1/46/annurev. environ.041008.093740

Lovett, G. M., Arthur, M. A., Weathers, K. C., Fitzhugh, R. D., \& Templer, P. H. (20I3). Nitrogen addition increases carbon storage in soils, but not in trees, in an Eastern U.S. deciduous forest. Ecosystems, 16(6), 980-100I. https://doi.org/10.1007/s1002I-013-9662-3

Lovett, G. M., \& Goodale, C. L. (20II). A new conceptual model of nitrogen saturation based on experimental nitrogen addition to an oak forest. Ecosystems, I4(4), 615-63I. https://doi.org/ I0.1007/s I002I-01 I-9432-z

Lu, C., \& Tian, H. (2013). Net greenhouse gas balance in response to nitrogen enrichment: perspectives from a coupled biogeochemical model. Global Change Biology, 19(2), 57 I-588. https://doi.org/ I 0 I I I I/gcb. I 2049

Lu, M., Zhou, X., Luo, Y., Yang, Y., Fang, C., Chen, J., \& Li, B. (20II). Minor stimulation of soil carbon storage by nitrogen addition: A meta-analysis. Agriculture, Ecosystems and Environment, I40(I-2), 234-244. https://doi. org/10.1016/j.agee.2010.12.010

Lu, X., Mao, Q., Gilliam, F. S., Luo, Y., \& Mo, J. (2014). Nitrogen deposition contributes to soil acidification in tropical ecosystems. Global Change Biology, 20(I2), 3790-380 I. https://doi.org/ I 0. I I I /gcb. 12665

Lucas, P. L., Wilting, H. C., Hof, A. F., \& van Vuuren, D. P. (2020). Allocating planetary boundaries to large economies: Distributional consequences of alternative perspectives on distributive fairness. Global Environmental Change, 60, 102017. https://doi.org//0.1016/j.gloenvcha.2019.102017

Luyssaert, S., Inglima, I., Jung, M., Richardson, A. D., Reichstein, M., Papa, D., ... Janssens, I. A. (2007). $\mathrm{CO}_{2}$ balance of boreal, temperate, and tropical forests derived from a global database. Global Change Biology, 13(12), 2509-2537. https://doi.org//0.1 III/j.1365-2486.2007.01439.x

Luyssaert, S., Schulze, E.-D., Börner,A., Knohl,A., Hessenmöller, D., Law, B. E., ... Grace, J. (2008). Old-growth forests as global carbon sinks. Nature, 455(72/0), 213-2/5. https://doi.org/ 0.1038/nature07276

Maaroufi, N. I., Nordin,A., Hasselquist, N. J., Bach, L. H., Palmqvist, K., \& Gundale, M.J. (2015).Anthropogenic nitrogen deposition enhances carbon sequestration in boreal soils. Global Change Biology, 2I(8), 3169-3180. https:// doi.org/ I0.1 I I I/gcb. 12904

MacDonald, G. K., Bennett, E. M., Potter, P. A., \& Ramankutty, N. (20I I). Agronomic phosphorus imbalances across the world's croplands. Proceedings of the National Academy of Sciences of the United States of America, 108(7), 3086-309I. https://doi.org//0.1073/pnas. 1010808108

Magill, A. H., Aber, J. D., Currie, W. S., Nadelhoffer, K. J., Martin, M. E., McDowell, W. H., ... Steudler, P. (2004). Ecosystem response to 15 years of chronic nitrogen additions at the Harvard Forest LTER, Massachusetts, USA. Forest Ecology and Management, 196(I), 7-28. https://doi.org//0.1016/j.foreco.2004.03.033

Magnani, F., Mencuccini, M., Borghetti, M., Berbigier, P., Berninger, F., Delzon, S., ... Grace, J. (2007). The human footprint in the carbon cycle of temperate and boreal forests. Nature, 447(7/46), 848-850. https://doi. org// 0. I038/nature05847

Mainwaring, D. B., Maguire, D. A., \& Perakis, S. S. (2014). Three-year growth response of young Douglas-fir to nitrogen, calcium, phosphorus, and blended fertilizers in Oregon and Washington. Forest Ecology and Management, 327, 178-188. https://doi.org//0.1016/j.foreco.2014.05.005

Markewitz, D., Figueiredo, R. de O., de Carvalho, C. J. R., \& Davidson, E. A. (20I2). Soil and tree response to P fertilization in a secondary tropical forest supported by an Oxisol. Biology and Fertility of Soils, 48(6), 665678. https://doi.org/10.1007/s00374-0II-0659-9

Maynard, D. G., Paré, D., Thiffault, E., Lafleur, B., Hogg, K. E., \& Kishchuk, B. (2014). How do natural disturbances and human activities affect soils and tree nutrition and growth in the Canadian boreal forest? Environmental Reviews, 22(2), I6I-178. https://doi.org/I0.1 I39/er-2013-0057

McCarthy, H. R., Oren, R., Finzi, A. C., \& Johnsen, K. H. (2006). Canopy leaf area constrains [CO2]-induced enhancement of productivity and partitioning among aboveground carbon pools. Proceedings of the National Academy of Sciences of the United States of America, 103(51), 19356-19361. https://doi.org//0.1073/ pnas.0609448103

McGrath, J. F., Copeland, B., \& Dumbrell, I. C. (2003). Magnitude and duration of growth and wood quality responses to phosphorus and nitrogen in thinned Pinus radiata in southern Western Australia. Australian Forestry, 
66(3), 223-230. https://doi.org// 0.129/2003GB002060

McNulty, S. G., Boggs, J., Aber, J. D., Rustad, L., \& Magill, A. (2005). Red spruce ecosystem level changes following 14 years of chronic $N$ fertilization. Forest Ecology and Management, 219(2-3), 279-29I. https://doi. org/I0.1016/j.foreco.2005.09.004

Mekonnen, M. M., \& Hoekstra, A. Y. (2015). Global Gray Water Footprint and Water Pollution Levels Related to Anthropogenic Nitrogen Loads to Fresh Water. Environmental Science and Technology, 49(2I), I2860-12868. https://doi.org/10.1021/acs.est.5b03191

Melillo, J. M., Butler, S., Johnson, J., Mohan, J., Steudler, P., Lux, H., ... Tang, J. (20II). Soil warming, carbon-nitrogen interactions, and forest carbon budgets. Proceedings of the National Academy of Sciences of the United States of America, 108(23), 9508-95 I2. https://doi.org/10.1073/pnas. 1018189108

Menge, D. N. L., Lichstein, J.W., \& Ángeles-Pérez, G. (2014). Nitrogen fixation strategies can explain the latitudinal shift in nitrogen-fixing tree abundance. Ecology, 95(8), 2236-2245. https://doi.org// 0. 1890/I3-2/24.I

Midolo, G., Alkemade, R., Schipper, A. M., Benítez-López, A., Perring, M. P., \& De Vries, W. (2019). Impacts of nitrogen addition on plant species richness and abundance:A global meta-analysis. Global Ecology and Biogeography, 28(3), 398-4 I3. https://doi.org/ I 0.1 I I I/geb. I 2856

Mitchell, T. D., Carter,T. R., Jones, P. D., Hulme, M., \& New, M. (2004). A comprehensive set of high-resolution grids of monthly climate for Europe and the globe: the observed record (I90I-2000) and I6 scenarios (200I-2I00). Working Paper 55. Tyndall Centre for Climate Change Reserach. Retrieved from http://www.ipcc-data.org/ docs/tyndall_working_papers_wp55.pdf

Monfreda, C., Ramankutty, N., \& Foley, J. A. (2008). Farming the planet: 2. Geographic distribution of crop areas, yields, physiological types, and net primary production in the year 2000. Global Biogeochemical Cycles, 22(I), I-19. https://doi.org//0.1029/2007GB002947

Mosnier, A., Havlík, P., Valin, H., Baker, J., Murray, B., Feng, S., .. Schneider, U. A. (2013). Alternative U.S. biofuel mandates and global GHG emissions: The role of land use change, crop management and yield growth. Energy Policy, 57, 602-614. https://doi.org/10.1016/j.enpol.2013.02.035

Mueller, N. D., Gerber, J. S., Johnston, M., Ray, D. K., Ramankutty, N., \& Foley, J.A. (2012). Closing yield gaps through nutrient and water management. Nature, 490(7419), 254-257. https://doi.org/ I0.1038/nature I I420

Mueller, N. D., Lassaletta, L., Runck, B. C., Billen, G., Garnier, J., \& Gerber, J. S. (2017). Declining spatial efficiency of global cropland nitrogen allocation. Global Biogeochemical Cycles, 3I(2), 245-257. https://doi. org/10.1002/2016GB0055/5

Mueller, N. D., West, P. C., Gerber, J. S., MacDonald, G. K., Polasky, S., \& Foley, J. A. (2014). A tradeoff frontier for global nitrogen use and cereal production. Environmental Research Letters, 9(5), 054002. https://doi. org// 0.1088/1748-9326/9/5/054002

Myneni, R. B., Dong, J.,Tucker, C. J., Kaufmann, R. K., Kauppi, P. E., Liski, J., ... Hughes, M. K. (200I).A large carbon sink in the woody biomass of Northern forests. Proceedings of the National Academy of Sciences of the United States of America, 98(26), 14784-14789. https://doi.org//0.1073/pnas.261555198

Nabuurs, G.J., Lindner, M., Verkerk, P. J., Gunia, K., Deda, P., Michalak, R., \& Grassi, G. (2013). First signs of carbon sink saturation in European forest biomass. Nature Climate Change, 3(9), 792-796. https://doi.org/ $0.1038 /$ nclimate 1853

Nabuurs, G.-J., Schelhaas, M.-.., Mohren, G. (Frits) M. J., \& Field, C. B. (2003). Temporal evolution of the European forest sector carbon sink from 1950 to 1999. Global Change Biology, 9(2), I52-160. https://doi.org//0.1046/ j.1365-2486.2003.00570.x

Nadelhoffer, K. J., Emmett, B. A., Gundersen, P., Kjønaas, O. J., Koopmans, C. J., Schleppi, P., ... Wright, R. F. (1999). Nitrogen deposition makes a minor contribution to carbon sequestration in temperate forests. Nature, 398(6723), 145-148. https://doi.org//0.1038//8205

Nave, L. E., Vance, E. D., Swanston, C. W., \& Curtis, P. S. (2009). Impacts of elevated N inputs on north temperate forest soil $\mathrm{C}$ storage, $\mathrm{C} / \mathrm{N}$, and net $\mathrm{N}$-mineralization. Geoderma, I53(I-2), 23I-240. https://doi.org/I0.1016/j. geoderma.2009.08.012

Neumann, K., Elbersen, B. S., Verburg, P. H., Staritsky, I., Pérez-Soba, M., de Vries, W., \& Rienks, W.A. (2009). Modelling the spatial distribution of livestock in Europe. Landscape Ecology, 24(9), |207-1222. https://doi.org//0.1007/ 
s10980-009-9357-5

Newton, P. F., \& Amponsah, I. G. (2006). Systematic review of short-term growth responses of semi-mature black spruce and jack pine stands to nitrogen-based fertilization treatments. Forest Ecology and Management, 237(I-3), I-I4. https://doi.org/I0.1016/j.foreco.2006.10.009

Nilsson, M., Chisholm, E., Griggs, D., Howden-Chapman, P., McCollum, D., Messerli, P., ... Stafford-Smith, M. (20I8). Mapping interactions between the sustainable development goals: lessons learned and ways forward. Sustainability Science, I3(6), | 489-1503. https://doi.org/ I0. I007/s | I625-0 I8-0604-z

Noguchi, K., Nagakura, J., Konôpka, B., Sakata, T., Kaneko, S., \& Takahashi, M. (20I3). Fine-root dynamics in sugi (Cryptomeria japonica) under manipulated soil nitrogen conditions. Plant and Soil, 364(I-2), I59-I69. https://doi.org/I0.1007/s I I 104-012-1354-9

Nykvist, B., Persson, Å., Moberg, F., Persson, L., Cornell, S., \& Rockström, J. (20I3). National Environmental Performance on Planetary Boundaries. Stockholm, Sweden: Swedish Environmental Protection Agency. Retrieved from https:/www.naturvardsverket.se/Documents/publikationer6400/978-9I-620-6576-8.pdf

Oenema, O., Witzke, H. P., Klimont, Z., Lesschen, J. P., \& Velthof, G. L. (2009). Integrated assessment of promising measures to decrease nitrogen losses from agriculture in EU-27. Agriculture, Ecosystems and Environment, I33(3-4), 280-288. https://doi.org/I0.1016/j.agee.2009.04.025

Oenema, O. (2019). Factsheet Stikstofbronnen. Retrieved December 22, 2020, from https://www.wur.nl/upload_ $\mathrm{mm} / \mathrm{e} / \mathrm{c} / \mathrm{d} / 2 \mathrm{fce}$ I598-fff7-4737-9319-8cbfa397664a_20191002 factsheet Oenema.pdf

Oenema, O., Bleeker, A., Braathen, N. A., Budňáková, M., Bull, K., Čermák, P., ... Winiwarter, W. (20II). Nitrogen in current European policies. In Mark A. Sutton, C. M. Howard, J.W. Erisman, G. Billen, A. Bleeker, P. Grennfelt, ... B. Grizzetti (Eds.), The European Nitrogen Assessment (pp. 62-8I). Cambridge University Press. https://doi. org/10.1017/CBO97805।1976988.007

Oenema, O., Oudendag, D., \& Velthof, G. L. (2007). Nutrient losses from manure management in the European Union. Livestock Science, I I2(3), 26I-272. https://doi.org/I0.10 I6/j.livsci.2007.09.007

Olson, D. M., Dinerstein, E.,Wikramanayake, E. D., Burgess, N. D., Powell, G.V. N., Underwood, E. C., ... Kassem, K. R. (200I). Terrestrial ecoregions of the world: a new map of life on Earth. BioScience, 5 I (I I), 933. https://doi. org/I0.164I/0006-3568(200I)05I [0933:TEOTWA]2.0.CO;2

Paerl, H.W., Scott, J. T., McCarthy, M. J., Newell, S. E., Gardner, W. S., Havens, K. E., ... Wurtsbaugh, W. A. (2016). It Takes Two to Tango: When and Where Dual Nutrient (N \& P) Reductions Are Needed to Protect Lakes and Downstream Ecosystems. Environmental Science and Technology, 50(20), 10805-I08I3. https://doi. org/10.1021/acs.est.6b02575

Pan, Y., Birdsey, R. A., Fang, J., Houghton, R., Kauppi, P. E., Kurz, W. A., ... Hayes, D. (20I la). A large and persistent carbon sink in the world's forests. Science, 333(6045), 988-993. https://doi.org/10.1 I 26/science. 1201609

Pan, Y., Chen, J. M., Birdsey, R., McCullough, K., He, L., \& Deng, F. (20I lb). Age structure and disturbance legacy of North American forests. Biogeosciences, 8(3), 7I5-732. https://doi.org/ 1 0.5 I 94/bg-8-7I 5-20I I

Paul, E.A., \& Clark, F. E. (1996). Soil Microbiology and Biochemistry, Second Edition. San Diego:Academic Press.

Payne, R. J., Dise, N. B., Field, C. D., Dore, A. J., Caporn, S. J., \& Stevens, C. J. (2017). Nitrogen deposition and plant biodiversity: past, present, and future. Frontiers in Ecology and the Environment, I5(8), 431-436. https://doi. org/I0.1002/fee. 1528

Peel, J. L., Haeuber, R., Garcia,V., Russell,A. G., \& Neas, L. (20I3). Impact of nitrogen and climate change interactions on ambient air pollution and human health. Biogeochemistry, II4(I-3), I2I-I34. https://doi.org//0.1007/ sl0533-0I 2-9782-4

Peñuelas, J., Poulter, B., Sardans, J., Ciais, P., van der Velde, M., Bopp, L., ... Janssens, I. A. (20I3). Human-induced nitrogen-phosphorus imbalances alter natural and managed ecosystems across the globe. Nature Communications, 4, 2934. https://doi.org/10.1038/ncomms3934

Peterson, B. J., \& Melillo, J. M. (1985). The potential storage of carbon caused by eutrophication of the biosphere. Tellus B, 37(3), II7-127. https://doi.org/10.1 I I I/j.I600-0889.1985.tb00060.x

Poikane, S., Kelly, M. G., Salas Herrero, F., Pitt, J. A., Jarvie, H. P., Claussen, U., ... Phillips, G. (2019). Nutrient criteria for surface waters under the European Water Framework Directive: Current state-of-the-art, challenges and future outlook. Science of the Total Environment, 695, 133888. https://doi.org//0.1016/j. 
scitotenv.2019.133888

Popp, A., Lotze-Campen, H., \& Bodirsky, B. (2010). Food consumption, diet shifts and associated non-CO greenhouse gases from agricultural production. Global Environmental Change, 20(3), 45I-462. https://doi. org/10.1016/j.gloenvcha.2010.02.00I

Poulter, B., Aragao, L., Andela, N., Bellassen, V., Ciais, P., Kato, T., ... Shivdenko, A. (2019). The global forest age dataset and its uncertainties (GFADvI.I). NASA National Aeronautics and Space Administration. PANGAEA. https:// doi.org/I0.I594/PANGAEA.897392

Powlson, D. S.,Addiscott, T. M., Benjamin, N., Cassman, K. G., de Kok, T. M., van Grinsven, H., ... van Kessel, C. (2008). When Does Nitrate Become a Risk for Humans? Journal of Environmental Quality, 37(2), 29I-295. https:// doi.org/10.2134/jeq2007.0177

Pozzer,A.,Tsimpidi,A. P., Karydis,V.A., de Meij,A., \& Lelieveld, J. (20I7). Impact of agricultural emission reductions on fine-particulate matter and public health. Atmospheric Chemistry and Physics, I7(20), I28I3-12826. https:// doi.org/I0.5194/acp-17-12813-2017

Pradhan, P., Fischer, G., van Velthuizen, H., Reusser, D. E., \& Kropp, J. P. (20I5). Closing Yield Gaps: How Sustainable Can We Be? Plos One, I0(6), e0 I29487. https://doi.org/I0.I37I/journal.pone.0I29487

Pradhan, P., Lüdeke, M. K. B., Reusser, D. E., \& Kropp, J. P. (20I4). Food self-sufficiency across scales: How local can we go? Environmental Science and Technology, 48( I6), 9463-9470. https://doi.org/10.1021/es5005939

Pregitzer, K.S., \& Euskirchen, E. S. (2004). Carbon cycling and storage in world forests: Biome patterns related to forest age. Global Change Biology, I0( I2), 2052-2077. https://doi.org/ I 0. I I I /j. I 365-2486.2004.00866.x

Pregitzer, K. S., Burton, A. J., Zak, D. R., \& Talhelm, A. F. (2008). Simulated chronic nitrogen deposition increases carbon storage in Northern Temperate forests. Global Change Biology, I4(I), I42-I53. https://doi. org/I0.IIII/j.I365-2486.2007.0I465.x

Puma, M. J., Bose, S., Chon, S. Y., \& Cook, B. I. (20I5). Assessing the evolving fragility of the global food system. Environmental Research Letters, I0(2), 024007. https://doi.org/I0. I088/I748-9326//0/2/024007

Putaud, J. P., Raes, F., Van Dingenen, R., Brüggemann, E., Facchini, M. C., Decesari, S., ... Wiedensohler, A. (2004). A European aerosol phenomenology - 2: Chemical characteristics of particulate matter at kerbside, urban, rural and background sites in Europe. Atmospheric Environment, 38(16), 2579-2595. https://doi.org/10.1016/j. atmosenv.2004.01.04I

R Core Team. (2019). R: A Language and environment for statistical computing. Vienna, Austria: R Foundation for Statistical Computing. Retrieved from http://www.r-project.org/

Rao, S., Klimont, Z., Smith, S. J., Van Dingenen, R., Dentener, F., Bouwman, L., ... Tavoni, M. (20I7). Future air pollution in the Shared Socio-economic Pathways. Global Environmental Change, 42, 346-358. https://doi. org/10.1016/j.gloenvcha.2016.05.012

Rappe-George, M. O., Gärdenäs, A. I., \& Kleja, D. B. (20I3). The impact of four decades of annual nitrogen addition on dissolved organic matter in a boreal forest soil. Biogeosciences, I0(3), I 365-I377. https://doi.org/I0.5 I 94/ bg-10-1365-2013

Ray, D. K., Mueller, N. D., West, P. C., \& Foley, J. A. (2013). Yield Trends Are Insufficient to Double Global Crop Production by 2050. PLOS ONE, 8(6), e66428. https://doi.org/I0.I37I/journal.pone.0066428

Ray, D. K., Ramankutty, N., Mueller, N. D., West, P. C., \& Foley, J.A. (20I2). Recent patterns of crop yield growth and stagnation. Nature Communications, 3(I), 1293. https://doi.org/10.1038/ncomms2296

Reay, D. S., Davidson, E. A., Smith, K.A., Smith, P., Melillo, J. M., Dentener, F., \& Crutzen, P. J. (20I2). Global agriculture and nitrous oxide emissions. Nature Climate Change, 2(6), 4I0-4I6. https://doi.org//0.1038/nclimate I458

Riahi, K., van Vuuren, D. P., Kriegler, E., Edmonds, J., O’Neill, B. C., Fujimori, S., ... Tavoni, M. (20I7). The Shared Socioeconomic Pathways and their energy, land use, and greenhouse gas emissions implications:An overview. Global Environmental Change, 42, I53-168. https://doi.org/I0.1016/j.gloenvcha.2016.05.009

Rockström, J., Steffen, W., Noone, K., Lambin, E., Lenton, T. M., Scheffer, M., ... Foley, J. (2009). Planetary Boundaries : Exploring the Safe Operating Space for Humanity. Ecology And Society, I4(2), 32.

Rockström, J., Steffen, W., Noone, K., Persson, Å., Chapin, F. S., Lambin, E. F., ... Foley, J. A. (2009). A safe operating space for humanity. Nature, 46 I (7263), 472-475. https://doi.org/ I0.1038/46 I472a

Rogelj, J., Hare, W., Lowe, J., van Vuuren, D. P., Riahi, K., Matthews, B., .. Meinshausen, M. (20I I). Emission pathways 
consistent with a $2{ }^{\circ} \mathrm{C}$ global temperature limit. Nature Climate Change, I(8), 4I3-4I8. https://doi. org/I0.1038/nclimate 1258

Rolinski, S., Müller, C., Heinke, J., Weindl, I., Biewald, A., Leon Bodirsky, B., ... Thonicke, K. (2018). Modeling vegetation and carbon dynamics of managed grasslands at the global scale with LPJmL 3.6. Geoscientific Model Development, I I(I), 429-45I. https://doi.org/I0.5I94/gmd-I I-429-20I8

Roth, T., Kohli, L., Rihm, B., \& Achermann, B. (2013). Nitrogen deposition is negatively related to species richness and species composition of vascular plants and bryophytes in Swiss mountain grassland. Agriculture, Ecosystems and Environment, 178, 121-126. https://doi.org/10.1016/j.agee.2013.07.002

Saarsalmi, A., Smolander, A., Kukkola, M., Moilanen, M., \& Saramäki, J. (2012). 30-Year effects of wood ash and nitrogen fertilization on soil chemical properties, soil microbial processes and stand growth in a Scots pine stand. Forest Ecology and Management, 278, 63-70. https://doi.org/I 0. I0I 6/j.foreco.20I2.05.006

Sachs, J., Schmidt-Traub, G., Kroll, C., Lafortune, G., \& Fuller, G. (2019). Sustainable Development Report 2019 - Tranformations to achieve the Sustainable Development Goals. New York. Retrieved from https://www. sdgindex.org/reports/sustainable-development-report-2019/

Sadowski, A., \& Baer-Nawrocka, A. (2016). Food self-sufficiency of the European Union countries - energetic approach. Journal of Agribusiness and Rural Development, 10(2). https://doi.org//0.17306/JARD.2016.44

Sánchez, P. A. (2010, May). Tripling crop yields in tropical Africa. Nature Geoscience, 3, 299-300. https://doi. org// $0.1038 /$ ngeo853

Sattari, S. Z., Bouwman, A. F., Giller, K. E., \& van Ittersum, M. K. (20I2). Residual soil phosphorus as the missing piece in the global phosphorus crisis puzzle. Proceedings of the National Academy of Sciences, 109(16), 6348-6353. https://doi.org//0.1073/pnas. III3675109

Schaefer, S. C., \& Alber, M. (2007). Temperature controls a latitudinal gradient in the proportion of watershed nitrogen exported to coastal ecosystems. Biogeochemistry, 85(3), 333-346. https://doi.org/I0.1007/s I0533007-9144-9

Schils, R., Höglind, M.,Van Middelkoop, J., Holshof, G.,Verloop, J.J., Rijk, B., ... Van Ittersum, M. K. (2018a). Framework for yield gap analysis in grasslands. In B. Horan, D. Hennessy, M. O'Donovan, E. Kennedy, B. McCarthy, J. A. Finn, \& B. O'Brien (Eds.), Grassland Science in Europe,Vol. 23 - Sustainable meat and milk production from grasslands. Proceedings of the 27th General Meeting of the European Grassland Federation Cork, Ireland 17-21 June 2018 (Vol. 23, pp. 90-92).Wageningen:Wageningen Academic Publishers.

Schils, R., Olesen, J. E., Kersebaum, K. C., Rijk, B., Oberforster, M., Kalyada, V., ... van Ittersum, M. K. (2018b). Cereal yield gaps across Europe. European Journal of Agronomy, 10I, 109-120. https://doi.org/10.1016/j. eja.2018.09.003

Schimel, J. P., \& Weintraub, M. N. (2003). The implications of exoenzyme activity on microbial carbon and nitrogen limitation in soil:A theoretical model. Soil Biology and Biochemistry, 35(4), 549-563. https://doi.org//0.1016/ S0038-0717(03)000I5-4

Schindler, D. W., \& Bayley, S. E. (1993). The biosphere as an increasing sink for atmospheric carbon: Estimates from increased nitrogen depostion. Global Biogeochemical Cycles, 7(4), 717-733. https://doi. org// 0. I029/93GB02562

Schindler, D.W., Carpenter, S. R., Chapra, S. C., Hecky, R. E., \& Orihel, D. M. (20I6). Reducing phosphorus to curb lake eutrophication is a success. Environmental Science and Technology, 50(I7), 8923-8929. https://doi. org/ $/ 0.102 \mathrm{I} /$ acs.est.6b02204

Schulte-Uebbing, L., \& De Vries, W. (202I). Reconciling food production and environmental boundaries for agricultural nitrogen inputs in the European Union. Science of The Total Environment, 786: 147427. https:// doi.org//0.1016/j.scitotenv.2021.147427

Schulte-Uebbing, L., \& DeVries,W. (2018). Global-scale impacts of nitrogen deposition on tree carbon sequestration in tropical, temperate, and boreal forests: A meta-analysis. Global Change Biology, 24(2), e4I6-e43I. https:// doi.org/10.1 II I/gcb. 13862

Schwede, D. B., Simpson, D., Tan, J., Fu, J. S., Dentener, F., Du, E., \& DeVries, W. (2018). Spatial variation of modelled total, dry and wet nitrogen deposition to forests at global scale. Environmental Pollution, 243, I287-|30I. https://doi.org/10.1016/j.envpol.2018.09.084 
Selman, M., Greenhalgh, S., Diaz, R., \& Sugg, Z. (2008). Eutrophication and Hypoxia in coastal areas: A global assessment of the state of knowledge. Retrieved from http://www.wri.org/sites/default/files/pdf/ eutrophication_and_hypoxia_in_coastal_areas.pdf

Sexton, J. O., Noojipady, P., Anand,A., Song, X. P., McMahon, S., Huang, C., ... Townshend, J. R. (20I5).A model for the propagation of uncertainty from continuous estimates of tree cover to categorical forest cover and change. Remote Sensing of Environment, I56, 418-425. https://doi.org//0.1016/j.rse.2014.08.038

Sexton, J. O., Noojipady, P., Song, X. P., Feng, M., Song, D. X., Kim, D. H., ... Townshend, J. R. (2016). Conservation policy and the measurement of forests. Nature Climate Change, 6(2), 192-196. https://doi.org//0.1038/ nclimate2816

Shen, G., Moore, J. A., \& Hatch, C. R. (200I). The effect of nitrogen fertilization, rock type, and habitat type on individual tree mortality. Forest Science, 47(2), 203-2I3.

Shen, J., Yuan, L., Zhang, J., Li, H., Bai, Z., Chen, X., ... Zhang, F. (20I I). Phosphorus Dynamics: From Soil to Plant. Plant Physiology, I 56(3), 997-1005. https://doi.org/I0.II04/pp.I II.I75232

Shryock, B., Littke, K., Ciol, M., Briggs, D., \& Harrison, R. (2014). The effects of urea fertilization on carbon sequestration in Douglas-fir plantations of the coastal Pacific Northwest. Forest Ecology and Management, 318, 34I-348. https://doi.org/10.1016/j.foreco.2014.01.040

Siddique, I., Vieira, I. C. G., Schmidt, S., Lamb, D., Carvalho, C. J. R., Figueiredo, R. de O., ... Davidson, E. A. (20I0). Nitrogen and phosphorus additions negatively affect tree species diversity in tropical forest regrowth trajectories. Ecology, 9 I (7), 2 I 2 I-2 I3I. https://doi.org/I0.1890/09-0636. I

Sigurdsson, B. D., Medhurst, J. L., Wallin, G., Eggertsson, O., \& Linder, S. (20I3). Growth of mature boreal Norway spruce was not affected by elevated [CO 2] and/or air temperature unless nutrient availability was improved. Tree Physiology, 33(I I), I 192-1205. https://doi.org/10.1093/treephys/tpt043

Simpson, D., Benedictow, A., Berge, H., Bergström, R., Emberson, L. D., Fagerli, H., ... Wind, P. (20I2). The EMEP MSC-W chemical transport model \&ndash; Technical description. Atmospheric Chemistry and Physics, I2(I6), 7825-7865. https://doi.org/I0.5I94/acp-12-7825-20I2

Sitch, S., Friedlingstein, P., Gruber, N., Jones, S. D., Murray-Tortarolo, G., Ahlström, A., ... Myneni, R. (20I5). Recent trends and drivers of regional sources and sinks of carbon dioxide. Biogeosciences, 12(3), 653-679. https:// doi.org/ I0.5194/bg-12-653-20I5

Skiba, U., Fowler, D., \& Smith, K.A. (1997). Nitric oxide emissions from agricultural soils in temperate and tropical climates: Sources, controls and mitigation options. Nutrient Cycling in Agroecosystems, 48(I-2), I39-I53. https://doi.org/I0.1023/a:I0097345|4983

Slootweg, J., Hettelingh, J.-P., Tamis, W., \& Van't Zelfde, M. (2005). Harmonizing European land cover maps. In M. Posch, J. Slootweg, \& J.-P. Hettelingh (Eds.), European Critical Loads and Dynamic Modelling (pp. 47-62). Bilthoven, Netherlands: Netherlands Environmental Assessment Agency (RIVM). Retrieved from http://www. rivm.nl/bibliotheek/digitaaldepot/PBL_CCE_SR05_Chapter3.pdf

Smil,V. (200I). Enriching the Earth. Fritz Haber, Carl Bosch, and the Transformation of World Food Production. The MIT Press.

Smit, H. J., Metzger, M. J., \& Ewert, F. (2008). Spatial distribution of grassland productivity and land use in Europe. Agricultural Systems, 98(3), 208-219. https://doi.org/10.1016/j.agsy.2008.07.004

Snyder, C. S. (2017). Enhanced nitrogen fertilizer technologies support the "4R" concept to optimise crop production and minimise environmental losses.' Soil Research, 55(6), 463. https://doi.org/I0.I07I/SRI6335

Sobota, D. J., Harrison, J. A., \& Dahlgren, R. A. (2009). Influences of climate, hydrology, and land use on input and export of nitrogen in California watersheds. Biogeochemistry, 94(I), 43-62. https://doi.org/I0.1007/s I0533009-9307-y

Solberg, S., Dobbertin, M., Reinds, G. J., Lange, H.,Andreassen, K., Fernandez, P. G., ... De Vries, W. (2009). Analyses of the impact of changes in atmospheric deposition and climate on forest growth in European monitoring plots: A stand growth approach. Forest Ecology and Management, 258(8), 1735-1750. https://doi.org/10.1016/j. foreco.2008.09.057

Spangenberg, J. H. (2019). Scenarios and Indicators for Sustainable Development:Towards a Critical Assessment of Achievements and Challenges. Sustainability, I I (4), 942. https://doi.org/ / 0.3390/su I I 040942 
Spillman, W. J. (1923). Application of the Law of Diminishing Returns to Some Fertilizer and Feed Data. Journal of Farm Economics (Vol. 5).

Spranger, T., Hettelingh, J. P., Slootweg, J., \& Posch, M. (2008). Modelling and mapping long-term risks due to reactive nitrogen effects: An overview of LRTAP convention activities. Environmental Pollution, I54(3), 482-487. https://doi.org/10.1016/j.envpol.2007.10.035

Springmann, M., Clark, M., Mason-D'Croz, D., Wiebe, K., Bodirsky, B. L., Lassaletta, L., ... Willett, W. (2018). Options for keeping the food system within environmental limits. Nature, 562(7728), 519-525. https://doi. org/I0.1038/s4I586-0I8-0594-0

Steffen,W., Crutzen, P. J., \& McNeill, J. R. (2007). The anthropocene:Are humans now overwhelming the great forces of nature? Ambio, 36(8):6I4-62I. https://doi.org/I0.1579/0044-7447(2007)36[6I4:TAAHNO]2.0.CO;2

Steffen, W., Richardson, K., Rockström, J., Cornell, S. E., Fetzer, I., Bennett, E. M., ... Sörlin, S. (2015). Planetary boundaries: Guiding human development on a changing planet. Science, 347(6223), 1259855. https://doi. org//0.1 I 26/science. 1259855

Stehfest, E., van Vuuren, D., Kram, T., Bouwman, L., Alkemade, R., Bakkenes, M., ... Prins, A. (2014). Integrated Assessment of Global Environmental Change with IMAGE 3.0 - Model description and policy applications. The Hague: PBL Netherlands Environmental Assessment Agency.

Stevens, C. J., Bell, J. N. B., Brimblecombe, P., Clark, C. M., Dise, N. B., Fowler, D., ... Wolseley, P. A. (2020, October 30). The impact of air pollution on terrestrial managed and natural vegetation: Air pollution impacts on vegetation. Philosophical Transactions of the Royal Society A: Mathematical, Physical and Engineering Sciences. Royal Society Publishing. https://doi.org// 0.1098/rsta.2019.0317

Stevens, C. J., Dupr, C., Dorland, E., Gaudnik, C., Gowing, D. J. G., Bleeker, A., ... Dise, N. B. (2010). Nitrogen deposition threatens species richness of grasslands across Europe. Environmental Pollution, 158(9), 29402945. https://doi.org/10.1016/j.envpol.2010.06.006

Stevens, C. J., \& Quinton, J. N. (2009). Diffuse Pollution Swapping in Arable Agricultural Systems. Critical Reviews in Environmental Science and Technology, 39(6), 478-520. https://doi.org//0.1080/I06433808019100I7

Stocker, T. F., Qin, D., Plattner, G.-K., Alexander, L.V.,Allen, S. K., Bindoff, N. L., ... Xie, S.-P. (20I3). Technical Summary. In T.F. Stocker, D. Qin, G.-K. Plattner, M.Tignor, S. K.Allen, J. Boschung, ... P. M. Midgley (Eds.), Climate Change 2013: The Physical Science Basis. Contribution of Working Group I to the Fifth Assessment Report of the Intergovernmental Panel on Climate Change (pp. 3I-II6). Cambridge, United Kingdom and Ney York, NY, USA: Cambridge University Press.

Stokstad, E. (2019). Nitrogen crisis threatens Dutch environment—and economy. Science, 366(6470), II80-1 I8I. https://doi.org/10.1 I26/science.366.6470.1180

Sun, Z., Liu, L., Peng, S., Peñuelas, J., Zeng, H., \& Piao, S. (2016). Age-Related Modulation of the Nitrogen Resorption Efficiency Response to Growth Requirements and Soil Nitrogen Availability in a Temperate Pine Plantation. Ecosystems, 19(4), 698-709. https://doi.org/I0.1007/s 1002I-016-9962-5

Sutton, M.A., Bleeker, A., Bekunda, M., Grizzetti, B., de Vries, W., van Grinsven, H., ... Zhang,Y. (2013). Our Nutrient World: The challenge to produce more food and energy with less pollution. Edinburgh, UK: Centre for Ecology and Hydrology (CEH), on behalf of the Global Partnership on Nutrient Management (GPNM) and the International Nitrogen Initiative (INI).

Sutton, M. A., Reis, S., Riddick, S. N., Dragosits, U., Nemitz, E., Theobald, M. R., ... de Vries, W. (20I3). Towards a climate-dependent paradigm of ammonia emission and deposition. Philosophical Transactions of the Royal Society B: Biological Sciences, 368(I62I). https://doi.org/I0.1098/rstb.2013.0166

Sutton, M.A., Oenema, O., Erisman, J.W., Leip, A., van Grinsven, H., \& Winiwarter,W. (20I I, April I4). Too much of a good thing. Nature. Nature Publishing Group. https://doi.org/ 10.1038/472159a

Sutton, M. A., Simpson, D., Levy, P. E., Smith, R. I., Reis, S., van Oijen, M., \& de Vries, W. (2008). Uncertainties in the relationship between atmospheric nitrogen deposition and forest carbon sequestration. Global Change Biology, I4(9), 2057-2063. https://doi.org/I 0.1 II I/j. I365-2486.2008.01636.x

Sutton, M.A., van Grinsven, H., Billen, G., Bleeker,A., Bouwman, A. F., Bull, K., ... Winiwarter,W. (201 I). Summary for policy makers. The European Nitrogen Assessment. https://doi.org/ I0.1017/CBO97805I 1976988.002

Sutton, M. A, Howard, C. M., Erisman, J. W., Billen, G., Bleeker, A., Grennfelt, P., ... Bouwman, A. F. (20II). The 
challenge to integrate nitrogen science and policies: the European Nitrogen Assessment approach. In $M$. Sutton, C. Howard, J. Erisman, G. Billen, A. Bleeker, P. Grennfelt, ... B. Grizzetti (Eds.), The European Nitrogen Assessment (pp. 82-96). Cambridge, United Kingdom: Cambridge University Press.

Tan, J., Fu, J. S., Dentener, F., Sun, J., Emmons, L., Tilmes, S., ... Keating, T. (2018). Multi-model study of HTAP II on sulfur and nitrogen deposition. Atmospheric Chemistry and Physics, 18(9), 6847-6866. https://doi.org/I0.5 I94/acp|8-6847-20|8

Tanner, E.V. J., Kapos, V., Freskos, S., Healey, J. R., \& Theobald, A. M. (1990). Nitrogen and phosphorus fertilization of Jamaican montane forest trees. Journal of Tropical Ecology, 6(2), 23I-238. https://doi.org/I0.2307/I938722

Tanner, E.V. J.,Vltousek, P. M., \& Cuevas, E. (1998). Experimental investigation of nutrient limitation of forest growth on wet tropical mountains. Ecology, 79(I), I0-22.

Templer, P. H., Mack, M. C., Chapin III, F. S., Christenson, L. M., Compton, J. E., Crook, H. D., ... Zak, D. R. (20I2). Sinks for nitrogen inputs in terrestrial ecosystems: a meta-analysis of ${ }^{15} \mathrm{~N}$ tracer field studies. Ecology, 93(8), |816-1829. https://doi.org//0.1890/II-I|46.I

Templer, P. H., Lovett, G. M., Weathers, K. C., Findlay, S. E., \& Dawson, T. E. (2005). Influence of Tree Species on Forest Nitrogen Retention in the Catskill Mountains, New York, USA. Ecosystems, 8(I), I-16. https://doi. org/I0.1007/s I 002I-004-0230-8

The World Bank. (2018). Fertility rate, total (births per woman). Retrieved from https://data.worldbank.org/ indicator/SP.DYN.TFRT.IN

Thomas, R. Q., Brookshire, E. N. J., \& Gerber, S. (2015). Nitrogen limitation on land: How can it occur in Earth system models? Global Change Biology, 2I (5), I777-1793. https://doi.org/I0.1 I I /gcb. I28I3

Thomas, R. Q., Canham, C. D., Weathers, K. C., \& Goodale, C. L. (2010). Increased tree carbon storage in response to nitrogen deposition in the US. Nature Geoscience, 3(I), I3-17. https://doi.org// 0.1038/ngeo72 I

Thomas, R. Q., Zaehle, S., Templer, P. H., \& Goodale, C. L. (2013). Global patterns of nitrogen limitation: confronting two global biogeochemical models with observations. Global Change Biology, I9(I0), 2986-2998. https://doi. org/10.1 II I/gcb. 12281

Thornton, P. E., Lamarque, J.-F., Rosenbloom, N. A., \& Mahowald, N. M. (2007). Influence of carbon-nitrogen cycle coupling on land model response to $\mathrm{CO} 2$ fertilization and climate variability. Global Biogeochemical Cycles, 2I, GB40 I8. https://doi.org// 0.1029/2006GB002868

Tian, D., \& Niu, S. (2015).A global analysis of soil acidification caused by nitrogen addition. Environmental Research Letters, I0(2). https://doi.org//0.1088//748-9326/10/2/024019

Tian, D., Wang, H., Sun, J., \& Niu, S. (2016). Global evidence on nitrogen saturation of terrestrial ecosystem net primary productivity. Environmental Research Letters, II(2), 0240I2. https://doi.org//0.1088//7489326/II/2/024012

Tian, H., Xu, R., Canadell, J. G.,Thompson, R. L.,Winiwarter,W., Suntharalingam, P., ... Yao,Y. (2020).A comprehensive quantification of global nitrous oxide sources and sinks. Nature, 586(December 2019). https://doi. org/I0.1038/s4I 586-020-2780-0

Tian, H., Yang, J., Xu, R., Lu, C., Canadell, J. G., Davidson, E.A., ... Zhang, B. (2019). Global soil nitrous oxide emissions since the preindustrial era estimated by an ensemble of terrestrial biosphere models: Magnitude, attribution, and uncertainty. Global Change Biology, 25(2), 640-659. https://doi.org/I 0. I I I/gcb. I45 I4

Tilman, D., Balzer, C., Hill, J., \& Befort, B. L. (20II). Global food demand and the sustainable intensification of agriculture. Proceedings of the National Academy of Sciences of the United States of America, 108(50), 20260-20264. https://doi.org/I0.1073/pnas. I I 16437/08

Townsend, A. R., Braswell, B. H., Holland, E. A., \& Penner, J. E. (1996). Spatial and temporal patterns in terrestrial carbon storage due to deposition of fossil fuel nitrogen. Ecological Applications, 6(3), 806-8I4. https://doi. org/10.2307/2269486

UN. (2015). Paris Agreement.

UNEP. (20I3). Drawing Down N2O to Protect Climate and the Ozone Layer.A UNEP Synthesis Report. Nairobi, Kenya.

Uwizeye, A., de Boer, I. J. M., Opio, C. I., Schulte, R. P. O., Falcucci, A., Tempio, G., ... Gerber, P. J. (2020). Nitrogen emissions along global livestock supply chains. Nature Food, I (7), 437-446. https://doi.org/10.1038/s430I6- 
020-0II3-y

Vadeboncoeur, M. A. (2010). Meta-analysis of fertilization experiments indicates multiple limiting nutrients in northeastern deciduous forests. Canadian Journal of Forest Research, 40(9), I766-I780. https://doi. org/10.1139/X10-127

van Bussel, L. G. J., Grassini, P., Van Wart, J., Wolf, J., Claessens, L., Yang, H., ... van Ittersum, M. K. (20I5). From field to atlas: Upscaling of location-specific yield gap estimates. Field Crops Research, 177, 98-108. https://doi. org/I0.1016/j.fcr.2015.03.005

van der Meer, H. (2002). Reducing inputs and losses of nitrogen and energy on dairy farms. Final Report Project AIR3 CT92-0332. Wageningen, Netherlands.

van der Meer, H., \& Baan Hofman, T. (1989). Contribution of legumes to yield and nitrogen economy of leys on a biodynamic farm. In P. Plancquaert \& R. Haggar (Eds.), Legumes in farming systems. Developments in plant and soil sciences (pp. 25-36). Dordrecht, The Netherlands: Kluwer Academic Publishers.

van Grinsven, H. J.M., Spiertz, J. H. J.,Westhoek, H. J., Bouwman, A. F., \& Erisman, J.W. (20I4). Nitrogen use and food production in European regions from a global perspective. Journal of Agricultural Science, I52(SI), S9-SI9. https://doi.org//0.1017/S00218596/3000853

van Grinsven, H. J. M., Ward, M. H., Benjamin, N., \& de Kok, T. M. (2006). Does the evidence about health risks associated with nitrate ingestion warrant an increase of the nitrate standard for drinking water? Environmental Health:A Global Access Science Source, 5(26). https://doi.org/doi:I 0.I I86/I476-069X-5- 26

van Grinsven, H. J. M., Bouwman, L., Cassman, K. G., van Es, H. M., McCrackin, M. L., \& Beusen, A. H. W. (20I5a). Losses of ammonia and nitrate from agriculture and their effect on nitrogen recovery in the European Union and the United States between 1900 and 2050. Journal of Environmental Quality, 44(2), 356-367. https://doi. org/10.2134/jeq2014.03.0102

van Grinsven, H. J. M., Holland, M., Jacobsen, B. H., Klimont, Z., Sutton, M. A., \& Jaap Willems, W. (20I3). Costs and benefits of nitrogen for europe and implications for mitigation. Environmental Science and Technology, 47(8), 357I-3579. https://doi.org/I0.102I/es303804g

van Grinsven, H. J. M., van Dam, J. D., Lesschen, J. P., Timmers, M. H. G., Velthof, G. L., \& Lassaletta, L. (20 I8). Reducing external costs of nitrogen pollution by relocation of pig production between regions in the European Union. Regional Environmental Change, 18(8), 2403-24I5. https://doi.org/I0.1007/s I 0 I I3-0 I8-I335-5

van Grinsven, H. J. M., Erisman, J.W., De Vries, W., \& Westhoek, H. (20I5b). Potential of extensification of European agriculture for a more sustainable food system, focusing on nitrogen. Environmental Research Letters, I0(2), 025002. https://doi.org// 0.1088/I748-9326/I0/2/025002

van Ittersum, M. K., \& Rabbinge, R. (1997). Concepts in production ecology for analysis and quantification of agricultural input-output combinations. Field Crops Research, 52(3), 197-208. https://doi.org/I0.1016/S03784290(97)00037-3

van Ittersum, M. K., Cassman, K. G., Grassini, P.,Wolf, J., Tittonell, P., \& Hochman, Z. (20I3).Yield gap analysis with local to global relevance-A review. Field Crops Research, I43, 4-I7. https://doi.org/I0.10I6/J.FCR.2012.09.009

van Ittersum, M. K., van Bussel, L. G. J., Wolf, J., Grassini, P., van Wart, J., Guilpart, N., .. Cassman, K. G. (20I6). Can sub-Saharan Africa feed itself? Proceedings of the National Academy of Sciences of the United States of America, I I3(52), |4964-|4969. https://doi.org/10.1073/pnas. I610359 II3

Van Meter, K. J., Basu, N. B., Veenstra, J. J., \& Burras, C. L. (2016). The nitrogen legacy: Emerging evidence of nitrogen accumulation in anthropogenic landscapes. Environmental Research Letters, II(3). https://doi. org/I0.1088/1748-9326/I I/3/035014

Velthof, G. L., \& Kuikman, P. (2000). Beperking van lachgasemissie uit beweid grasland. Rapport (Alterra-ra). Alterra, Wageningen. Retrieved from http://content.alterra.wur.nl/Webdocs/PDFFiles/Alterrarapporten/ AlterraRapport I 14.I.pdf

Velthof, G. L., Lesschen, J. P.,Webb, J., Pietrzak, S., Miatkowski, Z., Pinto, M., ... Oenema, O. (20I4). The impact of the Nitrates Directive on nitrogen emissions from agriculture in the EU-27 during 2000-2008. Science of the Total Environment, 468-469, I225-1233. https://doi.org/I0.1016/j.scitotenv.2013.04.058

Velthof, G. L., Oudendag, D.,Witzke, H. P., Asman,W.A. H., Klimont, Z., \& Oenema, O. (2009). Integrated Assessment of Nitrogen Losses from Agriculture in EU-27 using MITERRA-EUROPE. Journal of Environmental Quality, 
38(2), 402-417. https://doi.org/I 0.2134/jeq2008.0108

Vicca, S., Luyssaert, S., Peñuelas, J., Campioli, M., Chapin, F. S., Ciais, P., ... Janssens, I.A. (2012). Fertile forests produce biomass more efficiently. Ecology Letters, I5(6). https://doi.org/ I0. I I I I/j. I 46I-0248.20I 2.01775.x

Viechtbauer, W. (2010). Conducting meta-analyses in R with the metafor package. Journal of Statistical Software, $36(3), 1-48$.

Viechtbauer,W. (2017). Package "metafor"- Meta-Analysis Package for R. Retrieved from https://cran.r-project.org/ web/packages/metafor/metafor.pdf

Viechtbauer,W., Antonio Lopez-Lopez, J., Sanchez-Meca, J., \& Marin-Martinez, F. (2015).A comparison of procedures to test for moderators in mixed-effects meta-regression models. Psychological Methods, 20(3), 360-74. https://doi.org/10.1037/met0000023

Vitousek, P. M., Naylor, R., Crews, T., David, M. B., Drinkwater, L. E., Holland, E., ... Zhang, F. S. (2009). Nutrient imbalances in agricultural development. Science, 324(5934), 15/9-1520. https://doi.org//0.1/26/ science. $117026 \mid$

Vitousek, P. M., Aber, J. J. D., Howarth, R. W., Likens, G. E., Matson, P. A., Schindler, D. W., .. Tilman, D. G. (1997). Human alteration of the global nitrogen cycle: Sources and consequences. Ecological Applications, 7(3), 737-750. https://doi.org/I0.1890/I05I-076I(1997)007[0737:HAOTGN]2.0.CO;2

Vitousek, P. M., \& Howarth, R. W. (1991). Nitrogen limitation on land and in the sea: How can it occur? Biogeochemistry, I3(2), 87-I I5. https://doi.org//0.1007/BF00002772

Vitousek, P. M., Menge, D. N. L., Reed, S. C., \& Cleveland, C. C. (2013). Biological nitrogen fixation: Rates, patterns and ecological controls in terrestrial ecosystems. Philosophical Transactions of the Royal Society B: Biological Sciences, 368(I62I). https://doi.org/I0.1098/rstb.2013.0119

Vitousek, P. M, Walker, L. R., Whiteaker, L. D., \& Matson, P. A. (1993). Nutrient Limitations to Plant Growth during Primary Succession in Hawaii Volcanoes National Park. Biogeochemistry, 23(3), 197-215. https://doi. org// 0.2307// 469046

Wang, R., Goll, D., Balkanski,Y., Hauglustaine, D., Boucher, O., Ciais, P., ... Tao, S. (20I7). Global forest carbon uptake due to nitrogen and phosphorus deposition from 1850 to 2100. Global Change Biology, 23(II), 4854-4872. https://doi.org/I0.1 II I/gcb.13766

Wang, X., Feng, A., Wang, Q., Wu, C., Liu, Z., Ma, Z., \& Wei, X. (2014). Spatial variability of the nutrient balance and related NPSP risk analysis for agro-ecosystems in China in 2010. Agriculture, Ecosystems and Environment, 193, 42-52. https://doi.org//0.1016/j.agee.2014.04.027

Wang,Y.P., Law, R. M., \& Pak, B. (2010).A global model of carbon, nitrogen and phosphorus cycles for the terrestrial biosphere. Biogeosciences, 7(7), 226I-2282. https://doi.org/I0.5I94/bg-7-226I-2010

Wang, Y. P., \& Houlton, B. Z. (2009). Nitrogen constraints on terrestrial carbon uptake: Implications for the global carbon-climate feedback. Geophysical Research Letters, 36(24). https://doi.org// 0.1029/2009GL04I009

Ward, M. H., Jones, R. R., Brender, J. D., de Kok, T. M., Weyer, P. J., Nolan, B. T., ... van Breda, S. G. (2018). Drinking water nitrate and human health: An updated review. International Journal of Environmental Research and Public Health, 15(7), I557. https://doi.org/ /0.3390/ijerph I507/557

Waters, C. N., Zalasiewicz, J., Summerhayes, C., Barnosky, A. D., Poirier, C., Gałuszka, A., ... Wolfe, A. P. (2016). The Anthropocene is functionally and stratigraphically distinct from the Holocene. Science, 35I (6269). https://doi. org// $0.1126 /$ science.aad2622

Webb, J., Sørensen, P., Velthof, G., Amon, B., Pinto, M., Rodhe, L., ... Reid, J. (2013). An Assessment of the Variation of Manure Nitrogen Efficiency throughout Europe and an Appraisal of Means to Increase Manure-N Efficiency. In Advances in Agronomy (Vol. I 19, pp. 37/-442). Academic Press Inc. https://doi.org/10.1016/B978-0-12407247-3.00007-X

Westhoek, H. J., Rood, G. A., Berg, M. Van Den, \& Janse, J. H. (20I I). The Protein Puzzle :The Consumption and Production of Meat , Dairy and Fish in the European Union. European Journal of Food Research \& Review, I(3), 123-I44.

Westhoek, H. J., Lesschen, J. P., Rood, T., Wagner, S., De Marco, A., Murphy-Bokern, D., ... Oenema, O. (2014). Food choices, health and environment: Effects of cutting Europe's meat and dairy intake. Global Environmental Change, 26(I), 196-205. https://doi.org/I0.1016/j.gloenvcha.2014.02.004 
WHO. (20II). Nitrate and nitrite in drinking-water. Background document for development of WHO Guidelines for Drinking-water Quality. Report No.WHO/SDE/WSH/07.0I//6/Rev/I. Geneva. Retrieved from http:// www.who.int/water_sanitation_health/dwq/chemicals/nitratenitrite2ndadd.pdf

Wieder,W. R., Allison, S. D., Davidson, E.A., Georgiou, K., Hararuk, O., He,Y., ... Xu, X. (2015). Explicitly representing soil microbial processes in Earth system models. Global Biogeochemical Cycles, 29(10), 1782-1800. https:// doi.org//0.1002/2015GB005/88

Willett, W., Rockström, J., Loken, B., Springmann, M., Lang, T., Vermeulen, S., ... Murray, C. J. L. (2019). Food in the Anthropocene: the EAT-Lancet Commission on healthy diets from sustainable food systems. The Lancet, 393(10170), 447-492. https://doi.org/10.1016/50140-6736(18)31788-4

World Bank. (2020). Population, total. Retrieved July 30, 2020, from https://data.worldbank.org/indicator/SP.POP. TOTL? view=chart

Wright, S. J., Yavitt, J. B., Wurzburger, N., Turner, B. L., Tanner, E. V. J., Sayer, E. J., ... Corre, M. D. (20I I). Potassium, phosphorus, or nitrogen limit root allocation, tree growth, or litter production in a lowland tropical forest. Ecology, 92(8), 1616-1625. https://doi.org//0.1890//0-1558.1

Xia, J., \& Wan, S. (2008). Global response patterns of terrestrial plant species to nitrogen addition. New Phytologist, 179(2), 428-439. https://doi.org/I0.1 I I //j. 1469-8I37.2008.02488.x

Yahdjian, L., Gherardi, L., \& Sala, O. E. (20II). Nitrogen limitation in arid-subhumid ecosystems: A metaanalysis of fertilization studies. Journal of Arid Environments, 75(8), 675-680. https://doi.org//0.1016/j. jaridenv.20II.03.003

Yu, C. Q., Huang, X., Chen, H., Godfray, H. C. J., Wright, J. S., Hall, J.W., ... Taylor, J. (2019). Managing nitrogen to restore water quality in China. Nature, 567(7749), 516-520. https://doi.org//0.1038/s4I586-019-100I-I

Yuan, Z.Y., \& Chen, H.Y. H. (2015). Decoupling of nitrogen and phosphorus in terrestrial plants associated with global changes. Nature Climate Change, 5(5), 465-469. https://doi.org/I 0. I038/nclimate2549

Zaehle, S. (2013). Terrestrial nitrogen-carbon cycle interactions at the global scale. Philosophical Transactions of the Royal Society B: Biological Sciences, 368(162I). https://doi.org/10.1098/rstb.2013.0125

Zaehle, S., Ciais, P., Friend, A. D., \& Prieur, V. (20II). Carbon benefits of anthropogenic reactive nitrogen offset by nitrous oxide emissions. Nature Geoscience, 4(9), 60 I-605. https://doi.org/I 0. I038/ngeo 207

Zhang, L., Dawes, W. R., \& Walker, G. R. (200I). Response of mean annual evapotranspiration to vegetation changes at catchment scale. Water Resources Research, 37(3), 70I-708. https://doi.org/https://doi. org/ I0.1029/2000WR900325

Zhang, L., Jacob, D. J., Knipping, E. M., Kumar, N., Munger, J. W., Carouge, C. C., ... Chen, D. (2012). Nitrogen deposition to the United States: Distribution, sources, and processes. Atmospheric Chemistry and Physics, I2(I0), 4539-4554. https://doi.org//0.5194/acp-12-4539-20I2

Zhang, X., Davidson, E. A., Zou, T., Lassaletta, L., Quan, Z., Li, T., \& Zhang, W. (2020). Quantifying Nutrient Budgets for Sustainable Nutrient Management. Global Biogeochemical Cycles, 34(3). https://doi. org/ $10.1029 / 2018 \mathrm{~GB} 006060$

Zhang, X., \& Davidson, E. A, (2019). Sustainable Nitrogen Management Index. Earth and Space Science Open Archive. https://doi.org/I0.1002/essoar.1050IIII.I

Zhang, X., Davidson, E. A., Mauzerall, D. L., Searchinger, T. D., Dumas, P., \& Shen, Y. (2015). Managing nitrogen for sustainable development. Nature, 528(7580), 5 I-59. https://doi.org/ / 0. 1038/nature I5743

Zhang,Y., Zhou, Y., Shao, Q., Liu, H., Lei, Q., Zhai, X., Wang, X. (2016). Diffuse nutrient losses and the impact factors determining their regional differences in four catchments from North to South China. Journal of Hydrology, 543, 577-594. https://doi.org/10.1016/j.jhydrol.2016.10.031

Zhou, L., Zhou, X., Zhang, B., Lu, M., Luo, Y., Liu, L., \& Li, B. (2014). Different responses of soil respiration and its components to nitrogen addition among biomes: a meta-analysis. Global Change Biology, 20(7), 2332-2343. https://doi.org/ I0.1 I I I/gcb. 12490

Zhu, J., He, N., Zhang, J., Wang, Q., Zhao, N., Jia, Y., ... Yu, G. (2017). Estimation of carbon sequestration in China's forests induced by atmospheric wet nitrogen deposition using the principles of ecological stoichiometry. Environmental Research Letters, I2(II). https://doi.org/10.1088/I748-9326/aa94a4 

Supplementary
Material 



\section{Supplementary Material Chapter 2}

Supplementary Methods

S2.I. Calculation of spatially explicit nitrogen manure and nitrogen fertilizer application rates and nitrogen uptake

S2.2. Calculation of spatially explicit nitrogen losses to air and water

S2.3. Back-calculation of critical nitrogen inputs and nitrogen losses

Supplementary Tables S2. I-S2.6

228

Supplementary Figures S2.I-S2.8

234

\section{S2.I. Calculation of spatially explicit nitrogen manure and nitrogen fertilizer application rates and nitrogen uptake}

\section{S2.I.I. Nitrogen fertilizer inputs}

Nitrogen fertilizer inputs at NCU level were derived by a balanced $\mathrm{N}$ fertilization approach, based on the total crop $\mathrm{N}$ demand, the available non-fertilizer $\mathrm{N}$ inputs (i.e., $\mathrm{N}$ inputs by manure, biosolids, crop residues, $\mathrm{N}$ mineralization, $\mathrm{N}$ deposition and $\mathrm{N}$ fixation) and the $\mathrm{N}$ use efficiency (NUE) of the effective $\mathrm{N}$ input. The fertilizer inputs thus derived were scaled to national fertilizer consumption rates from FAOSTAT by multiplying the values with the ratio of FAO country data and the aggregated country level data. The results thus obtained were compared with $\mathrm{N}$ fertilizer input data at crop and country level by Fertilizers Europe for the reference year (2010). These data were derived from expert judgments by country experts, combining country $\mathrm{N}$ production figures with country information on relative use per crop.

For the balanced $\mathrm{N}$ fertilization approach, first total $\mathrm{N}$ demand of each crop is calculated as the sum of $\mathrm{N}$ in harvested products and in $\mathrm{N}$ crop residues:

$$
N_{u p}=N_{o f f} *\left(1+\frac{1}{N_{\text {index }}}\right)
$$


Where:

$N_{u p} \quad=\quad$ Total plant $\mathrm{N}$ uptake (above- and belowground parts) $\left(\mathrm{kg} \mathrm{N} \mathrm{ha}^{-1} \mathrm{yr}^{-1}\right)$

$N_{\text {off }} \quad=\mathrm{N}$ removed in harvested crops $\left(\mathrm{kg} \mathrm{N} \mathrm{ha}^{-1} \mathrm{yr}^{-1}\right)$

$N_{\text {index }}=\mathrm{N}$ removed in harvested crop divided by $\mathrm{N}$ amount in crop residues; $\left(\mathrm{N}_{\text {off }} / \mathrm{N}_{\text {cr }}\right)(-)$

The $\mathrm{N}$ offtake in harvested crops is calculated by multiplying crop yield (in terms of harvest) with crop N content:

$$
N_{\text {off }}=\text { Yield } * N_{\text {cont }}
$$

Where:

$$
\begin{aligned}
\text { Yield } & =\text { dry matter yield }\left(\mathrm{kg} \mathrm{DM} \mathrm{ha}^{-1} \mathrm{yr}^{-1}\right) \\
N_{\text {cont }} & =\text { crop } \mathrm{N} \text { content }\left(\mathrm{g} \mathrm{N} \mathrm{kg} \mathrm{DM}^{-1}\right)
\end{aligned}
$$

The $\mathrm{N}$ content, in turn, is a function of the effective $\mathrm{N}$ input, according to:

$$
N_{\text {cont }}=f r N_{\text {min }} * N_{\text {cont }, \text { max }}+\frac{\left(1-f r N_{\min }\right) * N_{\text {cont }, \max }}{N_{\text {in,eff }, \max }} * N_{\text {in, eff }}
$$

Where:

$$
\begin{aligned}
f r N_{\text {min }}= & \text { a fraction being equal to the ratio of the minimum/maximum crop } \mathrm{N} \text { content }(-) \\
N_{\text {cont, max }}= & \text { maximum crop } \mathrm{N} \text { content }\left(\mathrm{g} \mathrm{N} \mathrm{kg} \mathrm{DM}^{-1}\right) \\
N_{\text {in,eff,max }}= & \text { maximum effective } \mathrm{N} \text { input, being the effective } \mathrm{N} \text { input where the content in the } \\
& \text { crop is at is maximum and does not increase anymore }\left(\mathrm{kg} \mathrm{N} \mathrm{ha}^{-1} \mathrm{yr}^{-1}\right)
\end{aligned}
$$

The minimum $\mathrm{N}$ content, i.e. the content at negligible effective $\mathrm{N}$ input $\left(N_{\text {in,eff }}\right)$ has been set at 0 , as on the the long term, $\mathrm{N}$ uptake is negligible at no $\mathrm{N}$ fertilizer input (Lassaletta et al., 2014a). In reality, this is due to combination of effects of reduced $\mathrm{N}$ inputs on both crop yields and $\mathrm{N}$ contents, which we include in the $\mathrm{N}$ content only. This implies that $f r N_{\min }$ is set to 0 and Eq. (S2.1.3) thus simplifies to:

$$
N_{\text {cont }}=\frac{N_{\text {cont }, \max }}{N_{\text {in,eff,max }}} * N_{\text {in,eff }}
$$

The maximum effective $\mathrm{N}$ input is calculated as a function of the maximum $\mathrm{N}$ offtake (defined as yield times maximum $\mathrm{N}$ content) and uptake efficiency, according to:

$$
N_{\text {in,eff, max }}=\frac{\left(\text { Yield } * N_{\text {cont }, \text { max }}\right) *\left(1+\frac{1}{N_{\text {index }}}\right)}{f r N_{u p}}
$$

Where:

$f r N_{u p} \quad=$ efficiency factor of the effective $\mathrm{N}$ applied (-) 
The effective $\mathrm{N}$ input (total amount of plant-available $\mathrm{N}$ ) is calculated by distinguishing between organic nitrogen inputs by animal manure, crop residues and $\mathrm{N}$ mineralization, and more readily available nitrogen inputs (mineral $\mathrm{N}$ ) from animal manure, $\mathrm{N}$ deposition and $\mathrm{N}$ fixation, according to:

$$
\begin{aligned}
& N_{\text {in }, e f f}=N_{f e}+N_{\text {min }, a m}+f_{a v, a m} * N_{o r g, a m}+N_{\text {min }, g r}+f_{a v, g r} * N_{o r g, g r}+f_{a v, b s} * \\
& N_{b s}+f_{a v, c r} * N_{c r}+f_{a v, \text { min }} * N_{\text {min }}+f_{a v, d e p} * N_{d e p}+N_{f i x}-N_{e m, a p}
\end{aligned}
$$

Where:

$$
\begin{aligned}
& N_{f e} \quad=\text { Input of } \mathrm{N} \text { by fertilizer }\left(\mathrm{kg} \mathrm{N} \mathrm{ha}^{-1} \mathrm{yr}^{-1}\right) \\
& N_{\text {min,am }}=\text { Input of mineral (inorganic) } \mathrm{N} \text { in applied animal manure }\left(\mathrm{kg} \mathrm{N} \mathrm{ha}^{-1} \mathrm{yr}^{-1}\right) \\
& N_{\text {org,am }}=\text { Input of organic } \mathrm{N} \text { in applied animal manure }\left(\mathrm{kg} \mathrm{N} \mathrm{ha}^{-1} \mathrm{yr}^{-1}\right) \\
& N_{\text {min,gr }} \quad=\text { Input of mineral (inorganic) } \mathrm{N} \text { in manure excreted by grazing }\left(\mathrm{kg} \mathrm{N} \mathrm{ha}^{-1} \mathrm{yr}^{-1}\right) \\
& N_{\text {org.gr }}=\text { Input of organic } \mathrm{N} \text { in manure excreted by grazing }\left(\mathrm{kg} \mathrm{N} \mathrm{ha}^{-1} \mathrm{yr}^{-1}\right) \\
& N_{b s} \quad=\text { Input of } \mathrm{N} \text { by biosolids }\left(\mathrm{kg} \mathrm{N} \mathrm{ha}^{-1} \mathrm{yr}^{-1}\right) \\
& N_{c r} \quad=\mathrm{N} \text { mineralized from crop residues }\left(\mathrm{kg} \mathrm{N} \mathrm{ha}^{-1} \mathrm{yr}^{-1}\right) \\
& N_{\min } \quad=\mathrm{N} \text { mineralized from soil organic matter (change in soil } \mathrm{N} \text { pool, which is only } \\
& \text { included for peat soils) ( } \left.\mathrm{kg} \mathrm{N} \mathrm{ha}^{-1} \mathrm{yr}^{-1}\right) \\
& N_{\text {dep }} \quad=\text { Input of } \mathrm{N} \text { by deposition }\left(\mathrm{kg} \mathrm{N} \mathrm{ha}^{-1} \mathrm{yr}^{-1}\right) \\
& N_{f i x} \quad=\text { Input of } \mathrm{N} \text { by fixation }\left(\mathrm{kg} \mathrm{N} \mathrm{ha}^{-1} \mathrm{yr}^{-1}\right) \\
& N_{\text {em,ap }}=\text { Emission of } \mathrm{N} \text { due to application of } \mathrm{N} \text { by fertilizer, manure, grazing, biosolids } \\
& \left(\mathrm{NH}_{3}, \mathrm{~N}_{2} \mathrm{O} \text { and } \mathrm{NO}_{\mathrm{x}}\right) \text {, fixation and deposition }\left(\mathrm{N}_{2} \mathrm{O} \text { and } \mathrm{NO}_{\mathrm{x}} \text { only) }\left(\mathrm{kg} \mathrm{N} \mathrm{ha}^{-1} \mathrm{yr}^{-1}\right)\right. \\
& f_{a v, a m}=\text { Availability fraction of organic } \mathrm{N} \text { in applied manure compared to } \mathrm{N} \text { fertilizer (-) } \\
& f_{a v, g r}=\text { Availability fraction of organic } \mathrm{N} \text { in manure excreted by grazing animals compared } \\
& \text { to } \mathrm{N} \text { fertilizer (-) } \\
& f_{a v, b s}=\text { Availability fraction of } \mathrm{N} \text { in biosolids compared to } \mathrm{N} \text { fertilizer (-) } \\
& f_{a v, c r}=\text { Availability fraction of } \mathrm{N} \text { in crop residues compared to } \mathrm{N} \text { fertilizer (-) } \\
& f_{a v, \text { min }}=\text { Availability fraction of } \mathrm{N} \text { mineralized from soil compared to } \mathrm{N} \text { fertilizer (-) } \\
& f_{\text {avdep }}=\text { Availability fraction of } \mathrm{N} \text { deposition compared to } \mathrm{N} \text { fertilizer (-) }
\end{aligned}
$$

Total $\mathrm{N}$ in applied animal manure was distributed over an inorganic fraction $\left(N_{\text {min,am }}\right)$ and an organic fraction $\left(N_{\text {orgam }}\right)$, based on the ratio of total ammonium $\mathrm{N}$ (TAN) to total $\mathrm{N}$ content in manure and slurry as derived in the RAMIRAN network $\left(f_{\text {TAN }}\right.$; Menzi, 2002). Values for $\mathrm{f}_{\text {TAN }}$ for liquid manure/slurry were set to:

- liquid manure/slurry: 0.58 (cattle), 0.71 (pig) and 0.47 (poultry),

- $\quad$ solid manure: 0.27 (cattle), 0.32 (pig) and 0.28 (poultry).

The $\mathrm{N}$ in crop residues is calculated by dividing $\mathrm{N}$ offtake by an $\mathrm{N}$ index, calculated as $\mathrm{N}$ offtake divided by $\mathrm{N}$ crop residue $\left(N_{\text {index }}=N_{\text {off }} / N_{c r}\right)$. Mineral $\mathrm{N}$ from both fertilizer and manure was assumed fully available. Availability fractions for organic $\mathrm{N}$ sources and $\mathrm{N}$ 
deposition were set to:

- $\quad$ organic $\mathrm{N}$ in animal manure and mineralized $\mathrm{N}$ from (peat) soil: $f_{a v, a m}$ and $f_{a v, \min }$ are 0.7 for arable land and 0.9 for grassland

- $\quad$ organic $\mathrm{N}$ from grazing and $\mathrm{N}$ from biosolids: $f_{a v, g r}$ and $f_{a v, b s}$ are 0.4 .

- organic $\mathrm{N}$ from crop residues: $f_{a v, c r}$ is 0.9

- $\quad \mathrm{N}$ from deposition: $f_{\text {av, dep }}$ is 0.75 .

$\mathrm{N}$ fertilizer input is finally derived by subtracting the effective non-fertilizer $\mathrm{N}$ input from the crop $\mathrm{N}$ demand according to:

$$
\begin{aligned}
& N_{f e}=\frac{N_{u p}}{f r_{N u p}}-\left(N_{\text {min }, a m}+f_{a v, a m} * N_{o r g, a m}+N_{\text {min }, g r}+f_{a v, g r} * N_{o r g, g r}+f_{a v, b s} *\right. \\
& \left.N_{b s}+f_{a v, c r} * N_{c r}+f_{a v, \min } * N_{\text {min }}+f_{a v, d e p} * N_{d e p}+N_{f i x}-N_{e m, a p}\right)
\end{aligned}
$$

Initially, a maximum $\mathrm{N}$ content $\left(N_{\text {cont,max }}\right)$ is used to assess $N_{f e}$. Fertilizer input estimates for each location (NCU) are then aggregated at country-level and the resulting national fertilizer application rates are compared with country-level $\mathrm{N}$ fertilizer consumption from FAOSTAT. Finally, the fertilizer $\mathrm{N}$ input at NCU level are scaled (multiplied) with the ratio of the national $\mathrm{N}$ fertilizer consumption from FAOSTAT and the aggregated calculated countrylevel $\mathrm{N}$ fertilizer consumption based on the balanced $\mathrm{N}$ fertilization approach.

Input data to assess $\mathrm{N}$ uptake: Input data to assess $\mathrm{N}$ uptake include maximum $\mathrm{N}$ contents in harvested products, crop residue ratios and uptake fractions. The maximum $\mathrm{N}$ content in (intensively managed) grassland was set to $3 \%$. Nitrogen contents of crop products and the $\mathrm{N}$ index and $\mathrm{C} / \mathrm{N}$ ratio of crop residues were based on a literature review by Velthof \& Kuikman (2000) (Table S2.3). Results presented in Table S2.3 were derived from Dutch studies of the nineties. The uptake efficiency $\left(f r_{\text {Nup }}\right)$ was set to 0.8 for arable land and to 1.0 for grassland (Velthof et al., 2009).

\section{S2.I.2. Nitrogen excretion and nitrogen manure inputs}

Total manure production was calculated at NCU level from N excretion, correcting for losses (gaseous emissions and leaching) in housing and manure storage systems (see Table 3.1 in main text). Statistical data on livestock numbers for various animal categories at NUTS2 level were downscaled to $1 \mathrm{x} 1 \mathrm{~km}^{2}$ resolution using expert judgment combined with data on land use, slope, altitude and soil characteristics influencing livestock carrying capacity (see Neumann et al., 2009, for more details on the approach). Livestock numbers thus derived were aggregated to NCU level, and total $\mathrm{N}$ excreted was calculated by multiplying animal numbers with country-specific $\mathrm{N}$ excretion rates from Asman et al. (2011) for 8 animal 
categories (see Table S2.1). Total N excreted was then divided over excretion of animals in housing systems and by grazing animals in pastures, based on country-level data on the number of grazing days (Klimont and Brink, 2004).

Manure $\mathrm{N}$ excreted by grazing animals all enters grassland. Manure $\mathrm{N}$ excreted in housing systems was distributed over arable land and grassland (after subtracting $\mathrm{N}$ emissions and leaching from housing and manure storage systems). Manure produced in housing systems by sheep and goats was completely applied to grassland. For other manure, a fraction was applied to arable land and the remaining fraction was applied to grassland/fodder crops, based on data of Menzi (2002) and distinguishing three types of manure (see Table S2.2).

For the distribution of manure application on arable land, three crop groups were distinguished: group I with a high use of manure (sugar beet, barley, rape, and soft wheat), group II with an intermediate use of manure (potatoes, durum wheat, rye, oats, grain maize, other cereals including triticale, and sunflower), and group III with low use of manure (fruits, citrus, olives, oil crops, citrus, grapes and other crops). No manure was allocated to dry pulses and rice, fibre crops, other root crops and vegetables. First, the average manure application rate (in $\mathrm{kg} \mathrm{N} \mathrm{ha}^{-1}$ ) over all arable crops was calculated. The application rate ( $\left.\mathrm{kg} \mathrm{N} \mathrm{ha}^{-1}\right)$ for the three arable crop groups was then assessed by using weighing factors of 1.0 for group I, 0.5 for group II and 0.25 for group III, based on Velthof et al. (2009). For the distribution of manure application on grassland, we distinguished intensive grassland (including fodder), extensive grassland and rough grazing, using weighing factors of 1.0, 0.5 and 0.12 , respectively. The parameterization of weighing factors was based on comparison of calculated $\mathrm{N}$ fertilizer input data per crop per country with those estimated by country experts of Fertilizers Europe for the reference year 2010 .

Maximum $\mathrm{N}$ manure application rates were set to $170 \mathrm{~kg} \mathrm{~N} \mathrm{ha}^{-1} \mathrm{yr}^{-1}$ for both arable land and grassland, except for Denmark and the Netherland where the acceptable amounts for grassland and fodder is $250 \mathrm{~kg} \mathrm{~N} \mathrm{ha}^{-1} \mathrm{yr}^{-1}$. If $\mathrm{N}$ manure application based on the distribution approach described above exceeds these amounts, excess manure was distributed over nearby NCUs within a NUTS region, or over nearby NUTS regions within a country if application rates were still exceeded. Manure was distributed over NCUs (and NUTS) regions using an inverse distance method with closer NCUs receiving relatively more manure (the weighted centre of an NCU is used for the distance calculations). Excess manure on grassland was first distributed over grassland in neighbouring NCUs (NUTS regions), and only on arable land if maximum application rates in the receiving NCU (NUTS region) were also exceeded (and vice versa). No manure transport between countries was assumed. 


\section{S2.I.3. Nitrogen biosolid inputs}

Nitrogen inputs by biosolids (being the sum of inputs of sludge and compost) were first

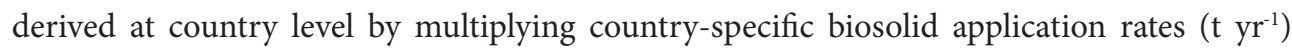
with $\mathrm{N}$ contents in biosolids $\left(\mathrm{g} \mathrm{kg}^{-1}\right.$, equivalent to $\mathrm{kg} \mathrm{t}^{-1}$ ). As biosolid inputs are derived from national application data, results were downscaled to NCU level using the distribution of manure $\mathrm{N}$ inputs as scaling factors. Country-level data on production and application rates for sludge were based on data compiled by Milieu Ltd (2009). Country-level data on total compost production and the percentage of compost applied in agriculture (on average 48 $\%$ in EU) were taken from Barth et al. (2008), while distinguishing between green waste compost (organic waste from gardens and parks), bio-waste compost (a mixture of kitchen and garden waste), and mixed waste compost (compost derived from refuse). Data on the $\mathrm{N}$ content of compost and sludge were based on the Working Document Sludge and Biowaste (EC, 2010), a screening of various national databases and information from composting organizations (e.g. VLACO, Attero) from the period 2000-2014. In the calculations, national data were used for sludge $\mathrm{N}$ contents, whereas EU-wide median values were used for the $\mathrm{N}$ content in each type of compost.

\section{S2.I.4. Nitrogen offtake}

$\mathrm{N}$ offtake is calculated as the product of crop yield and $\mathrm{N}$ content in the harvested product. National yields per crop were derived from FAOSTAT (www.faostat.org; average of years 2008-2012). Sub-national variation in actual crop yields in INTEGRATOR was derived based on sub-national wheat yields from the Global Yield Gap Atlas (GYGA) for 25 EU countries. GYGA provides estimates of actual yields for a variety of staple crops at sub-country (regional) level (for zones of similar climate). These sub-national estimates of actual yields are multi-year average yields obtained by farmers under dominant management practices, and are gathered from sub-national statistics, farm surveys and/or local agronomists. We used sub-national variation in rainfed wheat yields from GYGA for $25 \mathrm{EU}$ countries to estimate sub-national variation in yields for all INTEGRATOR crops, assuming that: (i) the relative differences in rainfed wheat yields also reflect differences in yields of other crops and (ii) the total national crop yield should be equal to the yield estimate from FAOSTAT. According to the first assumption, actual crop yields per climate zone were calculated as:

$$
Y a \_p_{\text {crop }_{n}, c z_{i j}}=Y a_{\text {crop }_{n}, c o_{j}} * \frac{Y a_{w_{\text {heat }, c z_{i j}}}}{Y a_{\text {wheat }, c o_{j}}}
$$

Where:

$\begin{aligned} Y a_{-} p, c r o p_{n}, c z_{i j}= & \text { preliminary scaled actual yield of crop } \mathrm{n} \text { for climate zone } \mathrm{i} \text { in country } \mathrm{j}\left(\mathrm{kg} \mathrm{ha}^{-1}\right. \\ & \left.\mathrm{yr}^{-1}\right) \\ Y a, c r o p_{n}, c o_{j}= & \text { average actual crop yield for country } \mathrm{j} \text { from FAOSTAT (data in INTEGRATOR) }\end{aligned}$ 


\begin{abstract}
$\left(\mathrm{kg} \mathrm{ha}^{-1} \mathrm{yr}^{-1}\right)$
$Y a$, wheat, $c z_{i j}=$ actual wheat yield for climate zone $\mathrm{i}$ in country $\mathrm{j}$ from GYGA $\left(\mathrm{kg} \mathrm{ha}^{-1} \mathrm{yr}^{-1}\right)$

$\mathrm{Ya}$, wheatco ${ }_{j} \quad=$ area-weighted average actual wheat yield for country j from GYGA $\left(\mathrm{kg} \mathrm{ha}^{-1} \mathrm{yr}^{-1}\right)$
\end{abstract}

Preliminary sub-national yields derived with Eq. (S2.1.8) were then corrected to ensure that the total national crop production after scaling remains equal to FAOSTAT national crop production:

$$
Y a_{c r o p}, c z_{i j}=Y a_{-} p_{c r o p_{n}, c z_{i j}} * \frac{Y a_{\text {crop }_{n}, c o_{j}} * A_{\text {crop }_{n}, c o_{j}}}{\sum\left(Y a_{-} p_{c r o p_{n}, c z_{i j}} * A_{c r o p}, c z_{i j}\right)}
$$

Where:

$$
\begin{aligned}
Y a, c r o p_{n}, c z_{i j}= & \text { the final scaled actual yield of crop } \mathrm{n} \text { for climate zone } \mathrm{i} \text { in country } \mathrm{j}\left(\mathrm{kg} \mathrm{ha}^{-1} \mathrm{yr}^{-1}\right) \\
A, c r o p_{n}, c z_{i j}= & \text { the crop area for crop } \mathrm{n} \text { in climate zone } \mathrm{i} \text { in country } \mathrm{j} \text {, derived by an overlay of } \\
& \text { climate zones in GYGA and crop areas per NCU in INTEGRATOR (based on } \\
& \text { Eurostat data for crop areas per NUTS region). (ha) } \\
A, c r o p_{n}, c o_{j}= & \text { the country-level crop area for crop } \mathrm{n} \text { in country } \mathrm{j} \text { in INTEGRATOR. (ha) }
\end{aligned}
$$

The area of arable land in INTEGRATOR is derived from the CLUE model and includes the CLUE categories non-irrigated arable land (1), irrigated arable land (6) and permanent crops (8). The area of each crop in NUTS 2 regions are derived from CAPRI, by using the CAPRI crop shares and multiplying these shares with the area of arable land as derived with CLUE. Crop areas are derived from the Lucas survey. Crop area of each NCU are then scaled by using data from Eurostat (derived from: http://ec.europa.eu/eurostat/data/database). For the scaling procedure, each NCU is assigned to a climate zone with available data on wheat yield (GYGA only provides actual wheat yields and yield potentials for climate zones containing more than $5 \%$ of the national crop area). The method for assigning a climate zone with wheat data to each NCU are presented in detail in De Vries et al. (2021a).

\title{
S2.2. Calculation of spatially explicit nitrogen losses to air and water
}

\section{S2.2.I. Ammonia emissions}

Figure S2.1 presents an overview of the calculation of $\mathrm{NH}_{3}$ emissions from animal manure (housing, storage, grazing, application) in INTEGRATOR. All ammonia emission fractions (EFs) are obtained from the GAINS model (Amann et al., 2011). All EFs are country-specific; manure emission fractions are further provided per animal category and manure type (liquid/solid). GAINS provides ammonia EFs for: 
- Manure deposited by grazing animals per country (not further distinguished by animal category). The average EF at EU level is $8 \%$, country-level EFs vary between 5 and $10 \%$.

- Manure in housing and manure storage systems per animal type (6 categories), further subdivided in manure type (liquid vs. solid) for dairy cows, other cows and pigs. For some countries, the basic EFs are modified based on assumptions on the implementation of low-emission manure storage or housing systems. For these countries, a new emission fraction is calculated based on the degree of implementation of emission-reducing technologies, and the reduction efficiency of the technology.

- Manure application per animal type (cattle, pigs and poultry) and manure types (liquid and solid manure; for cattle and pigs only). Manure application EFs are given per country, in view of differences in dominant manure application techniques.

- Fertilizer application per fertilizer type (urea-based fertilizers and nitrate-based fertilizers). The average EF is 15\% (range: 12-20\%) for urea-based fertilizers and 3\% (range: 1-7\%) for nitrate based fertilizers. Nitrate-based fertilizers are dominant in almost all countries, and therefore the average emission fraction for fertilizer application at EU-level is $4 \%$.

Details on used EFs per country in combination with variations in housing systems, manure application techniques and fertilizer types are given in De Vries et al (2021a).

\section{S2.2.2. Nitrogen leaching and runoff}

Leaching and runoff in INTEGRATOR is distinguished in (i) N leaching from manure in housing and/or manure storage systems (ii) $\mathrm{N}$ surface runoff, (iii) $\mathrm{N}$ leaching to surface water or sub-surface runoff and (iv) N leaching to groundwater; as illustrated in Figure S2.2. Nitrogen leaching from housing and manure storage systems is calculated as a fraction of $\mathrm{N}$ excreted in housing systems $\left(f_{l e, h s}\right.$, which is a function of the type of animal, manure and housing system). $\mathrm{N}$ leached from housing and storage systems is added to the $\mathrm{N}$ surplus in the soil system. The $\mathrm{N}$ surplus is divided over leaching below the root zone $\left[f_{l}\right]$ and denitrification $\left[1-f_{l}\right]$. N leached below the root zone is further divided between sub-surface runoff to surface water $\left[f_{r o}\right]$ and leaching to deep groundwater $\left[1-f_{r o}\right]$. Surface runoff is calculated as a fraction of $\mathrm{N}$ inputs to soil from grazing, manure application and fertilizer $\left[f_{s r}\right]$. Surface runoff and sub-surface runoff are added up to obtain total $\mathrm{N}$ runoff to surface water.

\section{Leaching from stored manure}

Leaching of $\mathrm{N}$ from manure in housing and/or manure storage systems is calculated as a fraction of the amount of $\mathrm{N}$ excreted and stored in those systems according to: 


$$
N_{l e, h s}=f_{l e, h s} * N_{h s}
$$

Where:

$N_{h s} \quad=\quad \mathrm{N}$ excreted and stored in housing and manure storage systems $\left(\mathrm{kg} \mathrm{N} \mathrm{Na}^{-1} \mathrm{yr}^{-1}\right)$

$f_{l e, h s} \quad=$ Leaching fraction for $\mathrm{N}$ in housing and manure storage systems (-)

$\mathrm{N}$ leaching fractions for housing and manure storage systems, $f_{l e, h s}$ are based on expert judgement (Velthof et al., 2009).

\section{Surface runoff}

Surface runoff $\left(N_{s r}\right)$ is calculated as:

$$
N_{s r}=f_{s r} *\left(N_{f e}+N_{a m}+N_{b s}\right)
$$

Where:

$$
\begin{aligned}
& N_{f e} \quad=\quad \mathrm{N} \text { input by fertilizer }\left(\mathrm{kg} \mathrm{N} \mathrm{ha}^{-1} \mathrm{yr}^{-1}\right) \\
& N_{a m} \quad=\quad \mathrm{N} \text { input by manure application and excretion during grazing }\left(\mathrm{kg} \mathrm{N} \mathrm{ha}^{-1} \mathrm{yr}^{-1}\right) \\
& N_{b s} \quad=\mathrm{N} \text { input by biosolids }\left(\mathrm{kg} \mathrm{N} \mathrm{ha}^{-1} \mathrm{yr}^{-1}\right) \\
& f_{s r}=\text { Surface runoff fraction in } \% \text { of the } \mathrm{N} \text { applied via fertilizer, manure (including } \\
& \text { grazing) and biosolids }
\end{aligned}
$$

As with MITERRA-EUROPE, the value of $f_{s r}$ is calculated from a maximum surface runoff and a set of reduction fractions according to Velthof et al. (2009):

$$
f_{s r}=f_{\text {sr.max }} * f_{l u} * \min \left(f_{p}, f_{s}, f_{r c}\right)
$$

Where:

$$
\begin{array}{ll}
f_{s, \text { max }} & =\text { Maximum surface runoff fraction for different slope classes (-) } \\
f_{l u} & =\text { Reduction fraction for land use or crop (-) } \\
f_{p} & =\text { Reduction fraction for precipitation surplus (-) } \\
f_{s} & =\text { Reduction fraction for soil type }(-) \\
f_{r c} & =\text { Reduction fraction for depth to rock }(-)
\end{array}
$$

The maximum surface runoff fraction $\left(f_{s, \text { max }}\right)$ is determined as a function of slope:

- Level (dominant slope ranging from 0 to $8 \%$ ):

- Sloping (dominant slope ranging from 8 to $15 \%$ ):

- Moderately steep (dominant slope ranging from 15 to $25 \%$ ):

- $\quad$ Steep (dominant slope over $25 \%$ ):

$$
\begin{aligned}
& \mathrm{f}_{\mathrm{sr} \text { max }}=10 \% \\
& \mathrm{f}_{\mathrm{sr} \text { max }}=20 \% \\
& \mathrm{f}_{\mathrm{sr} \text { max }}=35 \% \\
& \mathrm{f}_{\mathrm{sr} \text { max }}=50 \%
\end{aligned}
$$

The reduction fraction for precipitation, $f_{p}$, is a function of precipitation surplus (PS): 
- PS > 300mm:

- PS 100-300 mm:

- PS 50-100 mm:

- $\mathrm{PS}<50 \mathrm{~mm}$ :

$$
\begin{aligned}
\mathrm{f}_{\mathrm{p}} & =1 \\
\mathrm{f}_{\mathrm{p}} & =0.75 \\
f_{p} & =0.50 \\
f_{p} & =0.25
\end{aligned}
$$

The reduction fraction for land use, $f_{l u}$, is 0.25 for grassland and 1.0 for cropland.

The reduction fraction for soil type, $f_{s}$, is included as a function of texture:

- Very fine (clay $\geq 60 \%)$ :

- Fine $(35 \% \leq$ clay $<60 \%)$ :

- $\operatorname{Medium~}(18 \% \leq$ clay $<35 \%)$ :

- Coarse $(18 \%<$ clay $)$ :

- Peat:

$$
\begin{aligned}
& f_{s}=1.0 \\
& f_{s}=0.90 \\
& f_{s}=0.75 \\
& f_{s}=0.25 \\
& f_{s}=0.25
\end{aligned}
$$

The reduction fraction for depth to rock, $\mathrm{f}_{\mathrm{rc}}$, is included as:

- For a depth of less than $25 \mathrm{~cm}$ : $f_{r c}=1.0$

- For a depth $>25 \mathrm{~cm}$ : $\quad f_{r c}=0.8$

\section{Soil nitrogen surplus, leaching below the root zone and denitrification}

The soil $\mathrm{N}$ surplus available for subsurface runoff, leaching and denitrification is calculated as:

$$
N_{s u r}=N_{\text {in }}-N_{u p}-N_{e m}-N_{s r}+N_{m i}+N_{c r}
$$

Where:

$$
\begin{aligned}
& N_{\text {sur }} \quad=\mathrm{N} \text { surplus available for subsurface runoff, leaching \& denitrification }\left(\mathrm{kg} \mathrm{N} \mathrm{ha}^{-1} \mathrm{yr}^{-1}\right) \\
& N_{i n} \quad=\text { Total } \mathrm{N} \text { input via fertilizer, manure application, grazing, biosolids, atmospheric } \\
& N_{u p} \quad=\text { Total } \mathrm{N} \text { uptake (both harvested crops and crop residues) }\left(\mathrm{kg} \mathrm{N} \mathrm{ha}^{-1} \mathrm{yr}^{-1}\right) \\
& N_{e m}=\text { Total } \mathrm{N}\left(\mathrm{NH}_{3}, \mathrm{~N}_{2} \mathrm{O}, \mathrm{NO}_{\mathrm{x}}\right) \text { emission from soil applied fertilizer, manure, grazing, } \\
& \text { atmospheric deposition and biological } \mathrm{N} \text { fixation }\left(\mathrm{kg} \mathrm{N} \mathrm{ha}^{-1} \mathrm{yr}^{-1}\right) \\
& N_{s r} \quad=\mathrm{N} \text { in surface runoff }\left(\mathrm{kg} \mathrm{N} \mathrm{ha}^{-1} \mathrm{yr}^{-1}\right) \\
& N_{m i} \quad=\text { Net } \mathrm{N} \text { mineralisation }\left(\mathrm{kg} \mathrm{N} \mathrm{ha}^{-1} \mathrm{yr}^{-1}\right) \\
& N_{c r} \quad=\mathrm{N} \text { input by crop residues }\left(\mathrm{kg} \mathrm{N} \mathrm{ha}^{-1} \mathrm{yr}^{-1}\right)
\end{aligned}
$$

Subsequently, $\mathrm{N}$ leaching below the root zone, including leaching to groundwater (also denoted as leaching) and leaching to surface water (also denoted as subsurface runoff), and denitrification are calculated as:

$$
N_{l e}=f_{l e} * N_{\text {sur }}
$$




$$
N_{d e}=\left(1-f_{l e}\right) * N_{\text {sur }}
$$

Where:

$$
\begin{array}{ll}
N_{l e} & =\mathrm{N} \text { leaching below the root zone }\left(\mathrm{kg} \mathrm{N} \mathrm{ha}^{-1} \mathrm{yr}^{-1}\right) \\
N_{d e} & =\mathrm{N} \text { emission (totally included as } \mathrm{N}_{2} \text { emission) by denitrification }\left(\mathrm{kg} \mathrm{N} \mathrm{ha}^{-1} \mathrm{yr}^{-1}\right) \\
f_{l e} & =\text { Leaching fraction of } \mathrm{N} \text { surplus from the rooting zone (-) }
\end{array}
$$

As with MITERRA-EUROPE, the value of fle is calculated from a maximum leaching fraction and a set of reduction fractions according to Velthof et al. (2009), where the fractions for land use and precipitation surplus have (slightly) been adapted:

$$
f_{l e}=f_{\text {le.max }} * f_{l u} * \min \left(f_{p}, f_{t}, f_{c}\right)
$$

- $f_{l, \text { max }}=$ Maximum leaching fraction for different soil types (-)

- $f_{l u} \quad=$ Reduction fraction for land use (-)

- $f_{p}=$ Reduction fraction for precipitation surplus (-)

- $f_{t}=$ Reduction fraction for temperature (-)

- $f_{c} \quad=$ Reduction fraction for soil organic carbon content (-)

The following soil type dependent maximum leaching fractions $\left(\mathrm{f}_{\mathrm{le}, \mathrm{max}}\right)$ are used:

- sandy soil: $f_{l, \max }=1.0$

- loamy soil: $f_{l e, \max }=0.75$

- clay soil: $\quad f_{l e, \max }=0.50$

- $\quad$ peat soil: $f_{l, \max }=0.20$

The reduction fraction for land use, $f_{l u}$, is 0.85 for grassland and 1.0 for cropland.

Denitrification increases and thus leaching decreases at lower precipitation surplus due to longer residence times allowing enhanced denitrification The reduction fraction for precipitation surplus, $f_{p}$, is slightly adapted from Velthof et al. (2009) and calculated as a continuous function based on soil type according to:

For sandy and loamy soils :

- $\quad \mathrm{PS}<50 \mathrm{~mm}$ :

$\mathrm{f}_{\mathrm{p}}=0.25$

- $50 \mathrm{~mm} \leq \mathrm{PS}<300 \mathrm{~mm}$ :

$\mathrm{f}_{\mathrm{p}}=1+(\mathrm{PS}-300)^{\star} 0.003$

- $\quad P S \geq 300 \mathrm{~mm}$ :

$\mathrm{f}_{\mathrm{p}}=1$

For peat and clay soils: 
- $\quad P S<50 \mathrm{~mm}$ : $\quad \mathrm{f}_{\mathrm{p}}=0.25$

- $50 \mathrm{~mm} \leq \mathrm{PS}<100 \mathrm{~mm}: \quad \mathrm{f}_{\mathrm{p}}=1+(\mathrm{PS}-100)^{\star} 0.015$

- $100 \mathrm{~mm} \leq \mathrm{PS}<300 \mathrm{~mm}: \mathrm{f}_{\mathrm{p}}=1$

- $300 \mathrm{~mm} \leq \mathrm{PS}<400 \mathrm{~mm}: \mathrm{f}_{\mathrm{p}}=1$-(PS-300)*0.005

- $\quad$ PS $\geq 400 \mathrm{~mm}: \quad \mathrm{f}_{\mathrm{p}}=0.5$

Denitrification increases with increasing temperature and thus leaching decreases. The following reduction fractions for temperature $\left(f_{t}\right)$ are used (assuming that denitrification at $15^{\circ} \mathrm{C}$ is twice as high as at $5^{\circ} \mathrm{C}$; a general effect of temperature on microbial activity):

- $\quad<5^{\circ} \mathrm{C}: \quad f_{t}=1$

- $5-15^{\circ} \mathrm{C}: \quad f_{t}=0.75$

- $\quad>15^{\circ} \mathrm{C}: \quad f_{t}=0.50$

Denitrification increases with increasing total soil organic carbon (SOC) content and thus leaching decreases. The following reduction fractions for SOC content $\left(f_{c}\right)$ are used:

- $\mathrm{SOC}<1 \%: f_{c}=1$

- $\quad$ SOC 1-2\%: $f_{c}=0.90$

- SOC 2-5\%: $f_{c}=0.75$

- $\mathrm{SOC}>5 \%$ : $f_{c}=0.50$

\section{Division of leaching over groundwater and surface water}

The division of $\mathrm{N}$ leaching below the root zone to leaching to groundwater (also denoted as leaching) and leaching to surface water (also denoted as subsurface runoff) is calculated as:

$$
\begin{aligned}
& N_{r o}=f_{r o} * N_{l e} \\
& N_{g w}=\left(1-f_{r o}\right) * N_{l e}
\end{aligned}
$$

Where:

$$
\begin{array}{ll}
N_{r o} & =\mathrm{N} \text { subsurface runoff flux towards surface water }\left(\mathrm{kg} \mathrm{N} \mathrm{ha}^{-1} \mathrm{yr}^{-1}\right) \\
N_{g w} & =\mathrm{N} \text { leaching flux towards ground water }\left(\mathrm{kg} \mathrm{N} \mathrm{ha}^{-1} \mathrm{yr}^{-1}\right) \\
f_{\text {ro }} & \text { Subsurface runoff fraction, being the fraction of leached N laterally transported to } \\
& \text { surface water. }
\end{array}
$$

The value of $f_{\text {ro }}$ is calculated as function of lithology, area above sea level and the occurrence of natural surface waters, derived from the IMAGE groundwater model, as described in Keuskamp et al. (2012). Total $\mathrm{N}$ influx to surface water is calculated as:

$$
N_{s w}=N_{s r}+N_{r o}
$$


Data on soil organic carbon (SOC) and clay contents were based on the joint WISE, SPADE 1 and EFSDB databases, which jointly contain approximately 3,600 soil profiles, irregularly distributed over Europe. Data at NCU level were derived with a multivariate regression kriging model accounting for the spatial structure of the soil properties and their dependency on explanatory variables such as soil type and land cover (Heuvelink et al., 2016).

\section{S2.2.3 Nitrogen concentrations in leaching to groundwater and in runoff to surface water}

\section{Nitrogen concentrations in leaching to groundwater}

The $\mathrm{NO}_{3}{ }^{-}$concentration in the leaching flux to groundwater is calculated as:

$$
[N O 3]_{g w}=\frac{N_{g w}}{Q_{g w}} * c F_{c N O 3}
$$

Where:

$$
\begin{array}{ll}
{[\mathrm{NO} 3]_{g w}} & =\text { Nitrate concentration in the leaching flux towards groundwater }\left(\mathrm{mg} \mathrm{NO}_{3} \mathrm{l}^{-1}\right) \\
N_{g w} & =\mathrm{N} \text { leaching flux towards groundwater }\left(\mathrm{kg} \mathrm{N} \mathrm{ha}^{-1} \mathrm{yr}^{-1}\right) \\
Q_{g w} & =\text { Water flux leaching towards groundwater }\left(\mathrm{m}^{3} \mathrm{ha}^{-1} \mathrm{yr}^{-1}\right) \\
c F_{c N O 3} & =\text { Conversion factor from }\left(\mathrm{kg} \mathrm{N} \mathrm{ha}^{-1}\right) /\left(\mathrm{m}^{3} \mathrm{ha}^{-1}\right) \text { to } \mathrm{mg} \mathrm{NO}_{3} \mathrm{l}^{-1} \text {, i.e. }(62 / 14)^{\star} 1000
\end{array}
$$

Furthermore, the following equations hold:

$$
\begin{aligned}
& Q_{g w}=Q_{t o t}-Q_{s r}-Q_{r o} \\
& Q_{s r}=f_{s r} * Q_{t o t} \\
& Q_{r o}=f_{r o} *\left(Q_{t o t}-Q_{s r}\right)=f_{r o} *\left(1-f_{s r}\right) * Q_{t o t}
\end{aligned}
$$

Where:

$$
\begin{aligned}
& Q_{\text {tot }} \quad=\text { The total precipitation surplus discharging towards groundwater and surface water } \\
& Q_{s r} \quad=\text { Water flux to surface water via surface runoff }\left(\mathrm{m}^{3} \mathrm{ha}^{-1} \mathrm{yr}^{-1}\right) \\
& \text { Q } \quad=\text { Water flux to surface water via sub-surface runoff }\left(\mathrm{m}^{3} \mathrm{ha}^{-1} \mathrm{yr}^{-1}\right) \\
& f_{s r} \quad=\text { The surface runoff fraction of precipitation surplus, being equal to the value used }
\end{aligned}
$$

Combining the equations above leads to:

$$
[N O 3]_{g w}=\frac{N_{g w}}{\left(1-f_{s r}\right) *\left(1-f_{r o}\right) * Q_{t o t}} * c F_{c N O 3}
$$




\section{Nitrogen concentrations in runoff to surface water}

The $\mathrm{N}$ concentration in agricultural runoff to surface water (including surface and subsurface runoff) is calculated as:

$$
[N]_{s w}=\frac{N_{s r}+N_{r o}}{Q_{s r}+Q_{r o}} * c F_{c N}
$$

Combining with equations above leads to:

$$
[N]_{S w}=\frac{N_{s r}+f_{r o} * N_{l e}}{f_{s r}+f_{r o} *\left(1-f_{s r}\right) * Q_{t o t}} * c F_{c N}
$$

Where:

$$
\begin{aligned}
& \left.[\mathrm{N}]_{s w}=\mathrm{N} \text { concentration in the total runoff flux (surface }+ \text { subsurface runoff }\right) \text { towards } \\
& N_{s r} \quad=\mathrm{N} \text { surface runoff flux }\left(\mathrm{kg} \mathrm{N} \mathrm{ha}^{-1} \mathrm{yr}^{-1}\right) \\
& N_{l e} \quad=\mathrm{N} \text { leaching flux below the root zone (includes flux to groundwater and sub-surface } \\
& \text { flux to surface water) }\left(\mathrm{kg} \mathrm{N} \mathrm{ha}^{-1} \mathrm{yr}^{-1}\right) \\
& c F_{c N}=\text { Conversion factor from } \mathrm{kg} \mathrm{N} \mathrm{ha}^{-1} /\left(\mathrm{m}^{3} \mathrm{ha}^{-1}\right) \text { to } \mathrm{mg} \mathrm{N} \mathrm{l}^{-1} \text {, i.e. } 1000
\end{aligned}
$$

The $\mathrm{N}$ concentration in total $\mathrm{N}$ runoff to , surface waters is calculated by including the dilution of $\mathrm{N}$ from non-agricultural areas according to:

$$
[N]_{s w}\left(1-f_{a g}\right) * 0.5+f_{a g} * \frac{N_{s r}+f_{r o} * N_{l e}}{f_{s r}+f_{r o} *\left(1-f_{s r}\right) * Q_{t o t}} * c F_{c N}
$$

\section{S2.3. Back-calculation of critical nitrogen inputs and nitrogen losses}

Critical $\mathrm{N}$ inputs to agriculture were calculated using a simplified version of the INTEGRATOR model (see Figure S2.2). If not otherwise specified, all calculations are performed at the level of crop-NCU combinations (each NCU is sub-divided into different crops occurring in this NCU).

For the critical $\mathrm{N}$ input calculations, $\mathrm{N}$ inputs from fertilizer and fixation were lumped together, and $\mathrm{N}$ inputs from manure and biosolids were lumped together. The relative contribution of $\mathrm{N}$ fertilizer and $\mathrm{N}$ fixation $\left(N_{f e+f i x}\right)$ and $\mathrm{N}$ manure and $\mathrm{N}$ biosolids $\left(N_{e x+b s}\right)$ to total farmer-managed inputs was assumed constant:

$$
N_{f e+f i x(c r i t)}=f N_{f e} *\left(N_{f e+f i x(c r i t)}+N_{e x+b s(c r i t)}\right)
$$


Where:

$\begin{aligned} f N_{f e}= & \text { Fraction } \mathrm{N} \text { input from fertilizer \& fixation in total } \mathrm{N} \text { inputs from fertilizer, fixation, } \\ & \text { manure } \& \text { biosolids }(-) \\ N_{f e+f i x(c r i t)}= & \text { Critical } \mathrm{N} \text { inputs from fertilizer and biological } \mathrm{N} \text { fixation }\left(\mathrm{kg} \mathrm{N} \mathrm{ha}^{-1} \mathrm{yr}^{-1}\right) \\ N_{e x+b s(\text { crit })}= & \text { Critical } \mathrm{N} \text { inputs from manure and biosolids }\left(\mathrm{kg} \mathrm{N} \mathrm{ha}^{-1} \mathrm{yr}^{-1}\right)\end{aligned}$

The fraction $\mathrm{N}$ inputs from fertilizer and fixation in total critical $\mathrm{N}$ inputs $\left(f \mathrm{~N}_{f e}\right)$ is calculated by dividing actual $\mathrm{N}$ inputs from fertilizer and fixation by actual $\mathrm{N}$ inputs from fertilizer, fixation, manure and biosolids for each crop/NCU combination:

$$
f N_{f e}=\frac{N_{f e(2010)}+N_{f i x(2010)}}{N_{f e(2010)}+N_{f i x(2010)}+N_{a m(2010)}+N_{b s(2010)}}
$$

Where:

$N_{f e(2010)}=\mathrm{N}$ inputs from fertilizer for the year $2010\left(\mathrm{~kg} \mathrm{~N} \mathrm{ha}^{-1} \mathrm{yr}^{-1}\right)$

$N_{a m(2010)}=\mathrm{N}$ inputs from manure (application \& grazing) for the year $2010\left(\mathrm{~kg} \mathrm{~N} \mathrm{ha}^{-1} \mathrm{yr}^{-1}\right)$

$N_{f x(2010)}=\mathrm{N}$ inputs from biological $\mathrm{N}$ fixation for the year $2010\left(\mathrm{~kg} \mathrm{~N} \mathrm{ha}^{-1} \mathrm{yr}^{-1}\right)$

$N_{b s(2010)}=\mathrm{N}$ inputs from biosolids for the year $2010\left(\mathrm{~kg} \mathrm{~N} \mathrm{ha}^{-1} \mathrm{yr}^{-1}\right)$

Total critical $\mathrm{N}$ inputs are defined as the sum of $\mathrm{N}$ inputs from fertilizer, fixation, excretion, biosolids, deposition and mineralisation (peat soils only) according to:

$$
N_{i n(c r i t)}=N_{e x+b s(c r i t)}+N_{f e+f i x(c r i t)}+N_{d e p(c r i t)}+N_{\min (2010)}
$$

Where:

$$
\begin{aligned}
& N_{\text {dep(crit) }}=\mathrm{N} \text { inputs from deposition at critical } \mathrm{N} \text { inputs }\left(\mathrm{kg} \mathrm{N} \mathrm{ha}^{-1} \mathrm{yr}^{-1}\right) \\
& N_{\min (2010)}=\mathrm{N} \text { inputs from mineralization (assumed constant) }\left(\mathrm{kg} \mathrm{N} \mathrm{ha}^{-1} \mathrm{yr}^{-1}\right)
\end{aligned}
$$

$\mathrm{N}$ offtake by harvest at critical inputs ('critical offtake') is assumed to be a fixed fraction of total $\mathrm{N}$ inputs minus surface runoff and emissions (see Figure S2.2):

$$
N_{o f f(c r i t)}=f r N_{o f f} *\left(N_{i n(c r i t)}-N_{s r(c r i t)}-N_{e m(c r i t)}\right)
$$

Where:

$$
\begin{array}{ll}
f r N_{\text {off }} & =\mathrm{N} \text { offtake fraction (constant) }\left(\mathrm{kg} \mathrm{N} \mathrm{ha}^{-1} \mathrm{yr}^{-1}\right) \\
N_{\text {off(crit) }} & =\mathrm{N} \text { offtake by harvest at critical N inputs }\left(\mathrm{kg} \mathrm{N} \mathrm{ha}^{-1} \mathrm{yr}^{-1}\right) \\
N_{\text {sr(crit) }} & =\mathrm{N} \text { surface runoff at critical } \mathrm{N} \text { inputs }\left(\mathrm{kg} \mathrm{N} \mathrm{ha}^{-1} \mathrm{yr}^{-1}\right) \\
N_{\text {em(crit) }} & =\text { Total } \mathrm{N}\left(\mathrm{NH}_{3}+\mathrm{N}_{2} \mathrm{O}+\mathrm{NO}_{\mathrm{x}}\right) \text { emissions at critical N inputs }\left(\mathrm{kg} \mathrm{N} \mathrm{ha}^{-1} \mathrm{yr}^{-1}\right)
\end{array}
$$

The offtake fraction is assumed to be equal to the offtake fraction for the year 2010 and calculated as: 


$$
f r N_{o f f}=\frac{N_{o f f}(2010)}{N_{f e(2010)}+N_{a m(2010)}+N_{f i x(2010)}+N_{b s(2010)}+N_{\min (2010)}+N_{d e p(2010)}-N_{s r}(2010)-N_{e m(2010)}}(E q .
$$

Where:

$$
\begin{aligned}
& N_{\text {off(2010) }}=\mathrm{N} \text { offtake by harvest for the year } 2010\left(\mathrm{~kg} \mathrm{~N} \mathrm{ha}^{-1} \mathrm{yr}^{-1}\right) \\
& N_{\text {min(2010) }}=\mathrm{N} \text { inputs from mineralization for the year } 2010 \text { (peat soils only) }\left(\mathrm{kg} \mathrm{N} \mathrm{ha}^{-1} \mathrm{yr}^{-1}\right) \\
& N_{\text {dep(2010) }}=\mathrm{N} \text { inputs from deposition for the year } 2010\left(\mathrm{~kg} \mathrm{~N} \mathrm{ha}^{-1} \mathrm{yr}^{-1}\right) \\
& N_{\text {sr(2010) }}=\mathrm{N} \text { surface runoff for the year } 2010\left(\mathrm{~kg} \mathrm{~N} \mathrm{ha}^{-1} \mathrm{yr}^{-1}\right) \\
& N_{\text {em(2010) }}=\text { Total N }\left(\mathrm{NH}_{3}+\mathrm{N}_{2} \mathrm{O}+\mathrm{NO}_{\mathrm{x}}\right) \text { emissions for the year } 2010\left(\mathrm{~kg} \mathrm{~N} \mathrm{ha}^{-1} \mathrm{yr}^{-1}\right)
\end{aligned}
$$

$\mathrm{N}$ emissions $\left(\mathrm{NH}_{3}, \mathrm{~N}_{2} \mathrm{O}, \mathrm{NO}_{\mathrm{x}}\right)$ at critical inputs ('critical emissions') are calculated as a fraction of critical $\mathrm{N}$ inputs from fertilizer and fixation, and from excretion and biosolids (see Figure S2.2):

$$
\begin{aligned}
& N H 3_{e m(\text { crit })}=N_{f e+f i x(c r i t)} * f N H 3_{e m, f e}+N_{e x+b s(c r i t)} * f N H 3_{e m, e x} \\
& N 2 O_{e m(c r i t)}=N_{f e+f i x} * f N 2 O_{e m, f e}+N_{e x+b s(c r i t)} * f N 2 O_{e m, e x} \\
& N O x_{e m(c r i t)}=N_{f e+f i x(c r i t)} * f N O x_{e m, f e}+N_{e x+b s(c r i t)} * f N O x_{e m, e x} \\
& N_{e m(c r i t)}=N_{f e+f i x(c r i t)} * f N_{e m, f e}+N_{e x+b s(c r i t)} * f N_{e m, e x}
\end{aligned}
$$

Where:

$$
\begin{aligned}
& \mathrm{NH}_{\text {em(crit) }}=\mathrm{NH}_{3} \text { emissions from agriculture at critical } \mathrm{N} \text { inputs }\left(\mathrm{kg} \mathrm{N} \mathrm{ha}^{-1} \mathrm{yr}^{-1}\right) \\
& \mathrm{N}_{2} \mathrm{O}_{\text {em(crit) }}=\mathrm{N}_{2} \mathrm{O} \text { emissions from agriculture at critical } \mathrm{N} \text { inputs }\left(\mathrm{kg} \mathrm{N} \mathrm{ha}^{-1} \mathrm{yr}^{-1}\right) \\
& N O x_{\text {em(crit) }}=\mathrm{NO}_{\mathrm{x}} \text { emissions from agriculture at critical } \mathrm{N} \text { inputs }\left(\mathrm{kg} \mathrm{N} \mathrm{ha}^{-1} \mathrm{yr}^{-1}\right) \\
& N_{e m(c r i t)}=\text { Total } \mathrm{N}\left(\mathrm{NH}_{3}+\mathrm{N}_{2} \mathrm{O}+\mathrm{NO}_{\mathrm{x}}\right) \text { emissions at critical } \mathrm{N} \text { inputs }\left(\mathrm{kg} \mathrm{N} \mathrm{ha}^{-1} \mathrm{yr}^{-1}\right)
\end{aligned}
$$

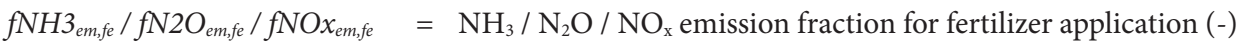

$$
\begin{aligned}
& f \mathrm{NH}_{\text {em,ex }} / f \mathrm{~N}^{2} \mathrm{O}_{\text {em,ex }} / f \mathrm{NOx}_{\text {em,ex }}=\mathrm{NH}_{3} / \mathrm{N}_{2} \mathrm{O} / \mathrm{NO}_{\mathrm{x}} \text { emission fraction for manure excretion (-) } \\
& f \mathrm{~N}_{\text {em,fe }}=\text { Total } \mathrm{N}\left(\mathrm{NH}_{3}+\mathrm{N}_{2} \mathrm{O}+\mathrm{NO}_{\mathrm{x}}\right) \text { emission fraction for fertilizer application (-) } \\
& f \mathrm{~N}_{\text {em,ex }}=\text { Total } \mathrm{N}\left(\mathrm{NH}_{3}+\mathrm{N}_{2} \mathrm{O}+\mathrm{NO}_{\mathrm{x}}\right) \text { emission fraction for manure excretion (-) }
\end{aligned}
$$

Values for $f \mathrm{NH}_{\text {em,fe }}\left(f \mathrm{~N} 2 \mathrm{O}_{\text {em,fe, }}\right.$ fNOx $\left.x_{\text {em,fe }}\right)$ were derived by dividing total $\mathrm{NH}_{3}\left(\mathrm{~N}_{2} \mathrm{O}, \mathrm{NO}_{\mathrm{x}}\right)$ emissions from fertilizer by total $\mathrm{N}$ inputs from fertilizer per crop and NCU. Values for $f \mathrm{NH}_{\text {em,ex }}\left(f \mathrm{~N}^{2} \mathrm{O}_{\text {em,ex }}, f \mathrm{NO} x_{\text {em,ex }}\right)$ were derived by dividing total $\mathrm{NH}_{3}\left(\mathrm{~N}_{2} \mathrm{O}, \mathrm{NO}_{\mathrm{x}}\right)$ emissions from housing and manure storage, application and grazing by total $\mathrm{N}$ excretion at country level.

$\mathrm{N}$ deposition at critical $\mathrm{N}$ inputs ('critical deposition') is assumed to be a fixed fraction of $\mathrm{NH}_{3}$ emissions at critical $\mathrm{N}$ inputs and the (constant) fraction agricultural land and the 
fraction $\mathrm{NH}_{3}$ deposition in total deposition (also see section "Calculation of critical ammonia emissions from critical nitrogen deposition on natural land"):

$$
N_{\text {dep }(\text { crit })}=N H 3_{\text {em }(\text { crit })} * \frac{f_{a g}}{f_{N H 3}}
$$

Where:

$$
\begin{array}{ll}
f_{\mathrm{NH} 3} & =\text { fraction } \mathrm{NH}_{3} \text { in total }\left(\mathrm{NO}_{\mathrm{x}}+\mathrm{NH}_{3}\right) \text { deposition (-) } \\
f_{\text {ag }} & =\text { fraction agricultural land in an NCU (-) }
\end{array}
$$

$\mathrm{N}$ surface runoff at critical $\mathrm{N}$ inputs ('critical surface runoff') is calculated as a fixed fraction of critical $\mathrm{N}$ inputs (see Figure S2.2):

$$
N_{s r(c r i t)}=f_{s r} *\left(N_{f e+f i x(c r i t)}+N_{e x+b s(c r i t)}\right)
$$

Where:

$f_{s r}=$ surface runoff fraction in $\%$ of $\mathrm{N}$ applied via fertilizer and manure (-)

$\mathrm{N}$ leaching below the rooting zone at critical $\mathrm{N}$ inputs ('critical leaching') is calculated as a fixed fraction of the critical $\mathrm{N}$ surplus, which in turn is calculated as the sum of total critical $\mathrm{N}$ inputs minus surface runoff, emissions and offtake (see Figure S2.2). Denitrification is calculated by multiplying $\mathrm{N}$ surplus by 1 minus the leaching fraction.

$$
\begin{aligned}
& N_{l e(\text { crit })}=f_{l e} * N_{\text {sur }(\text { crit })} \\
& N_{d e(\text { crit })}=\left(1-f_{l e}\right) * N_{s u r(c r i t)} \\
& N_{\text {sur (crit) }}=N_{\text {in }(\text { crit })}-N_{s r(\text { crit })}-N_{e m(\text { crit })}-N_{o f f(c r i t)}
\end{aligned}
$$

Where:

$$
\begin{array}{ll}
N_{l e(c r i t)} & =\mathrm{N} \text { leaching below the rooting zone at critical } \mathrm{N} \text { inputs }\left(\mathrm{kg} \mathrm{N} \mathrm{ha}^{-1} \mathrm{yr}^{-1}\right) \\
f_{l e} & =\text { Leaching fraction (equal to } 1 \text { minus denitrification fraction) }(-) \\
N_{\text {sur(crit) }} & =\mathrm{N} \text { surplus at critical } \mathrm{N} \text { inputs }\left(\mathrm{kg} \mathrm{N} \mathrm{ha}^{-1} \mathrm{yr}^{-1}\right) \\
N_{\text {de(crit) }} & =\mathrm{N} \text { denitrification at critical } \mathrm{N} \text { inputs }\left(\mathrm{kg} \mathrm{N} \mathrm{ha}^{-1} \mathrm{yr}^{-1}\right)
\end{array}
$$

$\mathrm{N}$ subsurface runoff to surface water ('critical subsurface runoff') is calculated as critical leaching times a subsurface runoff fraction (see Figure S2.2):

$$
N_{\text {ro(crit) }}=f_{\text {ro }} * N_{\text {le(crit })}
$$

Where:

$$
\begin{array}{ll}
N_{\text {ro(crit) }} & =\mathrm{N} \text { subsurface runoff to surface water at critical } \mathrm{N} \text { inputs }\left(\mathrm{kg} \mathrm{N} \mathrm{ha}^{-1} \mathrm{yr}^{-1}\right) \\
f_{\text {ro }} & =\text { Subsurface runoff fraction as } \% \text { of } \mathrm{N} \text { leaching below rooting zone }(-)
\end{array}
$$


The remainder of leaching $\left(N_{l e}-N_{r o}\right)$ is assumed to be $\mathrm{N}$ flux to groundwater $\left(N_{g w}\right)$ (see Figure S2.2):

$$
N_{g w(\text { crit })}=\left(1-f_{\text {ro }}\right) * N_{l e(c r i t)}
$$

Where:

$N_{g w(c r i t)}=\mathrm{N}$ flux to groundwater at critical $\mathrm{N}$ inputs $\left(\mathrm{kg} \mathrm{N} \mathrm{ha}^{-1} \mathrm{yr}^{-1}\right)$

Total $\mathrm{N}$ inputs to surface water $\left(N_{s w}\right)$ are the sum of $\mathrm{N}$ surface runoff and $\mathrm{N}$ subsurface runoff (see Figure S2.2):

$$
N_{s w(c r i t)}=N_{s r(c r i t)}+N_{r o(c r i t)}
$$

Where:

$N_{s w(c r i t)}=\mathrm{N}$ delivery to surface water via surface and subsurface runoff at critical $\mathrm{N}$ inputs $(\mathrm{kg}$ $\left.\mathrm{Nha}^{-1} \mathrm{yr}^{-1}\right)$

\section{S2.3. I. Critical ammonia emissions and associated critical nitrogen inputs in view of nitrogen deposition thresholds}

Calculation of critical ammonia emissions from critical nitrogen deposition on natural land

Critical $\mathrm{NH}_{3}$ emissions are calculated assuming that within an $\mathrm{NCU}$ (i) the average $\mathrm{N}$ deposition rate on agricultural land equals the average $\mathrm{N}$ deposition rate on non-agricultural land (both in $\mathrm{kg} \mathrm{N} \mathrm{ha}^{-1}$ ), (ii) the amount of $\mathrm{NH}_{3}$ that is emitted (coming from agriculture) is deposited in the same region, but then on all (agricultural land and non-agricultural) land (both in $\mathrm{kg} \mathrm{N}$ ) and (iii) the current shares of $\mathrm{NH}_{3}$ and $\mathrm{NO}_{\mathrm{x}}$ in total $\mathrm{N}$ deposition stay constant (and thus $\mathrm{NO}_{\mathrm{x}}$ emissions/deposition increase or decrease in the same proportion as $\mathrm{NH}_{3}$ emissions/deposition). All assumptions are discussed in more detail below.

Assumption (i) that $\mathrm{N}$ deposition rates on agricultural land and natural land are similar within a region holds specifically in areas where the surface roughness of non-agricultural land is comparable to that of arable land, which is true for low vegetation (grasslands, heathlands etc.) but not for forests. Overall, however, the assumption is reasonable, as illustrated by comparing average $\mathrm{N}$ deposition on agriculture and $\mathrm{N}$ deposition on nature at country level (see Figure S2.3). In formula:

$$
N H 3_{\text {dep }(a g)}+N O x_{\text {dep }(a g)}=N H 3_{\text {dep }(n o n-a g)}+N O x_{\text {dep }(n o n-a g)}
$$


Where:

$$
\begin{aligned}
& \mathrm{NH}_{\text {dep }(a g)}=\mathrm{N} \text { deposition due to } \mathrm{NH}_{3} \text { emissions on agricultural land }\left(\mathrm{kg} \mathrm{N} \mathrm{ha}^{-1} \mathrm{yr}^{-1}\right) \\
& N O x_{\text {dep(ag })}=\mathrm{N} \text { deposition due to } \mathrm{NO}_{\mathrm{x}} \text { emissions on agricultural land }\left(\mathrm{kg} \mathrm{N} \mathrm{ha}^{-1} \mathrm{yr}^{-1}\right) \\
& \mathrm{NH}_{\text {dep(non-ag) }}=\mathrm{N} \text { deposition due to } \mathrm{NH}_{3} \text { emissions on non-agricultural land }\left(\mathrm{kg} \mathrm{N} \mathrm{ha}^{-1} \mathrm{yr}^{-1}\right) \\
& N O x_{\text {dep(non-ag) }}=\mathrm{N} \text { deposition due to } \mathrm{NO}_{\mathrm{x}} \text { emissions on non-agricultural land }\left(\mathrm{kg} \mathrm{N} \mathrm{ha}^{-1} \mathrm{yr}^{-1}\right)
\end{aligned}
$$

Following assumption (ii), $\mathrm{N}$ deposition due to agricultural $\mathrm{NH}_{3}$ emissions within a region is calculated as:

$$
N H 3_{\text {dep }(a l l)}=f_{\text {ag }} * N H 3_{\text {em }(a g)}
$$

Where:

$$
\begin{aligned}
& N H 3_{\text {dep(all) }}= \mathrm{N} \text { deposition due to } \mathrm{NH}_{3} \text { emissions on all (agricultural and non-agricultural) land } \\
&\left(\mathrm{kg} \mathrm{N} \mathrm{ha}^{-1} \mathrm{yr}^{-1}\right) \\
&= \text { Fraction agricultural land }(-) \\
& f_{a g} \mathrm{NH}_{3} \text { emissions from agriculture }\left(\mathrm{kg} \mathrm{N} \mathrm{ha}^{-1} \mathrm{yr}^{-1}\right) \\
& N H 3_{\text {em(ag) }}=
\end{aligned}
$$

Total $\mathrm{N}$ deposition is the sum of deposition due to $\mathrm{NH}_{3}$ and due to $\mathrm{NO}_{\mathrm{x}}$ emissions. Following assumption (iii), the relative contribution of $\mathrm{NO}_{\mathrm{x}}$ and $\mathrm{NH}_{3}$ to total deposition is assumed constant, and thus:

$$
\begin{aligned}
& N_{\text {dep,tot }(\text { all })}=N H 3_{\text {dep }(\text { all })}+N O x_{\text {dep }(\text { all })} \\
& N H 3_{\text {dep }(\text { all })}=f_{N H 3} * N_{\text {dep,tot }(\text { all })} \\
& N O x_{\operatorname{dep}(\text { all })}=\left(1-f N H_{3}\right) * N_{\text {dep,tot }(\text { all })}
\end{aligned}
$$

Where:

$$
\begin{array}{ll}
N_{\text {dep,tot(all })} & =\text { Average total } \mathrm{N} \text { deposition }\left(\mathrm{kg} \mathrm{N} \mathrm{ha}^{-1} \mathrm{yr}^{-1}\right) \\
f_{N H 3} & =\text { Fraction } \mathrm{NH}_{3} \text { in total }\left(\mathrm{NO}_{\mathrm{x}}+\mathrm{NH}_{3}\right) \text { deposition (-) }
\end{array}
$$

Combining Eq. (S2.3.19), (S2.3.20) and (S2.3.22) gives:

$$
N_{\text {dep,tot }(a l l)}=\frac{f_{a g}}{f N H_{3}} * N H 3_{e m(a g)} \text { or } N H 3_{e m(a g)}=N_{\text {dep,tot }(a l l)} * \frac{f N H_{3}}{f_{a g}}
$$

As we assumed (see Eq. S2.3.18) that $N_{\text {deptot }(a g)}=N_{\text {deptot(non-ag) }}$, Eq. (S2.3.23) can be written as:

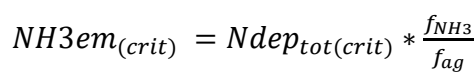

Where:

$\mathrm{NH}_{3} \mathrm{em}_{\text {(crit) }}=\mathrm{NH}_{3}$ emissions leading to critical $\mathrm{N}$ deposition ('critical $\mathrm{NH}_{3}$ emission') $\left(\mathrm{kg} \mathrm{N} \mathrm{ha}^{-1}\right.$ $\left.\mathrm{yr}^{-1}\right)$ 
$N d e p_{\text {tot(crit) }}=$ Critical $\mathrm{N}$ deposition on non-agricultural terrestrial ecosystems, calculated as the area-weighted average critical $\mathrm{N}$ load for those ecosystems $\left(\mathrm{kg} \mathrm{N} \mathrm{ha}^{-1} \mathrm{yr}^{-1}\right)$

\section{Calculation of critical nitrogen inputs from critical ammonia emissions}

As shown in Equation (S2.3.6), critical $\mathrm{NH}_{3}$ emissions are a function of critical $\mathrm{N}$ inputs from fertilizer (+ fixation) and from excretion (+ biosolids), and (constant) emission fractions for both inputs. Once critical $\mathrm{NH}_{3}$ emissions are calculated with Eq. (S2.3.24), Eq. (S2.3.6) contains two unknowns, i.e. $N_{f e+f i x(c r i t)}$ and $N_{e x+b s(c r i t)}$. By assuming that the relative contribution of $\mathrm{N}$ fertilizer and $\mathrm{N}$ fixation $\left(N_{f e+f i x}\right)$ and $\mathrm{N}$ manure excretion and $\mathrm{N}$ biosolids $\left(N_{e x+b s}\right)$ is equal to the 2010 value (see Eq. S2.3.1), we can express $N_{f e+f i x(c r i t)}$ as a function of $N_{e x+b s(c r i t)}$ :

$$
N_{f e+f i x(c r i t)}=\frac{f N_{f e}}{1-f N_{f e}} * N_{e x+b s(c r i t)}
$$

The value for $f N_{f e}$ is derived in Eq. (S2.3.2). By replacing $N_{f e+f i x(c r i t)}$ in Eq. (S2.3.6) with the right-hand side of Eq. (S2.3.25) and solving the equation for $N_{\text {extbs(crit) }}$, critical $\mathrm{N}$ inputs from excretion in view of critical $\mathrm{NH}_{3}$ emission can be derived as:

$$
N_{e x+b s(c r i t, N H 3)}=\frac{N H 3 \operatorname{em}_{(c r i t)}}{f N H 3_{e m, e x}+f N H 3_{e m, f e} e^{*} \frac{f N_{f e}}{1-f N_{f e}}}
$$

The related critical $\mathrm{N}$ input from fertilizer and fixation was calculated with Eq. (S2.3.25), while total critical $\mathrm{N}$ input (including inputs from deposition and - for peat soils - mineralisation) was calculated with Eq. (S2.3.3).

Equation (S2.3.26) implies that the critical nitrogen input in view of critical $\mathrm{NH}_{3}$ emissions depends on (i) the critical deposition load, the fraction agricultural area and the contribution of $\mathrm{NO}_{\mathrm{x}}$ to total $\mathrm{N}$ deposition (determining $\mathrm{NH}_{\text {em(crit) }}$ ), (ii) the $\mathrm{NH}_{3}$ emission fractions for fertilizer $\left(f N H 3_{\text {em, fe }}\right)$ and excretion $\left(f N H 3_{\text {em,ex }}\right)$ and (iii) the share of $\mathrm{N}$ fertilizer + fixation in total critical inputs $\left(f N_{f e}\right)$. The related offtake $N_{o f f(c r i t, N H 3)}$ was calculated with Eq. (S2.3.4), while related $\mathrm{N}$ flux to groundwater $N_{g w(c r i t, N H 3)}$ and surface water $N_{s w(c r i t, N H 3)}$ were calculated with Eqs. (S2.3.16) and (S2.3.17).

Equations for estimating $\mathrm{N}\left(\mathrm{NH}_{3}, \mathrm{~N}_{2} \mathrm{O}\right.$ and $\left.\mathrm{NO}_{\mathrm{x}}\right)$ emissions were parameterized in such a way that emission fractions include all losses, including those from animal housing and manure storage systems and from the application of animal manure, fertilizers and dung and urine from grazing animals to the soil. The approach implicitly assumes that manure applied to the soil in a given grid cell (external data) comes from the farms in the same grid cell (which is not always true, as manure excreted in housing systems is sometimes allocated for application in neighbouring NCUs if otherwise maximum application rates are exceeded). 


\section{S2.3.2. Critical nitrogen runoff and associated critical nitrogen inputs from critical nitrogen concentration thresholds in surface water}

Nitrogen inputs from fertilizer and manure are susceptible to runoff. Total runoff consists of two components: (i) surface runoff (or direct runoff) $\left(N_{s r}\right)$, being a fraction of $\mathrm{N}$ inputs and (ii) subsurface runoff $\left(N_{r o}\right)$, being a fraction of $\mathrm{N}$ leaching below the root zone (see Figure S2.2). Similarly, total precipitation surplus $\left(Q_{t o t}\right)$ is distributed over surface runoff $\left(Q_{s r}\right)$, subsurface runoff $\left(Q_{r o}\right)$ and leaching to groundwater $\left(Q_{g w}\right)$.

Runoff from non-agricultural land usually has a lower $\mathrm{N}$ concentration and thus dilutes the $\mathrm{N}$ concentration in runoff from agricultural land. As with critical $\mathrm{NH}_{3}$ emissions, we thus account for differences in the fraction agricultural land in a region, according to:

$$
[N]_{\text {water }}=f_{a g} *[N]_{a g}+\left(1-f_{a g}\right) *[N]_{\text {nag }}
$$

Where:

$$
\begin{array}{ll}
{[\mathrm{N}]_{\text {water }}} & =\mathrm{N} \text { concentrations in total runoff to surface water }\left(\mathrm{mg} \mathrm{N}^{-1}\right) \\
{[\mathrm{N}]_{\text {ag }}} & =\mathrm{N} \text { concentrations in runoff from agricultural land }\left(\mathrm{mg} \mathrm{N}^{-1}\right) \\
{[\mathrm{N}]_{\text {nag }}} & =\mathrm{N} \text { concentrations in runoff from natural land }\left(\mathrm{mg} \mathrm{N}^{-1}\right)
\end{array}
$$

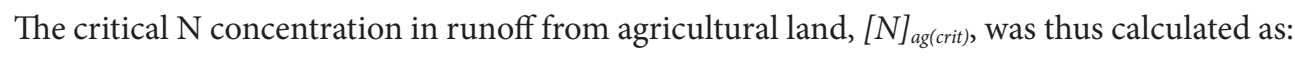

$$
[N]_{a g(\text { crit })}=\frac{[N]_{\text {water }(\text { crit })}-\left(1-f_{a g}\right) *[N]_{\text {nag }}}{f_{a g}}
$$

For the critical $\mathrm{N}$ concentration in runoff to surface water, we used a value of $2.5 \mathrm{mg} \mathrm{N}^{-1}$ (see main text). When using a critical concentration for total runoff to surface water of $2.5 \mathrm{mg} \mathrm{N}$ $\mathrm{l}^{-1}$ and concentration of $0.5 \mathrm{mg} \mathrm{N}^{-1}$ for runoff from natural land, equation (S2.3.28) becomes:

$$
[N]_{a g(\text { crit })}=\frac{2+0.5 * f_{a g}}{f_{a g}}
$$

The total critical $\mathrm{N}$ runoff flux towards surface water, $N_{s w(c r i t)}$, is the sum of surface and subsurface runoff (Eq. S2.3.17), and was derived from the critical $\mathrm{N}$ concentration in runoff from agricultural land by multiplying the critical $\mathrm{N}$ concentration with the total water runoff volume and a correction factor:

$$
N_{s w(c r i t)}=[N]_{a g(c r i t)} *\left(Q_{s r}+Q_{r o}\right) * c F_{c N}
$$

Where:

$Q_{s r}=$ Water flux to surface water via surface runoff $\left(\mathrm{m}^{3} \mathrm{~m}^{-2} \mathrm{yr}^{-1}\right)$

Q $\quad=$ Water flux to surface water via sub-surface runoff $\left(\mathrm{m}^{3} \mathrm{~m}^{-2} \mathrm{yr}^{-1}\right)$

$c F_{c N}=$ Conversion factor from $\mathrm{mg} \mathrm{N}^{-1}$ to $\mathrm{kg} \mathrm{N} \mathrm{ha}^{-1} /\left(\mathrm{m}^{3} \mathrm{~m}^{-2}\right)$, i.e. 10 
$[N]_{a g(c r i t)}$ is given from Eq. (S2.2.28); $Q_{s r}, Q_{r o}$ and $c f_{c N}$ are also given. By combining Eqs. (S2.3.12), (S2.3.14) and (S2.3.15), subsurface runoff is calculated as:

$$
\begin{aligned}
N_{r o(c r i t)}= & \left(N_{f e+f i x(c r i t)}+N_{e x+b s(c r i t)}+N_{d e p(c r i t)}+N_{\text {min }}-N_{e m(c r i t)}-\right. \\
& \left.N_{s r(c r i t)}-N_{o f f(c r i t)}\right) * f_{l e} * f_{r o}
\end{aligned}
$$

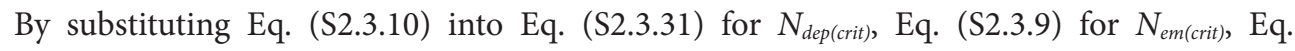
(S2.3.11) for $N_{\text {sr (crit) }}$ and Eq. (S2.3.4) for $N_{\text {off(crit) }}$, critical $\mathrm{N}$ inputs in view of critical $\mathrm{N}$ runoff to surface water were calculated as a function of the leaching fraction $\left(f_{l e}\right)$, the $\mathrm{N}$ mineralization rate $\left(N_{\min }\right.$, for peat soils), the $\mathrm{N}$ offtake fraction $\left(f r N_{o f f}\right), \mathrm{N}$ emission fractions for fertilizer and manure $\left(f \mathrm{~N}_{\text {em,fe }}\right.$ and $\left.f \mathrm{~N}_{\text {em,ex }}\right), \mathrm{NH}_{3}$ emission fractions for fertilizer and manure $\left(f \mathrm{NH} 3_{\text {em, fee }}\right.$, $\left.f \mathrm{NH} 3_{\text {em,ex }}\right)$, the surface runoff fraction $\left(f_{s r}\right)$, fraction agricultural land $\left(f_{a g}\right)$, the fraction $\mathrm{NH}_{3}$ deposition in total deposition $\left(f_{\mathrm{NH}}\right)$, the fraction of $\mathrm{N}$ fertilizer application compared to the sum of $\mathrm{N}$ fertilizer application and $\mathrm{N}$ excretion $\left(f \mathrm{~N}_{f e}\right)$ as:

$$
N_{e x+b s(c r i t, s w)}=\frac{N_{s w(c r i t)}-N_{\min } * f_{l e} * f_{r o} *\left(1-f r N_{o f f}\right)}{\frac{f N_{f e}}{1-f N_{f e}} *\left(f_{s r}+f_{l e} * f_{r o} * f_{x}\right)+\left(f_{s r}+f_{l e} * f_{r o} * f_{y}\right)}
$$

Where ' $\mathrm{f} x$ ' and 'fy' are defined as:

$$
\begin{aligned}
& f_{x}=1+f N H 3_{e m, f e} * \frac{f a g}{f_{N H 3}}-f N_{e m, f e}-f_{s r}+f r N_{o f f} *\left(f_{s r}-1-f N H 3_{e m, f e} * \frac{f_{a g}}{f_{N H 3}}+f N_{e m, f e}\right) \\
& f_{y}=1+f N H 3_{e m, e x} * \frac{f a g}{f_{N H 3}}-f N_{e m, e x}-f_{s r}+f r N_{o f f} *\left(f_{s r}-1-f N H 3_{e m, e x} * \frac{f_{a g}}{f_{N H 3}}+f N_{e m, e x}\right)
\end{aligned}
$$

The related critical $\mathrm{N}$ input from fertilizer and fixation was calculated with Eq. (S2.3.25), while total critical $\mathrm{N}$ input (including inputs from deposition and - for peat soils - mineralisation) was calculated with Eq. (S2.3.3).

\section{S2.3.3. Critical nitrogen leaching and associated nitrogen inputs from critical nitrogen concentration thresholds in groundwater}

The critical $\mathrm{N}$ leaching rate to groundwater $\left(N_{g w(c r i t)}\right)$ is derived from a critical $\mathrm{N}$ concentration in groundwater (set to $50 \mathrm{mg} \mathrm{NO}_{3}^{-} \mathrm{I}^{-1}$ or $11.3 \mathrm{mg} \mathrm{NO}_{3}-\mathrm{N} \mathrm{l}^{-1}$ ) as:

$$
[N O 3]_{g w(c r i t)}=\frac{N_{g w}(c r i t)}{Q_{g w}} * c F_{c N O 3}
$$

Or:

$$
N_{g w(c r i t)}=\frac{[N O 3]_{g w(c r i t)}}{c F_{c N O 3}} * Q_{g w}
$$


Where:

$$
\begin{aligned}
& {[\mathrm{NO} 3]_{g w(c r i t)}=\text { Critical nitrate concentration in leaching flux towards groundwater }\left(\mathrm{mg} \mathrm{NO}_{3} \mathrm{l}^{-1}\right)} \\
& N_{g w(c r i t)}=\text { Critical } \mathrm{N} \text { leaching flux towards groundwater }\left(\mathrm{kg} \mathrm{N} \mathrm{ha}^{-1} \mathrm{yr}^{-1}\right) \\
& Q_{g w}=\text { Water flux leaching towards groundwater }\left(\mathrm{m}^{3} \mathrm{~m}^{-2} \mathrm{yr}^{-1}\right) \\
& c F_{c \mathrm{NO} 3}=\text { Conversion factor from }\left(\mathrm{kg} \mathrm{N} \mathrm{ha}^{-1}\right) /\left(\mathrm{m}^{3} \mathrm{~m}^{-2}\right) \text { to } \mathrm{mg} \mathrm{NO}_{3} \mathrm{l}^{-1} \text {, i.e. }(62 / 14) / 10
\end{aligned}
$$

The critical $\mathrm{N}$ leaching flux towards groundwater is related to $\mathrm{N}$ inputs as:

$$
\begin{aligned}
N_{g w(c r i t)}= & \left(N_{f e+f i x(c r i t)}+N_{e x+b s(c r i t)}+N_{d e p(c r i t)}+N_{m i n}-N_{e m(c r i t)}-\right. \\
& \left.N_{s r(c r i t)}-N_{o f f(c r i t)}\right) * f_{l e} *\left(1-f_{r o}\right)
\end{aligned}
$$

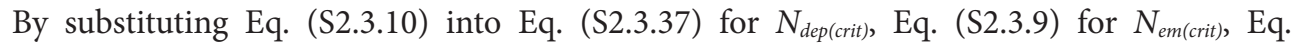
(S2.3.11) for $N_{s r(c r i t)}$ and Eq. (S2.3.4) for $N_{\text {off(crit), }}$ critical $\mathrm{N}$ inputs in view of critical $\mathrm{N}$ leaching to groundwater were calculated as a function of the leaching fraction $\left(f_{l e}\right), \mathrm{N}$ mineralisation $\left(N_{\text {min }}\right.$, for peat soils), the $\mathrm{N}$ offtake fraction $\left(f r N_{o f f}\right), \mathrm{N}$ emission fractions for fertilizer and manure $\left(f \mathrm{~N}_{\text {em,fe }}\right.$ and $\left.f \mathrm{~N}_{\text {em,ex }}\right), \mathrm{NH}_{3}$ emission fractions for fertilizer and manure $\left(f \mathrm{NH} 3_{\text {em,fe }}\right.$, $\left.f N H 3_{\text {em,ex }}\right)$, the surface runoff fraction $\left(f_{s r}\right)$, the sub-surface runoff fraction $\left(f_{r o}\right)$, the fraction agricultural land $\left(f_{\text {ag }}\right)$, the fraction $\mathrm{NH}_{3}$ deposition in total deposition $\left(f_{\mathrm{NH} 3}\right)$, the fraction of $\mathrm{N}$ fertilizer application compared to the sum of $\mathrm{N}$ fertilizer application and $\mathrm{N}$ excretion $\left(f \mathrm{~N}_{f e}\right)$ as:

$$
N_{e x+b s(c r i t, g w)}=\frac{\frac{N_{g w(c r i t)}}{f_{l e^{*}\left(1-f_{r o}\right)}-N_{\min } *\left(1-f r N_{o f f}\right)}}{\frac{f N_{f e}}{1-f N_{f e}} * f_{x}+f_{y}}
$$

The parameters $f_{x}$ and $f_{y}$ are defined in Eqs. (S2.3.33) and (S2.3.34), respectively.

The related critical $\mathrm{N}$ input from fertilizer and fixation was calculated with Eq. (S2.3.25), while total critical $\mathrm{N}$ input (including inputs from deposition and - for peat soils - mineralisation) was calculated with Eq. (S2.3.3). 
Table S2.I | Mean $\mathrm{N}$ excretion ( $\mathrm{kg} \mathrm{N}$ per animal per year) for dairy cows, other cattle, pigs, horses, sheep and goats, laying hens, other poultry and fur animals, for the year 2010, according to the RAINS database (after Asman et al., 20II).

\begin{tabular}{|c|c|c|c|c|c|c|c|c|}
\hline Country & $\begin{array}{l}\text { Dairy } \\
\text { cows }\end{array}$ & $\begin{array}{l}\text { Other } \\
\text { cattle }\end{array}$ & Pigs & Horses & $\begin{array}{l}\text { Sheep \& } \\
\text { goats }\end{array}$ & $\begin{array}{l}\text { Laying } \\
\text { hens }\end{array}$ & $\begin{array}{l}\text { Other } \\
\text { poultry }\end{array}$ & $\begin{array}{l}\text { Fur } \\
\text { animals }\end{array}$ \\
\hline Austria & 106 & 46 & 9 & 48 & 13 & 0.7 & 0.4 & 4.1 \\
\hline Belgium & 118 & 50 & 11 & 50 & 7 & 0.7 & 0.5 & 4.1 \\
\hline Bulgaria & 75 & 45 & 12 & 50 & 12 & 0.8 & 0.7 & 1.5 \\
\hline Cyprus & 103 & 40 & 12 & 50 & 12 & 0.8 & 0.7 & 4.1 \\
\hline Czech Republic & $|3|$ & 45 & 12 & 50 & 12 & 0.8 & 0.6 & 1.5 \\
\hline Denmark & 132 & 37 & 10 & 43 & 17 & 0.7 & 0.5 & 4.6 \\
\hline Estonia & 113 & 45 & 12 & 50 & 14 & 0.8 & 0.5 & 4.1 \\
\hline Finland & 121 & 53 & 10 & 50 & 16 & 0.8 & 0.4 & 1.9 \\
\hline France & 112 & 50 & 12 & 50 & 12 & 0.8 & 0.9 & 4.1 \\
\hline Germany & 130 & 40 & 15 & 48 & 8 & 0.8 & 0.6 & 4.1 \\
\hline Greece & 111 & 45 & 12 & 50 & 12 & 0.8 & 0.7 & 4.1 \\
\hline Hungary & 146 & 45 & 9 & 50 & 12 & 1.5 & 1.5 & 4.1 \\
\hline Ireland & 105 & 69 & 12 & 50 & 8 & 0.8 & 0.5 & 4.1 \\
\hline Italy & 112 & 47 & 12 & 50 & 16 & 0.7 & 0.5 & 4.1 \\
\hline Latvia & 88 & 51 & 10 & 51 & 7 & 0.9 & 0.9 & 4.1 \\
\hline Lithuania & 95 & 50 & 12 & 50 & 12 & 0.8 & 0.5 & 4.1 \\
\hline Luxembourg & 114 & 42 & 10 & 50 & 12 & 0.8 & 0.7 & 4.1 \\
\hline Malta & 98 & 40 & 12 & 50 & 12 & 0.8 & 0.7 & 0.7 \\
\hline Netherlands & 147 & 40 & 9 & 50 & 12 & 0.7 & 0.6 & 2.2 \\
\hline Poland & 81 & 35 & 11 & 50 & 14 & 0.7 & 0.6 & 4.1 \\
\hline Portugal & 102 & 50 & 9 & 39 & 7 & 0.6 & 0.9 & 0.7 \\
\hline Romania & 67 & 45 & 12 & 50 & 12 & 0.8 & 0.7 & 4.1 \\
\hline Slovakia & 135 & 45 & 12 & 50 & 12 & 0.8 & 0.7 & 4.1 \\
\hline Slovenia & 110 & 40 & 12 & 50 & 11 & 0.7 & 0.5 & 4.1 \\
\hline Spain & 71 & 52 & 9 & 40 & 5 & 0.8 & 0.6 & 4.1 \\
\hline Sweden & 132 & 39 & 11 & 50 & 6 & 0.6 & 0.3 & 4.1 \\
\hline United Kingdom & 133 & 49 & 12 & 50 & 6 & 0.9 & 0.7 & 4.1 \\
\hline Mean & 111 & 46 & 11 & 49 & 11 & 0.8 & 0.6 & 3.5 \\
\hline St. Deviation & 21 & 7 & 1 & 3 & 3 & 0.2 & 0.2 & 1.2 \\
\hline $\begin{array}{l}\text { St. Deviation (\% } \\
\text { of the Mean) }\end{array}$ & $19 \%$ & $14 \%$ & $13 \%$ & $6 \%$ & $29 \%$ & $20 \%$ & $35 \%$ & $33 \%$ \\
\hline
\end{tabular}


Table S2.2 | Share of total manure excreted in housing systems that is applied to arable land (\%) (remainder is applied to grassland and fodder crops) in European countries as used in INTEGRATOR (after Menzi, 2002).

\begin{tabular}{|c|c|c|c|}
\hline \multirow[b]{2}{*}{ Country } & \multicolumn{3}{|c|}{ Share of total manure applied to arable land (\%) } \\
\hline & $\begin{array}{l}\text { Liquid manure of dairy/ } \\
\text { other cattle, pigs }\end{array}$ & $\begin{array}{l}\text { Solid manure of dairy/ } \\
\text { other cattle, pigs }\end{array}$ & Poultry manure \\
\hline Austria & 40 & 60 & 95 \\
\hline Belgium & 80 & 100 & 100 \\
\hline Bulgaria & 80 & 80 & 80 \\
\hline Czech Republic & 20 & 80 & 90 \\
\hline Germany & 85 & 85 & 100 \\
\hline Denmark & 75 & 75 & 97 \\
\hline Estonia & 80 & 80 & 80 \\
\hline Spain & 75 & 100 & 100 \\
\hline Finland & 80 & 90 & 100 \\
\hline France & 80 & 95 & 98 \\
\hline Greece & 20 & 20 & 50 \\
\hline Hungary & 63 & 95 & 75 \\
\hline Ireland & 5 & 0 & 0 \\
\hline Italy & 74 & 90 & 80 \\
\hline Latvia & 80 & 80 & 80 \\
\hline Lithuania & 10 & 90 & 100 \\
\hline Luxembourg & 30 & 90 & 100 \\
\hline Netherlands & 35 & 50 & 100 \\
\hline Poland & 80 & 90 & 89 \\
\hline Portugal & 100 & 100 & 100 \\
\hline Romania & 80 & 80 & 80 \\
\hline Sweden & 22 & 70 & 100 \\
\hline Slovenia & 80 & 80 & 80 \\
\hline Slovakia & 80 & 100 & 100 \\
\hline United Kingdom & 25 & 50 & 56 \\
\hline
\end{tabular}


Table S2.3 | Maximum nitrogen contents of harvested crop products (fresh weight) and nitrogen indices used in the uptake calculation for the crops distinguished by INTEGRATOR (source: Velthof and Kuikman, 2000; Velthof et al., 2009), and total crop area for each crop. The table shows a categorization of crops under arable land and fodder/grassland.

\begin{tabular}{|c|c|c|c|c|c|c|}
\hline $\begin{array}{l}\text { CAPRI } \\
\text { CODE }\end{array}$ & $\begin{array}{l}\text { CAPRI } \\
\text { ID }\end{array}$ & CAPRI description & $\begin{array}{l}\text { Max. N } \\
\text { content } \\
\left(\mathrm{g} \mathrm{kg}^{-1}\right)\end{array}$ & $\begin{array}{l}\mathbf{N} \text { index } \\
\left(\mathbf{N}_{\text {off }} / \mathbf{N}_{\text {cr }}\right) \\
(-)\end{array}$ & frNup (-) & $\begin{array}{l}\text { Area } \\
\left(\mathbf{k m}^{2}\right)\end{array}$ \\
\hline \multicolumn{7}{|c|}{ Arable land } \\
\hline SWHE & 1 & Common wheat & 20 & 3.02 & 0.8 & 249,796 \\
\hline DWHE & 2 & Durum Wheat & 20 & 3.02 & 0.8 & 36,812 \\
\hline BARL & 3 & Barley & 17 & 2.37 & 0.8 & 139,898 \\
\hline RYEM & 4 & Rye & 14 & 1.79 & 0.8 & 24,060 \\
\hline OATS & 5 & Oats & 17 & 2.08 & 0.8 & 42,116 \\
\hline MAIZ & 6 & Maize (= grain maize) & 14 & 1.53 & 0.8 & 87,980 \\
\hline PARI & 7 & Rice & 20 & 3.02 & 0.8 & 4,853 \\
\hline OCER & 8 & Other cereals & 15 & 2.02 & 0.8 & 31,823 \\
\hline POTA & 9 & Potatoes & 3.5 & 3.13 & 0.8 & 16,262 \\
\hline SUGB & 10 & Sugar beet & 1.8 & 0.67 & 0.8 & $|6,37|$ \\
\hline SUNF & 12 & Sunflower & 32 & 1.79 & 0.8 & $4 I, 4 I 7$ \\
\hline RAPE & 13 & Rape and turnip rape & 35 & 1.79 & 0.8 & 76,525 \\
\hline SOYA & 14 & Soy & 58 & 1.061 & 0.8 & 3,849 \\
\hline TEXT & 15 & Fibre and oleaginous crops; Cotton & 4.0 & 1.11 & 0.8 & 3,513 \\
\hline TOBA & 16 & Tobacco & 30 & 2.05 & 0.8 & 960 \\
\hline PULS & 18 & Dry pulses & 42 & $1.10^{1}$ & 0.8 & 15,993 \\
\hline OVEG & 20 & Other fresh vegetables & 2.5 & 1.16 & 0.8 & 15,227 \\
\hline FRUI & 24 & Other Fruit & 6.7 & 3.00 & 0.8 & 25,435 \\
\hline CITR & 25 & Citrus fruits: Oranges & 2.7 & 2.05 & 0.8 & 5,342 \\
\hline OLIV & 26 & Olive groves & 20 & 2.05 & 0.8 & 47,681 \\
\hline TWIN & 27 & Vineyards /table wine & 4.6 & 2.05 & 0.8 & 22,645 \\
\hline OCRO & 29 & Other crops; Permanent industrial crops & 5.0 & 2.05 & 0.8 & 1,680 \\
\hline OWIN & 31 & Other wine & 0.5 & 2.10 & 0.8 & 9,917 \\
\hline TAGR & 35 & Table grapes & 4.6 & 2.10 & 0.8 & 961 \\
\hline TABO & 36 & Table olives & 20 & 2.10 & 0.8 & 2,848 \\
\hline OOIL & 37 & Other oil & 34 & 1.30 & 0.8 & 2,048 \\
\hline \multicolumn{7}{|c|}{ Fodder + Grassland } \\
\hline OFAR & 22 & $\begin{array}{l}\text { Fodder other on arable land; Temporary } \\
\text { grasslands }\end{array}$ & 5.8 & 2.43 & 1.0 & 153,833 \\
\hline GRAS & 33 & Grassland & $30^{2}$ & 2.00 & 1.0 & 382,486 \\
\hline MAIF & 34 & Fodder maize & 15 & 4.90 & 1.0 & 54,038 \\
\hline
\end{tabular}

' Data on the $\mathrm{N}$ index for soy and pulses are based on Herridge et al (2008).

${ }^{2} \mathrm{~N}$ contents in grass are given in dry weight since grassland yields are in dry weight. 
Table S2.4 | Average annual actual (year 2010) and critical N inputs for all agricultural land in the EU for different thresholds as calculated by INTEGRATOR

\begin{tabular}{|c|c|c|c|c|}
\hline & \multicolumn{4}{|c|}{$N$ budget EU (kg N ha-1 $\left.y r^{-1}\right)$} \\
\hline & Actual & $\begin{array}{l}\text { At critical } \mathrm{NH}_{3} \\
\text { emission }\end{array}$ & $\begin{array}{l}\text { At critical } N \\
\text { runoff to surface } \\
\text { water }\end{array}$ & $\begin{array}{l}\text { At critical } \mathrm{N} \text { leaching } \\
\text { to groundwater }\end{array}$ \\
\hline \multicolumn{5}{|l|}{$\mathrm{N}$ input to land } \\
\hline Fertilizer & 72 & 58 & $4 I$ & 76 \\
\hline Fixation & 8 & 5 & 4 & 7 \\
\hline Excretion & 54 & 28 & 29 & 48 \\
\hline Biosolids & I & I & I & I \\
\hline Deposition & II & 8 & 7 & 13 \\
\hline Mineralisation' & I & I & 1 & I \\
\hline Total $\mathrm{N}$ input & 145 & 100 & 83 & 147 \\
\hline \multicolumn{5}{|l|}{$\mathrm{N}$ output from land } \\
\hline Crop offtake ${ }^{2}$ & 92 & 66 & 56 & 97 \\
\hline Air emission $\left(\mathrm{NH}_{3}, \mathrm{~N}_{2} \mathrm{O}, \mathrm{NO}_{\mathrm{x}}\right)$ & 19 & 12 & 12 & 20 \\
\hline Denitrification & 17 & II & 7 & 15 \\
\hline Runoff to surface water & 8 & 113 & 4 & 8 \\
\hline Leaching to groundwater & 9 & & 3 & 7 \\
\hline Total N output & 145 & 100 & 83 & 147 \\
\hline
\end{tabular}

' Net $\mathrm{N}$ mineralisation is only calculated for (drained) peat soils. No change in soil $\mathrm{N}$ pool (neither mineralisation nor accumulation) was assumed for mineral soils. Results shown in the table, however, only refer to part of the peat soils, as approximately 2,500 crop-NCU combinations on peat soils were excluded. In these combinations, critical $\mathrm{N}$ inputs from fertilizer and excretion were negative because mineralisation alone leads to the exceedance of critical limits for runoff and/or leaching. This does not significantly affect results for critical $\mathrm{N}$ inputs, but does lower mean mineralisation rates from $5 \mathrm{~kg} \mathrm{~N}$ $\mathrm{ha}^{-1} \mathrm{yr}^{-1}$ to I $\mathrm{kg} \mathrm{N} \mathrm{ha}^{-1} \mathrm{yr}^{-1}$ (for all agricultural land).

${ }^{2}$ Crop $\mathrm{N}$ offtake refers to the net removal (crop or grass) from agricultural land.

${ }^{3}$ For the $\mathrm{N}$ budget at critical $\mathrm{NH}_{3}$ emissions, only the sum of the loss terms 'runoff to surface water' and 'leaching to groundwater' is provided. 
Table S2.5 | Actual (2010) $\mathrm{N}$ inputs (kton $\mathrm{N} \mathrm{yr}^{-1}$ ) and critical $\mathrm{N}$ inputs for all agricultural land, in view of critical thresholds for $\mathrm{NH}_{3}$ emissions, $\mathrm{N}$ runoff to surface water and $\mathrm{N}$ leaching to groundwater, per country.

\begin{tabular}{|c|c|c|c|c|}
\hline \multirow[b]{2}{*}{ Country } & \multicolumn{4}{|c|}{$\mathbf{N}$ inputs (kton $\mathbf{N}$ yr') } \\
\hline & Actual & $\begin{array}{l}\text { At critical } \mathrm{NH}_{3} \\
\text { emission }\end{array}$ & $\begin{array}{l}\text { At critical } N \text { runoff } \\
\text { to surface water }\end{array}$ & $\begin{array}{l}\text { At critical } \mathrm{N} \text { leaching } \\
\text { to groundwater }\end{array}$ \\
\hline Austria & 325 & 338 & 255 & 371 \\
\hline Belgium & 431 & 366 & 147 & 297 \\
\hline Bulgaria & 304 & 267 & 185 & 341 \\
\hline Czech Republic & 466 & 365 & 214 & 423 \\
\hline Germany & 3,426 & 2,096 & 1,664 & 3,143 \\
\hline Denmark & 453 & 185 & 175 & 476 \\
\hline Estonia & 72 & 72 & 70 & 72 \\
\hline Spain & ।,738 & 1,016 & 941 & ।,708 \\
\hline Finland & 236 & 241 & 246 & 272 \\
\hline France & 4,299 & 3,109 & 2,500 & 4,869 \\
\hline Greece & 316 & 220 & 128 & 259 \\
\hline Hungary & 470 & 336 & 227 & 471 \\
\hline Ireland & 955 & 389 & 869 & 1,132 \\
\hline Italy & ।,527 & 756 & 715 & ।,440 \\
\hline Lithuania & 261 & 194 & 202 & 271 \\
\hline Luxemburg & 28 & 18 & 21 & 29 \\
\hline Latvia & 90 & 113 & 115 & 120 \\
\hline Netherlands & 695 & 378 & 182 & 467 \\
\hline Poland & 1,869 & 1,023 & 628 & 1,415 \\
\hline Portugal & 193 & 146 & 136 & 174 \\
\hline Romania & 903 & 786 & 535 & 961 \\
\hline Sweden & 326 & 365 & 366 & 511 \\
\hline Slovenia & 69 & 51 & 64 & 69 \\
\hline Slovakia & 192 & $|2|$ & 109 & 194 \\
\hline United Kingdom & 2,149 & 2,096 & 1,715 & 2,578 \\
\hline EU & 21,791 & 15,045 & 12,409 & 22,062 \\
\hline
\end{tabular}


Table S2.6 | Actual $\mathrm{N}$ inputs and critical $\mathrm{N}$ inputs for all agricultural land, in view of critical $\mathrm{NH}_{3}$ emissions, critical runoff to surface water and critical leaching to groundwater, and difference between actual and critical $\mathrm{N}$ inputs (as percentage of actual $\mathrm{N}$ inputs). Negative values thus indicate by how much actual $\mathrm{N}$ inputs need to decrease in order to respect environmental thresholds, and positive values indicate by how much actual $\mathrm{N}$ inputs are allowed to increase while respecting environmental thresholds.

\begin{tabular}{|c|c|c|c|c|c|c|c|}
\hline \multirow[t]{2}{*}{ Country } & \multicolumn{4}{|c|}{$\mathbf{N}$ inputs (kg $\mathbf{N}$ ha $\left.^{-1} y^{\prime} \mathbf{r}^{\prime}\right)$} & \multicolumn{3}{|c|}{ Difference actual/critical (\%) } \\
\hline & Actual & $\begin{array}{l}\text { At critical } \\
\mathrm{NH}_{3} \text { emission }\end{array}$ & $\begin{array}{l}\text { At critical } \\
\mathrm{N} \text { runoff to } \\
\text { surface water }\end{array}$ & $\begin{array}{l}\text { At critical N } \\
\text { leaching to } \\
\text { groundwater }\end{array}$ & $\mathrm{NH}_{3}$ & $\begin{array}{l}\text { Surface } \\
\text { water }\end{array}$ & $\begin{array}{l}\text { Ground- } \\
\text { water }\end{array}$ \\
\hline Austria & 140 & 146 & 110 & 160 & $4 \%$ & $-22 \%$ & $14 \%$ \\
\hline Belgium & 319 & 272 & 109 & 220 & $-15 \%$ & $-66 \%$ & $-31 \%$ \\
\hline Bulgaria & 79 & 69 & 48 & 88 & $-12 \%$ & $-39 \%$ & $12 \%$ \\
\hline Czech Republic & 135 & 105 & 62 & 122 & $-22 \%$ & $-54 \%$ & $-9 \%$ \\
\hline Germany & 214 & $|3|$ & 104 & 197 & $-39 \%$ & $-51 \%$ & $-8 \%$ \\
\hline Denmark & 178 & 73 & 69 & 187 & $-59 \%$ & $-61 \%$ & $5 \%$ \\
\hline Estonia & 90 & 91 & 89 & 91 & $1 \%$ & $-2 \%$ & $1 \%$ \\
\hline Spain & 94 & 55 & 51 & 93 & $-42 \%$ & $-46 \%$ & $-2 \%$ \\
\hline Finland & 104 & 106 & 108 & 120 & $2 \%$ & $4 \%$ & $15 \%$ \\
\hline France & 168 & 122 & 98 & 190 & $-28 \%$ & $-42 \%$ & $13 \%$ \\
\hline Greece & 106 & 74 & 43 & 87 & $-31 \%$ & $-60 \%$ & $-18 \%$ \\
\hline Hungary & $12 \mid$ & 86 & 58 & $|2|$ & $-29 \%$ & $-52 \%$ & $0 \%$ \\
\hline Ireland & 231 & 94 & 210 & 274 & $-59 \%$ & $-9 \%$ & $19 \%$ \\
\hline Italy & 132 & 65 & 62 & 124 & $-51 \%$ & $-53 \%$ & $-6 \%$ \\
\hline Lithuania & 98 & 73 & 76 & 102 & $-26 \%$ & $-22 \%$ & $4 \%$ \\
\hline Luxemburg & 210 & 137 & 162 & 223 & $-35 \%$ & $-23 \%$ & $6 \%$ \\
\hline Latvia & 72 & 90 & 91 & 95 & $25 \%$ & $27 \%$ & $33 \%$ \\
\hline Netherlands & 385 & 209 & 101 & 259 & $-46 \%$ & $-74 \%$ & $-33 \%$ \\
\hline Poland & $14 \mid$ & 77 & 47 & 106 & $-45 \%$ & $-66 \%$ & $-24 \%$ \\
\hline Portugal & 88 & 66 & 61 & 79 & $-24 \%$ & $-30 \%$ & $-10 \%$ \\
\hline Romania & 73 & 63 & 43 & 78 & $-13 \%$ & $-41 \%$ & $6 \%$ \\
\hline Sweden & 108 & 121 & 121 & 169 & $12 \%$ & $13 \%$ & $57 \%$ \\
\hline Slovenia & 161 & 118 & 149 & 162 & $-26 \%$ & $-7 \%$ & $1 \%$ \\
\hline Slovakia & 106 & 67 & 61 & 108 & $-37 \%$ & $-43 \%$ & $1 \%$ \\
\hline United Kingdom & 182 & 177 & 145 & 218 & $-2 \%$ & $-20 \%$ & $20 \%$ \\
\hline EU & 145 & 100 & 83 & 147 & $-31 \%$ & $-43 \%$ & $1 \%$ \\
\hline
\end{tabular}




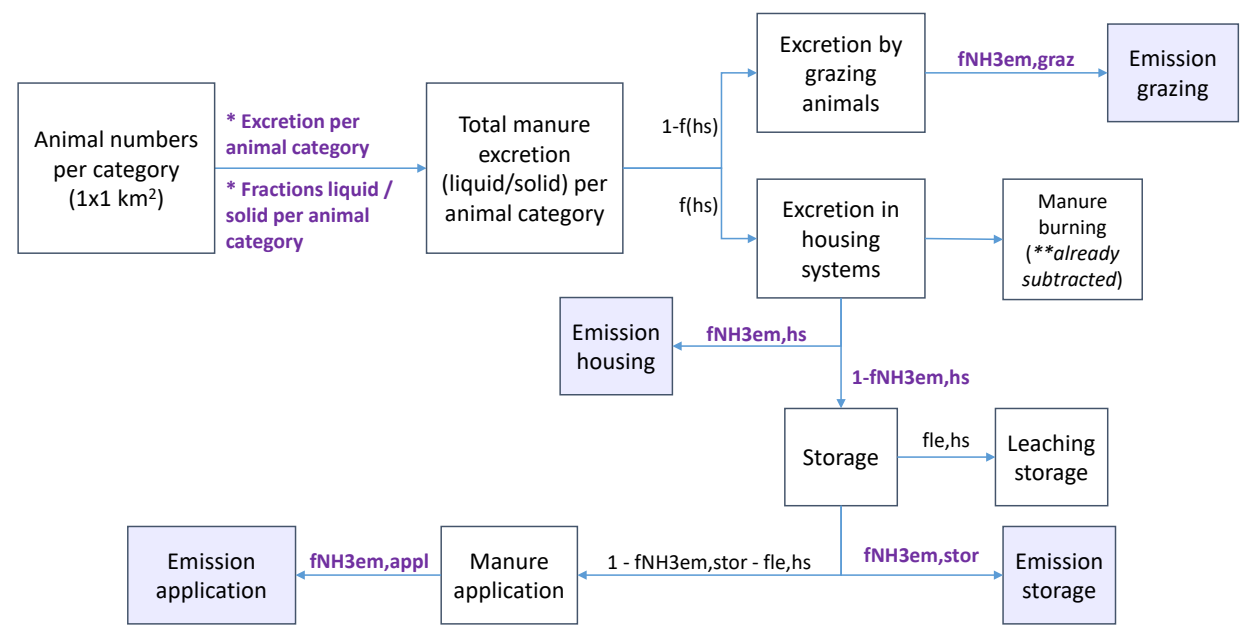

Figure S2.I | Overview of the calculation of $\mathrm{NH}_{3}$ emissions from animal manure in INTEGRATOR. $f(h s)=$ fraction manure excreted in housing systems; $\mathrm{fNH} 3 \mathrm{em}, \mathrm{graz}=\mathrm{NH}_{3}$ emission fraction for manure excreted by grazing animals; $\mathrm{fNH} 3 \mathrm{em}, \mathrm{hs}=\mathrm{NH}_{3}$ emission fraction for manure excreted in housing systems; $\mathrm{fNH} 3 \mathrm{em}$,stor $=\mathrm{NH}_{3}$ emission fraction for manure storage; $\mathrm{fNle}, \mathrm{hs}=\mathrm{N}$ leaching fraction for manure in storage systems; $\mathrm{fNH} 3 \mathrm{em}$,appl $=\mathrm{NH}_{3}$ emission fraction for manure application. 


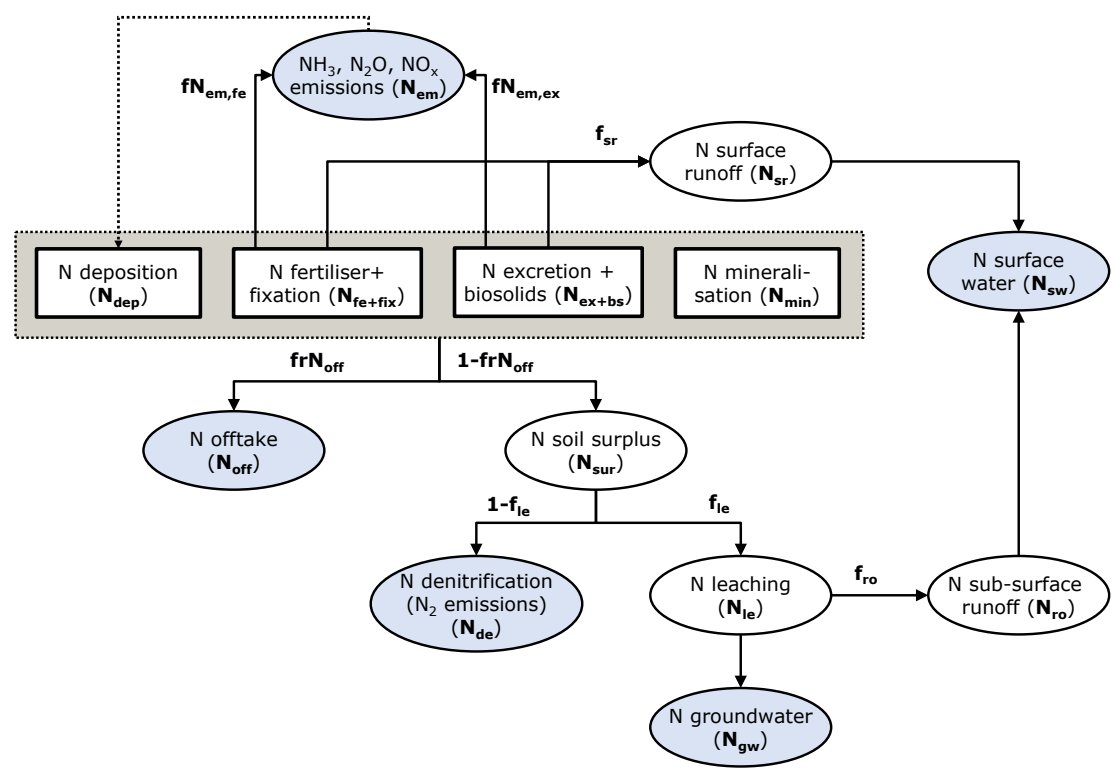

Figure S2.2 | Illustration of simplified model version used for calculating critical $\mathrm{N}$ input, showing links between $\mathrm{N}$ inputs, $\mathrm{N}$ losses to air as $\mathrm{N}$ emissions $\left(\mathrm{NH}_{3}, \mathrm{~N}_{2} \mathrm{O}\right.$ and $\left.\mathrm{NO}_{\mathrm{x}}\right)$ and denitrification $\left(\mathrm{N}_{2}\right.$ emissions) and $\mathrm{N}$ losses to groundwater and surface water due to $\mathrm{N}$ leaching and $\mathrm{N}$ runoff. All $\mathrm{N}$ flows are expressed in $\mathrm{kg} \mathrm{N} \mathrm{ha}^{-1} \mathrm{yr}^{-1}$. Grey box shows total $\mathrm{N}$ inputs, blue circles show total $\mathrm{N}$ outputs. Total $\mathrm{N}$ inputs equal total $\mathrm{N}$ outputs (assuming no soil accumulation). Critical $\mathrm{N}$ inputs are calculated for thresholds for $\mathrm{NH}_{3}$ emissions, $\mathrm{N}$ runoff to surface water or $\mathrm{NO}_{3}$ leaching to groundwater.

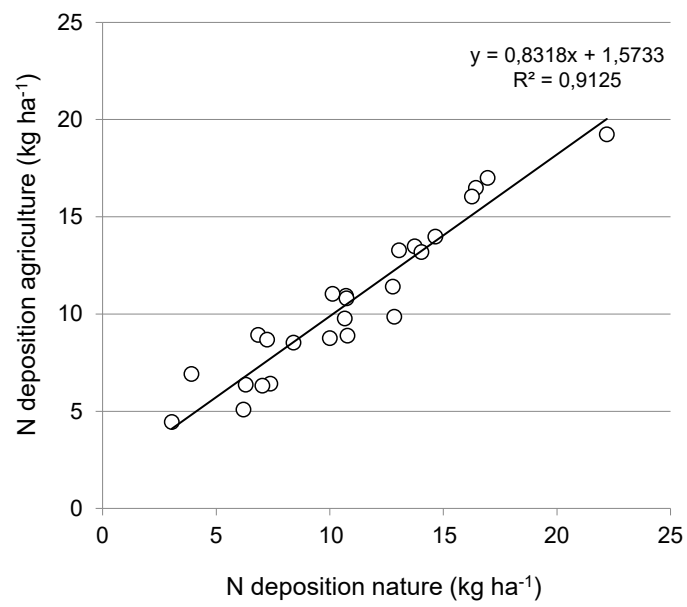

Figure S2.3 Relationship between total $\mathrm{N}\left(\mathrm{NH}_{3}-\mathrm{N}\right.$ and $\left.\mathrm{NO}_{x}-\mathrm{N}\right)$ deposition on agricultural land and total $\mathrm{N}$ deposition on non-agricultural land for the $27 \mathrm{EU}$ Member States (year 2010), based on EMEP data. 


\section{a. Arable land}

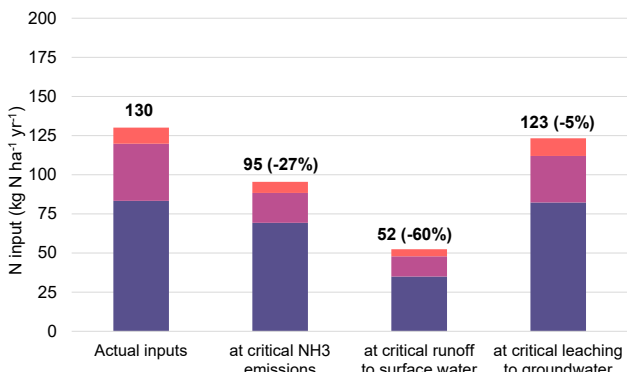

c. Wheat

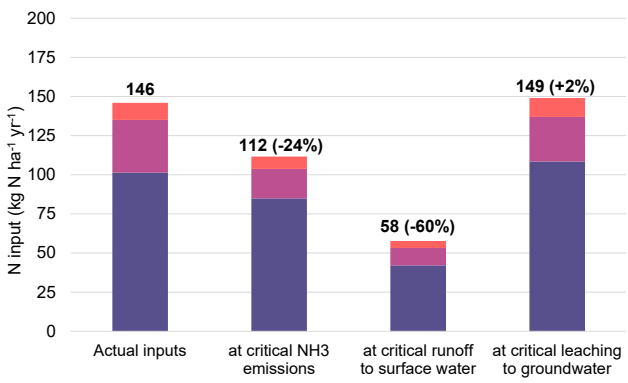

\section{e. Other $\mathrm{C} 3$ cereals}

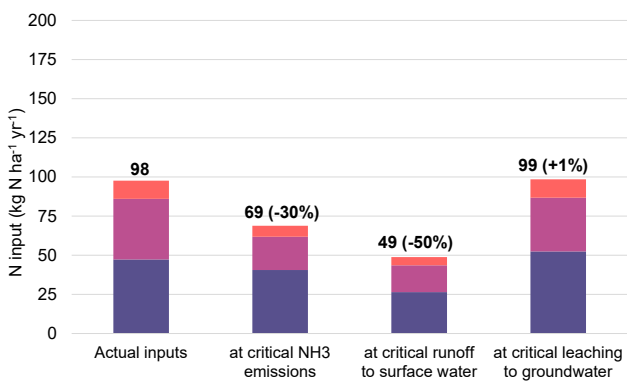

Fertiliser + BNF

\section{b. Grassland \& Fodder}

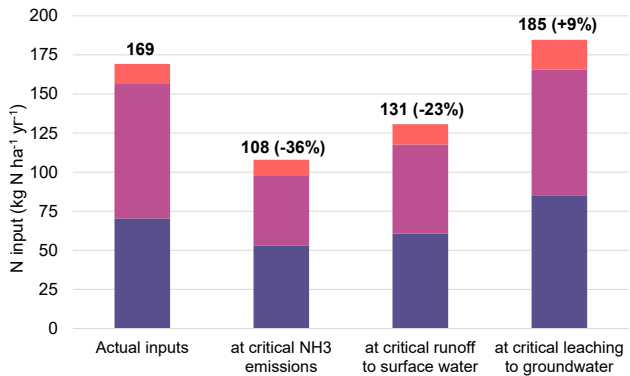

\section{d. Barley}

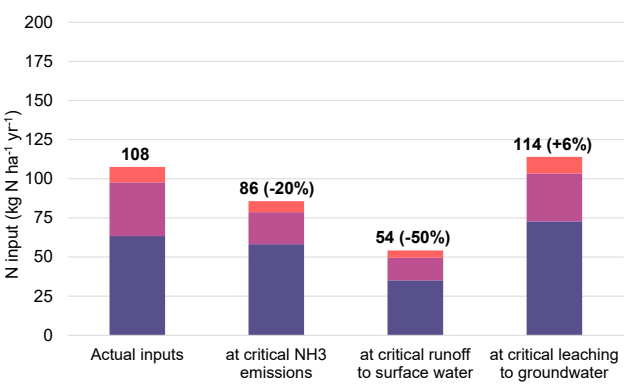

\section{f. Maize}

200

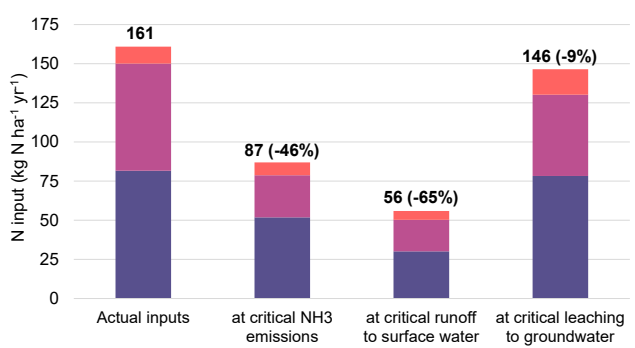

Deposition + mineralization

Figure S2.4 | Average actual (year 2010) and critical $\mathrm{N}$ inputs in view of thresholds for $\mathrm{NH}_{3}$ emissions, $\mathrm{N}$ runoff to surface water and $\mathrm{N}$ leaching to groundwater for the $\mathrm{EU}$ on $\mathbf{a}$, arable land, $\mathbf{b}$, grassland + fodder, c, wheat, $\mathbf{d}$, barley, e, other C3 cereals and f, maize. 'Other C3 cereals' includes rye, oats, rice and other cereals (see also Table S2.3). 


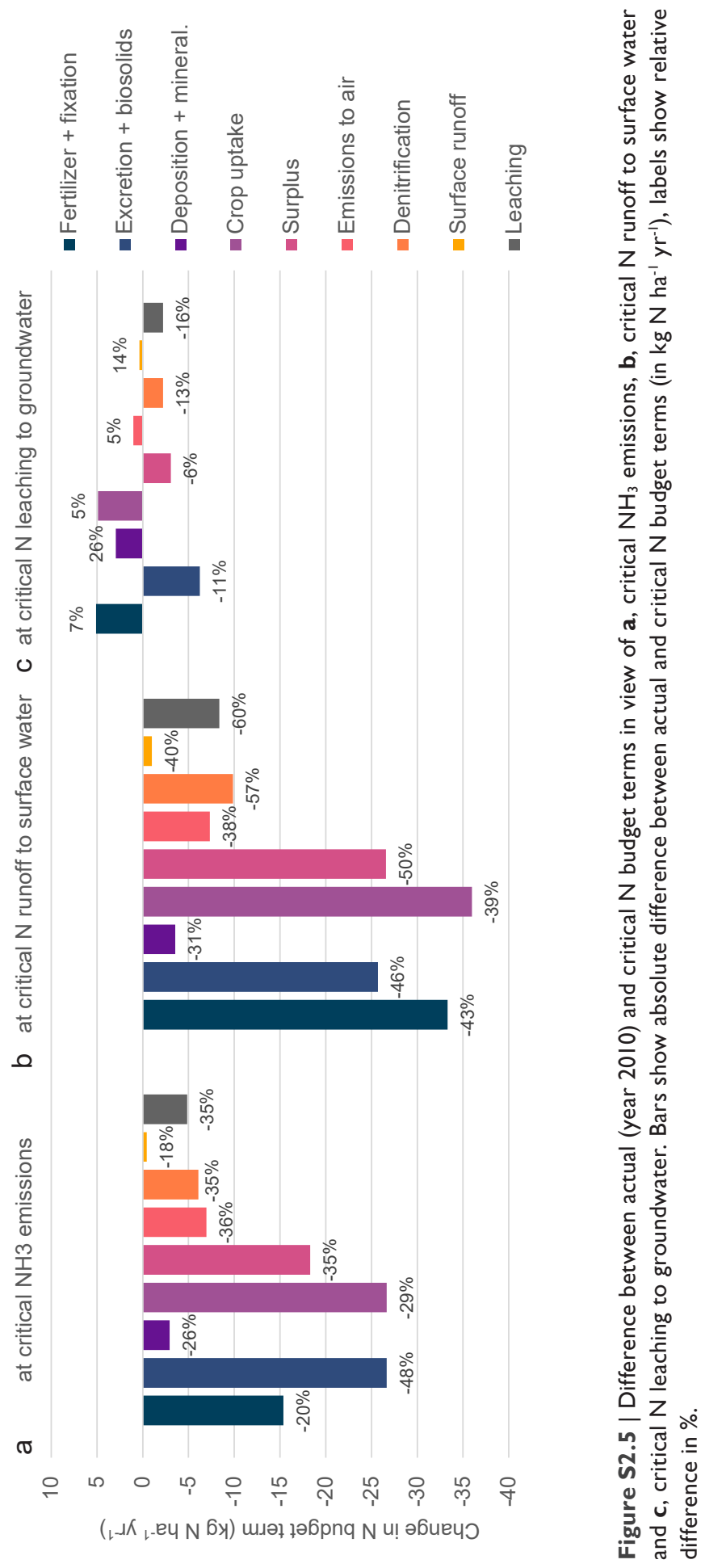



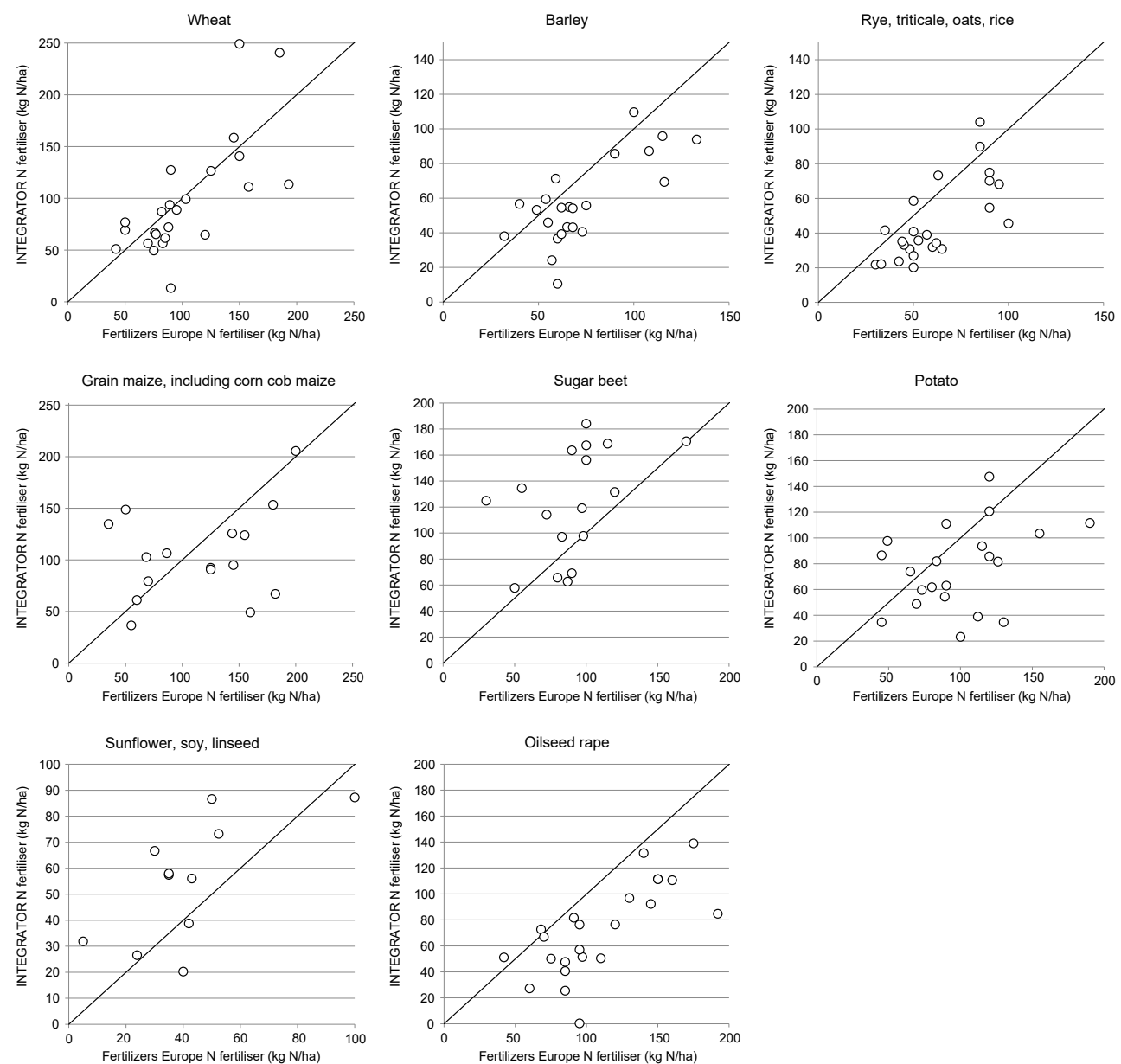

Figure S2.6 | Comparison of calculated N fertilizer application rates from INTEGRATOR with expert estimates provided by Fertilizers Europe for major crops. 

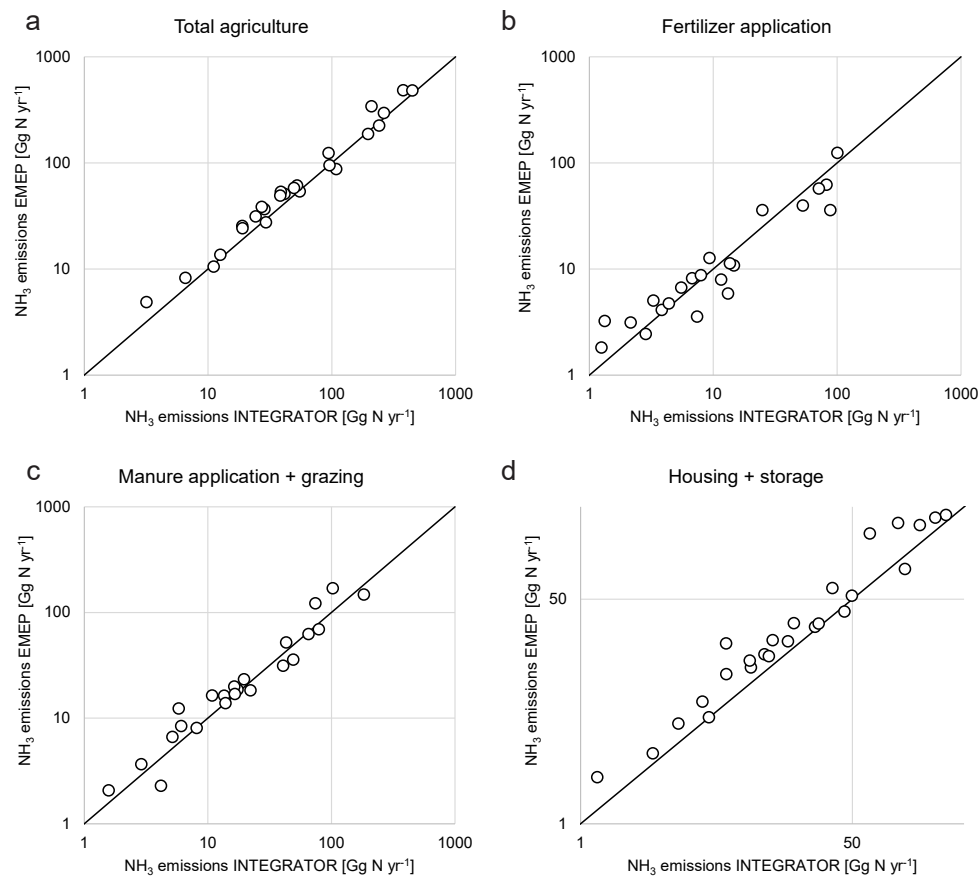

Figure S2.7 | Comparison of country-level $\mathrm{NH}_{3}$ emissions submitted by Parties to the LRTAP Convention to the EMEP programme (officially reported level 2 emissions for 2010 obtained from EMEP database) vs. country-level $\mathrm{NH}_{3}$ emissions from INTEGRATOR for a, total agriculture, b, fertilizer application, c, manure application \& grazing and d, housing \& storage. Scales of axes are logarithmic.

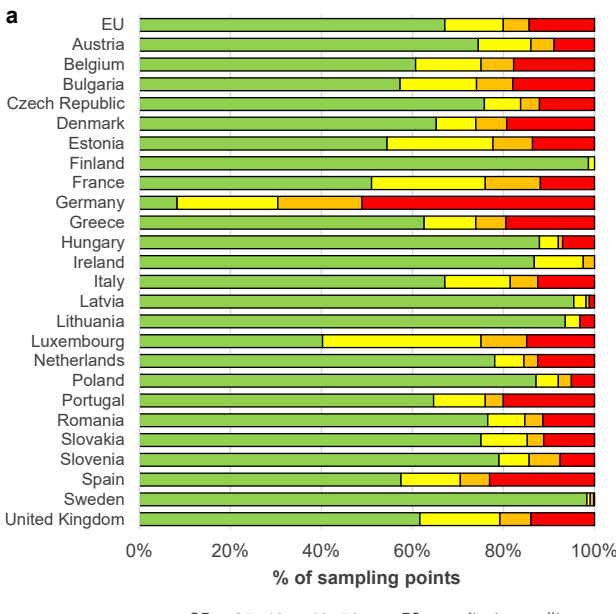

$\square<25 \square 25-40 \quad \square 40-50 \square>50$ mg nitrate per litre

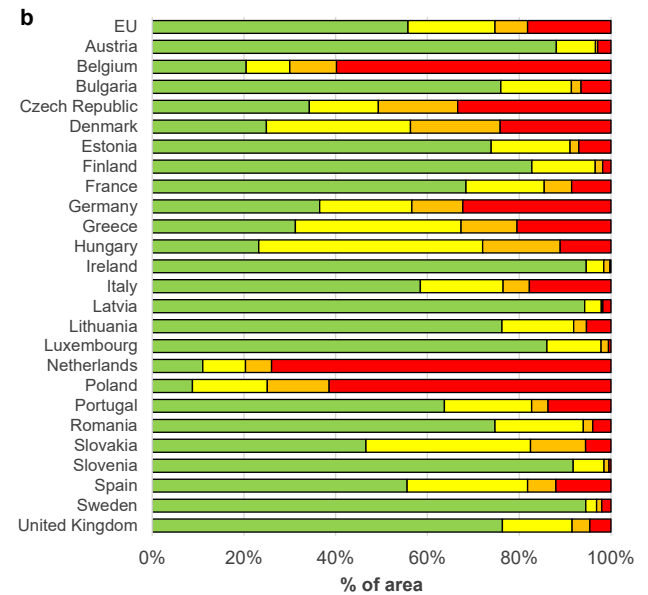

$\square<25 \square 25-40 \square 40-50 \square>50$ mg nitrate per litre

Figure S2.8 | a, Share of sampling points in a given $\mathrm{NO}_{3}{ }^{-}$concentration range reported by countries under the Nitrates Directive (EC, 20I3) and $\mathbf{b}$, share of area in a given $\mathrm{NO}_{3}{ }^{-}$concentration range in $\mathrm{N}$ leachate to groundwater calculated with INTEGRATOR. 


\section{Supplementary Material Chapter 3}

Supplementary Methods

S3.I. Method for deriving water-limited yield potentials per crop and country

S3.2. Calculation of necessary (reductions in) ammonia emission fractions for manure

S3.3. Calculation of necessary (increases in) nitrogen use efficiency

\section{S3.I. Method for deriving water-limited yield potentials per crop and country}

To estimate yield potentials for all INTEGRATOR crops and all EU countries, we multiplied actual yields per climate zone with yield gaps per crop and climate zone for wheat obtained from the Global Yield Gap Atlas (GYGA, www.yieldgap.org). To account for differences in yield variability and performance between wheat and other crops, we then multiplied with a ratio indicating the distance to the European maximum yield for the respective crop as compared to the distance to the European maximum wheat yield.

$$
Y w_{\text {crop }_{n}, c z_{i j}}=Y a_{\text {crop }_{n}, c z_{i j}} * Y R w_{w_{\text {heat }, c z_{i j}}} *\left(\frac{Y R m_{\text {crop }_{n}, c o_{j}}}{Y R m_{\text {wheat }, c o_{j}}}\right)
$$

Where:

$$
\begin{aligned}
& \mathrm{Yw}_{\mathrm{Crop}_{\mathrm{n}}, \mathrm{CZ}_{\mathrm{ij}}}=\text { water-limited yield potential for crop } \mathrm{n} \text { in climate zone } \mathrm{i} \text { and country } \mathrm{j}\left[\mathrm{kg} \mathrm{ha}^{-1}\right. \\
& \mathrm{yr}^{-1} \text { ] } \\
& \mathrm{Ya}_{\mathrm{Crop}_{\mathrm{n}}, \mathrm{CZ}_{\mathrm{ij}}}=\text { actual yield for crop } \mathrm{n} \text { in climate zone } \mathrm{i} \text { and country } \mathrm{j}\left[\mathrm{kg} \mathrm{ha}^{-1} \mathrm{yr}^{-1}\right. \text { (from }
\end{aligned}
$$




$$
\begin{aligned}
& \text { in climate zone } \mathrm{i} \text { and country } \mathrm{j} \text { from GYGA }\left[\mathrm{t} \mathrm{ha}^{-1} \mathrm{yr}^{-1}\right] \text {. } \\
& \mathrm{YRm}_{\text {wheat, } \mathrm{Co}_{j}}=\text { 'maximum yield ratio' for wheat in country } \mathrm{j}[-] \text {, defined as } \mathrm{Y}_{\text {max, wheat,EU/ }} \\
& \mathrm{Ya}_{\text {wheat, }} \mathrm{co}_{j} \text {, where } \mathrm{Y}_{\max } \text {,wheat,EU is the is highest country-level yield for } \\
& \text { wheat in the EU from INTEGRATOR }\left[\mathrm{kg} \mathrm{ha}^{-1} \mathrm{yr}^{-1}\right] \text { and } \mathrm{Ya}_{\text {wheat, }} \mathrm{co}_{j} \text { is the actual } \\
& \text { yield for wheat in country } \mathrm{j} \text { from INTEGRATOR }\left[\mathrm{kg} \mathrm{ha}^{-1} \mathrm{yr}^{-1}\right] \text {. }
\end{aligned}
$$

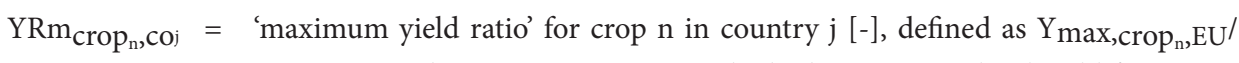

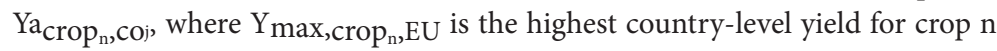

$$
\begin{aligned}
& \text { in the EU from INTEGRATOR [ } \mathrm{kg} \mathrm{ha}^{-1} \mathrm{yr}^{-1} \text { ] and } \mathrm{Ya}_{\mathrm{Crop}_{\mathrm{n}}, \mathrm{coj}} \text { is the actual yield } \\
& \text { for crop } \mathrm{n} \text { in country } \mathrm{j} \text { from INTEGRATOR }\left[\mathrm{kg} \mathrm{ha}^{-1} \mathrm{yr}^{-1}\right] \text {. }
\end{aligned}
$$

For grassland, we only applied the scaling to intensive grassland (dry matter production > $4,500 \mathrm{~kg} \mathrm{yr}^{-1}$ ), as we assumed that extensive grasslands will not be managed by farmers to maximize yields. If $80 \%$ of the water-limited yield potential was lower than the actual yield we set the target yield to the actual yield. The target yield for crop $\mathrm{n}$ in climate zone $\mathrm{i}$ of country $\mathrm{j}$ was thus calculated as:

$$
\operatorname{Ytarget}_{c r o p_{n}, c z_{i j}}=\max \left(0.8 * Y w_{\text {crop }_{n}, c z_{i j}} ; Y a\right)
$$

Certain crops in INTEGRATOR are actually 'crop groups', such as 'other fruit', containing several types of fruit with very different yields (e.g. melons and strawberries). For these crop groups, the 'maximum yield ratio' is not a meaningful measure, because the type of crops belonging to each group vary strongly per country. Therefore, for these crop groups yield potentials were calculated by scaling with the potential yield ratio for wheat, as:

$$
Y w_{\text {crop }_{n}, c z_{i j}}=Y a_{c r o p, c z_{i j}} * Y R w_{\text {wheat }, c z_{i j}}
$$

This exception applies to the following crop groups in INTEGRATOR: "Fibre and oleaginous crops; cotton", "Other fresh vegetables", "Fodder other on arable land, temporary grassland", "Other fruit", "Other crops", "Permanent industrial crops" and "Other oil".

\section{S3.2. Calculation of necessary (reductions in) ammonia emission fractions for manure}

For all regions where actual $\mathrm{NH}_{3}$ emissions exceeded critical $\mathrm{NH}_{3}$ emissions, we calculated 'necessary' $\mathrm{NH}_{3}$ emission fractions for manure. 'Necessary' emission fractions are defined as emission fraction at which current or target crop yields can be obtained without exceeding $\mathrm{N}$ deposition thresholds. At constant $\mathrm{N}$ input, reducing $\mathrm{NH}_{3}$ emission fractions also affects $\mathrm{N}$ offtake (at lower $\mathrm{NH}_{3}$ emissions, more $\mathrm{N}$ is available for uptake by the crop). We assumed 
that the fraction of effective $\mathrm{N}$ inputs ( $\mathrm{N}$ inputs after subtraction of $\mathrm{NH}_{3}$ emissions) that is taken up by the crop remains constant. This fraction is calculated as:

$$
N U E_{e f f}=\frac{\operatorname{Noff}_{(2010)}}{\operatorname{Nin}_{(2010)}-N_{3} \operatorname{em}_{(2010)}}
$$

Where:

$$
\begin{aligned}
& \operatorname{NUE}_{\text {eff }}=\text { Nitrogen use efficiency of effective } \mathrm{N} \text { inputs }[-] \\
& \operatorname{Noff}_{(2010)}=\text { Total crop N offtake for the year } 2010\left[\mathrm{~kg} \mathrm{~N} \mathrm{ha}^{-1} \mathrm{yr}^{-1}\right] \\
& \operatorname{Nin}_{(2010)}=\text { Total } \mathrm{N} \text { inputs to the soil for the year } 2010\left[\mathrm{~kg} \mathrm{~N} \mathrm{ha}^{-1} \mathrm{yr}^{-1}\right] \\
& N H 3_{\text {em(2010) }}=\text { Total NH3 emissions for the year } 2010\left[\mathrm{~kg} \mathrm{~N} \mathrm{ha}^{-1} \mathrm{yr}^{-1}\right]
\end{aligned}
$$

By re-arranging Eq. (S3.4), the maximum safe $\mathrm{N}$ input level ('critical' input level) at constant effective NUE was calculated from (i) the desired crop-uptake (either the current uptake or uptake at target yield) and (ii) a critical value for $\mathrm{NH}_{3}$ emissions (related to thresholds for $\mathrm{N}$ deposition on terrestrial ecosystems):

$$
\operatorname{Nin}_{(\text {crit }, \text { max })}=\frac{\operatorname{Noff} f_{(t a r)}}{N U E_{\text {eff }}}+N H 3 \operatorname{em}_{(\text {crit })}
$$

Where:

$$
\begin{aligned}
& \operatorname{Nin}_{(\text {crit,max })}=\text { Maximum safe (i.e. 'critical') level of } \mathrm{N} \text { inputs at target crop } \mathrm{N} \text { offtake and critical } \\
& \mathrm{NH}_{3} \text { emissions }\left[\mathrm{kg} \mathrm{N} \mathrm{ha}^{-1} \mathrm{yr}^{-1}\right] \\
& \left.\mathrm{Noff}_{\text {(tar) }} \quad=\text { Target crop } \mathrm{N} \text { offtake (current } \mathrm{N} \text { offtake or } \mathrm{N} \text { offtake at target yield) [ } \mathrm{kg} \mathrm{N} \mathrm{ha}^{-1} \mathrm{yr}^{-1}\right] \\
& \mathrm{NH}_{\text {em }} \text { (crit) }=\text { Critical } \mathrm{NH}_{3} \text { emissions in view of } \mathrm{N} \text { deposition thresholds for terrestrial ecosystems } \\
& {\left[\mathrm{kg} \mathrm{N} \mathrm{ha}^{-1} \mathrm{yr}^{-1}\right]}
\end{aligned}
$$

The share of $\mathrm{N}$ fertilizer and $\mathrm{N}$ manure in derived maximum critical $\mathrm{N}$ inputs was calculated assuming that the proportion of these two N sources stays constant (equal to 2010 values):

$$
\begin{aligned}
& N f e_{(\text {crit,max })}=f N_{f e} * \operatorname{Nin}_{(\text {crit }, \text { max })} \\
& \operatorname{Nman}_{(\text {crit,max })}=\left(1-f N_{f e}\right) * N i n_{(\text {crit }, \text { max })}
\end{aligned}
$$

Where:

$$
\begin{aligned}
& \mathrm{Nfe}_{(\text {(rit,max) }}= \text { Maximum critical level of } \mathrm{N} \text { fertilizer inputs at target crop } \mathrm{N} \text { offtake and critical } \\
& \mathrm{NH}_{3} \text { emissions }\left[\mathrm{kg} \mathrm{N} \mathrm{ha}^{-1} \mathrm{yr}^{-1}\right] \\
& \mathrm{Nman}_{\text {(crit,max) }}= \begin{array}{l}
\text { Maximum critical level of } \mathrm{N} \text { manure inputs at target crop } \mathrm{N} \text { offtake and critical } \\
\end{array} \\
& \mathrm{NH}_{3} \text { emissions }\left[\mathrm{kg} \mathrm{N} \mathrm{ha}^{-1} \mathrm{yr}^{-1}\right]
\end{aligned}
$$


As we assume the $\mathrm{NH}_{3}$ emissions fraction for fertilizer to remain unchanged, $\mathrm{NH}_{3}$ emissions from fertilizer application was calculated as:

$$
N H 3 e m_{f e(\text { crit })}=\text { fNH3em }_{f e} * N f e_{(\text {crit }, \text { max })}
$$

Where:

$$
\begin{aligned}
\mathrm{NH}_{3} \mathrm{em}_{\mathrm{fe}(\mathrm{crit})=} & \begin{array}{l}
\mathrm{NH}_{3} \text { emissions from fertilizer corresponding to maximum critical N input }[\mathrm{kg} \mathrm{N} \\
\left.\mathrm{ha}^{-1} \mathrm{yr}^{-1}\right]
\end{array} \\
\mathrm{fNH}_{\mathrm{Nem}}= & \mathrm{NH}_{3} \text { emission fraction for fertilizer inputs [-] }
\end{aligned}
$$

Finally, the necessary $\mathrm{NH}_{3}$ emission fraction for manure was derived by dividing the 'allowable' $\mathrm{NH}_{3}$ emissions from manure, given the critical $\mathrm{NH}_{3}$ emission level and the constant $\mathrm{NH}_{3}$ emissions from fertilizer, by maximum critical manure inputs:

$$
f N H 3 e m_{\operatorname{man}(n e c)}=\frac{N H 3 e m_{(\text {crit })}-N H 3 e m_{f e(c r i t)}}{N \operatorname{man}(\text { crit,max })}
$$

Because $\mathrm{NH}_{3}$ emissions from fertilizer application alone can exceed critical $\mathrm{NH}_{3}$ emission thresholds, $\mathrm{fNH}_{3} \mathrm{em}_{\operatorname{man}(n e c)}$ can become negative (this is also illustrated by Figure S2a, showing that even at a manure $\mathrm{NH}_{3} \mathrm{EF}$ of zero, current crop yields cannot be reconciled with thresholds for $\mathrm{NH}_{3}$ emissions on $\sim 11 \%$ of agricultural land). For these cases, we set



\section{S3.3. Calculation of necessary (increases in) nitrogen use efficiency}

For all regions where actual $\mathrm{N}$ runoff to surface water or $\mathrm{N}$ leaching to groundwater exceeded critical thresholds, we calculated the 'necessary' NUE, defined as NUEs at which current or target crop yields can be obtained without exceeding thresholds for $\mathrm{N}$ runoff or $\mathrm{N}$ leaching.

The necessary NUE was derived through iteration. First, a preliminary necessary NUE was calculated as:

$$
N U E_{(n e c)}^{*}=\frac{N_{o f f(t a r)}}{N_{o f f(2010)}+N_{l o s s(c r i t)}}
$$

Where:

$$
\begin{array}{ll}
N U E_{(\text {nec })}^{*}= & \text { Preliminary necessary nitrogen use efficiency }[-] \\
N_{\text {off(tar) }}= & \text { Target crop } \left.\mathrm{N} \text { offtake (current } \mathrm{N} \text { offtake or } \mathrm{N} \text { offtake at target yield) [ } \mathrm{kg} \mathrm{N} \mathrm{ha}^{-1} \mathrm{yr}^{-1}\right] \\
N_{\text {loss(crit) }}= & \mathrm{N} \text { losses at critical } \mathrm{N} \text { inputs, including denitrification, } \mathrm{N} \text { runoff to surface water, } \mathrm{N} \\
& \text { leaching to groundwater and } \mathrm{N} \text { emissions }\left[\mathrm{kg} \mathrm{N} \mathrm{ha}^{-1} \mathrm{yr}^{-1}\right]
\end{array}
$$


Second, $\mathrm{N}$ inputs corresponding to $N U E_{(\text {nec })}^{*}$ and the desired crop uptake were calculated by dividing the actual (or target) offtake by the preliminary NUE. Third, associated $\mathrm{N}$ losses were calculated based on current $\mathrm{N}$ loss fractions, and derived $\mathrm{N}$ runoff $+\mathrm{N}$ leaching were compared to critical runoff or leaching. If the calculated value deviated more than $1 \%$, we lowered or increased the necessary NUE until critical runoff + leaching associated with the 'necessary' NUE were within $1 \%$ of critical runoff + leaching.

As $\mathrm{N}$ surface runoff is a function of $\mathrm{N}$ inputs (rather than $\mathrm{N}$ surplus), the necessary NUE could become larger than one (this is also illustrated by Figure S2b, showing that even at a NUE of one, current crop yields cannot be reconciled with thresholds for $\mathrm{N}$ runoff to surface water on $\sim 4 \%$ of agricultural land). For these cases, we set $N U E_{(\text {nec }}$ to one before calculating the average.

Table S3.I | Availability of yield gap estimates for EU countries from the Global Yield Gap Atlas (www. yieldgap.org) as of October 2019.

\begin{tabular}{|c|c|c|c|c|}
\hline Country & Rainfed barley & Irrigated Maize & Rainfed Maize & Rainfed wheat \\
\hline Austria & $x$ & & $x$ & $x$ \\
\hline Belgium & $x$ & & $x$ & $x$ \\
\hline Bulgaria & $x$ & & $x$ & $x$ \\
\hline Czech Republic & $x$ & & $x$ & $x$ \\
\hline Denmark & $x$ & & & $x$ \\
\hline Estonia & $x$ & & & $x$ \\
\hline Finland & $x$ & & & $x$ \\
\hline France & $x$ & $x$ & $x$ & $x$ \\
\hline Germany & $x$ & & $x$ & $x$ \\
\hline Greece & $x$ & $x$ & & $x$ \\
\hline Hungary & $x$ & & $x$ & $x$ \\
\hline Ireland & $x$ & & & $x$ \\
\hline Italy & & $x$ & & $x$ \\
\hline Latvia & $x$ & & & $x$ \\
\hline Lithuania & $x$ & & & $x$ \\
\hline Luxemburg & $x$ & & & $x$ \\
\hline Netherlands & $x$ & & & $x$ \\
\hline Poland & $x$ & & $x$ & $x$ \\
\hline Portugal & & $x$ & & $x$ \\
\hline Romania & $x$ & & $x$ & $x$ \\
\hline Slovakia & $x$ & & $x$ & $x$ \\
\hline Slovenia & $x$ & & $x$ & $x$ \\
\hline Spain & $x$ & $x$ & & $x$ \\
\hline Sweden & $x$ & & & $x$ \\
\hline United Kingdom & $x$ & & & $\mathrm{x}$ \\
\hline
\end{tabular}


Table S3.2 | Actual (year 2010) crop yields, estimated water-limited yield potentials and target yields for different crop groups at EU level; relative difference between target yield and actual yield, and required increase in nitrogen $(\mathrm{N})$ inputs to obtain target yields.

\begin{tabular}{|c|c|c|c|c|c|c|c|}
\hline \multirow[b]{2}{*}{ Crop group } & Total area & $\begin{array}{l}\text { Share of } \\
\text { area }\end{array}$ & $\begin{array}{l}\text { Actual } N \\
\text { input }(2010)\end{array}$ & $\begin{array}{l}\text { Share of N } \\
\text { input }\end{array}$ & $\begin{array}{l}\text { Actual crop } \\
\text { prod. (2010) }\end{array}$ & $\begin{array}{l}\text { Crop prod. } \\
\text { at target } \\
\text { yield }\end{array}$ & $\begin{array}{l}\text { Difference } \\
\text { target / } \\
\text { actual }\end{array}$ \\
\hline & [Mha] & & {$\left[\mathrm{Mt} N \mathrm{yr}^{\prime}\right]$} & & {$\left[\mathrm{Mt} \mathrm{yr}^{-1}\right]$} & {$\left[\mathrm{Mt} y \mathrm{r}^{\prime}\right]$} & \\
\hline Cereals & 61.2 & $41 \%$ & 8.0 & $37 \%$ & 307 & 412 & $34 \%$ \\
\hline Roots \& tubers & 3.2 & $2 \%$ & 0.7 & $3 \%$ & 165 & 191 & $16 \%$ \\
\hline Oil crops & 12.3 & $8 \%$ & 1.7 & $8 \%$ & 31 & 37 & $19 \%$ \\
\hline Grass \& forage & 58.1 & $39 \%$ & 9.8 & $45 \%$ & 765 & 952 & $24 \%$ \\
\hline Other & 15.2 & $10 \%$ & 1.5 & $7 \%$ & 131 & 175 & $33 \%$ \\
\hline All crops & 150.0 & $100 \%$ & 21.8 & $100 \%$ & 1,400 & 1,767 & $26 \%$ \\
\hline
\end{tabular}

Table S3.3 | (see p. 257)

Table S3.4 | Share of agricultural area where thresholds are exceeded (i) at current $\mathrm{N}$ input and (ii) at required $\mathrm{N}$ input to obtain target yields. Results are shown for all agricultural land and separately for arable crops and grassland \& fodder crops.

\begin{tabular}{lcccccc}
\hline & \multicolumn{2}{c}{ (i) at current N input } & \multicolumn{2}{c}{ (ii) at required N input for target yields } \\
\cline { 2 - 7 } & $\begin{array}{l}\text { All agricultural } \\
\text { land }\end{array}$ & Arable crops & $\begin{array}{l}\text { Grassland \& } \\
\text { fodder crops }\end{array}$ & $\begin{array}{l}\text { All agricultural } \\
\text { land }\end{array}$ & $\begin{array}{c}\text { Arable crops } \\
\text { Grassland \& } \\
\text { fodder crops }\end{array}$ \\
\hline N deposition & $66 \%$ & $62 \%$ & $72 \%$ & $76 \%$ & $75 \%$ & $77 \%$ \\
Surface water & $74 \%$ & $89 \%$ & $51 \%$ & $80 \%$ & $94 \%$ & $58 \%$ \\
Groundwater & $18 \%$ & $23 \%$ & $11 \%$ & $28 \%$ & $37 \%$ & $13 \%$ \\
All thresholds & $85 \%$ & $90 \%$ & $76 \%$ & $89 \%$ & $95 \%$ & $80 \%$ \\
\hline
\end{tabular}


Table S3.3 | Actual (year 2010) crop yields, estimated water-limited yield potentials and target yields, relative difference between target yield and actual yield, and required increase in nitrogen $(\mathrm{N})$ inputs to obtain target yields for cereal crops for 25 EU countries.

\begin{tabular}{|c|c|c|c|c|c|c|c|}
\hline & $\begin{array}{l}\text { Actual } \\
\text { yield } \\
\text { (year } \\
2010 \text { ) }\end{array}$ & $\begin{array}{l}\text { Estimated } \\
\text { water- } \\
\text { limited } \\
\text { yield pot. }\end{array}$ & $\begin{array}{l}\text { Target } \\
\text { yield' }\end{array}$ & $\begin{array}{l}\text { Difference } \\
\text { target/ } \\
\text { actual } \\
\text { yield }\end{array}$ & $\begin{array}{l}\text { Actual N } \\
\text { inputs (year } \\
2010)\end{array}$ & $\begin{array}{l}\mathrm{N} \text { inputs } \\
\text { required } \\
\text { to obtain } \\
\text { target yields }\end{array}$ & $\begin{array}{l}\text { Difference } \\
\text { required/ } \\
\text { actual } \mathbf{N} \\
\text { inputs }\end{array}$ \\
\hline Country & {$\left[\mathrm{t} \mathrm{ha}^{-1} \mathrm{yr}^{-1}\right]$} & {$\left[\mathrm{t} \mathrm{ha}^{-1} \mathrm{yr}^{-1}\right]$} & {$\left[\mathrm{t} \mathrm{ha}^{-1} \mathrm{yr}^{-1}\right]$} & & {$\left[\mathrm{kg} \mathrm{N} \mathrm{ha-1} \mathrm{yr}^{-1}\right]$} & {$\left[\mathrm{kg} \mathrm{N} \mathrm{ha-1} \mathrm{yr}^{-1}\right]$} & \\
\hline Austria & 6.6 & 8.7 & 7.6 & $15 \%$ & 124 & 144 & $16 \%$ \\
\hline Belgium & 9.1 & 12.0 & 9.6 & $5 \%$ & 356 & 373 & $5 \%$ \\
\hline Bulgaria & 3.9 & 8.7 & 6.9 & $79 \%$ & 86 & 153 & $79 \%$ \\
\hline Czechia & 5.0 & 9.1 & 7.3 & $46 \%$ & 154 & 224 & $46 \%$ \\
\hline Germany & 6.9 & 9.1 & 7.4 & $7 \%$ & 206 & 220 & $7 \%$ \\
\hline Denmark & 6.3 & 7.7 & 6.5 & $3 \%$ & 164 & 169 & $3 \%$ \\
\hline Estonia & 2.8 & 7.2 & 5.8 & $105 \%$ & 85 & 175 & $105 \%$ \\
\hline Greece & 3.2 & 6.0 & 5.1 & $56 \%$ & 85 & 136 & $59 \%$ \\
\hline Spain & 3.5 & 6.7 & 5.4 & $53 \%$ & 84 & 128 & $53 \%$ \\
\hline Finland & 7.2 & 10.0 & 8.1 & $13 \%$ & 158 & 179 & $13 \%$ \\
\hline France & 4.1 & 6.0 & 5.5 & $34 \%$ & 116 & 161 & $39 \%$ \\
\hline Hungary & 5.0 & 8.2 & 6.6 & $33 \%$ & 121 & 162 & $34 \%$ \\
\hline Ireland & 7.5 & 10.7 & 8.5 & $14 \%$ & 139 & 158 & $14 \%$ \\
\hline Italy & 5.2 & 6.9 & 6.2 & $18 \%$ & 149 & 177 & $19 \%$ \\
\hline Lithuania & 3.3 & 8.2 & 6.5 & $98 \%$ & 95 & 188 & $97 \%$ \\
\hline Luxembourg & 5.7 & 8.3 & 6.6 & $16 \%$ & 170 & 198 & $17 \%$ \\
\hline Latvia & 3.1 & 7.6 & 6.1 & $96 \%$ & 68 & 135 & $98 \%$ \\
\hline Netherlands & 8.7 & 11.6 & 9.3 & $7 \%$ & 328 & 351 & $7 \%$ \\
\hline Poland & 3.4 & 7.5 & 6.0 & $78 \%$ & 129 & 230 & $78 \%$ \\
\hline Portugal & 3.3 & 6.7 & 5.6 & $72 \%$ & 111 & 210 & $89 \%$ \\
\hline Romania & 3.2 & 8.0 & 6.4 & $104 \%$ & 72 & 147 & $103 \%$ \\
\hline Sweden & 4.9 & 7.6 & 6.2 & $28 \%$ & 77 & 99 & $27 \%$ \\
\hline Slovenia & 5.8 & 10.4 & 8.3 & $43 \%$ & 176 & 254 & $45 \%$ \\
\hline Slovakia & 4.5 & 9.4 & 7.5 & $66 \%$ & 122 & 207 & $69 \%$ \\
\hline U. Kingdom & 7.0 & 10.7 & 8.6 & $23 \%$ & 140 & 173 & $23 \%$ \\
\hline EU & 5.0 & 8.2 & 6.7 & $34 \%$ & $|3|$ & 179 & $36 \%$ \\
\hline
\end{tabular}

' Target yield is set at $80 \%$ of estimated water-limited yield potentials. However, if this was lower than the actual yield, target yield was set to actual yield. Area-weighted average target yields are thus between 80 and $91 \%$ of water-limited yield potentials. 
Table S3.5 | Impacts of $\mathrm{N}$ input redistribution to maximise crop production within environmental thresholds on total $\mathrm{N}$ inputs ( $\mathrm{Mt} \mathrm{N} \mathrm{yr}^{-1}$ ) for different crop groups. Last column shows the net impact of both reducing $\mathrm{N}$ inputs to respect thresholds and increasing $\mathrm{N}$ inputs where this is possible within thresholds. Percentages in brackets show change relative to current total $\mathrm{N}$ inputs. Corresponding changes in crop production are shown in Table S3.6.

\begin{tabular}{|c|c|c|c|c|c|c|c|}
\hline \multirow[b]{2}{*}{ Threshold } & \multicolumn{3}{|c|}{$\begin{array}{l}\text { Total } \mathbf{N} \text { input on land where input } \\
\text { reductions are required to respect } \\
\left.\text { threshold [Mt } \mathbf{N y r}^{\prime}\right]\end{array}$} & \multicolumn{3}{|c|}{$\begin{array}{l}\text { Total } \mathbf{N} \text { input on land where } \\
\text { input increases are possible } \\
\left.\text { within threshold [Mt } \mathbf{N} \mathbf{y r}^{-1}\right]\end{array}$} & \multirow[b]{2}{*}{ Net impact } \\
\hline & $\begin{array}{l}\text { Current } \\
\mathrm{N} \text { input }\end{array}$ & $\begin{array}{l}\text { After } \\
\text { reductions }\end{array}$ & $\begin{array}{c}\text { Total } \\
\text { reduction }\end{array}$ & $\begin{array}{l}\text { Current } \\
\mathrm{N} \text { input }\end{array}$ & $\begin{array}{c}\text { After } \\
\text { increases }\end{array}$ & $\begin{array}{c}\text { Total } \\
\text { increase }\end{array}$ & \\
\hline \multicolumn{8}{|l|}{ a) Deposition } \\
\hline Cereals & 5.69 & 3.11 & $-2.58(-45 \%)$ & 2.35 & 2.89 & $+0.55(+23 \%)$ & $-2.03(-25 \%)$ \\
\hline Roots \& tubers & 0.53 & 0.27 & $-0.26(-49 \%)$ & 0.14 & 0.15 & $+0.02(+12 \%)$ & $-0.24(-36 \%)$ \\
\hline Oil crops & 1.14 & 0.60 & $-0.54(-48 \%)$ & 0.58 & 0.68 & $+0.10(+18 \%)$ & $-0.44(-26 \%)$ \\
\hline Grass \& forage & 7.76 & 3.84 & $-3.92(-51 \%)$ & 2.08 & 2.40 & $+0.32(+15 \%)$ & $-3.60(-37 \%)$ \\
\hline Other & 0.64 & 0.38 & $-0.26(-41 \%)$ & 0.90 & 1.21 & $+0.31(+35 \%)$ & $+0.06(+4 \%)$ \\
\hline Total & 15.76 & 8.19 & $-7.56(-35 \%)$ & 6.04 & 7.34 & $+1.30(+6 \%)$ & $-6.26(-29 \%)$ \\
\hline \multicolumn{8}{|c|}{ b) Surface water } \\
\hline Cereals & 7.55 & 2.81 & $-4.74(-63 \%)$ & 0.49 & 0.66 & $+0.17(+34 \%)$ & $-4.57(-57 \%)$ \\
\hline Roots \& tubers & 0.65 & 0.15 & $-0.49(-76 \%)$ & 0.02 & 0.02 & $+0.00(+29 \%)$ & $-0.49(-74 \%)$ \\
\hline Oil crops & 1.64 & 0.54 & $-1.10(-67 \%)$ & 0.08 & 0.10 & $+0.02(+30 \%)$ & $-1.07(-63 \%)$ \\
\hline Grass \& forage & 5.71 & 2.84 & $-2.87(-50 \%)$ & 4.12 & 4.81 & $+0.68(+17 \%)$ & $-2.19(-22 \%)$ \\
\hline Other & 1.35 & 0.45 & $-0.91(-67 \%)$ & 0.18 & 0.23 & $+0.05(+29 \%)$ & $-0.85(-56 \%)$ \\
\hline Total & 16.90 & 6.79 & $-10.11(-46 \%)$ & 4.89 & 5.82 & $+0.93(+4 \%)$ & $-9.18(-42 \%)$ \\
\hline \multicolumn{8}{|c|}{ c) Groundwater } \\
\hline Cereals & 2.42 & I.7I & $-0.7 \mathrm{I}(-29 \%)$ & 5.61 & 7.39 & $+1.78(+32 \%)$ & $+1.07(+13 \%)$ \\
\hline Roots \& tubers & 0.47 & 0.27 & $-0.19(-41 \%)$ & 0.20 & 0.23 & $+0.03(+17 \%)$ & $-0.16(-24 \%)$ \\
\hline Oil crops & 0.75 & 0.43 & $-0.32(-43 \%)$ & 0.97 & 0.18 & $+0.21(+22 \%)$ & $-0.11(-7 \%)$ \\
\hline Grass \& forage & 1.38 & 0.88 & $-0.48(-35 \%)$ & 8.47 & 10.08 & $+1.61(+10 \%)$ & $+1.13(+11 \%)$ \\
\hline Other & 0.64 & 0.26 & $-0.38(-59 \%)$ & 0.90 & 1.09 & $+0.19(+21 \%)$ & $-0.19(-12 \%)$ \\
\hline Total & 5.64 & 3.55 & $-2.09(-10 \%)$ & 16.15 & 19.97 & $+3.82(+18 \%)$ & $+1.73(+8 \%)$ \\
\hline \multicolumn{8}{|c|}{ d) All thresholds } \\
\hline Cereals & 7.63 & 2.80 & $-4.83(-63 \%)$ & 0.41 & 0.54 & $+0.14(+34 \%)$ & $-4.69(-58 \%)$ \\
\hline Roots \& tubers & 0.65 & 0.15 & $-0.50(-76 \%)$ & 0.01 & 0.01 & $+0.00(+29 \%)$ & $-0.49(-75 \%)$ \\
\hline Oil crops & 1.65 & 0.54 & -1.11 (-67\%) & 0.06 & 0.08 & $+0.02(+27 \%)$ & $-1.09(-64 \%)$ \\
\hline Grass \& forage & 8.16 & 3.70 & $-4.46(-55 \%)$ & 1.68 & 1.93 & $+0.25(+15 \%)$ & $-4.21(-43 \%)$ \\
\hline Other & 1.37 & 0.44 & $-0.92(-68 \%)$ & 0.16 & 0.21 & $+0.04(+27 \%)$ & $-0.88(-57 \%)$ \\
\hline Total & 19.46 & 7.64 & $-11.82(-54 \%)$ & 2.33 & 2.78 & $+0.45(+2 \%)$ & $-11.37(-52 \%)$ \\
\hline
\end{tabular}


Table S3.6 | Impacts of $\mathrm{N}$ input redistribution to maximise crop production within environmental thresholds (as shown in Table S3.5) on total crop production (Mt $\mathrm{yr}^{-1}$ ) for different crop groups. Last column shows the net impact of both reducing $N$ inputs to respect thresholds and increasing $N$ inputs where this is possible within thresholds. Percentages in brackets show change relative to current total $\mathrm{N}$ inputs.

\begin{tabular}{|c|c|c|c|c|c|c|c|}
\hline \multirow[b]{2}{*}{ Threshold } & \multicolumn{3}{|c|}{ 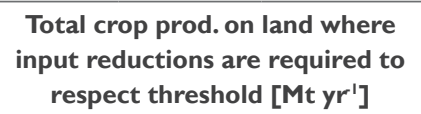 } & \multicolumn{3}{|c|}{$\begin{array}{l}\text { Total crop prod. on land where } \\
\text { input increases are possible } \\
\left.\text { within threshold [Mt } \mathrm{yr}^{\prime}\right]\end{array}$} & \multirow[b]{2}{*}{ Net impact } \\
\hline & $\begin{array}{l}\text { Current } \\
\mathrm{N} \text { input }\end{array}$ & $\begin{array}{c}\text { After } \\
\text { reductions }\end{array}$ & $\begin{array}{c}\text { Total } \\
\text { reduction }\end{array}$ & $\begin{array}{l}\text { Current } \\
\mathrm{N} \text { input }\end{array}$ & $\begin{array}{c}\text { After } \\
\text { increases }\end{array}$ & $\begin{array}{c}\text { Total } \\
\text { increase }\end{array}$ & \\
\hline \multicolumn{8}{|l|}{ a) Deposition } \\
\hline Cereals & 204 & 115 & $-89(-44 \%)$ & 103 & 126 & $24(+23 \%)$ & $-66(-21 \%)$ \\
\hline Roots \& tubers & 132 & 68 & $-64(-48 \%)$ & 33 & 37 & $+4(+13 \%)$ & $-60(-36 \%)$ \\
\hline Oil crops & 20 & 11 & $-9(-44 \%)$ & 11 & 13 & $+2(+18 \%)$ & $-7(-23 \%)$ \\
\hline Grass \& forage & 568 & 304 & $-264(-46 \%)$ & 197 & 240 & $+42(+21 \%)$ & $-221(-29 \%)$ \\
\hline Other & 63 & 37 & $-26(-41 \%)$ & 68 & 87 & $19(+27 \%)$ & $-7(-6 \%)$ \\
\hline Total & 988 & 536 & $-452(-32 \%)$ & 412 & 502 & $+91(+6 \%)$ & $-362(-26 \%)$ \\
\hline \multicolumn{8}{|c|}{ b) Surface water } \\
\hline Cereals & 286 & 111 & $-175(-61 \%)$ & 21 & 28 & $+7(+33 \%)$ & $-168(-55 \%)$ \\
\hline Roots \& tubers & 162 & 38 & $-123(-76 \%)$ & 3 & 4 & $+I(+28 \%)$ & $-122(-74 \%)$ \\
\hline Oil crops & 29 & 11 & $-19(-63 \%)$ & 2 & 2 & $0(+28 \%)$ & $-18(-58 \%)$ \\
\hline Grass \& forage & 467 & 258 & $-209(-45 \%)$ & 298 & 364 & $+66(+22 \%)$ & $-143(-19 \%)$ \\
\hline Other & 107 & 44 & $-62(-58 \%)$ & 24 & 31 & +7 (+29\%) & $-55(-42 \%)$ \\
\hline Total & $|, 05|$ & 462 & $-589(-42 \%)$ & 349 & 430 & $+81(+6 \%)$ & $-507(-36 \%)$ \\
\hline \multicolumn{8}{|c|}{ c) Groundwater } \\
\hline Cereals & 76 & 54 & $-22(-28 \%)$ & 231 & 303 & $+72(+31 \%)$ & $+51(+16 \%)$ \\
\hline Roots \& tubers & 111 & 68 & $-42(-38 \%)$ & 54 & 61 & $+7(+\mid 4 \%)$ & $-35(-21 \%)$ \\
\hline Oil crops & 10 & 6 & $-4(-38 \%)$ & 21 & 25 & $+4(+21 \%)$ & $+1(+2 \%)$ \\
\hline Grass \& forage & 44 & 30 & $-13(-3 \mid \%)$ & 722 & 893 & +172 (+24\%) & $+158(+21 \%)$ \\
\hline Other & 31 & 19 & $-12(-40 \%)$ & 100 & 126 & $+26(+26 \%)$ & $+13(+10 \%)$ \\
\hline Total & 272 & 178 & $-94(-7 \%)$ & $\mathrm{I}, 128$ & 1,409 & +281 (+20\%) & $+188(+13 \%)$ \\
\hline \multicolumn{8}{|c|}{ d) All thresholds } \\
\hline Cereals & 289 & 111 & $-178(-62 \%)$ & 18 & 24 & $+6(+33 \%)$ & $-172(-56 \%)$ \\
\hline Roots \& tubers & 162 & 38 & $-124(-76 \%)$ & 3 & 3 & +1 (+29\%) & $-123(-75 \%)$ \\
\hline Oil crops & 30 & II & $-19(-63 \%)$ & I & 2 & $+0(+26 \%)$ & $-18(-59 \%)$ \\
\hline Grass \& forage & 619 & 303 & $-316(-51 \%)$ & 146 & 179 & $+33(+23 \%)$ & $-283(-37 \%)$ \\
\hline Other & 108 & 44 & $-64(-59 \%)$ & 23 & 29 & $+6(+28 \%)$ & $-58(-44 \%)$ \\
\hline Total & 1,208 & 507 & -70 I (-50\%) & 191 & 238 & $+46(+3 \%)$ & $-655(-47 \%)$ \\
\hline
\end{tabular}




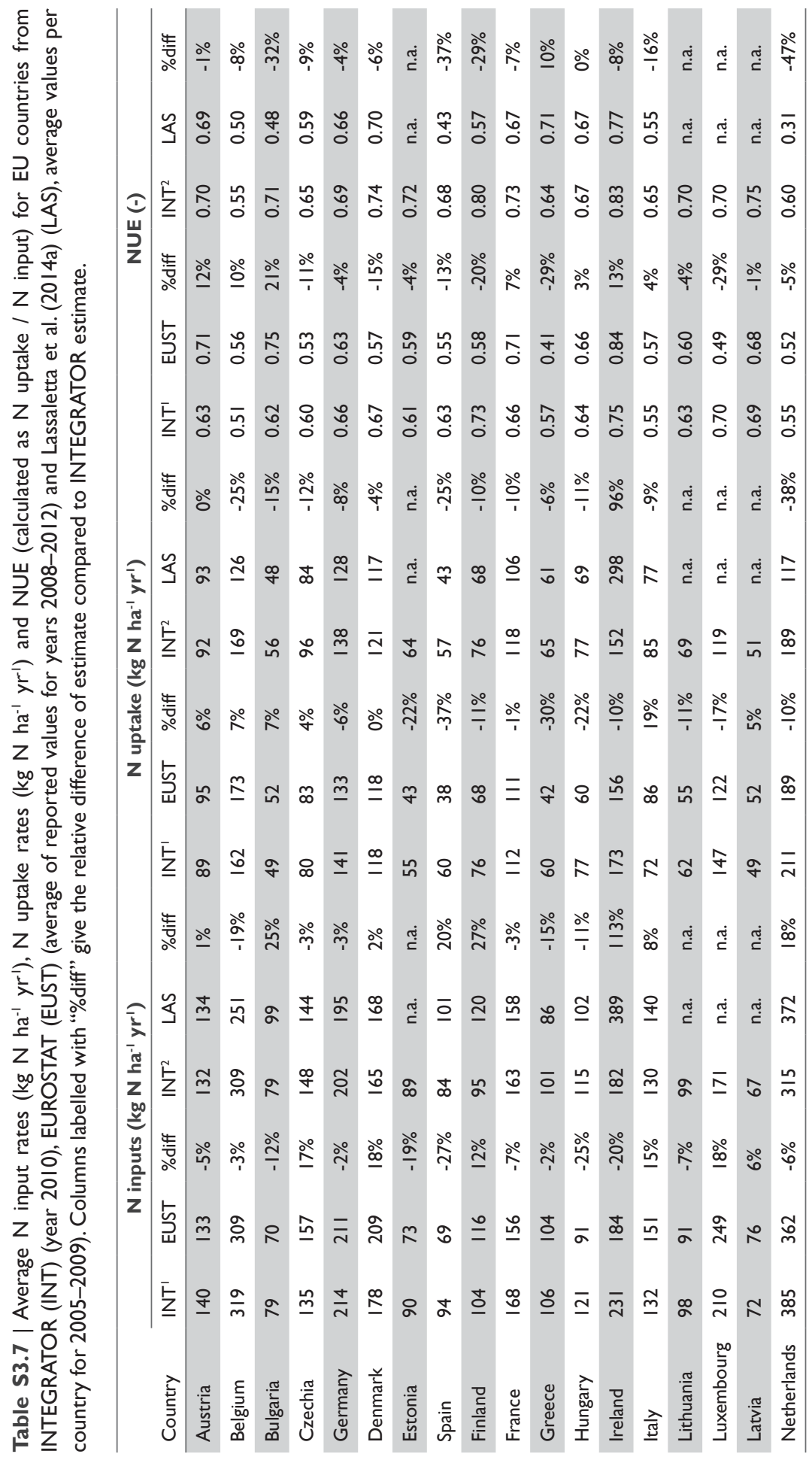




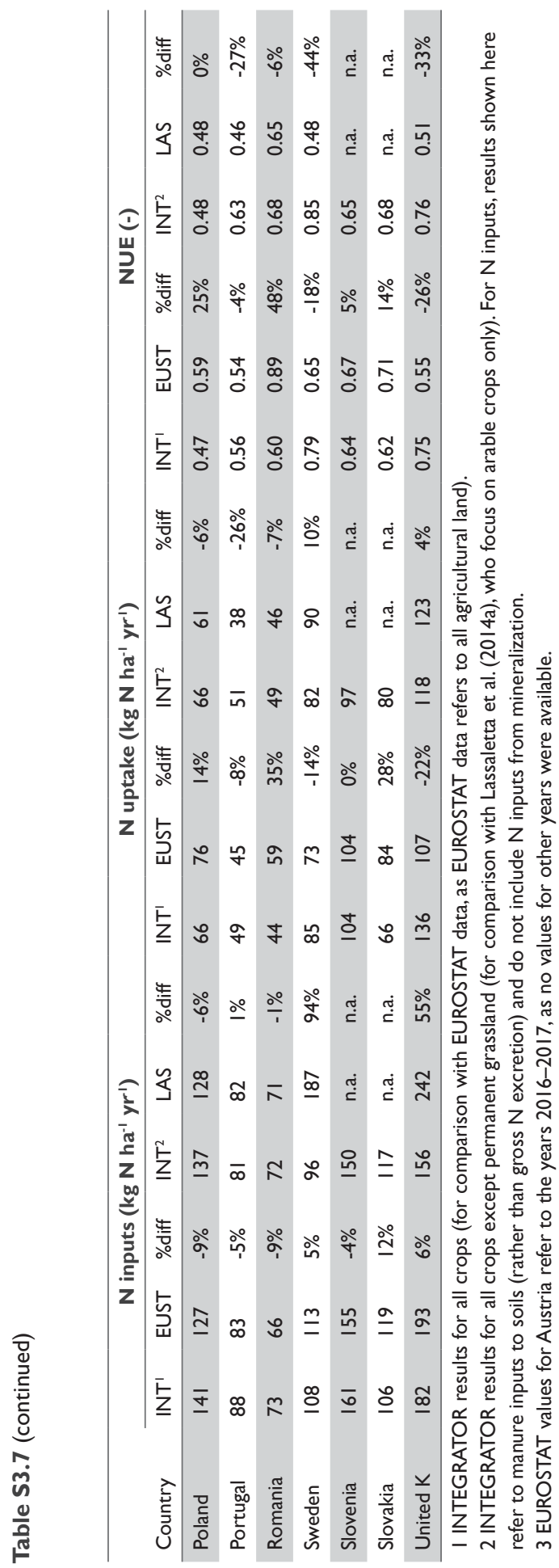



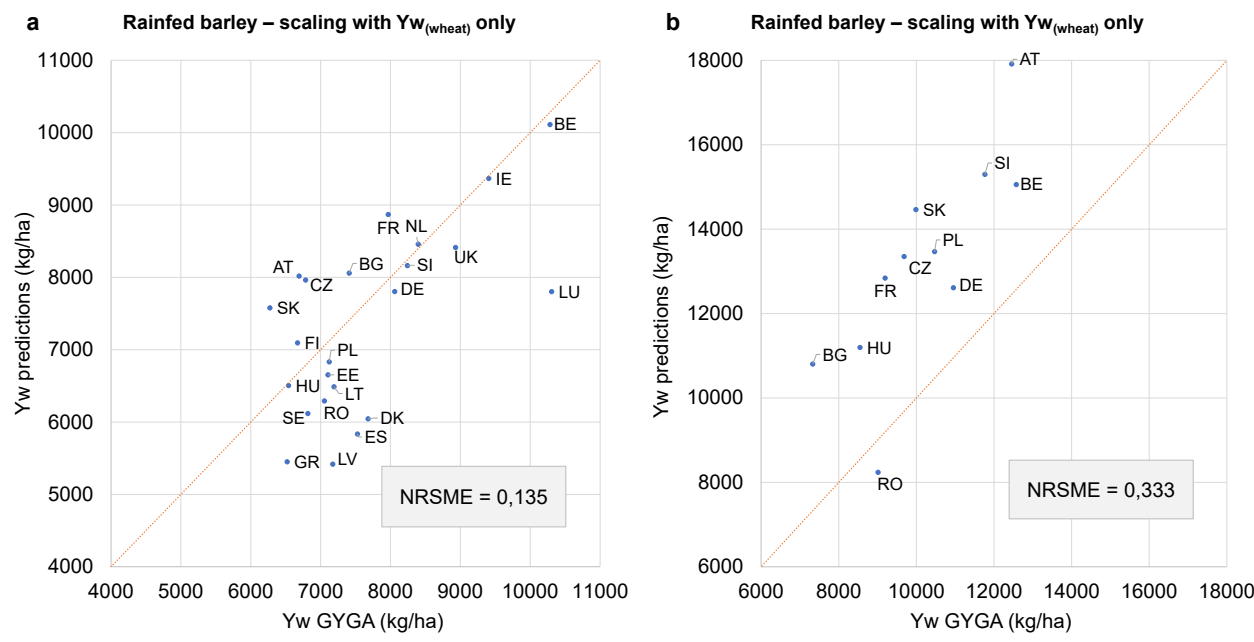

C Rainfed barley - scaling with max. yield ratio (Eq. S1)

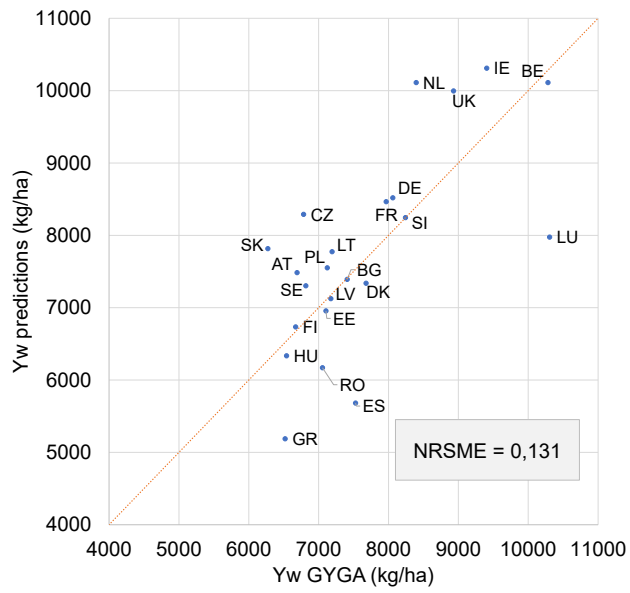

d Rainfed maize - scaling with max. yield ratio (Eq. S1)

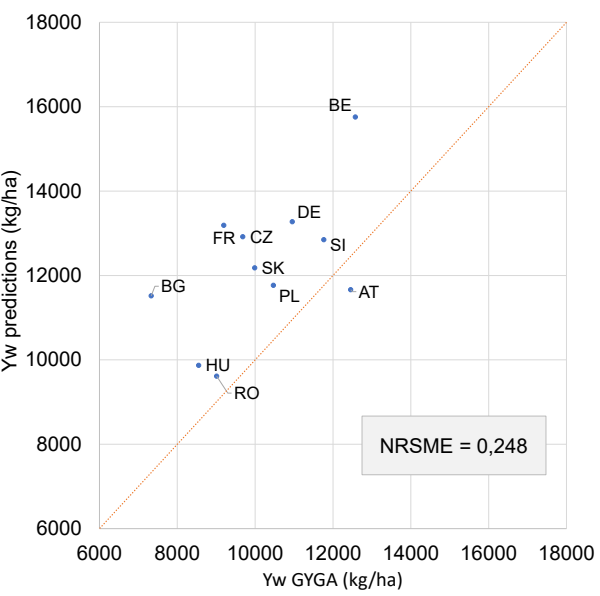

Figure S3.I | Comparison of yield potential estimates derived with two scaling approaches with yield potential estimates from GYGA for rainfed barley (left) and maize (right). Yield potentials were estimated by $\mathbf{a}, \mathbf{b}$, scaling with the yield gap for rainfed wheat only and $\mathbf{c}, \mathbf{d}$, by scaling with both the yield gap for rainfed wheat and the maximum yield ratios following Eq. S3.I. Red line is I:I line, NRSME = Normalized Root Square Mean Error. 
a

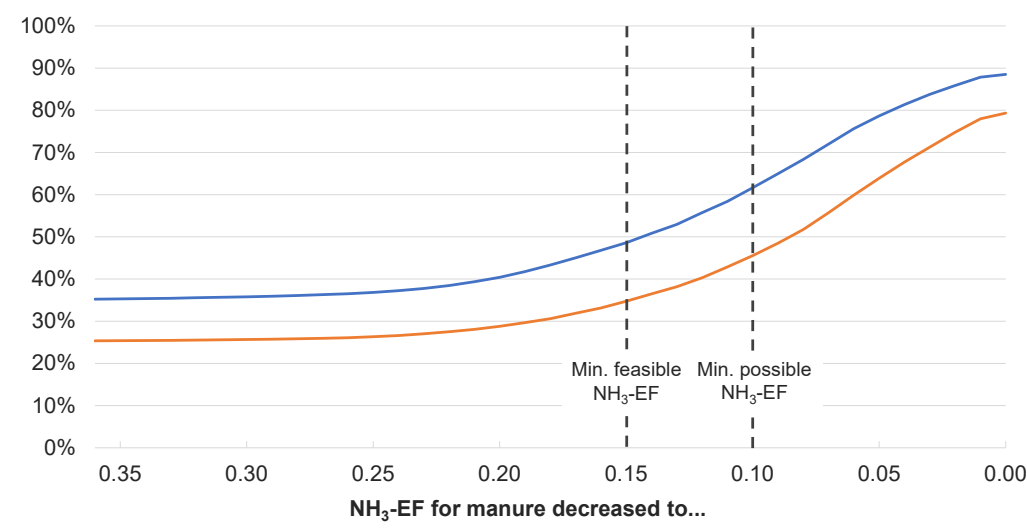

b
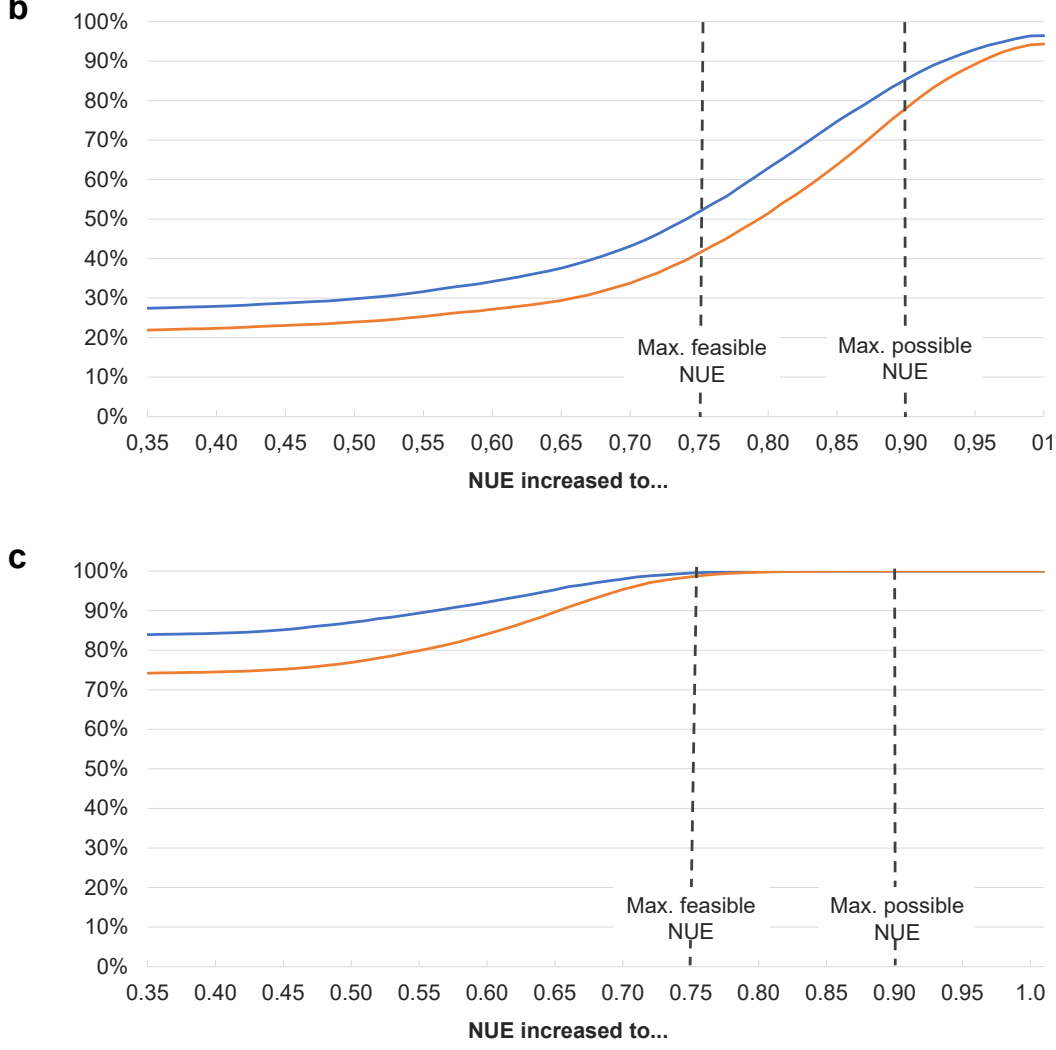

Figure S3.2 | Cumulative share of agricultural land where actual crop production (blue line) / target crop production (orange line) can be reconciled with environmental thresholds by gradually improving nitrogen management. Share of land where crop production can be reconciled with thresholds for a, $\mathrm{N}$ deposition by decreasing $\mathrm{NH}_{3}$ emission fraction for manure, $\mathbf{b}, \mathrm{N}$ runoff to surface water by increasing NUE, c, $\mathrm{N}$ leaching to groundwater by increasing NUE. 


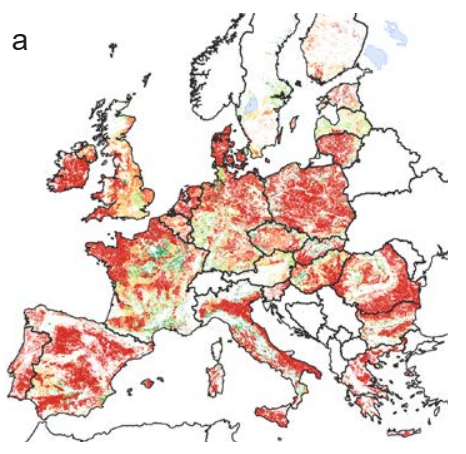

Necessary $\mathrm{NH}_{3}-\mathrm{EF}$ manure [-]
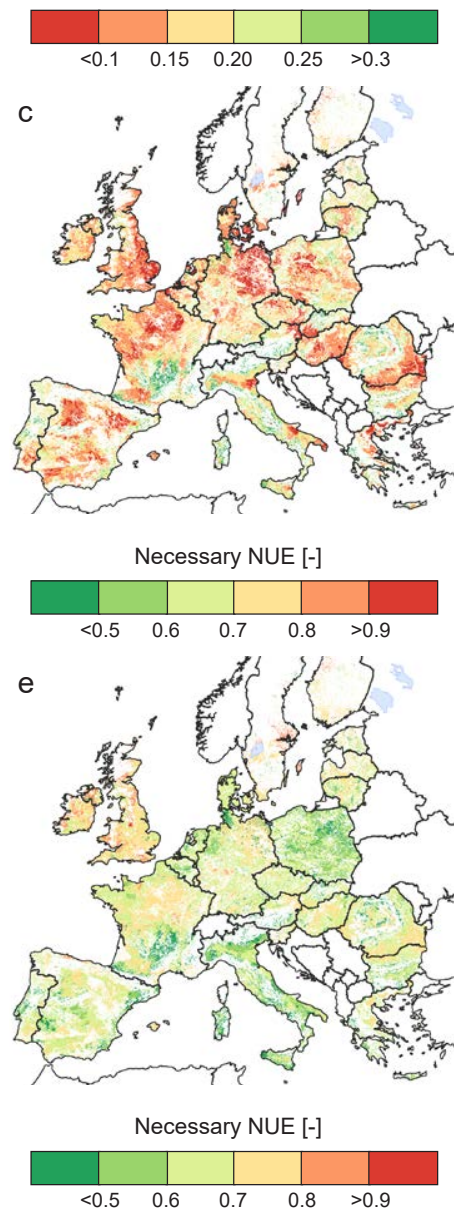

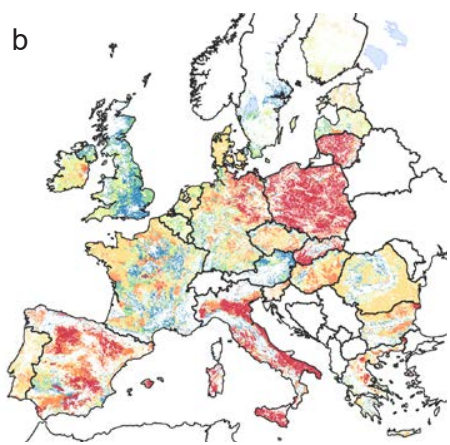

Necessary reduction $\mathrm{NH}_{3}-\mathrm{EF}$ manure [-]
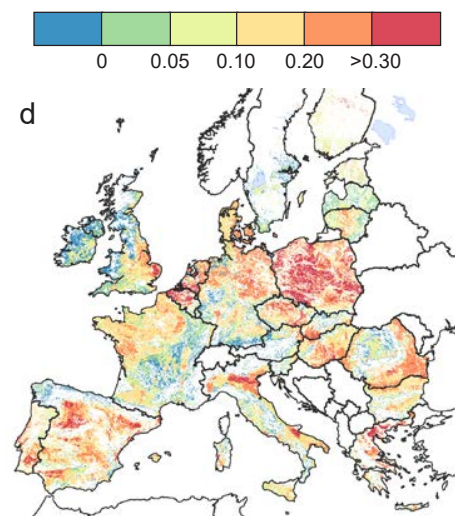

Necessary NUE increase [-]
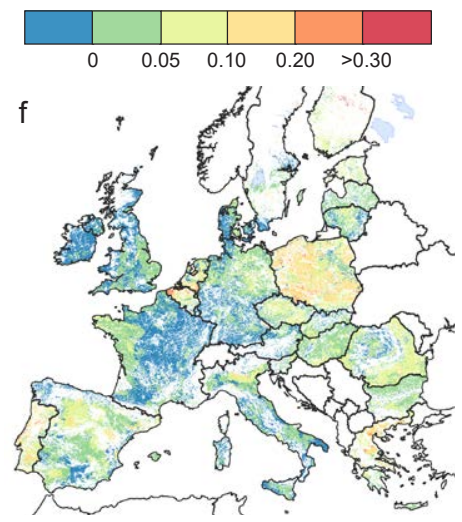

Necessary NUE increase [-]

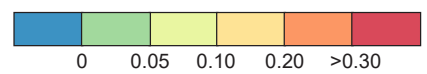

Figure S3.3 | Regional variation in necessary improvements in $\mathrm{N}$ management factors to obtain target yields while respecting environmental thresholds. a, Necessary $\mathrm{NH}_{3} \mathrm{EF}$ for manure to respect thresholds for $\mathrm{NH}_{3}$ emissions in view of $\mathrm{N}$ deposition, c, necessary NUE to respect thresholds for $\mathrm{N}$ runoff to surface water, e, necessary NUE to respect thresholds for $\mathrm{N}$ leaching to groundwater, $\mathbf{b}, \mathbf{d}, \mathbf{f}$, necessary changes in $\mathrm{NH}_{3} \mathrm{EF} / \mathrm{NUE}$ relative to current (year 2010) values. 


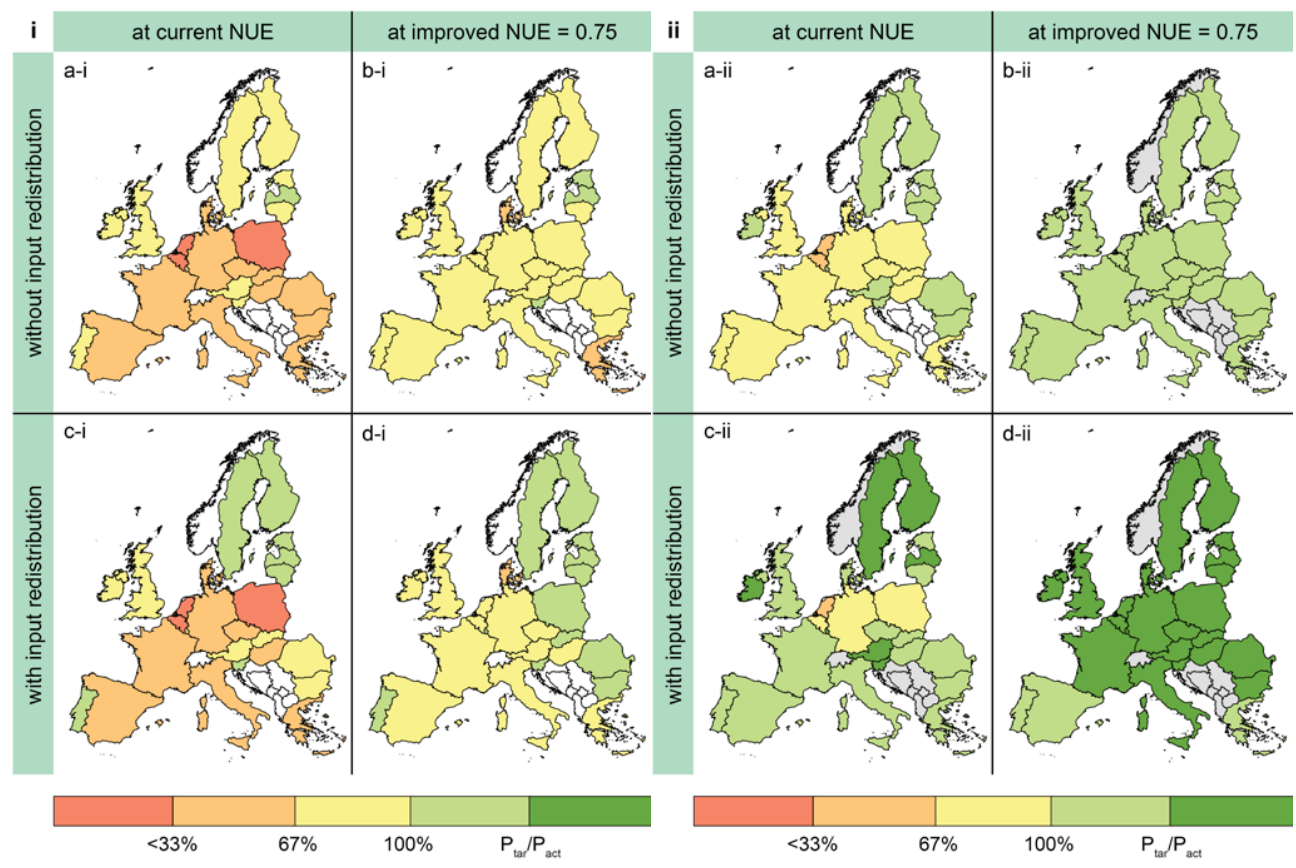

Figure S3.4 Share of actual (year 2010) crop production $\left(\mathrm{P}_{\text {act }}\right)$ that can be obtained within safe thresholds for (i) nitrogen $(N)$ runoff to surface water and (ii) $N$ leaching to groundwater in each EU country a, for the current situation, b, assuming an improved NUE of 0.75 , $\mathbf{c}$, assuming $N$ input redistribution and $\mathbf{d}$, assuming both an improved NUE of 0.75 and redistribution. $P_{\mathrm{tar}}=$ crop production at target yield. 


\section{Supplementary Material Chapter 4}

Supplementary Methods (incl. Suppl. Figures S4. I-S4.2 \& Suppl. Tables S4. I-S4.3)

S4.I. Critical deposition on natural ecosystems

S4.2. Critical concentration for $\mathrm{N}$ runoff in surface water

S4.3. Full mathematical description of the model for calculating critical inputs

S4.4. Method to estimate yield potentials

Supplementary Discussion (incl. Suppl. Figures S4.3-S4.4 \& Suppl. Tables S4.4-S4.5)

268

S4.5. Results for yield potentials and maximum $\mathrm{N}$ uptake

S4.6. Plausibility of estimated yield potentials

S4.7. Results for cut-off at actual $\mathrm{N}$ inputs

\section{S4.I. Critical deposition on natural ecosystems}

Table S4.1 shows biome-specific critical deposition rates; Figure S4.1 shows the resulting global spatial variation in critical $\mathrm{N}$ deposition rates.

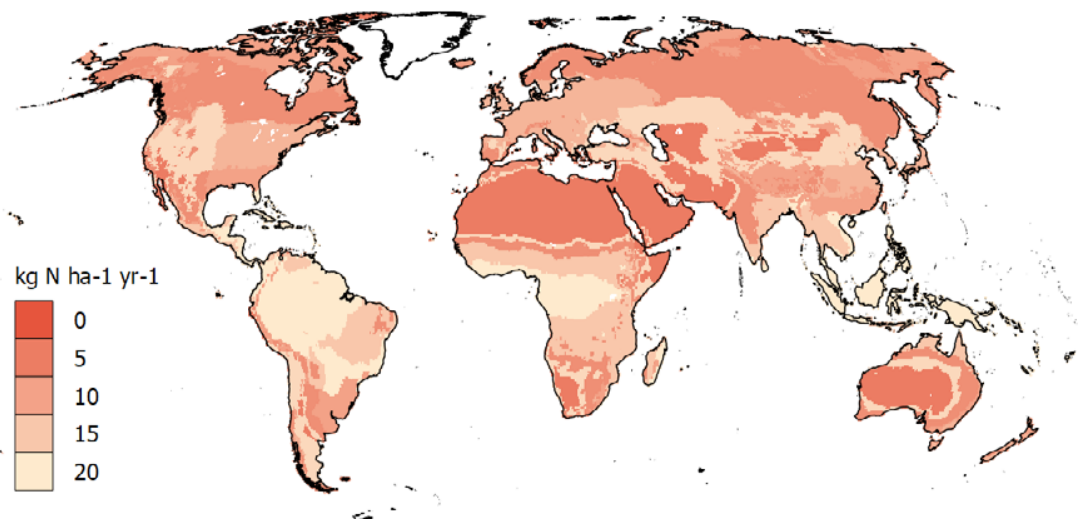

Figure S4.I | Spatial variation in critical $\mathrm{N}$ deposition rates $\left(\mathrm{kg} \mathrm{N} \mathrm{ha}^{-1} \mathrm{yr}^{-1}\right)$ used in the assessment of critical $\mathrm{N}$ inputs to agriculture, based on thresholds presented in Table S4.I and biome distribution from the IMAGE model for the year 2010. 
Table S4.I | Critical nitrogen (N) deposition threshold per IMAGE biome used in the calculation of critical $\mathrm{N}$ inputs from critical deposition to limit terrestrial biodiversity loss, and source from which threshold was obtained.

\begin{tabular}{|c|c|c|}
\hline IMAGE Biome & $\begin{array}{l}\text { Critical threshold } \\
{\left[\mathrm{kg} \mathrm{N} \mathrm{ha-1} \mathrm{yr}^{-1}\right]}\end{array}$ & Source \& explanation \\
\hline Ice & n.a. & -- \\
\hline Tundra & 10.0 & $\begin{array}{l}\text { Mean value of the range of } 5-15 \mathrm{~kg} \mathrm{~N} \mathrm{ha}^{-1} \mathrm{yr}^{-1} \text { for alpine tundra, } \\
\text { alpine/ subalpine scrub, and grassland proposed by Bobbink et al. } \\
(2010) \text {. }\end{array}$ \\
\hline Wooded tundra & 10.0 & Same critical threshold as for 'Tundra'. \\
\hline Boreal forest & 7.5 & $\begin{array}{l}\text { Mean value of the range of } 5-10 \mathrm{~kg} \mathrm{~N} \mathrm{ha}^{-1} \mathrm{yr}^{-1} \text { for boreal forests } \\
\text { proposed by Bobbink et al. }(2010) .\end{array}$ \\
\hline Cool coniferous forest & 7.5 & Same as for 'boreal forest' \\
\hline Temperate mixed forest & 12.5 & $\begin{array}{l}\text { Mean value of the range of } 10-15 \mathrm{~kg} \mathrm{~N} \mathrm{ha}^{-1} \mathrm{yr}^{-1} \text { for temperate } \\
\text { forests proposed by Bobbink et al. }(2010) \text {. }\end{array}$ \\
\hline $\begin{array}{l}\text { Temperate deciduous } \\
\text { forest }\end{array}$ & 12.5 & Same critical threshold as for 'temperate mixed forest'. \\
\hline Warm mixed forest & 10.0 & $\begin{array}{l}\text { Critical threshold assumed to be between the thresholds } \\
\text { proposed by Bobbink et al. (2010) for Mediterranean forest } \\
\left(3-10 \mathrm{~kg} \mathrm{~N} \mathrm{ha}^{-1} \mathrm{yr}^{-1}\right) \text { and temperate forests }\left(10-15 \mathrm{~kg} \mathrm{~N} \mathrm{ha-1}^{-1}\right)\end{array}$ \\
\hline Tropical forest & 20.0 & 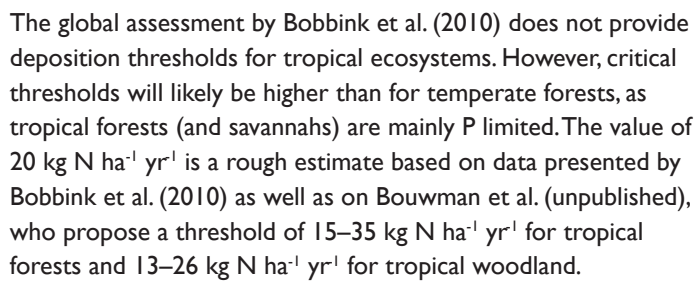 \\
\hline Tropical woodland & 20.0 & Same critical threshold as for 'tropical forest'. \\
\hline Scrubland & 7.5 & $\begin{array}{l}\text { Mean value of the range of } 5-10 \mathrm{~kg} \mathrm{~N} \mathrm{ha}^{-1} \mathrm{yr}^{-1} \text { for Mediterranean } \\
\text { grasslands proposed by Bobbink et al. }(2010) \text {. }\end{array}$ \\
\hline Grassland and steppe & 17.5 & $\begin{array}{l}\text { Mean value of the range of } 10-25 \mathrm{~kg} \mathrm{~N} \mathrm{ha}^{-1} \mathrm{yr}^{-1} \text { for temperate } \\
\text { heathlands proposed by Bobbink et al. }(20 \mathrm{l} 0) \text {. }\end{array}$ \\
\hline Savanna & 15.0 & Based on Bouwman et al. (unpublished). \\
\hline Hot desert & 5.0 & $\begin{array}{l}\text { Critical threshold of } 5 \mathrm{~kg} \mathrm{~N} \mathrm{ha}^{-1} \mathrm{yr}^{-1} \text { for semidesert and desert } \\
\text { proposed by Bobbink et al. (20l0). }\end{array}$ \\
\hline
\end{tabular}

\section{S4.2. Critical concentration for $\mathrm{N}$ runoff in surface water}

IMAGE-GNM calculates surface water $\mathrm{N}$ concentration for each $0.5 \mathrm{x} 0.5$ degree grid cell based on detailed modelling of water and $\mathrm{N}$ flows, removal and retention (Beusen et al., 2015). Apart from total $\mathrm{N}$ load from within a grid cell, the surface water $\mathrm{N}$ concentration in a specific location in a river basin is affected by $\mathrm{N}$ load from upstream grid cells. As these dependencies complicate back-calculations of critical $\mathrm{N}$ loads and related $\mathrm{N}$ inputs per grid 
cell, we use the $\mathrm{N}$ concentration in runoff to surface water as a proxy for actual surface water $\mathrm{N}$ concentration. This is based on the assumption that if in each grid cell the $\mathrm{N}$ concentration in runoff to surface water does not exceeded a certain limit, this limit will also never be exceeded in surface water itself.

Based on a critical $\mathrm{N}$ concentration in surface water of $2.5 \mathrm{mg} \mathrm{N}^{-1}$ and an estimated mean global retention fraction of 0.5 , we use a limit of $5 \mathrm{mg} \mathrm{N} \mathrm{l}^{-1}$ for runoff to surface water. The

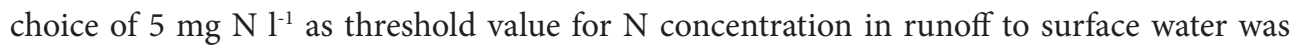
further validated by comparing the extent and spatial distribution of agricultural land in grid cells with surface water $\mathrm{N}$ concentration $>2.5 \mathrm{mg} \mathrm{N} \mathrm{l}^{-1}$ with that of agricultural land in grid cells with runoff $\mathrm{N}$ concentrations $>5.0 \mathrm{mg} \mathrm{N}^{-1}$ (Figure 44.2 ). $48 \%$ of all agricultural land is located in grid cells where surface water $\mathrm{N}$ concentration exceeds $2.5 \mathrm{mg} \mathrm{l}^{-1}$, and $51 \%$ of all agricultural land is located in grid cells where $\mathrm{N}$ concentration in runoff to surface water exceeds $5 \mathrm{mg} \mathrm{N}^{-1}$, and the spatial distribution for grid cells exceeding the two criteria is almost identical (Figure S4.2).

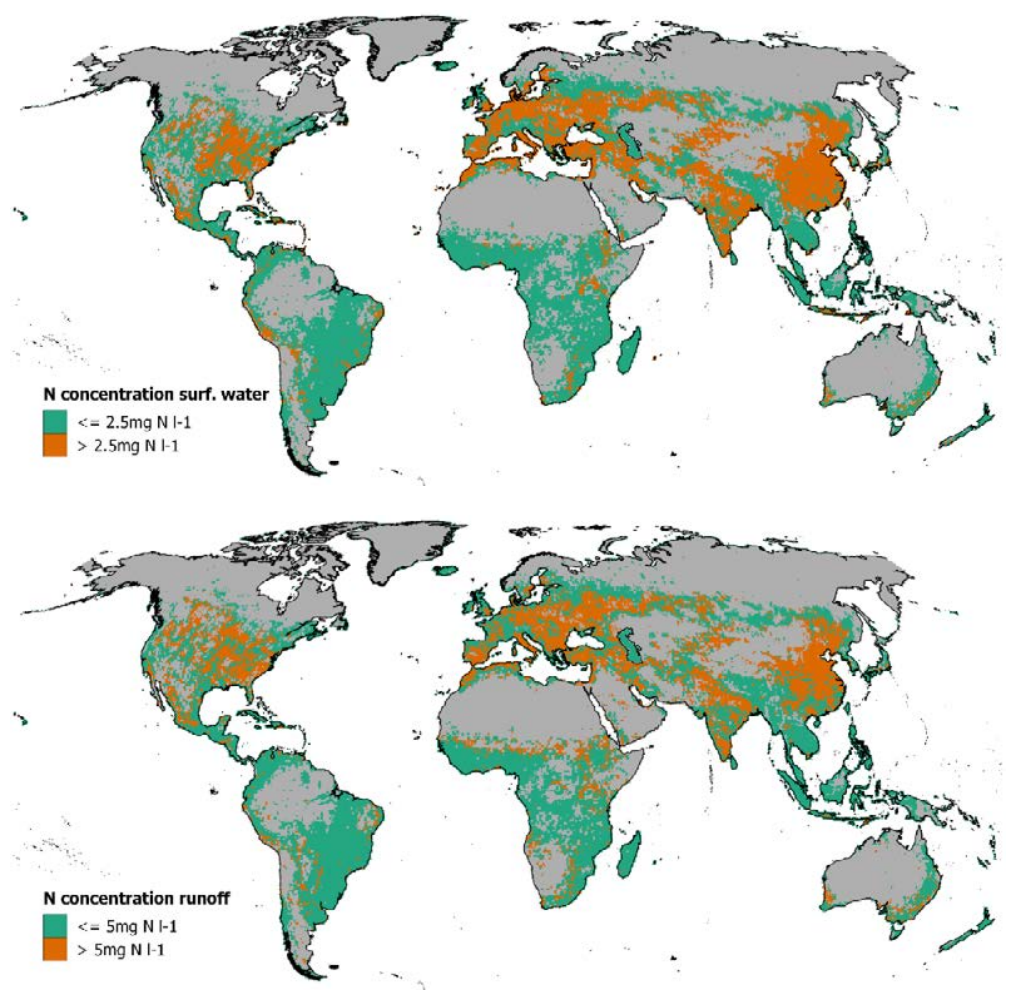

Figure S4.2 | a, Current (year 2010) N concentration in surface water as dynamically calculated by IMAGE-GNM, b, Current (year 20I0) $\mathrm{N}$ concentration in runoff, calculated as total $\mathrm{N}$ load within a grid cell divided by total runoff. Grid cells with no agricultural land or with no runoff are shown in grey. 


\section{S4.3. Full mathematical description of the model for calculating spatially explicit critical inputs}

[see Table S4.2 and Table S4.3 for explanations of all variables used in the equations]

Formulas for the calculations of critical $\mathrm{N}$ inputs presented in the following sections apply for those grid cells with only one agricultural land use types for which critical inputs are calculated ("ag", which could either refer to arable land or intensively managed grassland), whether or not in combination with natural land ("nat"). For grid cells that contain either a combination of arable land and extensively managed grassland (in which case critical $\mathrm{N}$ inputs to arable land are calculated while keeping inputs to extensively managed grassland constant), or a combination of arable land and intensively managed grassland (in which case a certain share of the critical $\mathrm{N}$ load is first allocated to arable land and intensively managed grassland, after which critical $\mathrm{N}$ inputs for both land use types are calculated), the formulas are different, but the basic approach is the same.

Total critical $\mathrm{N}$ inputs are calculated as:

$$
\operatorname{Nin}_{(\text {crit })}=N f e r_{(c r i t)}+\operatorname{Nman}_{(\text {crit })}+\boldsymbol{N f \boldsymbol { i x }}+\mathrm{Ndep_{(crit) }}
$$

Nitrogen inputs from deposition at critical $\mathrm{N}$ inputs are a linear function of $\mathrm{NH}_{3}$ emissions due to critical $\mathrm{N}$ inputs from fertilizer and manure within the same grid cell, and of constant $\mathrm{NO}_{\mathrm{x}}$ emissions:

$$
N d e p_{a g(c r i t)}=\left(N f e r_{(c r i t)} * f \mathbf{N H} \mathbf{3}, \boldsymbol{f e r}+\mathrm{Nman}_{(c r i t)} * \boldsymbol{f N H} \mathbf{H}, \boldsymbol{m a n}+\mathbf{N O x}\right) * \boldsymbol{f}_{a g}
$$

$\mathrm{N}$ inputs from fertilizer and manure are assumed to change proportionally, i.e. the share of $\mathrm{N}$ inputs from fertilizers in total $\mathrm{N}$ inputs from manure and fertilizer stays constant to the current share (see also Table S4.3, rows 30-31):

$$
N f e r_{(c r i t)}=\boldsymbol{f N f e r} *\left(N f e r_{(c r i t)}+\operatorname{Nman}_{(\text {crit })}\right)
$$

and thus:

$$
N f e r_{(c r i t)}=\frac{f N f e r}{1-f N f e r} * \operatorname{Nman}_{(\text {crit })}
$$

$\mathrm{N}$ loss fractions (e.g. surface runoff fraction, leaching fraction, $\mathrm{NH}_{3}$ emission fraction) are calculated for each grid cell by dividing total losses by total inputs. To calculate $\mathrm{NH}_{3}$ emission fractions for manure for each land use type (see Table S4.3, rows 11-14), storage $\mathrm{NH}_{3}$ emissions were allocated to either arable land, intensively managed grassland or extensively managed grassland based on the shares of (effective) manure inputs to each of these land use types (see Table S4.3, rows 8-10). 


\section{S4.3. I. Calculation of critical $\mathbf{N}$ inputs to limit terrestrial biodiversity loss}

First, the total critical deposition per grid cell is calculated by multiplying critical $\mathrm{N}$ deposition rates (see Table S4.1) by total grid cell area:

$$
N d e p_{(\text {crit })}=N d e p, \text { rate }_{\text {crit }} * \boldsymbol{a}_{-} \text {tot }
$$

As we assume that total deposition equals total $\mathrm{N}$ emissions within a grid cell, and that $\mathrm{NO}_{\mathrm{x}}$ emissions are constant, critical $\mathrm{NH}_{3}$ emissions for agriculture are calculated as the difference between total critical deposition and $\mathrm{NO}_{\mathrm{x}}$ emissions:

$$
\operatorname{Nin}_{(\text {crit })}=N f e r_{(\text {crit })}+\operatorname{Nman}_{(\text {crit })}+\boldsymbol{N f \boldsymbol { i x }}+\operatorname{Ndep}_{(\mathrm{crit})}
$$

Critical emissions are written as a function of critical $\mathrm{N}$ inputs from fertilizer and critical $\mathrm{N}$ inputs from manure, multiplied by emission fractions for manure and fertilizer:

$$
N H 3 e m_{a g(c r i t)}=\operatorname{Nman}_{(c r i t)} * \boldsymbol{f N H} \mathbf{3}, \boldsymbol{m a n}+N f e r_{(c r i t)} * \boldsymbol{f N H} \mathbf{3}, \boldsymbol{f e r}
$$

Solving Eq. (S4.7) for $\mathrm{Nman}_{\text {(crit) }}$ while substituting Eq. (S4.4) for $\mathrm{Nfer}_{\text {(crit) }}$ results in:

$$
\operatorname{Nman}_{(\text {crit })}=\frac{N H 3 e m_{a g(c r i t)}}{f N H 3, \text { man }+f N H 3, f e r * \frac{f N f e r}{1-f N f e r}}
$$

Associated critical inputs from fertilizer are calculated with Eq. (S4.4).

\section{S4.3.2. Calculation of critical $\mathbf{N}$ inputs to limit surface water eutrophication}

$\mathrm{N}$ concentration in runoff is calculated as the total $\mathrm{N}$ load to the river basin within a certain grid cell divided by the total runoff:

$$
\text { Nconc, qtot }=\frac{\text { Nload }}{\text { qtot }}
$$

Following Eq. (S4.9), the 'critical $\mathrm{N}$ load' to surface water is calculated as critical $\mathrm{N}$ concentration of $5 \mathrm{mg} \mathrm{N} \mathrm{l}^{-1}$ multiplied by total runoff:

$$
\operatorname{Nload}_{(\text {crit })}=\text { Nconc, } \text { qtot }_{(\text {crit })} * \boldsymbol{q t o t}
$$

The total critical $\mathrm{N}$ load to surface water is the sum of several sources contributing to total $\mathrm{N}$ load (see Figure 4.5b):

$$
\begin{aligned}
& \operatorname{Nload}_{(\text {crit })}=N g w, \text { rec }_{a g(\text { crit })}+N g w, \operatorname{rec}_{\text {nat }(\text { crit })}+\mathrm{Nsro}_{a g(\text { crit })}+ \\
& \mathrm{Nsro}_{\text {nat }(\text { crit })}+\mathrm{Nero}_{\text {ag }}+\mathrm{Nero}_{\text {nat }}+\mathrm{Ngw}, \text { fixed }_{\text {ag }}+ \\
& N g w, \text { fixed }_{\text {nat }}+N w w+N a l l o+N a q u a+N d e p, s w
\end{aligned}
$$

Several sources contributing to total $\mathrm{N}$ load are assumed to be constant in the calculations of critical $\mathrm{N}$ inputs. These sources are summarized as 'fixed' $\mathrm{N}$ load: 


$$
\begin{aligned}
\text { Nload, fixed }= & \text { Nero }_{a g}+\text { Nero }_{\text {nat }}+N g w, \text { fixed }_{a g}+N g w, \text { fixed }_{\text {nat }}+ \\
& N w w+N a l l o+N a q u a+N d e p, s w
\end{aligned}
$$

We thus can simplify Eq. (S4.11) to:

$$
\begin{aligned}
& \operatorname{Nload}_{(\text {crit })}=N g w, \operatorname{rec}_{a g(\text { crit })}+N g w, \text { rec }_{\text {nat }(\text { crit })}+N \operatorname{sro}_{a g(\text { crit })}+ \\
& \mathrm{Nsro}_{\text {nat(crit) }}+\text { Nload, fixed }
\end{aligned}
$$

In order to back-calculate critical $\mathrm{N}$ inputs from the critical $\mathrm{N}$ load, we express all components of the critical $\mathrm{N}$ load as functions of fertilizer and manure inputs to agriculture.

Critical $\mathrm{N}$ delivery to surface water via surface runoff is a fraction of critical $\mathrm{N}$ inputs:

$$
\begin{aligned}
& \operatorname{Nsro}_{a g(\text { crit })}=\boldsymbol{f s r o}_{\boldsymbol{a g}} * \operatorname{Nin} n_{\text {ag(crit })} \\
& \operatorname{Nsro}_{\text {nat }(\text { crit })}=\boldsymbol{f} \boldsymbol{s r} \boldsymbol{o}_{\text {nat }} * \operatorname{Nin}_{\text {nat }(\text { crit })}
\end{aligned}
$$

Critical $\mathrm{N}$ inputs to agriculture are the sum of critical manure and fertilizer inputs, critical $\mathrm{N}$ deposition and (constant) $\mathrm{N}$ fixation (see Eq. (S4.1)). $\mathrm{N}$ withdrawal or uptake at critical $\mathrm{N}$ inputs is calculated as

$$
\operatorname{Nup} p_{a g(\text { crit })}=\left(\operatorname{Nin}_{a g(c r i t)}-N s r o_{a g(c r i t)}\right) * \boldsymbol{f r N u p}_{\boldsymbol{a g}}
$$

$\mathrm{N}$ inputs to natural areas at critical inputs are the sum of $\mathrm{N}$ deposition at critical inputs and constant $\mathrm{N}$ fixation:

$$
\operatorname{Nin}_{\text {nat }(\text { crit })}=\boldsymbol{N} \boldsymbol{f i x _ { \text { nat } }}+\operatorname{Ndep}_{\text {nat }(\text { crit })}
$$

$\mathrm{N}$ deposition on agricultural and natural land at critical $\mathrm{N}$ inputs is calculated as:

$$
\begin{aligned}
& N d e p_{a g(c r i t)}=\boldsymbol{f}_{\boldsymbol{a g}} *\left(\operatorname{Nman}_{(\mathrm{crit})} * \boldsymbol{f N H} \mathbf{3}, \boldsymbol{m a n}+N f e r_{(c r i t)} * \boldsymbol{f N H}, \boldsymbol{f e r}+\boldsymbol{N O x}\right) \quad(E q . S 4.18) \\
& N d e p_{\text {nat }(\text { crit })}=\boldsymbol{f}_{\text {nat }} *\left(\operatorname{Nman}_{(\text {crit })} * \boldsymbol{f N H}, \boldsymbol{m a n}+N f e r_{(c r i t)} * \boldsymbol{f N H 3}, \boldsymbol{f e r}+\mathbf{N O x}\right) \quad(E q . S 4.19)
\end{aligned}
$$

Critical $\mathrm{N}$ delivery to surface water via groundwater is a fraction of critical $\mathrm{N}$ leaching:

$$
\begin{aligned}
& N g w, r e c_{a g(c r i t)}=\boldsymbol{f g} \boldsymbol{w}, \boldsymbol{r e c}, \boldsymbol{l e}_{\boldsymbol{a g}} * N l e_{a g(\mathrm{crit})} \\
& N g w, r e c_{\text {nat (crit) }}=\boldsymbol{f} \boldsymbol{g} \boldsymbol{w}, \boldsymbol{r e c}, \boldsymbol{l} \boldsymbol{e}_{\boldsymbol{n a t}} * N l e_{\text {nat }(\text { crit })}
\end{aligned}
$$


Critical $\mathrm{N}$ leaching is a fraction of the critical $\mathrm{N}$ inputs minus critical $\mathrm{N}$ uptake (only for agricultural land) minus critical $\mathrm{N}$ surface runoff:

$$
\begin{aligned}
& N l e_{a g(c r i t)}=\boldsymbol{f l e}, \boldsymbol{a g} *\left(\operatorname{Nin}_{a g(c r i t)}-N u p_{a g(c r i t)}-N s r o_{a g(c r i t)}\right) \\
& N l e_{\text {nat }(c r i t)}=\boldsymbol{f l \boldsymbol { e } _ { \text { nat } }} *\left(\operatorname{Nin}_{\text {nat }(\mathrm{crit})}-N \operatorname{sro} \mathrm{nat}_{\text {(crit) })}\right)
\end{aligned}
$$

By combining Eqs. (S4.1), (S4.4) and (S4.13) to (S4.23), critical $\mathrm{N}$ inputs from manure are calculated from the critical $\mathrm{N}$ load to surface water, $\operatorname{Nload}_{(\text {(rit) }}$, as:

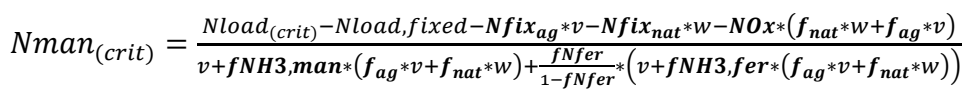

Where the variables ' $v$ ' and ' $w$ ' are defined as follows:

$$
v=\boldsymbol{f s r o}_{a g}+\boldsymbol{f l e _ { a g }} * \boldsymbol{f g w}, \boldsymbol{r e c}, \boldsymbol{l e}_{\boldsymbol{a g}} *\left(1-\boldsymbol{f N u p _ { a g }}+\boldsymbol{f N u p _ { a g }} * \boldsymbol{f s r o} \boldsymbol{o}_{a g}-\boldsymbol{f s r o}_{a g}\right)(E q . S 4.25)
$$

\section{S4.3.3. Calculation of critical $\mathbf{N}$ inputs to limit groundwater nitrate pollution}

Critical $\mathrm{N}$ leaching is calculated as the critical concentration in groundwater (i.e. $11.6 \mathrm{mg}$ $\mathrm{NO}_{3}-\mathrm{N}$ per liter) multiplied by the water flux leaching from the agricultural soil:

$$
N l e_{a g(\text { crit })}=\left(1-\boldsymbol{f s r o}_{\boldsymbol{a g}}\right) * \boldsymbol{q} \boldsymbol{t o t} * \boldsymbol{f}_{\boldsymbol{a g}} * N \text { conc, } l e_{a g(\text { crit })}
$$

By combining Eq. (S4.22) with Eqs. (S4.1), (S4.14), (S4.16) and (S4.18), we calculate critical $\mathrm{N}$ inputs from manure related to a critical $\mathrm{N}$ leaching to groundwater as:

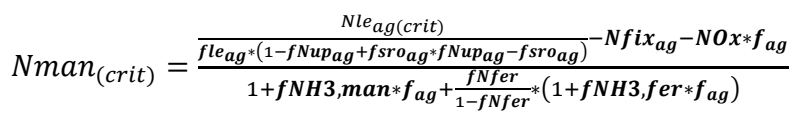


Table S4.2 | List of all input datasets used in the calculation of critical $\mathrm{N}$ inputs (all datasets are outputs from the IMAGE model). Names in the first column are those used in the equations in this section. The addition 'ara' refers to arable land, 'igl' refers to intensively managed grassland, 'egl' refers to extensively managed grassland and 'nat' refers to natural land.

\begin{tabular}{|c|c|c|}
\hline Variable name & Description & Unit \\
\hline a_tot, a_ara, a_igl, a_egl, a_nat & $\begin{array}{l}\text { Area: total grid cell area (a_tot) and area of arable land, } \\
\text { intensively managed grassland, extensively managed grassland and } \\
\text { natural land }\end{array}$ & ha \\
\hline Nfix_ara, Nfix_igl, Nfix_egl, Nfix_nat & $\begin{array}{l}\mathrm{N} \text { inputs from biological fixation on arable land, intensively } \\
\text { managed grassland, extensively managed grassland and natural } \\
\text { land }\end{array}$ & $\mathrm{kg} N \mathrm{yr}^{\prime}$ \\
\hline Nfer_ara, Nfer_igl & $\begin{array}{l}\mathrm{N} \text { inputs from synthetic fertilizer on arable land and intensively } \\
\text { managed grassland }\end{array}$ & $\operatorname{kg} N y r^{\prime}$ \\
\hline Nman_ara, Nman_igl, Nman_egl & $\begin{array}{l}\mathrm{N} \text { inputs form manure on arable land, intensively managed } \\
\text { grassland and extensively managed grassland }\end{array}$ & $\mathrm{kg} N \mathrm{yr}^{\prime}$ \\
\hline $\mathrm{NH} 3$, fer_ara, $\mathrm{NH} 3, \mathrm{fer} \_\mathrm{gg} \mid$ & $\begin{array}{l}\mathrm{NH}_{3} \text { emissions from fertilizer application on arable land and } \\
\text { intensively managed grassland }\end{array}$ & $\mathrm{kg} N y r^{\prime}$ \\
\hline $\begin{array}{l}\text { NH3,spr_ara, NH3,spr_igl, } \\
\mathrm{NH} 3, \text { spr_egl }\end{array}$ & $\begin{array}{l}\mathrm{NH}_{3} \text { emissions from manure spreading on arable land, intensively } \\
\text { managed grassland and extensively managed grassland }\end{array}$ & $\mathrm{kg} \mathrm{N}_{\mathrm{yr}} \mathrm{I}^{\mathrm{g}}$ \\
\hline NH3,graz_igl, NH3,graz_egl & $\begin{array}{l}\mathrm{NH}_{3} \text { emissions from manure deposited during grazing for } \\
\text { intensively and extensively managed grassland }\end{array}$ & $\mathrm{kg} \mathrm{N} \mathrm{yr}{ }^{1}$ \\
\hline $\mathrm{NH} 3$,stor & $\mathrm{NH}_{3}$ emissions from manure storage & $\mathrm{kg} N \mathrm{yr}^{\prime}$ \\
\hline Ndep & Total N Deposition & $\operatorname{kg} N y r^{\prime}$ \\
\hline Nup_ara, Nup_igl, Nup_egl & Crop $\mathrm{N}$ uptake & $\mathrm{kg} N \mathrm{yr}^{1}$ \\
\hline Nsro_ag, Nsro_nat & $\mathrm{N}$ surface runoff on agricultural and natural soils & $\operatorname{kg} N y r^{\prime}$ \\
\hline Nle_ag, Nle_nat & $\mathrm{N}$ leaching from agricultural and natural soils & $\operatorname{kg} N y r^{\prime}$ \\
\hline Ngw_ag, Ngw_nat & $\begin{array}{l}N \text { delivery to surface water via sub-surface runoff from } \\
\text { agricultural and natural soils }\end{array}$ & $\mathrm{kg} \mathrm{N} \mathrm{yr}{ }^{\prime}$ \\
\hline Nero_ag, Nero_nat & $\mathrm{N}$ inputs from soil erosion on agricultural and natural soils & $\operatorname{kg~N~yr}{ }^{\prime}$ \\
\hline Nallo & $\begin{array}{l}\text { Direct } \mathrm{N} \text { input to surface water from allochthonous organic } \\
\text { matter }\end{array}$ & $\mathrm{kg} N \mathrm{yr}^{\prime}$ \\
\hline Ndep,sw & Direct $\mathrm{N}$ input to surface water from deposition on water bodies & $\operatorname{kg} N y r^{\prime}$ \\
\hline Nww & Direct $\mathrm{N}$ input to surface water from wastewater & $\operatorname{kg} N y r^{\prime}$ \\
\hline Naqua & Direct $\mathrm{N}$ input to surface water from aquaculture & $\operatorname{kg} N y r^{\prime}$ \\
\hline qtot & $\begin{array}{l}\text { Total runoff (precipitation surplus), i.e. precipitation minus } \\
\text { evapotranspiration }\end{array}$ & Litres \\
\hline Biome & identifying each grid cell as belonging to one of 14 global biomes & - \\
\hline fgw,rec_ag, fgw_rec,nat & $\begin{array}{l}\text { Fraction of } \mathrm{N} \text { delivered to surface water via groundwater ( } \mathrm{Ngw}) \\
\text { that is affected by recent inputs for agricultural and natural soils. }\end{array}$ & - \\
\hline
\end{tabular}


Table S4.3 | Variable names, equations and units for intermediate variables in the calculation of critical $\mathrm{N}$ inputs. Variables used in the calculations are either IMAGE input datasets listed from Table S4.2 (regular font), or from this table (italic font, number in superscript denotes the row number where formula for the respective variable can be found).

\begin{tabular}{|c|c|c|c|}
\hline $\mathbf{N r}$ & Variable name & Formula & Unit \\
\hline \multicolumn{4}{|c|}{ Land use fractions } \\
\hline I & f_ara & $=$ a_ara / a_tot & - \\
\hline 2 & f_igl & = a_igl / a_tot & - \\
\hline 3 & f_egl & $=$ a_egl / a_tot & - \\
\hline 4 & f_nat & $=a \_$nat $/$a_tot & - \\
\hline \multicolumn{4}{|c|}{ Total $\mathrm{NH}_{3}$ emissions } \\
\hline 5 & $\mathrm{NH} 3$, tot & $\begin{aligned}= & \mathrm{NH} 3, \text { fer_ara }+\mathrm{NH} 3, \mathrm{fer} \_\mathrm{igl}+\mathrm{NH} 3, \mathrm{spr} \_ \text {ara }+\mathrm{NH} 3, \mathrm{spr} \_\mathrm{igl}+\mathrm{NH} 3, \mathrm{spr} \_ \text {egl }+ \\
& \mathrm{NH} 3, \text { graz_igl }+, \mathrm{NH} 3, \text { graz_egl }+\mathrm{NH} 3, \text { stor }\end{aligned}$ & $\operatorname{kg~Nyr^{-1}}$ \\
\hline \multicolumn{4}{|c|}{ Corrected $\mathrm{N}$ deposition } \\
\hline 6 & Ndep,corr & $=\operatorname{MAX}\left(\mathrm{Ndep}, \mathrm{NH} 3, \operatorname{tot}^{(5)}\right)$ & $\mathrm{kg} \mathrm{N} \mathrm{yr}{ }^{-1}$ \\
\hline \multicolumn{4}{|c|}{$\mathrm{NO}_{x}$ emissions } \\
\hline 7 & NOx & $=\mathrm{Ndep} \operatorname{corr}^{(6)}-\mathrm{NH} 3$, tot $^{(5)}$ & $\mathrm{kg} \mathrm{Ny} y^{-1}$ \\
\hline \multicolumn{4}{|c|}{ Allocation of $\mathrm{NH}_{3}$ emissions from storage to different land use types } \\
\hline 8 & NH3,stor_ara & $=$ Nman_ara / (Nman_ara + Nman_igl + Nman_egl) $* \mathrm{NH} 3$, stor & $\mathrm{kg} \mathrm{N} \mathrm{yr}^{-1}$ \\
\hline 9 & $\mathrm{NH} 3$,stor_igl & $=$ Nman_igl / (Nman_ara + Nman_igl + Nman_egl) $* \mathrm{NH} 3$,stor & $\mathrm{kg} \mathrm{Nyr}$ \\
\hline 10 & NH3,stor_egl & $=$ Nman_egl $/\left(\mathrm{Nman} \_\right.$ara $+\mathrm{Nman} \_i g l+\mathrm{Nman} \_$egl $) * \mathrm{NH} 3$, stor & $\mathrm{kg} N \mathrm{yr}^{-1}$ \\
\hline \multicolumn{4}{|c|}{$\mathrm{NH}_{3}$ emission fractions for inputs from fertilizer (fer) and manure (man) } \\
\hline II & $\mathrm{fNH} 3$,fer_ara & $=\mathrm{NH} 3 \_$fer_ara / Nfer_ara & - \\
\hline 12 & $\mathrm{fNH} 3$,fer_igl & $=\mathrm{NH} 3 \_f e r \_i g l / N f e r \_i g l$ & - \\
\hline 13 & $\mathrm{fNH} 3$,man_ara & $=\left(\mathrm{NH} 3, \mathrm{spr} \_\right.$ara $+\mathrm{NH} 3$, stor_ara $\left.{ }^{(8)}\right) / \mathrm{Nman} \_$ara & - \\
\hline 14 & $\mathrm{fNH} 3$, man_igl & 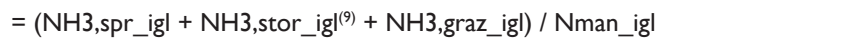 & - \\
\hline \multicolumn{4}{|c|}{$\mathrm{N}$ deposition per land use type } \\
\hline 15 & Ndep_ara & $=$ Ndep,corr ${ }^{(6)} * f \_$ara $^{(1)}$ & $\mathrm{kg} \mathrm{N} \mathrm{yr}^{-1}$ \\
\hline 16 & Ndep_igl & $=$ Ndep,corr $\left.{ }^{(6)} * f_{\text {_ig }}\right|^{(2)}$ & $\operatorname{kg~Nyr}{ }^{1}$ \\
\hline 17 & Ndep_egl & $=$ Ndep,corr ${ }^{(6)} * f \_$egl $\left.\right|^{(3)}$ & $\mathrm{kg} N \mathrm{yr}^{-1}$ \\
\hline 18 & Ndep_nat & $=$ Ndep,corr ${ }^{(6)} * f \_$nat ${ }^{(4)}$ & $\mathrm{kg} \mathrm{N} \mathrm{yr}^{\mathrm{l}}$ \\
\hline \multicolumn{4}{|c|}{ Total $\mathrm{N}$ inputs } \\
\hline 19 & Nin_ara & $=$ Nfer_ara + Nman_ara + Nfix_ara + Ndep_ara ${ }^{(15)}$ & $\mathrm{kg} \mathrm{N} \mathrm{yr}^{-1}$ \\
\hline 20 & Nin_igl & = Nfer_igl + Nman_igl + Nfix_igl + Ndep_ig $\left.\right|^{(16)}$ & $\operatorname{kg~N~yr-1}$ \\
\hline 21 & Nin_egl & $=$ Nman_egl + Nfix_egl + Ndep_eg( $\left.\right|^{(17)}$ & $\mathrm{kg} N \mathrm{yr}^{-1}$ \\
\hline 22 & Nin_nat & $=N f i x \_n a t+N d e p \_n a t^{(18)}$ & $\mathrm{kg} \mathrm{N} \mathrm{yr}^{-1}$ \\
\hline 23 & Nin_ag & $=N i n \_a r a^{(19)}+\left.N i n \_i g\right|^{(20)}+\left.N i n \_e g\right|^{(21)}$ & $\mathrm{kg} \mathrm{N} \mathrm{yr}{ }^{-1}$ \\
\hline \multicolumn{4}{|c|}{ Surface runoff fraction for agricultural and natural land } \\
\hline 24 & fsro_ag & = Nsro_ag / Nin_ag ${ }^{(23)}$ & - \\
\hline 25 & fsro_nat & = Nsro_nat / Nin_nat ${ }^{(22)}$ & - \\
\hline
\end{tabular}


Table S4.3 | (continued)

\begin{tabular}{|c|c|c|c|}
\hline $\mathbf{N r}$ & Variable name & Formula & Unit \\
\hline \multicolumn{4}{|c|}{ Leaching fraction for agricultural and natural land } \\
\hline 26 & fle_ag & $=$ Nle_ag $/\left(\right.$ Nin_ag ${ }^{(23)}-$ Nup_ag - Nsro_ag) & - \\
\hline 27 & fle_nat & $=$ Nle_nat $/\left(\right.$ Nin_nat ${ }^{(20)}-$ Nsro_nat $)$ & - \\
\hline \multicolumn{4}{|c|}{$\mathrm{N}$ uptake fraction } \\
\hline 28 & fNup_ara & $=$ Nup_ara / $\left(\mathrm{Nin} \_a r a^{(19)}-\mathrm{Nin} \_a r a^{(19)} *\right.$ fsro_ag $\left.{ }^{(24)}\right)$ & - \\
\hline 29 & fNup_igl & $=$ Nup_igl $/\left(\right.$ Nin,,$g^{(20)}-\left.N i n \_i g\right|^{(20)} *$ fsro_ag $\left.{ }^{(24)}\right)$ & - \\
\hline \multicolumn{4}{|c|}{ Fraction of $\mathrm{N}$ fertilizer $\mathrm{N}$ inputs in total inputs from manure + fertilizer } \\
\hline 30 & fNfer_ara & $=$ Nfer_ara / (Nfer_ara + Nman_ara) & - \\
\hline 31 & fNfer_igl & = Nfer_igl / (Nfer_igl + Nman_igl) & - \\
\hline \multicolumn{4}{|c|}{ Share of $\mathrm{N}$ groundwater load that is affected by recent inputs } \\
\hline 32 & Ngw,rec_ag & $=$ Ngw_ag $*$ fgw,rec_ag & $\mathrm{kg} \mathrm{N} y r^{-1}$ \\
\hline 33 & Ngw,rec_nat & $=N g w \_n a t * f g w, r e c \_n a t$ & $\operatorname{kg} \mathrm{N}_{y r^{-1}}$ \\
\hline \multicolumn{4}{|c|}{ Share of $\mathrm{N}$ groundwater load that is not affected by recent inputs ('legacy groundwater N') } \\
\hline 34 & Ngw,fixed_ag & $=N g w \_a g *\left(I-f g w, r e c \_a g\right)$ & $\mathrm{kg} \mathrm{Ny}^{-1}$ \\
\hline 35 & Ngw,fixed_nat & $=N g w \_n a t *(I-$ fgw,rec_nat $)$ & $\operatorname{kg} \mathrm{Ny}^{-1}$ \\
\hline \multicolumn{4}{|c|}{ Fraction of recent groundwater $\mathrm{N}$ load to leaching } \\
\hline 36 & fgw,rec,le_ag & $=$ Ngw,rec_ag ${ }^{(32)} /$ Nle_ag & - \\
\hline 37 & fgw,rec,le_nat & $=$ Ngw,rec_nat ${ }^{(33)} / \mathrm{Nle} \_$nat & - \\
\hline
\end{tabular}

\section{S4.4. Method to estimate yield potentials}

\section{S4.4.I. Arable land}

We based our estimates of yield potentials for arable land on an assessment by Mueller et al. (2012), who estimate 'attainable yields' for 17 crops and 155 countries by using estimates of harvested area and yield for the year 2000. They use a published dataset on harvested area and yield for 175 crops (grouped into 11 crop groups) on a $10 \times 10 \mathrm{~km}^{2}$ grid, created by combining national, state, and county level census statistics with a global cropland map based on satellite data (Monfreda et al., 2008). To obtain attainable yields, they calculate climate bins of similar annual precipitation and growing degree days, and estimate attainable yields as the 95-percentile yield that is achieved anywhere in a certain climate bin (with certain restrictions, for more detail see Supplementary Information Mueller et al., 2012). We acknowledge that 'bottom-up' estimates of yield potentials such as for example presented by the Global Yield Gap Atlas (GYGA, www.yieldgap.org) are generally considered more 
accurate than estimates of yield potentials that use global datasets on weather, soil and crop management such as Mueller et al. (van Ittersum et al., 2013); however, bottom-up estimates are currently only available for selected countries and crops and thus do not have the global coverage that we require.

\section{S4.4.2. Intensively managed grassland}

Although there are first efforts to establish a framework for yield gap assessments in grasslands and estimates for grassland yield gaps for certain countries (e.g., the Netherlands and Norway; Schils et al., 2018a), no global assessment of yield potentials and yield gaps in grassland is currently available. Grassland yield potentials are determined by climate, soil type, grassland species and management, i.e. grazing or mowing intensity and frequency. As a surrogate for grassland yield potentials, we used results from a study by Rolinski et al. (2018), who extended the Dynamic Global Vegetation Model (DGVM) LPJmL to include an assessment of the effects of four different types of grassland management on harvest, NPP and soil carbon content. They also assess for each grid cell the maximum livestock density that could be supported by potential local grass production under the management option 'daily grazing without mowing. We considered the $\mathrm{N}$ uptake related to these maximum livestock densities as a 'maximum' $\mathrm{N}$ uptake for grassland considering climate and soil parameters in each grid cell. The maximum livestock density presented by Rolinski et al. (2018) assumes a feed demand of $4000 \mathrm{~g} \mathrm{C} \mathrm{LSU}^{-1}$ day $^{-1}$, which (assuming a C:N content of

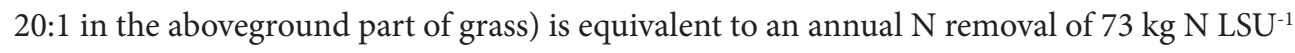
$\mathrm{ha}^{-1} \mathrm{yr}^{-1}$.

We extracted the mean maximum livestock density for each of the 26 IMAGE regions from the original data provided by the authors of the study (area-weighted mean based on the area of intensive grassland in each grid cell). The $\mathrm{N}$ uptake at maximum livestock density for each region was calculated as:

$$
N u p @ L S D \max (i)=\operatorname{LSDmax}_{(i)} * 73 \mathrm{kgN} L S U^{-1} y r^{-1}
$$

Where

$$
\begin{array}{ll}
\text { Nup@LSDmax }_{(\mathrm{i})} & =\mathrm{N} \text { removal at maximum livestock density for region i }\left[\mathrm{kg} \mathrm{N} \mathrm{ha}^{-1} \mathrm{yr}^{-1}\right] \\
\mathrm{LSD}_{\max } \max _{(\mathrm{i})} & =\quad \text { Modelled maximum livestock density for region i }\left[\mathrm{LSU} \mathrm{ha}^{-1}\right]
\end{array}
$$

As we required that the maximum $\mathrm{N}$ uptake should not be lower than the current (year 2010) $\mathrm{N}$ uptake, the maximum $\mathrm{N}$ uptake for intensively managed grassland in region i was defined as:

$$
N u p, \max _{(i)}=\max \left(N u p @ L S D \max (i) ; N u p_{(i)}\right)
$$




\section{S4.5. Results for yield potentials and maximum $\mathrm{N}$ uptake for arable land and intensively managed grassland}

Table S4.4 shows average actual yields, the derived yield potentials, the ratio between yield potentials and actual yields and the calculated maximum $\mathrm{N}$ uptake for arable land and intensively managed grassland per IMAGE region.

Maximum $\mathrm{N}$ uptake for arable land was calculated by multiplying current $\mathrm{N}$ uptake in arable land for each IMAGE region with the ratio between yield potential and actual crop yield. Maximum $\mathrm{N}$ uptake for intensively managed grassland was calculated by multiplying current $\mathrm{N}$ uptake in intensively managed grassland for each IMAGE region with the ratio between maximum $\mathrm{N}$ uptake derived from Rolinski et al. (2018) and current N uptake from IMAGE.

The difference between current $\mathrm{N}$ uptake and maximum $\mathrm{N}$ uptake in arable land varies from 18\% (Western Europe, Japan, Korea) to more than 150\% (Northern Africa, Ukraine region, Central Asia). Globally, the maximum N uptake is $56 \%$ higher than current $\mathrm{N}$ uptake. For intensively managed grassland, maximum $\mathrm{N}$ uptake is $86 \%$ higher than current $\mathrm{N}$ uptake, with regional values ranging from $0 \%$ (Canada, South Africa, Middle East, India, Japan) to $299 \%$ (Rest of Southern Africa). The estimated increase for Western Europe (4\%) is comparable to published estimates of the difference between actual yields and $80 \%$ of the water-limited yield potential for the Netherlands (6\%) and Norway (27\%) (Schils et al., 2018a).

The yield gap for arable land and grassland show marked differences within regions, for example for Northern Africa, the yield gap is 37\% for grassland and $171 \%$ for arable land, for the Middle East, the yield gap increase is $0 \%$ for grassland and $117 \%$ for arable land, while for Rest of South America, the yield gap is $186 \%$ for grassland and 53\% for arable land. As the two procedures follow very different approaches (grassland: modelled maximum production based on biophysical parameters, arable land: highest observed yield for zones of similar climate), such differences can be expected.

\section{S4.6. Plausibility of estimated yield potentials}

In order to assess the plausibility of the data on actual and attainable yields from Mueller et al. (2012), we compared actual and attainable yields from Mueller et al. with actual yields and (water-limited) yield potentials from the Global Yield Gap Atlas (GYGA). GYGA provides estimates of actual yields and yield potentials for a variety of staple crops at sub-country 
Table S4.4 | Average actual crop yields (Ya), average yield potentials (Yp), ratio Yp/Ya and the maximum $N$ uptake used to cap critical $\mathrm{N}$ inputs for arable land and intensively managed grassland (right), per IMAGE region. For arable land, values for $\mathrm{Ya}$ and $\mathrm{Yp}$ represent area-weighted averages over 17 different crops, and thus differences between regions reflect both variations in agricultural performance as well as in crop mix.

\begin{tabular}{|c|c|c|c|c|c|c|c|c|}
\hline & \multicolumn{4}{|c|}{ Arable Land } & \multicolumn{4}{|c|}{ Intensively Managed Grassland } \\
\hline & $\begin{array}{l}\text { Actual } \\
\text { yield } \\
(Y a)^{(I)}\end{array}$ & $\begin{array}{l}\text { Yield } \\
\text { potential } \\
\left(Y_{\mathrm{P}}\right)^{(2)}\end{array}$ & $\begin{array}{l}\text { Ratio } \\
Y p / Y a\end{array}$ & $\begin{array}{l}\text { Maximum } \\
\mathrm{N} \text { uptake } \\
(\mathrm{Nup}, \max )^{(3)}\end{array}$ & $\begin{array}{l}\text { Actual } \\
\text { yield }(Y a)^{(4)}\end{array}$ & $\begin{array}{l}\text { Yield } \\
\text { potential } \\
\left(Y_{p}\right)^{(5)}\end{array}$ & $\begin{array}{l}\text { Ratio } \\
Y_{p} / Y_{a}\end{array}$ & $\begin{array}{l}\text { Max. N } \\
\text { uptake } \\
\left(\text { Nup,max }^{(6)}\right.\end{array}$ \\
\hline IMAGE Region & $\mathrm{t} / \mathrm{ha} / \mathrm{yr}$ & $\mathrm{t} / \mathrm{ha} / \mathrm{yr}$ & - & $\mathrm{kg} \mathrm{N} / \mathrm{ha} / \mathrm{yr}$ & $\mathrm{kg} \mathrm{N} / \mathrm{ha} / \mathrm{yr}$ & $\mathrm{kg} \mathrm{N} / \mathrm{ha} / \mathrm{yr}$ & - & $\mathrm{kg} \mathrm{N} / \mathrm{ha} / \mathrm{yr}$ \\
\hline Canada & 2.6 & 3.4 & 1.27 & 41.4 & 118.6 & 73.1 & 0.62 & 118.6 \\
\hline USA & 5.2 & 6.5 & 1.25 & 97.6 & 19.5 & 45.6 & 2.34 & 45.6 \\
\hline Mexico & 6.8 & 10.7 & 1.57 & 58.8 & 31.6 & 77.9 & 2.47 & 77.9 \\
\hline Central America & 19.2 & 34.5 & 1.80 & 59.7 & 51.4 & 120.4 & 2.34 & 120.4 \\
\hline Brazil & 12.8 & 17.2 & 1.34 & 133.4 & 34.5 & 85.8 & 2.49 & 85.8 \\
\hline Rest of S.Amer. & 4.9 & 7.5 & 1.53 & 150.6 & 33.4 & 95.4 & 2.86 & 95.4 \\
\hline Northern Africa & 1.7 & 4.6 & 2.71 & 125.6 & 29.7 & 40.5 & 1.37 & 40.5 \\
\hline Western Africa & 2.3 & 5.3 & 2.36 & 54.3 & 32.9 & 86.8 & 2.64 & 86.8 \\
\hline Eastern Africa & 2.1 & 5.2 & 2.42 & 44.6 & 42.9 & 77.8 & 1.81 & 77.8 \\
\hline South Africa & 6.4 & 11.8 & 1.85 & 50.2 & 81.3 & 76.1 & 0.94 & 81.3 \\
\hline Western Europe & 8.3 & 9.8 & 1.18 & 101.7 & 99.0 & 102.8 & 1.04 & 102.8 \\
\hline Central Europe & 4.8 & 9.5 & 1.98 & 108.5 & 86.5 & 113.3 & 1.31 & 113.3 \\
\hline Turkey & 3.6 & 6.4 & 1.80 & 72.8 & 33.2 & 66.1 & 1.99 & 66.1 \\
\hline Ukraine region & 3.8 & 10.0 & 2.63 & 85.0 & 55.6 & 91.1 & 1.64 & 91.1 \\
\hline Central Asia & 1.3 & 3.9 & 2.93 & 65.7 & 23.7 & 35.6 & 1.50 & 35.6 \\
\hline Russia region & 2.6 & 6.3 & 2.39 & 41.5 & 36.9 & 83.6 & 2.26 & 83.6 \\
\hline Middle East & 2.7 & 5.8 & 2.17 & 77.8 & 41.0 & 29.1 & 0.71 & 41.0 \\
\hline India & 4.3 & 6.5 & 1.51 & 71.1 & 46.0 & 28.2 & 0.61 & 46.0 \\
\hline Korea region & 6.3 & 7.4 & 1.18 & 64.5 & 89.5 & 109.8 & 1.23 & 109.8 \\
\hline China region & 5.4 & 8.1 & 1.50 & 128.9 & 37.0 & 67.5 & 1.83 & 67.5 \\
\hline Southeast Asia & 7.0 & 10.4 & 1.48 & 109.3 & 70.3 & 101.3 & 1.44 & 101.3 \\
\hline Indonesia region & 7.4 & 9.4 & 1.27 & 86.1 & 58.2 & 86.4 & 1.49 & 86.4 \\
\hline Japan & 8.0 & 9.4 & 1.18 & 85.2 & 150.7 & 115.6 & 0.77 & 150.7 \\
\hline Oceania & 4.0 & 5.9 & 1.49 & 27.7 & 38.0 & 50.3 & 1.32 & 50.3 \\
\hline Rest of S.Asia & 4.4 & 8.2 & 1.87 & 88.9 & 59.9 & 94.2 & 1.57 & 94.2 \\
\hline Rest of S.Africa & 2.9 & 7.3 & 2.55 & 38.0 & 24.4 & 97.5 & 3.99 & 97.5 \\
\hline World & 5.0 & 7.9 & 1.56 & 83.0 & 39.8 & 73.9 & 1.86 & 73.9 \\
\hline
\end{tabular}

(1) Average crop yield (year 2000) from Mueller et al. (2012).

(2) Average crop yield at $100 \%$ of attainable yield from Mueller et al. (20I2).

(3) Calculated as the mean $\mathrm{N}$ uptake for arable land per region from IMAGE for the year 2010, multiplied by the ratio Yp/Ya.

(4) Area-weighted mean $\mathrm{N}$ uptake for intensively managed grassland per IMAGE region from IMAGE for the year 2010.

(5) Calculated as the area-weighted mean maximum Livestock Density per IMAGE region, obtained from Rolinski et al. (20I8), multiplied with a conversion factor of $73 \mathrm{~kg} \mathrm{~N} \mathrm{LSU}^{-1} \mathrm{yr}^{-1}$. The conversion factor is estimated by assuming a feed demand of $4 \mathrm{~kg}$ C LSU-1 d-1 (Rolinski et al., 2018) and a C:N ration in the aboveground-part of grass of 20:I $(4 * 365 / 20=73)$.

(6) Calculated as the maximum of $\mathrm{Ya}$ and $\mathrm{Ya} *(\mathrm{Yp} / \mathrm{Ya})$. 
(regional) level (for zones of similar climate). Sub-national estimates of actual yields are multi-year average yields obtained by farmers under dominant management practices, and are gathered from sub-national statistics, farm surveys and/or local agronomists. Estimates of yield potentials are obtained from crop models for specific weather stations that are scaled up to the country level by using zones of similar climate (Grassini et al., 2015; van Bussel et al., 2015). GYGA distinguishes between the biophysical yield potential (Yp); i.e. the yield of a crop when grown with water and nutrients non-limiting and biotic stress effectively controlled (crop growth rate only determined by solar radiation, temperature, atmospheric $\mathrm{CO}_{2}$ and genetic traits that govern the length of the growing season), and the water-limited yield potential $(\mathrm{Yw})$ which is also determined by water availability (and thus rainfall and soil properties). Yp is the most relevant benchmark for irrigated systems, and Yw for rainfed systems.

For six crops (wheat, barley, maize, millet, rice and sorghum), both GYGA and Mueller et al. (2012) present data on attainable yields and yield potentials for a number of countries. The 'attainable yields' presented by Mueller et al. (2012) represent the highest yields that are actually achieved by farmers in a certain climate bin under current management, and are thus a mix of water-limited yield potentials (for crops where no irrigation occurs anywhere in the climate bin) and irrigated yield potentials. For the best possible comparison with GYGA, we thus calculated the area-weighted average of Yw and Yp for each country and crop based on estimates of both Yw and Yp from GYGA.

For actual yields, estimates from GYGA and Mueller et al. (2012) show a good agreement ( $\mathrm{R}^{2}$ often between 0.7 and 0.9, except for millet and sorghum, see Table S4.5), though GYGA estimates are generally higher for all crops and countries (see Figure S4.3). The correlation between GYGA yield potentials and Mueller attainable yields at country level is mostly weak, with $\mathrm{R}^{2}$ values $>0.3$ only for rye (see Table S4.5). Again, GYGA estimates are generally higher, which can partially be explained by the more conservative approach of Mueller et al. (2012) who use actually observed yields in the same climate zone and thus under-estimate yield potentials when a climate zone contains no high-performing region. Because both estimated actual yields and yield potentials from GYGA are higher, the correlation between the ratio $\mathrm{Yp} /$ Ya for GYGA and Mueller et al., which we used to estimate maximum crop $\mathrm{N}$ uptake in IMAGE, is better than the correlation for yield potentials (between 0.37 and 0.62 , except for wheat and sorghum, see Table S.4.5). 
Table S4.5 | Comparison between estimates of actual yields, yield potentials and the ratio yield potential/ actual yield from the Global Yield Gap Atlas and Mueller et al. (2012) for 6 crops. $R^{2}$ values shown are for a liner fit which is not necessarily $x=y$, so high values can also occur if estimates from one source are consistently lower or higher. Scatter plots are shown in Figure S4.3.

\begin{tabular}{lllll}
\hline Crop & $\begin{array}{l}\text { No. of countries in } \\
\text { comparison }\end{array}$ & $\begin{array}{l}\mathbf{r}^{2} \text { value for actual } \\
\text { yields }(\text { Ya) }\end{array}$ & $\begin{array}{l}\mathbf{r}^{2} \text { value for yield } \\
\text { potentials }(\mathbf{Y p})\end{array}$ & $\begin{array}{l}\mathbf{r}^{2} \text { value for ratio } \\
\mathbf{Y p} / \mathbf{Y a}\end{array}$ \\
\hline Wheat & 47 & 0.89 & 0.66 & 0.44 \\
Barley & 39 & 0.88 & 0.57 & 0.43 \\
Maize & 43 & 0.88 & 0.13 & 0.37 \\
Millet & $1 \mathrm{0}$ & 0.15 & 0.27 & 0.52 \\
Rice & 20 & 0.74 & 0.22 & 0.62 \\
Sorghum & 10 & 0.34 & 0.02 & 0.003 \\
\hline
\end{tabular}


Figure continues on next page 

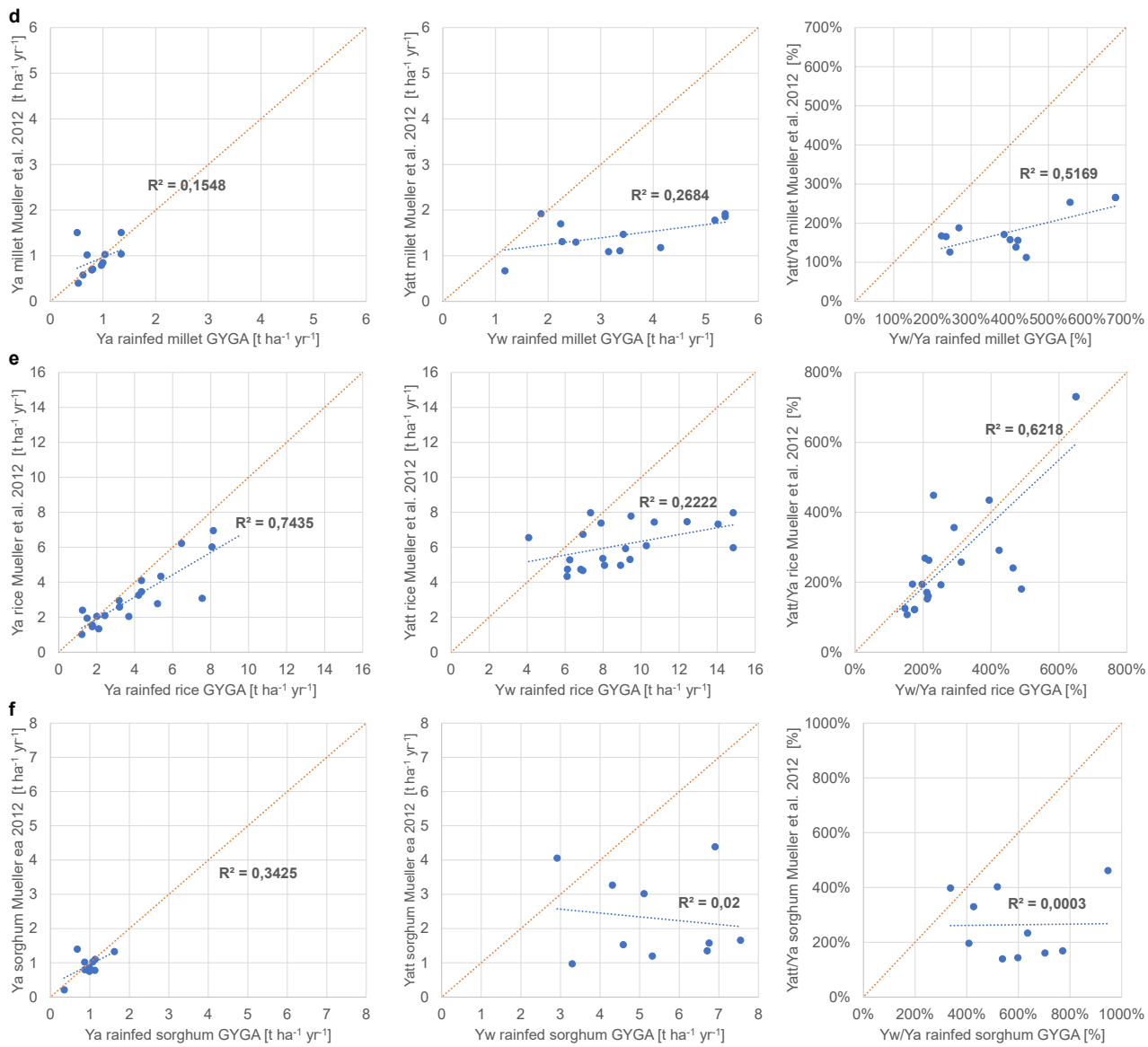

Figure S4.3 | Correlation between country-level estimates for actual yield (Ya) from Mueller et al. (2012) and the Global Yield Gap Atlas (GYGA) (left), correlation between estimates for attainable yield (Yatt) from Mueller et al. (20I2) and water-limited yield potentials (Yw) from GYGA (middle) and correlation between the estimated possible yield increase (ratio Yatt/Ya) from Mueller et al. (2012) and from GYGA (ratio Yw/Ya) for a, wheat, b, barley, c, maize, d, millet, e, rice and f, sorghum. Each dot is a country for which estimates of yield potentials are available from GYGA and in Mueller et al. (20I2). 


\section{S4.7. Results for cut-off at actual $\mathrm{N}$ inputs}

In allowing $\mathrm{N}$ inputs to increase where environmental thresholds are not yet exceeded (up to a maximum value, as described above), our approach varies from the earlier estimate of a planetary N boundary (Steffen et al., 2015; De Vries et al., 2013) which assumed that N inputs needed to decrease where environmental thresholds are transgressed, and stay constant at current values where they are not. In order to test the impact of allowing $\mathrm{N}$ inputs to increase on our results, we also calculated critical $\mathrm{N}$ inputs while capping at current $\mathrm{N}$ inputs (i.e., setting Nup(max) to current $\mathrm{N}$ uptake). Results are shown in Figure S4.4. Not allowing N inputs to increase where environmental thresholds are not yet transgressed reduces global critical $\mathrm{N}$ inputs by $22-33 \%$, depending on the criterion. The largest reductions (-33\%) occur for critical $\mathrm{N}$ inputs for the groundwater criterion, which is also the thresholds that allows for the highest increases in agricultural $\mathrm{N}$ inputs on land where thresholds are not yet exceeded in our standard run (+ $87 \mathrm{Mt} \mathrm{N} \mathrm{yr}^{-1}$, see Figure 4.1 in Main Text).

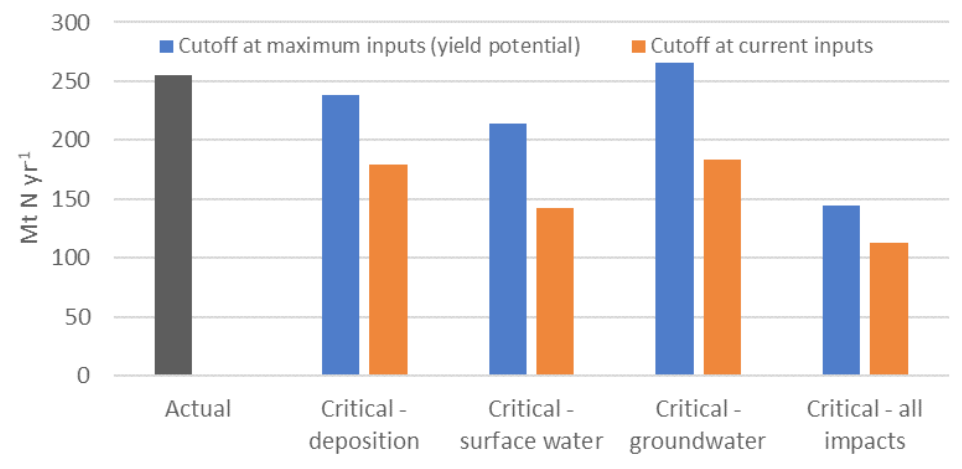

Figure S4.4 | Average global critical $\mathrm{N}$ inputs for different criteria, using two approaches for limiting maximum $\mathrm{N}$ inputs. 


\section{Supplementary Material Chapter 5}

Supplementary Methods

S5. I. Calculation of $\mathrm{N}$ deposition on forests per biome

Supplementary Tables S5. I-S5.7

\section{S5.I. Calculation of $\mathrm{N}$ deposition on forests per biome}

In order to calculate total $\mathrm{N}$ deposition per forest biome, we followed the following procedure: Data on $\mathrm{NH}_{3}$ and $\mathrm{NO}_{\mathrm{x}}$ deposition simulated with the TM5 atmospheric model on a $1^{\circ} \times 1^{\circ}$ grid for the year 2000 (Dentener, personal communication) were projected to an equal area (ALBERS) projection. The resulting spatial map of global $\mathrm{N}$ deposition was combined with a global land cover map (Global Land Cover product 2005-2006, http://due.esrin.esa.int/ page_globcover.php) to identify the area covered by forests. The following land use classes of the original global land cover map were classified as "forest":

- Closed to open ( $>15 \%)$ broadleaved evergreen or semi-deciduous forest $(>5 \mathrm{~m})$

- Closed ( $>40 \%)$ broadleaved deciduous forest $(>5 \mathrm{~m})$

- Open (15-40\%) broadleaved deciduous forest/woodland $(>5 \mathrm{~m})$

- Closed (>40\%) needle-leaved evergreen forest $(>5 \mathrm{~m})$

- Open (15-40\%) needle-leaved deciduous or evergreen forest $(>5 \mathrm{~m})$

- Closed to open (>15\%) mixed broadleaved and needle-leaved forest ( $>5 \mathrm{~m})$

- Closed to open (>15\%) broadleaved forest regularly flooded - Fresh or brackish water

- Closed (>40\%) broadleaved forest or shrubland permanently flooded - Saline or brackish water 
For land use classes that are classified partially as forest, a certain fraction of the total $\mathrm{N}$ deposition in the grid cell was allocated to forests, according to:

- Mosaic forest or shrubland (50-70\%) / grassland (20-50\%) $\rightarrow 65 \%$ of $\mathrm{N}$ deposition allocated to 'forest'

- Mosaic grassland (50-70\%) / forest or shrubland (20-50\%) $\rightarrow 35 \%$ of $\mathrm{N}$ deposition allocated to 'forest'

We classified all forests into one of three biomes (boreal, temperate or tropical) or "other", according to a WWF classification of terrestrial ecoregion (Olson et al., 2001). This classification consists of 14 Major habitat types, which were classified follows shown in Table S6.1. Forests classified as "other" according to the biome classification only accounted for $4 \%$ of total $\mathrm{N}$ deposition on forests, and was neglected in the calculations. 


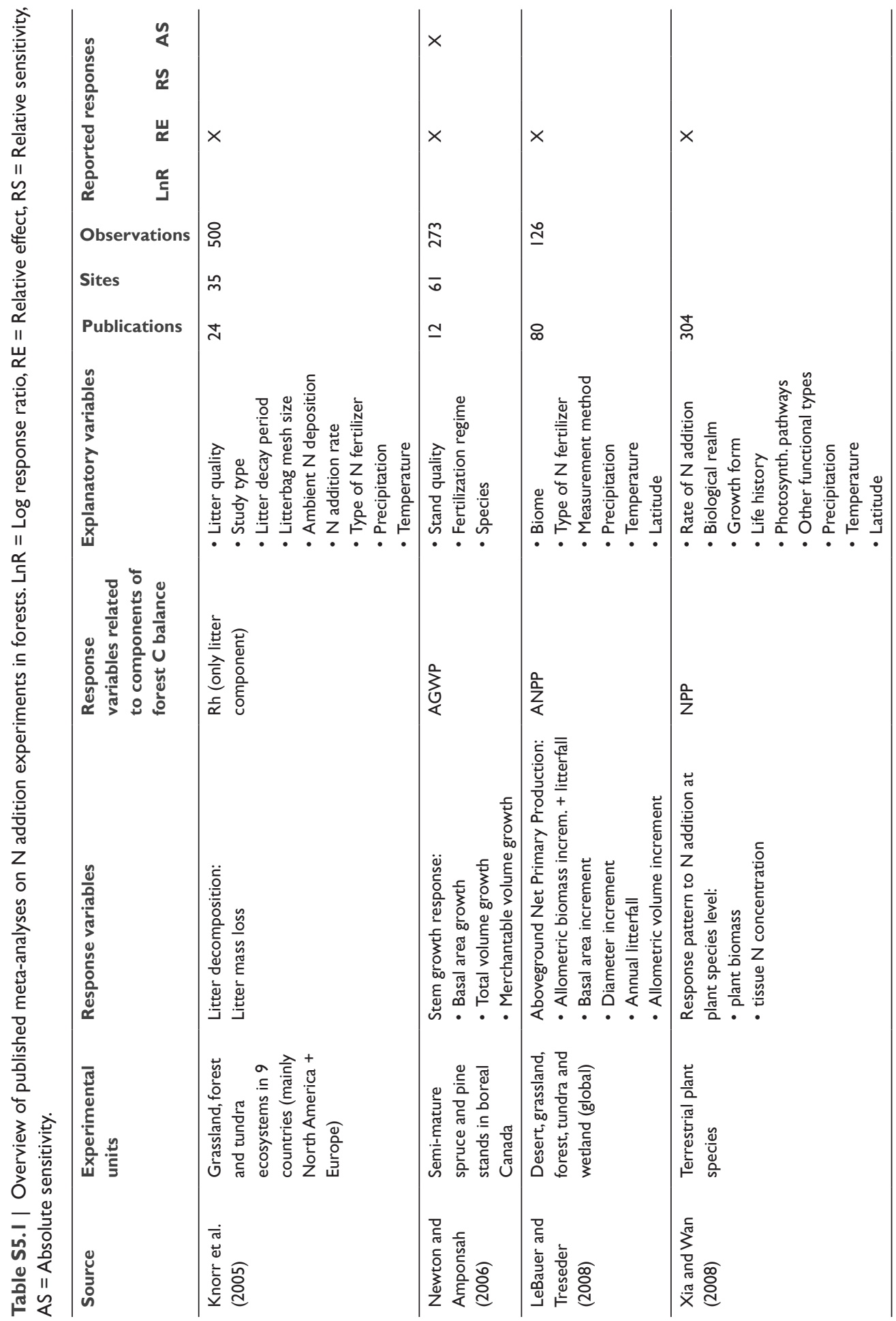




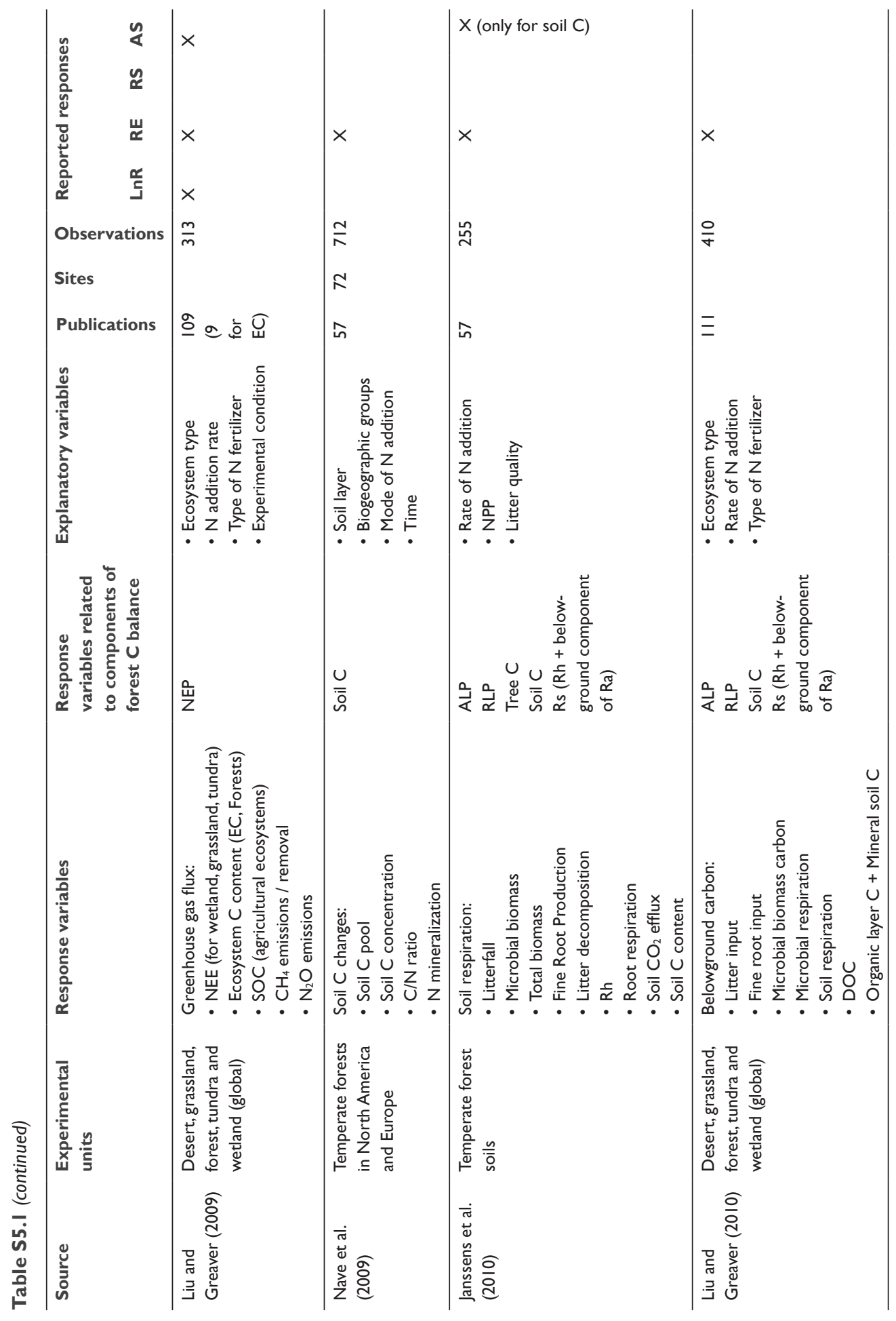




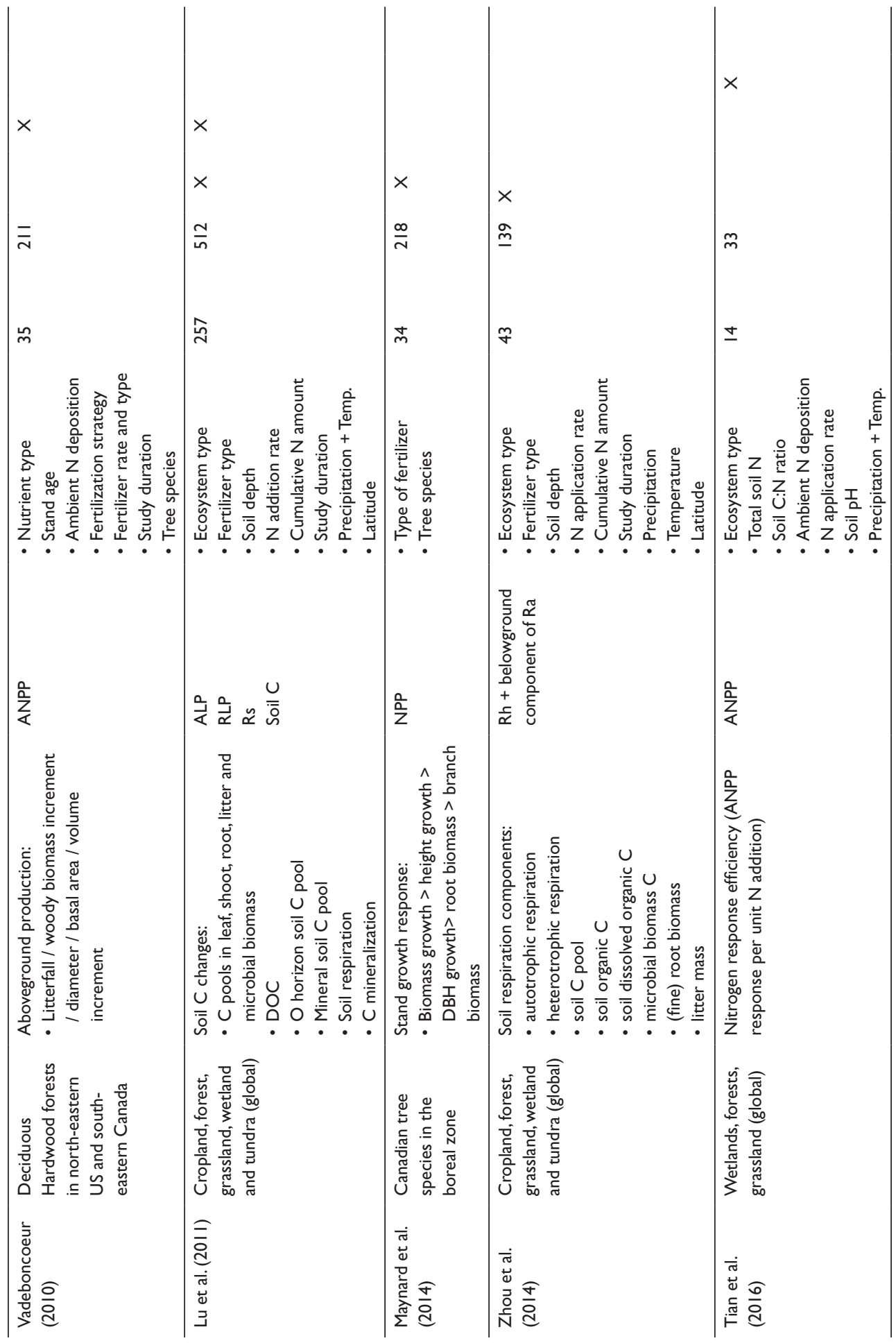


Table S5.2 | Search terms used to find relevant studies for in the meta-analysis of $\mathrm{N}$ addition effects on AGWP. A search in Scopus using these terms in august 2014 returned 2115 hits.

\begin{tabular}{|c|c|c|c|c|c|c|}
\hline $\begin{array}{l}\text { Terms related } \\
\text { to the study } \\
\text { object }\end{array}$ & & $\begin{array}{l}\text { Terms } \\
\text { related to } \\
\text { the nutrients }\end{array}$ & & $\begin{array}{l}\text { Terms related to } \\
\text { the experimental } \\
\text { treatment }\end{array}$ & & $\begin{array}{l}\text { Terms related to the } \\
\text { response variables }\end{array}$ \\
\hline$*_{\text {forest }}$ & AND & nitrogen* & AND & "nitrogen addition*" & AND & "net ecosystem product*" \\
\hline forest* & & ammoni* & & "N addition*" & & "NEP" \\
\hline tree* & & $\mathrm{NH} 3$ & & "nitrogen application" & & "net ecosystem exchange" \\
\hline \multirow[t]{42}{*}{ savanna* } & & $\mathrm{NH} 4$ & & "N application" & & "NEE" \\
\hline & & urea & & "addition of $\mathrm{N}^{*}$ " & & "net primary product*" \\
\hline & & "N fertili*" & & "addition of ammoni*" & & "*NPP" \\
\hline & & "P fertili*" & & "N treat*" & & "gross primary product*" \\
\hline & & phosph* & & "phosph* addition*" & & "GPP" \\
\hline & & & & "P addition*" & & "above-ground producti*" \\
\hline & & & & "phosph* application" & & "below-ground producti*" \\
\hline & & & & "P application" & & "aboveground producti*" \\
\hline & & & & "addition of phosph*" & & "belowground producti*" \\
\hline & & & & "addition of P" & & "above-ground biomass" \\
\hline & & & & "P treat*" & & "below-ground biomass" \\
\hline & & & & "nutrient addition*" & & "aboveground biomass" \\
\hline & & & & added & & "belowground biomass" \\
\hline & & & & adding & & "forest productivity" \\
\hline & & & & fertiliz* & & "forest production" \\
\hline & & & & fertiliz* & & "carbon pool" \\
\hline & & & & "nitrogen enrichment" & & "wood* biomass" \\
\hline & & & & "nitrogen deposition" & & diamet* \\
\hline & & & & "N deposition" & & $\mathrm{DBH}$ \\
\hline & & & & NPK & & "carbon gain" \\
\hline & & & & & & "root *mass" \\
\hline & & & & & & "root growth" \\
\hline & & & & & & "tree growth" \\
\hline & & & & & & "trunk growth" \\
\hline & & & & & & "stemwood growth" \\
\hline & & & & & & "stem growth" \\
\hline & & & & & & "stand growth" \\
\hline & & & & & & "biomass increment" \\
\hline & & & & & & "biomass increase*" \\
\hline & & & & & & "increase* in biomass" \\
\hline & & & & & & "growth increase" \\
\hline & & & & & & "carbon gain" \\
\hline & & & & & & "stem volume growth" \\
\hline & & & & & & "ecosystem carbon \\
\hline & & & & & & content" \\
\hline & & & & & & "ecosystem C content" \\
\hline & & & & & & "C biomass" \\
\hline & & & & & & "tree biomass" \\
\hline & & & & & & "tree height" \\
\hline & & & & & & "tree C?N ratio*" \\
\hline & & & & & & "foliar N concentration*" \\
\hline & & & & & & "basal area" \\
\hline
\end{tabular}









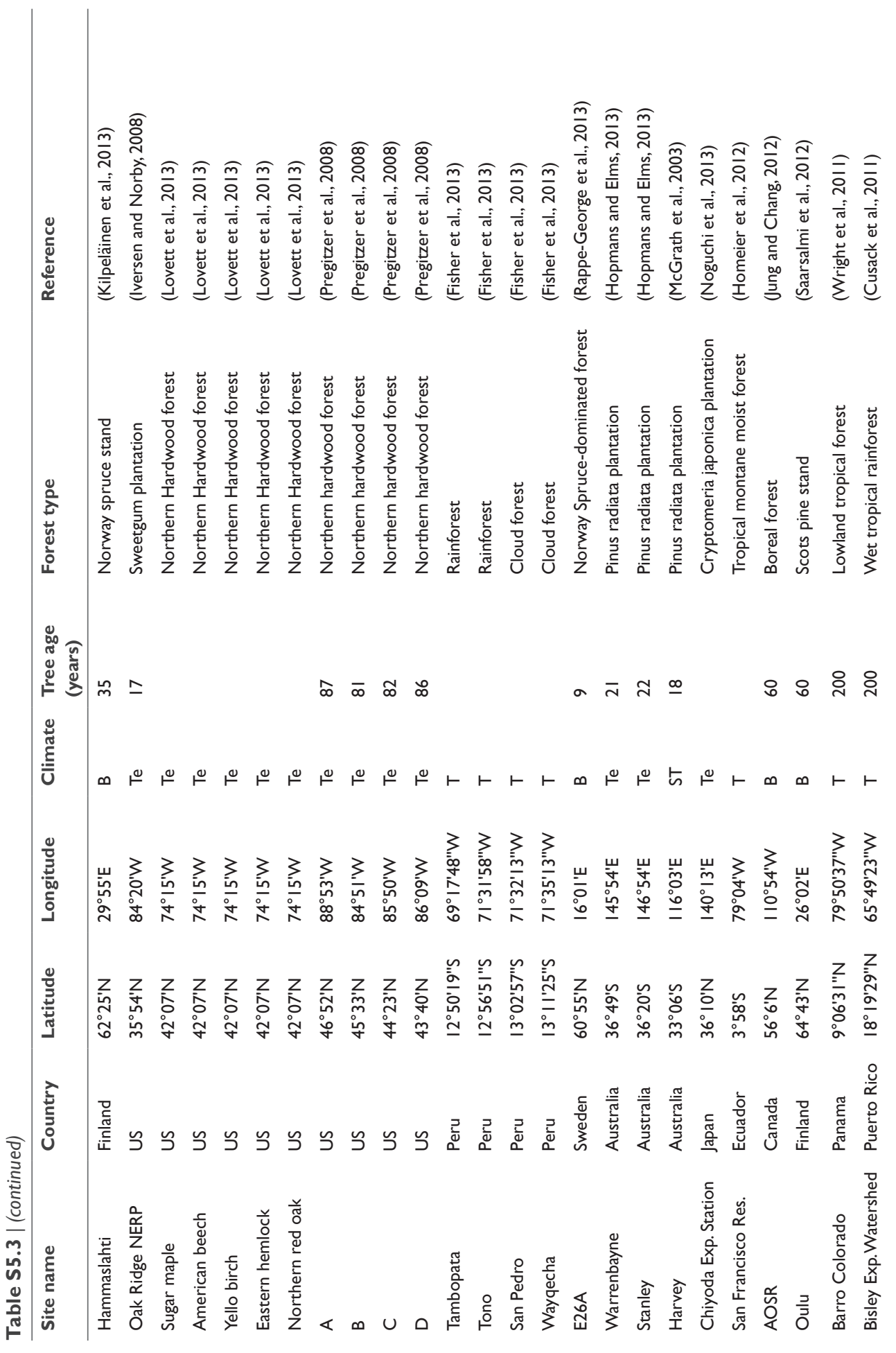


苞

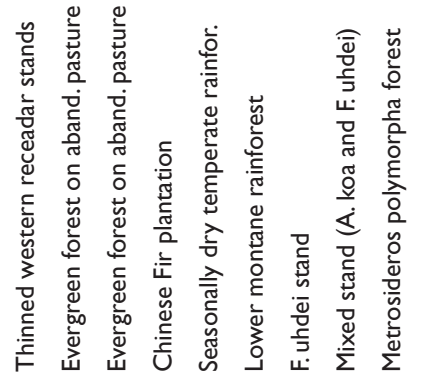

유

$\vdash \vdash \infty \varnothing \infty \varnothing \infty \varnothing \vdash \vdash \vdash \curvearrowleft \vdash \vdash \vdash$

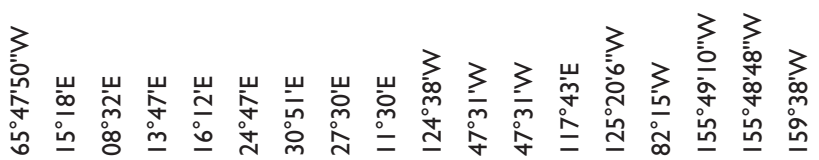

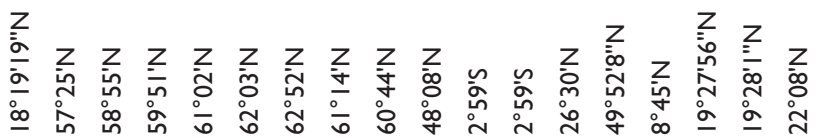

$\stackrel{\circ}{\check{2}}$

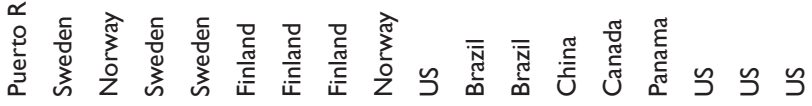

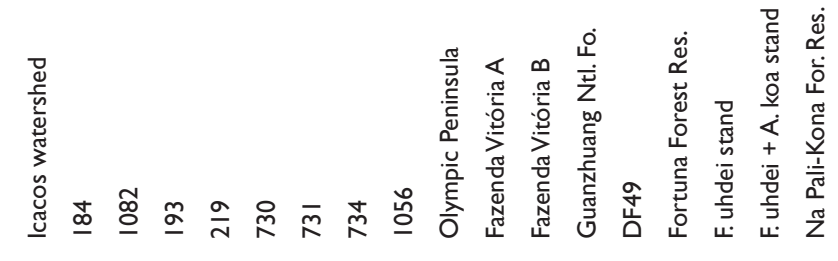


Table S5.4 | Information on $\mathrm{N}$ addition rates, duration of the measuring period, fertilization schemes and source of data that were used to assess effects on AGWB increment.

\begin{tabular}{|c|c|c|c|c|c|c|c|}
\hline Site name & $\begin{array}{l}N \text { add. per } \\
\text { fert. event } \\
\text { (kg N/ha) }\end{array}$ & $\begin{array}{l}\text { Av. } N \text { add. } \\
\text { rate (kg } \\
\text { N/ha/yr) }\end{array}$ & $\begin{array}{l}\text { Duration } \\
\text { measuring } \\
\text { period (yrs) }\end{array}$ & $\begin{array}{l}\text { Fertili- } \\
\text { zation } \\
\text { scheme' }\end{array}$ & $\begin{array}{l}\text { Data } \\
\text { source }^{2}\end{array}$ & $\begin{array}{l}\text { Level of } \\
\text { sampling } \\
\text { (tree/plot) }\end{array}$ & $\begin{array}{l}\text { Original } \\
\text { unit data }\end{array}$ \\
\hline СТС & 225 & 75 & 3 & $S$ & 2 & tree & $\mathrm{dm} 3 / \mathrm{yr}$ \\
\hline ODF & 225 & 75 & 3 & $S$ & 2 & tree & $\mathrm{dm} 3 / \mathrm{yr}$ \\
\hline OSU & 225 & 75 & 3 & $S$ & 2 & tree & $\mathrm{dm} 3 / \mathrm{yr}$ \\
\hline PB & 225 & 75 & 3 & $S$ & 2 & tree & $\mathrm{dm} 3 / \mathrm{yr}$ \\
\hline STR & 225 & 75 & 3 & $S$ & 2 & tree & $\mathrm{dm} 3 / \mathrm{yr}$ \\
\hline WE & 225 & 75 & 3 & $S$ & 2 & tree & $\mathrm{dm} 3 / \mathrm{yr}$ \\
\hline WF & 225 & 75 & 3 & $S$ & 2 & tree & $\mathrm{dm} 3 / \mathrm{yr}$ \\
\hline WW & 225 & 75 & 3 & $S$ & 2 & tree & $\mathrm{dm} 3 / \mathrm{yr}$ \\
\hline GDE & 225 & 75 & 3 & $S$ & 2 & tree & $\mathrm{dm} 3 / \mathrm{yr}$ \\
\hline GDH & 225 & 75 & 3 & $\mathrm{~S}$ & 2 & tree & $\mathrm{dm} 3 / \mathrm{yr}$ \\
\hline GPH & 225 & 75 & 3 & $S$ & 2 & tree & $\mathrm{dm} 3 / \mathrm{yr}$ \\
\hline HAGR & 225 & 75 & 3 & $S$ & 2 & tree & $\mathrm{dm} 3 / \mathrm{yr}$ \\
\hline HAK & 225 & 75 & 3 & $S$ & 2 & tree & $\mathrm{dm} 3 / \mathrm{yr}$ \\
\hline LRT & 225 & 75 & 3 & $S$ & 2 & tree & $\mathrm{dm} 3 / \mathrm{yr}$ \\
\hline MNN & 225 & 75 & 3 & $S$ & 2 & tree & $\mathrm{dm} 3 / \mathrm{yr}$ \\
\hline MNS & 225 & 75 & 3 & $S$ & 2 & tree & $\mathrm{dm} 3 / \mathrm{yr}$ \\
\hline Ardross & $|5|$ & 22 & 21 & $3 \mathrm{~A}$ & I & plot & $\mathrm{tC} / \mathrm{ha}$ \\
\hline Craigellachie & 160 & 32 & 20 & $4 \mathrm{~A}$ & 1 & plot & $\mathrm{tC} / \mathrm{ha}$ \\
\hline Drumtochty & 162 & 39 & 42 & $10 \mathrm{~A}$ & I & plot & $\mathrm{tC} / \mathrm{ha}$ \\
\hline Drumtochty & 152 & 11 & 42 & $3 \mathrm{~A}$ & I & plot & $\mathrm{tC} / \mathrm{ha}$ \\
\hline Shin I & 154 & 31 & 25 & $5 \mathrm{~A}$ & 1 & plot & $\mathrm{tC} / \mathrm{ha}$ \\
\hline Shin 2 & 160 & 30 & 21 & $4 \mathrm{~A}$ & 1 & plot & $\mathrm{tC} / \mathrm{ha}$ \\
\hline Speymouth & 160 & 31 & 26 & $5 \mathrm{~A}$ & 1 & plot & $\mathrm{tC} / \mathrm{ha}$ \\
\hline Great Mountain Fo. & 150 & 150 & 2 & 3 & 1 & plot & $\mathrm{gC} / \mathrm{m} 2 / \mathrm{yr}$ \\
\hline Housatonic State Fo. & 150 & 150 & 2 & 3 & 1 & plot & $\mathrm{gC} / \mathrm{m} 2 / \mathrm{yr}$ \\
\hline Hammaslahti & 180 & 15 & 12 & S & 2 & tree & $\mathrm{dm} 3 / \mathrm{ha}$ \\
\hline Oak Ridge NERP & 200 & 200 & 2 & 1 & 1 & plot & $\mathrm{g} / \mathrm{m} 2 / \mathrm{yr}$ \\
\hline Sugar maple & 13 & 50 & 4 & 4 & 1 & plot & $\mathrm{gCC} / \mathrm{m} 2 / \mathrm{yr}$ \\
\hline American beech & 13 & 50 & 4 & 4 & 1 & plot & $\mathrm{g} C / \mathrm{m} 2 / \mathrm{yr}$ \\
\hline Yello birch & 13 & 50 & 4 & 4 & 1 & plot & $\mathrm{gCC} / \mathrm{m} 2 / \mathrm{yr}$ \\
\hline Eastern hemlock & 13 & 50 & 4 & 4 & 1 & plot & $\mathrm{gC} / \mathrm{m} 2 / \mathrm{yr}$ \\
\hline Northern red oak & 13 & 50 & 4 & 4 & 1 & plot & $\mathrm{g} C / \mathrm{m} 2 / \mathrm{yr}$ \\
\hline A & 5 & 30 & 10 & 6 & 1 & plot & $\mathrm{g} C / \mathrm{m} 2$ \\
\hline B & 5 & 30 & 10 & 6 & 1 & plot & $\mathrm{g} \mathrm{C} / \mathrm{m} 2$ \\
\hline C & 5 & 30 & 10 & 6 & I & plot & $\mathrm{g} C / \mathrm{m} 2$ \\
\hline D & 5 & 30 & 10 & 6 & 1 & plot & $\mathrm{g} C / \mathrm{m} 2$ \\
\hline Tambopata & 23 & 92 & 3 & 4 & 2 & plot & $\mathrm{gC} / \mathrm{m} 2 / \mathrm{yr}$ \\
\hline
\end{tabular}


Table S5.4 | (continued)

\begin{tabular}{|c|c|c|c|c|c|c|c|}
\hline Site name & $\begin{array}{l}\mathrm{N} \text { add. per } \\
\text { fert. event } \\
\text { (kg N/ha) }\end{array}$ & $\begin{array}{l}\text { Av. } \mathbf{N} \text { add. } \\
\text { rate (kg } \\
\text { N/ha/yr) }\end{array}$ & $\begin{array}{l}\text { Duration } \\
\text { measuring } \\
\text { period (yrs) }\end{array}$ & $\begin{array}{l}\text { Fertili- } \\
\text { zation } \\
\text { scheme' }^{\prime}\end{array}$ & $\begin{array}{l}\text { Data } \\
\text { source }^{2}\end{array}$ & $\begin{array}{l}\text { Level of } \\
\text { sampling } \\
\text { (tree/plot) }\end{array}$ & $\begin{array}{l}\text { Original } \\
\text { unit data }\end{array}$ \\
\hline Tono & 23 & 92 & 3 & 4 & 2 & plot & $\mathrm{g} C / \mathrm{m} 2 / \mathrm{yr}$ \\
\hline San Pedro & 23 & 92 & 3 & 4 & 2 & plot & $\mathrm{g} C / \mathrm{m} 2 / \mathrm{yr}$ \\
\hline Wayqecha & 23 & 92 & 3 & 4 & 2 & plot & $\mathrm{gC} / \mathrm{m} 2 / \mathrm{yr}$ \\
\hline E26A & 37 & 37 & 43 & I & I & plot & $\mathrm{m} 3 /$ ha \\
\hline E26A & 73 & 41 & 43 & I & I & plot & $\mathrm{m} 3 /$ ha \\
\hline Warrenbayne & 300 & 50 & 6 & S & 2 & plot & $\mathrm{m} 3 / \mathrm{ha} / \mathrm{yr}$ \\
\hline Stanley & 300 & 50 & 6 & $S$ & 2 & plot & $\mathrm{m} 3 / \mathrm{ha} / \mathrm{yr}$ \\
\hline Harvey & 540 & 54 & 10 & $S$ & I & plot & $\mathrm{m} 3 / \mathrm{ha}$ \\
\hline Chiyoda Exp. Station & 28 & 280 & 2 & 12 & I & tree & $\mathrm{g} /$ tree \\
\hline San Francisco Res. & 25 & 50 & I & 2 & 2 & plot & $\mathrm{kg} / \mathrm{ha}$ \\
\hline AOSR & 30 & 30 & 3 & I & I & plot & $\mathrm{kg} / \mathrm{ha} / \mathrm{yr}$ \\
\hline Oulu & 185 & 6 & 31 & $S$ & 2 & plot & $\mathrm{m} 3 /$ ha \\
\hline Barro Colorado & 31 & 125 & 10 & 4 & I & plot & $\mathrm{Mg} / \mathrm{ha} / \mathrm{yr}$ \\
\hline Bisley Ex.Watershed & 25 & 50 & 7 & 2 & I & plot & $\mathrm{Mg} / \mathrm{ha} / \mathrm{yr}$ \\
\hline Icacos watershed & 25 & 50 & 7 & 2 & I & plot & $\mathrm{Mg} / \mathrm{ha} / \mathrm{yr}$ \\
\hline 184 & 150 & 15 & 10 & $S$ & 2 & plot & $\mathrm{m} 3 /$ ha \\
\hline 1082 & 150 & 15 & 10 & $S$ & 2 & plot & $\mathrm{m} 3 / \mathrm{ha}$ \\
\hline 193 & 150 & 15 & 10 & $S$ & 2 & plot & $\mathrm{m} 3 / \mathrm{ha}$ \\
\hline 219 & 150 & 15 & 10 & $S$ & 2 & plot & $\mathrm{m} 3 /$ ha \\
\hline 730 & 150 & 15 & 10 & $S$ & 2 & plot & $\mathrm{m} 3 / \mathrm{ha}$ \\
\hline 731 & 150 & 15 & 10 & $S$ & 2 & plot & $\mathrm{m} 3 /$ ha \\
\hline 734 & 150 & 15 & 10 & $S$ & 2 & plot & $\mathrm{m} 3 /$ ha \\
\hline 1056 & 150 & 15 & 10 & $S$ & 2 & plot & $\mathrm{m} 3 / \mathrm{ha}$ \\
\hline Olympic Peninsula & 300 & 24 & 25 & $2 \mathrm{~A}$ & I & plot & m3 / ha \\
\hline Fazenda Vitória B & 100 & 33 & 6 & I & I & plot & $\mathrm{Mg} / \mathrm{ha}$ \\
\hline Guanzhuang Ntl. For. & 5 & 60 & 4 & 12 & 2 & plot & $\mathrm{tC} / \mathrm{ha} / \mathrm{yr}$ \\
\hline Guanzhuang Ntl. For. & 10 & 120 & 4 & 12 & 2 & plot & $\mathrm{t} C / \mathrm{ha} / \mathrm{yr}$ \\
\hline Guanzhuang Ntl. For. & 20 & 240 & 4 & 12 & 2 & plot & $\mathrm{tC} / \mathrm{ha} / \mathrm{yr}$ \\
\hline DF49 & 200 & 100 & I & $S$ & 2 & plot & $\mathrm{m} 3 /$ ha \\
\hline Fortuna Forest Res. & 31 & 125 & 2 & 4 & I & plot & $\mathrm{Mg} / \mathrm{ha}$ \\
\hline F. uhdei stand & 500 & 333 & 1.5 & $S$ & I & plot & $\mathrm{g} / \mathrm{m} 2$ \\
\hline F. uhdei+A. koa stand & 500 & 333 & 1.5 & $S$ & I & plot & $\mathrm{g} / \mathrm{m} 2$ \\
\hline Na Pali-Kona Res. & 33 & 50 & I & 2 & I & plot & $\mathrm{g} / \mathrm{m} 2 / \mathrm{yr}$ \\
\hline
\end{tabular}

' Explanation of abbreviations for fertilization scheme: $S=$ one-time application; a number indicates multiple fertilization events per year (e.g., 3 = 3 applications per year). A number followed by an "A" indicates that several fertilization events took place with more than one year between fertilization events; the number before the $A$ indicates the number of fertilization events (e.g., $3 \mathrm{~A}=3$ fertilization events).

${ }^{2} \mathrm{I}$ = Data obtained from the publication or supplementary material; 2 = additional information/data was provided by authors 
Table S5.5 | Information on P addition rates, duration of the measuring period, fertilization schemes and source of data that were used to assess effects on AGWB increment.

\begin{tabular}{|c|c|c|c|c|c|c|c|}
\hline Site name & $\begin{array}{l}N \text { add. per } \\
\text { fert. event } \\
\text { (kg N/ha) }\end{array}$ & $\begin{array}{l}\text { Av. } N \text { add. } \\
\text { rate (kg } \\
\text { N/ha/yr) }\end{array}$ & $\begin{array}{l}\text { Duration } \\
\text { measuring } \\
\text { period (yrs) }\end{array}$ & $\begin{array}{l}\text { Fertili- } \\
\text { zation } \\
\text { scheme' }\end{array}$ & $\begin{array}{l}\text { Data } \\
\text { source }^{2}\end{array}$ & $\begin{array}{l}\text { Level of } \\
\text { sampling } \\
\text { (tree/plot) }\end{array}$ & $\begin{array}{l}\text { Original } \\
\text { unit data }\end{array}$ \\
\hline СТС & 580 & 193 & 3 & S & 2 & tree & $\mathrm{dm} 3 / \mathrm{yr}$ \\
\hline GDE & 580 & 193 & 3 & $\mathrm{~s}$ & 2 & tree & $\mathrm{dm} 3 / \mathrm{yr}$ \\
\hline GDH & 580 & 193 & 3 & S & 2 & tree & $\mathrm{dm} 3 / \mathrm{yr}$ \\
\hline GPH & 580 & 193 & 3 & S & 2 & tree & $\mathrm{dm} 3 / \mathrm{yr}$ \\
\hline HAGR & 580 & 193 & 3 & S & 2 & tree & $\mathrm{dm} 3 / \mathrm{yr}$ \\
\hline HAK & 580 & 193 & 3 & s & 2 & tree & $\mathrm{dm} 3 / \mathrm{yr}$ \\
\hline LRT & 580 & 193 & 3 & S & 2 & tree & $\mathrm{dm} 3 / \mathrm{yr}$ \\
\hline MNN & 580 & 193 & 3 & S & 2 & tree & $\mathrm{dm} 3 / \mathrm{yr}$ \\
\hline MNS & 580 & 193 & 3 & S & 2 & tree & $\mathrm{dm} 3 / \mathrm{yr}$ \\
\hline ODF & 580 & 193 & 3 & S & 2 & tree & $\mathrm{dm} 3 / \mathrm{yr}$ \\
\hline OSU & 580 & 193 & 3 & S & 2 & tree & $\mathrm{dm} 3 / \mathrm{yr}$ \\
\hline PB & 580 & 193 & 3 & S & 2 & tree & $\mathrm{dm} 3 / \mathrm{yr}$ \\
\hline STR & 580 & 193 & 3 & S & 2 & tree & $\mathrm{dm} 3 / \mathrm{yr}$ \\
\hline WE & 580 & 193 & 3 & S & 2 & tree & $\mathrm{dm} 3 / \mathrm{yr}$ \\
\hline WF & 580 & 193 & 3 & S & 2 & tree & $\mathrm{dm} 3 / \mathrm{yr}$ \\
\hline WW & 580 & 193 & 3 & $S$ & 2 & tree & $\mathrm{dm} 3 / \mathrm{yr}$ \\
\hline Tambopata & 5 & 20 & 3 & 4 & 2 & plot & $\mathrm{gC} / \mathrm{m} 2 / \mathrm{yr}$ \\
\hline Tono & 5 & 20 & 3 & 4 & 2 & plot & $\mathrm{g} C / \mathrm{m} 2 / \mathrm{yr}$ \\
\hline San Pedro & 5 & 20 & 3 & 4 & 2 & plot & $\mathrm{g} C / \mathrm{m} 2 / \mathrm{yr}$ \\
\hline Wayqecha & 5 & 20 & 3 & 4 & 2 & plot & $\mathrm{gC} / \mathrm{m} 2 / \mathrm{yr}$ \\
\hline San Francisco Res. & 5 & 10 & I & 2 & 2 & plot & $\mathrm{kg} / \mathrm{ha}$ \\
\hline Fazenda Vitória $\mathrm{A}$ & 50 & 16 & 6.4 & 1 & 1 & plot & $\mathrm{Mg} / \mathrm{ha}$ \\
\hline Barro Colorado $\mathrm{Na}$ & 13 & 50 & 6.4 & 4 & 1 & plot & $\mathrm{Mg} / \mathrm{ha} / \mathrm{yr}$ \\
\hline Fazenda Vitória B & 50 & 17 & 6.4 & 1 & 1 & plot & $\mathrm{Mg} / \mathrm{ha}$ \\
\hline Great Mountain Fo. & 50 & 17 & 6.4 & 3 & 1 & plot & $\mathrm{gCC} / \mathrm{m} 2 / \mathrm{yr}$ \\
\hline Housatonic State Fo. & 50 & 17 & 10 & 3 & 1 & plot & $\mathrm{gC} / \mathrm{m} 2 / \mathrm{yr}$ \\
\hline Harvey & 360 & 36 & 6 & S & 1 & plot & $\mathrm{m} 3 / \mathrm{ha}$ \\
\hline Na Pali-Kona Res. & 33 & 50 & 2 & 2 & 1 & plot & $\mathrm{g} / \mathrm{m} 2 / \mathrm{yr}$ \\
\hline
\end{tabular}


Table S5.6 | Estimates for the nitrogen-induced carbon sink in aboveground woody biomass (from metaanalysis) and belowground woody biomass (by assuming that belowground woody biomass production is $20 \%$ of aboveground woody biomass production), and the total nitrogen-induced woody biomass carbon sink.

\begin{tabular}{|c|c|c|c|}
\hline & $\begin{array}{l}\text { (I) } N \text {-induced C sink } \\
\text { aboveground woody } \\
\text { biomass }\end{array}$ & $\begin{array}{l}\text { (2) } N \text {-induced C sink } \\
\text { below-ground woody } \\
\text { biomass }=(1) * 0.2\end{array}$ & $\begin{array}{l}\text { (3) } N \text {-induced C sink } \\
\text { woody biomass }=(1) \\
+(2)\end{array}$ \\
\hline & {$\left[\mathrm{Tg} C \mathrm{yr}^{\prime}\right]$} & {$\left[\mathrm{Tg} C \mathrm{yr}^{\prime}\right]$} & {$\left[\mathrm{Tg} C \mathrm{yr}^{\prime}\right]$} \\
\hline Tropical forests & $15(-15-44)$ & $3(-3-9)$ & $18(-18-53)$ \\
\hline Temperate forests & 101 (84-119) & $20(17-24)$ & $121(10 \mid-142)$ \\
\hline Boreal forests & $32(24-39)$ & $6(5-8)$ & $38(28-47)$ \\
\hline All & 148 (93-202) & $30(19-40)$ & 177 (I I2-243) \\
\hline
\end{tabular}

Table S5.7 | Correlations between variables used to group studies in the meta-analysis. $\bar{x}=$ Arithmetic mean, $\mathrm{se}=$ standard error of the mean. Group means with a different superscript letter differ significantly from each other at $\mathrm{p}<0.05$. For categorical variables (age, climate zone, fertilizer type), the table shows the number and percentage of observations that fall into each category within another category.

\begin{tabular}{|c|c|c|c|c|c|c|c|c|c|}
\hline & \multicolumn{2}{|c|}{ Age } & \multicolumn{2}{|c|}{$\begin{array}{l}\text { Climate } \\
\text { zone }\end{array}$} & \multirow[t]{2}{*}{$\begin{array}{l}\text { Produc- } \\
\text { tivity } \\
\left(\mathrm{g} \mathrm{C} / \mathrm{m}^{2} / \mathrm{yr}\right)\end{array}$} & \multirow[t]{2}{*}{$\begin{array}{l}\mathbf{N} \text { add. } \\
\text { rate } \\
\left(\mathrm{g} \mathrm{N} / \mathrm{m}^{2} / \mathrm{yr}\right)\end{array}$} & \multicolumn{2}{|c|}{ Fertilizer type } & \multirow[t]{2}{*}{$\begin{array}{l}\text { Ambient } \mathbf{N} \\
\text { deposition } \\
\text { (g N/m²/yr) }\end{array}$} \\
\hline \multicolumn{7}{|l|}{ Age } & & & \\
\hline Young (Y) & Y: & $22(100 \%)$ & B: & $2(9 \%)$ & $\bar{x}=539^{a}$ & $\bar{x}=6.8^{a}$ & Urea: & 19 (86\%) & $\bar{x}=1.08 \mathrm{a}$ \\
\hline \multirow[t]{2}{*}{$(n=22)$} & M: & 0 & Te: & $15(68 \%)$ & $\mathrm{se}=74$ & $\mathrm{se}=1.2$ & $\mathrm{NH}_{4} \mathrm{NO}_{3}:$ & $3(14 \%)$ & $\mathrm{se}=0.21$ \\
\hline & O: & 0 & Tr: & $5(23 \%)$ & & & Other: & 0 & \\
\hline Medium (M) & Y: & 0 & B: & 7 (25\%) & $\bar{x}=4 \mid 3^{a}$ & $\bar{x}=7.6^{a}$ & Urea: & 14 (50\%) & $\bar{x}=0.86 a$ \\
\hline \multirow[t]{2}{*}{$(n=28)$} & M: & $28(100 \%)$ & Te: & $19(68 \%)$ & se $=68$ & $\mathrm{se}=1.7$ & $\mathrm{NH}_{4} \mathrm{NO}_{3}:$ & $6(21 \%)$ & se $=0.11$ \\
\hline & O: & 0 & Tr: & $2(7 \%)$ & & & Other: & $8(29 \%)$ & \\
\hline Old (O) & Y: & 0 & B: & $3(15 \%)$ & $\bar{x}=185^{b}$ & $\bar{x}=6.9^{a}$ & Urea: & $8(40 \%)$ & $\bar{x}=0.7 \mathrm{la}$ \\
\hline \multirow[t]{2}{*}{$(n=20)$} & M: & 0 & Te: & 7 (35\%) & $\mathrm{se}=22$ & $\mathrm{se}=1.0$ & $\mathrm{NH}_{4} \mathrm{NO}_{3}:$ & $9(45 \%)$ & $\mathrm{se}=0.12$ \\
\hline & O: & $20(100 \%)$ & Tr: & $10(50 \%)$ & & & Other: & $3(15 \%)$ & \\
\hline \multicolumn{10}{|l|}{ Climate zone } \\
\hline Boreal (B) & Y: & $2(17 \%)$ & B: & $12(100 \%)$ & $\bar{x}=158^{a}$ & $\bar{x}=2.0 \mathrm{a}$ & Urea: & $2(17 \%)$ & $\bar{x}=0.78^{a}$ \\
\hline \multirow[t]{2}{*}{$(n=12)$} & M: & $7(58 \%)$ & Te: & 0 & $\mathrm{se}=20$ & se $=0.3$ & $\mathrm{NH}_{4} \mathrm{NO}_{3}:$ & $3(25 \%)$ & se $=0.07$ \\
\hline & O: & $3(25 \%)$ & Tr: & 0 & & & Other: & $7(58 \%)$ & \\
\hline Temperate & O: & I5 (37\%) & B: & 0 & $\bar{x}=513^{b}$ & $\bar{x}=6.8^{b}$ & Urea: & $26(63 \%)$ & $\bar{x}=0.90^{\mathrm{a}}$ \\
\hline \multirow[t]{2}{*}{$(\mathrm{Te})(\mathrm{n}=4 \mathrm{I})$} & M: & $19(46 \%)$ & Te: & $4 \mathrm{l}(100 \%)$ & $\mathrm{se}=58$ & $\mathrm{se}=0.8$ & $\mathrm{NH}_{4} \mathrm{NO}_{3}:$ & 12 (29\%) & $\mathrm{se}=0.09$ \\
\hline & O: & $7(17 \%)$ & Tr: & 0 & & & Other: & $3(7 \%)$ & \\
\hline Tropical (Tr) & Y: & $5(29 \%)$ & B: & 0 & $\bar{x}=248^{c}$ & $\bar{x}=11.7^{b}$ & \multicolumn{2}{|c|}{ Urea: $13(76 \%)$} & $\bar{x}=0.91^{a}$ \\
\hline \multirow[t]{2}{*}{$(n=17)$} & M: & $2(12 \%)$ & Te: & 0 & $\mathrm{se}=38$ & $\mathrm{se}=2.3$ & \multicolumn{2}{|c|}{ NH4NO3: 3 (I8\%) } & $\mathrm{se}=0.28$ \\
\hline & O: & $10(59 \%)$ & Tr: & $17(100 \%)$ & & & Other: & I (6\%) & \\
\hline
\end{tabular}


Table S5.7 | (continued)

\begin{tabular}{|c|c|c|c|c|c|c|c|c|}
\hline & \multicolumn{2}{|c|}{ Age } & $\begin{array}{l}\text { Climate } \\
\text { zone }\end{array}$ & \multirow[t]{2}{*}{$\begin{array}{l}\text { Produc- } \\
\text { tivity } \\
\left(\mathrm{g} \mathrm{C} / \mathrm{m}^{2} / \mathrm{yr}\right)\end{array}$} & \multirow[t]{2}{*}{$\begin{array}{l}\mathrm{N} \text { add. } \\
\text { rate } \\
\left(\mathrm{g} \mathrm{N} / \mathrm{m}^{2} / \mathrm{yr}\right)\end{array}$} & \multicolumn{2}{|c|}{ Fertilizer type } & \multirow[t]{2}{*}{$\begin{array}{l}\text { Ambient } N \\
\text { deposition } \\
\left(\mathrm{g} \mathrm{N} / \mathrm{m}^{2} / \mathrm{yr}\right)\end{array}$} \\
\hline \multicolumn{6}{|l|}{ Productivity } & & & \\
\hline \multirow[t]{3}{*}{ Low $(n=40)$} & Y: & 7 (I8\%) & B: $\quad$ I2 (30\%) & $\bar{x}=159^{a}$ & $\bar{x}=6.2^{\mathrm{a}}$ & Urea: & 14 (35\%) & $\bar{x}=0.89^{a}$ \\
\hline & M: & $16(40 \%)$ & Te: 17 (43\%) & $\mathrm{se}=10$ & $\mathrm{se}=1 . \mathrm{I}$ & $\mathrm{NH}_{4} \mathrm{NO}_{3}:$ & 15 (38\%) & $\mathrm{se}=0.09$ \\
\hline & & $17(43 \%)$ & Tr: II (28\%) & & & Other: & II (28\%) & \\
\hline \multirow[t]{3}{*}{ High $(n=30)$} & Y: & I5 (50\%) & B: 0 & $\bar{x}=692^{b}$ & $\bar{x}=8.5^{\mathrm{a}}$ & Urea: & 27 (90\%) & $\bar{x}=0.87^{a}$ \\
\hline & M: & $12(40 \%)$ & Te: 24 (80\%) & $\mathrm{se}=53$ & $\mathrm{se}=1.2$ & $\mathrm{NH}_{4} \mathrm{NO}_{3}:$ & $3(10 \%)$ & $\mathrm{se}=0.17$ \\
\hline & О: & $3(10 \%)$ & Tr: $6(20 \%)$ & & & Other: & 0 & \\
\hline \multicolumn{9}{|l|}{$\mathrm{N}$ addition rate } \\
\hline \multirow[t]{3}{*}{$<30(n=13)$} & Y: & $2(15 \%)$ & B: $\quad 9(69 \%)$ & $\bar{x}=214^{a}$ & $\bar{x}=1.5^{\mathrm{a}}$ & Urea: & $4(3 \mid \%)$ & $\bar{x}=0.85^{a}$ \\
\hline & M: & $9(69 \%)$ & Te: 4 (3।\%) & se $=42$ & se $=0.1$ & $\mathrm{NH}_{4} \mathrm{NO}_{3}:$ & 0 & $\mathrm{se}=0.08$ \\
\hline & O: & $2(15 \%)$ & Tr: 0 & & & Other: & $9(69 \%)$ & \\
\hline \multirow[t]{3}{*}{$30-70(n=26)$} & Y: & $10(38 \%)$ & B: $\quad 3(12 \%)$ & $\bar{x}=230^{a}$ & $\bar{x}=4.2^{b}$ & Urea: & $10(38 \%)$ & $\bar{x}=1.03^{a}$ \\
\hline & M: & $7(27 \%)$ & Te: $16(62 \%)$ & se $=29$ & $\mathrm{se}=0.2$ & $\mathrm{NH}_{4} \mathrm{NO}_{3}:$ & I5 (58\%) & $\mathrm{se}=0.15$ \\
\hline & О: & $9(35 \%)$ & Tr: 7 (27\%) & & & Other: & I (4\%) & \\
\hline \multirow[t]{3}{*}{$>70(n=3 I)$} & Y: & $10(32 \%)$ & B: 0 & $\bar{x}=592^{b}$ & $\bar{x}=12.0^{c}$ & Urea: & 27 (87\%) & $\bar{x}=0.77^{a}$ \\
\hline & M: & 12 (39\%) & Te: 2 I (68\%) & $\mathrm{se}=68$ & $\mathrm{se}=1.4$ & $\mathrm{NH}_{4} \mathrm{NO}_{3}:$ & $3(10 \%)$ & $\mathrm{se}=0.15$ \\
\hline & O: & $9(29 \%)$ & Tr: 10 (32\%) & & & Other: & I (3\%) & \\
\hline \multicolumn{9}{|l|}{$\mathrm{N}$ source } \\
\hline \multirow[t]{3}{*}{ Urea $(n=4 I)$} & Y: & 19 (46\%) & B: $\quad 2(5 \%)$ & $\bar{x}=530^{a}$ & $\bar{x}=8.5^{a}$ & Urea: & $4 \mathrm{I}(100 \%)$ & $\bar{x}=0.78^{a}$ \\
\hline & M: & $14(34 \%)$ & Te: $26(63 \%)$ & $\mathrm{se}=57$ & $\mathrm{se}=\mathrm{I} . \mathrm{I}$ & $\mathrm{NH}_{4} \mathrm{NO}_{3}:$ & 0 & $\mathrm{se}=0.12$ \\
\hline & O: & $8(20 \%)$ & Tr: 13 (32\%) & & & Other: & 0 & \\
\hline $\mathrm{NH}_{4} \mathrm{NO}_{3}$ & Y: & $3(17 \%)$ & B: $\quad 3(17 \%)$ & $\bar{x}=185^{b}$ & $\bar{x}=6.7^{a}$ & Urea: & 0 & $\bar{x}=1.21^{b}$ \\
\hline \multirow[t]{2}{*}{$(n=18)$} & M: & $6(33 \%)$ & Te: $12(67 \%)$ & $\mathrm{se}=22$ & $\mathrm{se}=1.5$ & $\mathrm{NH}_{4} \mathrm{NO}_{3}:$ & $18(100 \%)$ & $\mathrm{se}=0.16$ \\
\hline & O: & $9(50 \%)$ & Tr: 3 (17\%) & & & Other: & 0 & \\
\hline Other/ & Y: & 0 & B: 7 (64\%) & $\bar{x}=189^{b}$ & $\bar{x}=2.7^{b}$ & Urea: & 0 & $\bar{x}=0.73^{a}$ \\
\hline Unknown & M: & $8(73 \%)$ & Te: 3 (27\%) & se $=16$ & $\mathrm{se}=0.8$ & $\mathrm{NH}_{4} \mathrm{NO}_{3}:$ & 0 & $\mathrm{se}=0.12$ \\
\hline$(n=11)$ & O: & 3 (27\%) & Tr: I (9\%) & & & Other: & II (100\%) & \\
\hline \multicolumn{9}{|c|}{ Ambient $\mathrm{N}$ deposition } \\
\hline \multirow[t]{3}{*}{$<5(n=23)$} & Y: & $8(35 \%)$ & B: I (4\%) & $\bar{x}=624^{a}$ & $\bar{x}=9.0^{a}$ & Urea: & $16(70 \%)$ & $\bar{x}=0.32^{\mathrm{a}}$ \\
\hline & M: & $10(43 \%)$ & Te: $\quad$ I $6(70 \%)$ & $\mathrm{se}=80$ & $\mathrm{se}=1.6$ & $\mathrm{NH}_{4} \mathrm{NO}_{3}:$ & $4(17 \%)$ & $\mathrm{se}=0.03$ \\
\hline & O: & $5(22 \%)$ & Tr: $6(26 \%)$ & & & Other: & $3(13 \%)$ & \\
\hline \multirow[t]{3}{*}{$5-15(n=36)$} & Y: & $10(28 \%)$ & B: $\quad$ II (3|\%) & $\bar{x}=272^{b}$ & $\bar{x}=4.9^{b}$ & Urea: & 21 (58\%) & $\bar{x}=0.82^{b}$ \\
\hline & M: & 13 (36\%) & Te: $\quad$ I7 (47\%) & $\mathrm{se}=39$ & $\mathrm{se}=0.9$ & $\mathrm{NH}_{4} \mathrm{NO}_{3}:$ & 7 (19\%) & $\mathrm{se}=0.05$ \\
\hline & O: & $13(36 \%)$ & Tr: $8(22 \%)$ & & & Other: & $8(22 \%)$ & \\
\hline \multirow[t]{3}{*}{$>15(n=I I)$} & Y: & $4(36 \%)$ & B: 0 & $\bar{x}=268^{b}$ & $\bar{x}=10.6^{a}$ & Urea: & $4(36 \%)$ & $\bar{x}=2.28^{c}$ \\
\hline & M: & $5(45 \%)$ & Te: 8 (73\%) & $\mathrm{se}=59$ & $\mathrm{se}=2.1$ & $\mathrm{NH}_{4} \mathrm{NO}_{3}:$ & 7 (64\%) & $\mathrm{se}=0.20$ \\
\hline & O: & $2(18 \%)$ & Tr: 3 (27\%) & & & Other: & 0 (4\%) & \\
\hline
\end{tabular}




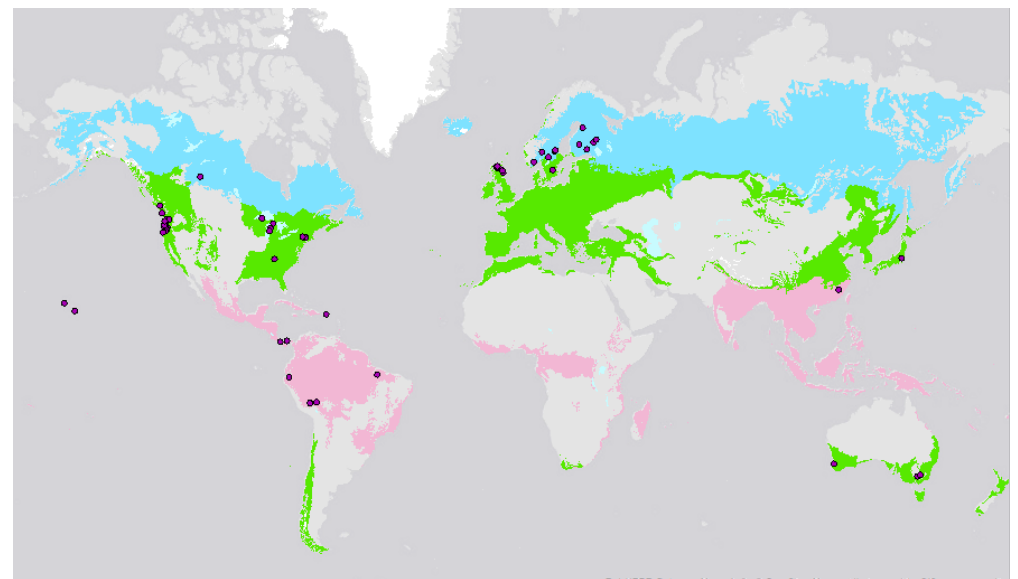

Figure S5.I | Location of the forest plots included in the meta-analysis $(n=70)$. Blue = boreal forests/ taiga; green $=$ temperate forests; pink $=$ tropical and subtropical forests. 


\section{Supplementary Material Chapter 6}

Table S6.I | Classification of WWF ecoregions (Olson et al., 200I) and aggregation to biome classification used in this study. Grid cells classified as 'other' based on WWF ecoregions were classified as either boreal, temperate or tropical based on FAO Global Ecological Zones (Figure S6.Ib). The final biome delineation used in our study is shown in Figure S6. Ia.

\begin{tabular}{lll}
\hline Biome ID & WWF Ecoregion & Biome classification for this study \\
\hline I & Tropical and subtropical moist broadleaf forests & Tropical \\
2 & Tropical and subtropical dry broadleaf forests & Tropical \\
3 & Tropical and subtropical coniferous forests & Tropical \\
4 & Temperate broadleaf and mixed forests & Temperate \\
5 & Temperate Coniferous Forest & Temperate \\
6 & Boreal forest / taiga & Boreal \\
7 & Tropical and subtropical grasslands, savannas and shrublands & Tropical \\
8 & Temperate grasslands, savannas and shrublands & Temperate \\
9 & Flooded grasslands and savannas & Other \\
10 & Montane grasslands and shrublands & Other \\
11 & Tundra & Boreal \\
12 & Mediterranean Forests, woodlands and scrubs & Temperate \\
13 & Deserts and xeric shrublands & Other \\
14 & Mangroves & Tropical \\
98 & Lakes & Other \\
99 & Rock and ice & Other \\
\hline
\end{tabular}


Table S6.2 | Results of the meta-regression for individual predictors of C-N response, including model intercept, coefficient with $95 \% \mathrm{Cl}$, pseudo $\mathrm{R}^{2}$ (indicating the proportional reduction in the variance components of a model compared to a model with no moderators) and Akaike Information Criterion (AIC). $* * *=p<0.01 ; * *=p<0.05, *=p<0.1$.

\begin{tabular}{|c|c|c|c|c|c|c|}
\hline Predictor variable & Intercept & Coefficient & Lower-95\% & Upper-95\% & $\mathbf{p s R}^{2}$ & AIC \\
\hline Log(age) & $4.1 * * *$ & $-0.21 * *$ & -0.36 & -0.07 & 33.2 & 77.0 \\
\hline $\log (\mathrm{NDEP})$ & $3.4 * * *$ & -0.03 & -0.20 & 0.14 & 0.0 & 83.7 \\
\hline $\log ($ NDEPcum) & $3.5 * * *$ & -0.04 & -0.18 & 0.10 & 0.0 & 83.5 \\
\hline $\log (\mathrm{Nadd})$ & $3.6 * * *$ & $-0.15^{*}$ & -0.30 & 0.01 & 15.7 & 80.8 \\
\hline $\log (\mathrm{PET})$ & $8.7 * * *$ & $-0.80 * * *$ & -1.14 & -0.46 & 56.3 & 69.2 \\
\hline TEMP & $3.5^{* * * *}$ & $-0.02 *$ & -0.03 & 0.00 & 11.5 & 81.1 \\
\hline $\log (\mathrm{PREC})$ & $3.6 * * *$ & -0.04 & -0.21 & 0.13 & 0.0 & 84.8 \\
\hline $\log (\mathrm{PE})$ & $3.3 * * *$ & 0.00 & -0.09 & 0.09 & 0.0 & 85.2 \\
\hline $\log (\mathrm{CEC})$ & $3.0 * * *$ & 0.09 & -0.15 & 0.34 & 0.0 & 83.7 \\
\hline $\log (\mathrm{CLAY})$ & $3.8^{* * * *}$ & -0.19 & -0.43 & 0.06 & 18.1 & 82.1 \\
\hline $\log (O C)$ & $2.9 * * *$ & 0.10 & -0.04 & 0.24 & 6.6 & 82.9 \\
\hline $\log (\mathrm{C}: \mathrm{N})$ & $3.1 * * *$ & -0.11 & -0.34 & 0.12 & 1.4 & 84.2 \\
\hline $\log ($ SoilN $)$ & $1.7^{* * *}$ & $0.27 * * *$ & 0.09 & 0.46 & 22.1 & 76.9 \\
\hline $\mathrm{pH}$ & $4.3 * * *$ & -0.20 & -0.50 & 0.09 & 10.9 & 82.6 \\
\hline Absolute latitude (LAT) & $2.9 * * *$ & $0.01 * * *$ & 0.004 & 0.02 & 34.2 & 76.3 \\
\hline
\end{tabular}

Table S6.3 | Share of global forest area in regions with a high confidence in positive C-N response (C-N > $0, p<0.05)$, with a high confidence in a negative $C-N$ response $(C-N<0, p<0.05)$ and where the direction of the $\mathrm{C}-\mathrm{N}$ response is uncertain, for different forest biomes.

\begin{tabular}{lcccc}
\hline & Boreal & Temperate & Tropical & Total \\
\hline Positive C-N response $(\mathrm{p}<0.05)$ & $21 \%$ & $13 \%$ & $2 \%$ & $36 \%$ \\
Negative C-N response $(\mathrm{p}<0.05)$ & $0 \%$ & $0 \%$ & $5 \%$ & $5 \%$ \\
Insignificant C-N response & $0 \%$ & $8 \%$ & $51 \%$ & $59 \%$ \\
Total & $21 \%$ & $21 \%$ & $58 \%$ & $100 \%$ \\
\hline
\end{tabular}

Table S6.4 | Forest area, total and average $\mathrm{N}$ deposition, average $\mathrm{C}-\mathrm{N}$ response, and total and average $\mathrm{N}$-induced $\mathrm{C}$ sequestration per forest biome as presented in Table , but using the classification of biomes according to FAO Global Ecological Zones (GEZ), see Figure S6. Ib.

\begin{tabular}{|c|c|c|c|c|c|c|}
\hline & $\begin{array}{l}\text { Forest area } \\
\left(\mathbf{k m}^{2} \times \mathbf{1 0}^{6}\right)\end{array}$ & $\begin{array}{l}\text { Total N dep } \\
\left(T g y^{\prime}\right)\end{array}$ & $\begin{array}{l}\text { Mean N dep } \\
\left(\mathbf{k g ~ h a}^{-1} \mathrm{yr}^{-1}\right)\end{array}$ & $\begin{array}{l}\text { C-N response } \\
(-)\end{array}$ & $\begin{array}{l}\text { Total C seq. } \\
\left(T_{g} y^{\prime}\right)\end{array}$ & $\begin{array}{l}\text { Mean C seq. } \\
\left(\mathrm{kg} \mathrm{ha}^{-1} \mathrm{yr}^{\prime}\right)\end{array}$ \\
\hline Boreal & 7.3 & 1.3 & 1.8 & II (4-20) & $15(5-26)$ & $19(7-36)$ \\
\hline Temperate & 4.6 & 4.3 & 9.3 & $5(I-9)$ & $20(4-40)$ & 44 (8-87) \\
\hline Sub-tropical & 2.7 & 4.5 & 16.7 & $2(-1-7)$ & $10(-6-29)$ & $37(-22-109)$ \\
\hline Tropical & 17.2 & 13.0 & 7.6 & $0(-4-5)$ & $-3(-58-67)$ & $-2(-34-39)$ \\
\hline World & 31.8 & 23.1 & 7.3 & $2(-2-7)$ & $4 \mid(-55-163)$ & $13(-|7-5|)$ \\
\hline
\end{tabular}


Table S6.5 | Differences in estimated $\mathrm{N}$-induced $\mathrm{C}$ sequestration between this study and $\mathrm{Du}$ and de Vries (2018), based on mean $\mathrm{C}-\mathrm{N}$ response, $\mathrm{N}$ deposition and forest area per biome.

\begin{tabular}{|c|c|c|c|c|c|}
\hline Biome & Study & $\begin{array}{l}\text { C-N response } \\
\left(\mathbf{k g ~ C ~} \text { kg N}^{-1}\right)\end{array}$ & $\begin{array}{c}\text { N deposition } \\
\left(\mathbf{k g ~ N} \text { ha }^{-1} \mathbf{y r}^{\prime \prime}\right)\end{array}$ & $\begin{array}{c}\text { Forest area } \\
\left(\text { ha } \times 10^{7}\right)\end{array}$ & $\begin{array}{c}\mathrm{N} \text {-induced } \mathrm{C} \\
\text { seq. }\left(\mathrm{Tg} C \mathrm{yr}^{\prime}\right)\end{array}$ \\
\hline \multirow[t]{2}{*}{ Boreal } & Du \& DeVries & 14 & 2 & 122 & 34 \\
\hline & This study & 11 & 2 & 68 & 13 \\
\hline \multirow[t]{2}{*}{ Temperate } & Du \& De Vries & 5 & 12 & 97 & 58 \\
\hline & This study & 4 & 10 & 68 & 25 \\
\hline \multirow[t]{2}{*}{ Tropical } & Du \& DeVries & 4 & 7 & 187 & 52 \\
\hline & This study & 0.2 & 8 & 183 & 3 \\
\hline \multirow[t]{2}{*}{ Global } & Du \& DeVries & & 7 & 406 & 144 \\
\hline & This study & & 7 & 319 & 41 \\
\hline
\end{tabular}

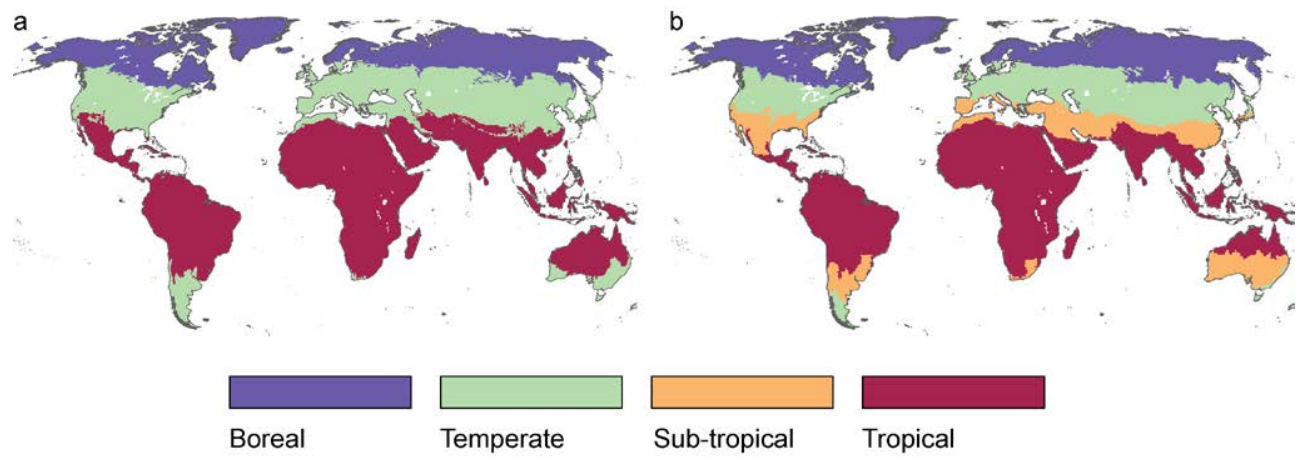

Figure 6.I | a, Used biome delineation based on a combination of WWF ecoregions and FAO Global Ecological zones, (GEZ), b, Global biomes according to FAO GEZ (FAO, 20I2b). 

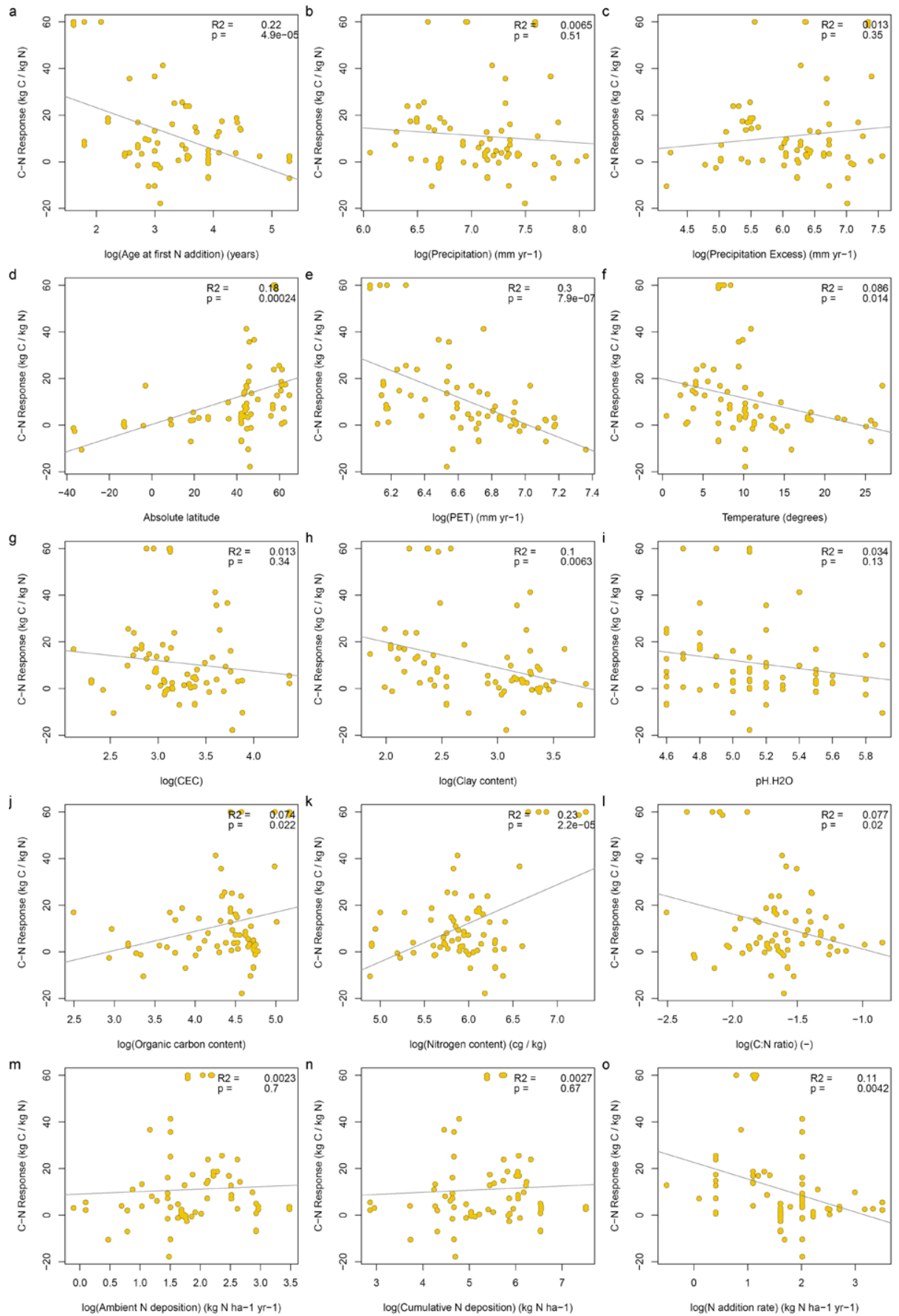

Figure 6.2 | Scatter plots showing linear regressions of predictor variables against C-N response. $\mathrm{p}$-values differ from those presented in Table $\mathrm{S} 6.2$ because (i) $\mathrm{C}-\mathrm{N}$ response is not log-transformed for easier interpretation and no random structure is introduced. 

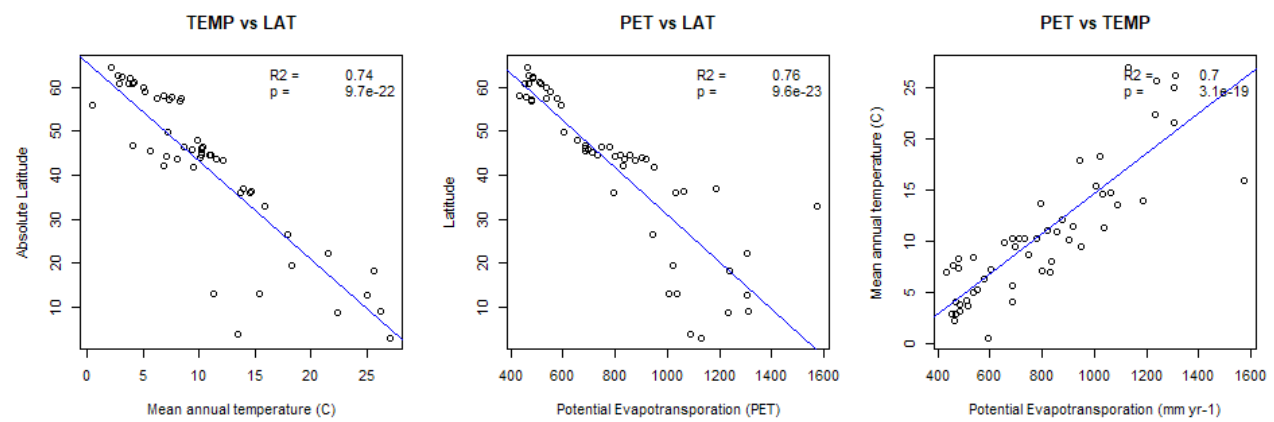

Figure 6.3 | Correlation between variables related to climate zone.
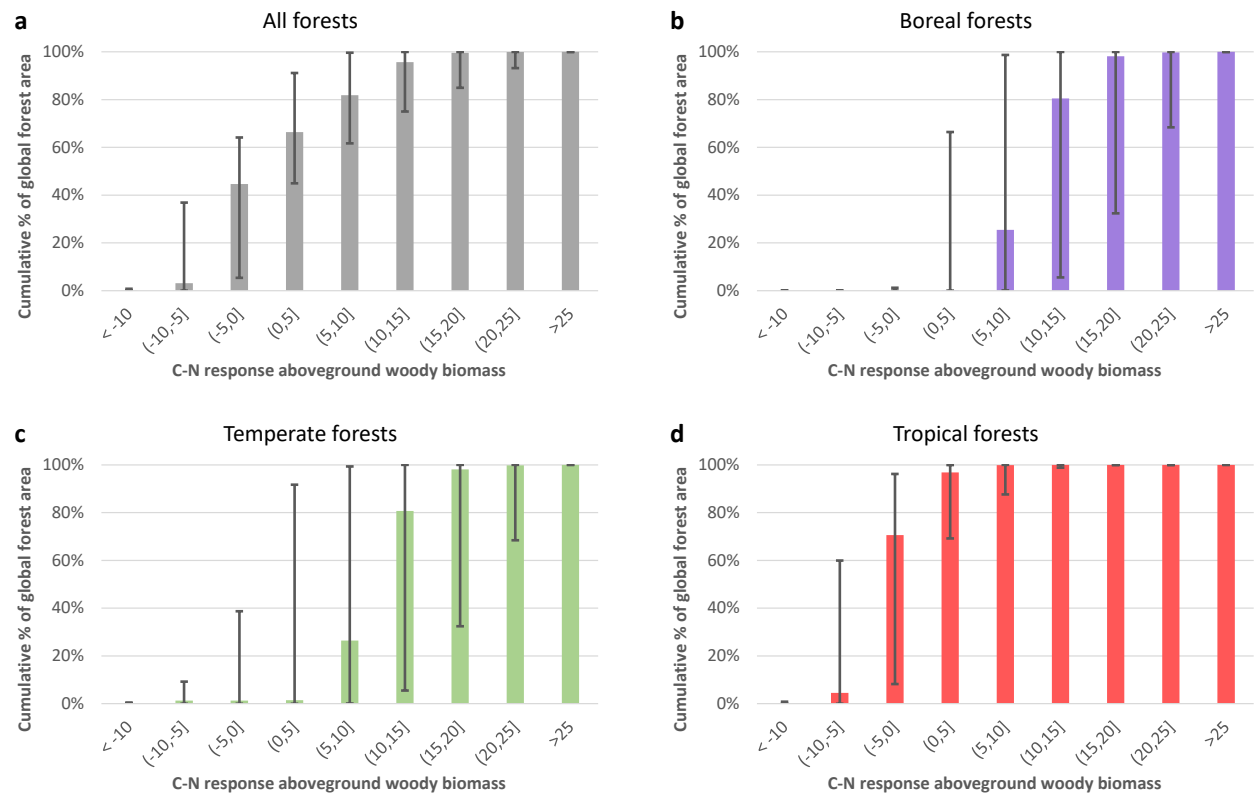

Figure 6.4 Cumulative frequency histogram showing frequency of predicted mean C-N response (frequency $=$ number of $\mathrm{km}^{2}$ for which response is predicted) for $\mathbf{a}$, all forests, b, boreal forests, $\mathbf{c}$, temperate forests and $\mathbf{d}$, tropical forests. Error bars show cumulative frequency distributions for $\mathrm{C}-\mathrm{N}$ responses based on the upper and lower bound of the $95 \%$ Confidence Interval. 

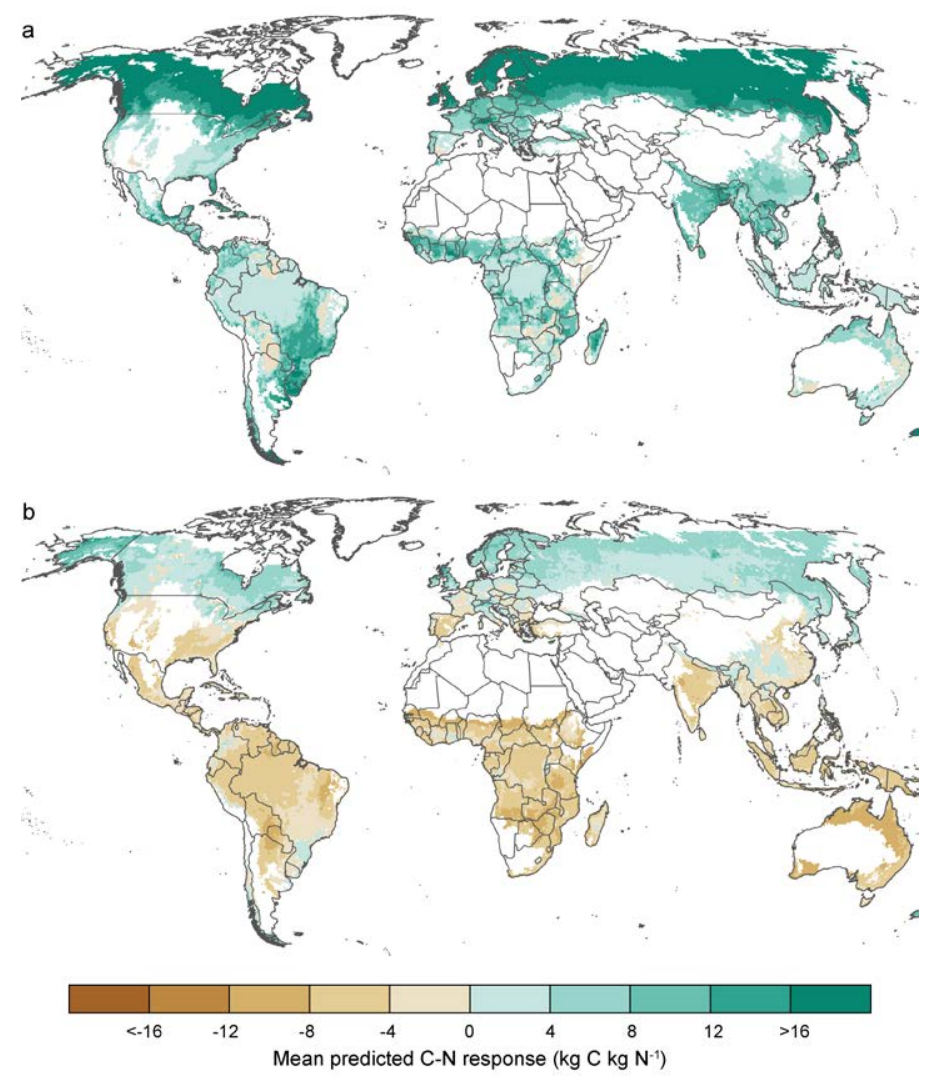

Figure 6.5 | a, upper and b, lower boundaries of $95 \%$ confidence interval for mean predicted C-N response shown in Figure 6.I.

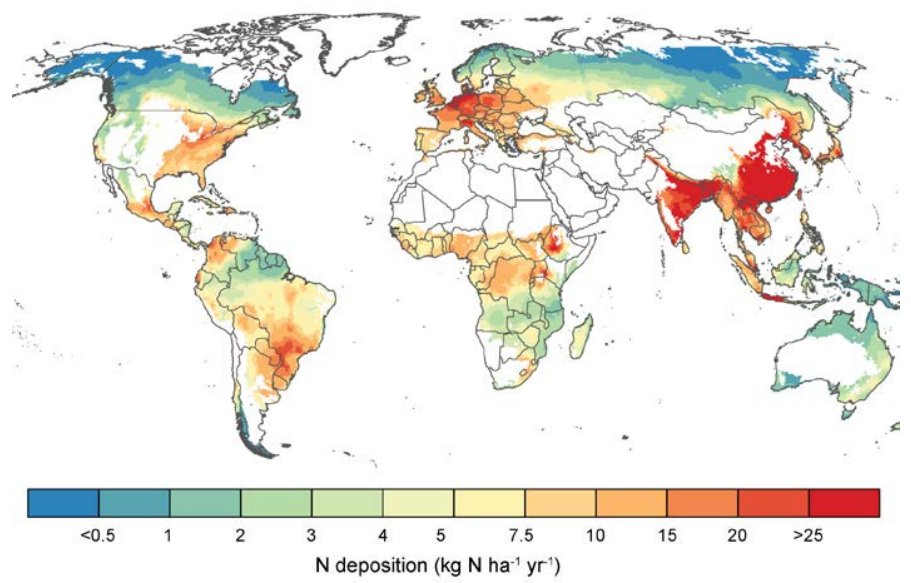

Figure 6.6 | N deposition to forests for the year 2010 used for estimating the $\mathrm{N}$-induced $\mathrm{C}$ sink, data from Schwede et al. (2018). Grid cells with forest area $<5 \%$ are masked. 

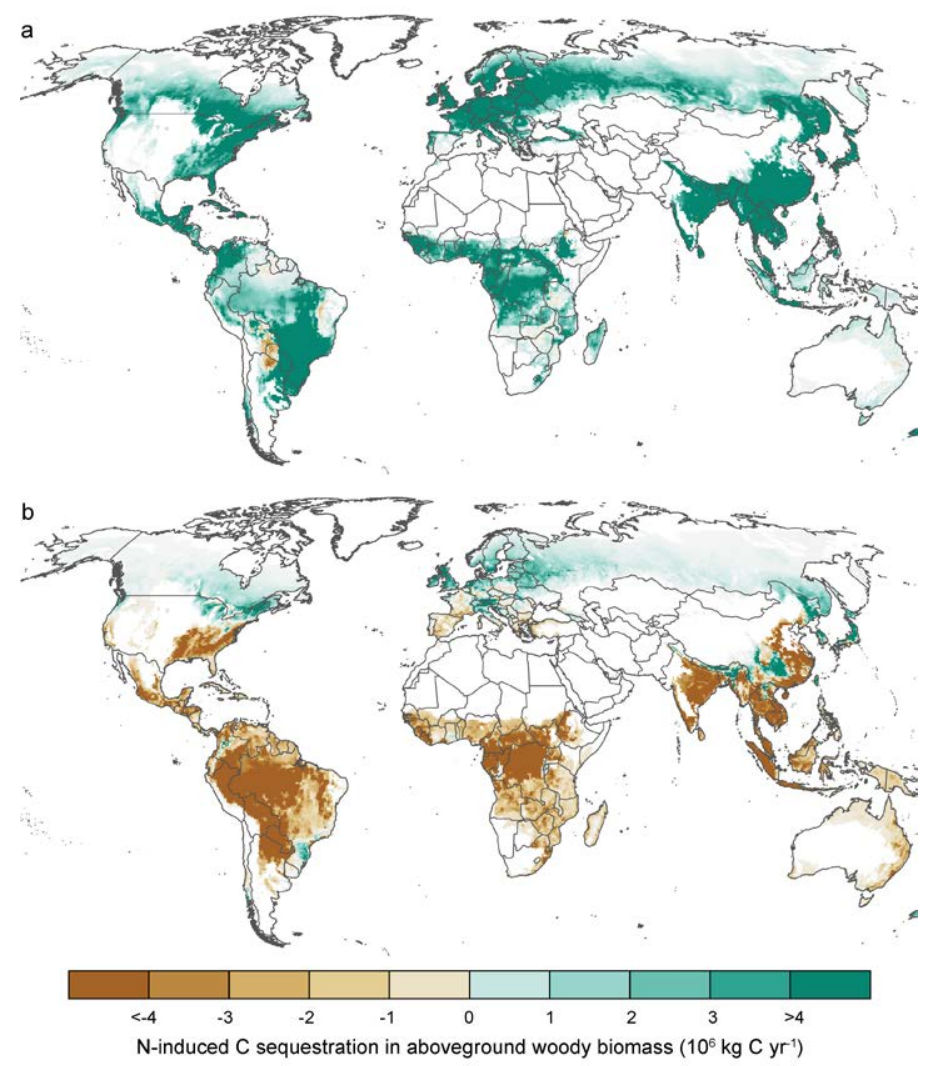

Figure 6.7 | a, Upper and b, lower bound of 95\% confidence interval for $\mathrm{N}$-induced $\mathrm{C}$ sequestration in forest aboveground woody biomass predicted by overlay of $\mathrm{C}-\mathrm{N}$ responses with $\mathrm{N}$ deposition. 


\section{Boreal forests}
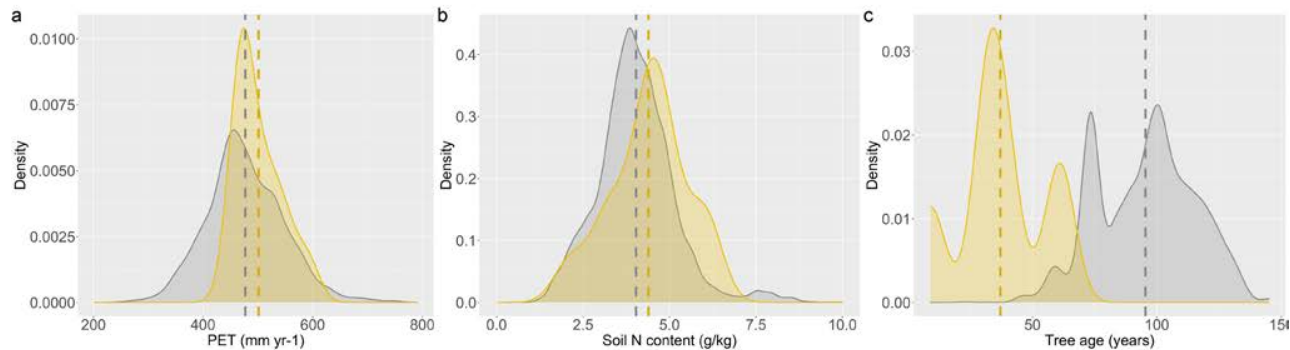

Temperate forests
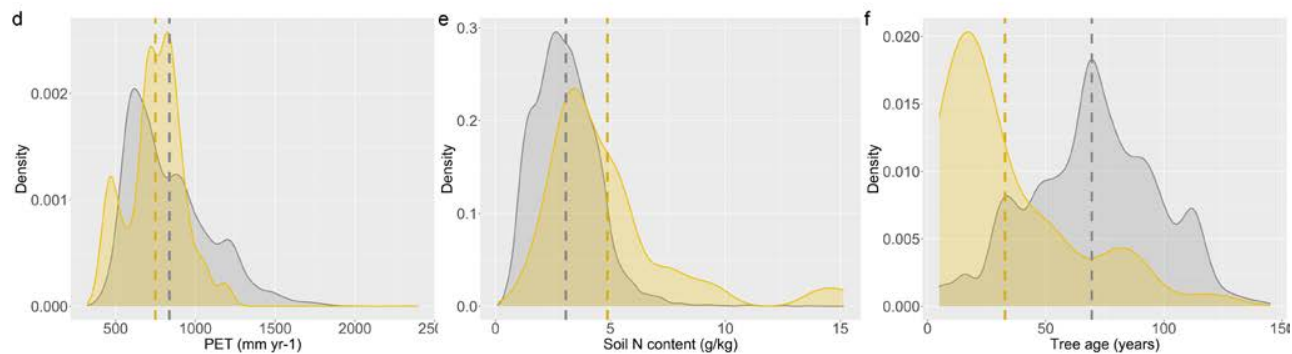

Tropical forests
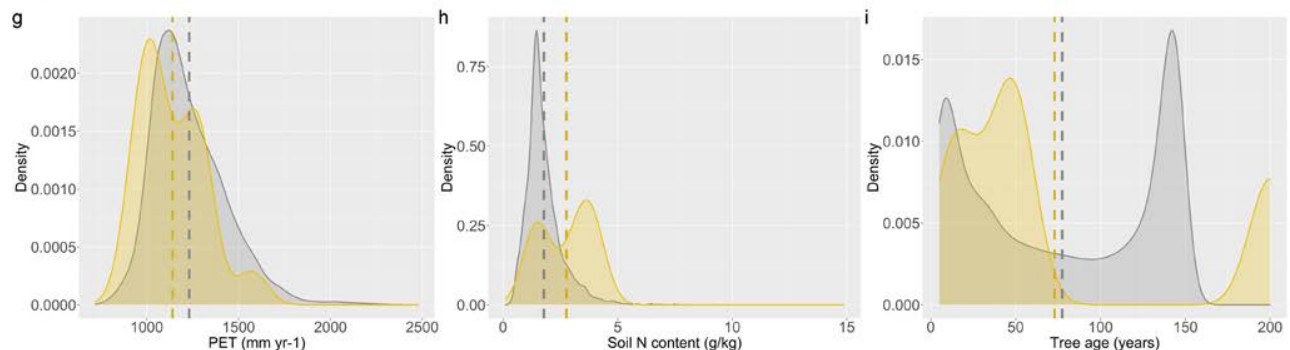

All forests
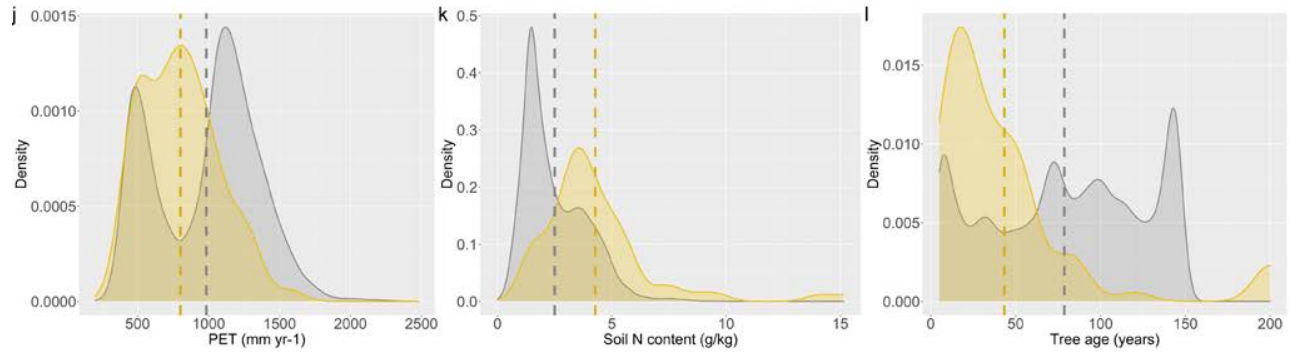

Figure 6.8 | Density plots showing the distribution of predictor variables (PET, soil $\mathrm{N}$ content and tree age) in the database (yellow) and in global forests (grey) for a-c, boreal forests, d-f, temperate forests, $\mathbf{g}-\mathbf{i}$, tropical forests and $\mathbf{j}-\mathbf{I}$, all forests. Dashed lines indicate the average value of the variable in the database (yellow) and in forests (grey). For the density plots showing distribution in the database, frequency refers to 'number of observations', while for the density plots showing distribution in global forests, frequency refers to 'number of $\mathrm{km}^{2}$ forest'. 
SUPPLEMENTARY MATERIAL CHAPTER 6 


\section{Supplementary Material Chapter 7}

Table S7.I | Overview of 26 IMAGE regions (https://models.pbl.nl/image/index.php/Region_classification_ map), including acronyms used in Figure 7.6.

\begin{tabular}{|c|c|c|c|c|c|}
\hline Acronym & Region name & Acronym & Region name & Acronym & Region name \\
\hline Can & Canada & SAf & South Africa & Kor & Korea region \\
\hline USA & USA & WEu & Western Europe & Chi & China region \\
\hline Mex & Mexico & CEu & Central Europe & SAs & South Asia \\
\hline $\mathrm{CAm}$ & Central America & Tur & Turkey & Indo & Indonesia \\
\hline Bra & Brazil & Ukr & Ukraine Region & Jap & Japan \\
\hline RSAm & Rest of South Amer. & CAs & Central Asia & Ocea & Oceania \\
\hline NAf & North Africa & Rus & Russia region & RSAs & Rest of South Asia \\
\hline WAf & West Africa & ME & Middle east & RSAf & Rest of South Africa \\
\hline EAf & East Africa & Ind & India & & \\
\hline
\end{tabular}

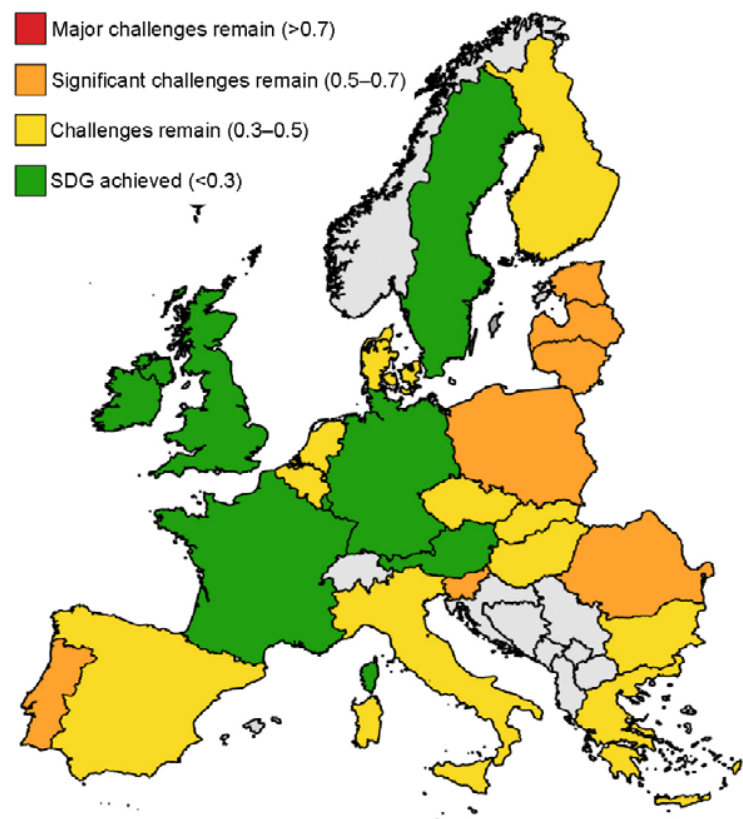

Figure 7.I | Average performance scores for the sustainable nitrogen management index (SNMI) for EU countries calculated with INTEGRATOR from spatially explicit normalized yield (using target yield as benchmark) and normalized NUE (using required NUE to protect ground- and surface water while also obtaining target yields), see "Approach B" in Figure 7.5. For description of methodology to derive spatially explicit target yields and required NUEs for the EU with INTEGRATOR, see Section 3.2. 


\section{Summary}

Before the industrial revolution, nitrogen was scarce and its availability severely constrained crop production. This changed with the invention of the Haber-Bosch process, allowing humans to fix atmospheric di-nitrogen at unprecedented rates. Currently, rates of human nitrogen fixation have surpassed natural rates by a factor $2-3$. This has greatly contributed to increases in crop yields, but also led to adverse impacts on the environment and human health.

Sustainable nitrogen management requires a systems approach, including tools that can quantitatively assess trade-offs between benefits of nitrogen for crop production and the adverse impacts of nitrogen on the environment. This thesis describes the further development and application of spatially explicit models to assess these trade-offs at the European and global scale. More specifically, the thesis addresses the following questions:

1. How much nitrogen can we safely apply in agriculture before crossing thresholds for air and water quality?

2. How can we manage nitrogen to both achieve environmental targets and meet current and future feed and food demand?

3. What is the climatic impact of anthropogenic nitrogen inputs, i.e., how much additional carbon is stored in terrestrial systems due to anthropogenic nitrogen deposition, and to what extent does this 'carbon bonus' offset the climate impact of $\mathrm{N}_{2} \mathrm{O}$ emissions?

This thesis aims to provide information on policy-relevant nitrogen indicators that capture trade-offs between nitrogen's adverse impacts and benefits, to support policies on sustainable nitrogen management in Europe and globally. Questions relevant to this objective are explored in seven chapters.

Chapter 1 ("Introduction") describes the challenge of sustainable nitrogen management and presents knowledge gaps that are addressed by the research described in the thesis.

Chapter 2 ("Spatially explicit boundaries for agricultural nitrogen inputs in the European Union to meet air and water quality targets") presents a method for deriving 'critical' agricultural nitrogen inputs related to targets for to nitrogen deposition (in view of critical limits to protect terrestrial ecosystems), nitrogen runoff to surface water (in view of water 
quality targets) and nitrogen leaching to groundwater (in view of drinking water norms). The method is applied to estimate spatially explicit critical nitrogen inputs in the European Union using the nitrogen balance model INTEGRATOR.

Chapter 3 ("Reconciling food production and environmental boundaries for agricultural nitrogen inputs in the European Union") builds on the work described in Chapter 2 and assesses how crop production can be maximized while keeping nitrogen losses to air and water below critical levels. Strategies that are explored include redistributing nitrogen inputs to close yield gaps in regions where thresholds are not exceeded and increasing nitrogen use efficiency in crop and livestock production.

Chapter 4 ("From planetary to regional nitrogen boundaries for targeted policy support") presents spatially explicit critical nitrogen inputs to agriculture at the global scale, which are derived based on the IMAGE-GNM model. The assessment of critical nitrogen inputs explicitly accounts for non-agricultural nitrogen losses as well as opportunities to increase nitrogen inputs to close yield gaps in regions where environmental thresholds are not exceeded. Critical inputs are aggregated to derive a safe 'planetary boundary' for agricultural nitrogen inputs.

Chapter 5 ("Global-scale impacts of nitrogen deposition on tree carbon sequestration in tropical, temperate, and boreal forests: A meta-analysis") describes results from a meta-analysis of nitrogen addition experiments in forests to estimate additional carbon sequestration in forest aboveground woody biomass resulting from nitrogen addition. Average carbon-to-nitrogen response rates are derived for tropical, temperate and boreal forests, and the global nitrogen-induced carbon sink is estimated by multiplying mean responses with nitrogen deposition in each forest biome.

Chapter 6 ("Experimental evidence shows minor contribution of nitrogen to global forest carbon sequestration") further builds on Chapter 5 by exploring sources of heterogeneity in nitrogen-induced forest carbon sequestration using meta-regression. The derived regression model predicts forest carbon-to-nitrogen response based on soil, climate and tree characteristics and is used to derive global maps of nitrogen-induced carbon sequestration in forest aboveground biomass.

Chapter 7 ("Synthesis") puts the findings of the thesis into context and presents two additional applications of the developed models to policy-relevant question on sustainable nitrogen management. 


\section{Acknowledgements}

This book is the outcome of a long journey, however, if it were a representation of that journey, it would look quite different. The neatly structured proposal on its first pages would be followed by many torn-out pages for ideas that were never carried out and research questions that were never answered. It would be filled with question marks scribbled in the margins from doubting where all this is going. The book would be stained from being thrown in the trash a couple of times when its owner wanted to quit altogether - only to retrieve it again shortly after. It would contain To Do-lists with trivial tasks serving as an excuse to procrastinate working on the thesis. A few dents and scratches from being dragged along to conferences around the world. A couple of big fat shiny smiley-stickers for the rare but precious moments of accomplishment, when a paper was finally accepted or a model did what it was supposed to. But most importantly, this book would have more than one name of the cover, because this journey was not travelled by me alone.

Wim, thank you for your unrelenting support, guidance and optimism throughout the years. No matter how high your workload was at times, it never seemed to affect your good mood - on the contrary, your enthusiasm often worked contagious. We both really like to get to the bottom of things, which makes it a pleasure to work together (though sometimes challenging to meet deadlines). Thank you also for making it possible for me to continue my research as a Postdoc. Lex, I am super grateful that you came on board as my second promotor half-way through my PhD. The collaboration with you and Arthur on the IMAGE work gave me a boost of new energy and motivation. I will always remember your mantra to write about my research as if I was 'explaining it to your dad'. Your pragmatic attitude contributed greatly to the completion of this book. You helped me make a plan, reminded me of deadlines and assured me that sometimes 'good is good enough'. Simple as it may sound, it was much needed! Carolien, you were initially one of my promotors and it is partly thanks to you that the proposal got selected for funding. Although our paths eventually parted, it meant a lot to me that you always let me know you were there for me if I needed you. You are a role model for me in many ways.

Modelling was one of the most fun parts of my thesis work, partly thanks to people helping me take the first baby-steps. Arthur, I really enjoyed the sessions at your kitchen table in Bilthoven. Thanks for introducing me to Python, and for your patience and good mood while doing so! Gerard, whenever I couldn't figure out how to do something in R, you came up with an answer, often within minutes! Your extensive knowledge of statistical methods 
was a great help. Sometimes our discussions left me with more questions than answers, but probably that was your intention all along ;-) .

During my PhD I discovered that I really enjoy teaching. Thanks to all the students I had the pleasure to supervise over the years, the exchanges with you often let me return to my $\mathrm{PhD}$ work with much more energy. Karen, Lars and Rik, thanks for giving me the opportunity to teach several courses, and for your faith in my abilities to do so.

Rik, your lectures on global environmental change as part my BSc minor first got me interested in this field. Later I joined your group, first as an MSc and then as a PhD student. I have always very much appreciated your qualities as a chairholder. You show real interest in people and initiate many social activities, which ensured a good cohesion within the group despite the diversity of research topics. Thanks to all ESA colleagues for the pleasant working atmosphere. In the beginning, I often smiled about the somewhat peculiar Dutch tradition of celebrating birthdays and accomplishments by sitting in a big circle and eating very sweet cake. However, after one year of Covid, I am starting to miss it! Mathilde, Lenny, Karen, Arnold, Wichertje, Dolf, Wim, Rik, Niklas, Bas, Sophie, Rob, Lenny, Marjolein, Claudia, Gerbert, Lars, Hidde, Kasper, Koen, Solen, Jannik, Gerard, Maria, Sarahí, Zoran, Aritta, Jana - I hope to treat you to a home-baked German cake again soon!

A PhD can be lonely at times, so I was lucky to always be surrounded by a nice bunch of fellow PhDs to share the griefs and joys of PhD life over a cup of coffee. Lucie, Alexander, Roy, Matthias, Ingeborg, Clara and Martine, you were my partners-in-crime when it came to 'real' cappuccinos and extended lunch breaks when I first started at ESA, and soon became good friends. Even years after most of you have left ESA, I still enjoy following how your lives unfold, and I sincerely hope that our last game of Kubb hasn't been played yet! Lucie, thank you for your friendship and for being my paranymph, I can't think of a better person to have with me in a stressful situation. Maddy, my other paramynph, thanks for being my roomie and sharing many ups and downs with me over the last years. It always makes me happy to see your smile in our office! I promise to do the dishes more often once this is all over ;-) Sarahí and Eka, we were all $\mathrm{PhD}$ students at ESA when we became pregnant around the same time, it was nice to share that experience with you (and see our girls play together)! To all my other ESA PhD colleagues: Ilan, Jerry, Jillian, Anna, Michael, Yu, Glory, Susana, Siiatwinda, Arnan, Magdalena, Nicolas, Gabriela, Leonardo, Donghao, Adil, Xingjuan - due to Covid I haven't seen many of you in months or even more than a year. I truly hope that we will soon be able to revive the tradition of $\mathrm{PhD}$ dinners and have the opportunity to catch up!

To keep up the hard work on a dissertation, moments of fun and relaxation are indispensable! Thanks to my friends in Wageningen and elsewhere for their support and good times, 
especially to Bernice \& Erwin for the countless adventures, Didi for the relaxing sauna sessions and for gently pushing me outside my comfort zone when I need it, Chris for the moral support on all aspects regarding $\mathrm{PhD}$-life, Roos for taking me out on walks, bike-tours and hikes, Anniek for many encouraging words, Marloes for spontaneously dropping in for a cup of tea once in a while, Jasper for the delicious and gezellige lamb-roasts, Roeland for your unconventional creativity that made me smile many times, Franca \& Lara for never running out of stuff to talk about after two decades of friendship, David for your unshakable trust that I will become professor one day, and all lekkere-BIL friends for sharing both life-events and the worst humour in our app-group. Living on the Wolfswaard during my $\mathrm{PhD}$ gave me plenty of opportunity to recover from too much screen-time by using my hands to take care of the animals or work in the garden. I feel fortunate to share this beautiful home with a great bunch of people: dear fellow Wolfjes, thanks for the gezelligheid during work-Sundays, Easter breakfasts, Christmas dinners, Sinterklaas celebrations, and, above all, spontaneous encounters, chats and shared meals. Thanks especially to Didi and Froutje for letting me use your storage room as an office during the first lockdown, and to Bart, Athziri and Wyke for assisting with the artwork in this book.

Thanks to my parents for their love and support. Jörg, without you pushing me to do a study-choice coaching, I never would have come to Wageningen at all. This choice eventually not only led to this $\mathrm{PhD}$ degree but also to a family, so I owe you a lot :-) . Bea, thank you so much for every time you stood in front of our door with freshly baked cake, ready to help us taking care of the kids. That was a great relief, especially during the final writing phase. Also thanks to my other family members - my brother, aunts, uncles and grandparents - for the countless times one of you asked when I would finish my $\mathrm{PhD}$, and for sharing my joy when I finally did. Anne and Toon, thanks for becoming a second family in the Netherlands over the years, and for always making me feel at home.
Liebe Eltern, danke für eure Liebe und Unterstützung. Jörg, ohne dein Andrängen, ein Studienwahl-Coaching zu machen, wäre ich nie in Wageningen gelandet. Damit verdanke ich dir indirekt nicht nur diesen Doktortitle, sondern auch meine Familie - ich steh in deiner Schuld :-) . Bea, 1000 Dank für die unzähligen Male, die du mit frisch gebackenem Kuchen vor unserer Tür standest. Deine Unterstützung bei der Kinderbetreuung war besonders in der letzten Phase der Doktorarbeit eine große Entlastung. Danke auch an meinen Bruder, Tanten, Onkel und Großeltern - für die unzähligen Male, die einer von euch gefragt hat, wann die Doktorarbeit denn endlich fertig sei - und dafür, dass ihr meine Freude geteilt habt, als es so weit war. Anne en Toon, het is fijn om zo'n lieve schoonfamilie te hebben, dank dat ik me bij jullie altijd thuis mag voelen. 
Dear Jinte and Anouk, there is no better remedy for work-related worries than your happy faces when I pick you up from daycare. Thank you for letting me share in your sense of wonder every day. Dear Hendrik, it has sometimes been a puzzle to find a balance between careers and children, time for yourself and attention for your partner, grand ambitions and household chores. Thank you for your patience in solving this puzzle time and again. Like no other, you can put my worries into perspective and remind me of what really counts. You were very much looking forward to being able to call yourself "Herr Doktor" as the husband of a woman with a $\mathrm{PhD}$ degree - even though it turns out that this is not formally permitted, you certainly more than deserve it! Your support while finishing this thesis was invaluable. Hopefully, after this busy phase, another one will follow with more room for joint adventures. I am looking forward to it!
Lieve Jinte en Anouk, er is geen beter medicijn tegen gepieker over werk dan jullie vrolijke koppies die bij het hek van de opvang op me wachten. Bedankt dat jullie me elke dag meenemen in jullie verwondering. Lieve Hendrik, het is soms een hele puzzel om een balans te vinden tussen carrières en kinderen, tijd voor jezelf en aandacht voor je partner, een groots en meeslepend leven en de was die nog opgehangen moet worden. Dank voor je geduld om er toch elke keer weer uit te komen. Je kan als geen ander mijn zorgen relativeren en me eraan herinneren wat écht telt. Je had er erg naar uitgekeken om je als echtgenoot van een vrouw met een $\mathrm{PhD}$ "Herr Doktor" te mogen noemen - al blijkt dat formeel helaas toch niet te mogen, verdien je het absoluut - zonder jouw steun had ik dit project nooit op deze manier af kunnen ronden. Hopelijk volgt er na deze drukke fase weer een met meer ruimte voor gezamenlijke avonturen. Ik heb er zin in! 


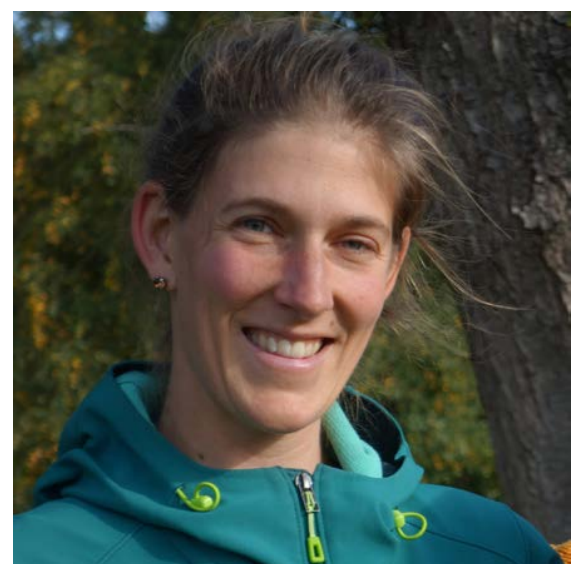

\section{About the author}

Lena Franziska Schulte-Uebbing was born on 23 September 1987 in Cologne, Germany. Nature and systems have been her passions from a young age, as witnessed by the carefully labelled collection of stones and shells that she treasured as a child. After high school, she spent a year in São Paulo doing voluntary work and studied communication and sociology in Münster. In 2008, the interdisciplinary and applied character of the BSc "International Land and Water Management" drew her to Wageningen University, a choice she never regretted. During her BSc, Lena did an internship at the Technical Support Unit of IPCC Working Group 2 in Stanford, California. Afterwards, she continued supporting the author team of the Africa Chapter of the $5^{\text {th }}$ IPCC Assessment Report as a Chapter Scientist. During her MSc in Climate Studies, she became increasingly interested in the relation between agriculture and global environmental change. Her MSc thesis on the global greenhouse gas mitigation potential in agriculture won the KLV thesis award for best thesis in Environmental Sciences. She participated in the SENSE Honours programme and wrote a $\mathrm{PhD}$ proposal on 'modelling nitrogen from field to fork', which was selected for funding by NWO. Lena started her $\mathrm{PhD}$ at the ESA group in 2014. During her PhD, she alternated research work with teaching several MSc courses and supervising student projects. Since November 2020, Lena works as a Postdoc at the ESA group where she continues here research on integrated nitrogen modelling in a project funded by the International Fertilizer Association. 


\section{Selected publications}

Schulte-Uebbing, L., G. Hansen, A. M. Hernández \& M. Winter (2015). Chapter scientists in the IPCC AR5 - experience and lessons learned. Current Opinion in Environmental Sustainability, 14: 250-256. https://doi.org/10.1016/j.cosust.2015.06.012

De Vries, W., E. Du, K. Butterbach-Bahl, F. Dentener \& L. Schulte-Uebbing (2017). Global-scale impact of human nitrogen fixation on greenhouse gas emissions. Oxford Research Encyclopedia of Environmental Science. https://doi.org/10.1093/ acrefore/9780199389414.013.13

Schulte-Uebbing, L. \& W. De Vries (2018). Global-scale impacts of nitrogen deposition on tree carbon sequestration in tropical, temperate, and boreal forests: A meta-analysis. Global Change Biology, 24(2): e416-e431. https://doi.org/10.1111/gcb.13862

De Vries, W. \& L. Schulte-Uebbing (2019). Impacts of nitrogen deposition on forest ecosystem services and biodiversity. In M. Schröter, A. Bonn, S. Klotz, R. Seppelt, \& C. Baessler (Eds.): Atlas of Ecosystem Services. Drivers, Risks, and Societal Responses (pp. 183-189). Springer. https://doi.org/10.1007/978-3-319-96229-0

De Vries, W., L. Schulte-Uebbing, H. Kros, H., J. C. Voogd \& G. Louwagie (2021). Spatially explicit boundaries for agricultural nitrogen inputs in the European Union to meet air and water quality targets. Science of The Total Environment, 147283. https://doi.org/10.1016/j. scitotenv.2021.147283

Schulte-Uebbing, L., \& W. De Vries (2021). Reconciling food production and environmental boundaries for agricultural nitrogen inputs in the European Union. Science of The Total Environment, 786, 147427. https://doi.org/10.1016/j.scitotenv.2021.147427

Schulte-Uebbing, L., A. H. W. Beusen, A. F. Bouwman \& W. De Vries. From planetary to regional nitrogen boundaries for targeted policy support. Under review.

Schulte-Uebbing, L., G. H. Ros \& W. De Vries. Experimental evidence shows minor contribution of nitrogen deposition to global forest carbon sequestration. Submitted. 


\section{SENSE}

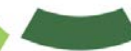

Netherlands Research School for the

Socio-Economic and Natural Sciences of the Environment

\section{I P L O M A \\ for specialised PhD training}

The Netherlands research school for the Socio-Economic and Natural Sciences of the Environment (SENSE) declares that

\section{Lena Franziska Schulte-Uebbing}

born on 23 September 1987 in Cologne, Germany

has successfully fulfilled all requirements of the educational PhD programme of SENSE.

Wageningen, 11 June 2021
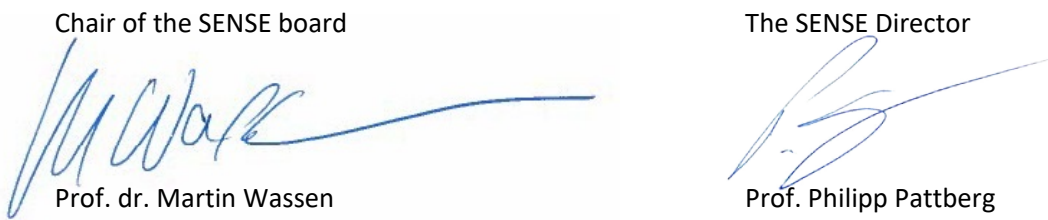

The SENSE Research School has been accredited by the Royal Netherlands Academy of Arts and Sciences (KNAW)

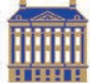

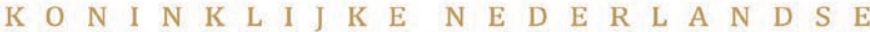

A K A D E M I E 


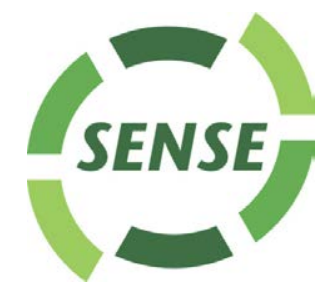

The SENSE Research School declares that Lena Franziska Schulte-Uebbing has successfully fulfilled all requirements of the educational PhD programme of SENSE with a work load of $48.6 \mathrm{EC}$, including the following activities:

\section{$\underline{\text { SENSE PhD Courses }}$}

- Environmental research in context (2014)

- Research in context activity: Project member 'International Nitrogen Management System (INMS)' and co-author of the International Nitrogen Assessment (2017-2021)

\section{Selection of Other PhD and Advanced MSc Courses}

- Linear and Mixed linear models, PE\&RC and SENSE (2014)

- Meta-analysis, PE\&RC and SENSE (2014)

- Introduction to R, PE\&RC and SENSE (2015)

- Exploring Teaching Outside Academia, Wageningen Graduate Schools (2017)

Data Visualization, SENSE \& PBL (2018)

Data management, Wageningen University (2018)

- Pitch training \& competition "Rising Soil Stars", Wageningen Soil Conference (2019)

\section{Scientific training and Societal impact}

- IPCC Chapter Scientist: Supporting the author team \& contributing author to the regional chapter on Africa of the $5^{\text {th }}$ IPCC Assessment Report (2011-2014)

- Visiting researcher at University of Melbourne (2016)

\section{Selection of Management and Didactic Skills Training}

- Teaching in the MSc courses 'Introduction to Global Change' (2014-2018), 'Interdisciplinarity in Scientific Research \& Education' (2014-2016), 'Pollution Management' (2017-2021), 'Methods \& Applications in ESA' (2015 \& 2017)

- Teaching the MSc course 'European Workshop' (interdisciplinary consultancy training), including coordination of student field trips to Vilnius (2017) \& Lisbon (2019)

- Supervising MSc thesis student (2016)

- Guest lecture “De mondiale stikstofkringloop", HAS Dronten (2017 \& 2018)

- Coordinating SENSE PhD Course 'Grasping Sustainability' (2017)

\section{Selection of Oral Presentations}

- Does nitrogen-induced forest carbon sequestration offset $\mathrm{N}_{2} \mathrm{O}$ emissions? $7^{\text {th }}$ International Nitrogen Conference, 4-8 December 2016, Melbourne, Australia

- Needed improvements in nitrogen use efficiency to achieve environmental quality objectives: the EU case. IFA High Level Forum on Sustainable Plant Nutrition, 18-19 November 2019, Versailles, France

SENSE coordinator PhD education

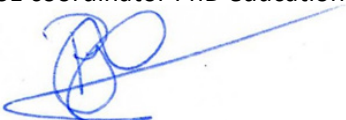

Dr. ir. Peter Vermeulen 
The PhD research was supported by the NWO (project number 022.003.009), provided through a project initiated by the SENSE Research School (SENSE Honours programme). Financial support from Wageningen University for printing this thesis is gratefully acknowledged.

Cover design \& photos by Lena Schulte-Uebbing Printed by GVO drukkers \& vormgevers on FSC-certified paper 



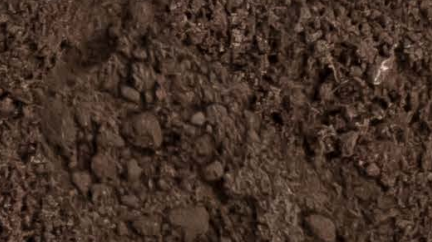

$52 \pi \mathrm{a}$

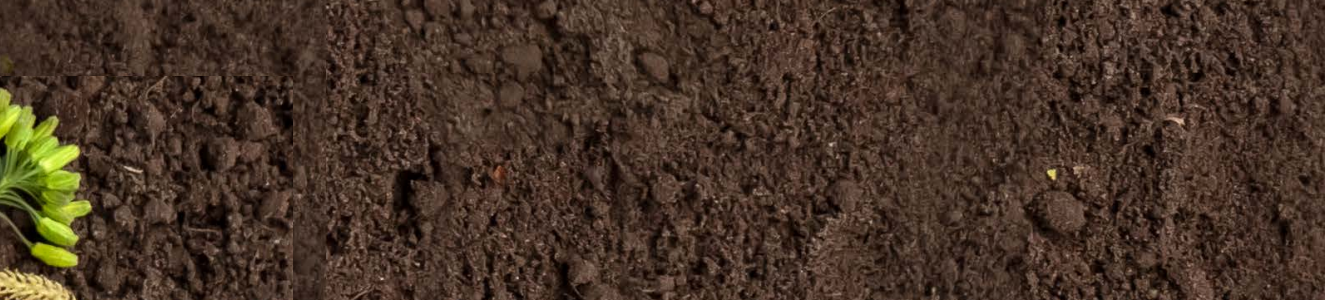

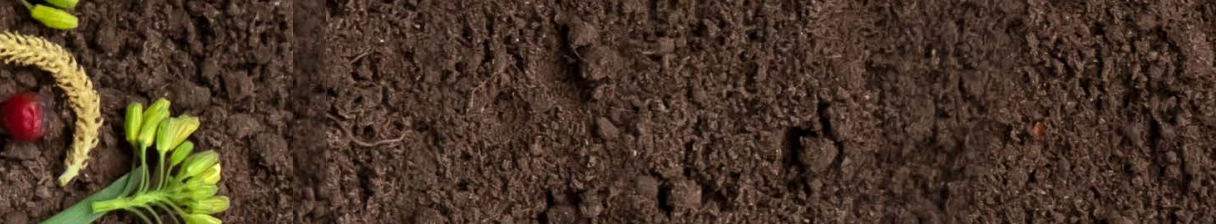

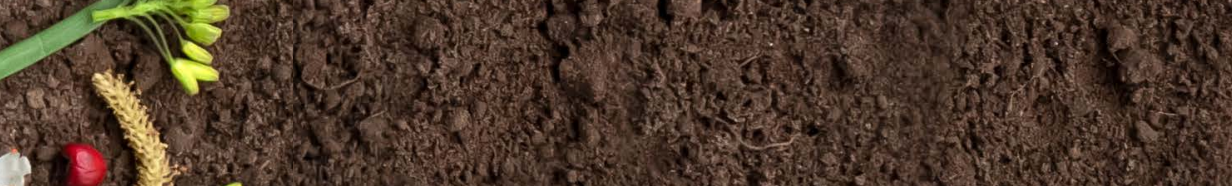

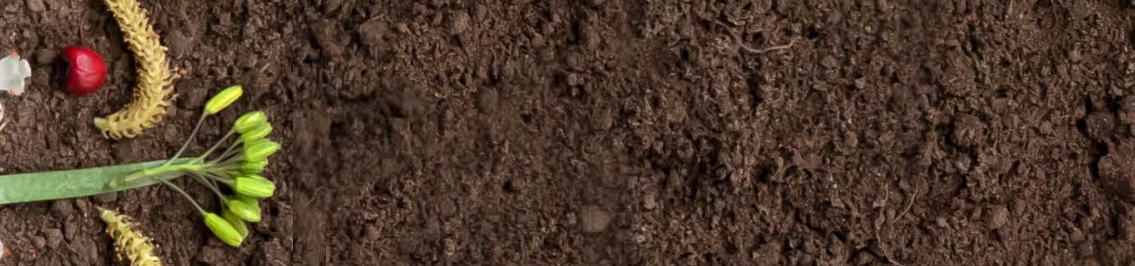
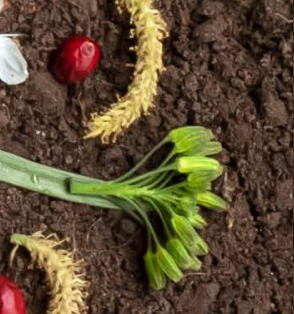

(3)
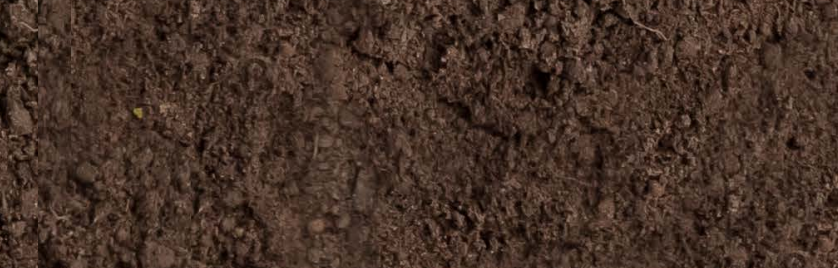

r.m. als 40

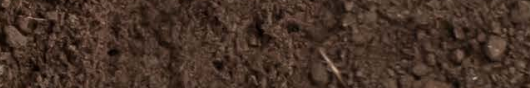

